





\section{ELEMENTARY BOTANY}

BY

GEORGE FRANCIS ATKINSON, Pн.B.

Professor of Botany in Cornell University

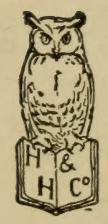

NEW YORK

HENRY HOLT AND COMPANY

I 898 


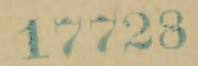

Copyright, r898, BY

HENRY HOLT \& CO.

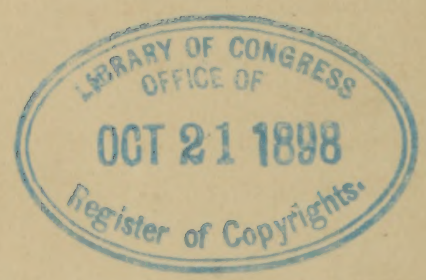

\section{TWO COPIES RECEIVED.}

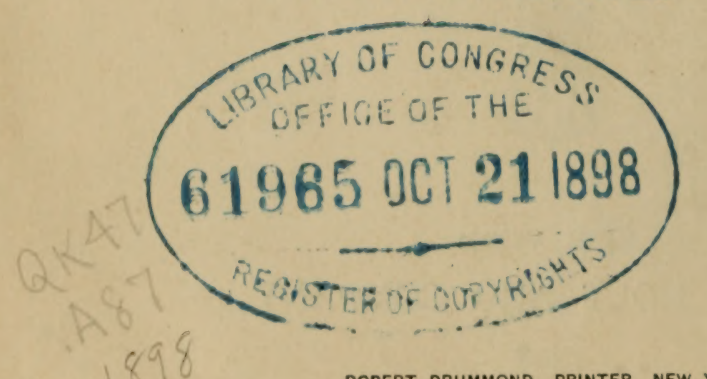

ROBERT DRUMMOND, PRINTER, NEW YORK.

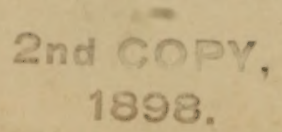





\section{3}

\section{PREFACE.}

UNTIL recent years the prevalent method of teaching botany in the secondary schools, and in the first courses in many colleges, has been based on the "analysis" of flowers. The method had its impetus in the study of systematic botany pursued with such vigor by the pioneers of the science in America. The great progress in our knowledge of the morphology and physiology of plants during the last quarter of this century has changed the whole problem of elementary instruction in botany, and led to almost universal dissatisfaction with the old method of secondary instruction in this subject. It is now generally ognized that a study of the lower plants, like the algæ, fungi, erworts, mosses, and ferns should form a part of a course of condary education in botany.

To meet this end a number of books have sprung into existıce during the past few years. If the need for some guidnce in the selection of topics, and an outline of the character of the study, could be met by number alone of books, this want would be fully met in the new treatises recently published, and there would be no place for the present book. But a judicious sulection of a few forms to illustrate function, process, and relationship throughout the wide range of plant life, and the training in logical methods of induction, and accuracy of drawing conclusions, is vastly more important in its influence on the character of the pupil, even though he forget all about the plants studied, than the handling -of a great vasiety of objects, and the drawing of haphazard conclùsions, which are left to the pupil in a large number of cases by the methods pursued in many of the recent elementary works. 
For several years the author has been deeply interested in the teaching of elementary botany, and has had an opportunity to study methods in a practical way, in having charge of the instruction of a large class of beginners, the majority of whom had never studied the subject before. One of the great difficulties encountered in attempting to introduce the study of the lower plants is the fact that these plants are in most cases entirely unknown to the pupil. The difficulty does not lie in the attempt to introduce the study of unknown objects. But it lies rather in the attempt to study the lower plants, at the outset, in a more or less thorough manner, to learn their characters, relationships, etc., in order to group them into their natural orders. This is attempting too much for the young beginner, to whom these plants are totally unfamiliar objects.

The method followed in this book has been thoroughly tested in practical work. It is to first study some of the life processes of plants, especially those which illustrate the fundamental principles of nutrition, assimilation, growth, and irritability. In studying each one of these topics, plants are chosen, so far as possible, from several of the great groups. Members of the lower plants as well as of the higher plants are employed, in order to show that the process is fundamentally the same in all plants. Then another process is studied in a similar way, using so far as possible, especially where the lower plants are concerned, the same plant. In this way the mind is centered on this process, and the discovery to the pupil that it is fundamentally the same in such widely different plants arouses a keen interest not only in the plants themselves, but in the method which attends the discovery of this general principle. In the study of the life processes, the topics can be arranged so that they show progression of function.

At the same time it is well for the teacher to select for this study of the life processes those plants which represent well the great groups, and show gradual progression of form and structure, and also those which are easily obtained.

A second period of the session can then be devoted to study- 
ing a few representatives of the different groups of the algæ, fungi, liverworts, mosses, ferns, and the higher plants. This should be done with special reference to form, reproduction, general classification, progression, and retrogression of parts or organs, in passing from the lower to the higher plants. In taking up this study of representative forms now, if a wise selection has been made in dealing with the life processes, the same plant can be used here in most cases. These plants now are familiar to the pupil, and the mind can be centered on form, organs, reproduction, relationship, etc. In this study of general morphology it is very important that a careful study be made of some of the lower plants, and of the ferns. Here the sexual organs are well formed, and the processes of reproduction can be more easily observed. In the higher plants the sexual organs are very much reduced, and the processes more difficult to observe. It is only through a study of the lower plants that we are able to properly interpret the floral structures, and the sexual organs of the spermatophytes, and to rid ourselves of the erroneous conceptions which the prevalent method of elementary instruction has fixed so firmly on the lay mind.

A third period of the elementary course may be employed in studying special morphology of the higher plants. Even here it seems to the author wise that the "analysis" of plants should be deferred until after a general notion of the characters and habit of several of the important families has been obtained. The pupil may be told the names of the several plants used as examples, and emphasis can be laid on ordinal and generic characters, which can then be recognized in many plants without resort to a key. The matter of determining the names of plants by the old method can, if desired, be pursued to greater advantage after this critical study of relationships has been made, even though the pupil may pursue it independently at a later time.

In the study of plants one should not lose sight of the value of observing plants in their natural surroundings. If judiciously pursued it forms at once a means of healthful recreation, of communion with the very soul of nature, and of becoming ac- 
quainted with the haunts, the lives, the successes and failures of plants; the influences of soil, moisture, and other environmental conditions upon plants, and, what is also important, the influence which plants exert upon their environment. Classes may be taken into the field, at different seasons of the year, to observe flower and bud formation, pollenation, seed production, seed distribution, germination of seeds and nutrition of the embryo, protection of plants against foes and extremes of weather; the relationships of plants in colonies, and their distribution in plant formations, etc. In all this study a knowledge of some of the lower plants is important.

It is not intended that the matter in the book should be memorized for the purpose of recitations. It should be used as a guide to the practical work, and as a reference book. The paragraphs arranged in coarse print are intended in general to indicate the studies which will serve as the basis for the practical work by the student. In most cases the material for these studies can be quite easily obtained and the laboratory work is not difficult. The paragraphs in fine print are intended to further illustrate the subject by discussion and illustration of the more difficult phases of each topic. Some of these can be made the basis for demonstrations by the teacher before the class, and all will serve as a convenient means of getting at the important reference matter by the student in a single book. Suggestions on the study and the taking of notes, etc., by the student are given in the appendix.

Acknowledgments. - The author desires here to express his gratefulness to his associates in the botanical department of Cornell University who have read the manuscript and have made useful suggestions (Messrs. E. J. Durand, B. M. Duggar, K. M. Wilgand, and Professor W. W. Rowlee). Valuable suggestions were also given by Dr. J. C. Arthur, of Purdue University, who kindly read the chapters on physiology, and by Professor W. F. Ganong, of Smith College, who read some of the chapters on ecology and the tables on the homologies of the gymnosperms and angiosperms. 
Illustrations. - The large majority of the illustrations are new, and were made with especial reference to the method of treatment followed in the text. Most of the photographs were made by the author. Others were contributed by Professor P. H. Mell, of the Alabama Polytechnic Institute, Auburn, Ala.; Professor Rowlee, Cornell University; Mr. H. J. Webber, Washington, D. C.; by the New Jersey Geological Survey through the courtesy of Mr. Gifford Pinchot, of New York; by Mr. B. M. Duggar, Cornell University, and Mr. Herman von Schrenk, of the Missouri Botanical Garden.

Many of the drawings, especially those of microscopic objects, were made by the author; others by Mr. H. Hasselbring, Cornell University, and Dr. Bertha Stoneman, now professor of botany in the Huguenot College, Wellington, Cape Colony, South Africa. The drawings to illustrate the gross characters of plants were made by Mr. W. G. Holdsworth, Michigan Agricultural College; Mr. Joseph Bridgham, Providence, R. I.; Messrs. W'. C. Furlong and W. C. Baker, Cornell University; and a few by Miss Edna Porter, Buffalo, N. Y., and by Mrs. E. L. Nichols and Mrs. J. G. Needham, Cornell University. Professor Chas. A. Davis kindly furnished the sketches from which the drawings of the transformed trillium flower were made.

Other illustrations have been obtained from the following sources: from the author's Study of the Biology of Ferns, through the courtesy of the Macmillan Co.; and from the Annals of Botany, Jahrbücher für wissenschaftliche Botanik, Flora, Botanical Gazette, Vines' Student's Text Book of Botany, and Warming's Botany.

Above all the author is under great obligations to Professors Ikeno and Hirase, of the Imperial University of Japan, Tokio, for their unparalleled courtesy in sending drawings of the spermatozoids, and of fertilization, in cycas and gingko, in advance of their publication.

Cornell University, June, 1898 . 



\title{
CONTENTS.
}

\author{
(References are to paragraphs.)
}

\section{CHAPTER I.}

PROTOPLASM.

The plant spirogyra, 4. Chlorophyll bands in spirogyra, 5 . The spirogyra thread consists of cylindrical threads end to end, 6. Protoplasm, 7. Cell-sap in spirogyra, 8. Reaction of protoplasm to certain reagents, 9. Earlier use of the term protoplasm, II. Protoplasm in mucor, I2. Mycelium of mucor, 13. Appearance of the protoplasm, I4. MoveEent of the protoplasm in mucor, 15. Test for protoplasm, 16. Protoplasm in nitella, I7. Form of nitella, 18. Internode of nitella, 19. Cyclosis in nitella, 20. Test for protoplasm, 21. Protoplasm in one of the higher plants, 22. Movement of protoplasm in the higher plants, 23. Movement of protoplasm in cells of staminal hair of spiderwort, 24. Cold retards the movement, 25. Protoplasm occurs in the living parts of all plants, $26 \ldots \ldots \ldots \ldots \ldots \ldots$ page

\section{CHAPTER II.}

ABSORPTION, DIFFUSION, OSMOSE.

Osmose in spirogyra, 30. Turgescence, 3I. Experiment with beet in salt and sugar solutions, 32. Osmose in the cells of the beet, 34. The coloring matter in the cell-sap does not readily escape from the living protoplasm of the beet, 35 . The coloring matter escapes from dead protoplasm, 36. Osmose experiments with leaves, 37. Absorption by roothairs, 39. Cell-sap a solution of certain substances, 40. Diffusion through an animal membrane, 4 . Importance of these physical processes in plants, $44 \ldots \ldots \ldots \ldots \ldots$ page 


\section{CHAPTER III.}

\section{ABSORPTION OF LIQUID NUTRIMENT.}

Formula for solution of nutrient materials, 46. Plants take liquid food from the soil, 5o. How food solutions are carried into the plant, 5I. How the root-hairs get the watery solutions from the soil, 52. Plants cannot remove all the moisture from the soil, 53. Acidity of root-hairs, $56 \ldots$ page

\section{CHAPTER IV.}

TURGESCENCE.

Turgidity of plant parts, 58 . Restoration of turgidity in shoots, 59. Tissue tensions, 6r. Longitudinal tissue tension, 62. Transverse tissue tension, $65 \ldots \ldots \ldots \ldots \ldots \ldots$ page

\section{CHAPTER V.}

ROOT PRESSURE.

Root pressure may be measured, 67. Experiment to demonstrate root pressure, $68 \ldots \ldots \ldots \ldots \ldots \ldots \ldots \ldots \ldots$ page

\section{CHAPTER VI.}

T RA NSPIRATION.

Loss of water from excised leaves, 7I. Loss of water from growing plants, 72 . Water escapes trom the surfaces of living leaves in the form of water vapor, 73. Experiment to compare loss of water in a dry and a humid atmosphere, 74. The loss of water is greater in a dry than in a humid atmosphere, 75. How transpiration takes place, 76. Structure of a leaf, 79. Epidermis of the leaf, 8o. Soft tissue of the leaf, 8r. Stomata, 82 . The living protoplasm retards the evaporation of water from the leaf, 83 . Action of the stomata, 84. Transpiration may be in excess of root pressure, 85. Negative pressure, 86. Lifting power of transpiration, 87. Root pressure may exceed transpiration, 88. Injuries caused by excessive root pressure, 89. Demonstration of stomates and intercellular spaces, $92 \ldots$ page 


\section{CHAPTER VII.}

PATH OF MOVEMENT OF LIQUIDS IN PLANTS.

Place the cut ends of leafy shoots in a solution of some red dye, 94. These solutions color the tracts in the stem and leaves through which they flow, 95. Structure of the fibro-vascular bundles, 98. Woody portion of the bundle, 99. Bast portion of the bundle, roo. Cambium region of the bundle, ror. Longitudinal section of the bundle, ro2. Vessels or ducts, 103. Sieve tubes, 105. Fibro-vascular bundle in Indian corn, I07. Rise of water in the vessels, ro8. Synopsis

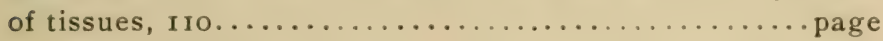

\section{CHAPTER VIII. \\ DIFFUSION OF GASES.}

Gas given off by green plants in the sunlight, III. What this gas is, II7. Oxygen given off by green land plants also, II8. Absorption of carbon dioxide, II9. The gases are exchanged in the plants, 122 . A chemical change of the gas takes place within the plant cell, I23. Gases as well as water can diffuse through the protoplasmic membrane, I 24

page

\section{CHAPTER IX.}

\section{RESPIRATION.}

Oxygen from the air consumed during germination of seed, 127. Carbon dioxide given off during germination, 128. Respiration is necessary for growth, I30. Energy set free during respiration, 132. Respiration in a leafy plant, I33. Respiration in fungi, I34. Respiration in plants in general, 135 . Respiration a breaking-down process, 136 . Detailed result of the above experiment, 137 . Another way of performing the experiment, 138 . Intramolecular respiration, I39..page

\section{CHAPTER X.}

THE CARBON FOOD OF PLANTS.

Starch formed as a result of carbon conversion, I4I. Iodine used as a test for starch, I42. Schimper's method of testing 
for the presence of starch, 143. Green parts of plants form starch when exposed to the light, 147. Starch is formed only in the green parts of plants, 148. Translocation of starch, I49. Star'ch in other parts of plants than the leaves, I5I. Form of starch grains, $153 \ldots \ldots \ldots \ldots \ldots \ldots$ page

\section{CHAPTER XI.}

CHLOROPHYLL AND FORMATION OF STARCH.

Fungi cannot form starch, I55. Etiolated plants cannot convert carbon, 156. Chlorophyll and chloroplasts, I57. Form of the chlorophyll bodies, I58. Chlorophyll is a pigment which resides in the chloroplast, I59. Chlorophyll absorbs energy from sunlight for carbon conversion, I60. Rays of light concerned in carbon conversion, I6I. Starch grains formed in the chloroplasts, I62. Carbon conversion in other than green plants, 164 . Influence of light on the movement of chlorophyll bodies, $165 \ldots \ldots \ldots \ldots \ldots \ldots \ldots \ldots \ldots \ldots \ldots$ page

\section{CHAPTER XII.}

NUTRITION; MEMBERS OF THE PLANT BODY.

Nutrition of liverworts, I67. Riccia, I67. Marchantia, I68. Frullania, I69. Nutrition in the mosses, I70. The plant body, I7I. Members of the plant body, I72. Stem series, 173. Leaf series, I74. The root, I75 ............. 70

\section{CHAPTER XIII.}

GROWTH.

Growth in mucor, 177. Formation of the gonidia, 178. The gonidia absorb water and increase in size before germinating, 179. How the gonidia germinate, I80. The germ tube branches and forms the mycelium, I8I. Growth in length takes place only at the end of the thread, I82. Protoplasm increases by assimilation of nutrient substances, $\mathrm{I} 8_{3}$. Growth of roots, I84. Roots of the pumpkin, 185. The region of elongation, 186 . Movement of the region of the greatest elongation, I87. Formative region, I88. Growth of the stem, I89. Force exerted by growth, I9o. Grand period of growth, I9I. Energy of growth, I93. Nutation,

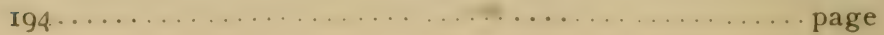




\section{CHAPTER XIV.}

IRRITABILITY.

Influence of the earth on the direction of growth, 197. Influence of light on growth, 199. Influence of light on the direction of growth, 200. Diaheliotropism, 20I. Epinasty and hyponastv, 202. Leaves with a fixed diurnal position, 203. Importance of these movements, 204. Influence of light on the structure of the leaf, 205. Movement influenced by contact, 206. Sensitive plants, 207. Movement in response to stimuli, 208. Transmission of the stimulus, 209. Cause of the movement, 210. Paraheliotropism of the leaves of the sensitive plant, 2Ir. Sensitiveness of insectivorous plants, 212. Hydrotropism, 213. Temperature,

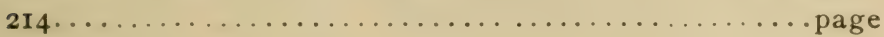

\section{- PART II.}

\section{MORPHOLOǴY.}

\section{CHAPTER XV.}

SPIROGYRA.

Form of spirogyra, 220. Multiplication of the threads, 22x. How some of the threads break, 222. Conjugation of spirogyra, 223. How the threads conjugate or join, 225. How the protoplasm moves from one cell to another, 226. The zygospores, 227. Life cycle, 228. Fertilization, 229. Simplicity of the process, 230. Position of the plant spirogyra,

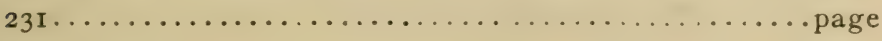

\section{CHAPTER XVI.}

\section{EDOGONIUM.}

Form of œdogonium, 235. Fruiting stage of œdogonium, 236. Sexual organs of œdogonium; oogonium and egg, 237. Dwarf male plants, 238. Antheridium, 239. Zoospore stage of œdogonium, 240. Asexual reproduction, 241. Sexual reproduction, 242. Antheridia, 242. Oogonia, 243. Edogonium compared with spirogyra, 244. Position of œdogonium, 245. Relatives of œdogonium, $246 \ldots \ldots$ page 


\section{CHAPTER XVII.}

VAUCHERIA.

Zoogonidia of vaucheria, 248. Sexual reproduction in vaucheria, 249. Vaucheria sessilis, the sessile vaucheria, 250. Sexual organs of vaucheria, Antheridium, 25I. Oogonium, 252. Fertilization, 253. The twin vaucheria (V.geminata),

254. Vaucheria compared with spirogyra, $255 \ldots \ldots \ldots$ page 109

\section{CHAPTER XVIII.}

COIEOCH.ETE.

The shieli-shaped coleochxte, 257. Fruiting stage of coleochrte, 258. Zoospore stage, 259. Asexual reproduction, 260. Sexual reproduction, oogonium, 26I; antheridium, 262. Sporocarp, 263. Comparative table for spirogyra, vaucheria, odogonium, and coleochæte, $264 \ldots . . . .$. page iı

\section{CHAPTER XIX.}

BROWN AND RED ALG.E.

Brown algx (phrophycex), 266. Form and occurrence of fucus, 267. Structure of the conceptacles, 268. Fertilization, 269. The red algæ, 270. Gracillaria, 271. Rhabdonia, 272. Principal groups of algæ, $273 \ldots \ldots \ldots \ldots \ldots \ldots \ldots$ page II 5

\section{CHAPTER XX.}

FUNGI; MOULDS; WATER MOULDS; DOWNY MILDEWS.

Mucor, 275. Asexual reproduction, 276. Sexual stage, 277. Gemmx, 278. Water moulds (saprolegnia), 279. Appearance of the saprolegnia, 280 . Sporangia of saprolegnia, 251. Zoogonidia of saprolegnia, 252. Sexual reproduction of saprolegnia, $2 s_{3}$. Downy mildews, $285 \ldots \ldots \ldots \ldots$ page 120

\section{CHAPTER XXI.}

FU'NGI (confinued); RUSTS; ASCOMYCETES.

Wheat rust (Puccinia graminis), 28g. Teleutospores of the black-rust form. 290. Uredospores of the red-rust form, 291. Cluster-cup form on the barberry, 292. Spermagonia, 
293. How the cluster-cup stage was found to be a part of the wheat rust, 293a. Uredospores can produce successive crops, 294. Teleutospores the last stage in the season, 295. How the fungus gets back from the wheat to the barberry, 296. Synopsis of life history of wheat rust, 297. Sac fungi, 299. Fruit bodies of the willow mildew, 300. Asci and ascospores, 30I. The sac fungi or ascomycetes, 302. Classification of the fungi, $304 \ldots \ldots \ldots \ldots \ldots \ldots$ page 129

\section{CHAPTER XXII.}

\section{I.IVER WORTS.}

Riccia, 307. Form of the floating riccia (R. fluitans), 307. Form of the circular riccia (R. crystallina), 308. Sexual organs, 309. Archegonia, 3IO. Antheridia, 3Ir. Embryo, 312. Sporogonium of riccia, 3I3. A new phase in plant life, $3 I_{4}$ Riccia compared with coleochæte, œdogonium, etc., 3 I5. Marchantia, 3I6. Antheridial plants, 3I7. Archegonial

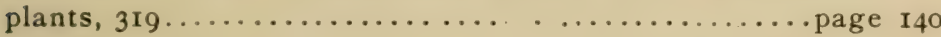

\section{CHAPTER XXIII.}

LIVERWORTS (continued).

Sporogonium of marchantia, 320. Spores and elaters, 321. Sporophyte of marchantia compared with riccia, 322. Sporophyte dependent on the gametophyte for its nourishment, 323. Development of the sporogonium, 324. Embryo, 325. How marchantia multiplies, 326. Buds or gemmæ of marchantia, 327. Leafy-stemmed liverworts, 328. Frullania, 329. Porella, 330. Sporogonium of a foliose liverwort, 33 . ............................... 149

\section{CHAPTER XXIV.}

\section{MOSSES.}

Mnium, 334. The fruiting moss plant, 336. The male and female moss plants, 337. Sporogonium, 338. Structure of the moss capsule, 339. Development of the sporogonium, 342. Protonema of the moss, 343. Table showing relation of gametophyte and sporophyte in the liverworts and

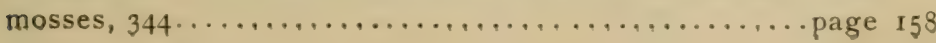




\section{CHAPTER XXV.}

FERNS.

The Christmas fern, 346. Fruit dots, 347. Sporangia, 348. Structure of a sporangium, 349. Opening of the sporangium and dispersion of the spores, 35I. How does the opening and snapping of the sporangium take place? 352 . The movement of the sporangium can take place in old and dried material, 354. The common polopody, 356. Other ferns, 357. Opening of the leaves of ferns, 358. Longevity of ferns, 359. Budding of ferns, 36o. The fern plant is a sporophyte, 363 . Is there a gametophyte phase in ferns?

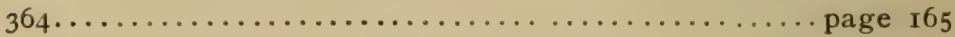

\section{CH A P T E X X VI.}

\section{FERNS (concluded).}

Gametophyte of ferns, 365. Sexual stage of ferns, 365. Spores, 367. Germination of the spores, 368. Protonema, 369. Prothallium, 370. Sexual organs of ferns, 371. Antheridia, 372. Archegonia, 373. Sporophyte, 374. Embryo, 374.

Comparison of ferns with liverworts and mosses, 375 . page 176

\section{CHAPTER XXVII.}

HORSETAILS.

The field equisetum, 380. Fertile shoot, 380 . Sporangia, 38 r. Spores, 382. Sterile shoot of the common horsetail, 383 . The scouring rush or shave grass, 384. Gametophyte of

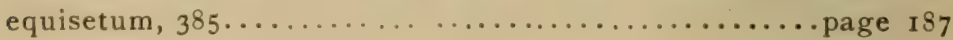

\section{CHAPTER XXVIII.}

\section{CLUB MOSSES.}

The clavate lycopodium, 387. Fruiting spike of Lycopodium clavatum, 388. Lycopodium lucidulum, 389. Bulbils on Lycopodium lucidulum, 39o. The little club mosses, 392. Sporangia, macrospores and microspores, 393. Male prothallia, 394. Female prothallia, 395. Embryo, 396....page I9I 


\section{CHAPTER XXIX.}

QUILLWORTS.

Sporangia of isoetes, 398. Male prothallia, 40I. Female prothallia, $402 . \quad$ Embryo, $403 \ldots \ldots \ldots \ldots \ldots \ldots \ldots \ldots \ldots \ldots$ page 196

\section{CHAPTER XXX.}

COMPARISON OF FERNS AND THEIR RELATIONS.

Comparison of selaginella and isoetes with the ferns, 404. General classification of ferns, 407 . Table showing relation of gametophyte and sporophyte in the pteridophyta, 408..page 199

\section{CHAPTER XXXI.}

GYMNOSPERMS

The white pine, 409. General aspect of the white pine, 409. The long shoots of the pine 4ro. The dwarf shoots of the pine, 4II. Spore-bearing leaves of the pine, 4I2. Male cones or male flowers, $4 \mathrm{I} 3$. Microspores of the pine, or pollen grains, 4I4. Form of the mature female cone, 4I5. Form of a scale of the female flower, 417. Ovules or macrosporangia of the pine, 418. Pollenation, 4I9. Female prothallium of the pine, 422. Archegonia, 423. Male prothallia, 424. Farther growth of the male prothallium, 425. Fertilization, 426. Homology of the parts of the female

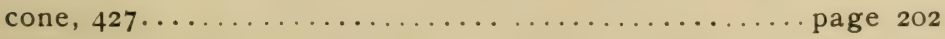

\section{CHAPTER XXXII.}

FARTHER STUDIES ON GYMNOSPERMS.

Cycas, 428. Female prothallium of cycas, 429. Microspores or pollen of cycas, 431. The gingko tree, 432. Spermatozoids in some gymnosperms, 434. The sporophyte in the gymnosperms, 435. The gametophyte has become dependent on the sporophyte, 436. Gymnosperms are naked seed plants, 437. Classification of gymnosperms, 438. Table showing homologies of sporophyte and gametophyte in the pine,

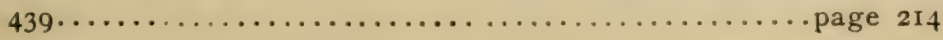




\section{CHAPTER XXXIII.}

MORPHOLOGY OF THE ANGIOSPERMS. TRILLIUM; DENTARIA.

Trillium, 440. General appearance, 440. Parts of the flower, calyx, 44I. Corolla, 442. Andrœcium, 443. The stamen a sporophyll, 444. Gynœcium, 445. Transformation of the flower of trillium, 446. Dentaria, 447. General appearance, 447. Parts of the flower, $448 \ldots \ldots \ldots \ldots \ldots \ldots$ page 22 I

\section{CHAPTER XXXIV.}

\section{GAMETOPHYTE AND SPOROPHYTE OF ANGIOSPERMS.}

Male prothallium of angiosperms, 450. Macrospore and embryo-sac, 453. Embryo-sac is the young female prothallium, 445. Fertilization, 456. Fertilization in plants is fundamentally the same as in animals, 457. Embryo, 458. Endosperm the mature female prothallium, 459. Seed, 460. Perisperm, 46r. Presence or absence of endosperm in the seed, 462. Sporophyte is prominent and highly developed, 463. The gametophyte once prominent has become degenerate, 464. Synopsis of members of the sporophyte in angiosperms, 467. Table showing homologies of sporophyte and gametophyte in angiosperms, $468 \ldots \ldots \ldots$ page

\section{CHAPTER XXXV.}

MORPHOLOGY OF THE NUCLEUS AND SIGNIFICANCE OF GAMETOPHYTE AND SPOROPHYTE.

Direct division of the nucleus, 470 . Indirect division of the nucleus, 47r. Chromatin and linin of the nucleus, 472. The chromatin skein, 473. Chromosomes, nuclear plate, and nuclear spindle, 474 . The number of chromosomes usually the same in a given species throughout one phase of the plant, $474 \pi$. When fertilization takes place the number of chromosomes is doubled in the embryo, $474 b$. Reduction of the number of chromosomes in the nucleus, 475. Significance of karyokinesis and reduction, 476. The gametophyte may develop directly from the tissue of the sporophyte, 477 . The sporophyte may develop directly from the tissue of the gametophyte, 478. Perhaps there is not a fundamental difference between the gametophyte and sporophyte, 479.page 239 


\section{LESSONS ON PLANT FAMILIES.}

\section{CHAPTER XXXVI.}

RELATIONSHIPS SHOWN BY FLOWER AND FRUIT.

Importance of the flower in showing kinships among the higher plants, 48o. Arrangement of flowers, 482. The fruit, 485

\section{CHAPTER XXXVII.}

MONOCOTYLEDONS.

(For lessons and topics see synopsis at close of the lessons.)

Classification, 486. Species, 486. Genus, 487. Genus trillium, 488. Genus erythronium, 489. Genus lilium, 490. Family liliaceæ, 49r. Floral formula, 492. Cohesion and adhesion, 493. Floral diagram, $494 \ldots \ldots \ldots \ldots \ldots \ldots \ldots$ page $25 \mathrm{I}$

\section{CHAPTER XXXVIII.} MONOCOTYLEDONS (concluded)............ 258

CHAPTER XXXIX. Dicotyledons................... 262

CHAPTER XL. DICOTYLEDONS (coniinued)..............265

CHAPTER XLI. DICOTYLEDONS (continued)............. 273

CHAPTER XLII. DiCOTYLEDONS (concluded)............. 283 CHAPTER XIIII. 


\title{
PART III.
}

\section{ECOLOGY.}

\author{
INTRODUCTION.
}

page 300

\section{CHAPTER XLIV.}

WINTER BUDS; GROWTH OF WOODY SHOOTS; LEAF ARRANGEMENT.

Winter buds and how the young leaves are protected, 564 .

Twigs and buds of the horse-chestnut, 565 . Leaf scars, 566 .

Lateral buds, 567. Bud leaves, 568 Opening of the buds in the spring, 569. Growth in thickness of woody stems, 57I. Difference in the firmness of the woody rings, 575 . Annual rings in woody stems. 576. Phyllotaxy or arrangement of leaves, $579 \ldots \ldots \ldots \ldots \ldots \ldots \ldots \ldots \ldots$ page 302

\section{CHAPTER XLV.}

SEEDLINGS.

The common garden bean, $5 s_{4}$. The castor-oil bean, 5 $s_{5}$. How the embryo gets out of a pumpkin seed, 586. Arisama trifhyllum, 58s. Germination of the seed of "jack-in-thepulpit," 58s. How the embryo backs out of the seed, 589 . How the first leaf appears, 59I. The first leaf of "jack-inthe-pulpit" is a simple one, $592 \ldots \ldots \ldots \ldots \ldots$ page 307

\section{CHAPTER XLVI.}

\section{FURTHER STLDIES ON NUTRITION.}

Nutrition in lemna, 504. Spirodela polyrrhiza, 595. Nutrition in wolffia, 596. Nutrition in lichens. 597. Nitrogen gatherers, 599. How clovers, peas, and other legumes gather nitrigen, 599). A fungal or bacterial organism in these root tubercles, 600 . How the organism gets in the roots of the legumes. 60I. The root organism assimilates free nitrogen for its host, 602. Mycorhiza, 603. Nutrition of the dodcter, 605. Carnivorous plants, 606. Nutrition of bacteria, $607 \ldots \ldots \ldots \ldots \ldots \ldots \ldots \ldots \ldots \ldots \ldots \ldots . \ldots \ldots$ p. . . . . . 


\section{CHAPTER XLVII.}

FURTHER STUDIES ON NUTRITION (concluded).

Nutrition of moulds, 608. Nutrition of parasitic fungi, 609. Nutrition of the larger fungi, 610. Studies of mushrooms, 613. Form of the mushroom, 613. Fruiting surface of the mushroom, 614. How the mushroom is formed, 6I5. Beware of the poisonous mushrooms, 617. Wood-destroying

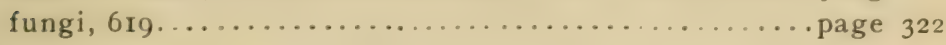

\section{CHAPTER XLVIII. \\ DIMORPHISM OF FERNS.}

Dimorphism in the leaves of ferns, 624. The sensitive fern, 625. Transformation of the fertile leaves of onoclea to sterile ones, 626 . The sporangia decrease as the fertile leaf expands, 628. The ostrich fern, 629. Dimorphism in tropi-

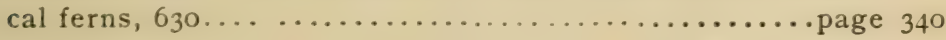

\section{CHAPTER XLIX. \\ FORMATION OF EARLY SPRING FLOWERS.}

Trillium, 631. The adder tongue (erythronium), 633. Indian

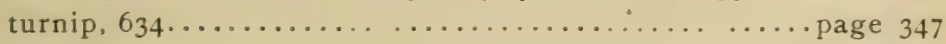

\section{CHAPTER L.}

\section{HEIEROSPORY. POLLENATION.}

Origin of heterospory and the necessity for pollenation, 639 . Both kinds of sexual organisms on the same prothallium, 639. Cross fertilization in monœcious prothallia, 640. Tendency toward diœcious prothallia, 64I. The two kinds of sexual organs on different prothallia, 642 . Permanent separation of the sexes by different amounts of nutriment supplied the spore, 643. Heterospory, 644. In the pteridophytes water serves as the medium for conveying the sperm cell to the female organ, 645 . In the higher plants a modification of the prothallium is necessary, 646 . Pollenation, 649. Self pollenation or close pollenation, 649. Wind pollenation, 650 Pollenation by insects, 65I. Pollenation of the bluet, 653. Pollenation of the primrose, 654. Pol- 
lenation of the skunk's cabbage, 655 . Spiders have discovered this curious relation of the flowers and insects, 657 . Pollenation of jack-in-the-pulpit, 658. Pollenation of orchids, 66o. Pollenation of canna, $664 \ldots \ldots \ldots \ldots \ldots$ page $35 \mathrm{I}$

\section{CHAPTER LI.}

SEED DISTRIBUTION.

Means for dissemination of seed, 672. The prickly lettuce, 676 .

The wild lettuce, 677. The milk-weed or silk-weed, 678 .

The virgin's bower, $680 \ldots \ldots \ldots \ldots \ldots \ldots \ldots \ldots \ldots \ldots$ page 368

\section{CHAPTER LII.}

STRUGGLE FOR OCCUPATION OF LAND.

Retention of made soil, 68I. Vegetation of sand dunes, 683. Reforestation of lands, 684 . Beauty of old fields, 689. page 374

\section{C.HAPTER LIII.}

SOIL FORMATION IN ROCKY REGIONS AND IN MOORS.

Lichens, 690. Lichens are among the pioneers in soil formation, 69r. Other plants of rocky regions, 692. Filling of ponds by plants, 694. A plant atoll, 695. Topography of the atoll moor, 696. A floating inner zone, 698. How was the atoll formed? 700. A black-spruce moor, 703. Fall of the trees of the marginal zone when the windbreak was removed, 704. Dying of the spruce of the central area, 705 . Other morainic moors, 708. The bald cypress (taxodium),

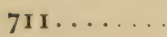
page $38 \mathrm{I}$

\section{CHAPTER LIV.}

ZONAL DISTRIBUTION OF PI.ANTS.

On the margins of lakes and ponds, 712. On the banks of a

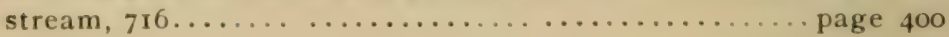

\section{CHAPTER LV.}

PLANT COMMUNITIES; SEASONAL CHANGES.

Plants of widely different groups may exist in the same community, 720. Seasonal succession in plant communities, 
722. The landscape a changing panorama, 725. Refoliation of bare forests in the spring, 726. The summer tints are more subdued, 728. Autumn colors, 729. Fall of the leaf,

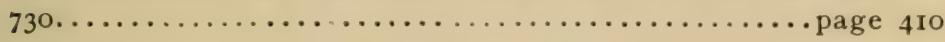

\section{CHAPTER LVI.}

adaptation of plants to Climate.

Some characteristics of desert vegetation. 73r. Some plants of temperate regions possess characters of desert vegetation, 735. Alpine plants with desert characters, 737. Low stature of alpine plants a protection against wind and cold, 738 . Some plants of swamps and moors present characters of arctic or desert vegetation, 739. Hairs on young leaves protect against cold, $740 \ldots \ldots \ldots \ldots \ldots \ldots \ldots \ldots \ldots$ page $4 \mathrm{I} 9$ 



\title{
BOTANY.
}

\author{
CHAPTER I. \\ PROTOPLASM.*
}

1. In the study of plant life and growth, it will be found convenient first to inquire into the nature of the substance which we call the living material of plants. For plant growth, as well as some of the other processes of plant life, are at bottom dependent on this living matter. This living matter is called in general protoplasm.

2. In most cases protoplasm cannot be seen without the help of a microscope, and it will be necessary for us here to employ one if we wish to see protoplasm, and to satisfy ourselves by examination that the substance we are dealing with is protoplasm.

3. We will find it convenient first to examine protoplasm in some of the simpler plants; plants which from their minute size and simple structure are so transparent that when examined with the microscope the interior can be seen.

For our first study we will take a plant known as spirogyra, though there are a number of others which would serve the purpose quite as well, and may quite as easily be obtained for study.

* For apparatus, reagents, collection and preservation of material, etc., see Appendix. 


\section{Protoplasm in spirogyra.}

4. The plant spirogyra.-This plant is found in the water of pools, ditches, ponds, or in streams of slow-running water. It is green in color, and occurs in loose mats, usually floating near the surface. The name "pond-scum" is sometimes given to this plant, along with others which are more or less closely related. It is an $\operatorname{alg} a$, and belongs to a group of plants known as alga. If we lift a portion of it from the water, we see that the mat is made up of a great tangle of green silky threads. Each one of these threads is a plant, so that the number contained in one of these floating mats is very great.

Let us place a bit of this thread tangle on a glass slip, and examine with the microscope and we will see certain things about the plant which are peculiar to it, and which enable us to distinguish it from other minute green water plants. We shall also wish to learn what these peculiar parts of the plant are, in order to demonstrate the protoplasm in the plant.*

5. Chlorophyll bands in spirogyra.-We first observe the presence of bands; green in color, the edges of which are usually very irregularly notched. These bands course along in a spiral manner near the surface of the thread. There may be one or several of these spirals, according to the species which we happen to select for study. This green coloring matter of the band is chlorophyll, and this substance, which also occurs in the higher green plants, will be considered in a later chapter. At quite regular intervals in the chlorophyll band are small starch grains, grouped in a rounded mass enclosing a minute body, the pyrenoid, which is peculiar to many algæ.

\section{The spirogyra thread consists of cylindrical cells end to} end.-Another thing which attracts our attention, as we examine a thread of spirogyra under the microscope, is that the thread is

* If spirogyra is forming fruit some of the threads will be lying parallel in pairs, and connected with short tubes. In some of the cells there will be found rounded or oval bodies known as zygospores. These may be seen in fig. 86, and will be described in another part of the book. 
made up of cylindrical segments or compartments placed end to end. We can see a distinct separating line between the ends. Each one of these segments or compartments of the thread is a cell, and the boundary wall is in the form of a cylinder with closed ends.

7. Protoplasm.-Having distinguished these parts of the plant we can look for the protoplasm. It occurs within the cells. It is colorless (i.e., hyaline) and consequently requires close observation. Near the center of the cell can be seen a rather dense granular body of an elliptical or irregular form, with its long diameter transverse to the axis of the cell in some species; or triangular, or quadrate in others. This is the nucleus. Around the nucleus is a granular layer from which delicate threads of a shiny granular substance radiate in a starlike manner, and terminate in the chlorophyll band at one of the pyrenoids. A granular layer of the same substance lines the inside of the cell wall, and can be seen through the microscope if it is properly focussed. This granular substance in the cell is protoplasm.

8. Cell-sap in spirogyra.--The greater part of the interior space of the cell, that between the radiating strands of protoplasm, is occupied by a watery fluid, the "cell-sap."

9. Reaction of protoplasm to certain reagents. -We can employ certain tests to demonstrate that this granular substance which we have seen is protoplasm, for it has been found, by repeated experiments with a great many kinds of plants, that protoplasm gives a definite reaction in response to treatment with certain substances called reagents. Let us mount a few threads of the

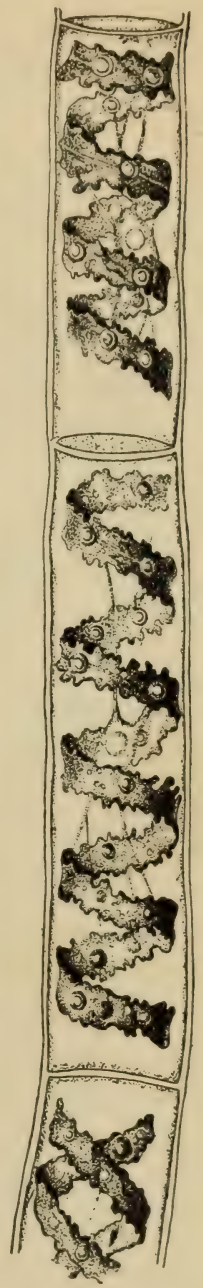

Fig. $\mathrm{r}$.

Thread of spirogyra, showing long cells, chlorophyll $\mathrm{b}$ and, nucleus, strands of protoplasm, and the granular wall layer of protoplasm spirogyra in a drop of a solution of iodine, and observe the 
results with the aid of the microscope. The iodine gives a yellowish-brown color to the protoplasm, and it can be more distinctly seen. The nucleus is also much more prominent since it colors deeply, and we can perceive within the nucleus one small rounded body, sometimes more, the nucleolus. The iodine here has stained the living protoplasm. The protoplasm, however, in a living condition will resist for a time some

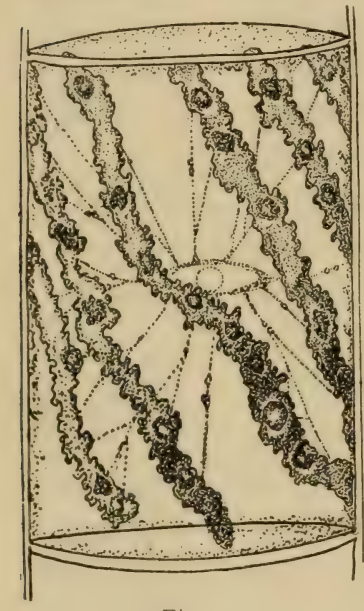

Fig. 2.

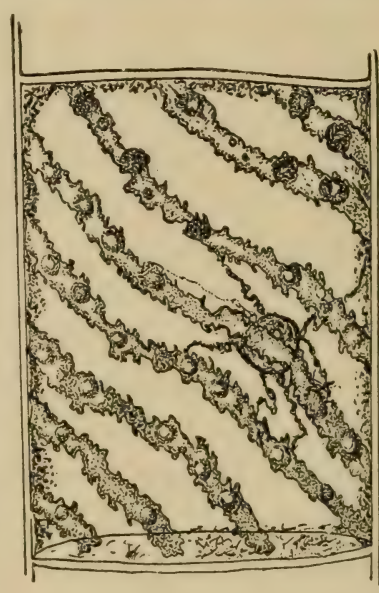

Fig. 3. other reagents, as we shall see if we attempt to stain it with a one per cent aqueous solution of a dye known as eosin. Let us mount a few living threads in such a solution of eosin, and after a time wash off Cell of spirogyra before treat- Cell of spirogyra after treatment ment with iodine. with alcohol and iodine. protoplasm remains uncolored. Now let us place these threads for a short time, two or three minutes, in strong alcohol, which kills the protoplasm. Then mount them in the eosin solution. The protoplasm now takes the eosin stain. After the protoplasm has been killed we note that the nucleus is no longer elliptical or angular in outline, but is rounded. The strands of protoplasm are no longer in tension as they were when alive.

10. Let us now take some fresh living threads and mount them in water. Place a small drop of dilute glycerine on the slip) at one side of the cover glass, and with a bit of filter paper at the other side draw out the water. The glycerine will flow uncler the cover glass and come in contact with the spirogyra threads. Glycerine absorlss water promptly. Being in contact with the threads it draws water out of the cell cavity, thus caus- 
ing the layer of protoplasm which lines the inside of the cell wall to collapse, and separate from the wall, drawing the chlorophyll band inward toward the center also. The wall layer of protoplasm can now be m ore distinctly seen and its granular character observed.

We have thus employed three tests to demonstrate that this substance with which we are dealing shows the reactions which we know by experience to be given

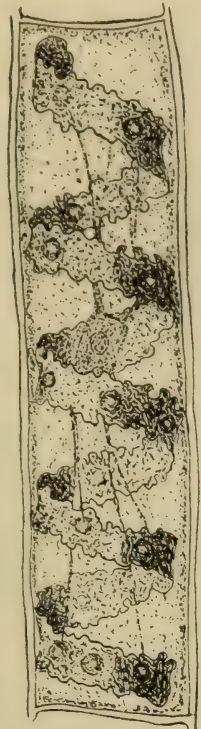

Fig. 4.

Cell of spirogyra before treatment with glycerine.

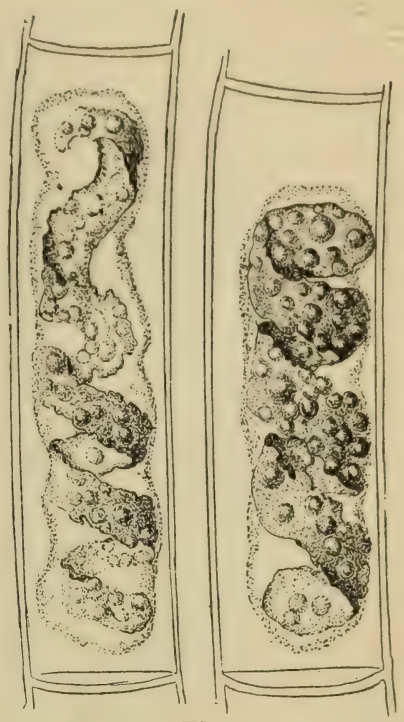

Fig. 5.

Cells of spirogyra after treatment with glycerine.

by protoplasm. We therefore conclude that this colorless and partly granular, slimy substance in the spirogyra cell is protoplasm, and that when we have performed these experiments, and noted carefully the results, we have seen protoplasm.

11. Earlier use of the term protoplasm. - Early students of the living matter in the cell considered it to be alike in substance, but differing in density; so the term protoplasm was applied to all of this living matter. The nucleus was looked upon as simply a denser portion of the protoplasm, and the nucleolus as a still denser portion. Now it is believed that the nucleus is a distinct substance, and a permanent organ of the cell. The remaining portion of the protoplasm is now usually spoken of as the cytoplasm.

In spirogyra then the cytoplasm in each cell consists of a layer which lines the inside of the cell wall, a nuclear layer, which surrounds the nucleus, and radiating strands which connect the nucleus and wall layers, thus suspending the nucleus near the center of the cell. But it seems best in this elementary study to use the term protoplasm in its general sense. 


\section{Protoplasm in mucor.}

12. Let us now examine in a similar way another of the simple plants with the special object in view of demonstrating the protoplasm. For this purpose we may take one of the plants belonging to the group of fungi. These plants possess no chlorophyll. Onz of several species of mucor, a common mould, is readily obtainable, and very suitable for this study.*

13. Mycelium of mucor. - A few days after sowing in some gelatinous culture medium we find slender, hyaline threads, which are very much branched, and, radiating from a central point, form circular colonies, if the plant has not been too thickly sown, as shown in fig. 6. These threads of the fungus form the mycelium. From these characters of the plant, which we can readily see without the aid of a microscope, we note how different it is from spirogyra.

To examine for protoplasm let us lift carefully a thin block of gelatine containing the mucor threads, and mount it in water on a glass slip. Under the microscope we see only a small portion of the branched threads. In addition to the absence of chlorophyll, which we have already noted, we see that the mycelium is not divided at short intervals into cells, but appears like a delicate tube with branches, which become successively smaller toward the ends.

14. Appearance of the protoplasm.-Within the tube-like thread now note the protoplasm. It has the same general appearance as that which we noted in spirogyra. It is slimy, or semi-fluid, partly hyaline, and partly granular, the granules consisting of minute particles (the morosomes). While in mucor the protoplasm has the same general appearance as in spirogyra, its arrangement is very different. In the first place it is plainly

* The most suitable preparations of mucor for study are made by growing the plant in a nutrient substance which largely consists of gelatine, or, better, agar-agar, a gelatinous preparation of certain seaweeds. This, after the plant is sown in it, should be poured into sterilized shallow glass plates, called Petrie dishes. 
continuous throughout the tube. We do not see the prominent radiations of strands around a large nucleus, but still the proto-

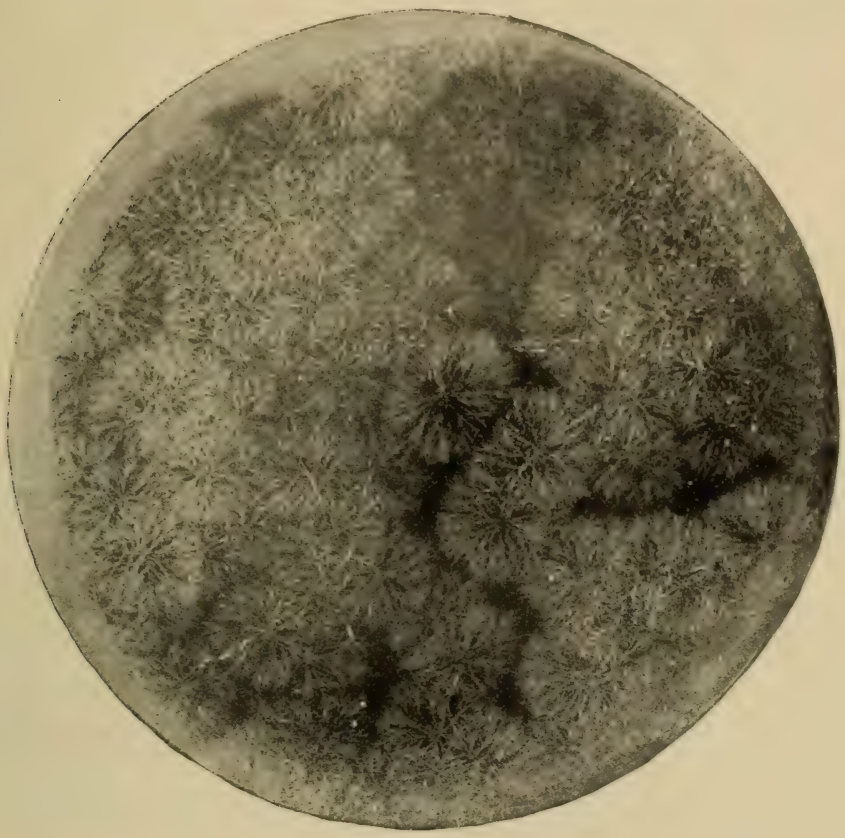

Fig 6.

Colonies of mucor.

plasm does not fill the interior of the threads. Here and there are rounded clear spaces termed vacuoles, which are filled with the watery fluid, cell-sap. The nuclei in mucor are very minute, and cannot be seen except after careful treatment with special reagents.

15 Movement of the protoplasm in mucor.- While examining the protoplasm in mucor we are likely to note streaming movements. Often a current is seen flowing slowly down one side of the thread, and another flowing back on the other side, or it may all stream along in the same direction.

16. Test for protoplasm.-Now let us treat the threads with a solution of iodine. The yellowish-brown color appears which is characteristic of protoplasm when subject to this reagent. 
If we attempt to stain the living protoplasm with a one per cent aqueous solution of eosin it resists it for a time, but if we first kill the protoplasm with strong alcohol, it reacts quickly to the application of the eosin. If we treat the living threads with glycerine the protoplasm is contracted away from the wall, as we found to be the case with spirogyra. While the color,

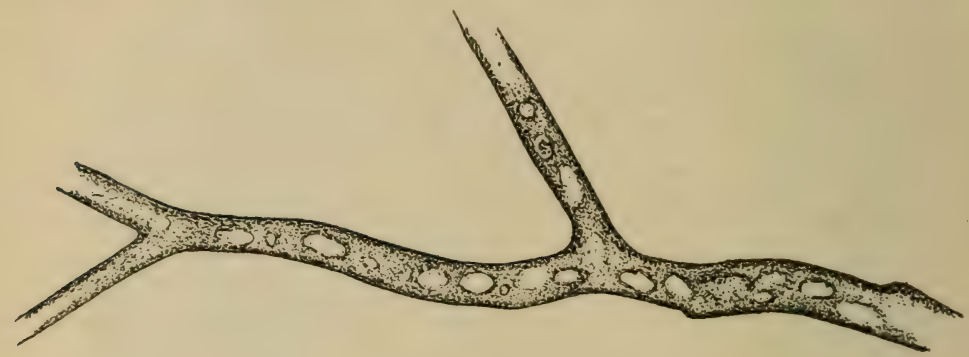

Fig. 7

Thread of mucor, showing protoplasm and vacuoles.

form and structure of the plant mucor is different from spirogyra, and the arrangement of the protoplasm within the plant is also quite different, the reactions when treated by certain reagents are the same. We are justified then in concluding that the two plants possess in common a substance which we call protoplasm.

\section{Protoplasm in nitella.}

17. One of the most interesting plants for the study of one remarkable peculiarity of protoplasm is Nitelli. This plant belongs to a small group known as stoneworts. They possess chlorophyll, and, while they are still quite simple as compared with the higher plants, they are much higher in the scale than spirogyra or mucor.

18. Form of nitella - A common species of nitella is Nitella flexilis. It grows in quiet pools of water. The plant consists of a main axis, in the form of a cylinder. At quite regular intervals are whorls of several smaller thread-like outgrowths, which, because of their position, are termed "leaves," though they are not true leaves. These are branched in a characteristic fashion at the tip. The main axis also branches, these branches arising in the axil of a whorl, usually singly. The portions of the axis where the whorls arise are the node's. Each node is made up of a number of small cells definitely arranged. The portion of the axis between two adjacent whorls is an inter- 
node. These internodes are peculiar. They consist of but a single "cell," and are cylindrical, with closed ends. They are sometimes $5^{-10} \mathrm{~cm}$. long.

19. Internode of nitella.-For the study of an internode of nitella, a small one, near the end, or the ends of one of the "leaves" is best suited, since it is more transparent. A small portion of the plant should be placed on the glass slip in water with the cover glass over a tuft of the branches near the growing end. Examined with the microscope the green chlorophyll bodies, which form oval or oblong discs, are seen to be very numerous. They lie quite closely side by side and form in perfect rows along the inner surface of the wall. One peculiar feature of the arrangement of the chlorophyll bodies is that there are two lines, extending from one end of the internode to the other on opposite sides, where the chlorophyll bodies are wanting. These are known as neutral lines. They run parallel with the axis of the internode, or in a more or less spiral manner as shown in fig. 9 .

20. Cyclosis in nitella.-The chlorophyll bodies are stationary on the inner surface of the wall, but if the microscope be properly focussed just beneath this layer we notice a rotary motion of particles in the protoplasm. There are small granules and quite large masses of granular matter which glide slowly along in one direction on a given side of the neutral line. If now we examine the protoplasm on the other side of the neutral line, we see that the movement is in the opposite direction. If we examine this movement at the end of an internode the particles are seen

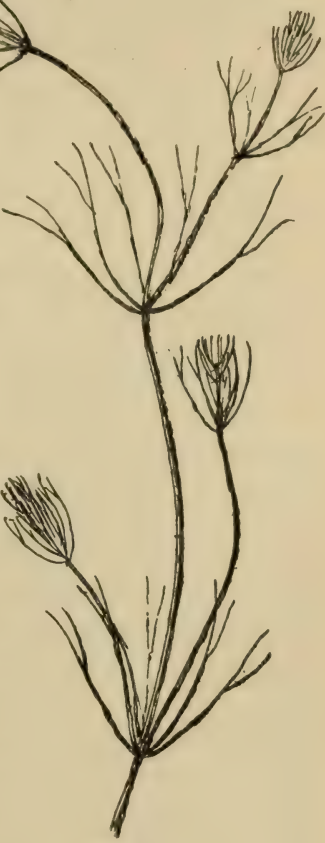

Fig. 8.

Portion of plant nitella. to glide around the end from one sioe of the neutral line to the other. So that when conditions are favorable, such as temperature, healthy state of the plant, etc., this gliding of the particles or apparent streaming of the protoplasm down one side of the "cell," and back upon the other, continues in an uninterrupted rotation, or cyclosis. There are many nuclei in an internode of nitella, and they move also.

21. Test for protoplasm. - If we treat the plant with a solution of iodine we get the same reaction as in the case of spirogyra and mucor. The protoplasm becomes yellowish brown.

22. Protoplasm in one of the higher plants. - We now wish to examine, and test for, protoplasm in one of the higher plants. 
Young or growing parts of any one of various plants-the petioles of young leaves, or young stems of growing plants-are suitable for study. Tissue from the pith of corn (Zea mays) in young

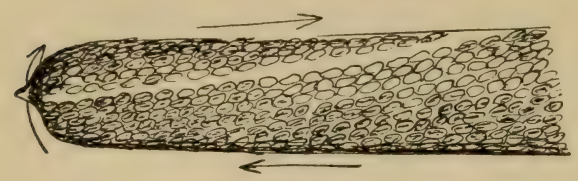

Fig. 9.

Cyclosis in nitella. shoots just back of the growing point or quite near the joints of older but growing corn stalks furnishes excellent material.

If we should place part of the stem of this plant under the microscope we should find it too opaque for observation of the interior of the cells. This is one striking difference which we note as we pass from the low and simple plants to the higher and more complex ones; not only in general is there an increase of size, but also in general an increase in thickness of the parts. The cells, instead of lying end to end or side by side, are massed together so that the parts are quite opaque. In order to study the interior of the plant we have selected it must be cut into such thin layers that the light will pass readily through them.

For this purpose we section the tissue selected by making with a razor, or other very sharp knife, very thin slices of it. These are mounted in water in the usual way for microscopic study. In this section we notice that the cells are polygonal in form. This is brought about by mutual pressure of all the cells. The granular protoplasm is seen to form a layer just inside the wall, which is connected with the nuclear layer by radiating strands of the same substance. The nucleus does not always lie at the middle of the cell, but often is near one side. If we now kill with alcohol and treat with iodine the characteristic yellowishbrown color appears. So we conclude here also that this substance is identical with the living matter in the other very different plants which we have studied.

23. Movement of protoplasm in the higher plants.-Certain parts of the higher plants are suitable objects for the study of the so-called streaming movement of protoplasm, especially the delicate hairs, or thread-like outgrowths, such as the silk of 
corn, or the delicate staminal hairs of some plants, like those of the common spiderwort, tradescantia, or of the tradescantias grown for ornament in greenhouses and plant conservatories.

Sometimes even in the livirg cells of the corn plant which we have just studied, slow streaming or gliding movements of the granules are seen along the strands of protoplasm where they radiate from the nucleus.

\section{Movement of protoplasm in cells of the staminal hair of} "spiderwort." - A cell of one of these hairs from a stamen of a tradescantia grown in glass houses is shown in fig. Io. The

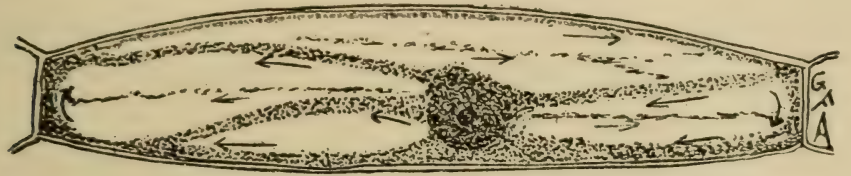

Fig. 10.

Cell from stamen hair of tradescantia showing movement of the protoplasm.

nucleus is quite prominent, and its location in the cell varies considerably in different cells and at different times. There is a layer of protoplasm all around the nucleus, and from this the strands of protoplasm extend outward to the wall layer. The large spaces between the strands are, as we have found in other cases, filled with the cell-sap.

An entire stamen, or a portion of the stamen, having several hairs attached, should be carefully mounted in water. Care should be taken that the room be not cold, and if the weather is cold the water in which the preparation is mounted should be warm. With these precautions there should be little difficulty in observing the streaming movement.

The movement is detected by observing the gliding of the granules. These move down one of the strands from the nucleus along the wall layer, and in towards the nucleus in another strand. After a little the direction of the movement in any one portion may be reversed.

25. Cold retards the movement.--While the protoplasm is moving, if we rest the glass slip on a block of ice, the movement will become slower, or will cease altogether. Then if we 
warm the slip gently, the movement becomes normal again. We may now apply here the usual tests for protoplasm. The result is the same as in the former cases.

\section{Protoplasm occurs in the living parts of all plants.-} In these plants representing such widely different groups, we find a substance which is essentially alike in all. Though its arrangement in the cell or plant body may differ in the different plants or in different parts of the same plant, its general appearance is the same. Though in the different plants it presents, while alive, varying phenomena, as regards mobility, yet when killed and subjected to well known reagents the reaction is in general identical. Knowing by the experience of various investigators that protoplasm exhibits these reactions under given conditions, we have demonstrated to our satisfaction that we have seen protoplasm in the simple alga, spirogyra, in the common mould, mucor, in the more complex stonewort, nitella, and in the cells of tissues of the highest plants.

27. By this simple process of induction of these facts concerning this substance in these different plants, we have learned an important method in science study. Though these facts and deductions are well known, the repetition of the methods by which they are obtained on the part of each student helps to form habits of scientific carefulness and patience, and trains the mind to logical processes in the search for knowledge.

28. While we have by no means exhausted the study of protoplasm, we can, from this study, draw certain conclusions as to its occurrence and appearance in plants. Protoplasm is found in the living and growing parts of all plants. It is a semi-fluid, or slimy, granular, substance; in some plants, or parts of plants, the protoplasm exhibits a streaming or gliding movement of the granules. It is irritable. In the living condition it resists more or less for some time the absorption of certain coloring substances. The water may be withdrawn by glycerine. The protoplasm may be killed by alcohol. When treated with iodine it becomes a yellowish-brown color. 
ABSORPTION, DIFFUSION, OSMOSE.

29. We may next endeavor to learn how plants absorb water or nutrient substances in solution. There are several very instructive experiments, which can be easily performed, and here again some of the lower plants will be found useful.

30. Osmose in spirogyra. - Let us mount a few threads of this plant in water for microscopic examination, and then draw under the cover glass a five per cent solution of ordinary table salt $(\mathrm{NaCl})$ with the aid of filter paper. We shall soon see that the result is similar to that which was obtained when glycerine was used to extract the water from the cell-sap, and to contract the protoplasmic membrane from the cell wall. But the process goes on evenly and the plant is not injured. The protoplasmic layer contracts slowly from the cell wall, and the movement of the membrane can be watched by looking through the microscope. The membrane contracts in such a way that all the contents of the cell are finally collected into a rounded or oval mass which occupies the center of the cell.

If we now add fresh water and draw off the salt solution, we can see the protoplasmic membrane expand again, or move out in all directions, and occupy its former position against the inner surface of the cell wall. This would indicate that there is some pressure from within while this process of absorption is going on, which causes the membrane to move out against the cell wall.

The salt solution draws water from the cell-sap. There is thus a tendency to form a vacuum in the cell, and the jressure on the outside of the protoplasmic membrane causes it 
to move toward the center of the cell. When the salt solution is removed and the thread of spirogyra is again bathed with

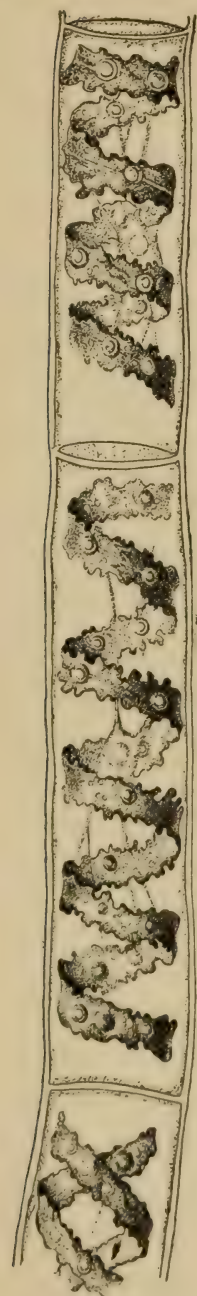

Fig. 11 .

Spirogyra before placing in salt solution. water, the movement of the water is inward in the cell. " This would suggest that there is some substance dissolved in the cell-sap which does not readily filter out through the membrane, but draws on the water outside. It is this which produces the pressure from within and crowds the membrane out against the cell wall again.
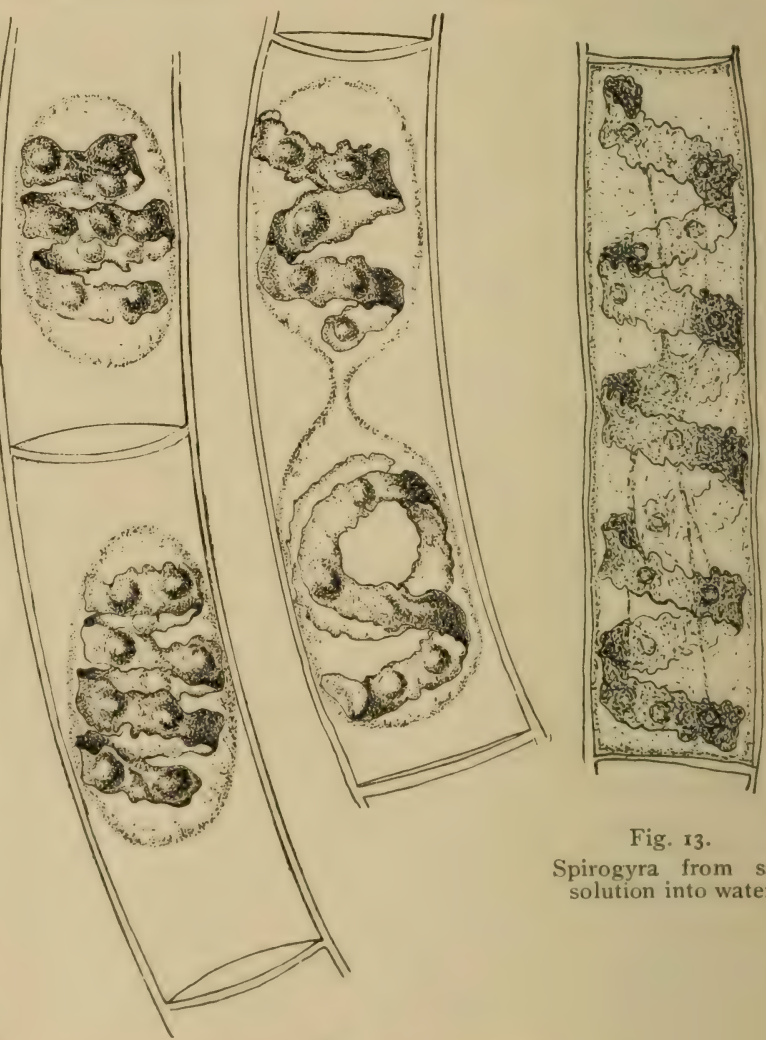

Fig. 13.

Spirogyra from salt solution into water.

Fig. 12.

Spirogyra in $5 \%$ salt solution.

31. Turgescence.-Were it not for the resistance which the cell wall offers to the pressure from within, the lelicate proto- 
plasmic membrane would stretch to such an extent that it would be ruptured, and the protoplasm therefore would be killed. If

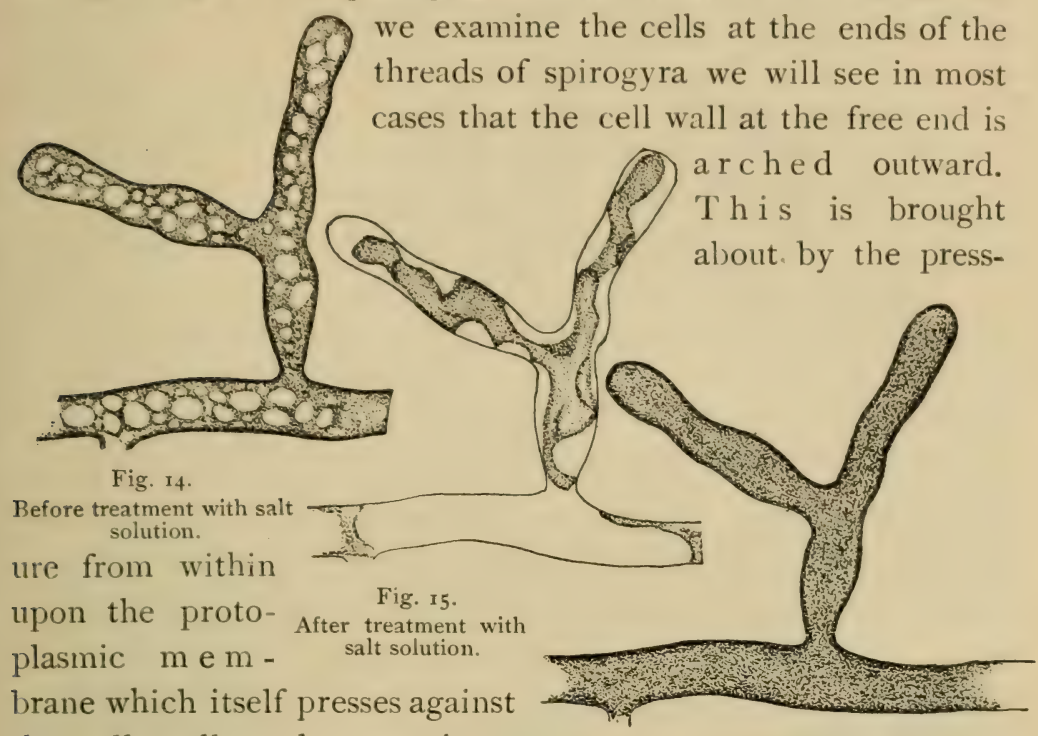
the cell wall, and causes it to arch outward. This is beautifully shown in the case of threads
Fig. I6.

From salt solution placed in water. Figs. 14-16.-Osmosis in threads of mucor. which are recently broken. The cell wall is therefore elastic; it yields to a certain extent to the pressure from within, but a point is soon reached beyond which it will not stretch, and an equilibrium then exists between the pressure from within on the protoplasmic membrane, and the pressure from without by the elastic cell wall. This state of equilibrium in a cell is turgescence, or such a cell is said to be turgescent, or turgid.

\section{Experiment with beet in salt and sugar solutions.-} We may now test the effect of a five per cent salt solution on a portion of the tissues of a beet or carrot. Let us cut several slices of equal size and about $5 \mathrm{~mm}$ in thickness. Immerse a few slices in water, a few in a five per cent salt solution and a few in a strong sugar solution. It should be first noted that all the slices are quite rigid when an attempt is made to bend them between the fingers. In the course of one or two hours or less, 
if we examine the slices we will find that those in water remain, as at first, quite rigid, while those in the salt and sugar solutions are more or less flaccid or limp, and will readily bend by pres-

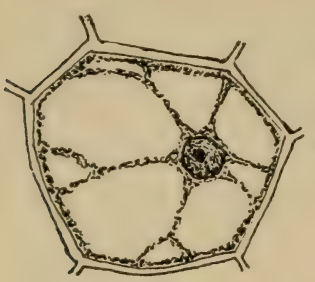

Fig. 17 .

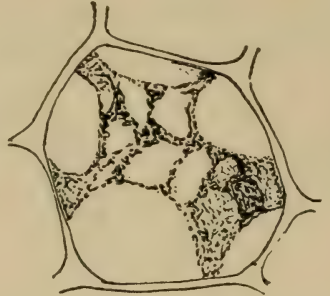

Fig. 18.

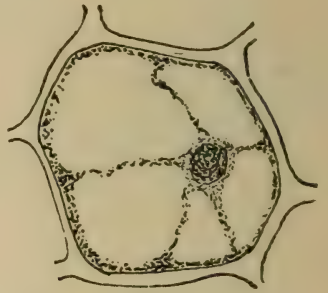

Fig. 19.

Before treatment with salt After treatment with salt From salt solution into water solution. solution. again.

Figs. 17-19.-Osmosis in cells of Indian corn.

sure between the fingers, the specimens in the salt solution, perhaps, being more flaccid than those in the sugar solution. The salt solution, we judge after our experiment with spirogyra,

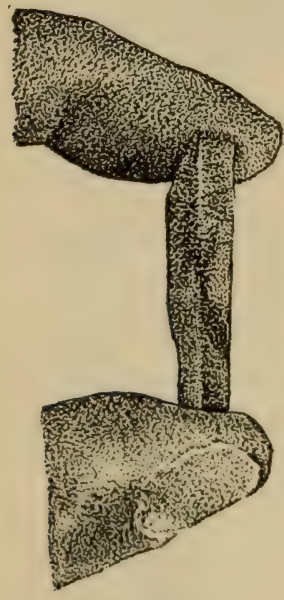

Fig. 20,

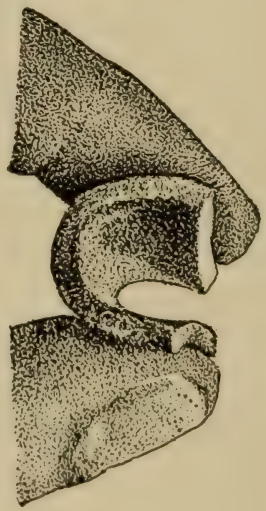

Fig. 2x.

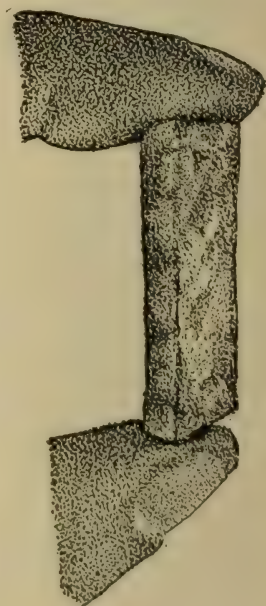

Fig. 22.

Rigid condition of fresh beet Limp condition after lying in Rigid again after lying again section. salt solution. in water.

Figs, 20-22.-Turgor and osmosis in slices of beet.

withdraws some of the water from the cell-sap, the cells thus losing their turgidity and the tissues becoming limp or flaccid from the loss of water. 
33. Let us now remove some of the slices of the beet from the sugar and salt solutions, wash them with water and then immerse them in fresh water. In the course of thirty minutes to one hour, if we examine them again, they will be found to have regained, partly or completely, their rigidity. Here again we infer from the former experiment with spirogyra that the substances in the cell-sap now draw witer inward; that is, the diffusion current is inward through the cell walls and the protoplasmic membrane, and the tissue becomes turgid again.

34. Osmose in the cells of the beet.-We should now make a section of the fresh tissue of a red colored beet for examination with the microscope, and treat this section with the salt solution. Here we can see that the effect of the salt solution is to draw water out of the cell, so that the protoplasmic mem-
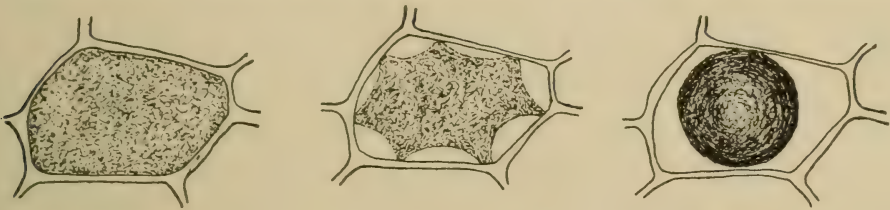

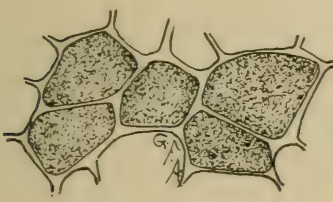

Fig. 23 .

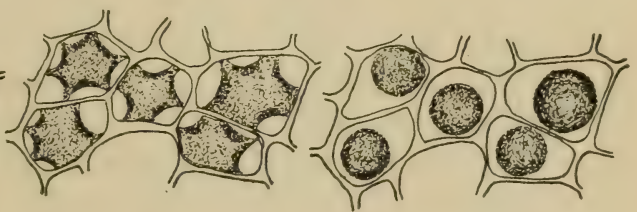

Fig. 24.

Fig. 25 .

Before treatment with salt After treatment with salt Later stage of the same. solution. solution.

Figs. 23-25.-Cells from beet treated with salt solution to show osmosis and movement of the protoplasmic membrane.

lrane can be seen to move inward from the cell wall just as was observed in the case of spirogyra.* Now treating the section with water and removing the salt solution, the diffusion current is in the opposite direction, that is in-

* We should note that the coloring matter of the beet resides in the cellsap. It is in these colored cells that we can best see the movement take place, since the red color serves to differentiate well the moving mass from the cell wall. The protoplasmic membrane at several points usually clings tenaciously so that at several places the membrane is arched strongly away from the cell wall as shown in fig. 24. While water is removed from the cell-sap, we note that the coloring matter does not escape through the protoplasmic membrane. 
ward through the protoplasmic membrane, so that the latter is pressed outward until it comes in contact with the cell wall again, which by its elasticity soon resists the pressure and the cells again become turgid.

35. The coloring matter in the cell-sap does not readily escape from the living protoplasm of the beet.-The red coloring matter, as seen in the section under the microscope, does not escape from the cell-sap through the protoplasmic membrane. When the slices are placed in water, the water is not colored thereby. The same is true when the slices are placed in the salt or sugar solutions. Although water is withdrawn from the cell-sap, this coloring substance does not escape, or if it does it escapes slowly and after a considerable time.

36. The coloring matter escapes from dead protoplasm.-If, however, we heat the water containing a slice of beet up to a point which is sufficient to kill the protoplasm, the red coloring matter in the cell-sap filters out through the protoplasmic membrane and colors the water. If we heat a preparation made for study under the microscope up to the thermal death point we can see here that the red coloring matter escapes through the membrane into the water outside. This teaches that certain substances cannot readily filter through the living membrane of protoplasm, but that they can filter through when the protoplasm is dead. A very important condition, then, for the successful operation of some of the physical processes connected with absorption in plants is that the protoplasm should be in a living condition.

37. 0smose experiments with leaves.-We may next take the leaves of certain plants like the geranium, coleus or other plant, and place them in shallow vessels containing water, salt, and sugar solutions respectively. The leaves should be immersed, but the petioles should project out of the water or solutions. Seedlings of corn or beans, especially the latter, may also be placed in these solutions, so that the leafy ends are immersed. After one or two hours an examination will show that the specimens in the water are still turgid. But if we lift a leaf or a bean plant from the salt or sugar solution, it will be found to be flaccid and limp. The blade, or lamina, of the leaf droops as if wilted, though it is still wet. The bean seedling also is flaccid, the succulent stem bending nearly double as the lower part of the stem is held upright. This loss of turgidity is brought about by the loss of water from the tissues, and judging from the experiments on spirogyra and the beet, we conclude that the loss of turgidity is caused by the withdrawal of some of the water from the cell-sap by the strong salt solution.

38. Now if we wash carefully these leaves and seedlings, which have been in the salt and sugar solutions, with water, and then immerse them in fresh water for a few hours, they will regain their turgidity. Here again we are led to infer that the diffusion current is now inward through the protoplasmic membranes of all the living cells of the leaf, and that the resulting turgidity of the individual cells causes the turgiclity of the leaf or stem. 
39. Absorption by root hairs.-If we examine seedlings, which have been grown in a germinator or in the folds of paper or cloths so that the roots will be free from particles of soil, we will see near the growing point of the roots that the surface is covered with numerous slender, delicate, threadlike bodies, the root hairs. Let us place a portion of a small root containing some of these root hairs in water on a glass slip, and prepare it for examination with the microscope. We will see that each thread, or root hair, is a continuous tube, or in other words it is a single cell which has become very much elongated. The protoplasmic membrane lines the wall, and strands of protoplasm extend across at irregular intervals, the interspaces being occupied by the cell-sap.

We should now draw under the cover glass some of the five per cent salt solution. The protoplasmic membrane moves away from the cell wall at certain points, showing that plasmolysis is taking place, that is, the diffusion current is outward so that the cell-sap loses some of its water, and the pressure from the outside moves the membrane inward. We should not allow the salt solution to work on the root hairs long. It should be very soon removed by drawing in fresh water before the protoplasmic membrane has been broken at intervals, as is apt to be the case by the strong diffusion current and the consequent strong pressure from without. The membrane Seedling of radish, showing root

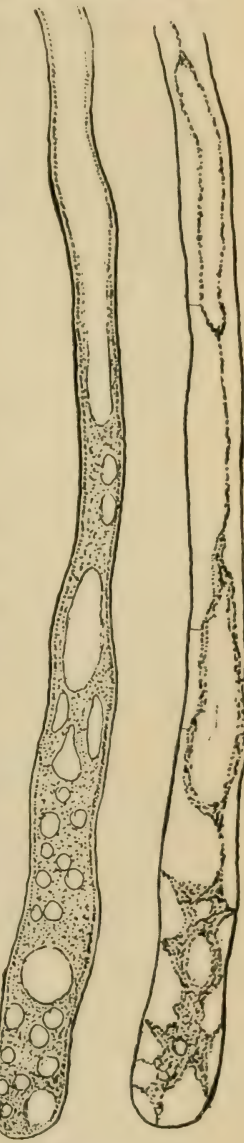

Fig. 27

Root hair of corn before and after treatment with $5 \%$ sait solution. of protoplasm now moves outward as the diffusion current is inward, and soon regains its former position next the inner side of the cell wall. The root hairs then, like other parts of the plant which we have 
investigated, have the fower of taking up water under pressure.

40. Cell-sap a solution of certain substances. - From these experiments we are led to believe that certain substances reside in the cell-sap of plants, which behave very much like the salt solution when separated from water by the protoplasmic membrane. Let us attempt to interpret these phenomena by recourse to diffusion experiments, where an animal membrane separates two liquids of difterent concentration.

41. Diffusion through an animal membrane.-For this experiment we may use a thistle tube, across the larger end of which should be stretched and tied tightly a piece of a bladder membrane. A strong sugar solution (three parts sugar to one part water) is now placed in the tube so that the bulb is filled and the liquid extends part way in the neck of the tube. This is immersed in water within a wide-mouth bottle, the neck of the tube being supported in a perforated cork in such a way that the sugar solution in the tube is on a level with the water in the bottle or jar. In a short while the liquid begins to rise in the thistle tube, in the course of several hours having risen several centimeters. The diffusion current is thus stronger through the membrane in the direction of the sugar solution, so that this gains more water than it loses.

42. We have here two liquids separated by an animal membrane, water on the one hand which diffuses readily through the membrane, while on the other is a solution of sugar which diffuses through the animal membrane with diffculty. The sugar solution is also what is called a concentrated solution, i.e., it is more highly concentrated than water. The water, therefore, according to a general law which has been found to obtain in such cases, diffuses more readily through the membrane into the sugar solution, which thus increases in volume, and also becomes more dilute. The bladder membrane is what is sometimes called a diffusion membrane, since the diffusion currents travel through it.

43. In this experiment then the bulk of the sugar solution is increased, and the liquid rises in the tube by this pressure above the level of the water in the jar outside of the thistle tube. The diffusion of liquids through a membrane is osmosis, and the membrane, since it permits one liquid to pass in one direction more rapidly than in the other, is sometimes called a semipermeable memlirane.

44. Importance of these physical processes in plants. - Now if we recur to our experiment with spirogyra we find that exactly the same processes take place. The protoplasmic membrane is the diffusion membrane, or semipermeable membrane, through which the diftusion takes place. The salt solution which is first used to bathe the threads of the plant is a more highly concentrated solution than that of the cell-sap within the cell. Water therefore is 
drawn out of the cell-sap, but the substances in solution in the cell-sap do not readily move out. As the bulk of the cell-sap diminishes the pressure from the outside pushes the protopiasmic membrane away from the wall. Now when we remove the salt solution and bathe the thread with water again, the cell-sap, being a more highly concentrated solution than water, diffuses with more difficulty and the diffusion current is inward, while the protoplasmic membrane moves out against the cell wall, and turgidity again results. Also in the experiments with salt and sugar solutions on the leaves of geranium, on the leaves and stems of the seedlings, on the tissues and cells of the beet and carrot, and on the root hairs of the seedlings, the same processes take place.

These experiments not only teach us that in the protoplasmic membrane, the cell wall, and the cell-sap of plants do we have structures which are capable of performing these physical processes, but they also show that these processes are of the utmost importance to the plant ; not only in giving the plant the power to take up solutions of nutriment from the soil, but they serve also other purposes, as we shall see later. 


\section{CHAPTER III.}

\section{ABSORPTION OF LIQUID NUTRIMENT.}

45. We are now ready to inquire how plants obtain food from the soil or water. Chemical analysis shows that certain mineral substances are common constituents of plants. By growing plants in different solutions of these various substances it has been possible to determine what ones are necessary constituents of plant food. While the proportion of the mineral elements which enter into the composition of plant food may vary considerably within certain limits, the concentration of the solutions should not exceed certain limits. A very useful solution is one recommended by Sachs, and is as follows :

46. Formula for solution of nutrient materials:

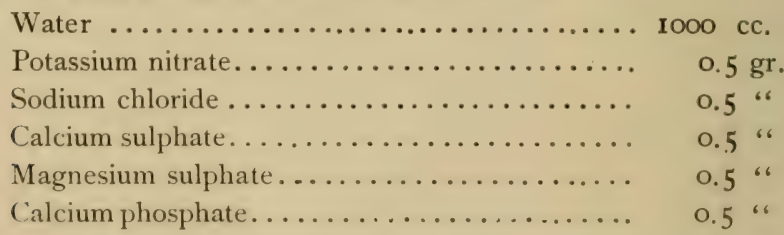

The calcium phosphate is only partly soluble. The solution which is not in use should be kept in a dark cool place to prevent the growth of minute algæ.

47. Several different plants are useful for experiments in water cultures, as peas, corn, beans, buckwheat, etc. The seeds of these plants may be germinated, after soaking them for several hours in warm water, by placing them between the folds of wet paper on shallow trays, or in the folds of wet cloth. The seeds should not be kept immersed in water after they have imbibed enough to thoroughly soak and swell them. At the same time that the seeds are placed in damp paper or cloth for germination, one lot of the soaked seeds 
should be planted in good soil and kept under the same temperature conditions, for control. When the plants have germinated one series should be grown in distilled water, which possesses no plant food; another in the nutrient solution, and still another in the nutrient solution to which has been added a few drops of a solution of iron chloride or ferrous sulphate. There would then be four series of cultures which should be carried out with the same kind of seed in each series so that the comparisons can be made on the same species under the different conditions. The series should be numbered and recorded as follows :

No. I, soil.

No. 2, distilled water.

No. 3, nutrient solution.

No. 4, nutrient solution with a few drops of iron solution added.

48. Small jars or wide-mouth bottles, or crockery jars, can be used for the water cultures, and the cultures are set up as follows: A cork which will just fit in the mouth of the bottle, or which can be supported by pins, is perforated so that there is room to insert the seedling. with the root projecting below into the liquid. The seed can be fastened in position by inserting a pin through one side, if it is a large one, or in the case of small seeds a cloth of a coarse mesh can be tied over the mouth of the bottle instead of using the cork. After properly setting up the experiments the cultures should be arranged in a suitable place, and observed from time to time during several weeks. In order to obtain more satisfactory results several duplicate series should be set up to guard against the error which might arise from variation in individual plants and from accident. Where there are several students in a class, a single series set up by several will act as checks upon one another. If glass jars are used for the liquid cultures they should be wrapped with black paper or cloth to exclude the light from the

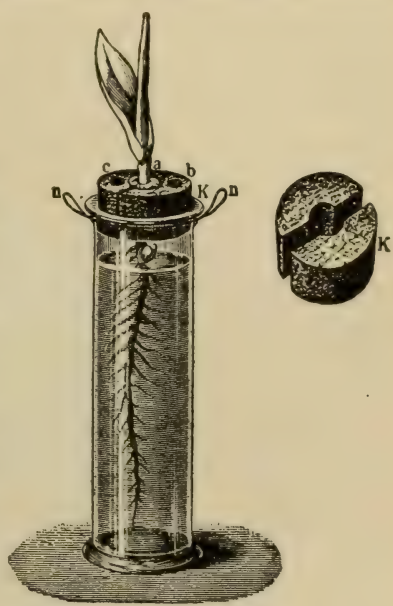

Fig. 28

Culture cylinder to show position of corn seedling (Hansen).

liquid, otherwise numerous minute algæ are apt to grow and interfere with the experiment. Or the jars may be sunk in pots of earth to serve the same purpose. If crockery jars are used they will not need covering.

49. For some time all the plants grow equally well, until the nutriment stored in the seed is exhausted. The numbers I, 3 and 4 , in soil and nutrient solutions, should outstrip number 2 , the plants in the distilled water. No. 4 in the nutrient solution with iron, having a perfect food, compares favorably with the plants in the soil. 
50. Plants take liquid food from the soil. - From these experiments then we judge that such plants take up the food they receive from the soil in the form of a liquid, the elements being in solution in water.

If we recur now to the experiments which were performed with the salt solution in producing plasmolysis in the cells of spirogyra, in the cells of the beet or corn, and in the root hairs of the corn and bean seedlings, and the way in which these cells become turgid again when the salt solution is removed and they are again bathed with water, we will have an explanation of the way in which plants take up nutrient solutions of food material through their roots.

51. How food solutions are carried into the plant.-We can

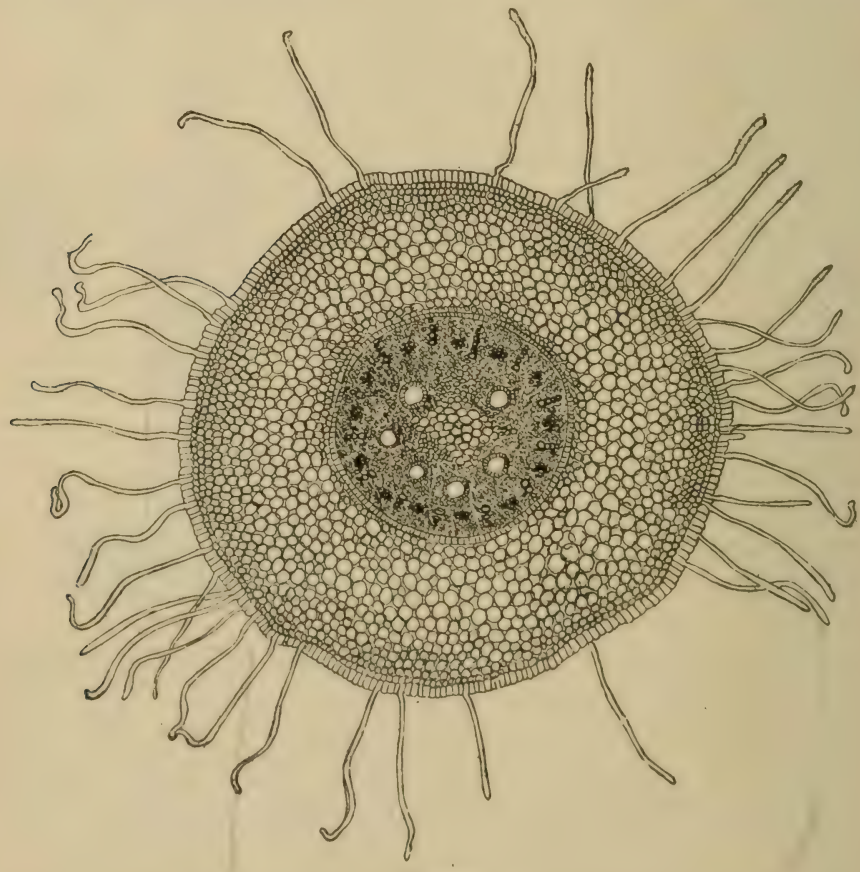

Fig. 29.

Section of com root, showing rhizonds formed from elongated epidermal cells.

ses how the root hairs are able to take up solutions of plant food, and we must next turn our attention to the way in which these 
solutions are carried farther into the plant. We should make a section across the root of a seedling in the region of the root hairs and examine it with the aid of a microscope. We here see that the root hairs are formed by the elongation of certain of the surface cells of the root. These cells elongate perpendicularly to the root, and become $3 \mathrm{~mm}$ to $6 \mathrm{~mm}$ long. They are flexuous or irregular in outline and cylindrical, as shown in fig. 29. The end of the hair next the root fits in between the adjacent superficial cells of the root and joins closely to the next deeper layer of cells. In studying the section of the young root we see that the root is made up of cells which lie closely side by side, each with its wall, its protoplasm and cell-sap, the protoplasmic membrane lying on the inside of each cell wall.

52. In the absorption of the watery solutions of plant food by the root hairs, the cell-sap, being a more concentrated solution, gains some of the former, since the liquird of less concentration flows through the protoplasmic membrane into the more concentrated cell-sap, increasing the bulk of the latter. This makes the root hairs turgid, and at the same time dilutes the cellsap so that the concentration is not so great. The cells of the root lying inside and close to the base of the root hairs have a cell-sap which is now more concentrated than the diluted cell-sap of the hairs, and consequently gain some of the food solutions from the latter, which tends to lessen the content of the root hairs and also to increase the concentration of the cell-sap of the same. This makes it possible for the root hairs to draw on the soil for more of the food solutions, and thus, by a variation in the concentration of the substances in solution in the cell-sap of the different cells, the food solutions are carried along until they reach the vascular bundles, through which the solutions are carried to distant parts of the plant. Some believe that there is a rhythmic action of the elastic cell walls in these cells between the root hairs and the vascular bundles. This occurs in such a way that, after the cell becomes turgid, it contracts, thus reducing the size of the cell and forcing some of the food solutions into the adjacent cells, when by absorption of more food solutions, or water, the cell increases in turgidity again. This rhythmic action of the cells, if it does take place, would act as a pump to force the solutions along, and would form one of the causes of root pressure.

53. How the root hairs get the watery solutions from the soil.-If we examine the root hairs of a number of seedlings which are growing in the soil under normal conditions, we shall see that a large quantity of soil readily clings to the roots. We should note also that unless the soil has been recently watered there is no free water in it; the soil is only moist. We are curious 
to know how plants can obtain water from soil which is not wet. If we attempt to wash off the soil from the roots, being careful not to break away the

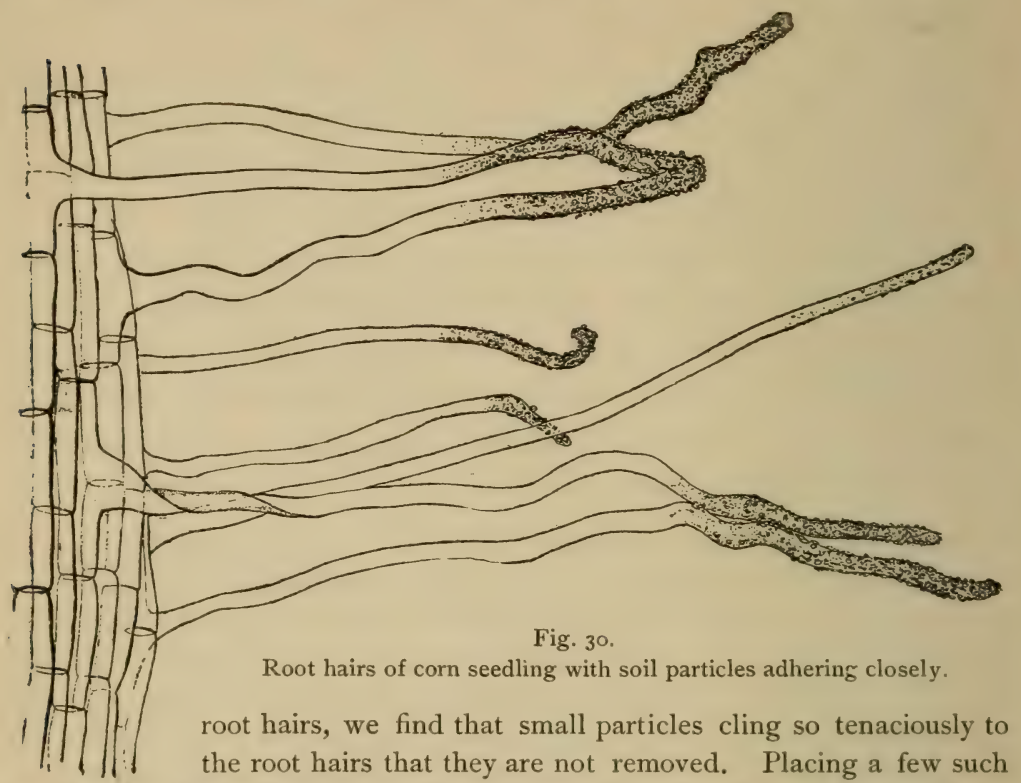
root hairs under the microscope it appears as if here and there the root hairs were glued to the minute soil particles.

54. If now we take some of the soil which is only moist, weigh it, and then permit it to become quite dry on exposure to dry air, and weigh again, we will find that it loses weight in drying. Moisture has been given off. This moisture, it has been found, forms an exceedingly thin film on the surface of the minute soil particles. Where these soil particles lie closely together, as they usually do when massed together in the pot or elsewhere, this thin film of moisture is continuous from the surface of one particle to that of another. Thus the soil particles which are so closely attached to the root hairs connect the surface of the root hairs with this film of moisture. As the cellsap of the root hairs draws on the moisture film with which they are in contact, the tension of this film is sufficient to draw moisture from distant particles. In this way the roots are supplied with water in soil which is only moist.

55. Plants cannot remove all the moisture from the soil. - If we now take a potted plant, or a pot containing a number of seedlings, place it in a moderately dry room, and do not add water to the soil it will be found in a few days that the plant is wilting. The soil if examined will appear quite dry to the sense of touch, Let us weigh some of this soil, then dry it by artificial 
heat, and weigh again. It has lost in weight. This has been brought alout by driving off the moisture which still remained in the soil after the plant began to wilt. This teaches that while plants can obtain water from soil which is only moist or which is even rather dry, they are not able to withdraw all the moisture from the soil.

56. Acidity of root hairs. - If we take a seedling which has been grown in a germinator, or in the folds of cloths or paper, so that the roots are free from the soil, and touch the moist root hairs to blue litmus paper, the paper becomes red in color where the root hairs have come in contact. This is the reaction for the presence of an acid substance, and indicates that the root hairs excrete certain acids. This acid property of the root hairs serves a very important function in the preparation of certain of the elements of plant food in the soil. Certain of the chemical compounds of potash, phosphoric acid, etc, become deposited on the soil particles, and are not soluble in water. The acid of the root hairs dissolves some of these compounds where the particles of soil are in close contact with them, and the solutions can then be taken up by the roots.

57. This corrosive action of the roots can be shown by the well-known experiment of growing a plant on a marble plate which is covered by soil. After a few weeks, if the soil be washed from the marble where the roots have been in close contact, there will be an outline of this part of the root system. Several different acid substances are excreted from the roots of plants which have been found to redden blue litmus paper by contact. Experiments by Czapek, however, show that it is carbonic acid which has the power of dissolving these compounds, while the other acids excreted by the roots do not have this power. 


\section{CHAPTER IV.}

\section{TURGESCENCE.}

58. Turgidity of plant parts. - As we have seen by the experiments on the leaves, turgescence of the cells is one of the conditions which enables the leaves to stand out from the stem, and the lamina of the leaves to remain in an expanded position, so that they are better exposed to the light, and to the currents of air. Were it not for this turgidity the leaves would hang down close against the stem.

59. Restoration of turgidity in shoots. - If we cut off a living stem of geranium, coleus, tomato, or ' balsam,' ' and allow the leaves to partly wilt so that the shoot loses its turgidity, it is possible for this shoot to regain turgidity. 'The end may be freshly cut again, placed in a vessel of water, covered with a bell

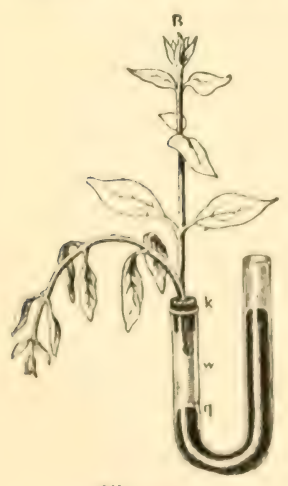

l'ig. 31 .

Restoration of turg dity (Siachs). jar and kept in a room where the temperature is suitable for the growth of the plant. The shoot will usually become turgid again from the water which is absorbed through the cut end of the stem and is carried into the leaves where the individual cells become turgid, and the leaves are again expanded. Such shoots, and the excised leaves also, may often be made turgid again by simply immersing them in water, as one of the experiments with the salt solution would teach.

60. Turgidity may be restored more certainly and quickly in a partially wilted shoot in another way. The cut end of the shoot may be inserted in a $U$ tube as shown in fig. $3 \mathbf{I}$, the (rod of the tube around the stem of the plant heing made air tight. The arm 
of the tube in which the stem is inserted is filled with water and the water is allowed to partly fill the other arm. Into this other arm is then poured mercury. The greater weight of the mercury causes such pressure upon the water that it is pushed into the stem, where it passes up through the vessels in the stems and leaves, and is brought more quickly and surely to the cells which contain the protoplasm and cell-sap, so that turgidity is more quickly and certainly attained.

61. Tissue tensions. - Besides the turgescence of the cells of the leaves and shoots there are certain tissue tensions without which certain tender and succulent shoots, etc., would be limp, and would droop. There are a number of plants usually accessible, some at one season and some at others, which may be used to illustrate tissue tension.

62. Longitudinal tissue tension. - For this in early summer one may use the young and succulent shoots of the elder (sambucus); or the petioles of rhubarb during the summer and early autumn; or the petioles of richardia. Petioles of caladium are excellent for this purpose, and these may be had at almost any season of the year from the greenhouses, and are thus especially advantageous for work during late autumn or winter. The tension is so strong that a portion of such a petiole $10-\mathrm{I} 5 \mathrm{~cm}$ long is ample to demonstrate it. As we grasp the lower end of the petiole of a caladium, or rhubarb leaf, we observe how rigid it is, and how well it supports the heavy expanded lamina of the leaf.

63. The ends of a portion of such a petiole or other object which may be used are cut off squarely. With a knife a strip from $2-3 \mathrm{~mm}$ in thickness is removed from one side the full length of the object. This strip will now be found to be shorter than the larger part from which it was removed. The outer tissue then exerts a tension upon the petiole which tends to shorten it. Let us remove another strip lying next this one, and another, and so on until the outer tissues remain only upon one side. The object will now bend toward that side. Now remove this strip and compare the length of the strips removed with the central portion. They will be found to be much 
shorter now. In other words there is also a tension in the tissue of the central portion of the petiole, the direction of which is opposite to that of the superficial tissue. The parts of the petiole now are not rigid, and they easily bend. These two longitudinal tissue tensions acting in opposition to each other therefore give rigidity to the succulent shoot. It is only when the individual cells of such shoots or petioles are turgid that these tissue tensions in succulent shoots manifest themselves or are prominent.

64. To demonstrate the efficiency of this tension in giving support, let us take a long petiole of caladium or of rhubarb. Hold it by one end in a horizontal position. It is firm and rigid, and does not droop, or but little. Remove all of the outer portion of the tissues, as described above, leaving only the central portion. Now attempt to hold it in a horizontal position by one end. It is flabby and droops downward because the longitudinal tension is removed.

65. Transverse tissue tension.-To illustrate this one may take a willow shoot $3-5 \mathrm{~cm}$ in diameter and saw off sections about $2 \mathrm{~cm}$ long. Cut through the bark on one side and peel it off in a single strip. Now attempt to replace it. The bark will not quite cover the wood again, since the ends will not meet. It must then have been held in transverse tension by the woody part of the shoot. 


\section{CHAPTER V. \\ ROOT PRESSURE.}

66. It is a very common thing to note, when certain shrubs or vines are pruned in the spring, the exudation of a watery fluid from the cut surfaces. In the case of the grape vine this has been known to continue for a number of days, and in some cases the amount of liquid, called "sap," which escapes is considerable. In many cases it is directly traceable to the activity of the roots, or root hairs, in the absorption of water from the soil. For this reason the term root pressure is used to denote the force exerted in supplying the water from the soil.

67. Root pressure may be measured.--It is possible to measure not only the amount of water which the roots will raise in a given time, but also to measure the force exerted by the roots during root pressure. It has been found that root pressure in the case of the nettle is sufficient to hold a column of water about 4.5 meters ( $15 \mathrm{ft}$.) high(Vines), while the root pressure of the vine (Hales, I $72 \mathrm{I}$ ) will hold a column of water about Io meters (36.5 ft.) high, and the birch (Betula lutea) (Clark, I 873) has a root pressure sufficient to hold a column of water about 25 meters $(84.7 \mathrm{ft}$.$) high.$

68. Experiment to demonstrate root pressure - By a very simple method this power of root pressure may be demonstrated. During the summer season plants in the open may be used if it is preferred, but plants grown in pots are also very serviceable, and one may use a potted begonia or balsam, the latter being especially useful. The plants are usually convenient to obtain from the greenhouses, to illustrate this phenomenon. The stem is cut off rather close to the soil and a long glass tube is attached to the cut end of the stem, still connected with the roots, by tne use of rubber tubing as shown in figure 32 , and a 
very small quantity of water may be poured in to moisten the cut end of the stem. In a few minutes the water begins to rise in the glass tube. In some

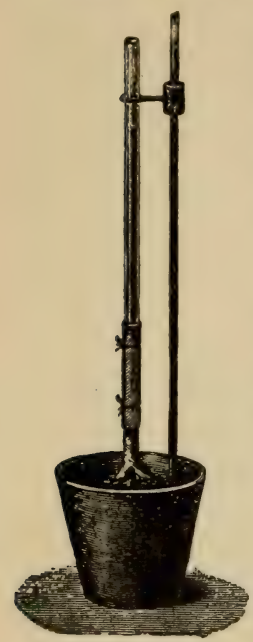

Fig. 32. cases it rises quite rapidly, so that the column of water can readily be seen to extend higher and higher up in the tube when observed at quite short intervals. The height of this column of water is a measure of the force exerted by the roots. The pressure force of the roots may be measured also by determining the height to which it will raise a column of mercury.

69. In either case where the experiment is continued for several days it is noticed that the column of water or of mercury rises and falls at different times during the same day, that is, the column stands at varying heights; or in other words the root pressure varies during the day. With some plants it has been found that the pressure is greatest at certain times of the day, or at certain seasons of the year. Such variation of root pressure exhibits what Experiment to is termed a periodicity, and in the case of some
show root pressure (Detmer).

plants there is a daily periodicity; while in others there is in addition an annual periodicity. With the grape vine the root pressure is greatest in the forenoon, and decreases from I 2-6 P.M., while with the sunflower it is greatest before ro A.M., when it begins to decrease. Temperature of the soil is one of the most important external conditions affecting the activity of root pressure. 


\section{CHAPTER VI.}

\section{TRANSPIRATION.}

70. We should now inquire if all the water which is taken up in excess of that which actually suffices for turgidity is used in the elaboration of new materials of construction. We notice when a leaf or shoot is cut away from a plant, unless it is kept in quite a moist condition, or in a damp, cool place, that it becomes flaccid, and droops. It wilts, as we say. The leaves and shoot lose their turgidity. This fact suggests that there has been a loss of water from the shoot or leaf. It can be readily seen that this loss is not in the form of drops of water which issue from the cut end of the shoot or petiole. What then becomes of the water in the cut leaf or shoot?

71. Loss of water from excised leaves. - Let us take a handful of fresh, green, rather succulent leaves, which are free from water on the surface, and place them under a glass bell jar, which is tightly closed below but which contains no water. Now we will place this in a brightly lighted window, or in sunlight. In the course of fifteen to thirty minutes we notice that a thin film of moisture is accumulating on the inner surface of the glass jar. After an hour or more the moisture has accumulated so that it appears in the form of small drops of condensed water. We should set up at the same time a bell jar in exactly the same way but which contains no leaves. In this jar there will be no condensed moisture on the inner surface. We thus are justified in concluding that the moisture in the former jar comes from the leaves. Since there is no visible water on the surfaces of the leaves, or at the cut ends, before it may have condensed there, 
we infer that the water escapes from the leaves in the form of water vapor, and that this water vapor, when it comes in contact with the surface of the cold glass, condenses and forms the moisture film, and later the drops of water. The leaves of these cut shoots therefore lose water in the form of water vapor, and thus a loss of turgidity results.

72. Loss of water from growing plants.--Suppose we now take a small and actively growing plant in a pot, and cover the pot and the soil with a sheet of rubber cloth which fits tightly around the stem of the plant (or the pot and soil may be enclosed in a hermetically sealed vessel) so that the moisture from the soil cannot escape. Then place a bell jar over the plant, and set in a brightly lighted place, at a temperature suitable for growth. In the course of a few minutes on a dry day a moisture film forms on the inner surface of the glass, just as it did in the case of the glass jar containing the cut shoots and leaves. Later the moisture has condensed so that it is in the form of drops. If we have the same leaf surface here as we had with the cut shoots, we will probably find that a larger amount of water accumulates on the surface of the jar from the plant that is still attached to its roots.

73. Water escapes from the surfaces of living leaves in the form of water vapor.-- This living plant then has lost water, which also escapes in the form of water vapor. Since here there are no cut places on the shoots or leaves, we infer that the loss of water vapor takes place from the surfaces of the leaves and from the shoots. It is also to be noted that, while this plant is losing water from the surfaces of the leaves, it does not wilt or lose its turgidity. The roots by their activity and pressure supply water to take the place of that which is given off in the form of water vapor. This loss of water in the form of water vapor by plants is transpiration.

74. Experiment to compare loss of water in a dry and a humid atmosphere.--We should now compare the escape of water from the leaves of a plant covered by a bell jar, as in the last experiment, with that which takes place when the plant is 
exposed in a normal way in the air of the room or in the open. To do this we should select two plants of the same kind growing in pots, and of approximately the same leafsurface. The potted plants are placed one each on the arms of a scile. One of the plants is covered in this position with a bell jar. With weights placed on the pan of the other arm the two sides are balanced. In the course of an hour, if the air of the room is dry, moisture has probably accumulated on the inner surface of the glass jar which is used to cover one of the plants. This indicates that there has here been a loss of water. But there is no escape of water vapor into the surrounding air so that the weight on this arm is practically the same as at the beginning of the experiment. We see, however, that the other arm of the balance has risen. We infer that this is the result of the loss of water vapor from the plant on that arm. Now let us remove the bell jar from the other llant, and with a cloth wipe off all the moisture from the inner surface, and replace the jar over the plant. We note that the end of the scale which holds this plant is still lower than the other end.

75. The loss of water is greater in a dry than in a humid atmosphere.-This teaches us that while water vapor escaped from the plant under the bell jar, the air in this receiver soon became saturated with the moisture, and thus the farther escape of moisture from the leaves was checked. It also teaches us another very important fact, viz., that plants lose water more rapidly through their leaves in a dry air than in a humid or moist atmosphere. We can now understand why it is that during the very hot and dry part of certain days plants often wilt, while at nightfall, when the atmosphere is more humid, they revive. They lose more water through their leaves during the dry part of the day, other things being equal, than at other times.

76. How transpiration takes place.-Since the water of transpiration passes off in the form of water vapor we are led to inquire if this process is simply evaporation of water through the surlace of the leaves, or whether it is controlled to any appreciable extent by any condition of the living plant. An experiment 
which is instructive in this respect we will find in a comparison between the transpiration of water from the leaves of a cut shoot, allowed to lie unprotected in a dry room, and a similar cut shoot the leaves of which have been killed.

77. Almost any plant will answer for the experiment. For this purpose I have used the following method. Small branches of the locust (Robinia pseudacacia), of sweet clover (Melilotus alba), and of a heliopsis were selected. One set of the shoots was immersed for a moment in hot water near the boiling point to kill them. The other set was immersed for the same length of time in cold water, so that the surfaces of the leaves might be well wetted, and thus the two sets of leaves at the beginning of the experiment would be similar, so far as the amount of water on their surfaces is concerned. All the shoots were then spread out on a table in a dry room, the leaves of the killed shoots being separated where they are inclined to cling together. In a short while all the water has evaporated from the surface of the living leaves, while the leaves of the dead shoots are still wet on the surface. In six hours the leaves of the dead shoots from which the surface water had now evaporated were beginning to dry up, while the leaves of the living plants were only becoming flaccid. In twenty-four hours the leaves of the dead shoots were crisp and brittle, while those of the living shoots were only wilted. In twenty-four hours more the leaves of the sweet clover and of the heliopsis were still soft and flexible, showing that they still contained more water than the killed shoots which had been crisp for more than a day.

78. It must be then that during what is termed transpiration the living plant is capable of holding back the water to some extent, which in a dead plant would escape more rapidly by evaporation. It is also known that a body of water with a surface equal to that of a given leaf surface of a plant loses more water by evaporation during the same length of time than the plant loses by transpiration.

79. Structure of a leaf.-We are now led to inquire why it is that a living leaf loses water less rapidly than dead ones, and why less water escapes from a given leaf surface than from an equal surface of water. To understand this it will be necessary to examine the minute structure of a leaf. For this purpose we will select the leaf of an ivy, though many other leaves will answer equally well. From a portion of the leaf we should make very thin cross sections with a razor or other sharp instrument. These sections should be perpendicular to the surface of the leaf 
and sholild be then mounted in water for microscopic examination.*

80. Epidermis of the leaf.-In this section we see that the green part of the leaf is bordered on what are its upper and lower surfaces by a row of cells which possess no green color. The walls of the cells of each row have nearly parallel sides, and the cross walls are perpendicular. These cells form a single layer over both surfaces of the leaf and are termed the epidermis. Their walls are quite stout and the outer walls are cuticularized.

81. Soft tissue of the leaf.-The cells which contain the green chlorophyll bodies are arranged in two different ways. Those on the upper side

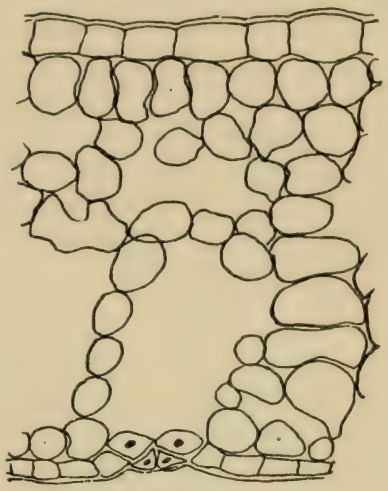

Fig. 33 .

Section through ivy leaf showing communication between stomate and the large intercellular spaces of the leaf; stoma closed. of the leaf are usually long and prismatic in form and lie closely parallel to each other. Because of this arrangement of these cells they are termed the palisade cells, and form what is called the palisade layer. The other green

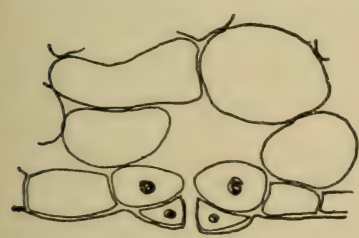

Fig. 34 .

Stoma open.

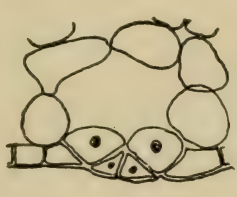

Fig. 35 .

Stoma closed.

Figs. 34, 35.-Section through stomata of ivy leaf. cells, lying below, vary greatly in size in different plants and to some extent also in the same plant. Here we notice that they are elongated, or oval, or somewhat irregular in form. The most striking peculiarity, however, in their arrangement is that they are not usually packed closely together, but each cell touches the other adjacent cells only at certain points. This arrangement of these cells forms quite large spaces between them, the intercellular spaces. If we should examine such a section of a leaf before it is mounted in water we would see that the inter-

* Demonstrations may be made with prepared sections of leaves. 
cellular spaces are not filled with water or cell-sap, but are filled with air or some gas. Within the cells, on the other hand, we find the cell-sap and the protoplasm.

82. Stomata. - If we examine carefully the row of epidermal cells on the under surface of the leaf, we will find here and there a peculiar arrangement of cells shown at figs. 33-35. This

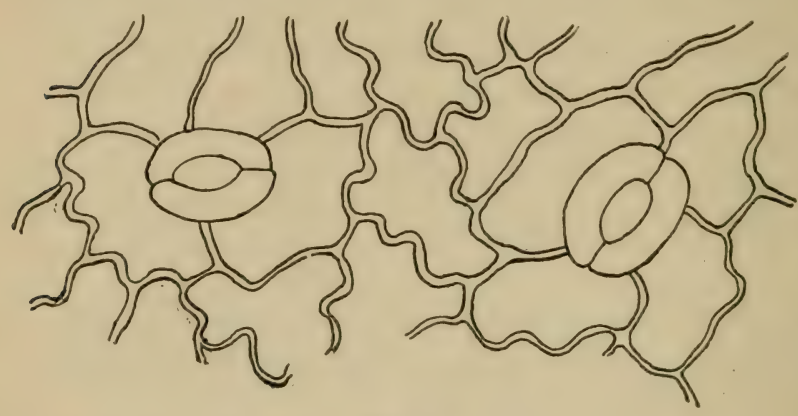

Fig. 36 . o p e $n$ in $g$ through the e pi dermal layer is a stoma. The cells which i m mediately surround the openings are the guard Portion of epidermis of ivy, showing irregular epidermal cells, stoma cells. The and guard cells.

form of the

guard cells can be better seen if we tear a leaf in such a way as to strip off a short piece of the lower epidermis, and mount this in water. The guard cells are nearly crescent shaped, and the stoma is elliptical in outline. The epidermal cells are very irregular in outline in this view. We should also note that while the epidermal cells contain no chlorophyll, the guard cells do.

83. The living protoplasm retards the evaporation of water from the leaf.-If we now take into consideration a few facts which we have learned in a previous chapter, with reference to the physical properties of the living cell, we will be able to give a partial explanation of the comparative slowness with which the water escapes from the leaves. The inner surfaces of the cell walls are lined with the membrane of protoplasm, and within this is the cellsap. These cells have become turgid by the absorption of the water which has passed up to them from the roots. While the protoplasmic membrane of the cells does not readily permit the water to filter through, yet it is saturated with water, and the elastic cell wall with which it is in contact is also saturated. From the cell wall the water evaporates into the intercellular spaces. But the water is given up slowly through the protoplasmic membrane so that the water vapor cannot be given off as rapidly from the cell walls as it could if the protoplasm were dead. The living protoplasmic 
membrane then which is only slowly permeable to the water of the cell-sap is here a very important factor in checking the too rapid loss of water from the leaves.

By an examination of our leaf section we see that the intercellular spaces are all connected, and that the stomata, where they occur, open also into intercellular spaces. There is here an opportunity for the water vapor in the intercellular spaces to escape when the stomata are open.

84. Action of the stomata.-Besides permitting the escape of the water vapor when the stomata are open they serve a very important office in regulating the amount of transpiration. During normal transpiration the stomata remain open, that is, when the amount of transpiration from the leaf is not in excess of the supply of water to the leaves. But when the transpiration from the leaves is in excess, as often happens, and the air becomes very dry, the stomata close and thus the rapid transpiration is checked.

85. Transpiration may be in excess of root pressure.-If the supply of water from the roots was always equal to that transpired from the laves during hot, dry days the leaves would not become flaccid and droop. But during the hot and dry part of the day it often happens that the transpiration is in excess of the amount of water supplied the plant by root pressure.

86. Negative pressure.-This is not only indicated by the drooping of the leaves, but may be determined in another way. If the shoot of such a plant be cut underneath mercury, or underneath a strong solution of eosin, it will be found that some of the mercury or eosin, as the case may be, will be forcibly drawn up into the stem toward the roots. This is seen on quickly splitting the cut end of the stem. When plants in the open cannot be obtained in this condition, one may take a plant like a balsam plant from the greenhouse, or some other potted plant, knock it out of the pot, free the roots from the soil and allow to partly wilt. The stem may then be held under the eosin solution and cut.

87. Lifting power of transpiration.-Not only does transpiration go on quite independently of root pressure, as we have discovered from other experiments, but transpiration is capable of exerting a lifting power on the water in the plant. This may be demonstrated in the following way: Place the cut end of a leafy shoot in one end of a $U$ tube and fit it water-tight. Partly fill this arm of the $U$ tube with water, and add mercury to the other arm until it stands at a level in the two

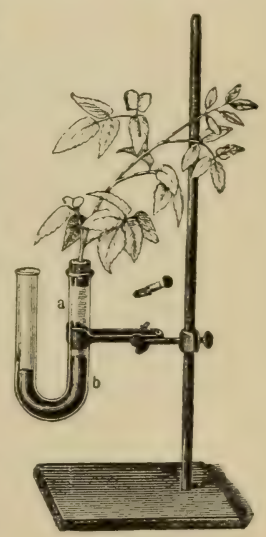

Fig. 37.

Experiment to show lifting power of transpiration. arms as in fig. 37. In a short time we note that the mercury is rising in the tube, 
88. Root pressure may exceed transpiration.--If we cover small actively growing plants, such as the pea, corn, wheat, bean, etc., with a bell jar, and place in the sunlight where the temperature is suitable for growth, in a few hours, if conditions are favorable, we will see that there are drops of water

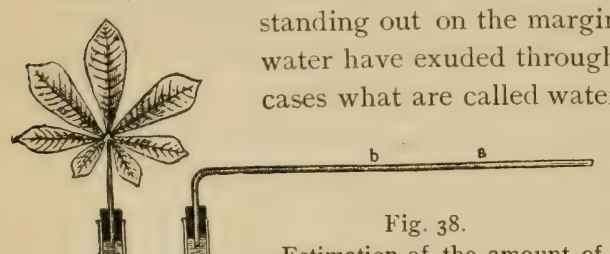

Estimation of the amount of transpiration. The tubes are filled with water, and as the water transpires from the leaf surface its movement in the tube from $a$ to $b$ can be measured. (After Mangin.) (2) These drops of the ordinary stomata, or in other stomata, through the influence of root pressure. The plant being covered by the glass jar, the air soon becomes saturated with moisture and transpiration is checked. Root pressure still goes on, however, and the result is shown in the exuding drops. Root pressure is here in excess of transpiration.

This phenomenon is often to be observed during the summer season in the case of low-growing plants. During the bright warm day transpiration equals, or may be in excess of, root pressure, and the leaves are consequently flaccid. As nightfall comes on the air becomes more moist, and the conditions of light are such also that transpiration is lessened. Root pressure, however, is still active because the soil is still warm. In these cases drops of water may be seen exuding from the margins of the leaves due to the excess of root pressure over transpiration. Were it not for this provision for the escape of the excess of water raised by root pressure, serious injury by lesions, as a result of the great pressure, might result. The plant is thus to some extent a self-regulatory piece of apparatus so far as root pressure and transpira-Guttation of tomato plants after connecting the stems by tion are concerned.

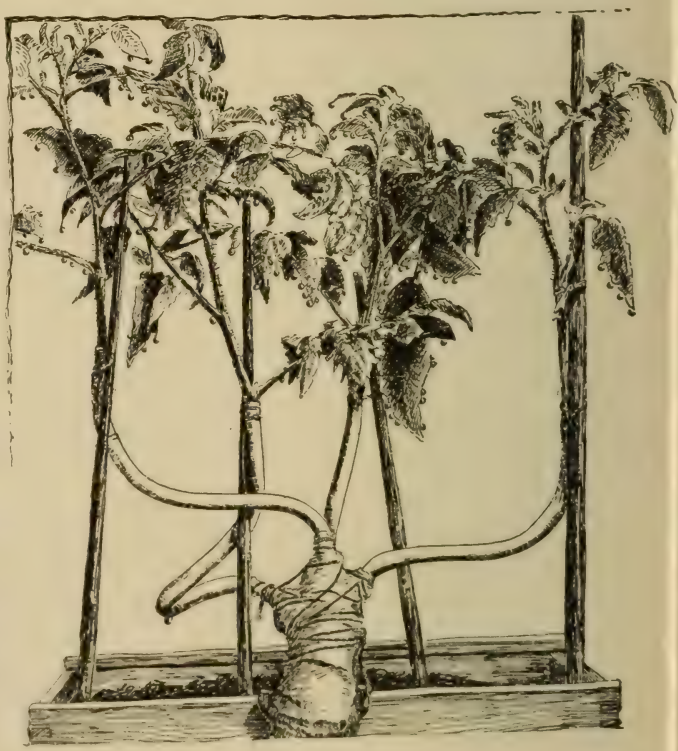

Fig. 39.

89. Injuries caused by excessive root pressure.-Some varieties of tomatoes when grown in poorly lighted and poorly ventilated greenhouses suffer 
serious injury through lesions of the tissues. This is brought about by the cells at certain parts becoming charged so full with water through the activity of root pressure and lessened transpiration. asisisted also probably by an accumulation of certain acids in the cell-sap which cannot be got rid of by transpiration. Under these conditions some of the cells here swell out forming extensive cushions, and the cell walls become so weakened that they burst. It is possible to imitate the exeess of root presirure in the case of some plants by connecting the stems with a system of water pressure, when very quickly the drops of water will begin to exuck from the margins of the leaves.

90. It should be stated that in reality there is no difference between transpiration and evaporation, if we bear in mind that cvaporation takes place more slowly from living plants than from dead ones, or from an equal surface of water.

91. The escape of water vapor is not the only function of the stomata. The exchange of gases takes place through them as we shall later see. A large number of experiments show that normally the stomata are open when the leaves are turgid. But when plants lose excessive quantities of water on dry and hot days, so that the leaves become flaccid, the guard cells automatically close the stomata to check the escape of water vapor. Some water escapes through the epidermis of many plants, though the cuticularized membrane of the epidermis largely prevents evaporation. In arid regions plants are usually provided with an epidermis of several layers of cells to more securely prevent evaporation there. In such cases the guard cells are often protected by being sunk deeply in the epidermal layer.

92. Demonstration of stomates and intercelluiar air spaces.-A good demonstration of the presence of stomates in leaves, as well as the presence and intercommunication of the intercellular spaces, can be made by blowing into the cut end of the petiole of the leaf of a calla lily, the lamina being immersed in water. The air is forced out through the stomata and rises as bubbles to the surface of the water. At the close of the experiment some of the air bubbles will still be in contact with the leaf surface at the opening of the stomata. The pressure of the water gradually forces this back into the leaf. Other plants will answer for the experiment, but some are more suitable than others. 


\section{CHAP'TER VII.}

\section{PATH OF MOVEMENT OF LIQUIDS IN PLANTS.}

93. In our study of root pressure and transpiration we have seen that large quantities of water or solutions move upward through the stems of plants. We are now led to inquire through what part of the stems the liquid passes in this upward movement, or in other words, what is the path of the "sap" as it rises in the stem. This we can readily see by the following trial.

94. Place the cut ends of leafy shoots in a solution of some of the red dyes. - We may cut off leafy shoots of various plants and insert the cut ends in a vessel of water to which have been added a few crystals of the dye known as fuchsin to make a deep red color (other red dyes may be used, but this one is especially good). If the study is made during the summer, the "touchme-not" (impatiens) will be found a very useful plant, or the garden-balsam, which may also be had in the winter from conservatories. Almost any plant will do, however, but we should also select one like the corn plant (zea mays) if in the summer, or the petioles of a plant like caladium, which can be obtained from the conservatory. If seedlings of the castor-oil bean are at hand we may cut off some shoots which are 8-io inches high, and place them in the solution also.

95. These solutions color the tracts in the stem and leaves through which they flow. - After a few hours in the case of the impatiens, or the more tender plants, we can see through the stem that certain tracts are colored red by the solution, and after 12 to 24 hours there may be seen a red coloration of the 
leaves of some of the plants used. After the shoots have been standing in the solution for a few hours, if we cut them at various places we will note that there are several points in the section where the tissues are colored red. In the impatiens perhaps from four to five, in the sunflower a larger number. In these plants the colored areas on a cross section of the stem are situated in a concentric ring which separates more or less completely an outer ring of the stem from the central portion. If we now split portions of the stem lengthwise we see that these colored areas continue throughout the length of the stem, in some cases even up to the leaves and into them.

96. If we cut across the stem of a corn plant which has been in the solution, we see that instead of the colored areas being in a concentric ring they are irregularly scattered, and on splitting

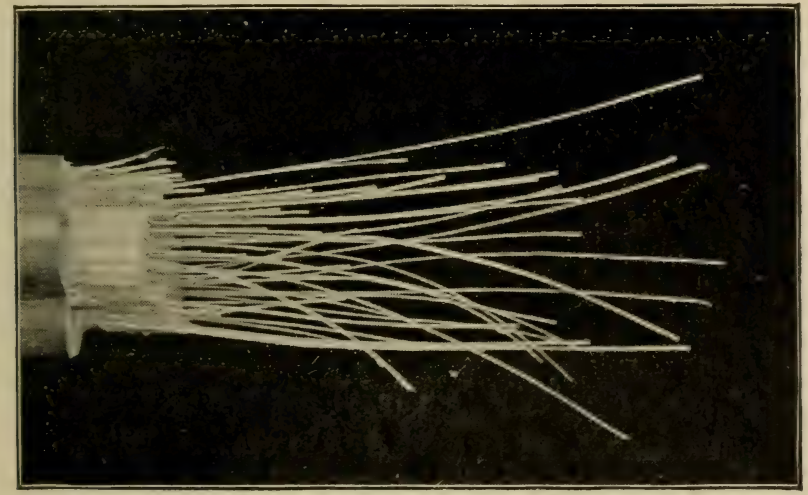

Fig. 40.

Broken corn stalk, showing fibro-vascular bundles.

the stem we see here also that these colored areas extend for long distances through the stem. If we take a corn stem which is mature, or an old and dead one, cut around through the outer hard tissues, and then break the stem at this point, from the softer tissue long strings of tissue will pull out as shown in fig. 40. These strings of denser tissue correspond to the areas which are colored by the dye. They are in the form of minute bundles, and are called vascular bundles. 
97. We thus see that instead of the liquids passing through the entire stem they are confined to definite courses. Now that we have discovered the path of the upward movement of water in the stem, we are curious to see what the structure of these definite portions of the stem is.

98. Structure of the fibro-vascular bundles. - We should now make quite thin cross sections, either free hand and mount in water for microscopic examination, or they may be made with a microtome and mounted in Canada balsam, and in this condition will answer for future study. To illustrate the structure of the bundle in one type we may take the stem of the castor-oil bean. On examining these cross sections we see that there are groups of cells which are denser than the ground tissue. These groups correspond to the colored areas in the former experiments, and are the vascular bundles

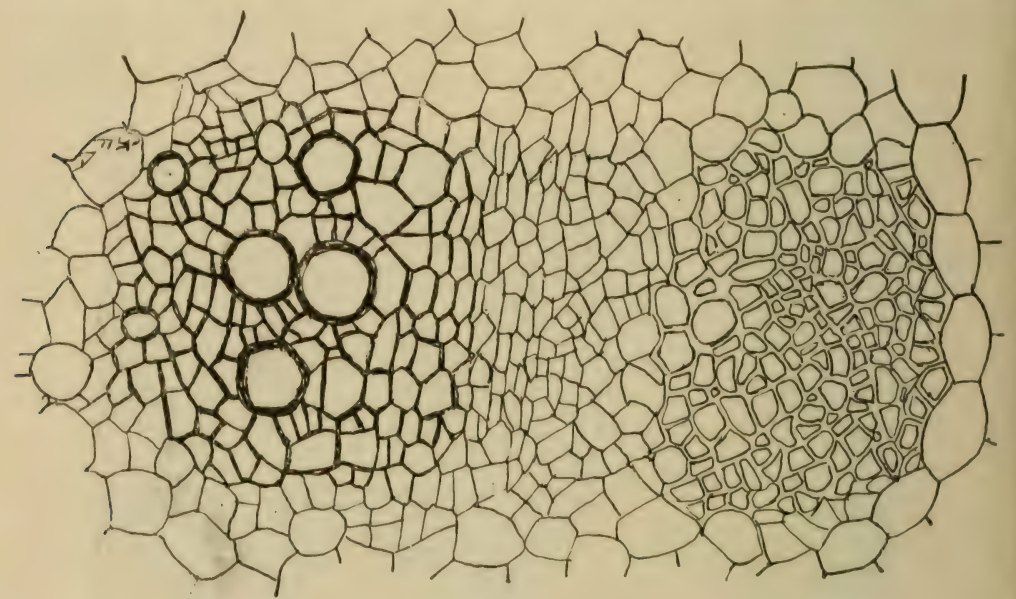

Fig. 41.

Xylem portion of bundle. Cambium portion of bundle. Bast portion of bund!c Section of vascular bundle of sunflower stem.

cut across. These groups are somewhat oval in outline, with the pointed end directed toward the center of the stem. If we look at the section as a whole we will see that there is a narrow continuous ring* of small cells

* This ring and the bundles separate the stem into two regions, an outer one composed of large cells with thin walls, known as the cortical cells, or collectively the cortix. The inner portion, corresponding to what is called the pith, is made up of the same kind of cells and is called the meduller, or pith. When the acthe of the cortex, as well as of the pith. remain thin walled the tis-me is called parenchymat. Parenchyma belongs to the group of tissues callerl fundamental. 
situated at the same distance from the center of the stem as the middle part of the bundles, and that it divides the bundles into two groups of cells.

99. Woody portion of the bundle. - In that portion of the bundle on the inside of the ring, i.e., toward the "pith," we note large, circulat, or angular cavities. The walls of these cells are quite thick and wooly. They are therefore called wood cells, and because they are continuous with cells above and below them in the stem in such a way that long tubes are formed, they are called woody vessels. Mixed in with these are smaller cells, some of which also have thick walls and are wood cells. Some of these cells may have thin walls. This is the case with all when they are young, and they are then classed with the funclamental tissue or soft tissuc (parenchyma). This part of the bundle, since it contains workly vessels and fibres, is the wood portion of the bundle, or technically the xylem.

100. Bast portion of the bundle. - If our section is through a part of the stem which is not too young, the tissues of the outer part of the bundle will show either one or several groups of cells which have white and shiny walls, that are thickened as much or more than those of the word vessels. These cells are bast cells, and for this reation this part of the bundle is the bast portion, or the phloem. Intermingled with these, cells may often be found which have thin walls, unless the bundle is very old. Nearer the center of the bundle and still within the bast portion are cells with thin walls, angular and irregularly arranged. This is the softer portion of the bast, and some of these cells are what are called sieve tubes, which can be better seen and studied in a longitudinal section of the stem.

101. Cambium region of the bundle.-Extending across the center of the bundle are several rows of small cells, the smallest of the bundle, and we can see that they are more regularly arranged, usually in quite regular rows, like bricks piled upon one another. These cells have thinner walls than any others of the bundle, and they usually take a deeper stain when treated with a solution of some of the dyes. This is because they are younger, and are therefore richer in protoplasmic contents. This zone of young cells across the bundle is the cambium. Its cells grow and divide, and thus incruase the size of the bundle. By this increase in the number of the cells of the cambium layer, the outermost cells on either side are continually passing over into the phloem, on the one hand, and into the wood portion of the bundle, on the other hand.

102. Longitudinal section of the bundle. - If we make thin longisections of the vascular bundle of the castor-oil seedling (or other dicotyledon) so that we have thin ones ruming through a bundle radially, as shown in fig. 42. we can see the structure of these parts of the bundle in sisle view. We see here that the form of the cells is very difierent from what is presented in a corss section of the same. The walls of the various ducts have peculiar markings on them. There markings are caused by the walls being thicker in some 
places than in others, and this thickening takes place so regularly in some instances as to form regular spiral thickenings. Others have the thickenings

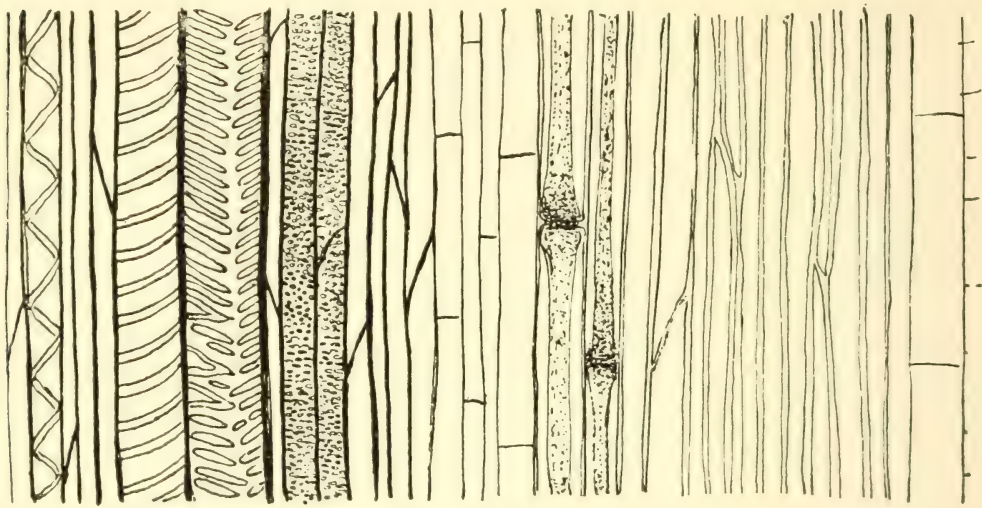

Fig. 42 .

Longitudinal section of vascular bundle of sunflower stem ; spiral, scalariform and pitted vessels at left; next are wood fibers with oblique cross walls; in middle are cambium cells with straight cross walis, next two sieve tubes, then phloem or bast cells.

in the form of the rounds of a ladder. while still others have pitted walls or the thickenings are in the form of rings.

103. Vessels or ducts. - One way in which the cells in side view differ greatly from an end view, in a cross section in the bundle, is that they are much longer in the direction of the axis of the stem. The cells have become elongated greatly. If we search for the place where two of these large cells with spiral, or ladder-like, markings meet end to end, we will see that the wall which formerly separated the cells has nearly or quite disappeared. In other words the two cells have now an open communication at the ends. This is so for long distances in the stem. so that long columns of these large cells form tubes or vessels through which the water rises in the stems of plants.

104. In the bast portion of the bundle we detect the cells of the bast fibers by their thick walls. They are very much elongated and the ends taper out to thin points so that they overlap. In this way they serve to strengtlien tie stem.

105. Sieve tubes. - Lying near the bast cells, usually toward the cambium. are elongated cells standing end to end, with delicate markings on their cross walls which appear like finely punctured p'ates or sieves. The protoplasm in such cells is usually quite distinct, and sometimes contracted away from the side walls. but attached to the cross walls. and this aids in the detection of the sieve tubes (fig. 42.) The granular appearance which these plates present is caused by minute perforations through the wall so that there is a communication between the cells. The tules thus formed are therefore called sieve tubes and they extend for long distances through the tube so that there 
is communication throughout the entire length of the stem. (The function of the sieve tubes is supposed to be that for the downward transportation of substances elaborated in the leaves.)

106. If we section in like manner the stem of the sunflower we shall see similar bundles, but the number is greater than eight. In the garden balsam the number is from four to six in an ordinary stem 3-4mm diameter. Here we can see quite well the origin of the vascular bundle. Between the larger bundles we can see especially in free-hand sections of stems through which a colored solution has been lifted by transpiration, as in our former experiments, small groups of the minute cells in the cambial ring which are colored. These groups of cells which form strands running through the stem are procambium strands. The cells divide and increase just like the cambium cells, and the older ones thrown off on either side change, those toward the center of the stem to wood vessels and fibers, and those on the outer side to bast cells and sieve tubes.

107. Fibrovascular bundles in the Indian corn.-We should now make a thin transection of a portion of the center of the stem of Indian corn, in order to compare the structure of the bundle with that of the plants which we have just examined. In fig. 43 is represented a fibrovascular bundle of the stem of the Indian corn. The large cells are those of the spiral and reticulated and annular vessels. This is the woody portion of the bundle or xylem, Opposite this is the bast portion or phloem, marked by the lighter colored tissue at $i$. The larger of these cells are the sieve tubes, and intermingled with them are smaller cells with thin walls. Surrounding the entire bundle are small cells with thick walls. These are elongated and the tapering ends overlap. They are thus slender and long and form fibers. In such a bundle all of the cambium has passed over into permanent tissue and is said to be closed.

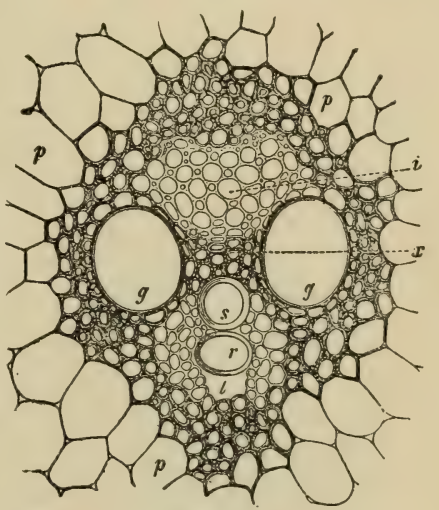

Fig. 43.

Transection of fibrovascular bundle of Indian corn. $a$, toward periphery of stem; $g$, large pitted vessels; $s$, spiral vessel ; $r$, annular vessel : $l$, air cavity formed by breaking apart of the cells : $i$, soft bast, a form of sieve tissue; $p$, thinwalled parenchyma. (Sachs.)

108. Rise of water in the vessels.-During the movement of the water or nutrient solutions upward in the stem the vessels of the wood portion of the bundle in certain plants are nearly or quite filled, if root pressure is active and transpiration is not very rapid. If, however, on dry days transpiration is in excess of root pressure, as often happens, the vessels are not filled with the water, but are partly filled with certain gases because the air or other 
crases in the plant be omme rirefied as a result of the excessive loss of water. There are then successive rows of air or gas bubbles in the vessels separated by films of water which also line the walls of the vessels. The condition of the vessel is much like that of a glass tube through which one might pass the "froth" which is formed on the surface of soapy water. This forms a chain of bubbles in the vessels. This chain has been called Jamin's chain because of the discoverer.

109 Why water or food solutions can be raised by the plant to the height attained by some trees has never been satisfactorily explained. There are several theories propounded which cannot be discussed here. It is probably a very complex process. Root pressure and transpiration both play a part, or at least can be shown, as we have seen, to be capable of lifting water to a considerable height. In addition to this, the walls of the vessels absorb water by diffusion, and in the small vessels capillarity comes also into play, as well as osmosis.

\section{Synopsis of tissues.}

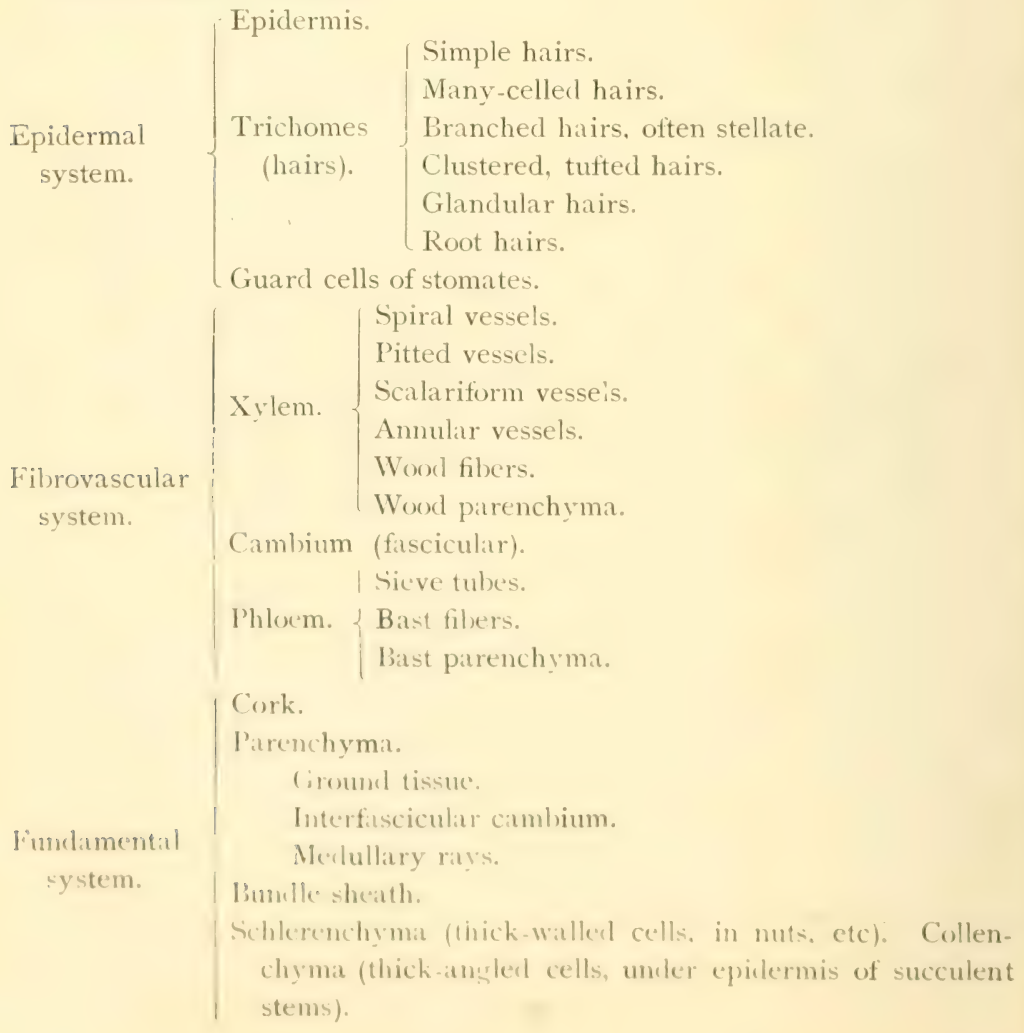




\section{CHAPTER VIII.}

\section{DIFFUSION OF GASES.}

111. Gas given off by green plants in the sunlight.-Let us take some green alga, like spirogyra, which is in a fresh condition, and place one lot in a beaker or tall glass vessel of water and set this in the direct sunlight or in a well lighted place. At the same time cover a similar vessel with spirogyra with black cloth so that it will be in the dark, or at least in very weak light.

112. In a short time we note that in the first vessel small bubbles of gas are accumulating on the surface of the threads of the spirogyra, and now and then some free themselves and rise to the surface of the water. Where there is quite a tangle of the threads the gas is apt to become caught and held back in larger bubbles, which on agitation of the vessel are freed.

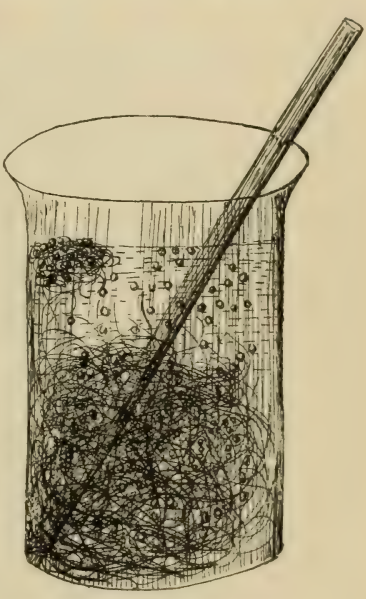

Fig. 44 .

If we now examine the second vessel Oxygen gas given off by spirogyra. we see that there are no bubbles, or only a very few of them. We are led to believe then that sunlight has had something to do with the setting free of this gas from the plant.

113. We may now take another alga like vaucheria and perform the experiment in the same way, or to save time the two may be set up at once. In fact if we take any of the green 
algæ and treat them as described above gas will be given off in a similar manner.

114. We may now take one of the higher green plants, an aquatic plant like elodea, callitriche, etc. Place the plant in

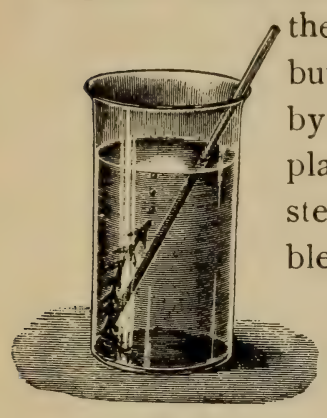

Fig. 45

Bubbles of oxygen gas given off from elodea in a large part of the gas is furnished by the
presence of sunlight. presence of sunlight.
(Oels.)

115. Another vessel fitted up in the same way should be placed in the dark or shaded by covering with a box or black cloth. It will be seen here, as in the case of spirogyra, that very few or no bubbles of gas will be set free. Sunlight here also is necessary for the rapid escape of the gas.

116. We may easily compare the rapidity with which light of varying intensity effects the setting free of this gas. After cutting the end of the stem let us plunge the cut surface several times in melted paraffine, or spread over the cut surface a coat of varnish. Then prick with a needle a small hole through the paraffine or varnish. Immerse the plant in water and place in sunlight as before. The gas now comes from the puncture through the coating of the cut end, and the number of bubbles given off during a given period can be ascertained by counting. If we duplicate this experiment by placing one plant in weak light or diffused sunlight, and another in the shade, we can easily compare the rapidity of the escape of the gas under the different conditions, which represent varying intensities of light. We see then that not only is sunlight necessary for the setting free of this gas, but that in diffused light or in the shade the activity of the plant in this respect is less than in direct sunlight.

117. What this gas is. - If we take quite a quantity of the plants of elodea and place them under an inverted funnel which is immersed in water, the gas will be given off in quite large quantities and will rise into the narrow exit of the funnel. 
The funnel should be one with a short tube, or the vessel one which is quite deep so that a small test tube which is filled with water may in this condition be inverted over the opening of the funnel tube. With this arrangement of the experiment the gas will rise in the inverted test tube, slowly displace a portion of the water, and become collected in a sufficient quantity to afford us a test. When a considerable quantity has accumulated in the test tube, we may close the end of the tube in the water with the thumb, lift it from the water and invert. The gas will rise against the thumb. A dry soft pine splinter should be then lighted, and (Detmer.)

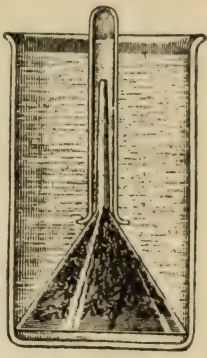

Fig. 46.

Apparatus for colecting quantity of oxygen from elodea. after it has burned a short time, extinguish the flame by blowing upon it, when the still burning end of the splinter should be brought to the mouth of the tube as the thumb is quickly moved to one side. The glowing of the splinter shows that the gas is oxygen.

118. 0xygen given off by green land plants also.--If we should extend our experiments to land plants we would find that oxygen is given off by them under these conditions of light. Land plants, liowever, will not do this when they are immersed in water, but it is necessary to set up rather complicated apparatus and to make analyses of the gases at the beginning and at the close of the experiments. This has been done, however, in a sufficiently large number of cases so that we know that all green plants in the sunlight, if temperature and other conditions are favorable, give off oxygen.

119. Absorption of carbon dioxide. - We have next to inquire where the oxygen comes from which is given off by green plants when exposed to the sunlight, and also to learn something more of the conditions necessary for the process. We know that water which has been for some time exposed to the air and soil, and has been agitated, like running water of streams, or the water of springs, has mixed with it a considerable quantity of oxygen and carbon dioxide.

120. If we boil spring water or hyclrant water which comes from a stream containing oxygen and carbon dioxide, for about 20 
minutes, these gases are driven off. We should set this aside where it will not be agitated, until it has cooled sufficiently to receive plants without injury. Let us now place some spirogyra or vaucheria, and elodea, or other green water plant, in this boiled water and set the vessel in the bright sunlight under the same conditions which were employed in the experiments for the evolution of oxygen. No oxygen is given off.

121. Can it be that this is because the oxygen was driven from the water in boiling? We will see. Let us take the vessel containing the water, or some other boiled water, and agitate it so that the air will be thoroughly mixed with it. In this way oxygen is again mixed with the water. Now place the plant again in the water, set in the sunlight, and in several minutes observe the result. No oxygen is given off. There must be then some other requisite for the evolution of the oxygen.

122. The gases are interchanged in the plants.-We will now introduce carbon dioxide again in the water. This can be done by blowing into the water through a glass tube in such a manner as to violently agitate the water for some time, when the carbon dioxide from the "breath" will become mixed with the water. Now if we place the plant in the water and set the vessel in the sunlight, in a few minutes the oxygen is given off rapidly.

123. A chemical change of the gas takes place within the plant cell. - This leads us to believe then that $\mathrm{CO}_{2}$ is in some way necessary for the plant in this process. Since oxygen is given off while carbon dioxide, a different gas, is necessary, it would seem that a chemical change takes place in the gases within the plant. Since the process takes place in such simple plants as spirogyra as well as in the more bulky and higher plants, it appears that the changes go on within the cell, in fact within the protoplasm.

124. Gases as well as water can diffuse through the protoplasmic membrane.-Carbon dioxide then is absorbed by the plant while oxygen is given off. We see therefore that gases as well as water can diffuse through the protoplasmic membrane of plants under certain conditions. 
125. Note. If we kill the plant. for example, by placing it for a short tume in nearly boiling water, oxygen will not be given off when the plant ss placed in the sunlight in water. In other words the plant must be alive. Farther, if we introduce $\mathrm{CO}_{2}$ in the water by blowing into it and have not introduced oxygen, oxygen will not be evolved. Not only must the plant be alive. it must have access to oxygen, which we will see later is very essential to the continuance of one of the important life processes. 


\section{CHAPTER IX. \\ RESPIRATION.}

126. One of the life processes in plants which is extremely interesting, and which is exactly the same as one of the life processes of animals, is easily demonstrated in several ways.

127. 0xygen from the air consumed during germination of seeds. - Let us take a half pint or a pint of peas, tie them in a

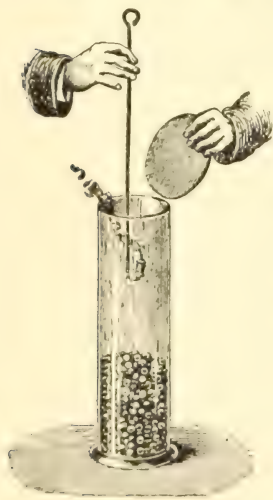

lig. 47 . bag or loose cloth, soak them in warm water for Io or I 2 hours, or in cool water for about 24 hours. Drain off the surplus water and lower the cloth with the peas in a tall glass cylinder which holds I to 2 liters. This should be covered with a glass plate after vaseline has been smeared on the edges of the cylinder to make the vessel air tight. Set aside in a warm room for about i 2 hours. Now lower a lighted taper or short candle into the vessel after having carefully removed the cover. The flame is extinguished. This indicates that there is no

Test for presence of

carbon dioxide in vessel oxygen in the vessel.
with germinating peas. (.)ahs.)

128. Carbon dioxide given off during germination. - Now let us lower a small resisel containing lime water into it. Very soon, almost immediately, there is formed on the surface of the lime water a film. The film formed under these conditions is known w le carlonate of lime, which is formed by the union of arbon dioxide in the vessel with the lime in the water. (Note. Where there are a number of students and large vessets are 100 at hand. luttles of a pint capacity and a smaller number of peas will answer.) 
129. If we now take some of the lime water and blow our "breath" upon it the same film will be formed. The carbon dioxide which we exhale unites with the lime in the water, and forms carbonate of lime, just as in the case of the peas. In the case of animals the process by which oxygen is taken into the body and carbon dioxide is given off is respiration. The process in plants which we are now studying is the same, and also is respiration. The oxygen in the vessel was used up in the process, and carbon dioxide was given off. (It will be seen that this process is exactly the opposite of that which takes place in carbon conversion.)

130. Respiration is necessary for growth.-After we have performed this experiment, if the vessel has not been open too long so that oxygen has entered, we may use the vessel for another experiment, or set up a new one to be used in the course of $\mathbf{I} 2$ to 24 hours, after all the oxygen has been consumed. Place some folded damp filter paper on the germinating peas in the jar. Upon this place one-half dozen peas which have just been germinated, and in which the roots are about $\mathbf{2 0 - 2 5} \mathrm{mm}$ long. The vessel should be covered tightly again and set aside in a warm room. A second jar with water in the bottom instead of the germinating peas should be set up as a check. Damp folded filter paper should be supported above the water, and on this should be placed one-half dozen peas with roots of the same length as those in the jar containing carbon dioxide.

131. In 24 hours examine and note how much growth has taken place. It will be seen that the Pea seedlings; the one roots have elongated but very little or none in the and little growth took first jar, while in the second one we see that the place, the one at the right roots have elongated considerably, if the experi- evident. ment has been carried on carefully. Therefore

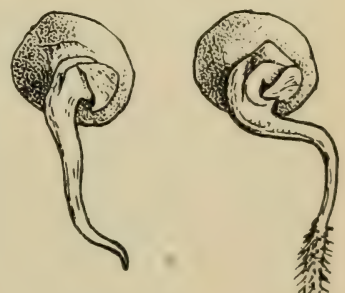

Fig. 48 . in an atmosphere devoid of oxygen very little growth will take place, which shows that normal respiration with access of oxygen is necessary for growth.

132. Energy set free during respiration.-From what we have learned of the exchange of gases during respiration we infer that the plant loses carbon during this process. If the process of respiration is of any benefit to the plant, there must be some gain in some direction to compensate the plant for the loss of carbon which takes place.

It can be shown by an experiment that during respiration there is a slight elevation of the temperature in the plant tissues. The plant then 
gains some heat during respiration. We have also seen in the attempt to grow seedlings in the absence of oxygen that very little growth takes place. But when oxygen is admitted growth takes place rapidly. The process of respiration, then, also sets free energy which is manifested in one direction, by growth.

133. Respiration in a leafy plant.-We may take a potted plant which has a well-devcloped leaf surfice and place it under a tightly fitting bell jar.

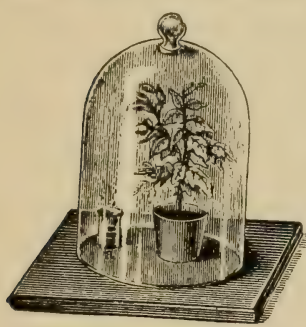

Fig. 49 .

Test for liberation of carbon dioxide from leafy plant during respiration. Baryta water in smaller vessel. (Sachs.) Under the bell jar there also should be placed a smali vessel containing lime water. A similar apparatus should be set up, but with no plant, to serve as a check. The experiment must be set up in a room which is not frequented by persons, or the carbon dioxide in the room from respiration will vitiate the experiment. The bell jar containing the plant should be covered with a black cloth to prevent carbon assimilation. In the course of ten or twelve hours, if everything has worked properly, the lime water under the jar with the plant will show the film of carbonate of lime, while the other one will show none. Respiration, therefore, takes place in a leafy plant as well as in germinating seeds.

134. Respiration in fungi.- If several large actively growing mushrooms are accessible, place them in a tall glass jar as described for determining respiration in germinating peas. In the course of twelve hours test with the lighted taper and the lime water. Respiration takes place in fungi as well as in green plants.

135. Respiration in plants in general.-Respiration is general in all plants, though not universal. There are some exceptions in the lower plants, notably in certain of the bacteria, which can only grow and thrive in the absence of oxygen.

136. Respiration a breaking-down process.-We have seen that in respiration the plant absorbs oxygen and gives off carbon ilioxide. We should endeavor to note some of the effects of respiration on the plant. Let us take, say, two dozen dry peas, weigh them, suak for 12-24 hours in water, and, in the folds of a cloth kept moist by covering with wet paper or sphagnum, germinate them. When well germinated and before the green color appears dry well in the sun, or with artificial heat, being careful not to burn or scorch them. The aim should be to get them about as dry as the seed were before germination. Now weigh. The germinated seeds weigh less than the dry peas. There has then been a loss of plant substance during respiration.

137. Detailed result of the above experiment to show that respiration is necessary for growth.- The experiment was started at 9.30 A.M. on July 
8 , and the roots measured $20-25 \mathrm{~mm}$. At 3 P.M. on the following day, 29 hours after the experiment was started, the roots were examined. Those in the $\mathrm{CO}_{2}$ gats had not grown perceptibly, while those in the jar containing air had increased in length $10-20 m m$. In fig. 48 are represented two of the peas, drawn at the close of the experiment. a represents the one from the $\mathrm{CU}_{2}$ jar which had the longest root, b represents one of the longer ones from the jar with air. Here we have also a goor comparison with the peas grown in the mercury tubes. since those in the tube which contained some air were checked in growth to a consiclerable extent, by the accumulation of carbon dioxide in the small space in the tube, and clud not represent a fair comparison of root growth in air and in $\mathrm{CO}_{2}$.

138. Another way of performing the experiment.-If we wish we may use the following experiment instead of the simple one indicated above. Soak a handful of peas in water for $12-24$ hours, and germinate so that twelve with the radicles $20-25 \mathrm{~mm}$ long may be selected. Fill a test tube with mercury and carefully invert it in a vessel of mercury so that there will be no air in the upper end (there may be a small vacuum). Now nearly fill another tube and invert in the same way. In the latter there will be some air. Remove the outer coats from the peas so that no air will be introduced in the tube filled with the mercury, and insert them one at a time under the edge of the tube beneath the mercury, six in each tube, having first measured the length of the radicles. Place in a warm room. In 24 hours measure the roots. Those in the air will have grown considerably, while those in the other tube will have grown but little or none.

The apparatus to demonstrate this was set up at IO A.M. on July

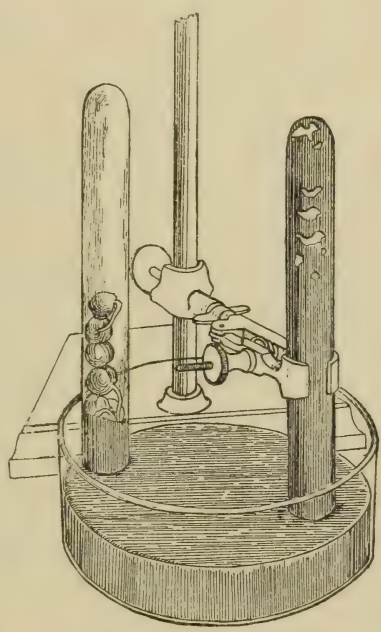

Fig. 50,

Experiment to show that growth takes place more rapidly in presence of oxygen than in absence of oxygen. At the beginning of the experiment the two tubes in the vessel represent the condition at the beginning of the experiment. At the close the roots in the tube at the left were longer than those in the tube filled at the start with mercury. The tube outside of the vessel represents the condition of things where the peas grew in absence of oxygen; the carbon dioxide given off has displaced a portion of the mercury. This also shows intramolecular respiration.

8, 1897. The tube filled with mercury was supported by a clamp, while the tube which was only partly filled was stable enough to support itself until by the accumulation of gas nearly all the mercury moved out, when it was weighted down. 
The twelve peis were selected so that six for each lot showed the same length of root, which varied from 15 to $25 \mathrm{~mm}$ long. Fig. 50 shows the apparatus just after the experiment was started. The peas in tube $a$ (the right-hand tube) are nearly hidden by the mercury.

At 2 P.M. the accumulation of gas had caused the lowering of the mercury in this tube so that the upper pea was entirely uncovered. At 4 P.M. another pea was uncovered. By this time it was evident that the roots of the peas in tube $b$ (left-hand one) were elongating, while no increase could be detected in the roots of the peas in $a$. At 6 P.M. three peas in $a$ were uncovered. At Iо P.M. all six peas were uncovered. The roots of the peas in $b$ were still longer than when noted at 4 P.M., but in $a$ no elongation was perceptible at that time. At 9 A.M. on the following day the mercury had lowered so that it was nearly level with the mercury in the dish, while that in tube $b$ was below the level of that in the dish. There was no perceptible elongation of the roots in $a$, while the roots in $b$ measured about $5 \mathrm{~mm}$ longer than when the experiment was started.

139. Intramolecular respiration.-The last experiment is also an excellent one to show what is called intramolecular respiration. In the tube filled with mercury so that when inverted there will be no air, it will be seen after 24 hours that a gas has accumulated in the tube which has crowded out some of the mercury. With a wash bottle which has an exit tube properly curved, some water may be introduced in the tube. Then insert underneath a small stick of caustic potash. This will form a solution of potash and the gas will be partly or completely absorbed. This shows that the gas was carbon dioxide. This evolution of carbon dioxide by living plants when there is no access of oxygen is called intramolecular respiration. It occurs markedly in oily seeds and especially in the yeast plant. 


\section{CHAPTER X.}

\section{THE CARBON FOOD OF PLANTS.}

140. We came to the conclusion in a former chapter that some chemical change took place within the protoplasm of the green cells of plants during the absorption of carbon dioxide and the giving off of oxygen. We should examine some of the green parts of those plants used in the experiments, or if they are not at hand we should set up others in order to make this examination.

141. Starch formed as a result of carbon conversion. - We may take spirogyra which has been standing in water in the bright sunlight for several hours. A few of the threads should be placed in alcohol for a short time to kill the protoplasm. From the alcohol we transfer the threads to a solution of iodine in potassium iodide. We will find that at certain points in the chlorophyll band a bluish tinge, or color, is imparted to the ring or sphere which surrounds the pyrenoid. In our first study of the spirogyra cell we noted this sphere as being composed of numerous small grains of starch which surround the pyrenoid.

142. Iodine used as a test for starch.-This color reaction which we have obtained in treating the threads with iodine is the well-known reaction, or test, for starch. We have demonstrated then that starch is present in spirogyra threads which have stood in the sunlight with free access to carbon dioxide.

If we examine in the same way some threads which have stood in the dark for a day we will get no reaction for starch, or at best only a slight reaction. This gives us some evidence that a chemical change does take place during this process (absorption 
of $\left({ }^{(}\right)_{2}$ and giving off of oxygen), and that starch is a product of that chemical change.

\section{Schimper's method of testing for the presence of starch.}

- Another convenient and quick method of testing for the presence of starch is what is known as Schimper's method. A strong solution of chloral hydrate is made by taking 8 grams of chloral hydrate for every $5 c c$ of water. To this solution is added a little of an alcholic tincture of iodine. The threads of spirogyra mat be placed directly in this solution, and in a few moments momted in water on the glass slip) and examined with the microscope. The reaction is strong and easily seen.

144. We may test vaucheria which has been grown under like conditions in the same way. We find here also that the starch is present in the threads which have been exposed to the sunlight, while it is alssent from those which have been for a sufficiently long time in the dark.

145. We should also examine the leaves of elodea, or one of the higher green plants which has been for some time in the sunlight. We may use here schimper's method by placing the leaves directly in the solution of chloral hydrate and iodine. The leaves are made transparent by the chloral hydrate so that the starch reaction from the iodine is easily detected.

146 If we wish to use the potissium iodide of iodine the leaves should be first boiled for a short time in water, then heated for some time in alcohol, or the alcohol changed several times. The green color is extracted slowly by this process, and will be hastened if the preparation is placed in the sunlight. (If care is used the leaves maty be boiled in alcohol.) After the leaves are decolorized they should be immersed in the potissium iodide of iodine.

\section{Green parts of plants form starch when exposed to} light. - Thus we find that in the case of all the green plants we have examined, starch is present in the green reils of those which have been standing for some time in the sunlight where the process of the absorption of $\left(\mathrm{C}_{2}\right.$ and the giving off of oxygen can go on, and that in the case of plants grown in the dark, or in leaves of plants which have stood for some time in the dark, starrh is abont. We reason from this that starn is the product 
of the chemical change which takes place in the green cells under these conditions. Because $\mathrm{CO}_{2}$ is absorbed during this process, and because of the chemical changes which take place in the formation of starch, by means of which the carbon is changed from its attraction in the molecule of carbon dioxide to its attraction in the molecule of starch, the process may be termed carbon conversion.

This process has been termed carbon assimilation, but since it is not truly an assimilatory process, and because sunlight is necessary in the first step of the conversion, it has also been recently termed photosyntax, or photosynthesis. These terms, however, seem inappropriate, since the synthetic part of the process is not known to be due to the action of light. In the presence of chlorophyll light reduces the carbon dioxide, while the synthetic part of the process may not be influenced by light. Since the process is similar to that which chemists call conversion, and since the carbon is the important food element derived from the air, for popular treatment the term carbon conversion seems more appropriate.

\section{Starch is formed only in the green parts of variegated} leaves.-If we test for starch in variegated leaves like the leaf of a coleus plant, we shall have an interesting demonstration of the fact that the green parts of plants only form starch. We may take a leaf which is partly green and partly white, from a plant which has been standing for some time in bright light. Fig. $5 \mathrm{I}$ is from a photograph of such a leaf. We should first boil it in alcohol to remove the green color. Now immerse it in the potassium iodide of iodine solution for a short time. The parts which were formerly green are now dark blue or nearly black, showing the presence of starch in those portions of the leaf, while the white part of the leaf is still uncolored. This is well shown in fig. $5^{2}$, which is from a photograph of another coleus leaf treated with the iodine solution.

149. Translocation of starch.-It has been found that leaves of green plants grown in the sunlight contain starch when examined after being in the sunlight for several hours. But when the plants are left in the dark for a day or two the leaves contain no starch, or a much smaller amount. This suggests that starch after it has been formed may be transferred from the leaves, or from those areas of the leaves where it has been formed. 
150. To test this let us perform an experiment which is often made. We may take a plant such as a garden tropxolum or a clover plant, or other land

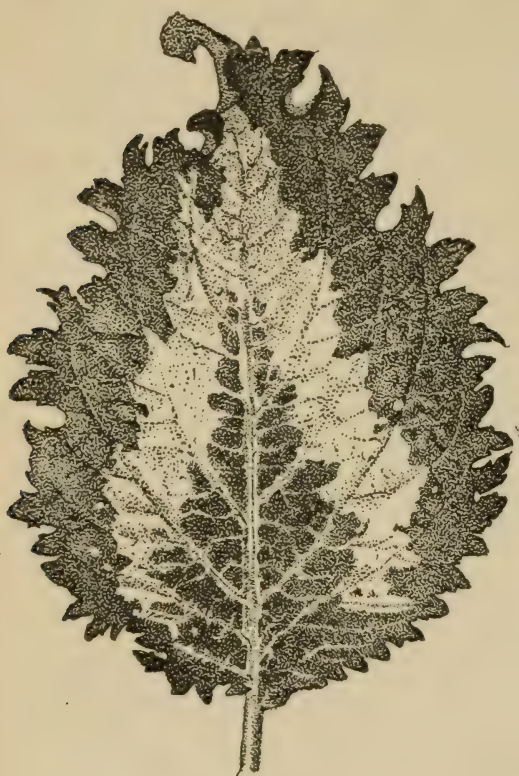

Fig. 51,

Leaf of coleus showing green and white areas, before treatment with iodine.

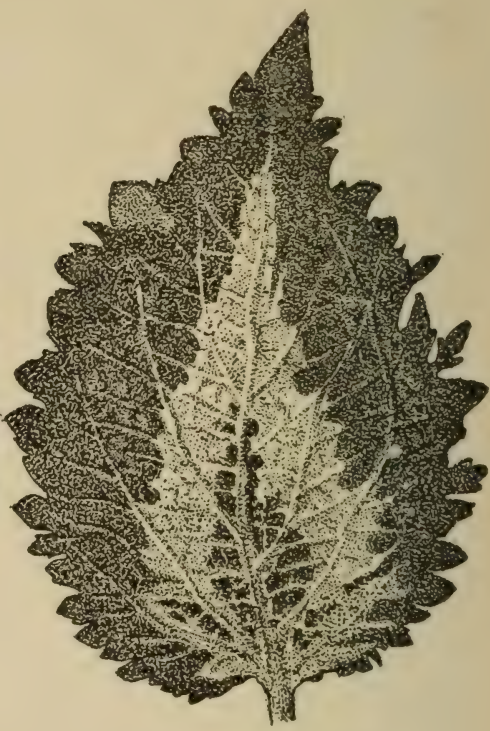

Fig. 52 .

Similar leaf treated with iodine, the starch reaction only showing where the leaf was green.

plant in which it is easy to test for the presence of starch. Pin a piece of circular cork, which is smaller than the area of the leaf, on either side of the

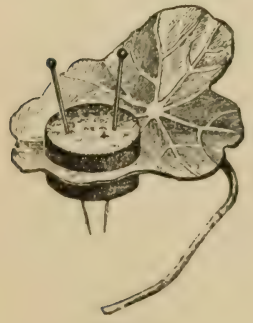

Fig. 53 .

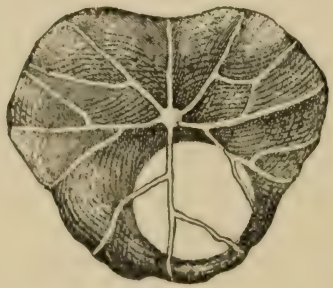

Fig. 54.

Leaf of tropxolum treated with portion covered with iodine after removal of with corks to prevent cork, to show that starch is rethe formation of starch. moved from the leaf during the (After Detmer.) night. leaf, as in fig. 53. Place the plant where it will be in the sunlight. On the afternoon of the following day, if the sun has been shining, we may remove the corks and test for starch, using the entire leaf, by Schimper's method. Or the method described in $\mathbf{1 4 6}$ may be employed. The part covered by the cork will not give the reaction for starch, as shown by the absence of the bluish color, while the other parts of the leaf will show it. The starch which was in that part of the leaf the day betore was dissolved and removed 
during the night, and then during the following day, the parts being covered from the light, no starch was formed in them.

\section{Starch in other parts of plants than the leaves.-We} may use the iodine test to search for starch in other parts of plants than the leaves. If we cut a potato tuber, scrape some of the cut surface into a pulp, and apply the iodine test, we obtain a beautiful and distinct reaction showing the presence of starch. Now we have learned that starch is only formed in the parts containing chlorophyll. We have also learned that the starch which has been formed in the leaves disappears from the leaf or is transferred from the leaf. We judge therefore that the starch which we have found in the tuber of the potato was formed first in the green leaves of the plant, as a result of carbon assimilation. From the leaves it is transferred in solution to the underground stems, and stored in the tubers. The starch is stored here by the plant to provide food for the growth of new plants from the tubers, which are thus much more vigorous than the plants would be if grown from the seed.

152. The potato is only one example of a great many cases where starch is stored up as a reserve material by plants, but not always in the form of tubers. In the sweet potato and some other plants it is stored in the roots, certain ones of the roots becoming very much thickened; in the onion it is stored in certain leaves which form the onion bulb.

153. Form of starch grains.--Where starch is stored as a reserve material it occurs in grains which usually have certain characters peculiar to the species of plant in which they are found. They vary in size in many different plants, and to some extent in form aiso. If we scrape some of the cut surface of the potato tuber into a pulp and mount a small quantity in water, or make a thin section for microscopic examination, we will find large starch grains of a beautiful structure. The grains are oval in form and more or less irregular in outline. But the striking peculiarity is the presence of what seem to be alternating dark and light lines in the starch grain. We note that the lines form irregular rings, which are smaller and smaller until we come to the small central spot termed the "hilum " of the starch grain. It is supposed that these apparent lines in the starch grain are caused by the starch substance being deposited in alternating dense and dilute layers, the dilute layers containing more water than the dense ones; others think that the successive layers from the hilum outward are 
regularly of diminishing density, and that this gives the appearance of alternating lines. The starch formed by plants is one of the organic substances which are manufactures by plants, and it is the basis for the formation of other organic substances in the plant. Without carbon food green plants cannot make any appreciable increase of plant substance, though a considerable increase in size of the plant may take place. 
CHAPTER XI.

\section{CHLOROPHYLL AND THE FORMATION OF STARCH.}

154. In our experiments thus far in treating of the absorption of carbon dioxide and the evolution of oxygen, with the accompanying formation of starch, we have used green plants.

155. Fungi cannot form starch.-If we should extend our experiments to the fungi, which lack the green color so characteristic of the majority of plants, we should find that carbon conversion does not take place even though the plants are exposed to direct sunlight. These plants cannot then form starch, but obtain carbohydrates for food from other sources.

\section{Etiolated plants cannot convert carbon.-Moreover} carbon assimilation is usually confined to the green plants, and if by any means one of the ordinary green plants loses its green color carbon conversion cannot take place in that plant, even when brought into the sunlight, until the green color has appeared under the influence of light.

This may be very easily demonstrated by growing seedlings of the bean, squash, corn, pea, etc. (pine seedlings are green even when grown in the dark), in a dark room, or in a dark receiver of some kind which will shut out the rays of light. The room or receiver must be quite dark. As the seedlings are "coming up," and as long as they remain in the dark chamber, they will present some other color than green; usually they are somewhat yellowed. Such plants are said to be eliolated. If they are brought into the sunlight now for a few hours and then tested for the presence of starch the result will be negative. But if the plant is left in the light, in a few days the leaves begin to take 
on a green color, and then we find that carbon conversion begins.

157. Chlorophyll and chloroplasts. - The green substance in plants is then one of the important factors in this complicated process of forming starch. This green substance is chlorophyll, and it usually occurs in definite bodies, the chlorophyll bodies, or chloroplasts.

The material for new growth of plants grown in the dark is derived from the seed. Plants grown in the dark consist largely of water and protoplasm, the walls being very thin.

158. Form of the chlorophyll bodies. - Chlorophyll bodies vary in form in some different plants, especially in some of the lower plants. This we have already seen in the case of spirogyra, where the chlorophyll body is in the form of a very irregular band, which courses around the inner side of the cell wall in a spiral manner. In zygnema, which is related to spirogyra, the chlorophyll bodies are star-shaped. In the desmids the form varies greatly. In œdogonium, another of the thread-like algæ, illustrated in fig. 95, the chlorophyll bodies

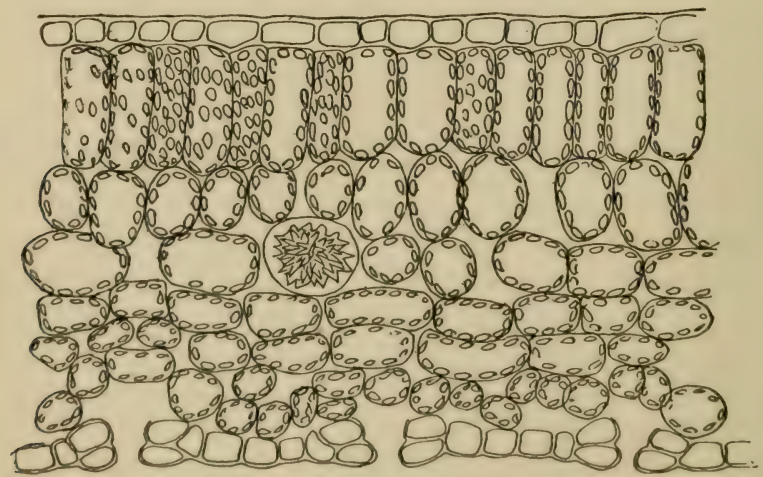

Fig. 55 .

Section of ivy leaf, palisade cells above, loose parenchyma, with large intercellular spaces in center. Epidermal cells on either edge, with no chlorophyll bodies.

are more or less flattened oval disks. In vaucheria, too, a branched thread-like alga shown in fig. Io6, the chlorophyll bodies are oval in outline. These two plants, cedogonium and 
vaucheria, should be examined here if possible, in order to become familiar with their form, since they will be studied later under morphology (see chapters on wdogonium and vaucheria, for the occurrence and form of these plants). The form of the chlorophyll body found in wedogonium and vaucheria is that which is common to many of the green algæ, and also occurs in the mosses, liverworts, ferns, and the higher plants. It is a more or less rounded, oval, flattened disk.

159. Chlorophyll is a pigment which resides in the chloroplast. - That the chlorophyll is a coloring substance which resides in the chloroplasticl. and dex not form the body itself, can be demonstrated by dissolving out the chlorophyll when the framework of the chloroplastid is apparent. The green parts of plants which have been placed for some time in alcohol luse their green color. The alcohol at the same time becomes tinged with green. In sectioning such plant tissue we find that the chlorophyll bodies, or chloroplastids as they are more properly called, are still intact, though the green color is absent. From this we know that chlorophyll is a substance distinct from that of the chloroplastid.

160. Chlorophyll absorbs energy from sunlight for carbon conversion.-It has leen found by analysis with the spectrum that chlorophyll absorbs certain of the rays of the sunlight. The energy which is thus obtained from the sun, called kinetic energy, is supposed to act on the molecules of $\mathrm{CO}_{2}$ and $\mathrm{H}_{2} \mathrm{O}$, separating them into other molecules of $\mathrm{C} . \mathrm{H}$, and $\mathrm{O}$, and that after a series of complicated chemical changes starch is formed by the union of molecules of carbon. oxygen. and hydrogen, the hydrogen and some of the oxygen at least coming from the water in the cells of the plant. In this process of the reduction of the $\mathrm{CO}_{2}$ and the formation of starch there is a surplus of oxygen, which accounts for the giving off of oxygen during the process.

161. Rays of light concerned in carbon conversion.-If a solution of chlorophyll be made, and light be passed through it, and this light be examined with the spectrum, there appear what are called absorption bands. These are dark bands which lie across certain portions of the spectrum. These bands lie in the red, orange, yellow, green, blue. and violet, but the bands are stronger in the red. which shows that chlorophyll absorbs more of the red rays of light than of the other rays. These are the rays of low refrangibility. The kinetic energy derived by the absorption of these rays of light is transferred into potential energy. That is, the molecule of $\mathrm{CO}_{2}$ is broken up. and then by a different combination of certain clements starch is formed.*

* In the formation of starch during carbon conversion the separated molecules from the carlon dioxide and water unite in such a way that carbon, 
162. Starch grains formed in the chloroplasts. -During carbrn conversion the starch formed is deposited generally in small grains within the green chloroplast in the leaf. We can see this easily by examining the leaves of some moss like funaria which has been in the light, or in the chloroplasts of the prothallia of ferns, etc. Starch grains may also be formed in the chloroplasts from starch which was formed in some other part of the plant, but which has passed in solution. Thus the functions of the chloroplast are twofold, that of the conversion of carbon and the formation of starch grains.

163. In the translocation of starch when it becomes stored up in various parts of the plant, it passes from the state of solution. into starch grains in connection with plastids similar to the chloroplasts, but which are not green. The green ones are sometimes called chromoplasts, while the colorless ones are termed leucoplists.

164. Carbon conversion in other than green plants.-While organic compounds are usually only formed by green plants, there are some exceptions. Apparent exceptions are found in the blue-green algæ like oscillatoria, nostoc, or in the brown and red sea weeds like fucus, rhabdonia, etc. These plants, however, possess chlorophyll, but it is disguised by another pigment or color. There are plants, however, which do not have chlorophyll and yet form organic substance with evolution of oxygen in the presence of light, as for example a purple bacterium, in which the purple coloring substance absorbs light, though the rays absorbed most energetically are not the red.

165. Influence of light on the movement of chlorophyll bodies. - In firn prothallia.-If we place fern prothallia in weak light for a few hours, and then examine them under the microscope, we find that the most of the chlorophyll bodies in the cells are arranged along the inner surface of the horizontal wall. If now the same prothallia are placed in a brightly lighted place for a short time most of the chlorophyll bodies move so that they are arranged along the surfaces of the perpendicular walls, and instead of having the flattened surfaces exposed to the light as in the former case, the edges of the chlorophyll bodies are now turned toward the light. (See figs. 56, 57.) The same phenomenon has been observed in many plants. Ligit then has an influence on chlorophyll bodies, to some extent determining their position. In weak light they are arranged so that the flattened surfaces are exposed to the incidence of the rays of light. so that the chlorophyll will absorb as great an amount as possible of kinetic energy; but intense light is

hydrogen, and oxygen are united into a molecule of starch. This result is usually represented by the following equation: $\mathrm{CO}_{2}+\mathrm{H}_{2} \mathrm{O}=\mathrm{CH}_{2} \mathrm{O}+\mathrm{O}_{2}$. Then by polymerization $6\left(\mathrm{CH}_{2} \mathrm{O}\right) \equiv \mathrm{C}_{6} \mathrm{H}_{12} \mathrm{O}_{6}=$ grape sugar. Then $\mathrm{C}_{6} \mathrm{H}_{12} \mathrm{O}_{6}-\mathrm{H}_{2} \mathrm{O}=\mathrm{C}_{6} \mathrm{H}_{10} \mathrm{O}_{6}=$ starch. It is believed, however, that the process is much more complicated than this, and that several different compounds are formed before starch finally appears. 
stronger than necessary, and the chlorophyll bodies move so that their edges are exposed to the incidence of the rays. This movement of the chlorophyll bodies is different from that which takes place in some water plants like

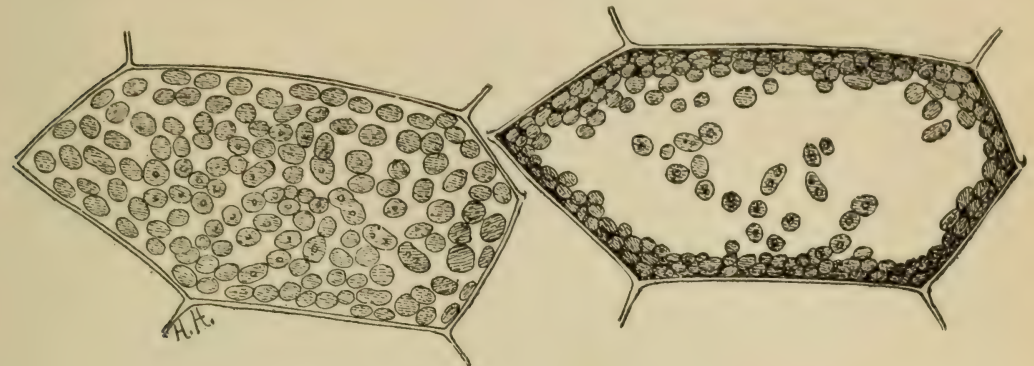

Fig. 56 .

Cell exposed to weak diffused light showing chlorophyll bodies along the horizontal walls.
Fig. 57 .

Same cell exposed to strong light, showing chlorophyll bodies have moved to perpendicular walls.

Figs. 56, 57.-Cell of prothallium of fern.

elodea. The chlorophyll bodies in elodea are free in the protoplasm. The protoplasm in the cells of elodea streams around the inside of the cell wall much as it does in nitella and the chlorophyll bodies are carried along in the currents, while in nitella they are stationary. 


\section{CHAPTER XII.}

\section{NUTRITION AND MEMBERS OF THE PLANT BOLY.}

166. In connection with the study of the means for obtaining nutriment from the soil or water by the green plants it will be found convenient to observe carefully the various forms of the plant. Without going into detail here the suggestion is made that simple thread forms like spirogyra, œedogonium, and vaucheria; expanded masses of cells as are found in the thalloid liverworts, the duckweed, etc., be compared with those liverworts, and with the mosses, where leaf-like expansions of a central axis have been differentiated, and how this differentiation, from the physiological standpoint, has been carried farther in the higher land plants.

167. Nutrition of liverworts. - In many of the piants termed liverworts the vegetative part of the plant is a thin, flattened, more or less elongated green body known as a thallus.

Riccia.-One of these, belonging to the genus riccia, is shown in fig. 58. Its shape is somewhat like that of a minute ribbon which is forked at

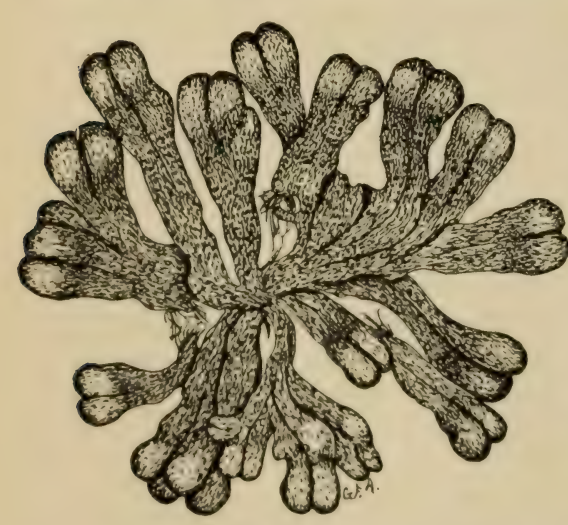

Fig. $5^{8}$.

Thallus of riccia lutescens. intervals in a dichotomous manner, the characteristic kind of branching found in these thalloid liverworts. This riccia (known as R. lutescens) occurs on damp soil; long, slender, hair-like processes grow out from the under surface of the thallus, which resemble root hairs and serve the same purpose in the processes of nutrition. Another species of riccia ( $R$. crystallina) is shown in fig. $17 \mathrm{I}$. This plant is quite circular in outline and occurs on muddy flats. Some species float on the water.

168. Marchantia. - One of the larger and coarser liverworts is figured at 59. This is a very common liverwort, growing in 
very damp and muddy places and also along the margins of streams, on the mud or upon the surfaces of rocks which are bathed with the water. This is known as Marchantia polymorpha. If we examine the under surface of the marchantia we see numerous hair-like processes which attach the plant to the soil. Under the microscope we see that some of these are exactly like the root hairs of the seedlings which we have been studying, and they here serve the same purpose. Since, however, there are no roots on the marchantia plant, these hair-like outgrowths are

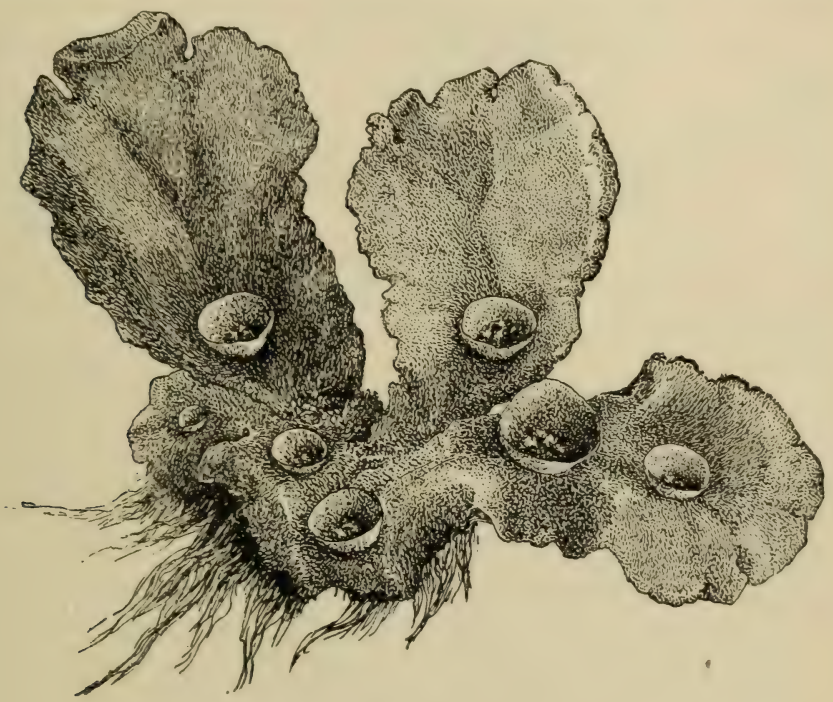

Fig. 59 .

Marchantia plant with cupules and gemmæ; rhizoids below.

usually termed here rhizoids. In marchantia they are of two kinds, one kind the simple ones with smooth walls, and the other kind in which the inner surfaces of the walls are roughened by processes which extend inward in the form of irregular toothlike points. Besides the hairs on the under side of the thallus we note especially near the growing end that there are two rows of leaf-like scales, those at the end of the thallus curving up over the growing end, and thus serve to protect the delicate tissues at the growing point. 
169. Frullania.--In fig. 60 is shown another liverwort, which differs greatly in form from the ones we have just been

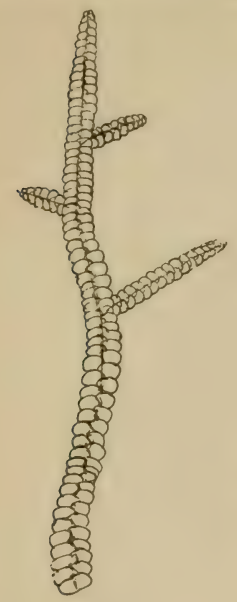

Fig. 60 .

Portion of plant of F-ullania, a foliose liverwort. studying in that there is a well-defined axis with lateral leaf-like outgrowths. Such liverworts are called foliose liverworts. Besides these two quite prominent rows of leaves there is a third row of poorly developed leaves on the under surface. Also from the under surface of the axis

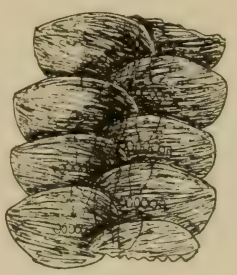

Fig. 6r.

Portion of same more highly magnified, showing overlapping leaves. we see here and $\mathrm{there}$ slender outgrowths, the rhizo ids, t h r o u g h which much Fig. 62. of the liquid Under $\mathrm{side}$ showing forked nutriment is under row of leaves and lobes absorbed. of lateral leaves.

170. Nutrition of the mosses. - Among the mosses which are usually common in moist and shaded situations, examples are abundant which are suitable for the study of the organs of absorption. If we take for example a plant of Mnium (M. affine) which is illustrated in fig. 64 , we note that it consists of a slender axis with thin flat, green, leaf-like expansions. Fxamining with the microscope the lower end of the axis, which is attached to the substratum, there are seen numerous brown colored threads more or less branched. (For nutrition of moulds, mushrooms, parasitic fungi, dodder, carnivorous plants, lichens, aquatic plants, etc., see Part III. Ecology.)

171. The plant body. - In the simpler forms of plant life, as in spirogyra and many of the algae and fungi, the plant body is not differentiated into parts. In many other cases the only differentiation is between the growing part and the fruiting part. In the algie and fungi there is 16 differentiation into stem and leaf, thengh there is an approach to it in some of the higher forms. Where this simple plant body is flattened, as in the sea-wrack, or ulva, it is a frond. The Iatin word for frond is thallus, and this name is 
applied to the plant body of all the lower plants, the algae and fungi. The algæ and fungi together are sometimes called the thallophytes, or thallus plants. The word thallus is also sometimes applied to the flattened body of the liverworts. In the foliose liverworts and mosses there is an axis with leaf-like expansions. These are believed by some to represent true stems and leaves, by others to represent a flattened thallus in which the margins are deeply and regularly divided, or in which the expansion has only taken place at regular intervals.

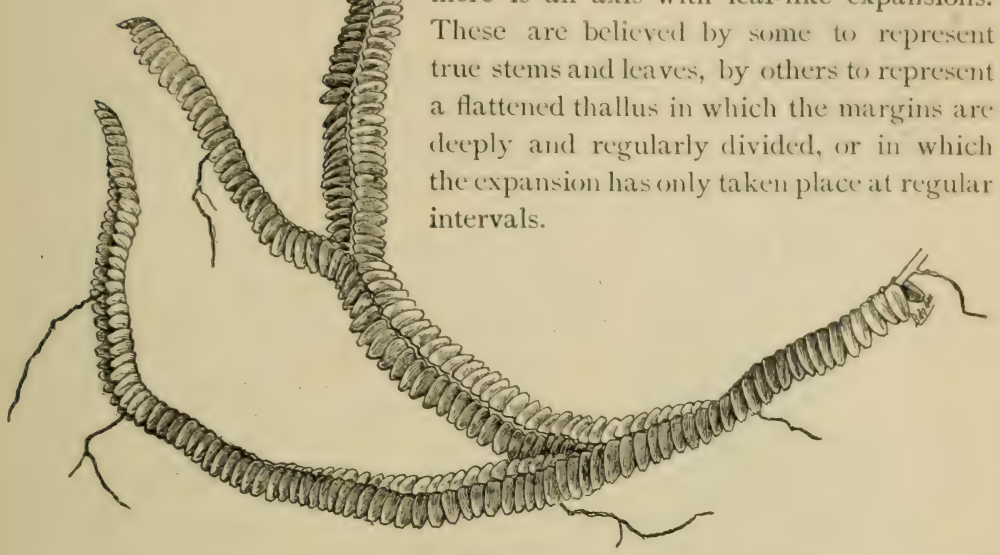

Fig. 63 .

Foliose liverwort (Bazzania) showing dichotomous branching and overlapping leaves.

172. Members of the plant body.-In the higher plants there is usually great differentiation of the plant body, though in many forms, as in the duckweeds, it is a frond. While there is great variation in the form and function of the members of the plant body, they are reducible to a few fundamental members. Some reduce these forms to three, the root, stem, and liaf, while others to two, the root and shoot, which is perhaps the better arrangement. Here the shoot is farther divided into stem and leaf, the leaf being a lateral outgrowth of the stem. The different forms of the members are usually designated by special names, but it is convenient to group them in the single series. Examples are as follows:

\section{Stem series.}

Tubers, underground thickened stems, bearing buds and scale leaves; ex.. Irish potato.

Koot-stocks, underground, usually elongated, learing scales or bracts. and a leafy shoot; ex., trillium, mandrake, etc. Koot-stocks of the ferms buar expanded, green leaves.

Runners, slender, trailing, bearing bracts, and leafy stems as branches; ex., strawberry vines.

Corms, underground, short, thick, leaf bearing and sal le bearing; cx., Indian turnip. 
Bulbs, usually underground, short, conic, leaf and scale bearing; ex.,

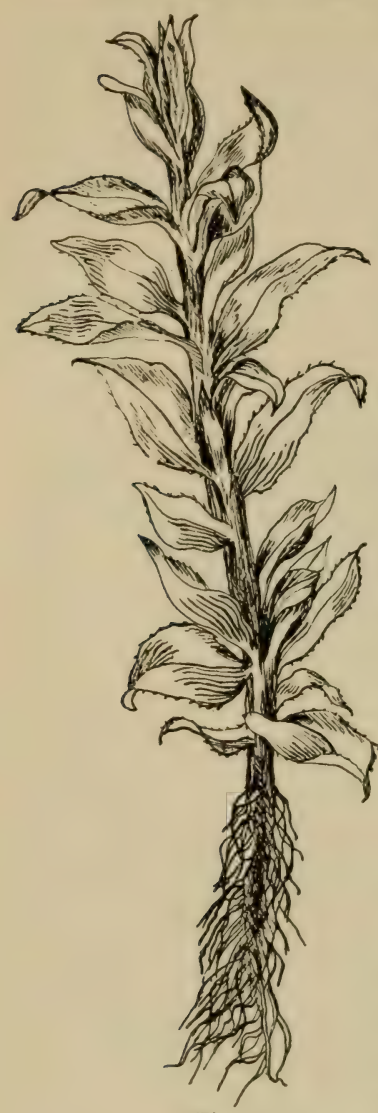

Fig. 64 . lily.

Thorns, stout, thick, poorly developed branches with rudiments of leaves (scales); ex., hawthorn.

Tendrils, slender reduced stems.

Flower axes (see morphology of the angiosperms).

174. Leaf series.-Besides the foliage leaves, the following are some of their modifications:

Flower parts (see morphology of the angiosperms).

Bracts and scales, small, the former usually green (flower bracts), the latter usually chlorophylless. Bud scales are sometimes green.

Tendrils, modifications of the entire leaf (tendrils of the squash where the branched tendril shows the principal veins of the leaf), modification of the terminal pinnæ of the leaf (vetch), etc.

Spines (examples are found in the cacti, where the stem is enlarged and green, functioning as a leaf).

Other modifications occur as in the pitcher plant, insectivorous plants, etc.

175. The root shows less modification. Besides normal roots, which are fibrous in most small plants and stout in the larger ones, some of the modifications are found in fleshy roots, where nourishment is stored (ex., dahlia, sweet potato, etc.), aerial roots (ex., poison

Female plant (gametophyte) of a moss (mnium), showing rhizoids below, and the tuft of leaves above, which protect the archegonia. ivy, the twining form), aerial orchids, etc. For modifications of roots due to symbiotic fungi, see chapter on Nutrition in Part III. 


\section{CHAPTER XIII.}

\section{GROWTH.}

176. By growth is usually meant an increase in the bulk of the plant accompanied generally by an increase in plant substance. Among the lower plants growth is easily studied in some of the fungi.

177. Growth in mucor.- Some of the gonidia (often called spores) may be sown in nutrient gelatine or agar, or even in prune juice. If the culture has been placed in a warm room, in the course of 24 hours, or even less, the preparation will be ready for study.

178. Form of the gonidia. - It will be instructive if we first examine some of the gonidia which have not been sown in the culture medium. We should note their rounded or globose form, as well as their markings if they belong to one of the species with spiny walls. Particularly should we note the size, and if possible measure them with the micrometer, though this would not be absolutely necessary for a comparison, if the comparison can be made immediately. Now examine some of the gonidia which were sown in the nutrient medium. If they have not already germinated we will note at once that they are much larger than those which have not been immersed in a moist medium.

179. The gonidia absorb water and increase in size before germinating.-From our study of the absorption of water or watery solutions of nutriment by living cells, we will easily understand the cause of this enlargement of the gonidium of the mucor when surrounded by the moist nutrient medium. The cell-sap in the spore takes up more water than it loses by diffu- 
sion, thus drawing water forcibly through the protoplasmic membrane. Since it does not filter out readily, the increase in

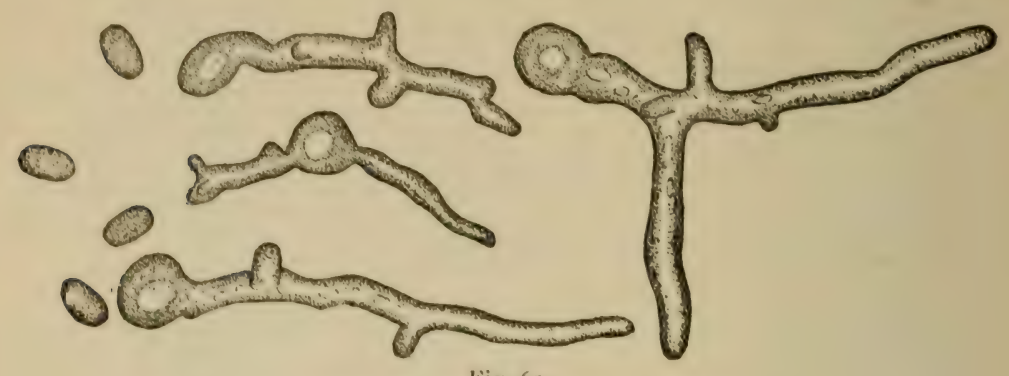

Fig. 65 .

Spores of mucor, and different stages of germination.

quantity of the water in the cell produces a pressure from within which stretches the membrane, and the elastic cell wall yields. Thus the gonidium becomes larger.

180. How the gonidia germinate.-We should find at this time many of the gonidia extended on one side into a tube-like process the length of which varies according to time and temperature. The short process thus legun continues to elongate. This elongation of the plant is swowth, or, more properly speaking, one of the phenomena of growth.

181. The germ tube branches and forms the mycelium.In the course of a day or so branches from the tube will appear. This branched form of the threads of the fungus is, as we will remember, the mycelium. We can still see the point where growth started from the gonidium. Perhaps by this time several tubes have grown from a single one. The threads of the mycelium near the gonidium, that is, the older portions of them, have increased in diameter as they have elongated, though this increase in diameter is by no means so great as the increase in length. After increasing to a certain extent in diameter, growth in this direction ceases, while apical growth is practically unlimited, being limited only by the supply of nutriment.

182 Growth in length takes place only at the end of the thread.-If there were any branches on the mycelium when the 
culture was first examined, we can now see that they remain practically the same distance from the gonidium as when they were first formed. That is, the older portions of the mycelium do not elongate. Growth in length of the mycelium is confined to the ends of the threarls.

183. Protoplasm increases by assimilation of nutrient substances. - As the plant increases in bulk we note that there is an increase in the protoplasm, for the protoplasm is very easily detected in these cultures of mucor. This increase in the quantity of the protoplasm has come about by the assimilation of the nutrient substance, which the plant has absorled. The increase in the protoplasm, or the formation of additional plant substance, is another phenomenon of growth quite different from that of elongation, or increase in bulk.

184. Growth of roots. - For the study of the growth of roots we may take any one of many different plants. The seedlings of such plants as peas, beans, corn, squash, pumpkin, etc., serve excellently for this purpose.

185. Roots of the pumpkin.-The seeds, a handful or so, are soaked in water for about I 2 hours, and then placed between layers of paper or between the folds of cloth, which must be kejt quite moist but not very wet, and should be kept in a warm place. A shallow crockery plate, with the seeds lying on wet filter paper, and covered with additional filter paper, or with a bell jar, answers the purpose well.

The primary or first root (radicle) of the embryo pushes its way out between the seed coats at the small end. When the seeds are well germinated, select several which have the root $4-5 \mathrm{~cm}$ long. With a crow-quill pen we may now mark the terminal portion of the root off into very short sections as in fig. 66. The first mark should be not more than $\mathbf{I} \mathrm{mm}$ from the tip, and the others not more than $\mathrm{I} m \mathrm{~m}$ apart. Now place the seedlings down on damp filter paper, and cover with a bell jar so that they will remain moist, and if the season is cold place them in a warm room. At intervals of 8 or io hours, if convenient, observe them and note the farther growth of the root. 
186. The region of elongation.-While the root has elongated, the region of elongation is not at the tip of the root. It lies

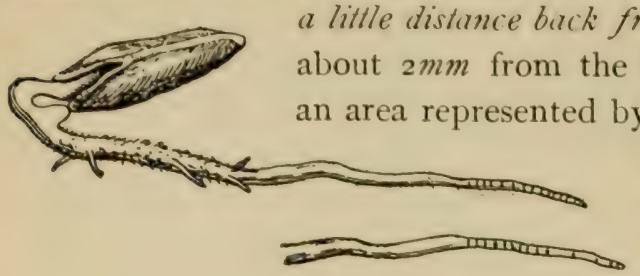

a lithe distonce bick from the tip, beginning at about $2 \mathrm{~mm}$ from the tip and extending over an area represented by from $4-5$ of the millimeter marks. The root shown in fig. 66 was marked at IO A.M. on July 5. At 6 P.M.

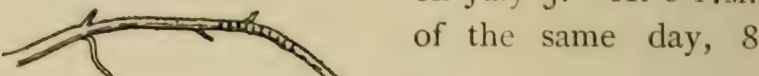

Fig. 66.

Root of germinating pumpkin, showing region of elongation just back of the tip.

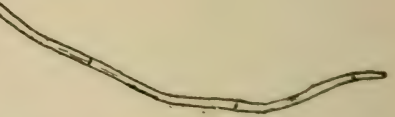

hours later, growth had taken place as shown in the middle figure. At 9 A.m. on the following day, 5 hours later, the growth is represented in the lower one. Similar experiments upon a number of seedlings gives the same result : the region of elongation in the growth of the root is situated a little distance back from the tip. Farther back very little or no elongation takes place, but growth in diameter continues for some time, as we should discover if we examined the roots of growing pumpkins, or other plants; at different periods.

187. Movement of region of greatest elongation.-In the region of elongation the areas marked off do not all elongate equally at the same time. The middle spaces elongate most rapidly and the spaces marked off by the 6,7 , and $8 \mathrm{~mm}$ marks elongate slowly, those farthest from the tip more slowly than the others, since elongation has nearly ceased here. The spaces marked off between the $2-4 \mathrm{~mm}$ marks also elongate slowly, but soon begin to elongate more rapidly, since that region is becoming the region of greatest elongation. Thus the region of greatest elongation moves forward as the root grows, and remains approximately at the same distance behind the tip.

188. Formative region.-If we make a longitudinal section of the tip of a growing root of the pumpkin or other seedling, and examine it with the mi- 
croscope, we will see that there is a great difference in the character of the cells of the tip and those in the region of elongation of the root. First there is in the section a V-shaped cap of losse cells which are comstantly being sloughed off. Just back of this tip the cells are quite regularly isodiametric, that is, of equal diameter in all directions. They are alse very rich in protoplasm, and have thin walls. This is the region of the root where new cells are formed by division. It is the formative region. The cells on the outside of this area are the older, and pass over into the older parts of the root and root cap. If we examine successively the cells back from this formative region we find that they become more and more elongated in the direction of the axis of the root. The elongation of the cells in this older portion of the root explains then why it is that this region of the root elongates more rapidly than the tip.

189. Growth of he stem.-We may use a bean seedling growing in the soil. At the junction of the leaves with the stem there are enlargements. These are the nodes, and the spaces on the stem between successive nodes are the internodes. We should mark off several of these internodes, especially the younger ones, into sections about $5 \mathrm{~mm}$ long. Now observe these at several times for two or three days, or more. The region of elongation is greater than in the case of the roots, and extends back farther from the end of the stem. In some young garden bean plants the region of elongation extended over an area of $40 \mathrm{~mm}$ in one internode.

190. Force exerted by growth.-One of the marvelous things connected with the growth of plants is the force which is exerted by various members of the plant under certain conditions. Observations on seedlings as they are pushing their way through the soil to the air often show us that considerable force is required to lift the hard soil and turn it to one side. A very striking illustration may be had in the case of mushrooms which sometimes make their way through the hard and packed soil of walks or roads. That succulent and tender plants should be capable of lifting such comparatively heavy weights seems incredible until we have witnessed it. Very striking illustrations of the force of roots are seen in the case of trees which grow in rucky situations, where rocks of considerable weight are lifted, or small rifts in large rocks are widened by the lateral pressure exerted by the growth of a root, which entered when it was small and wedged its way in.

191. Grand period of growth.-Great variation exists in the rapidity of growth even when not influenced by outside conditions. In our study of the elongation of the root we found that the cells just back of the formative region 
elongated slowly at first. The rapidity of the elongation of these cells increases until it reaches the maximum. Then the rapidity of elongation lessens as the cells come to lie farther from the tip. The period of maximum elongation here is the grand period of growth of these cells.

192. Just as the celis exhibit a grand period of growth, so the members of the plant exhibit a similar grand period of growth. In the case of leaves, when they are young the rapidity of growth is comparatively slow, then it increases, and finally diminishes in rapidity again. So it is with the stem. When the plant is young the growth is not so rapid; as it approaches middle age the rapidity of growth increases; then it declines in rapidity at the close of the season.

193. Energy of growth. - Clowily related to the grand period of growth is what is termed the energy of growth. This is manifested in the compara-

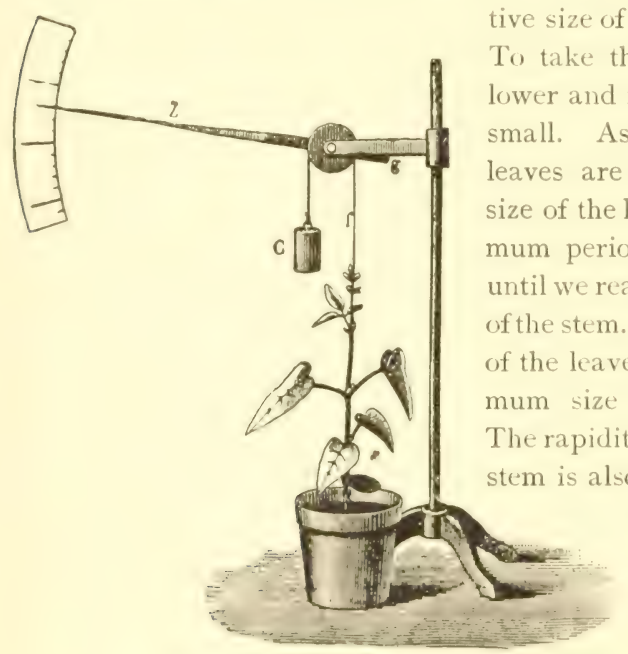

Fig. 67 .

Lever auxanometer (Oels) for measuring elongation of the stem during growth. tive size of the members of a given plant. Take the sunflower for example, the lower and first leaves are comparatively small. As the plant grows larger the leaves are larger, and this increase in size of the leaves increases up to a maximum period, when the size decreases until we reach the small leaves at the top of the stem. The grand period of growth ves corresponds with the maxim size of the leaves on the stem. isidy and energy of growth of the crrelated with that of the leaves, and the grand period of growth is coincident with that of the leaves. It would be instructive to note it in the case of other plants and also in the case of fruits.

194. Nutation.-I)uring the growth of the stem all of the cells of a given section of the stem (1) not elongate simultaneously. For example the cells at a given moment on the south side are elongating more rapilly than the cells on the other sisk. This will cause the stem to bend slightly to the north. In a few moments later the cells on the west side are elongating more rapilly, and the stem is turned to the east; and so on, groups of cells in succession around the stem elongate more rapidly than the others. This causes the stem te de-crile at circle or ellipere alome a central proint. Since the regrom of greatest efengattion of the cells of the stem is gratually moving toward the atpex of the growing sem, this line of etongation of the cells which is 
traveling around the stem does so in a spiral manner. In the same way, while the end of the stem is moving upward by the elongation of the cells, and at the same time is slowly moved around, the line which the end of the stem describes must be a spiral one. This movement of the stem, which is common to all stems, leaves, and roots, is nutation.

195. The importance of nutation to twining stems in their search for a place of support, as well as for the tendrils on leaves or stems, will be seen. In the case of the root it is of the utmost importance, as the root makes its way through the soil, since the particles of soil are more easily thrust aside. The same is also true in the case of many stems before they emerge from the soil. 


\section{CHAPTER XIV.}

\section{IRRIT A B I L ITY.}

196. We should now examine more carefully certain movements which the members of the plants exhibit. By this time we have probably observed that the direction which the root and stem take upon germination of the seed is not due to the position in which the seed happens to lie. Under normal conditions we have seen that the root grows downward and the stem upward.

197. Influence of the earth on the direction of growth.When the stem and root have been growing in these directions for a short time let us place the seedling in a horizontal position, so that the end of the root extends over an object of support in such a way that it will be free to go in any direction. It should be placed under a bell jar so as to prevent drying, or a germinated pea may be pinned to the lower side of a cork, which is then placed in the mouth of a bottle containing a little water. In the course of twelve to twenty-four hours the root which was formerly horizontal has turned the tip downward again. If we should mark off millimeter spaces beginning at the tip of the root, we should find that the motor zone, or region of curvature, lies in the same region as that of the elongation of the root.

It was found by Knight, as a result of experiments, that the force which causes the roots to take the downward direction is gravity. This force is geotropism, which means a turning influenced by the earth, and is applied to the growth movements of plants influenced by the earth, with regard to the direction of growth. Growth toward the earth is also termed progeotro. 
pism. So the lateral growth of the secondary roots is termed diageotropism.

The stem, on the other hand, which was placed in a horizontal position has become again erect. This turning of the stem in

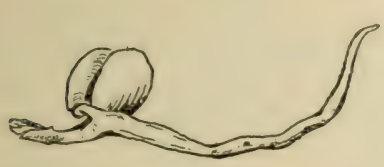

Fig. 68.

Germinating pea placed in a horizontal position.

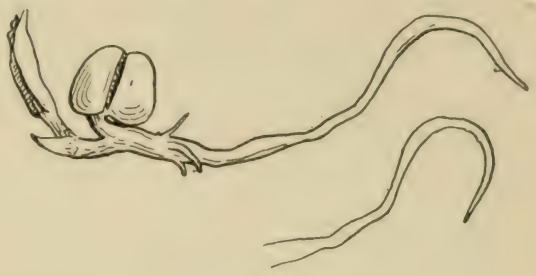

Fig. 69 .

In 24 hours gravity has caused the root to turn downward.

Figs. 68, 69.-Progeotropism of the pea root.

the upward direction takes place in the dark as well as in the light, as we can see if we start the experiment at nightfall, or

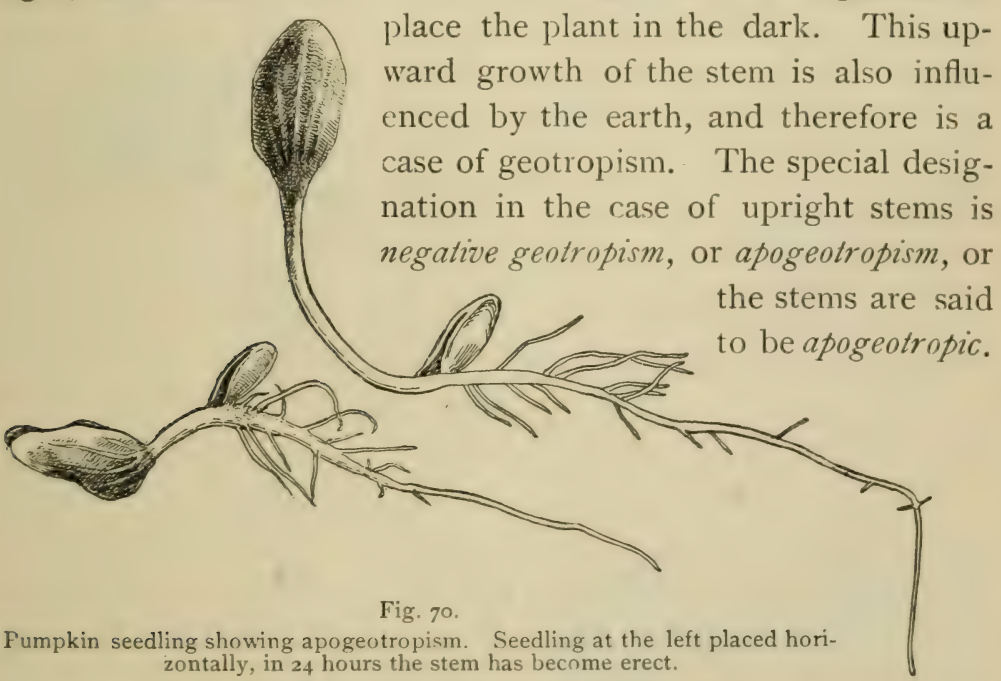

If we place a rapidly growing potted plant in a horizontal position by laying the pot on its side, the ends of the shoots will soon turn upward again when placed in a horizontal position. Young bean plants growing in a pot began within two hours to turn the ends of the shoots upward. 
Horizontal leaves and shoots can be shown to be subject to the same influence, and are therefore diageotropic.

198. Influence of light.- - Not only is light a very important factor for plants during carbon conversion, it exerts great influence on plant growth and movement.

199. Retarding influence of light on growth.-We have only to return to the experiments performed in growing plants in the dark to see one of the influences which light exerts on plants. The plants grown in the dark were longer and more slender than those grown in the light. Light then has a retarding influence on the elongation of the stem.

200. Influence of light Radish seedlings grown in the of light on direc- dark, long, slender, not green. tion of growth.-While we are growing seedlings, the pots or boxes of some of them should be placed so that the plants will have a one-sided illumination. This can be done by placing them near an open window, in a room with a one-sided illu-

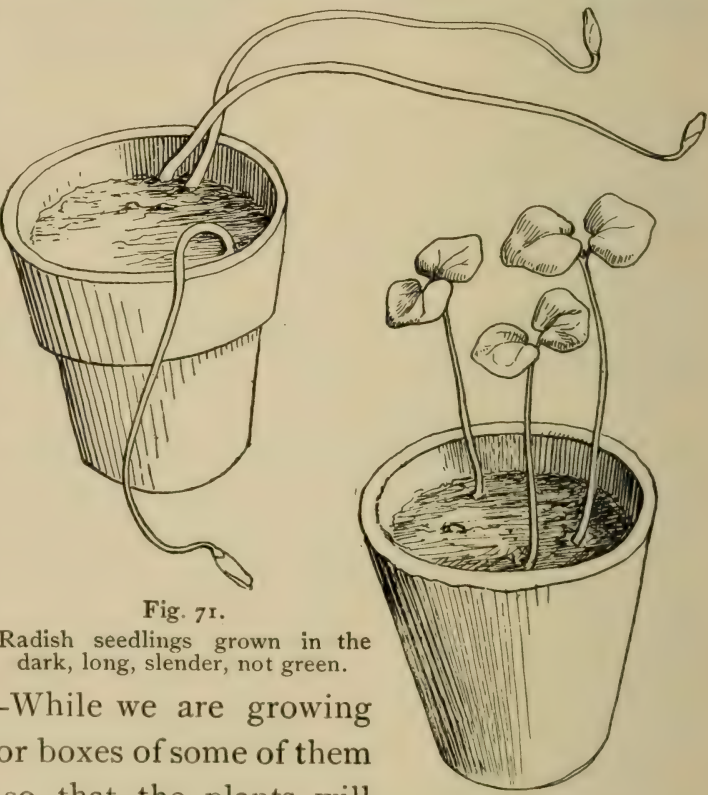

Fig. 72.

Radish seedlings grown in the light, shorter, stouter, and green in color. Growth retarded by light.

mination, or they may be placed in a box closed on all sides but one which is facing the window or light. In $\mathrm{r}_{2-24}$ hours, or even in a much shorter time in some cases, the stems of the seedlings will be directed toward the source of light. This influence exerted by the rays of light is heliotropism, a turning influenced by the sun or sunlight.

201. Diaheliotropism.-Horizontal leaves and shoots are diaheliotropic as well as diageotropic. The general direction 
which leaves assume under this influence is that of placing them with the upper surface perpendicular to the rays of light which

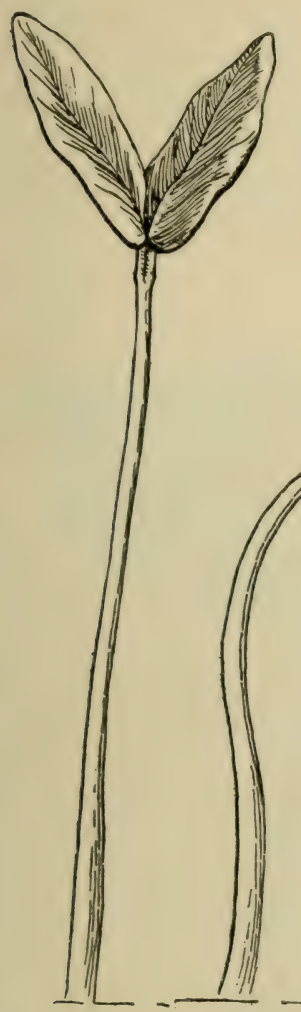
fall upon them. Leaves, then, exposed to the brightly lighted sky are, in general, horizontal. This position is taken in direct

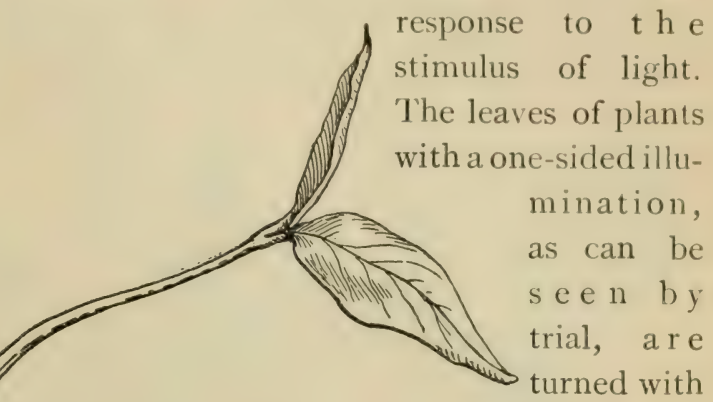

Fig. 73 .
Seed'ing of castor-oil bean, before and after their upper a one-sided illumination. surfaces toward the source of light, or perpendicular to the incidence of the light rays. In this way light overcomes for the time being the direction which growth gives to the leaves. The so-called "sleep" of plants is of course not sleep, though the leaves " nod," or hang downward, in many cases. There - are many plants in which we can note this drooping of the leaves at nightfall, and in order to prove that it is not determined by the time of day we can resort to a well-known experiment to induce this condition during the day. The plant which has been used to illustrate this is the sunflower. Some of these plants, which

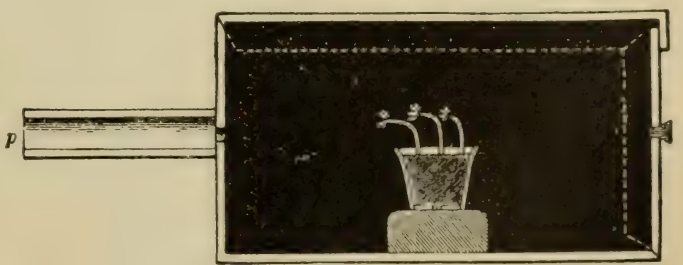

Fig. 74 .

Dark chamber with opening at one side to show heliotropism. (After Schleichert.) 
were grown in a box, when they were about $35 \mathrm{~cm}$ high were covered for nearly two days, so that the light was excluded. At midday on the second day the box was removed, and the leaves on the covered plants are well represented by fig. 75 , which was made from one of them. The leaves of the other plants in the box which were not covered were horizontal, as shown by fig. 76 . Now on leaving these plants, which had exhibited

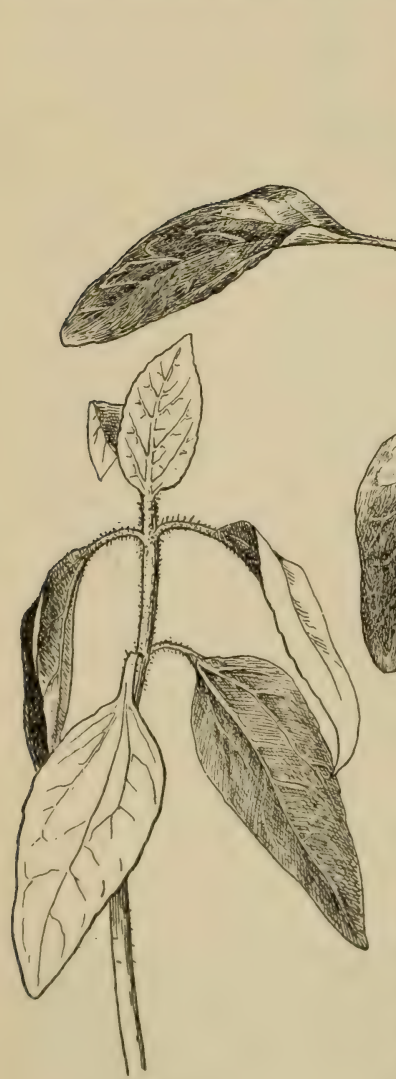

Fig. 75 .

Sunflower plant. Epinastic condition of leaves induced during the day in darkness.

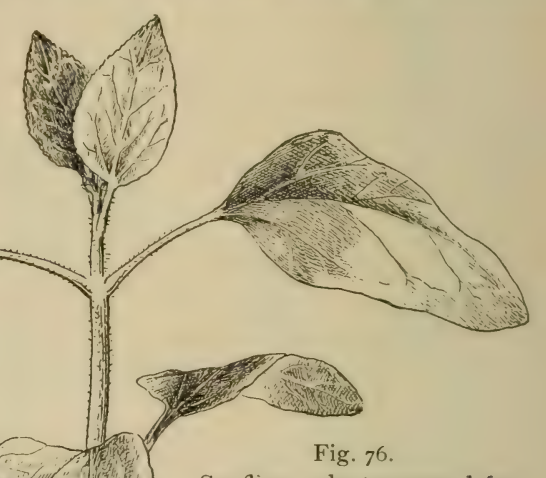

Sunflower plant removed from darkness, leaves extending under influence of light (diaheliotropism.)

induced "sleep" movements, exposed to the light they gradually assumed the horizontal position again.

202. Epinasty and hyponasty.-During the early stages of growth of many leaves, as in the sunflower plant, the direction of growth is different from what it is at a later period. The under surface of the young leaves grows more rapidly in a longitudinal direction than the upper side, so that the leaves are held upward close against the bud at the end of the stem. This is termed hyponasty, or the leaves are said to be hyponastic. Later the growth is more rapid
ves turn downward or away from the bud. on the upper side and the leaves turn downward or awa from the bud.
This is termed efinasty, or the laves are said to be cpinastic. This is shown by the night position of the leaves, or in the induced "sleep" of the sun. 
flower plant in the experiment detailed above. The day position of the leaves on the other hand, which is more or less horizontal, is induced because of their irritability under the influence of light, the inherent downward or epinastic growth is overcome for the time. Then at nightfall or in darkness, the stimulus of light being removed, the leaves assume the position induced by the direction of growth.

In the case of the cotyledons of some plants it would seem that the growth was hyponastic even after they have opened. The day position of the coty-

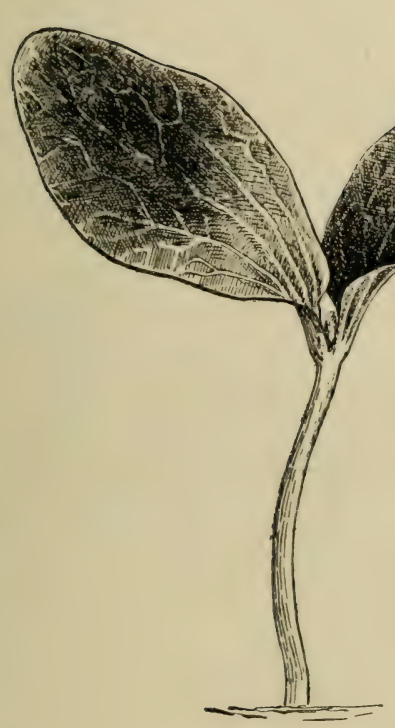

Fig. 77 .

Squash seedling. Position of cotyledons in light.

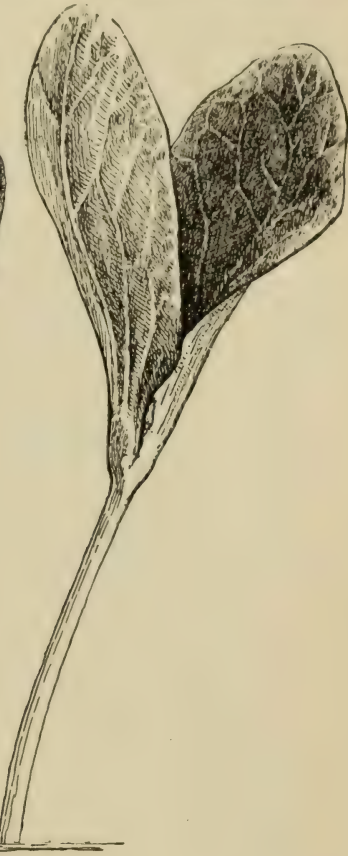

Fig. 78 .

Squash seedling. Position of cotyledons in the dark.

ledons of the pumpkin is more or less horizontal, as shown in fig. 77. At night, or if we darken the plant by covering with a tight box, the leaves assume the position shown in fig. 78 .

While the horizontal position is the general one which is assumed by plants under the influence of light, their position is dependent to a certain extent on the intensity of the light as well as on the incidence of the light rays. Some plants are so strongly heliotropic that they change their positions all during the day.

203. Leaves with a fixed diurnal position.-Leaves of some plants when they are developed have a fixed diurnal position and are not subject to 
variation. Such leaves tend to arrange themselves in a vertical or paraheliotropic position, in which the surfaces are not exposed to the incidence of light of the greatest intensity, but to the incidence of the rays of diffused light. Interesting cases of the fixed position of leaves are found in the socalled compass plants (like Silphium laciniatum, Lactuca scariola, etc.). In these the horizontal leaves arrange themselves with the surfices vertical, and also pointing north and south, so that the surfaces face east and west.

204. Importance of these movements. - Not only are the leaves placed in a position favorable for the absorption of the rays of light which are concerned in making carlom a vailable for food, but they derive other forms of energy from the light, as heat, which is absorbed during the day. Then with the nocturnal position, the leaves leing drooped down toward the stem, or with the margin toward the sky, or with the cotyledons as in the pumpkin, castor-oil bean, etc., clasped upward together, the loss of heat hy radiation is less than it would be if the upper surfaces of the leaves were exposed to the sky.

205. Influence of light on the structure of the leaf.- In our study of the structure of a leaf we found that in the iny leaf the palisade cells were on

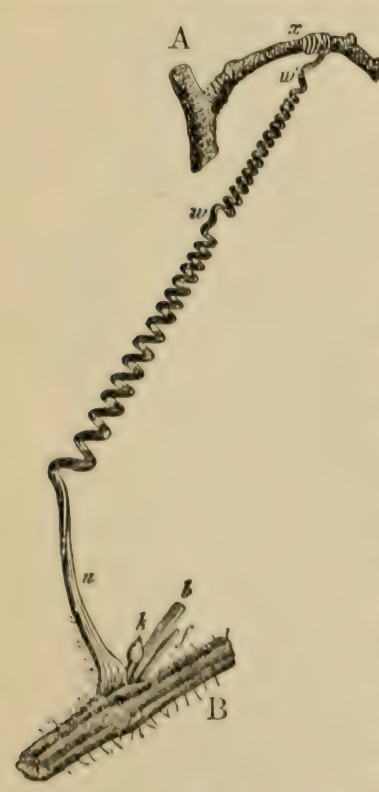

Fig. 79.

Coiling tendril of bryony the upper surface. This is the case with a great many leaves, and is the normal arrangement of "dorsiventral" leaves which are diaheliotropic. Leaves which are paraheliotropic tend to have palisade cells on both surfaces. The palisade layer of cells as we have seen is made up of cells lying very close together, and they thus prevent rapid evaporation. They also check to some extent the entrance of the rays of light, at least more so than the loose spongy parenchyma cells do. Leaves developed in the shade have looser palisade and parenchyma cells. In the case of some plants, if we turn over a very young leaf, so that the under side will be uppermost, this side will develop the palisade layer. This shows that light has a great influence on the structure of the leaf.

206. Movement influenced by contact.-In the case of tendrils, twining leaves, or stems, the irritability to contact is shown in a movement of the tendril, etc., toward the object in touch. This causes the tendril or stem to coil around the object for suppert. The stimulus is alos extended down the part

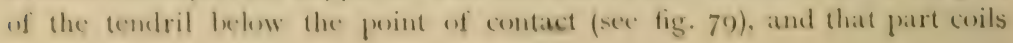


up like a wire coil spring, thus drawing the leaf or loranch from which the tendril grows clesere to the object of support. This coil between the object of support and the plant is ales very impertint in easing up the plant when subject to violent gusts of wind which might tear the plant from its support were it not for the yielding and springing motion of this coil.

207. Sensitive plants. - These plants are remarkable for the rapid response to stimuli. Mimosa pudica is an exrellent plant to study for this purpose.

208. Movement in response to stimuli. If we pinch with the forceps one of the terminal leaflets, or tap it with a pencil, the two end leaflets fold above the "vein" of the pinna. This

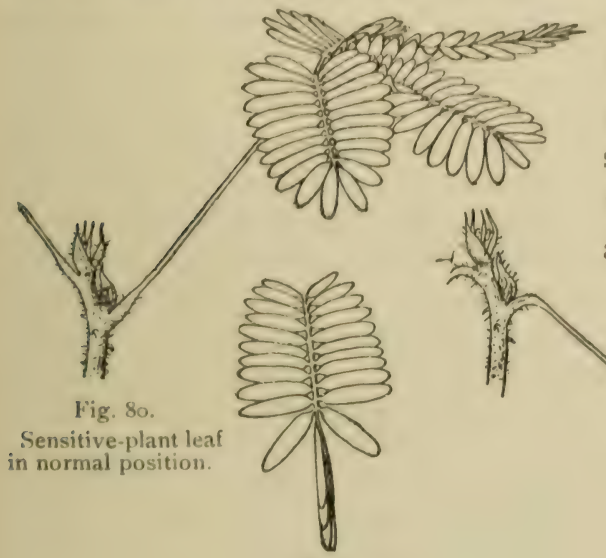

\footnotetext{
Fig. 8 .

Pinna folding up after stimulus.
}

soon the pinnæ approximate each other and the leaf then drops downward as shown in by the movement of the next pair, and so on as shown in fig. 8I, until all the leaflets on this pinna are closed, then the stimulus travels down the other pinnæ in a similar manner, and fig. 82. The normal position of the leaf is folded and leaf drooped. shown in fig. 8o. If we jar the plant by striking it or by jarring the pot in which it is grown all the leaves quickly collapse into the position shown in fig. 82 . If we examine the leaf now we will see minute cushions at the hase of each leaflet, at the junction of the pinne with the petiole, and a larger one at the junction of the petiole with the stem. We will also note that the movement resides in these cushions. 
209. Transmission of the stimulus. - The transmission of the stimulus in this mimosa from one part of the plant has been found to be along the cells of the bast.

210. Cause of the movement. - The movement is caused by a sudden loss of turgidity on the part of the cells in one portion of the pulvinus, as the cushion is called. In the case of the large pulvinus at the base of the petiole this loss of turgidity is in the cells of the lower surface. There is a sudden change in the condition of the protoplasm of the cells here so that they lose a large part of their water. This can be seen if with a sharp knife we cut off the petiole just above the pulvinus before movement takes place. A drop of liquid exudes from the cells of the lower side.

211. Paraheliotropism of the leaves of the sensitive plant. - If the mimosa plant is placed in very intense light the leaflets will turn their edges toward the incidence of the rays of light. This is also true of other plants in intense light, and is paraheliotropism. Transpiration is thus lessened, and chlorophyll is protected from too intense light.

We thus see that variations in the intensity of light have an important influence in modifying movements. Variations in temperature also exert

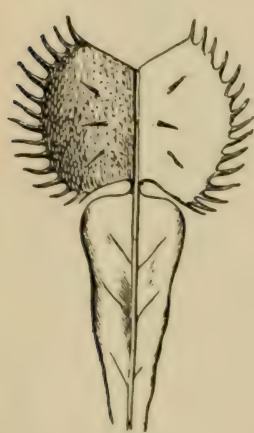

Fig. 83 .

Leaf of Venus fly. trap (Dionæa muscipula), showing winged petiole and toothed lobes.

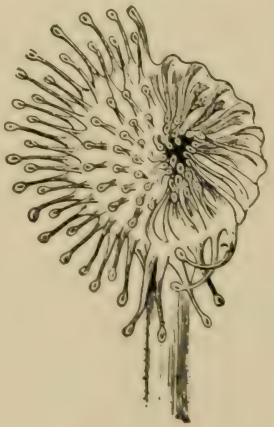

Fig. 84 .

Leaf of Drosera rotundifolia, some of the glandular hairs folding inward as a result of a stimulus. a considerable influence, rapid elevation of temperature causing certain flowers to open, and falling temperature causing them to close.

212. Sensitiveness of insectivorous plants. - The Venus fly-trap (Dionæa muscipula) and the sundew (drosera) are interesting examples of sensitive plants, since the leaves close in response to the stimulus from insects.

\section{Hydrotropism.-}

Roots are sensitive to moisture. They will turn toward moisture. This is of the greatest importance for the well-being of the plant, since the roots will seek those places in the soil where suitable moisture is present. On 
the other hand, if the soil is too wet there is a tendency for the roots to grow away from the soil which is saturated with water. In such cases roots are often seen growing upon the surface of the soil so that they may obtain oxygen, which is important for the root in the processes of absorption and growth. Plants then may be injured by an excess of water as well as by a lack of water in the soil.

214. Temperature. - In the eaperiments which have thus far becn carried on it will probably have been noted that the temperature has much to do with the length of time taken for seeds to germinate. It also influences the rate of growth. The effect of different temperatures on the germination of seed can be very well noted by attempting to germinate some in rorms at various temperatures. It will be found, other conditions being equal, that in a moderately warm room, or even in one quite warm, 25-30 degrees centigrade, germination and growth goes on more rapidly than in a corol room, and here more rapidly than in one which is decidedly colde. In the case of most plants in temperate climates, growth may go on at a temperature but little above freezing, but few will thrive at this temperature.

215. If we place dry peas or leans in a temperature of abrut $70^{\circ} \mathrm{C}$. for 15 minutes they will not be killed, but if they have been thoroughly soaked in water and then placed at this temperature they will be killed, or even at a somewhat lower temperature. The same seeds in the dry condition will withstand a temperature of $10^{\circ} \mathrm{C}$. below, lout if they are first soaked in water this low temperature will kill them.

216. In order to see the effect of freezing we may thoroughly freeze a section of a beet root, and after thawing it out place it in water. The water is colored by the cell-sap which escapes from the cells, just as we have seen it does as a result of a high temperature, while a section of an unfrozen beet placed in water will not color it if it was previously washed.

If the slice of the beet is placed at about $60^{\circ} \mathrm{C}$. in a shallow glass vessel, and covered, ice will be formed over the surface. If we examine it with the microscope ice crystals will be seen formed on the outside, and these will not be colored. The water for the formation of the crystals came from the cell-sap, but the concentrated solutions in the sap were not withdrawn by the freezing over the surface.

217. If tox much water is not withdrawn from the cells of many plants in freezing, and they are thawed out slowly, the water which was withdrawn from the cells will be absorbed again and the plant will not be killed. Ijut if the plant is thawed out quickly the water will not be absorbed, but will remain on the surface and evalporate. Some will also remain in the intercellular spaces, and the plant will die. Some plants, however, no matter how 
slowly they are thawed out, are killed after freezing, as the leaves of the pumpkin, dahlia, or the tubers of the potato.

218. It has been found that as a general rule when plants, or plant parts, contain little moisture they will withstand quite high degrees of temperature, as well as quite low degrees, but when the parts are filled with sap or water they are much more casily killed. For this reason dry seeds and the winter buds of trees, and other plants, because they contain but little water, are better able to resist the cold of winters. But when growth begins in the spring. and the tissues of these same parts become turgid and filled with water, they are quite easily killed by frosts. It should be borne in mind, however, that there is great individual variation in plants in this respect, some being more susceptible to cold than others. There is also great variation in plants as to their resistance to the cold of winters, and of arctic climates, the plants of the latter regions being able to resist very low temperatures. We have examples also in the arctic plants, and those which grow in arctic climates on high mountains, of plants which are able to carry on all the life functions at temperatures but little above freezing. 


\section{MORPHOLOGY AND LIFE HISTORY OF REPRE- SENTATIVE PLANTS.}

\section{CHAPTER XV.}

\section{SPIROGYRA.}

219. In our study of protoplasm and some of the processes of plant life we became acquainted with the general appearance of the plant spirogyra. It is now a familiar object to us. And in taking up the study of representative plants of the different groups, we shall find that in knowing some of these lower plants the difficulties of understanding methods of reproduction and relationship are not so great as they would be if we were entirely ignorant of any members of the lower groups.

220. Form of spirogyra.--We have found that the plant spirogyra consists of simple threads, with cylindrical cells attached end to end. We have also noted that each cell of the thread is exactly alike, with the exception of certain "holdfasts " on some of the species. If we should examine threads in different stages of growth we should find that each cell is capable of growth and division, just as it is capable of performing all the functions of nutrition and assimilation. The cells of spirogyra then multiply by division. Not simply the cells at the ends of the threads but any and all of the cells divide as they grow, and in this way the threads increase in length.

221. Multiplication of the threads.-- In studying living material of this plant we have probathly uoteel that the threads often become broken by two of the adjacent cells of a thread lecoming separated. This may be and is accom- 
plished in many cases without any injury to the cells. In this manner the

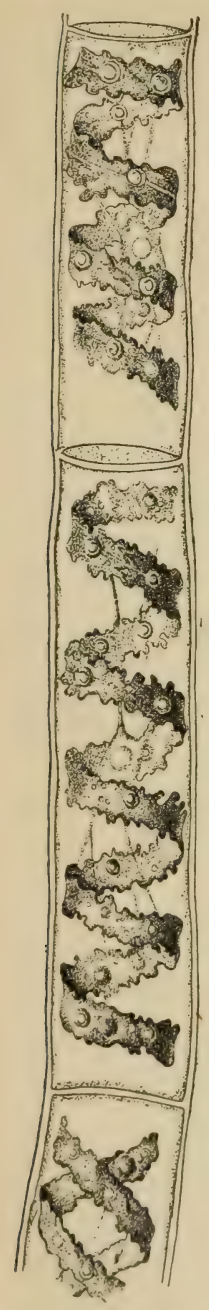

Fig. 85 .

Thread of spirogyra, showing long cells, chlorophyll b a nd, nucleus, strands of protoplasm, and the granular wall layer of protoplasm. threads or plants of spirogyra, if we choose to call a thread a plant, multiply, or increase. In this breaking of a thread the cell wall which separates any two cells splits. If we should examine several species of spirogyra we would probably find threads which present two types as regards the character of the walls at the ends of the cells. In fig. 85 we see that the ends are plain, that is, the cross walls are all straight. But in some other species the inner wall of the cells presents a peculiar appearance. This inner wall at the end of the cell is at first straight across. But it soon becomes folded back into the interior of its cell, just as the end of an empty glove finger may be pushed in. Then the infolded end is pushed partly out again, so that a peculiar figure is the result.

222. How some of the threads break.-In the separation of the cells of a thread this peculiarity is often of advantage to the plant. The cell-sap within the protoplasmic membrane absorbs water and the pressure pushes on the ends of the infolded cell walls. The inner wall being so much longer than the outer wall, a pull is exerted on the latter at the junction of the cells. Being weaker at this point the outer wall is ruptured. The turgidity of the two cells causes these infolded inner walls to push out suddenly as the outer wall is ruptured, and the thread is snapped apart as quickly as a pipe-stem may be broken.

\section{Conjugation of spirogyra.-Under cer-} tain conditions, when vegetative growth and multiplication cease, a process of reproduction takes place which is of a kind termed sexual reproduction. If we select mats of spirogyra which have lost their deep green color, we are likely to find different stages of this sexual process, which in the case of spirogyra and related plants is called conjugation. A few threads of such a mat we should examine with the microscope. If the material is in the right condition we will see in certain of the cells an oval or elliptical body. If we note carefully the cells in which these oval bodies are situated, there will be scen a tube at one side which con- 
nects with an empty cell of a thread which lies near as shown in fig. 86. If we search through the material we may see other threads connected in this ladder fashion, in which the contents of the cells are in various stages of collapse from what we have seen in the growing cell. In some the protoplasm and chlorophyll band have moved but little from the wall; in others it forms a mass near the center of the cell, and again in others we will see that the contents of the cell of one of the threads has moved partly through the tube into the cell of the thread with which it is connected.

224. This suggests to us that the oval bodies found in the cells of one thread of the ladder, while the cells of the other thread were empty, are formed by the union of the contents of the two cells. In fact that is what does take place. This kind of union of the contents of two similar or nearly similar cells is conjugation. The oval bodies which are the result of this conjugation are zygotes, or zygospores. When we are examining living material of spirogyra in this stage it is possible to watch this process of conjugation. Fig. 87 represents the different stages of conjugation of spirogyra.

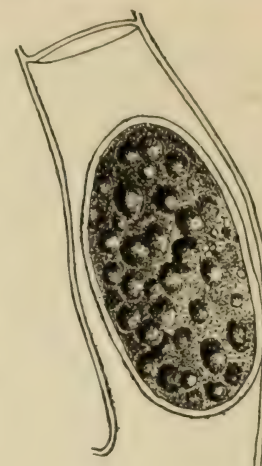

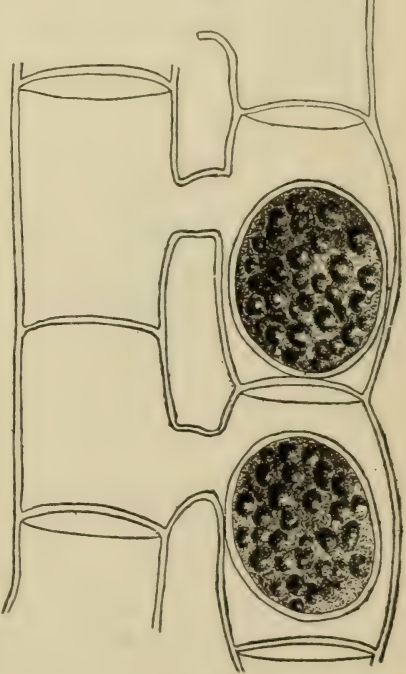

Fig. 86 .

Zygospores of spirogyra.

225. How the threads conjugate, or join.-The cells of two threads lying parallel put out short processes. The tubes from two opposite cells meet and join. The walls separating the contents of the two tubes dissolve so that there is an open communication between the two cells. The contents of each one of these cells which take part in the conjugation is a gamete. The one which passes through the tube to the receiving cell is the supply- 
ing gamete, while that of the receiving cell is the receiving gamete.

226. How the protoplasm moves from one cell to another.-Before any movement of the protoplasm of the supplying cell takes place we can see
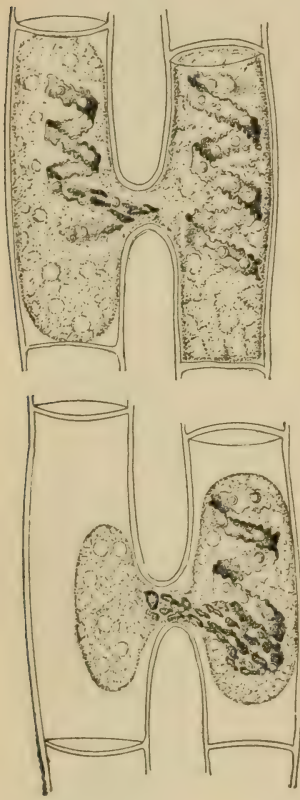
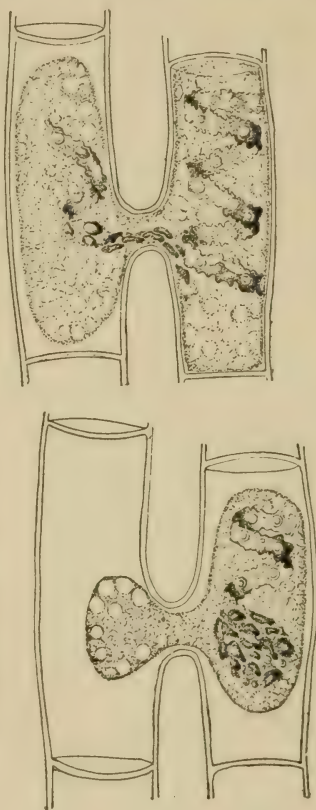

Fig. 87
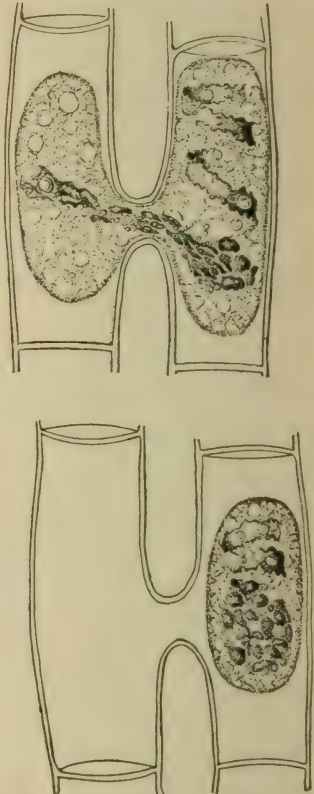

Conjugation in spirogyra; from left to right beginning in the upper row is shown the gradual passage of the protoplasm from the supplying gamete to the receiving gamete.

that there is great activity in its protoplasm. Rounded vacuoles appear which increase in size, are filled with a watery fluid, ancl swell up like a vesicle, and then suddcrily contract and disappear. As the vacuole disappears it causes a sudden movement or contraction of the protoplasm around it to take its place. Simultaneously with the disappearance of the vacuole the membrane of the protoplasm is separated from a part of the wall. This is probably brought about by a sudden loss of some of the water in the cellsap. These activities go on, and the proteplasmic membrane continues to slip away from the wall. Every now and then there is a movement by which the protoplasm is moved a short distance. It is moved toward the tule and finally a portion of it with one end of the chlorophyll band begins to move into the tube. Alout this time the vacuoles can be seen in an active condition in the receptive cell. $-A t$ short intervals movement con- 
tinues until the content of the supplying cell has passed over into that of the receptive cell. The protoplism of this one is now slipping away from the cell wall, until finally the two masses round up into the one zygospore.

227. The zygospore. - This zygospore now accpuires a thick wall which eventually becomes brown in color. The chlorophyll color fades out, and a large part of the protoplitsm patsecs into an vily substance which makes it more resistant to conditions which would be fatal to the vegetative threads. The zygo:pores are capable therefore of enduring extremes of cold and dryness which would destroy the threads. They pass through a "resting" period, in which the water in the pond may be frozen, or dried, and with the oncoming of favorable conditions for growth in the spring or in the autumn they germinate and produce the green thread again.

228. Life cycle.- The growth of the spirogyra thread, the conjugation of the gametes and formation of the zygospore. and the growth of the thread from the zygospore again, makes what is called a complete life cycle.

229. Fertilization. - While conjugation results in the fusion of the two masses of protoplasm. fertilization is accomplished when the nuclei of the two cells come together in the zygospore and fuse into a single nucleus. The
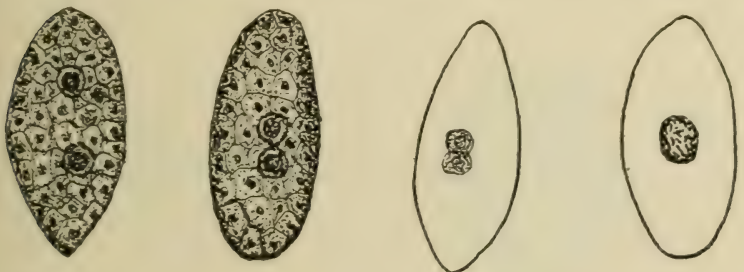

Fig. 88 .

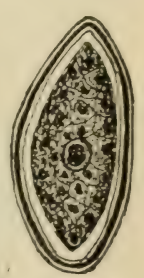

Fertilization in spirogyra : show's different stages of fusion of the two nuclei, with mature zygospore at right. (After Overton.)

different stages in the fusion of the two nuclei of a recently formed zygospore are shown in figure 88 .

In the conjugation of the two cells, the chlorophyll band of the supplying cell is said to degenerate, so that in the new plant the number of chlorophyll bands in a cell is not increased by the union of the two cells.

230. Simplicity of the process.-In spirogyra any cell of the thread may form a gamete (excepting the holdfasts of some species). Since all of the cells of a thread are practically alike, there is no structural difference between a vegetative cell and a cell about to conjugate. The difference is a physiolegical one. All the cells are capable of conjugation if the physiological conclitions are present. All the cells therefore are potential gametes. (Strictly speaking the wall of the cell is the gametangium. while the contents make the gamete.)

While there is sometimes a slight difference in si betwecon the conjugat. 
ing cells, and the supplying cell may be the smaller, this is not general. We say, therefore, that there is no differentiation among the gametes, so that usually before the protoplasm begins to move one cannot say which is to be the supplying and which the receiving gamete.

231. Position of the plant spirogyra.-From our study then we see that there is practically no differentiation among the vegetative cells. except where holdfasts grow out from some of the cells for support. They are all alike in form, in capacity for growth, division, or multiplication of the threads. Each cell is practically an independent plant. There is no differentiation between vegetative cell and conjugating cell. All the cells are potential gametes. Finally there is no structural differentiation between the gametes. This indicates then a simple condition of things, a low grade of organization.

232. The alga spirogyra is one of the representatives of the lower algæ belonging to the group called Conjugata. Zygnema with star-shaped chloroplasts, mougeotia with straight or sometimes twisted chlorophyll bands, belong to the same group. In the latter genus only a portion of the protoplasm of each cell unites to form the zygospore, which is located in the tube between the cells.

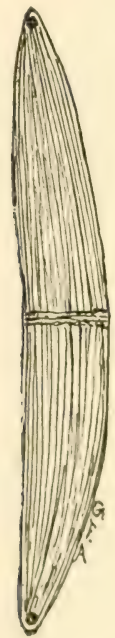

Fig. 89.

Closterium

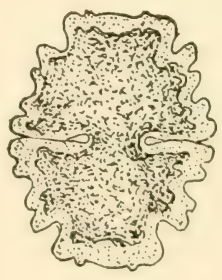

Fig. 9o.

Micrasterias.

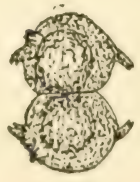

Fig. 92. Staurastrum.

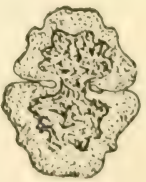

Fig. 93 . Euastrum.

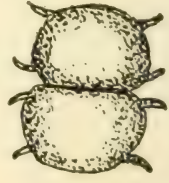

Fig. 91, Xanthidium.

233. The de-midsatedreteng to the same group. The desmids usually live ats separate cells. Many of them are beautiful in form. They grow entangled among other algre, or on the surface of aquatic plants, or on wet soil. Several genera are illustrated in figures 89-94. 


\section{CHAP'TER XVI.}

\section{EDOGONIUM.}

234. CEdogonium is also an alga. The plant is sometimes associated with spirogyra, and occurs in similar situations. Our attention was called to it in the study of chlorophyll bodies. These we recollect are, in this plant, small oval disks, and thus differ from those in spirogyra.

235. Form of œdogonium.-Like spirogyra, œdogonium forms simple threads which are made up of cylindrical cells placed end to end. But the plant is very different from any member of the group to which spirogyra belongs. In the first place each cell is not the equivalent of an individual plant as in spirogyra. Growth is localized or confined to certain cells of the thread which divide at one end in such a way as to leave a peculiar overlapping of the cell walls in the form of a series of shallow caps or vessels (fig. 95), and this is one of the characteristics of this genus. Other differences we find in the manner of reproduction.

236. Fruiting stage of cedogonium.-Material in the fruiting stage is quite easily obtainable, and may be preserved for study in formalin if there is any doubt about obtaining it at the time we need it for study. This condition of the plant is easily detected because of the swollen condition of some of the cells, or by the presence of brown bodies with a thick wall in some of the cells.

237. Sexual organs of œdogonium. Oogonium and egg.The enlarged cell is the oogonium, the wall of the cell being the wall of the oogonium. (See fig.96.) The protoplasm inside, before 
fertilization, is the egg cell. In those cases where the brown body with a thick wall is present fertilization has taken place, and this body is the fertilized egg, or oospore. It contains

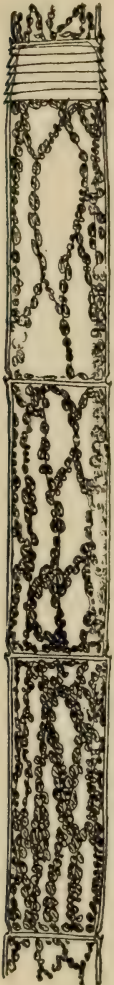

Fig. 95

Portion of thread of œedogonium, showing chlorophyll grains, and peculiar cap cell walls. large quantities of an oily substance, and, like

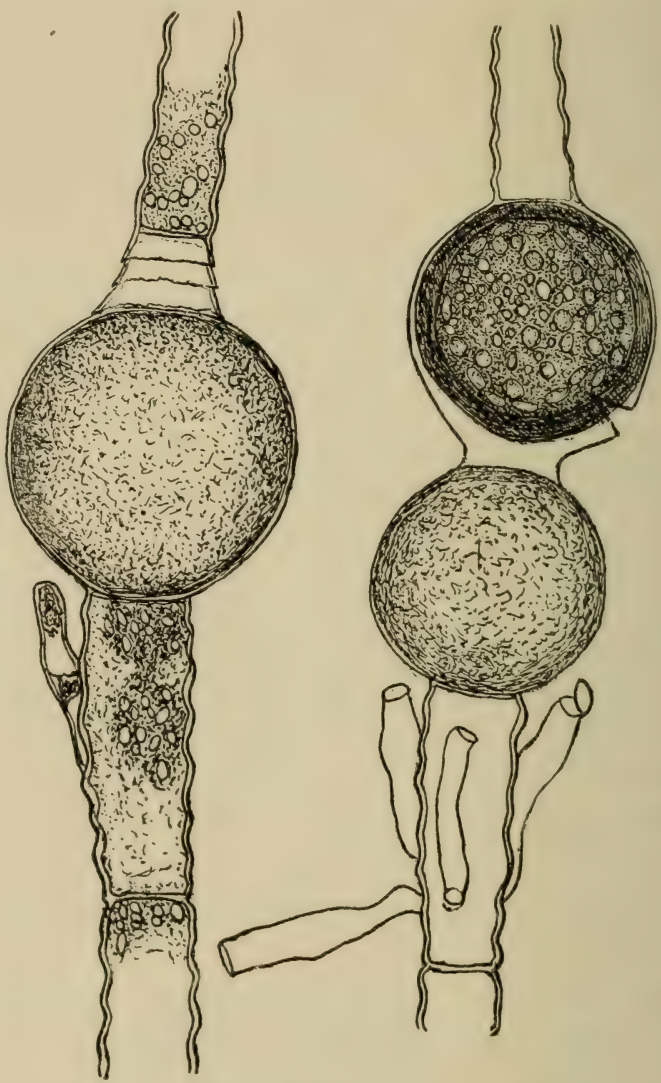

liig. 96.

Edogonium undulatum, with oogonia and dwarf males; the upper oogonium at the right has a mature oospore.

the fertilized egg of spirogyra and vaucheria, is able to withstand greater changes in temperature than the vegetative stage, and can endure drying and freezing for some time without injury.

In the oogonium wall there can frequently be seen a rift near the middle of one side, or near the upper end. 'This is the 
opening through which the spermatozoid entered to fecundate the egg.

238. Dwarf male plants. - In some species there will also be seen peculiar club-shaped dwarf plants attached to the side of the oogonium, or near it, and in many cases the end of this dwarf plant has an open lid on the end.

239. Antheridium. - The end cell of the dwarf male in such species is the antheridium. In other species the spermatozoids are developed in different cells (antheridia) of the same thread which bears the oogonium, or on a different thread.

240. Zoospore stage of œdogonium. - The egg after a period of rest starts into active life again. In doing so it does not develop the thread-like plant directly as in the case of vaucheria and spirogyra. It first divides into four zoospores which are exactly like the zoogonidia in form. (See fig. IO3.) These germinate and develop the thread form again. This is a quite remarkable peculiarity of œdogonium when compared with either vaucheria or spirogyra. It is the introduction of an intermediate stage between the fertilized egg and that form of the plant which bears the sexual organs, and should be kept well in mind.

241. Asexual reproduction.-Material for the study of this stage of œdogonium is not readily obtainable just when we wish it for study. But fresh plants brought in and placed in a quantity of fresh water may yield suitable material, and it should be examined at intervals for several days. This kind of reproduction takes place by the formation of zoogonidia. The entire contents of a cell round off into an oval body, the wall of the cell breaks, and the zoogonidium escapes. It has a clear space at the small end, and around this clear space
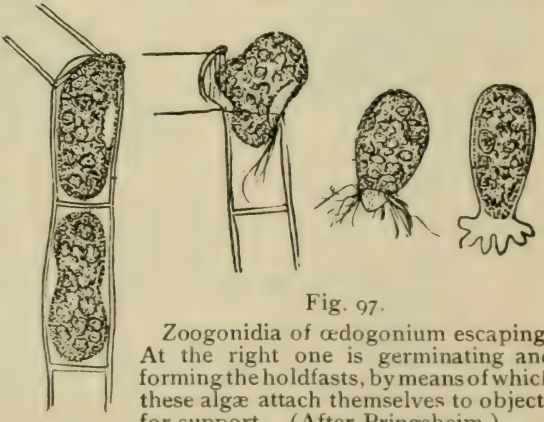

Fig. 97 .

Zoogonidia of oedogonium escaping. At the right one is germinating and forming the holdfasts, by means of which these algæ attach themselves to objects for support. (After Pringsheim.)

is a row or crown of cilia as shown in fic. 97. By the vibration of these cilia the zoogonidium swims a round for a time, then settles down on some object of support, and several slender holdfasts grow out in the form of short rhizoids which attach the young plant.

242. Sexual reproduction. Antheridia.-The antheridia are short cells which are formed by one of the ordinary cells dividing into a number of disk-shaped ones as shown in fig. 98. The protoplasm in each antheridium 
forms two spermatozoids (sometimes only one) which are of the same form as the zoogonidia but smaller, and yeilowish instead of green. In some species

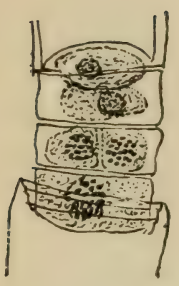

Fig. 98 .

Portion of thread of adogonium showing antheridia.

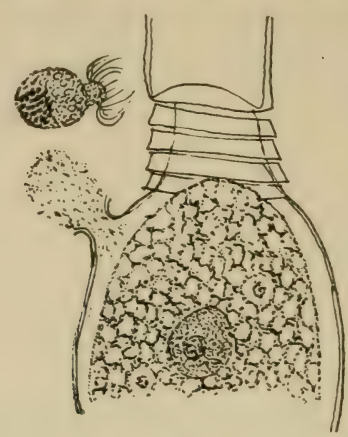

Fig. 99.

Portion of thread of œdogonium showing upper half oogonia are formed diof egg open, and a spermatozoid ready to enter. (After Oltmans). a motile body intermediate in size and color between the spermatozoids and zoogonidia is first formed, which after swimming around comes to rest on the oogonium, or near it, and develops what is called a "dwarf male plant" from which the real spermatozoid is produced.

243. Oogonia. - The rectly from one of the vegetative cells. In most species this cell first enlarges in diameter, so that it is easily detected. The protoplasm inside is the egg cell. The oogonium wall opens, a bit of the protoplasm is emitted, and the spermatozoid then enters and fertilizes it (fig. 99). Now a hard brown wall is formed around it, and, just.as in spirogyra

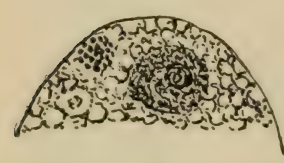

Fig. 100.

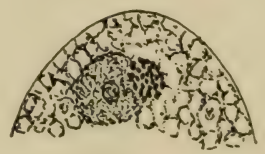

Fig. ror.

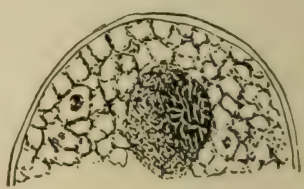

Fig. 102.

Male nucleus just entering Male nucleus fusing with The two nuclei fused, and egg at left side. female nucleus.

Figs, roo-ro2.-Fertilization in œedogonium. (After Oltmans).

and vaucheria, it passes through a resting period. At the time of germination it does not produce the thread-like plant again directly, but first forms four zoospores exactly like the zoogonidia (fig. IO3). These zoospores then germinate and form the plant.

244. EEdogonium compared with spirogyra. - Now if we compare œedogonium with spirogyra, as we did in the case of vaucheria, we will find here also that there is an advance upon the simple condition which exists in spirogyra. Growth and division of the thread is limited to certain portions. The sexual organs are differentiated. They usuaily differ in form and size from the vegetative cells, though the ougonium is simply a changed vegetative 
cell. The sexual organs are differentiated among themselves, the antheridium is small, and the oogonium large. The gametes are also differentiated in size, and the male gamete is motile, and carries in its body the nucleus which fuses with the nucleus of the egg cell.

But a more striking advance is the fact that the fertilized egrg does atot
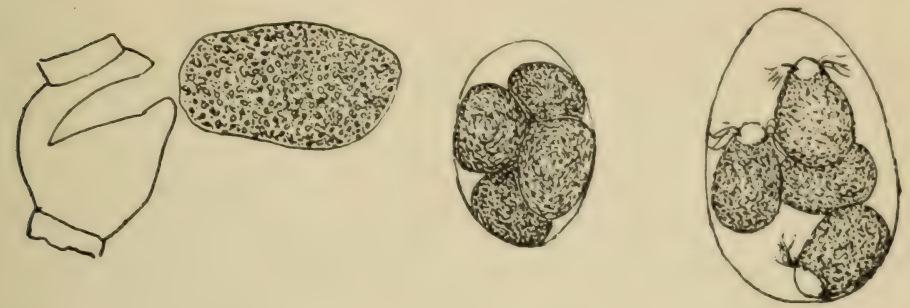

Fig. 103.

Fertilized egg of œdogonium after a period of rest escaping from the wall of the oogonium, and dividing into the four zoospores. (After Juranyi.)

produce the vegetative thread of œdogonium directly, but first forms four zoospores, each of which is then capable of developing into the thread. On the other hand we found that in spirogyra the zygospore develops directly into the thread form of the plant.

245. Position of œdogonium.-Edogonium is one of the true thread-like algæ, green in color, and the threads are divided into distinct cells. It, Tuft of chætoalong with many relatives, phora, natural was once placed in the old genus conferva. These are all now placed in the group Confervoidea, that is, the conferva-like alga.

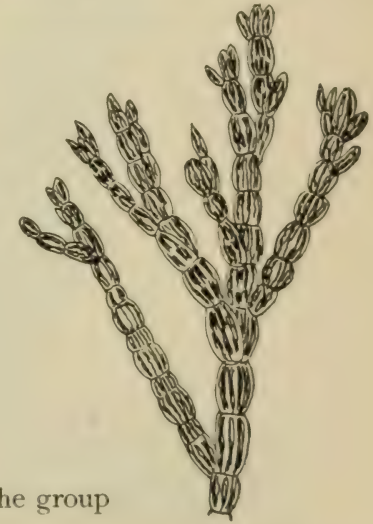

Fig. 105.

246. Relatives of œdogonium.-Many other genera Portion of chatophora are related to œdogonium. Some consist of simple showing branching. threads, and others of branched threads. An eximple of the branched forms is found in chretophora, represented in figures 104. 105. This plant grows in quiet pools or in slow-running water. It is attached to sticks, rocks, or to larger aquatic plants. Many threads spring from the same point of attachment and radiate in all directions. This. togrether with the brarching of the threads, makes a small, compact, greenish, rounded mass, which is 
held firmly together by a gelatinous substance. The masses in this species are about the size of a small pea, or smaller. Growth takes place in chætophora at the ends of the threads and branches. That is, growth is apical. This, together with the branched threads and the tendency to form cell masses, is a great advance of the vegetative condition of the plant upon that which we find in the simple threads of œdogonium. 


\section{CHAPTER XVII.}

\section{VAUCHERIA.}

247. The plant vaucheria we will remember from our study in an earlier chapter. It usually occurs in dense mats floating on the water or lying on damp soil. The texture and feeling of these mats remind one of "felt," and the species are sometimes called the "green felts." The branched threads are continuous, that is there are no cross walls in the vegetative threads. This plant multiplies itself in several ways which would be too tedious to detail here. But when fresh bright green mats can be obtained they should be placed in a large vessel of water and set in a cool place. Only a small amount of the alga should be placed in a vessel, since decay will set in more rapidly with a large quantity. $\quad \mathrm{F}$ or several days one should look fo $\mathrm{r}$

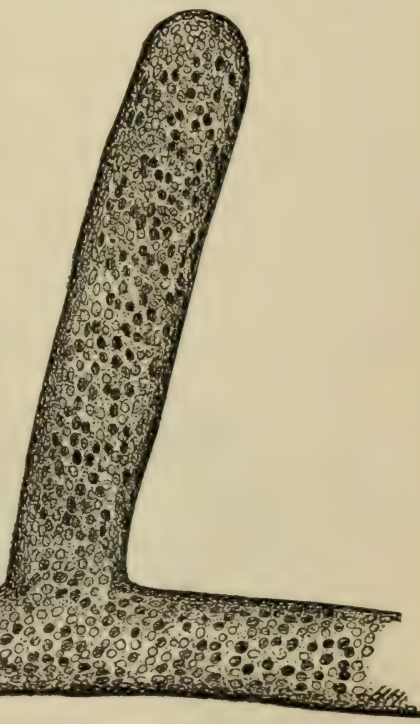

Fig. 106.

small green bodies which may be floating at the side of the vessel next the lighted window.

248. Zoogonidia of vaucheria. - If these minute floating green bodies are found, a small drop of water containing them should be mounted for exami- 
nation. If they are rounded, with slender hair-like appendages over the surface, which vibrate and cause motion, they very likely are one of the kinds of reproductive bodies of vaucheria. The hair-like appendages are cilia, and they occur in pairs, several of them distributed over the surface. These rounded bodies are gonidia, and because they are motile they are called zoosonidia.

By examining some of the threads in the vessel where they occurred we may have perhaps an opportunity to see how they are produced. Short branches are formed on the threads, and the contents are separated from those of the main thread by a septum. The protoplasm and other contents of this branch separate from the wall, round up into a mass, and escape through an opening which is formed in the end. Here they swim around in the water for a time, then come to rest, and germinate by growing out into a tube which forms another vaucheria plant. It will be observed that this kind of reproduction is not the result of the union of two different parts of the plant. It thus differs from that which is termed sexual reproduction. A small part of the plant simply becomes separated from it as a special body, and then grows into a new plant, a sort of multiplication. This kind of reproduction has been termed asexual reproduction.

249. Sexual reproduction in vaucheria. - The organs which are concerned in sexual reproduction in vaucheria are very readily obtained for study if one collects the material at the right season. They are found quite readily during the spring and autumn, and may be prescrved in formalin for study at any season, if the material cannot be collected fresh at the time it is desired for study. Fine material for study often occurs on the soil of pots in

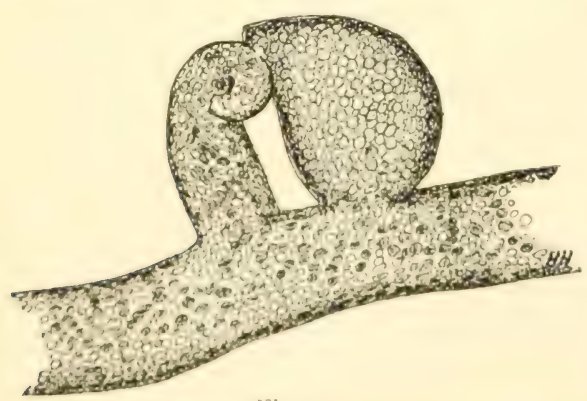

Fig. 107 .

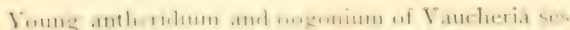

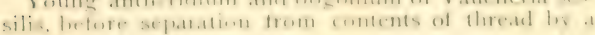
septum. greenhouses during the winter. While the zoogonidia are more apt to be found in material which is quite green and freshly growing, the sexual organs are usually more abundant when the threats appeat somewhat ye" owish, or yellow green.

250. Vaucheria sessilis; the sessile vaucheria.--ln this plant the sexulal organs are sessile, that is they are not loorne on a stalk as in some other species. 'The sesual organs usually ocrur several in a group. lig. 107 represents a portion of a fruiting plant. 
251. Sexual organs of vaucheria. Antheridium.-The antheridia are short. slender, curved branches from a main thread. A septum is formed which separates an end portion from the stalk. This end cell is the antheridium. Frequently it is collapsed or empty as shown in fig. 108. The protoplasm in

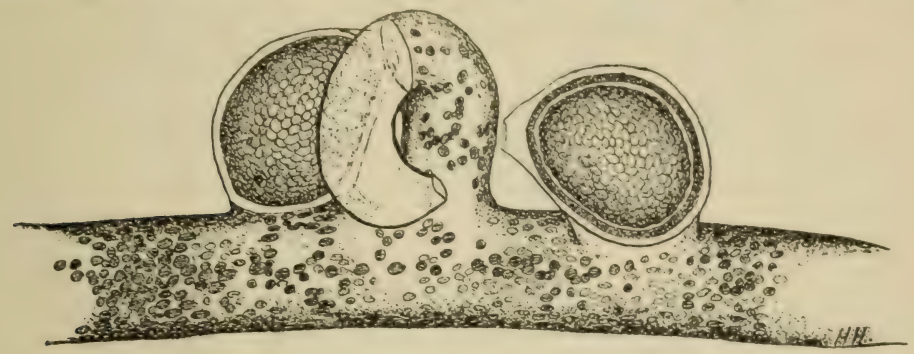

Fig 108.

Vaucheria sessilis, one antheridium between two oogonia.

the antheridium forms numerous small oval bodies each with two slender lashes, the cilia. When these are formed the antheridium opens at the end and they escape. It is after the escape of these spermatozoids that the antheridium is collapsed. Each spermatozoid is a male gamete.

252. 0ogonium. - The oogonia are short branches also, but they become large and somewhat oval. $\mathrm{T} \mathrm{h} \mathrm{e}$ septum which separates the protoplasm from that of the main thread is as we see near the junction of the branch with the main thread. The oogonium, as shown in the figure, is usually turned somewhat

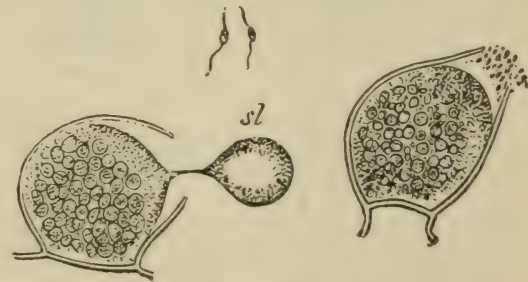

Fig. 109.

Vaucheria sessilis: oogonium opening and emitting a bit of protoplasm ; spermatozoids: spermatozoids entering orgmium. (After Pringsheim and Goebel.)

to one side. When mature the pointed end opens and a bit of the protoplasm escapes. The remaining protoplasm forms the large rounded egg cell which fills the wall of the oogonium. In some of the oogonia which we examine this egg is surrounded by a thick brown wall, with starchy and oily contents. 'This is the 
fertilized egg (sometimes called here the oospore). It is freed from the oogonium by the disintegration of the latter, sinks into
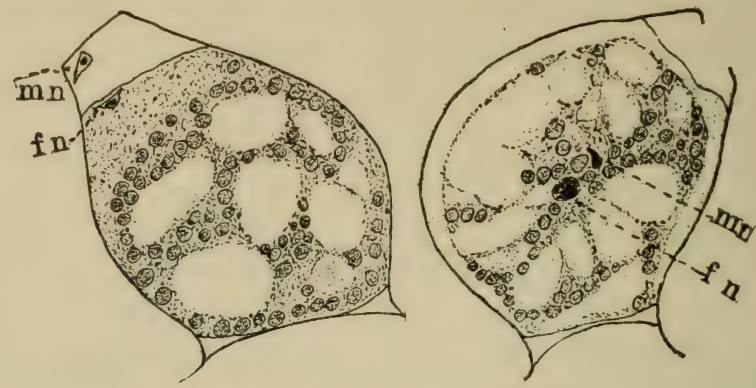

Fig. I ro.

Fertilization in vaucheria. $m n$, male nucleus; $f n$, female nucleus. Male nucleus entering the egg and approaching the female nucleus. (After Oltmans.)

the mud, and remains here until the following autumn or spring, when it grows directly into a new plant.

253. Fertilization.-Fertilization is accomplished by the spermatozoids swimming in at the open end of the oogonium,
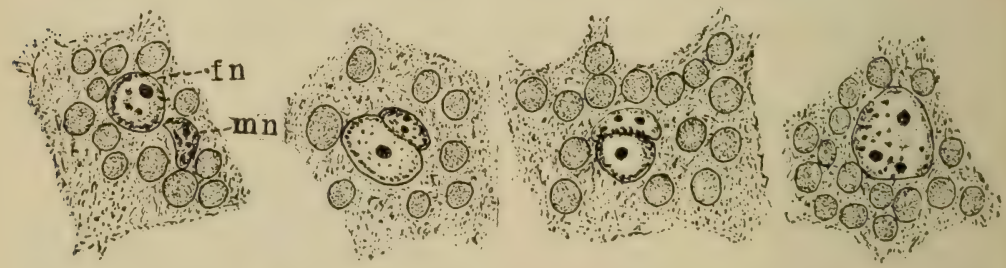

Fig. III.

Fertilization of vaucheria. $f n$, female nucleus; $m n$, male nucleus. The different figures show various stages in the fusion of the nuclei.

when one of them makes its way down into the egg and fuses with the nucleus of the egg.

254. The twin vaucheria (V. geminata).-Another specics of vaucheria is the twin vaucheria. This is also a common one, and may be used for study instearl of the sessile vitucheria if the latter cimnot be obtained. The sexual organs are borne at the end of a club-shaped branch. There are usually two oxsonial, and one antheridium between them which terminates the branch. In a closely relaterl species, instead of the two oogonia there is a whorl of them with the antheridium in the center.

255. Vaucheria compared with spirogyra. - In vaucheria we have a plant which is very interesting to compare with spirogyra in several respects. 
Growth takes place, not in all parts of the thread, but is localized at the ends of the thread and its branches. This represents a distinct advance on such a plant as spirogyrat. Agatin, only specialized parts of the plant in vatucheria form the sexual organs. These are short branches. Farther there is a great difference in the size of the two organs, and especially in the size of the gametes, the supplying gametes (spermatozoids) lesing very minute, while the receptive gamete is large and contains all the nutriment for the fertilized egg. In spirogyra, on the other hand, there is usually mo difference in size of the gametes, as we have seen, and each contributes equally in the matter of nutriment for the fertilized eggr. Vatucheria, therefore, represents a distinct advance, not only in the vegetative condition of the plant, but in the specialization of the sexual organs. Vaucheria, with other related algæ. belongs to a group known as the Siphonere, so called because the plants are tube-like or siphon-like. 


\section{CHAPTER XVIII.}

\section{COLEOCH ETE.}

256. Among the green algæ coleochæte is one of the most interesting. Several species are known in this country. One of these at least should be examined if it is possible to obtain it. It occurs in the water of fresh lakes and ponds, attached to aquatic plants.

25\%. The shield-shaped coleochæte.-This plant (C. scutata)

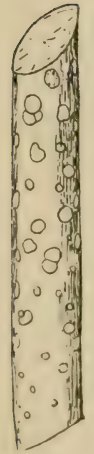

Fig. 12 .

Stem of aquatic plant showing coleochate, natural size.

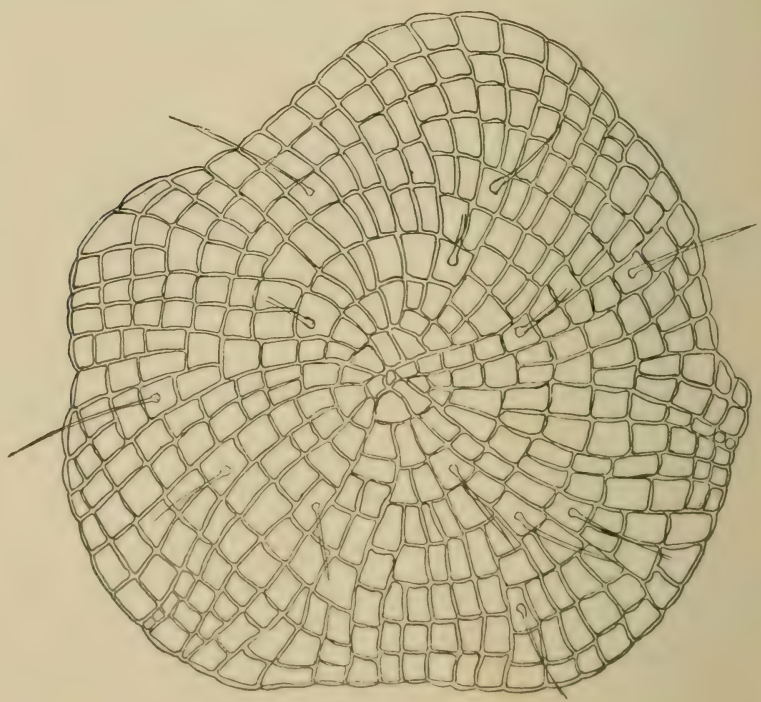

Fig. 113 .

Thallus of Coleochæte scutata.

is in the form of a flattened, circular, green plate, as shown in fig. I12. It is attached near the center on one side to rushes 
and other plants, and has been found quite abundantly for several years in the waters of Cayuga Lake at its southern extremity. As will be seen it consists of a single layer of green cells which radiate from the center in branched rows to the outside, the cells lying so close together as to form a continuous plate. The plant started its growth from a single cell at the central point, and grew at the margin in all directions. Sometimes they are quite irregular in outline, when they lie quite closely side by side and interfere with one another by pressure. If the surface is examined carefully there will be found long hairs, the base of which is enclosed in a narrow sheath. It is from this character that the genus takes its name of coleochæe (sheathed hair).

258. Fruiting stage of coleochæte.-It is possible at some seasons of the year to find rounded masses of cells situated near the margin of this green disk. These have developed from a fertilized egg which remained attached to the plant, and probably by this time the parent plant has lost its color.

259. Zoospore stage.-This mass of tissue does not develop directly into the circular green disk, but each of the cells forms a zoospore. Here then, as in œdogonium, we have another stage of the plant interpolated between the fertilized egg and that stage of the plant which bears the gametes. But in coleochæte we have a distinct advance in this stage upon what is present in œdogonium, for in coleochæte the fertilized egg develops first into a one from each cell; zoogoseveral-celled mass of tissue Pringsheim.)

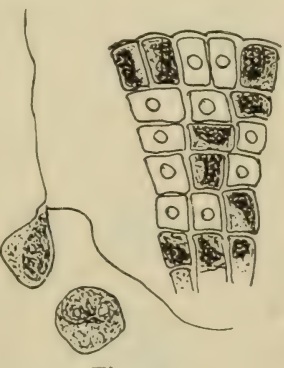

Fig. 114.

Portion of thallus of $\mathrm{C}^{\prime} \mathrm{O}$ leochæete scutata, showing empty cells trom which

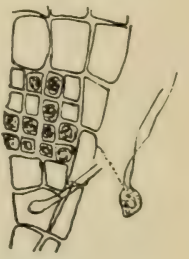

Fig. II5

Portion of thallus of Coleochate scutata, showing f o u $\mathrm{r}$ antheridia formed from one thallus cell; a single spermatozoid at the iight. (After Pringsheim.) before the zoospores are formed, while in aclogonium only four zoospores are formed directly from the egg.

260. Asexual reproduction. - In asexual reprexluction any of the green cells on the plant may form zoogronida. The conterits of a cell round off and 
form a single zoogonidium which has two cilia at the smaller end of the oval body, fig. II4. After swimming around for a time they come to rest, germinate, and produce another plant.

261. Sexual reproduction.-0ogonium.-The oogonium is formed by the enlargement of a cell at the end of one of the threads, and then the end of the
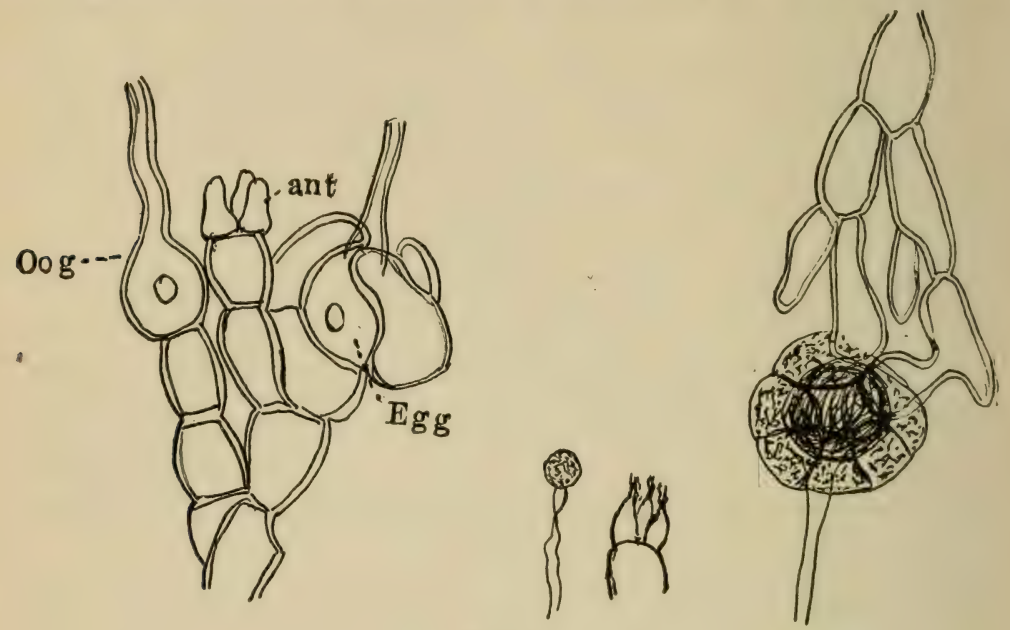

Fig. 116 .

Coleochæte soluta; at left branch bearing oogonium $(\circ o g)$; antheridia $(a n t)$; egg in oogonium and surrounded by enveloping threads; at center three antheridia open, and one spermatozoid; at right sporocarp, mature egg inside sporocarp wall.

cell elongates into a slender tube which opens at the end to form a chanmel through which the spermatozoid may pass down to the egg. The egg is f formed of the contents of the cell (fig. Ii6). Several oogonia are formed on

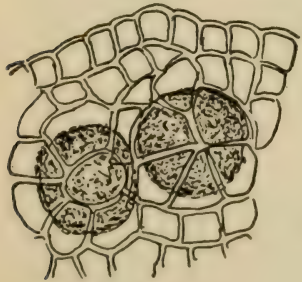

Fig. 117 .

Two sporocarps still surrounded by thallus. Thallus finally decays and sets sporocarp free.

Figs, $117,118, \mathrm{C}$. scutata. one plant, and in such a plant as C. scutata they are formed in a ring near the margin of the disk.

262. Antheridia.-In C. scutata certain of the cells of the plant divide into four smaller cells, and each one of these becomes an antheri-

Fig. 118 .

Sporocarp ruptured by growth of egg to form cell mass. Cells of this sporomass. Cells of this sp
phyte forming zoospores.

dium. In C. soluta the anthericlia grow out from the end of terminal cells in the form of short flasks, sometimes four in number or less (fig. I I6). A single spermatozoid is formed from the contents. It is oval and possesses two long cilia. After swim- 
ming around it passes down the tube of the oogonium and fertilizes the egg.

263. Sporocarp.-After the egrg is fertilized the cells of the threads near the egg grow up around it and form a firm covering one cell in thickness. This envelope becomes brown and hard, and serves to protect the egg. Th: is the "fruit" of the coleochate, and is sometimes called a sperocarp (spore fruit). The development of the cell mass and the zoospores from the egg has been described above.

some of the species of colenchrete consist of branched threads, while others form circular cushions several layers in thickness. These forms together with the form of our plant C. scutata make an interesting series of transitional forms from filamentuus structures to an expanded plant body formed of a mass of cells. 


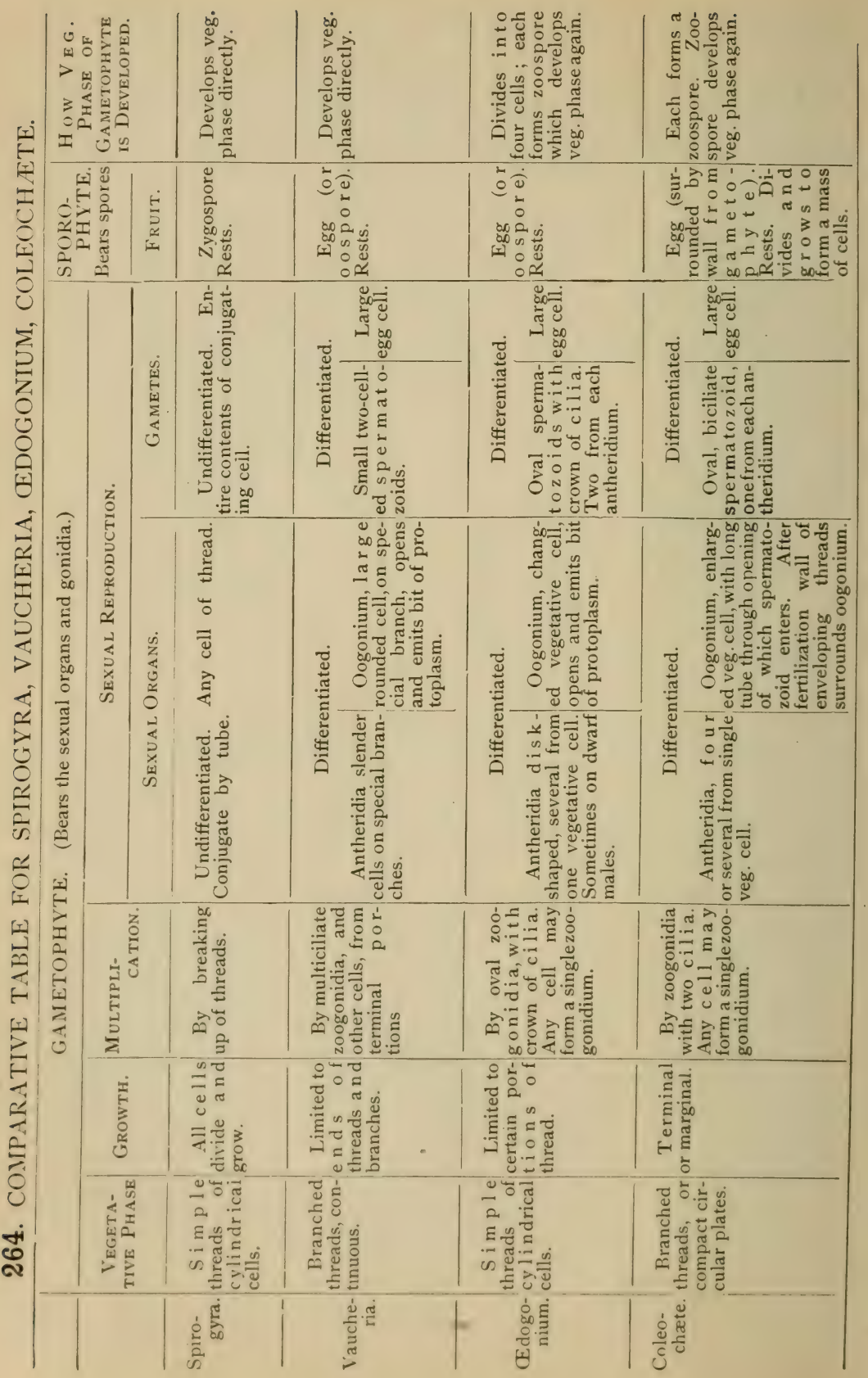




\section{CHAPTER XIX.}

\section{BROWN AND RED ALGA.}

265. If it is desired to extend the study of the algre to other groups, especially to some of the marine forms, examples of the brown algæe and of the red algæe may be obtained. These are accessible at the seashore, and for inland laboratories material may be preserved in formalin $(2 \pi / 2 \%)$.

266 The brown algæ (Phæophyceæ).*_A good representative of one division of the brown algæ and one often used for study is the genus fucus.

267. Form and occurrence of fucus.-This plant is a more or less branched and flattened thallus or "frond." One of them, illustrated in fig. II9, measures $15-30 \mathrm{~cm}$ (6-12 inches) in length. It is attached to rocks and stones which are more or less exposed at low tille. From the base of the plant are developed several short and more or less branched expansions called "holdfasts," which, as their name implies, are organs of attachment. Some species (F. vesiculosus) have vesicular swellings in the thallus.

The fruiting portions are somewhat thickened as shown in the figure. Within these portions are numerous oval cavities opening by a circular pore, which gives a punctate appearance to these fruiting cushions. Tufts of hairs frequently project through them.

268. Structure of the conceptacles.-On making sections of the fruiting portions one finds the walls of the cavities covered with outgrowths. Some of these are short branches which bear a large rounded terminal sac, the oogonium, at maturity containing eight egg cells. More slender and much branched threads bear narrowly oval antheridia. In these are developed several two-ciliated spermatozoids.

269. Fertilization.-At maturity the spermatozoids and eggr cells float outside of the oval cavities where fertilization takes place. The spermatozoil sinks into the protoplasm of the egg cell, makes its way to the nuckeus of the egg, and fuses with it as shown in fig. 125. The fertilized egg then grows into a new plant. Nearly all the brown algæ are marine.

* The memhers of the group possess chlorophyll. but it is obscured by a brown pigment. 
270. The red algæ (Rhodophyceæ). - The larger number of the so-called red algæ occur in salt water, though a few genera occur in fresh water.

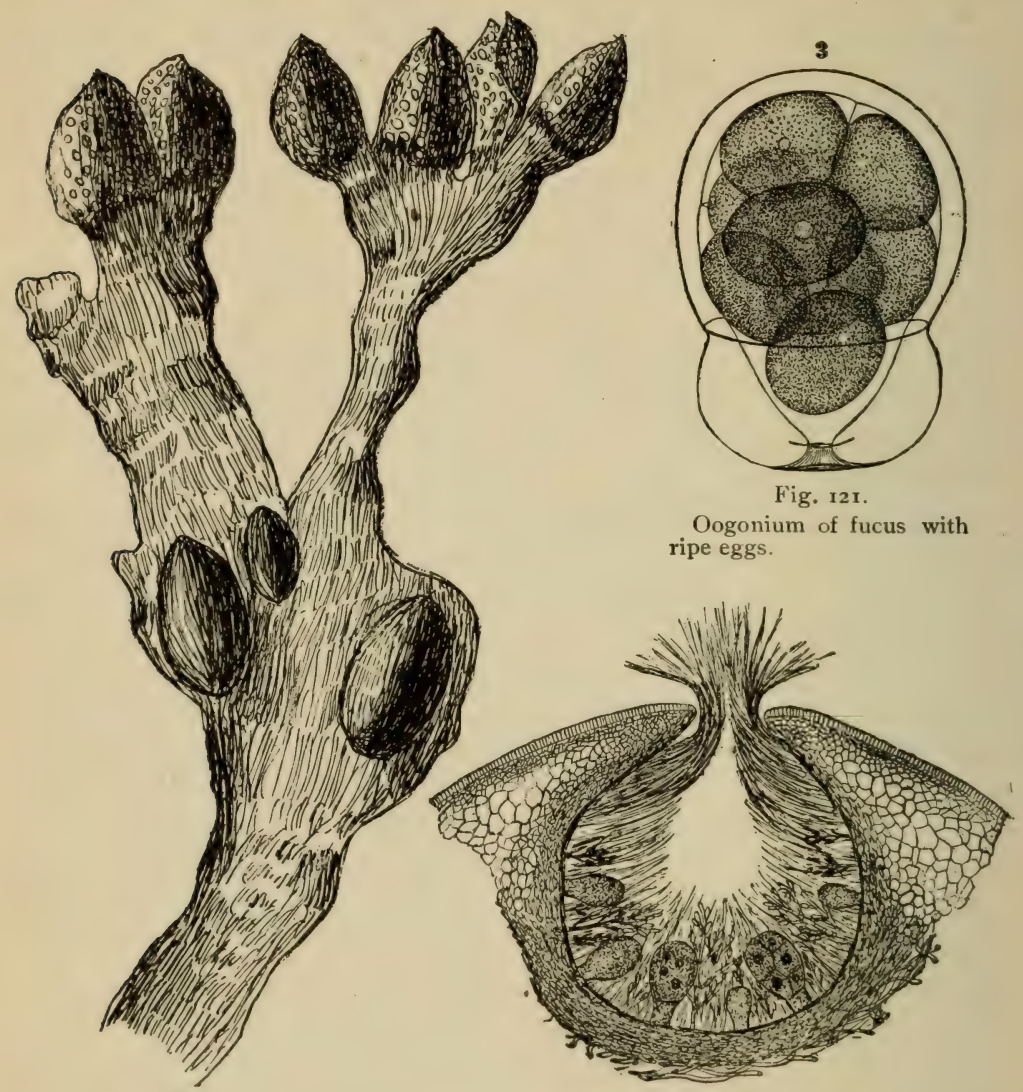

Fig. II 9 .

Portion of plant of fucus showing conceptacles in enlarged ends; and below the vesicles (Fucus vesciculosus). oogonia, and tufts of antheridia.
Section of conceptacle of fucus, showing

(Lemanea grows only in winter in turbulent water of quite large streams. Batrachospermum grows in rather slow-running water of smaller streams. Both of these inhabit fresh water.) The plants of the group possess chlorophyll, but it is usually obscured by a reddish or purple pigment.

271. Gracillaria - (iracillaria is one of the marine forms, and one species is illustrated in fig. $\mathbf{1 2 6}$. It measures $15-20 \mathrm{~cm}$ or more long, and is profusely branched in a palmate manner. The parts of the thallus are more or less flattened. The fruit is a cystocarp, which is characteristic of the rhodo- 
phycex (floridex). In gracillaria these fruit bodies occur scattered over the thallus. They are somewhat flask-shaped, are partly sunk in the

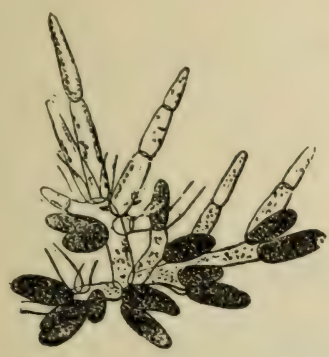

Fig. 122.

Antheridia of fucus, on branched threads.

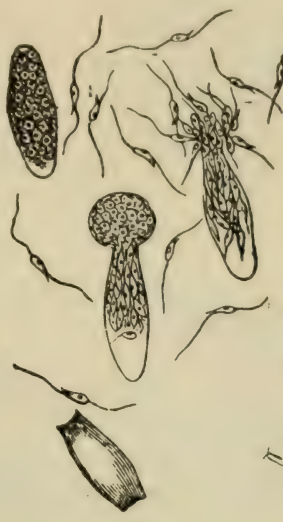

Fig. 123.

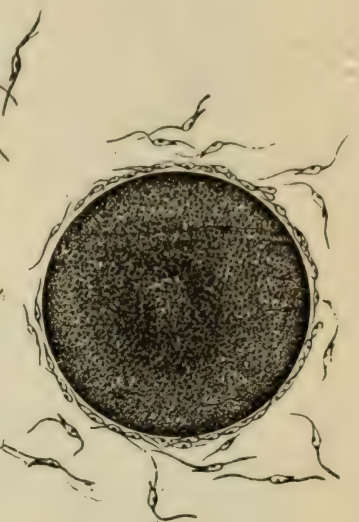

Fig. 124 .

Antheridia of fucus with Egg of fucus surrounded escaping spermatozoids. by spermatozoids.

thallus, and the conical end projects strongly above the surface. The carpospores are grouped in radiating threads within the oval c: vity of the
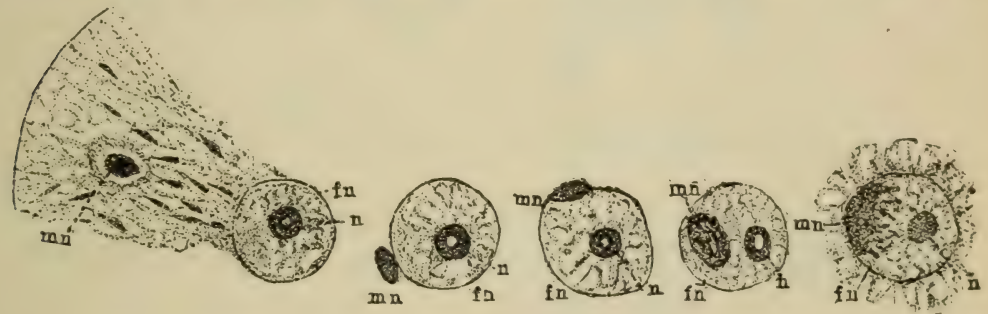

Fig. 125.

Fertilization in fucus : $f n$, female nucleus : $m n$, male nucleus ; $n$, nucleolus. In the left figure the male nucleus is shown moving down through the cytoplasm of the egg; in the remaining figures the cytoplasm of the egg is omitted. (After Strasburger.)

cystocarp. These cystocarps are developed as a result of fertilization. Other plants bear gonidia in groups of four, the so-called tetraspore's.

272. Rhabdonia.-This plant is about the same size as the gracillaria, though it possesses more filiform branches. The cystocarps form prominent elevations, while the carpospores lie in separated groups around the periphery of a sterile tissue within the cavity. (See figs. 128, 129.) Goniclia in the form of tetraspores are also developed in rhabdonia. 


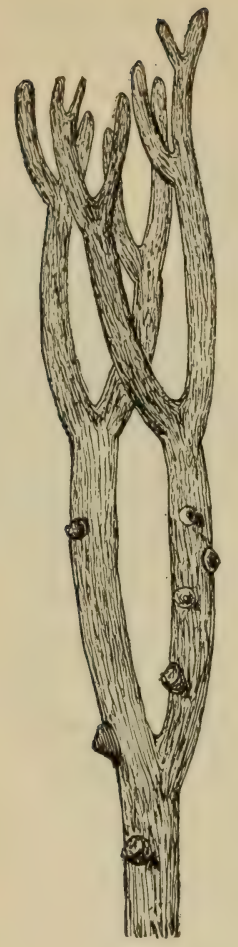

Fig. 126.

Gracillaria, portion of frond, showing position of cystocarps.

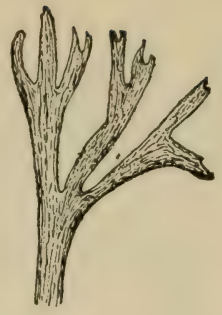

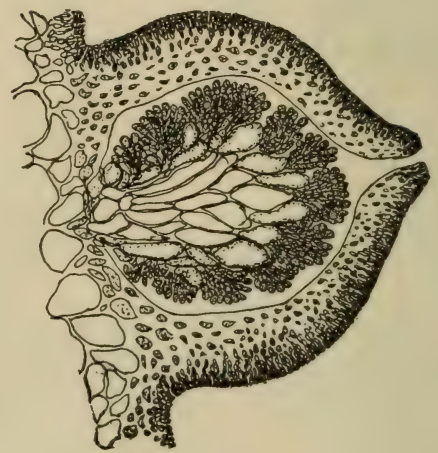

Fig. 127 .

Gracillaria, section of cystocarp showing spores.

273. The principal groups of the algæ are the following:

Chlorophycece. Green algæ.
Protococcoideæ (the protococcus (Pleurococcus vulgaris); the red-snow plant (Sphærella nivalis), etc.

Conjugateæ (spirogyra, zygnema, mougeotia, desmids, etc.).

Siphoneæ (vaucheria).

Confervoideæ (œdogonium, chætophora, coleochæte).

Cvanophycea (nostoc, oscillatoria, etc.). 'The blue-green algæ. Phaophycew (fucus, etc.). The brown algæ. 
Rhodophycee (rhabdonia, gracillaria, callithamnion, champia, etc.). The red algæ.

274. Some of the protococcoidex are belicved to lie very near some of the lower animals like the flagellates. They are mostly

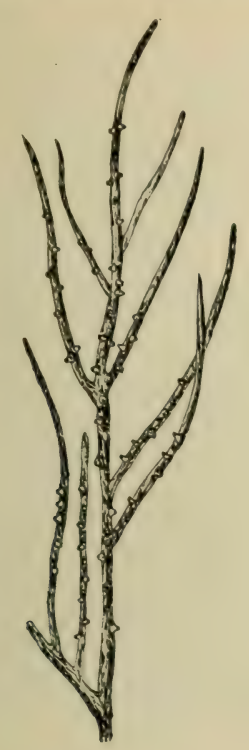

Fig. 128 .

Rhabdonia,branched portion of frond showing cystocarps. single-celled plants; some of them art motile during the vegetative stage, and others are not motile, while others are

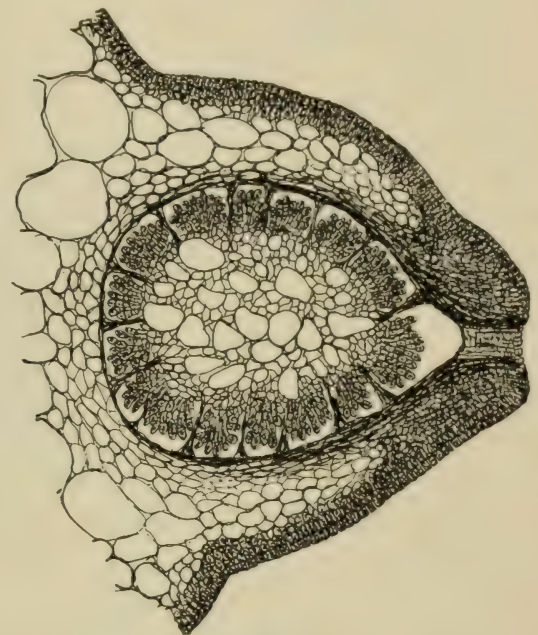

Fig. 129.

Section of cystocarp of rhabdonia, showing spores.

motile during certain stages. The red-snow plant may be obtained by scraping the red-looking matter out of the bottom of dry shailow basins in the rocks, close by fresh-water streams or lakes. By placing some of this material in a vessel of water for a few days the motile stage may be obtained. The protococcus, or Pleurococcus vul- tococcus) vulgaris. garis, may be obtained on the north side of trees, rocks, and walls, in damp places. 
CHAPTER XX.

\section{FUNGI: MUCOR AND SAPROLEGNIA.}

\section{Mucor.}

275. In the chapter on growth, and in our study of protoplasm, we have become familiar with the vegetative condition of mucor. We now wish to learn how the plant multiplies and reproduces itself. For this study we may take one of the mucors. Any one of several species will answer. This plant may be grown by placing partially decayed fruits, lemons, or oranges, from which the greater part of the juice has been removed, in a moist chamber; or often it occurs on animal excrement when placed under similar conditions. In growing the mucor in this way we are likely to obtain Mucor mucedo, or another plant sometimes known as Mucor stolonifer, or Rhizopus nigricans, which is illustrated in fig. I 32. This latter one is sometimes very injurious to stored fruits or vegetables, especially sweet potatoes or rutabagas. Fig. I $3 \mathbf{I}$ is from a photograph of this fungus on a banana.

276. Asexual reproduction.-On the decaying surface of the vegetable matter where the mucor is growing there will be seen numerous small rounded bodies borne on very slender stalks. These heads contain the gonidia, and if we sow some of them in nutrient gelatine or agar in a Petrie dish the material can be taken out very readily for examination under the microscope. Or we may place glass slips close to the growing fungus in the moist chamber, so that the fungus will develop on them, though cultures in a nutrient medium are much better. Or we maly take the material directly from the substance on which it is growing. 
After mounting a small quantity of the mycelium bearing these heads, if we have been careful to take it where the heads appear quite young, it may be possible to study the early stages of their

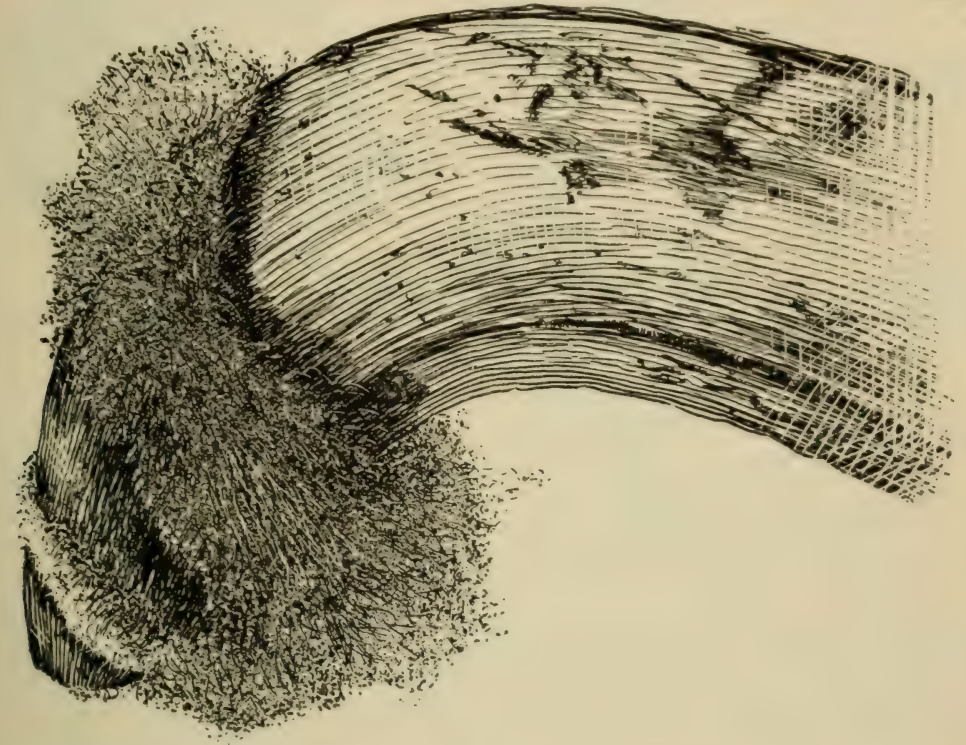

Fig. 131

Portion of banana with a mould (Rhizopus nigricans) growing on one end.

development. We will probably note at once that the stalks or upright threads which support the heads are stouter than the threads of the mycelium.

These upright threads soon have formed near the end a cross wall which separates the protoplasm in the end from the remainder. This end cell now enlarges into a vesicle of considerable size, the head as it appears, but to which is applied the name of sporangium (sometimes called gonidangium), because it encloses the gonidia.

At the same time that this end cell is enlarging the cross wall is arching up into the interior. This forms the columellir. All the protoplasm in the sporangium now divides into gonidia. These are small rounded or oval bodies. The wall of the spo- 
rangium becomes dissolved, except a small collar around the stalk which remains attached below the columella (fig. I33).

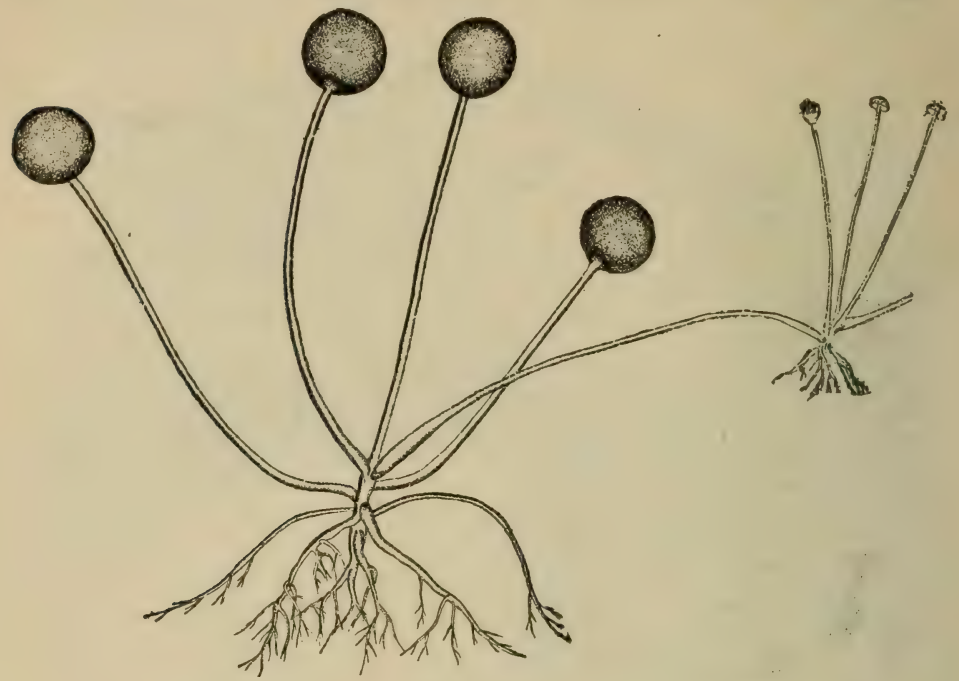

Fig. 132 .

Group of sporangia of a mucor (Rhizopus nigricans) showing rhizoids and the stolon extending from an older group.

By this means the gonidia are freed. These gonidia germinate and produce the mycelium again.

277. Sexual stage. - This stage is not so frequently found, but may sometimes be obtained by growing the fungus on bread.

Conjugation takes place in this way. Two threads of the mycelium which lie near each other put out each a short branch which is clavate in form. The ends of these branches meet, and in each a septum is formed which cuts off a portion of the protoplasm in the end from that of the rest of the mycelium. The meeting walls of the branches now dissolve and the protoplasm of each gamete fuses into one mass. A thick wall is now formed around this mass, and the outer layer becomes rough and brown. This is the zysote or zygrospore. The mycelium dies and it becomes free often with the suspensors, as the stalks of these sexual branches are called, still attached. This zycrospore passes through a period of rest, when with the entrance of favorable conditions of growth it germinates, and usually proluces directly a sporangium with goniclia. This completes the normal life cycle of the plant.

278. Gemmæ-Cicmmx, as they are sometimes called, are often formed on the mycelium. A short cell with a stout wall is formed on the side of a 
thread of the mycelium. In other cases large portions of the threarls of the mycelium may separate into chains of cells. Both these kinds of cells are

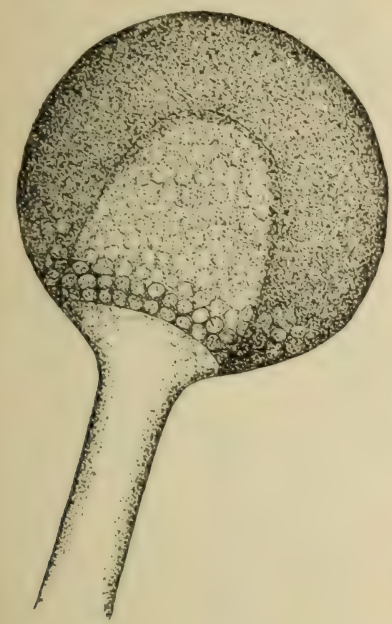

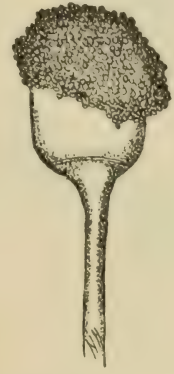
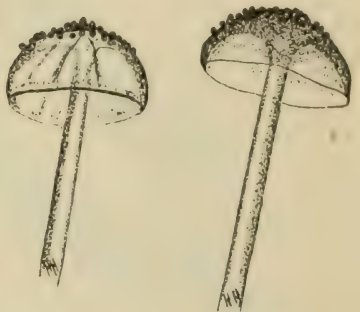

Fig. 133 .

A mucor (Rhizopus nigricans); at left nearly mature sporangium with columella showing within; in the middle is ruptured sporangium with some of the gonidia clinging to the columella; at right two ruptured sporangia with everted columella.

capable of growing and forming the mycelium again. They are sometimes called chlamydospores.

\section{Water Moulds (Saprolegnia).}

279. The water moulds are very interesting plants to study because they are so easy to obtain, and it is so easy to observe a type of gonidium here to which we have referred in our studies of the algæ, the motile gonidium, or zoogonidium. (See appendix for directions for cultivating this mould.)

280. Appearance of the saprolegnia.-In the course of a few days we are quite certain to see in some of the cultures dilicate whitish threads, radiating outward from the loody of the fly in the water. A few threads should be examined from day to day to determine the stage of the fungus.

281. Sporangia of saprolegnia.-The sporangia of saprolegnia can be easily detected because they are much stouter than the 
ordinary threads of the mycelium. Some of the threads should be mounted in fresh water. Search for some of those which

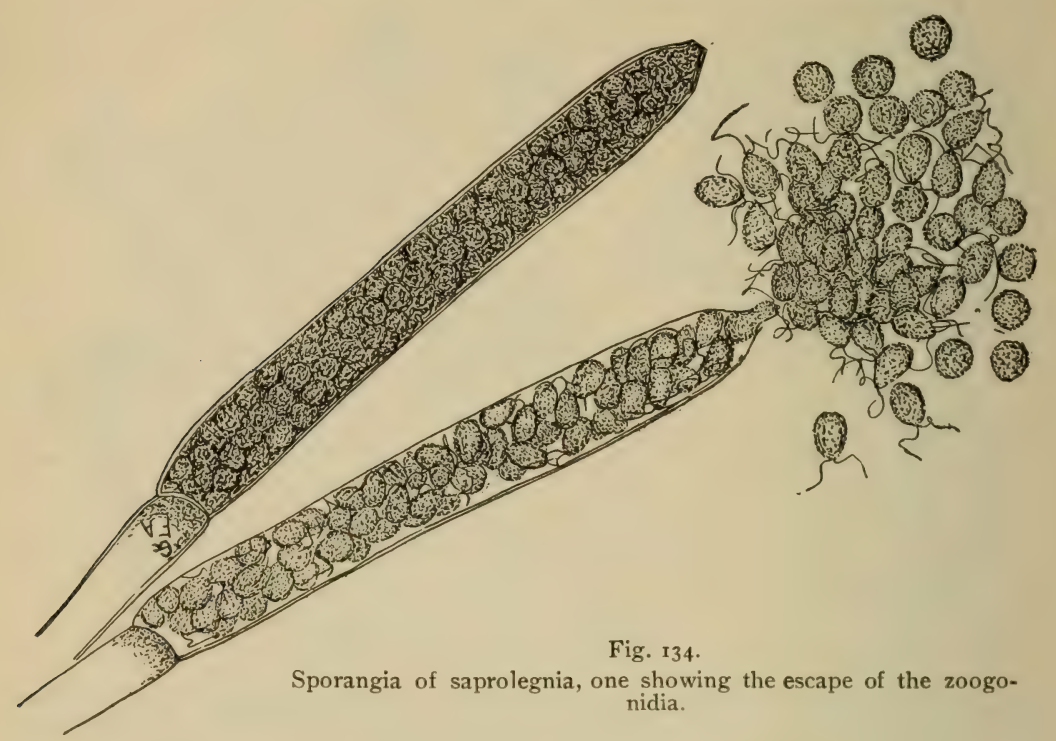

show that the protoplasm is divided up into a great number of small areas, as shown in fig. I34.

With the low power we should watch some of the older appearing ones, and if after a few minutes they do not open, other preparations should be made.

282. Zoogonidia of saprolegnia.-The sporangium opens at

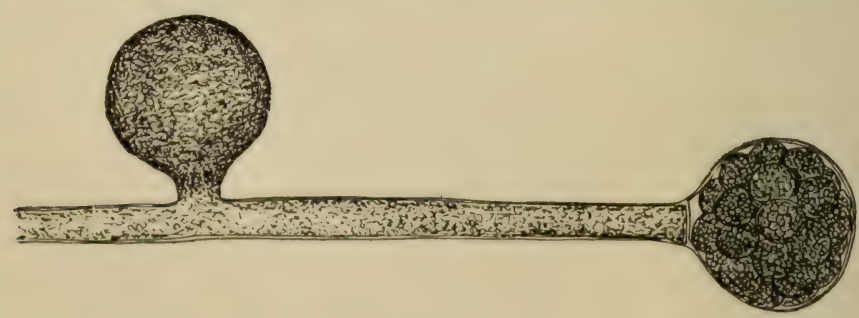

Fig. 135 .

Branch of saprolegnia showing oogonia with oospores, eggs matured parthenogenetically.

the end, and the zoogoniclia swirl out and swim around for a short time, when they come to rest. With a good magnifying 

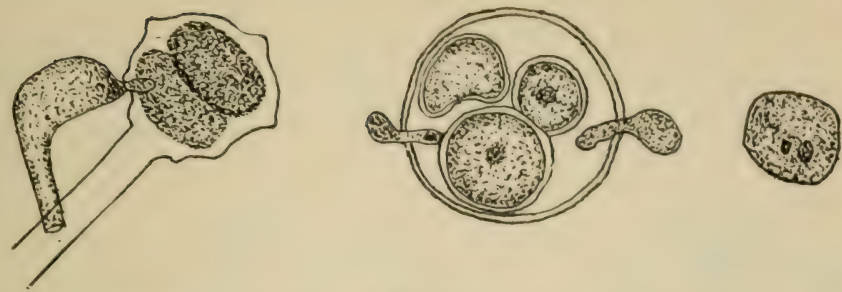

Fig. 136 .

Fertilization in saprolegnia, tube of antheridium carrying in the nucleus of the sperm cell to the egg. In the right-hand figure a smaller sperm nucleus is about to fuse with the nucleus of the egg. (After Humphrey and Trow.)

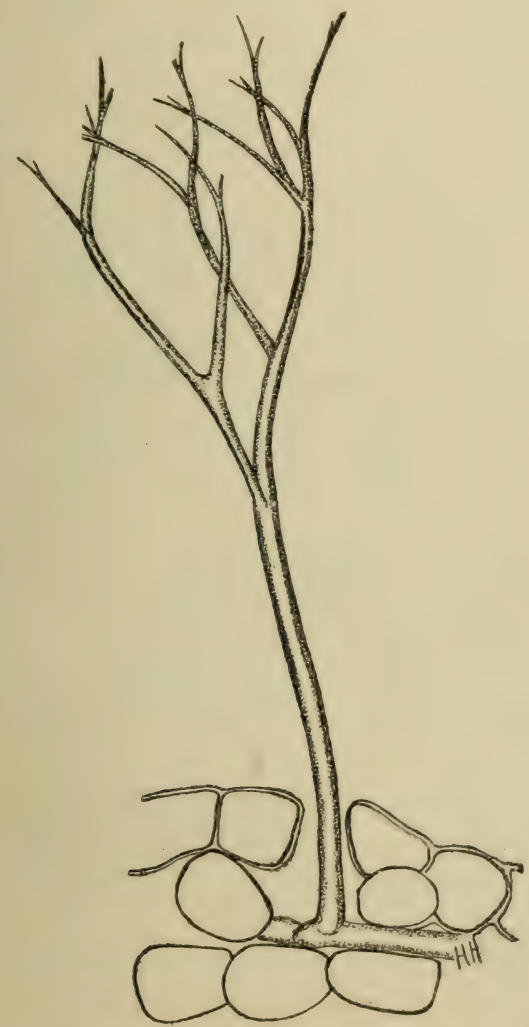

Fig. 137.

Branching hypha of Peronospora alsinearum.

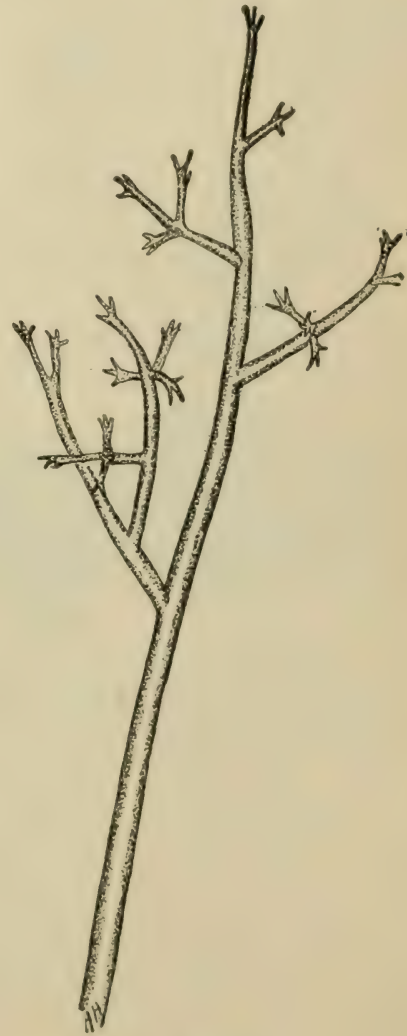

Fig. 138 .

Brancled hypha of downy mildew of grape showing peculiar branching (Plasmopara viticola). 
power the two cilia on the end may be seen, or we may make them more distinct by treatment with Schultz's solution, drawing some under the cover glass. The zoogonidium is oval and the cilia are at the pointed end. After they have been at rest

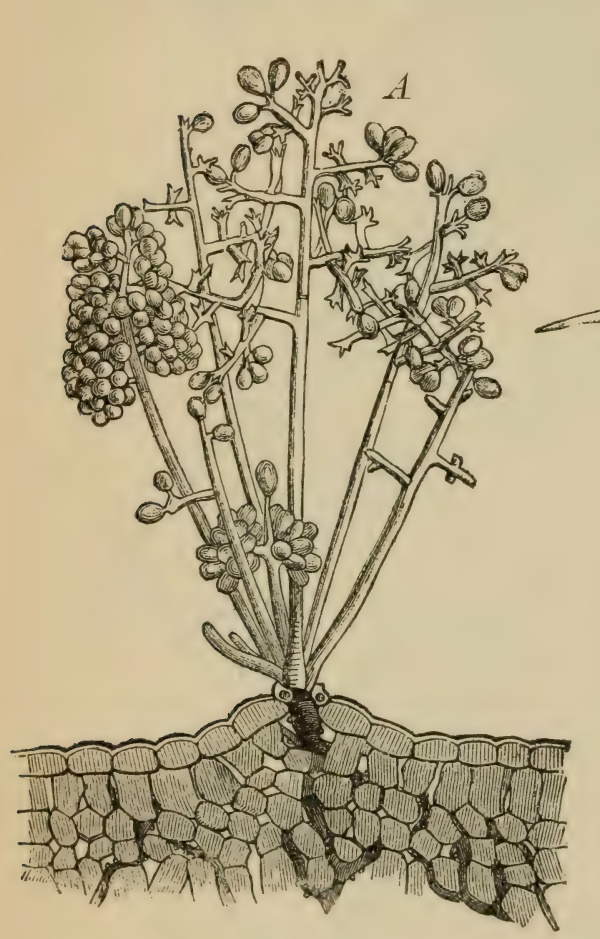

Fig. 139 .

Downy mildew of grape (Plasmopora viticola), showing tuft of gonidiophores bearing gonidia, also intercellular mycelium. (After Millardet.)

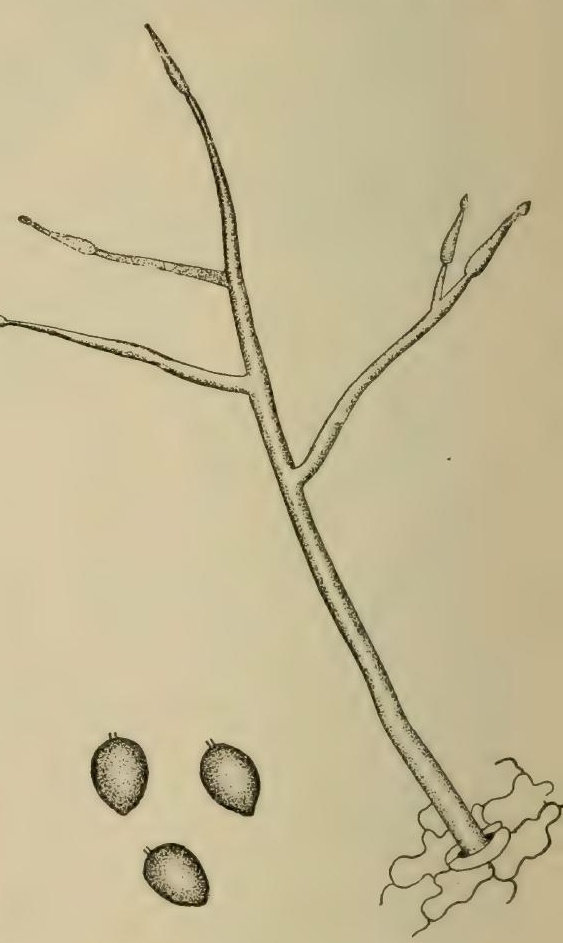

Fig. 140.

Phytophthora infestans showing peculiar branches; gonidia below.

for some time they often slip out of the thin wall, and swim again, this time with the two cilia on the side, and then the zoogonidium is this time more or less bean-shaped or reniform.

283 Sexual reproduction of saprolegnia. - When such cultures are older we often see large rounded bodies either at the end of a thread, or of a branch. which contatin several smaller rounderl hodies as shown in fig. I 35 . These are the oogonia (unless the plant is attacked by a parasite), and the round berles inside are the eggr cells, if before fertilization, or the eggs, if 
after this process has taken place. Sometimes the slender antherilium can be seen coiled partly around the ongonium, and one end entering to come in contact with the egg cell. But in some species the antheridium is not present, and that is the case with the species figured at 135 . In this case

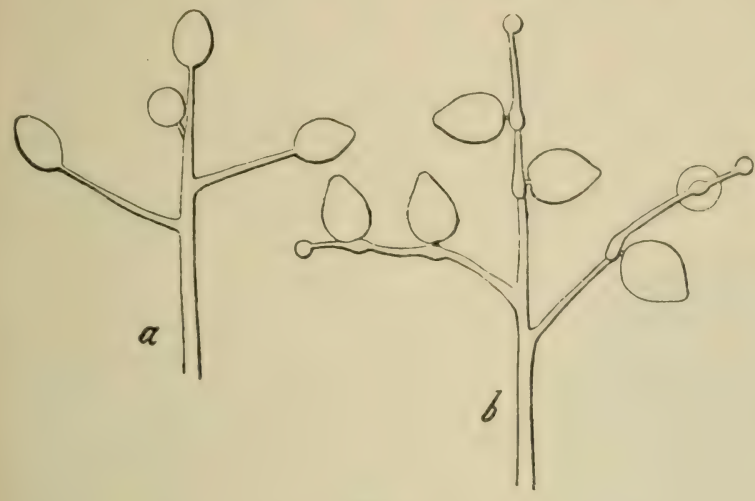

Fig. r41.

Gonidiophores and gonidia of potato blight (Phytophthora infestans). $b$, an older stage showing how the branch enlarges where it grows beyond the older gonidium. (After de Bary.)

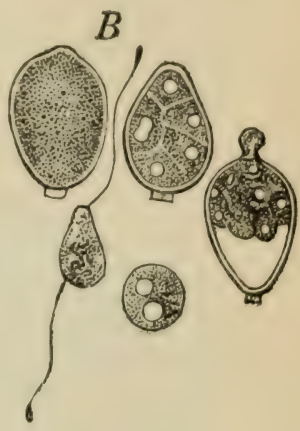

Fig. 142.

Gonidia of potato blight forming zoogonidia. (After de Bary.)

the eggs mature without fertilization. This maturity of the egg without fertilization is called parihinosinesis, which occurs in other plants also, but is a rather rare phenomenon.

284. In fig. 136 is shown the oogonium and an antheridium, and the antheridium is carrying in the male nucleus to the egrg cell. Spermatozoids
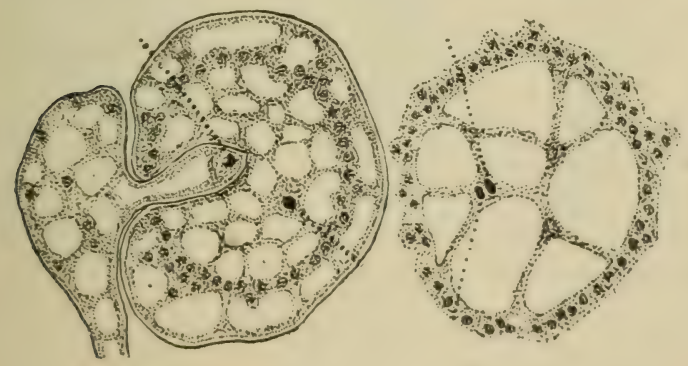

Fig. 143 .

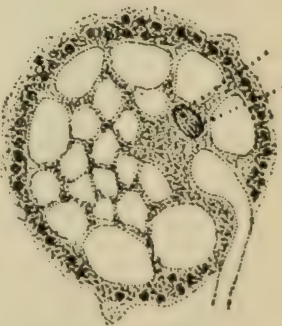

Fertilization in Peronospora alsinearum; tube from antheridium carrying in the sperm nucleus in figure at the left, female nucleus near; fusion of the two nuclei shown in the two other figures. (After Berlese.)

are not developed here. but a nucleus in the antheridium reaches the egg cell. It sinks in the protoplasm of the egg, comes in contact with the nucleus of the egg, and fuses with it. Thus lertilization is accomplished. 


\section{Downy Mildews.}

285. The downy mildews make up a sroup of plants which are closely related to the water moulds, but they are parasitic on land plants, and some species produce very serious diseases. The mycelium grows between the cells of the leaves, stems, etc., of their hosts, and sends haustoria into the cells to take up nutriment. Gonidia are formed on threads which grow through the stomates to the outside and branch as shown in figs. 137-140.

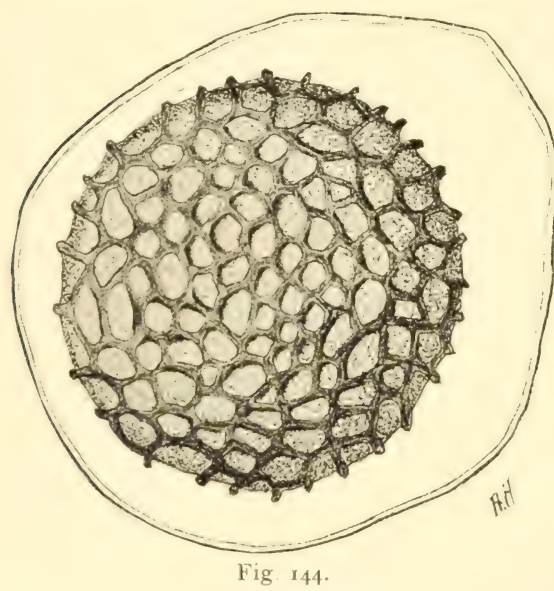

Ripe oospore of Peronospora alsinearum.

The gonidia are borne on the tips of the branches. The kind of branching bears some relation to the different genera. Fig. 137 is from Peronospora alsinearum on leaves of cerastium; figs. I 388 and $\mathbf{1} 39$ are Plasmopara viticola, the grape mildew, while figs. $\mathbf{4} 40$ and I4I are from Phytophthora infestans, which causes a disease known as potato blight. The gonidia of peronospora germinate by a germ tube, those of plasmop. ara first form zoogonidia, while in phytophthora the gonidium may either germinate forming a thread, or each gonidium may

first form several zoogonidia as shown in fig. I42.

286. In sexual reproduction oogronia and antheridia are developed on the mycelium within the tissues. Fig. It3 represents the antheridium entering the oxemium, and the male nucleus fusing with the fomale nucleus in fertilization. The sexual organs of Phytophthora infestans are not known.

287. Mucor, saprolegnia, peronospora, and their relatives have few or no septa in the mycelium. In this respect they resemble certain of the algre like vaucheria, but they lack chlorophyll. They are sometimes called the alga-like fungi and belong to a large group called Phycomycetes. 


\section{CHAPTER XXI.}

FUNGI CONTINUED (RUSTS AND SAC FUNGI).

\section{"Rusts" (Uredineæ).}

288. The fungi known as "rusts" are very important ones to study, since all the species are parasitic, and many produce serious injuries to crops.

289. Wheat rust (Puccinia graminis). - The wheat rust is one of the best known of these fungi, since a great deal of study has been given to it. One form of the plant occurs in long

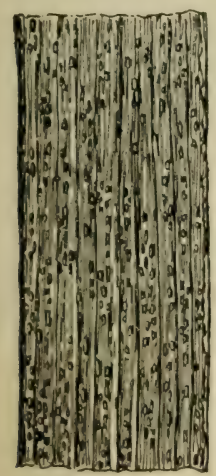

Fig. 145.

Wheat leaf with red rust, natural size.

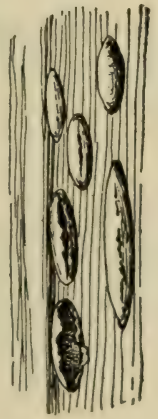

Fig. 146.

Portion of leaf enlarged to show sori.

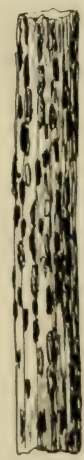

Fig. 147 . Natural size.

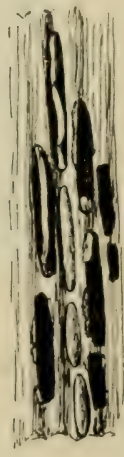

Fig. 148. Enlarged.

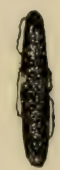

Fig. 149. $S$ ingle sorus.

Figs. $145,146 .-$ Puccinia graminis, red-rust stage (uredo stage).

Figs. 147-149.-Black rust of wheat, showing sori of teleutospores.

reddish-brown or reddish pustules, and is known as the "red rust " (figs. I 45, I 46). Another form occurs in elongated black pustules, and this form is the one known as the "black rust" 
(figs. I 47-I 50). These two forms occur on the stems, blades, etc., of the wheat, also on oats, rye, and some of the grasses.

290. Teleutospores of the black-rust form. - If we scrape off some portion of one of the black pustules (sori), tease it out

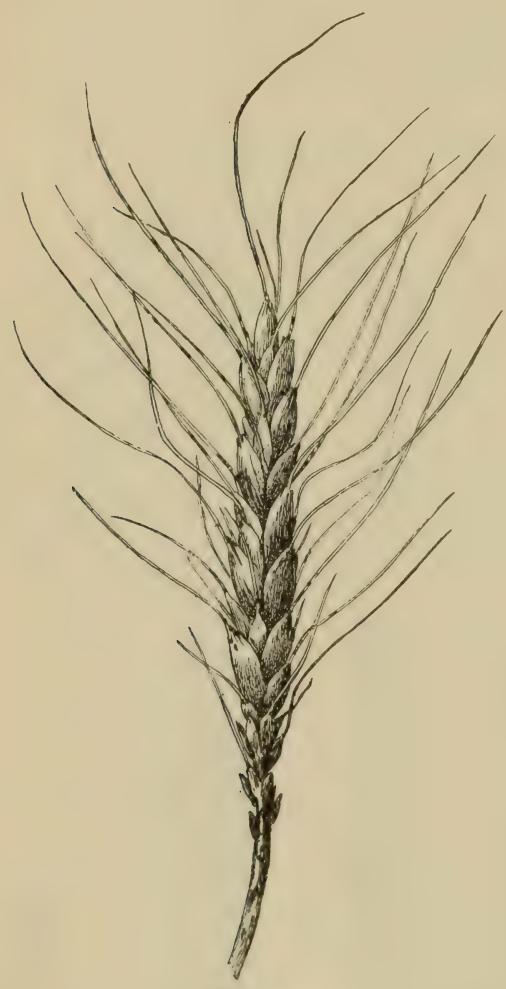

Fig. 150.

Head of wheat showing black rust spots on the chaff and awns.

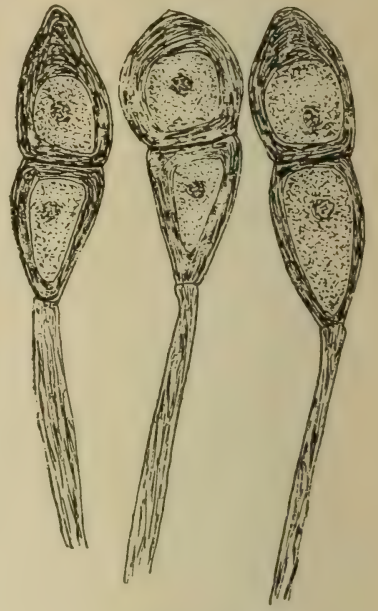

Fig. 15r.

Teleutospores of wheat rust, showing two cells and the pedicel.

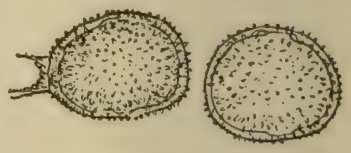

Fig. 152 .

Uredospores of wheat rust, one showing remnants of the pedicel.

in water on a slide, and examine with a microscope, we will see numerous gonidia, composed of two cells, and having thick, brownish walls as shown in fig. I $5 \mathrm{I}$. Usually there is a slender lorownish stalk on one end. These gonidia are called teleutospores. They are somewhat ollong or elliptical, a little constricted where the septum separates the two cells, and the end cell varies from ovate to rounded. The mycelium of the fungus 
courses between the cells, just as is found in the case of the carnation rust, which belongs to the same family (see l'art III).

291. Uredospores of the red-rust form. - If we make a similar preparation from the pustules of the red-rust form we will sce that instead of two-celled gonidia they are one-celled. The walls are thinner and not so clark in color, and they are covered with minute spines. 'They have also short stalks, but these fall away very easily. These one-celled gonidia of the red-rust form are called "uredospores." 'The uredospores and teleutospores are sometimes found in the same pustule.

It was once supposed that these two kinds of gonidia belonged to different plants, but now it is known that the one-celled

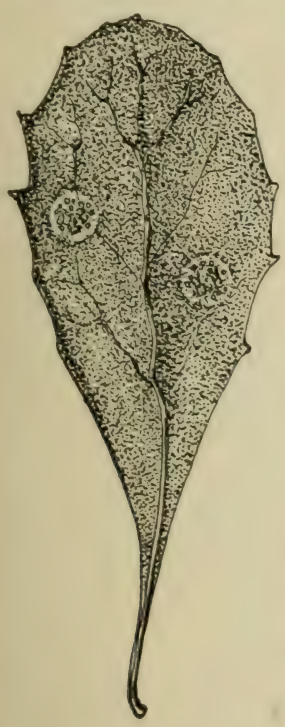

Fig. 153.

Barberry leaf with two diseased spots, natural size. form, the uredospores, is a form developed earlier in the season than the teleutospores.

\section{Cluster-cup form on the barberry.} -On the barberry is found still another form of the wheat rust, the "cluster cup" stage. The pustules on the under side of the barberry leaf are cup-shaped, the cups bcing partly sunk in the tissue of the leaf, while the rim is more or less curved back-

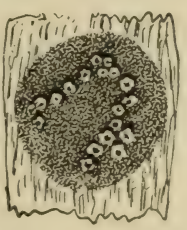

Fig. 154.

Single spot showing cluster cups enlarged.

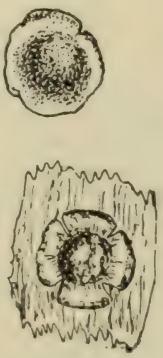

Fig. 155 .

Two cluster cups more enlarged, showing split margin

Figs. 153-155 --Cluster-cup stage of wheat rust.

ward against the leaf, and split at several places. 'These cups occur in clusters on the affected spots of the barberry leaf as shown in fig. I 54 . Within $\mathrm{t} \mathrm{h}$ e cups numbers of one-celled gonidia (orange in color, called recicliospores) are borne in chains from short branches of the mycelium, which fill the base of the cup. In fact the wall of the cup (peridium) 
is formed of similar rows of cells, which, instead of separating into gonidia, remain united to form a wall. These cups are usually borne on the under side of the leaf.

293. Spermagonia.-Upon the upper side of the leaves in the same spot occur small, orange-colored pustules which are flask-shaped. They bear inside, minute, rod-like bodies on the ends of slender threads, which ooze

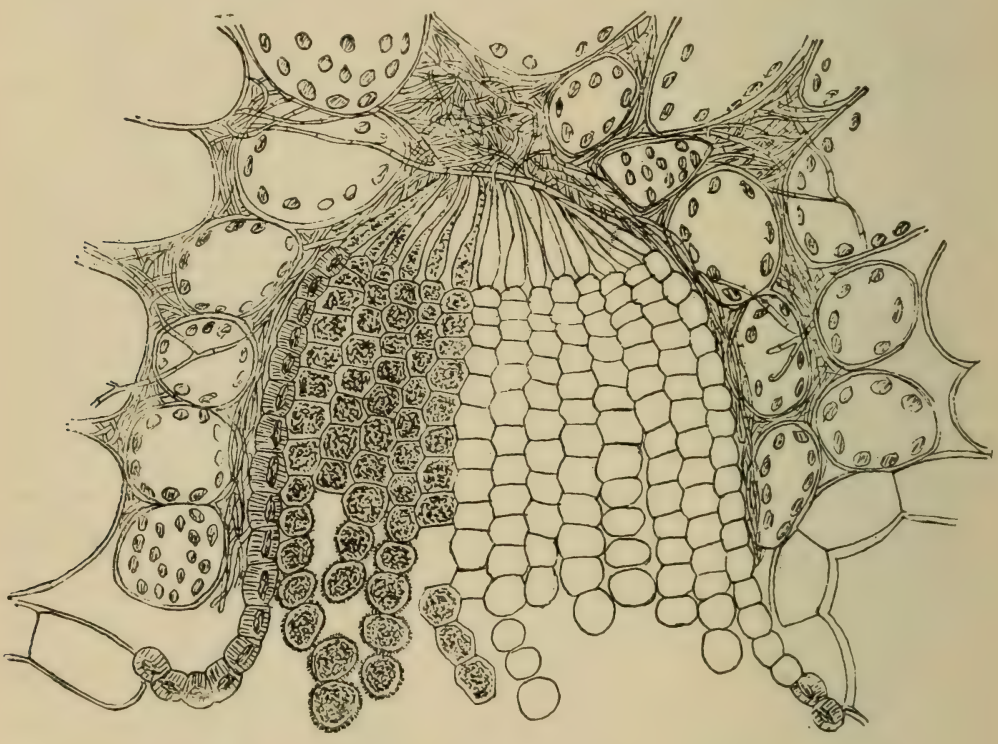

Fig. 156 .

Section of an æcıdium (cluster cup) from barberry leaf. (After Marshall-Ward.)

out on the surface of the leaf. These flask-shaped pustules are called spermagonia, and the minute bodies within them spermatia, since they were once supposed to be the male element of the fungus. Their function is not known. They appear in the spots at an earlier time than the cluster cups.

293a. How the cluster-cup stage was found to be a part of the wheat rust. - The cluster-cup stage of the wheat rust was once supposed also to be a different plant, and the genus was called cicidium. The occurrence of wheat rust in great abundance on the leeward side of affected barberry bushes in England suggested to the farmers that wheat rust was caused by barberry rust. It was later found that the xcicliospores of the barberry, when sown on wheat, germinate and the thread of mycelium enters the tissues of the wheat, forming mycelium between the cells. This mycelium then bears the uredospores, and later the teleutospores. 
294. Uredospores can produce successive crops of uredospores. - Tine uredospores are carried by the wind to other wheat or grass plants, germinate,

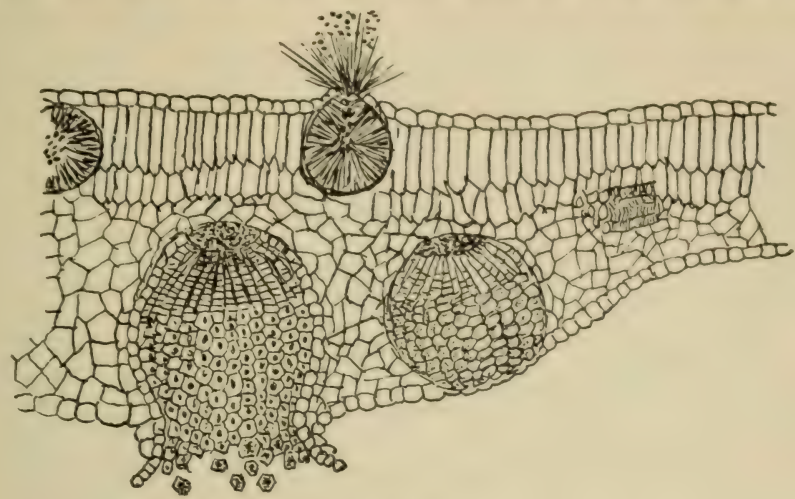

Fig. 157 .

Section through leaf of barberry at point affected with the cluster-cup stage of the wheat rust; spermagonia above, xcidia below. (After Marshall-Ward.)

form mycelium in the tissues. and later the pustules with a second crop of uredospores. Several successive crops of uredospores may be developed in
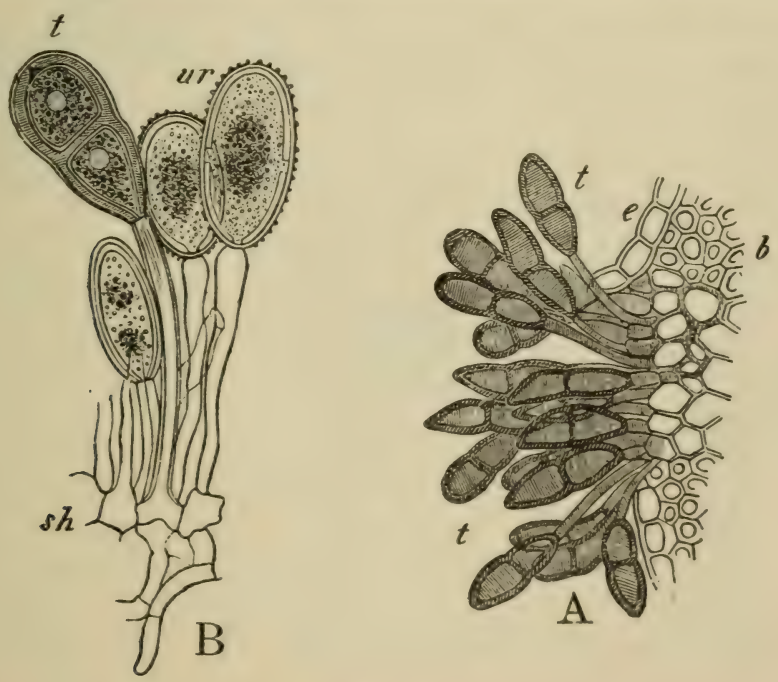

Fig. 158

$A$, section through sorus of black rust of wheat, showing teleutospores. $B$, mycelium bearing both teleutospores and uredospores. (After de Bary.)

one season, so this is the form in which the fungus is greatly multiplied and widely distributed. 
295. Teleutcspores the last stage of the fungus in the season.-The teleutospores are developed late in the season, or late in the development of the

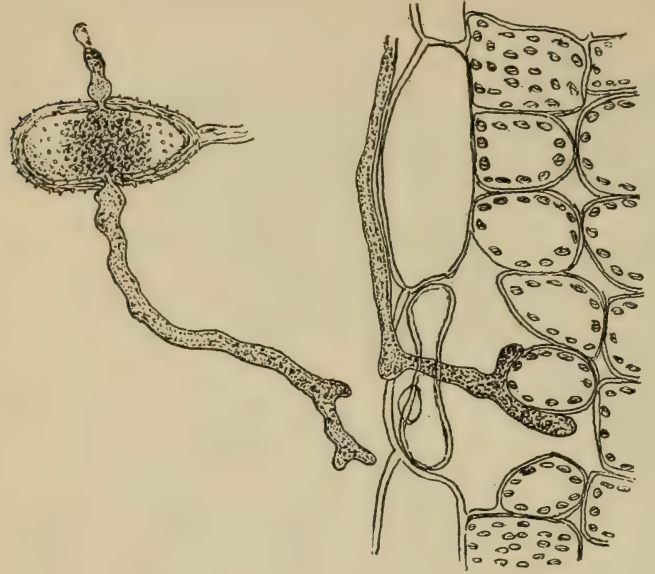

Fig. 159 .

Germinating uredospore of wheat rust. (After MarshallWard.)
Germ tube entering the Germ tube entering
leaf through a stoma.
Fig. I6o. host plant (in this case the wheat is the host). They then rest during the winter. In the spring under favorable conditions each cell of the teleutospore germinates, producing a short mycelium called a promy. celium, as shown in figs. I61, I62. This promycelium is usually divided into four cells. From each cell a short, pointed process is formed called a "sterigma." Through this the protoplasm moves and forms a small gonidium on the end, sometimes called a sporidium.

296. How the fungus gets from the wheat back to the barberry.-If these sporidia from the teleutospores are carried by the wind so that they lodge on

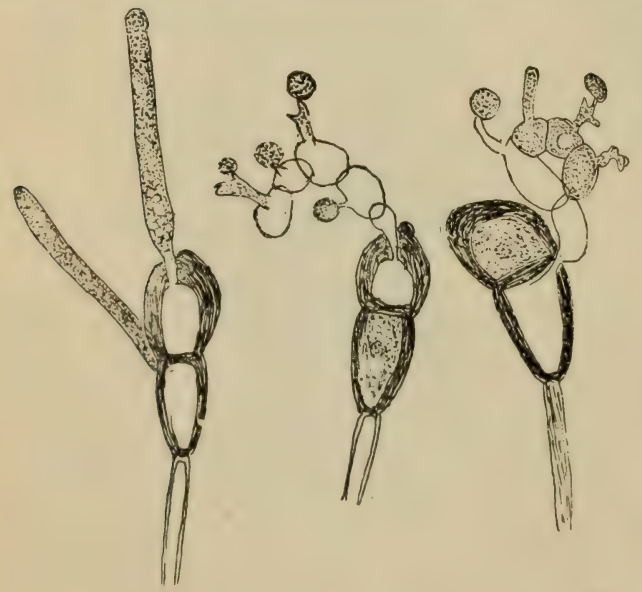

Fig. $x$ x.

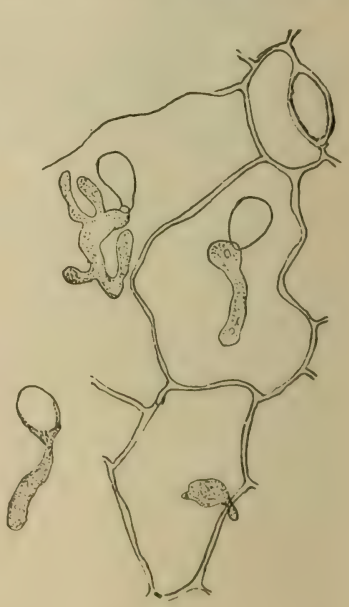

Fig. 163 .

Teleutospore germi- Promycelium of ger- Germinating sporidia entering leaf nating, forming promy- minating teleutospore, of barberry by mycelium. celium. forming sporidıa

Figs. 161-163.-Puccinia graminis (wheat rust). (After Marshall-Ward.) 
the leaves of the barherry. they germinate and proxluce the cluster cup a a a in. The plant has thus a very complex life history. Because of the presence of several different forms in the life cyle, it is called a polymorphic fungus.

The presence of the barberry does not seem necessary in all cases for the development of the fungus from one year to another.

\section{Synopsis of life history of wheat rust.}

Cluster-cup stage on leaf of barberry.

Mycelium between cells of leaf in affected spots.

Spermagonia (sing. spermagonium), small flask-shaped bodies sunk in upper side of leaf ; contain "spermatia."

Acidia (sing. æcidium), cup-shaped bociies in under side of leaf.

Wall or peridium, made up of outer layer of fungus threads which are divided into short cells but remain united.

At maturity bursts through epidermis of leaf; margin of cup curves outward and downward toward surface of leaf.

Central threads of the bundle are closely packed, but free. Threads divide into short angular cells which separate and become æcidiospores, with orange-colored content.

Æcidiospores carried by the wind to wheat, oats, grasses, etc. Here they germinate, mycelium enters at stomate, and forms mycelium between cells of the host.

Uredo stage (red rust) on wheat, oats, grasses, elc.

Mycelium between cells of host.

Bears uredospores (I-celled) in masses under epidermis, which is later ruptured and uredospores set free.

Uredospores carried by wind to other individual hosts, and new crops of uredospores formed.

Teleutospore stage (black rust), also on wheat, etc.

Mycelium between cells of host.

Bears teleutospores (2-celled) in masses (sori) under epidermis, which is later ruptured.

Teleutospores rest during winter. In spring cach cell germinates and produces a promycelimm, a short thread, divided into four cells. 
Promycelium bears four sterigmata and four gonidia (or sporidia), which in favorable conditions pass back to the barberry, germinate, the tube enters between cells into the intercellular spaces of the host to produce the cluster cup again, and thus the life cycle is completed.

298. Higher fungi divided into two series.-Of the higher fungi there are two large series. One of these is represented by the mushrooms, a good example of which is the common mushroom (Agaricus campestris).

(For the study of the mushrooms see Part III, Ecology.)

The large group of fungi to which the mushroom belongs is called the basidiomycetes because in all of them a structure resęmbling a club, or basidium, is present, and bears a limited number of spores, usually four, though in some genera the number is variable. Some place the rusts (uredineæ) in the same series (basidium series) because of the short promycelium, and four sporidia developed from each cell of the teleutospore.

\section{Sac Fungi.}

299. The other large series of the higher fungi may be represented by what are popularly called the "powdery mildews." Fig. I 64 is from a photograph of two willow leaves affected by one of these mildews. The leaves are first partly covered with a whitish growth of mycelium, and numerous chains of colorless gonidia are borne on short erect threads. The masses of gonidia give the leaf a powdery appearance. The mycelium lives on the outer surface of the leaf, but sends short haustoria into the epidermal cells.

300. Fruit bodies of the willow mildew.-On this same mycelium there appear later numerous black specks scattered over the affected places of the leaf. These are the fruit bodies (perithecia). If we scrape some of these from the leaf, and mount them in water for microscopic examination, we shall be able to see their structure. Examining these first with a low power of the microscope, each one is seen to be a rounded body, from which radiate numerous filaments, the afpendages. Each one of these appendages is coiled at the end into the form of a little hook. Because of these hooked appendages this genus is called uncimula. This rounded body is the perithecium. 
301. Asci and ascospores. - While we are looking at a few of these through the microscope with the low power, we should

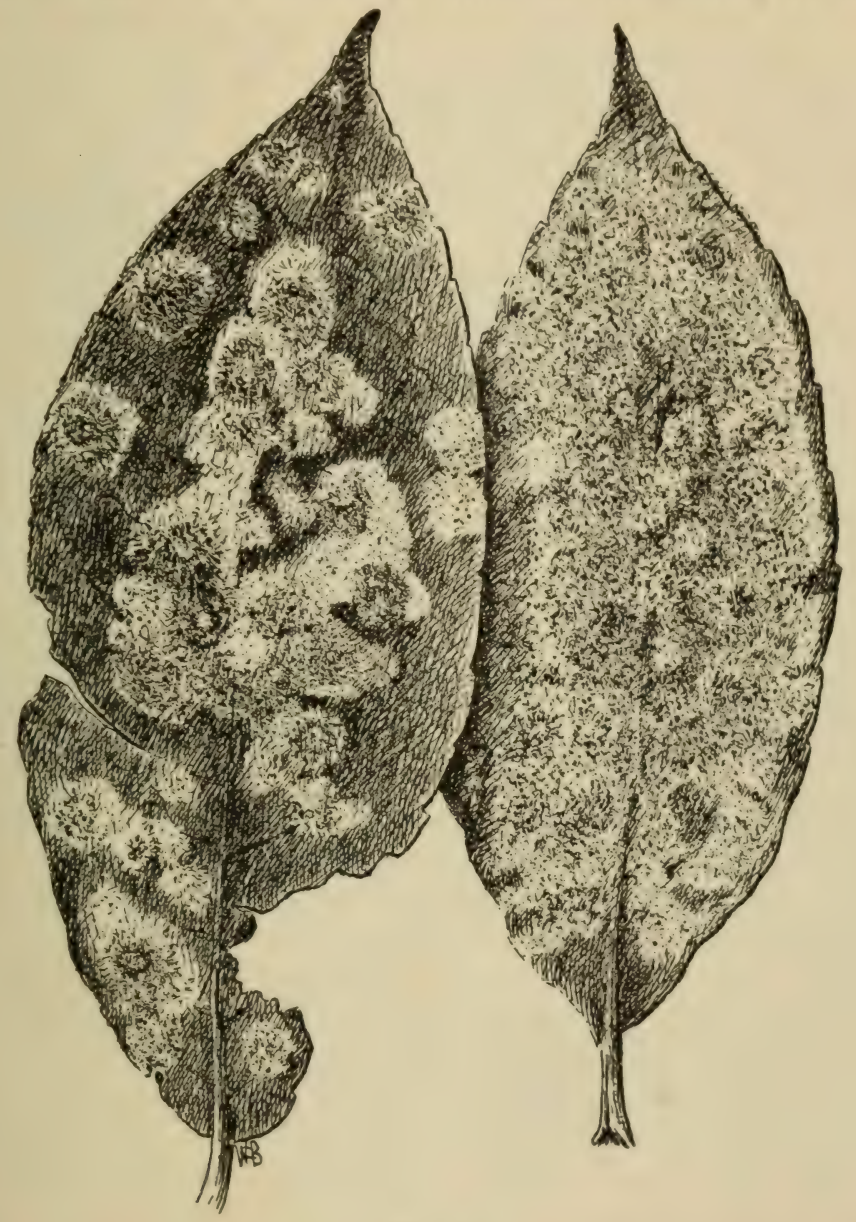

Fig. 164 .

Leaves of willow showing willow mildew. The black dots are the fruit bodies (perithecia) seated on the white mycelium.

press on the cover glass with a needle until we see a few of the perithecia rupture. If this is done carefully we will see several small ovate sacs issue, each containing a number of spores, as shown in fig. 166. Such a sac is an ascus, and the spores are ascospores. 
302. The sac fungi or ascomycetes. - The large group of fungi to which this uncinula belongs is known as the sac fungi, or ascomycetes. While

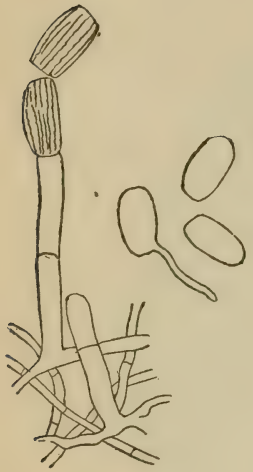

Fig. 165 .

Willow mildew; bit of mycelium wit h erect conidiophores, bearing chain of gonidia; gonidium at left germinating.

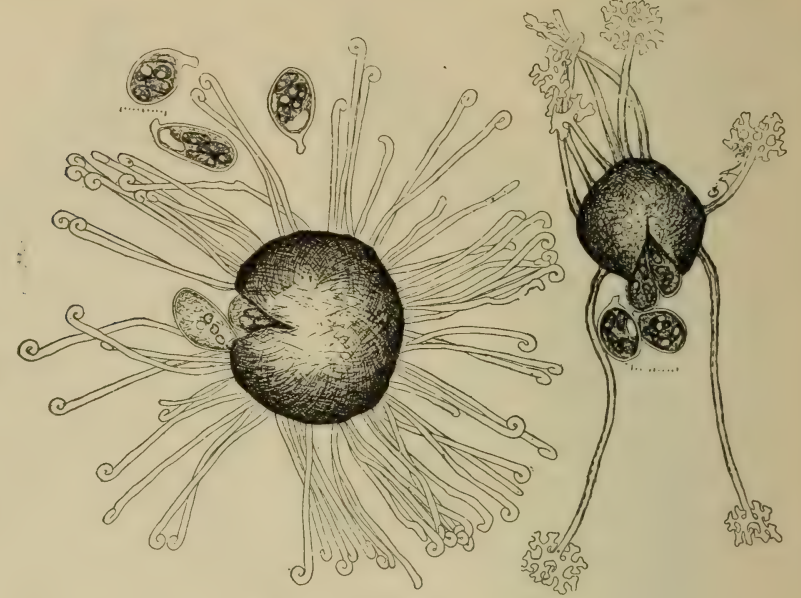

Fig. 166.

Fruit of willow mildew, showing hooked appendages. Genus uncinula.

Figs. 166, 167.-Perithecia (perithecium) of two powdery mildews, showing escape of asci containing the spores from the crushed fruit bodies.
Fig. 167.

Fruit body of another mildew with dichoto mous appendages. Genus microsphæra.

many of the powdery mildews have a variable number of spores in an ascus, a large majority of the ascomycetes have just 8 spores in an ascus, while

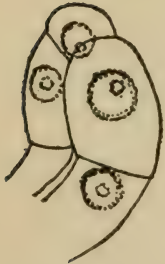

Fig. 168 .

Contact of an theridium and carpogonium (carpogonium the larger cell); the beginning of fertilization.

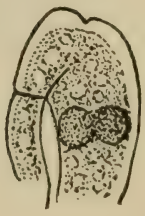

Fig. 160 .

Disappearance of contact walls of antheridium and carpogonium. and fusion of the two nuclei.

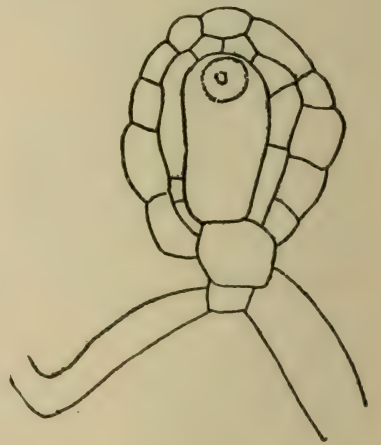

Fig. 170,

Fertilized egg surrounded by the enveloping threads which grow up around it.

Figs. $168-170$.- Fertilization in sphærotheca; one of the powdery mildews. (After Harper.) some have 4 , others 16 , and some an indefinite number. The complex structure of the fruit body, as well as the usually definite and limited number of 
spores in an ascus, places these fungi on a higher scale than the mucors, saprolegnias, and their relatives, where the number of gonidia in a sporangium is always indefinite.

303. Leaf curl of the peach, black knot of the plum and cherry, ergot of the rye and gratses, and many other fungi are members of the ascomycetes. The majority of the lichens are ascomycetes, while a few are basidiomycetes.

304. Classification of the fungi. - These who believe that the fungi represent a natural group of plants arrange them in three large series related to each other somewhat as follows:

The Gonidium Type or Series. The number of gonidia in the sporangium is indefinite and variable. It may be very large or very small, or even only one in a sporangium. To this series belong the lower fungi; ex., mucor, saprolegnia, peronospora, etc.

The Basidium Type or Series. The number of gonidia on a basidium is limited and definite, and the basidium is a characteristic structure; ex. uredineæ (rusts), mushrooms, etc.

The Ascus Type or Series. The number of spores in an ascus is limited and lefinite, and the ascus is a characteristic structure; ex. leaf curl of peach (exoascus), powdery mildews, black knot of plum, black rot of grapes, etc.

305. Others believe that the fungi do not represent a natural group, but that they have developed off from different groups of the algæ by becoming parasitic. As parasites they no longer needed chlorophyll, and consequently lost it. They thus derive their carbohydrates from organic material manufactured by the green plants.

According to this view the lower fungi have developed off from the lower algæ (saprolegnias, mucors, peronosporas, etc., being developed off from siphonaceous algæ like vaucheria), and the higher fungi being developed off from the higher algæ (the ascomycetes perhaps from the rhodophycex). 


\section{CHAPTER XXII.}

\section{LIVERWORTS (HEPATIC $Æ)$.}

306. We come now to the study of representatives of another group of plants, a few of which we examined in studying the organs of assimilation and nutrition. I refer to what are called the liverworts. Two of these liverworts belonging to the genus riccia are illustrated in figs. 58 , I 7 I.

\section{Riccia.}

307. Form of the floating riccia ( $R$. fluitans).-The general form of floating riccia is that of a narrow, irregular, flattened, ribbon-like object, which forks repeatedly, in a dichotomous manner, so that there are several lobes to a single plant. It receives its name from the fact that at certain seasons of the year it may be found floating on the water of pools or lakes. When the water lowers it comes to rest on the damp soil, and rhizoids are developed from the under side. Now the sexual organs, and later the fruit capsule, are developed.

308. Form of the circular riccia (R. crystallina).-The circular riccia is shown in fig. I 7 I. The form of this one is quite different from the floating one, but the manner of growth is much the same. The branching is more compact and even, so that a circular plant is the result. This riccia inhabits muddy banks, lying flat on the wet surface, and deriving its soluble food by means of the little rootlets (rhizoids) which grow out from the under surface.

Here and there on the margin are narrow slits, which extend 
nearly to the central point. They are not real slits, however, for they were formed there as the plant grew. Fach one of these $\mathrm{V}$-shaped portions of the thallus is a lobe, and they were formed in the young condition of the plant by a branching in a forked manner. Since growth took place in all directions radially the plant became circular in form. These large lobes we can see are forked once or twice again, as shown by the seeming shorter slits in the margin.

309. Sexual organs. - In

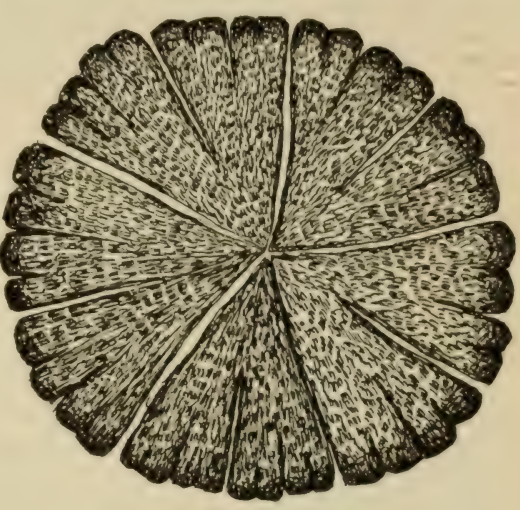

Fig. $17 \mathrm{r}$.

Thallus of Riccia crystallina.

order to study the sexual organs we must make thin sections through one of these lolses lengthwise and perpendicular to the thallus surface. These sections are mounted for examination with the microscope.

310. Archegonia. - We are apt to find the organs in various stages of development, but we will select one of the flask-shaped structures shown in fig. $\mathbf{I} 72$ for study. This flask-shaped body we see is entirely sunk in the tissue of the thallus. This structure is the female organ, and is what we term in these plants the archegonizm. It is more complicated in structure than the oogonium. The lower portion is enlarged and bellied out, and is the venter of the archegonium, while the narrow portion is the neck. We here see it in section. The wall is one cell layer in thickness. In the neck is a canal, and in the base of the venter we see a large rounded cell with a distinct and large nucleus. This cell is the egg cell.

311. Antheridia.-The antheridia are also borne in cavities sunk in the tissue of the thallus. There is here no illustration of the antheridium of this riccia, but fig. 178 represents an antheridium of another liverwort, and there is not a great difference between the two kinds. Each one of those little rectangular sperm mother cells in the antheridium changes into a swiftly moving body like a little club with two long lashes attached to the smaller end By the violent lashing of these organs the spermatozoid is moved through the water, or moisture which is on the surface of the thallus. It moves through the camal of the archegonium neck and into the eggr. where it fuses with the nucleus of the egg, and thus fertilization is effected. 
312. Embryo.- In the plants which we have selected thus far for study, the egg, immediately after fecundation, we recollect, passed into a resting state, and was enclosed by a thick protecting wall. But in riccia, and in the other plants of the group which we are now studying, this is not the case.

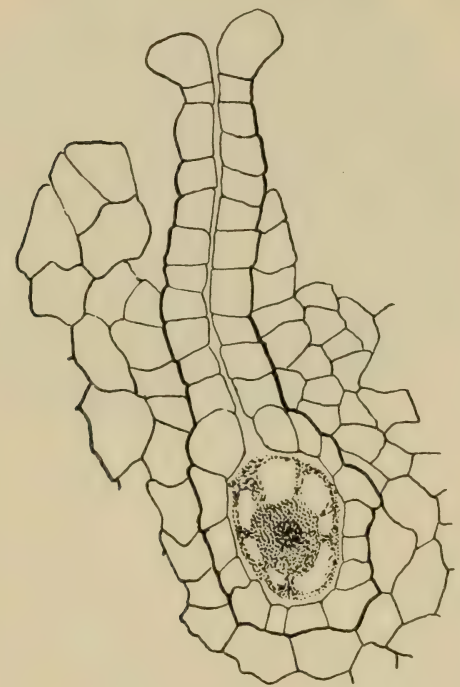

Fig. 172.

Archegonium of riccia, showing neck, venter, and the egg; archegonium is partly surrounded by the tissue of the thallus. (Riccia crystallina.)

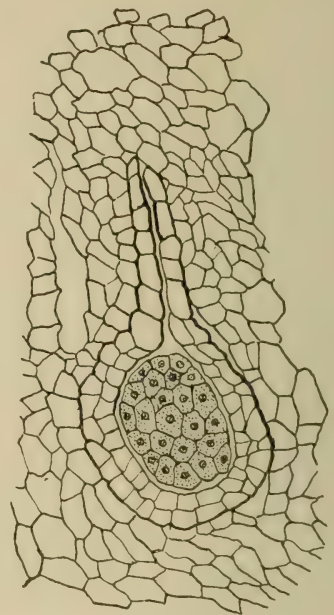

Fig. 173 .

Young embryo (sporogonium) of riccia, within the venter of the archegonium; the latter has now two layers of cells. (Riccia crystaliina.)

The egg, on the other hand, after acquiring a thin wall, swells up and fills the cavity of the venter. Then it divides by a cross wall into two cells. These two grow, and divide again, and so on until there is formed a quite large mass of cells rounded in form and still contained in the venter of the archegonium, which itself increases in size by the growth of the cells of the wall.

313. Sporogonium of riccia.-The fruit of riccia, which is developed from the fertilized egg in the archegonium, forms a rounded capsule still enclosed in the venter of the archegonium, which grows also to provide space for it. Therefore a section through the plant at this time, as described for the study of the archegonium, should show this capsule. The capsule then is a rounded mass of cells developed from the egg. A single outer layer of cells forms the wall, and therefore is sterile. 
Ali the inner cells, which are richer in protoplasm, divide into four cells each. Each of these cells becomes a spore with a thick wall, and is shaped like a triangular pyramid whose sides are of the same extent as the base (tetrahedral). These cells formed in

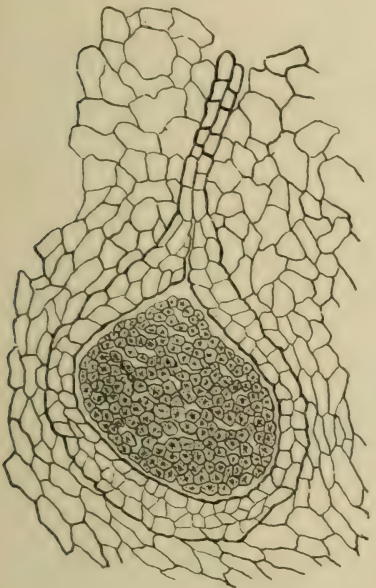

Fig. ${ }^{174}$.

Nearly mature sporogonium of Riccia crystallina; mature spore at the right.
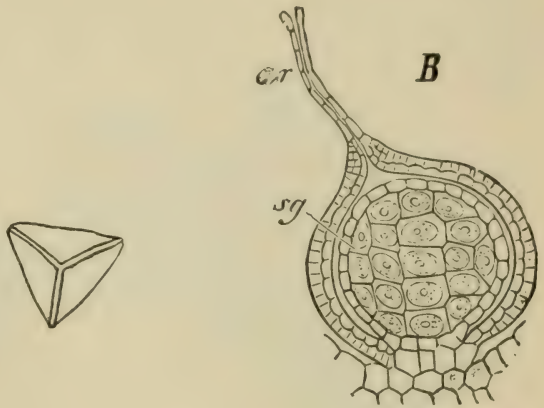

Fig. 175

Riccia glauca ; archegonium containing neariy mature sporogonium. $s g$, spore-producing cells surrounded by single layer of sterile cells, the wall of the sporogonium.

fours are the spores. At this time the wall of the spore-case dissolves, the spores separate from each other and fill the now enlarged venter of the archegonium. When the thallus dies they are liberated, or escape between the loosely arranged cells of the upper surface.

314. A new phase in plant life.-Thus we have here in the sporogonium of riccia a very interesting phase of plant life, in which the egg, after fertilization, instead of developing directly into the same phase of the plant on which it was formed, grows into a quite new phase, the sole function of which is the development of spores. Since the form of the plant on which the sexual organs are developed is called the gametophyte, this new phase in which the spores are developed is termed the sporophyte.

Now the spores, when they germinate, develop the gametophyte, or thallus, again. So we have this very interesting condi- 
tion of things, the thallus (gametophyte) bears the sexual organs and the unfertilized egg. The fertilized egg, starting as it does from a single-celled stage, develops the sporogonium (sporophyte). Here the single-cell stage is again reached in the spore, which now develops the thallus.

315. Riccia compared with coleochæte, œdogonium, etc.-We have said that in the sporogonium of riccia we have formed a new phase in plant life. If we recur to our study of coleochæte we may see that there is here possibly a state of things which presages, as we say, this new phase which is so well formed in riccia. We recollect that after the fertilized egg passed the period of rest it formed a small rounded mass of cells, each of which now forms a zoospore. The zoospore in turn develops the normal thallus (gametophyte) of the coleochrte again. In coleochrte then we have two phases of the plant, each having its origin in a one-celled stage. Then if we go back to œdogonium, we will remember that the fertilized egg, before it developed into the œdogonium plant again (which is the gametophyte), at first divides into four cells which become zoospores. These then develop the œdogonium plant.

Note. Too much importance should not be attached to this seeming homology of the sporophyte of odogonium, coleochæte, and riccia, for the nuclear phenomena in the formation of the zoospores of aedosonium and coleochæte are not known. They form, however, a very suggestive series.

\section{Marchantia.}

316. The marchantia (M. polymorpha) has been chosen for study because it is such a common and easily olstained plant, and also for the reason that with comparative ease all stages of development can be olotained. It illustrates also very well certain features of the structure of the liverworts.

The plants are of two kinds, male and female. 'The two different organs, then, are developed on different plants. In appearance, however, before the begimning of the structures which lear the sevual organs they are practically the same. The thallus is flattened like nearly all of the thalloid forms, and branches in a forked manner. The color is dark green, and through the midelle line of the thallus the texture is different from that of the margins, so that it possesses what we term a 
midrib, as shown in figs. I 76, I80. The growing point of the thallus is situated in the little depression at the free end. If we examine the upper surface with a hand lens we see diamond-shaped areas, and at the center of each of these areas are the openings known as the stomates.

317. Antheridial plants.-One of the male plants is figured at 176 . It bears curious structures, each held aloft by a short stalk. These are the antheridial receptacles (or male gametophores). Each one is circular, thick, and shaped somewhat like a bi-

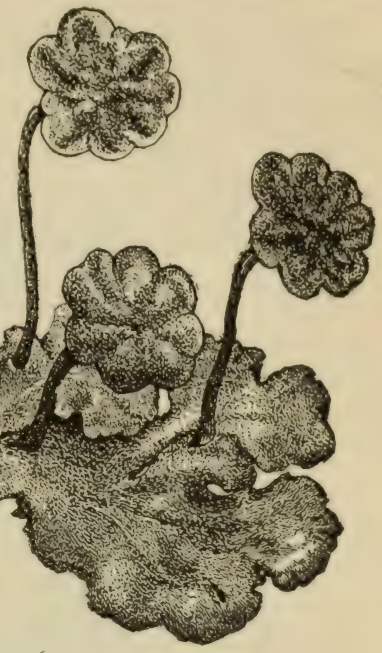

Fig. 176 .

Male plant of marchantia bearing antheridiophores. convex lens. The upper surface is marked by radiating furrows, and the margin is crenate. Then we note, on careful examination of the upper surface, that there are numerous minute openings. If we make a thin section of this structure perpen-

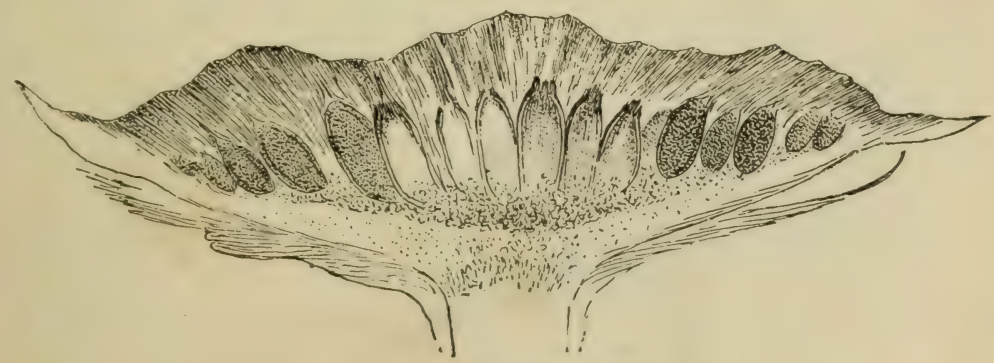

Fig. 177 .

Section of antheridial receptacle from male plant of Marchantia polymorpha, showing cavities where the antheridia are borne.

dicular to its surface we shall be able to unravel the mystery of its interior. Here we see, as shown in fig. I 77, that earh one of these little openings on the surface is an entrance to guite 
a large cavity. Within each cavity there is an oval or elliptical body, supported from the base of the cavity on a short stalk. This is an antheridium, and one of them is shown still more enlarged in fig. 178 . This shows the structure of the antheridium, and that there are within several angular areas, which are divided by numerous straight cross-lines into countless tiny cuboidal cells, the sperm mother cells. Each of these, as stated in the former chapter, changes into a swiftly moving body resembling a serpent with two long lashes attached to its tail.

318. The way in which one of these sperm mother cells changes into this spermatozoid is very curious. We first note that a coiled spiral body is appear-

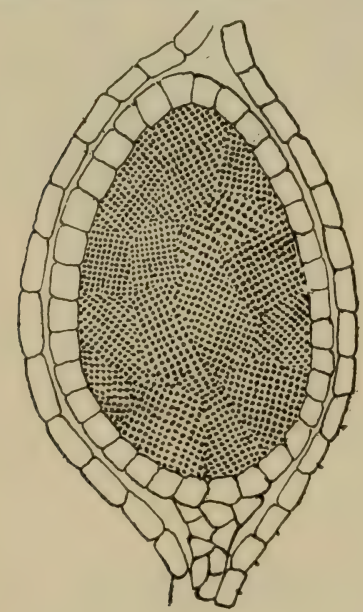

Fig. 178 .

Section of antheridium of marchantia, showing the groups of sperm mother cells.

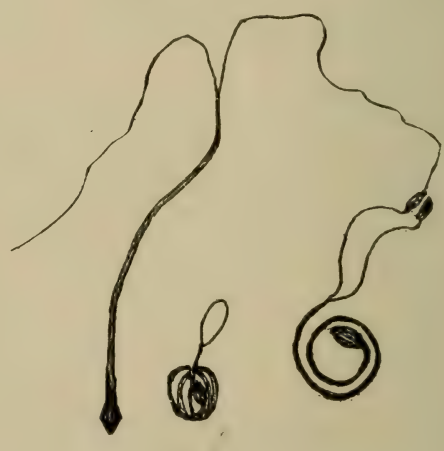

Fig. 179 .

Spermatozoids of marchantia, uncoiling and one extended, showing the two cilia.

ing within the thin wall of the cell, one end of the coil larger than the other. The other end terminates in a slender hair-like outgrowth with a delicate vesicle attached to its free end. This vesicle becomes more and more extended until it finally breaks and forms two long lashes which are clubbed at their free ends as shown in fig. $\mathbf{I 7 9}$.

319. Archegonial plants.-In fig. i 80 we see one of the female plants of marchantia. Upon this there are also very curious structures, which remind one of miniature umbrellas. The general plan of the archegonial receptacle (or female 
gametophore), for this is what these structures are, is similar to that of the antheridial receptacle, but the rays are more pronounced, and the details of structure are quite different, as we shall see. Underneath the arms there hang down delicate fringed curtains. If we make sections of this in the same direc-

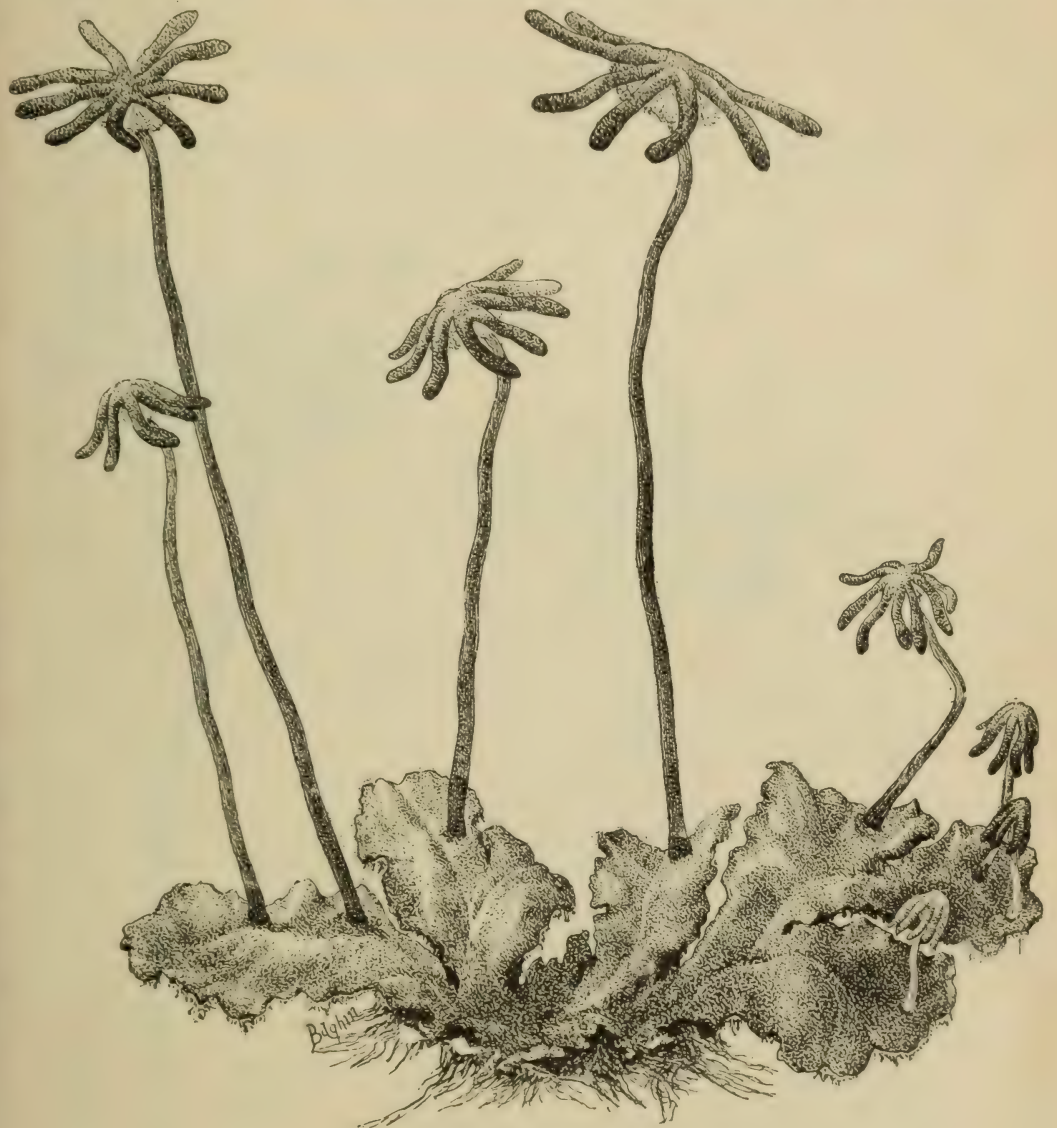

Fig. 180 .

Marchantia polymorpha, female plants bearing archegoniophores.

tion as we did of the antheridial receptacle, we will be able to find what is secreted behind these curtains. Such a section is figured at 184 . Here we find the archegonia. lut instead of being sunk in cavities their bases are attached to the under 
surface, while the delicate, pendulous fringes afford them protection from drying. An archegonium we see is not essentially different in marchantia from what it is in riccia, and it will be interesting to learn whether the sporogonium is essentially different from what we find in riccia. 


\section{CHAP'TER XXIII.}

\section{LIVERWORTS CONTINUED.}

320. Sporogonium of marchantia. - If we examine the plant shown in fig. I 8 I we will see oval bodies which stand out be-

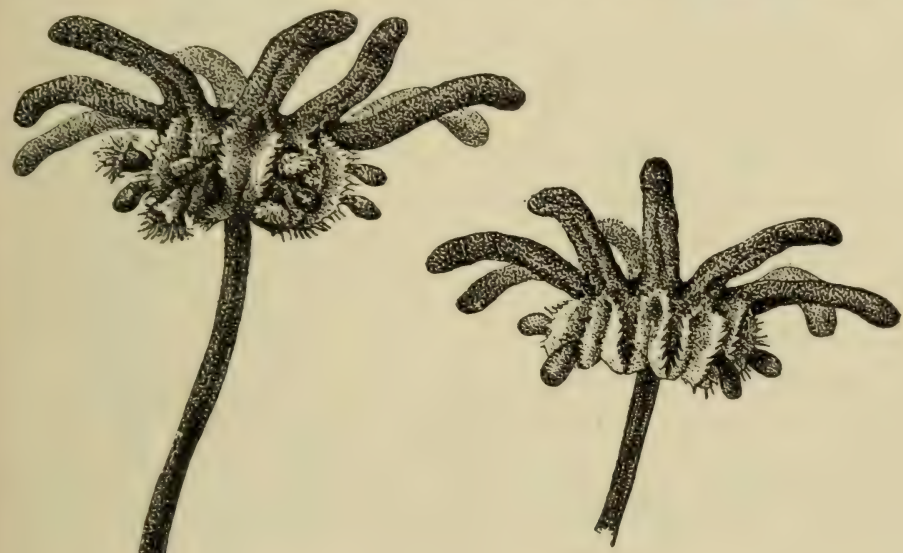

Fig. 181.

Archegonial receptacles of marchantia bearing ripe sporogonia The capsule of the sporogonium projects outside, while the stalk is attached to the receptacle underneath the curtain. In the left figure two of the capsules have burst and the elaters and spores are escaping.

tween the rays of the fenale receptacle, supported on short stalks. These are the sporogonia, or spore-cases. We judge at once that they are quite different from those which we have studied in riccia, since those were not stalked. We can see that some of the spore-cases have opened, the wall splitting down from the apex in several lines. This is caused by the drying of the wall. These toothlike divisions of the wall now curl backward, and we can see the yellowish mass of the spores in slow motion, 
falling here and there. It appears also as if there were twisting threads which aided the spores in becoming freed from the capsule.

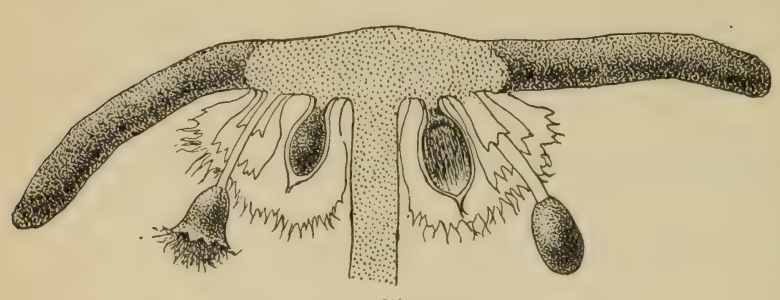

Fig. 182

Section of archegonial receptacle of Marchantia polymorpha; ripe sporogonia. One is open, scattering spores and elaters; two are still enclosed in the wall of the archegonium. The junction of the stalk of the sporogonium with the receptacle is the point of attachment of the sporophyte of marchantia with the gametophyte.

321. Spores and elaters. - If we take a bit of this mass of spores and mount it in water for examination with the microscope, we will see that, besides the spores, there are very peculiar thread-like bodies, the markings of which remind one of a twisted rope. These are very long cells from the

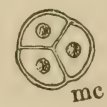
inner part of the spore-case, and their walls are marked by spiral thickenings. This causes them in dirying, and also when they absorb moisture, to twist and curl in all

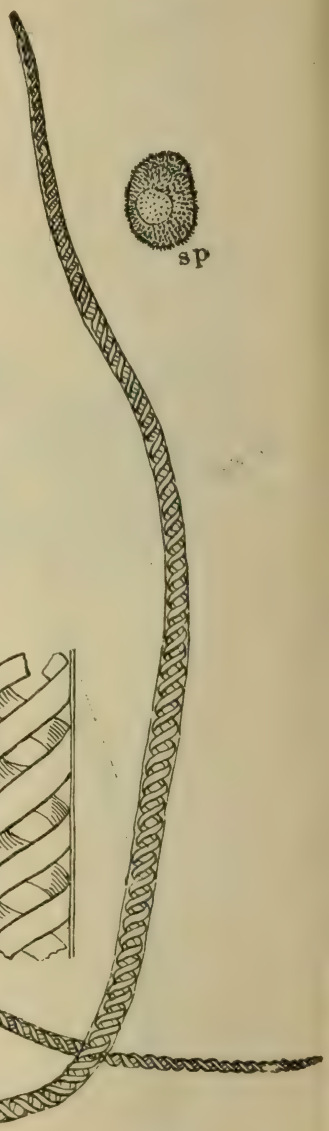

Fig. 183 .

Elater and spore of marchantia. sp, spore; $m c$, mother-cell of spores, showing partly formed spores.

sorts of ways. They thus aid in pushing the spores out of the capsule as it is drying.

322. Sporophyte of marchantia compared with riccia.We must recollect that the sporogonium in marchantia is larger than in riccia, and that it is also not lying in the tissue of the thallus, but is only attached to it at one side by a slender stalk. 
This shows us an increase in the size and complex structure of this new phase of the plant, the sporophyte. This is one of the very interesting things which we have to note as we go on in the study of the higher plants.
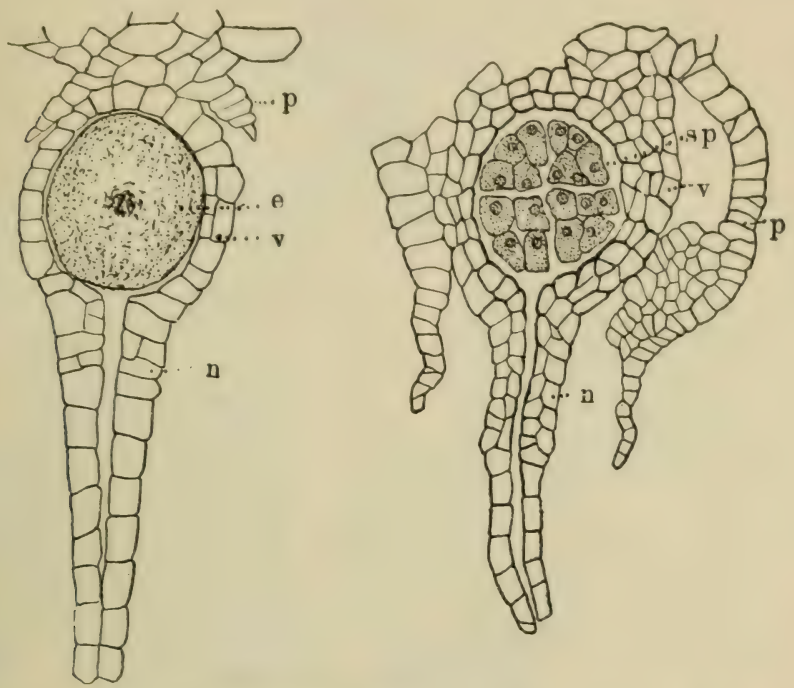

Fig. 184 .

Marchantia polymorpha, archegonium at the left with egg: archegonium at the right with young sporogonium: $\phi$; curtain which hangs down around the archegonia; $e$, egg; $\tau^{\prime}$, venter of archegonium: $n$, neck of archegonium; sp, young sporogonium.

\section{Sporophyte dependent on the gametophyte for its nutri-} ment. - We thus see that at no time during the development of the sporogonium is it independent from the gametophyte. This new phase of plants then, the sporophyte, has not yet become an independent plant, but must rely on the earlier phase for sustenance.

324. Development of the sporogonium.- It will be interesting to note briefly how the development of the marchantia sporogonium differs from that of riccia. The first division of the fertilized egg is the same as in riccia, that is a wall which runs crosswise of the axis of the archegonium diviles it into two cells. In marchantia the cell at the base develops the stalk, so that here there is a radical difference. The outer cell forms the capsule. But here after the wall is formed the inner tissue does not all go to make spores, as is the case with riccia. But some of it forms the elaters. While in riccia only the outside layer of cells of the sporogonium remained sterile. in marchantia the basal half of the egg remains completely sterile and 
develops the stalk, and in the outer half the part which is formed from some of the inner tissue is also sterile.

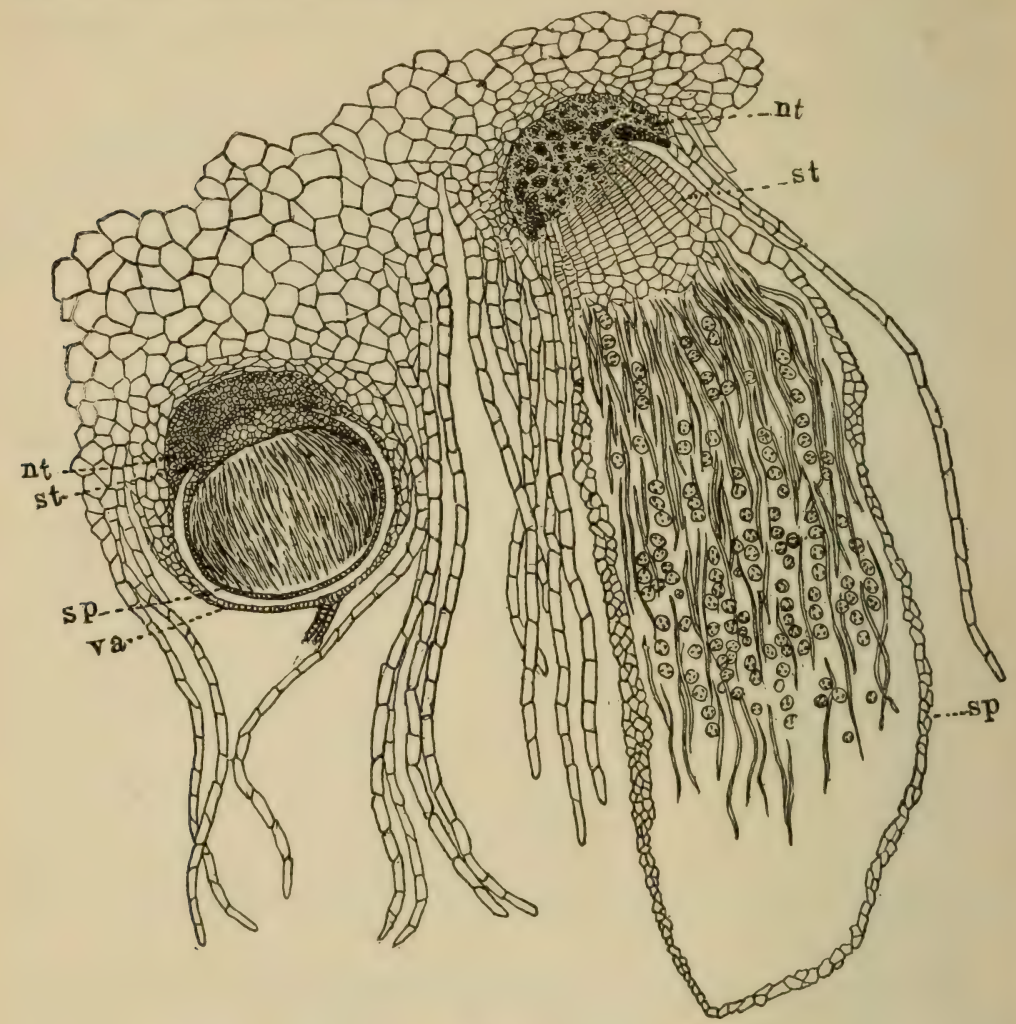

Fig. 185 .

Section of developing sporogonia of marchantia : $n t$, nutritive tissue of gametophyte; st, sterile tissue of sporophyte; sf, fertile part of sporophyte; va, enlarged venter of archegonium.

325. Embryo.- In the development of the embryo we can see all the way through this division line between the basal half, which is completely sterile, and the outer half, which is the fertile part. In fig. I 85 we see a young embryo, and it is nearly circular in section although it is composed of numerous cells. The basal half is attached to the base of the inner surface of the archegonium, and at this time the archegonium still surrounds it. The archegonium continues to grow then as the embryo grows, and we can see the remains of the shrivelled neck. The portion of the embryo attached to the base of the archegronium is the sterile part and is called the "foot," and later develops the stalk. The sporogonium during all the stages of its development derives its nourishment from the gametophyte at this point of 
attachment at the base of the archegonium. Soon, as shown in fig. 185 at the right, the outer portion of the sporogonium begins to differentiate into the cells which form the elaters and those which form spores. These lic in radiating lines side by side, and form what is termed the archesporium. Each fertile cell forms four spores just as in riccia. They are thus called the mother cells of the spores, or spore mother cells.

326. How marchantia multiplies. - New plants of marchantia are formed by the germination of the spores, and growth of the same to the thallus. The plants may also be multiplied by parts of the old ones breaking away by the action of strong currents of water, and when they lodge in suitable places grow into well-formed plants. As the thallus lives from year to year and continues to grow and branch the older portions die off, and thus separate plants may be formed from a former single one.

327. Buds, or gemmæ, of marchantia.-But there is another way in which marchantia multiplies itself. If we examine the upper surface of such a

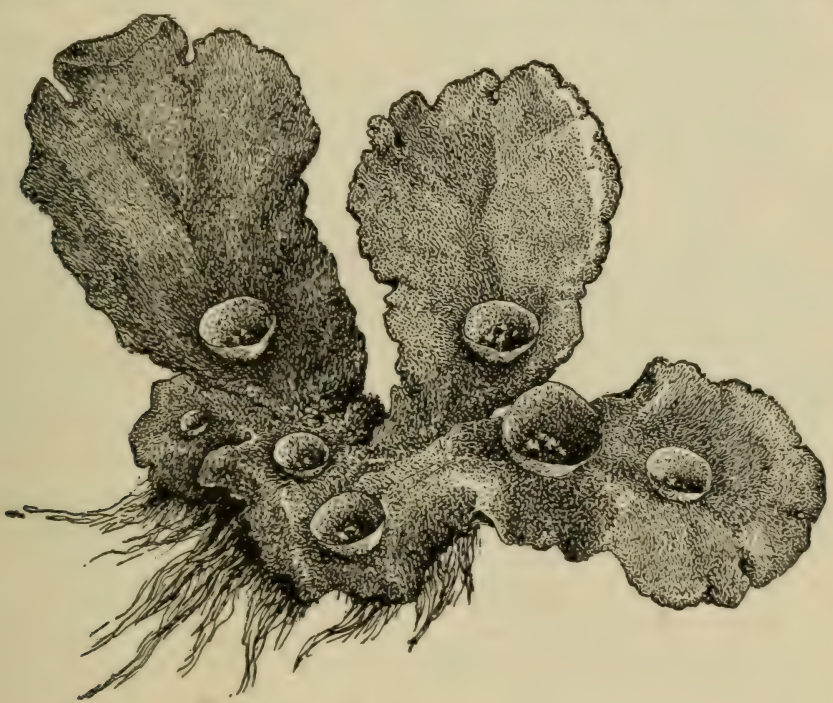

Fig. 186 .

Marchantia plant with cupules and gemmæ; rhizoids below.

plant as that shown in fig. 186, we will see that there are minute cupshaped or saucer-shaped vessels, and within them minute green bolies. If we examine a few of these minute bodies with the microscope we will see that they are flattened, biconvex. and at two opposite points on the margin there is an incientation similar to that which appears at the growing end of the old marchantia thallus. These are the growing points of these little buds. When they free themselves from the cups they come to lie on one 
side. It does not matter on what side they lie, for whichever side it is, that will develop into the lower side of the thallus, and forms rhizoids, while the upper surface will develop the stomates.

\section{Leafy-stemmed liverworts.}

328. We should now examine more carefully than we have done formerly a few of the leafy-stemmed liverworts (called foliose liverworts).

329. Frullania (Fig. 60).- This plant grows on the bark of logs, as well as on the bark of standing trees. It lives in quite
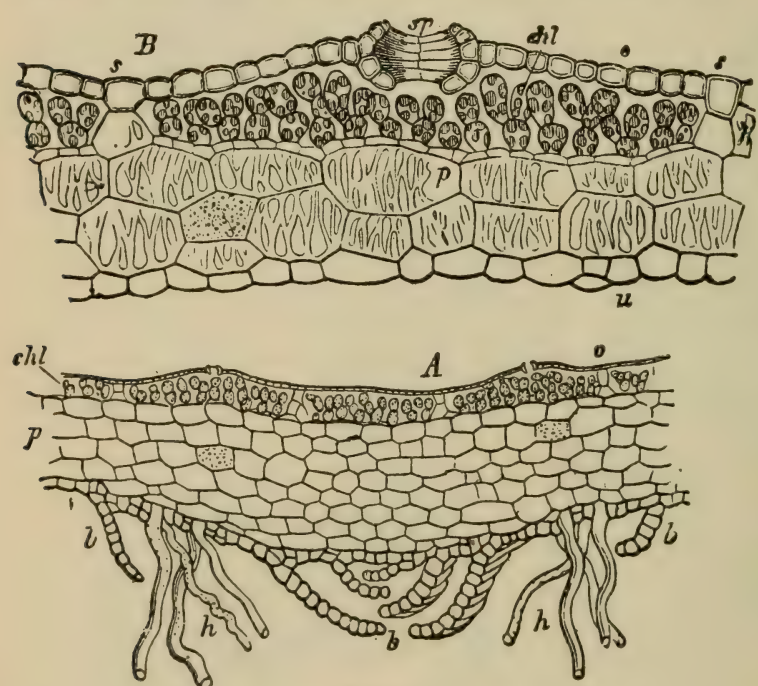

Fig. 187 . dry situations. If we examine the leaves we will see how it is able to do this. We note that there are two rows of lateral leaves, which are very close together, so close in fact that they overlap like the shingles o n a roof. Then, as the

Section of thallus of marchantia. $A$, through the middle portion ; $B$, through the marginal portion; $f$, colorless layer; $i h l$, chlorophyll creeping stems layer; $s p$, stomate; $h$, rhizoids; $b$, leaf-like outgrowths on under side (Goebel).

lie very close to the bark of the tree, these overlapping leaves, which also hug close to the stem and bark, serve to retain moisture which trickles down the bark during rains. If we examine these leaves from the under side as shown in fig. 62, we see that the lower or basal part of each one is produced into a peculiar lobe which is more or less cup-shaped. This catches water and holds it during dry weather, and it also holds moisture which the plant absorbs during the night and in damp days. 
There is so much moisture in these little pockets of the under side of the leaf that minute animals have found them good places to live in, and one frequently discovers them in this retreat. There is here also a third row of poorly developed leaves on the under side of the stem.

330. Porella.-Crowing in similar situations is the plant known as porella. Sometimes there are a few plants in a group, and at other times large mats occur on the bark of a trunk. This plant, porella, also has closely overlapping leaves in rows on opposite sides of the stem, and the lower margin of each leaf is curved under somewhat as in frullania, though the pocket is not so well formed.

The larger plants are female, that is they bear archegonia, while the male plants, those whi-h bear antheridia, are smaller and the antheridia are borre on small lateral branches. The antheridia are borne in the axils of the leaves. Others of the leafy-stemmed liverworts live in damp situations. Some of these, as

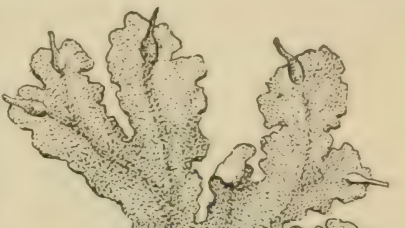

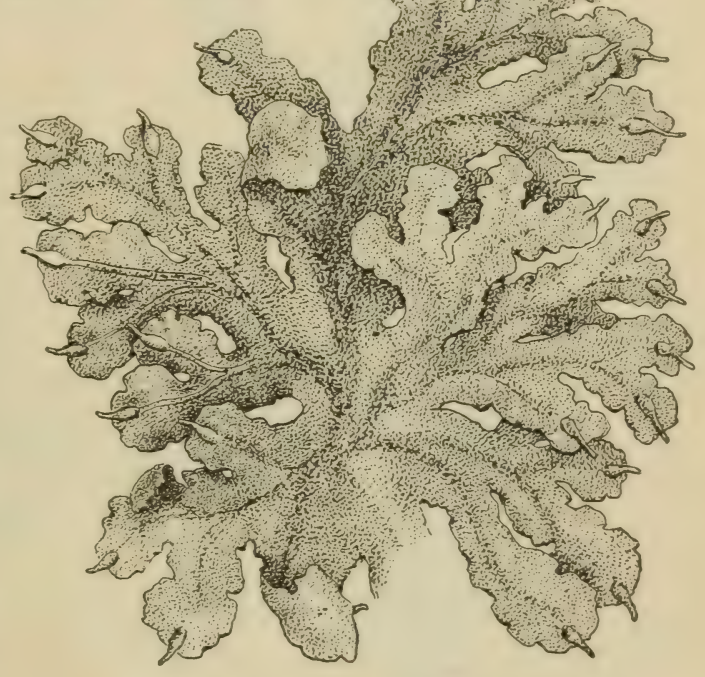

Fig. 188 .

Thallus of a thalloid liverwort (blasia) showing lobed margin of the frond, intermediate between thalloid and foliose plant.

Cephalozia, grow on damp rotten logs. Cephalozia is much more delicate, and the leaves are farther apart. It could not live in such dry situations where the frullania is sometimes found. If posible the two plants should be compared in order to see the arlaptation in the structure and form to their environment.

331. Sporogonium of a foliose liverwort. - The sporogonium of the leafy-stemmed liverworts is well represented by that of several genera. We may take for this study the one illustrated 
in fig. I92, but another will serve the purpose just as well. We note here that it consists of a rounded capsule borne aloft on a long stalk, the stalk being much longer proportionately than in marchantia. At maturity the capsule splits down into four

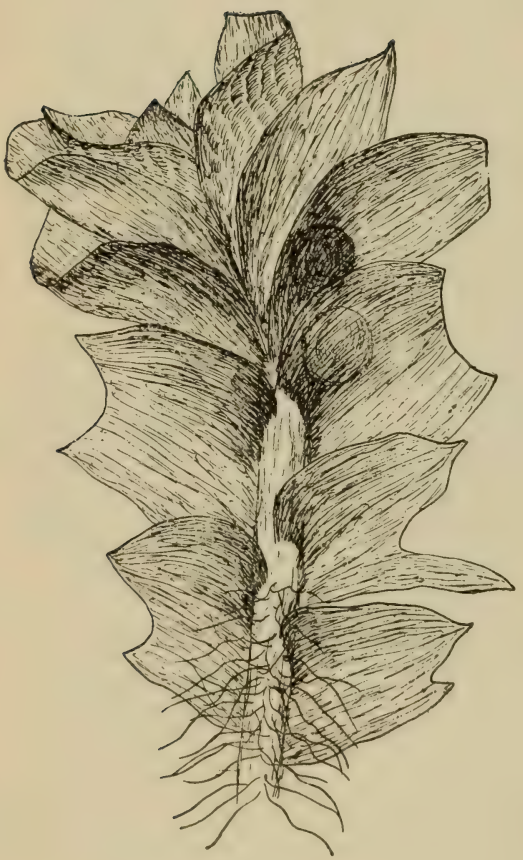

Fig. 189 .

Foliose liverwort, male plant showing antheridia in axils of the leaves (a jungermannia).

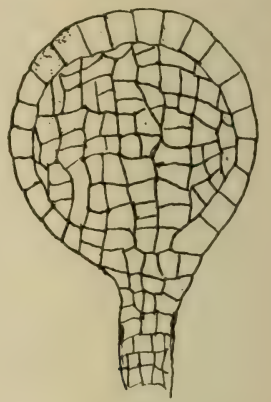

Fig. I9o.

Antheridium of a foliose liverwort (jungermannia).

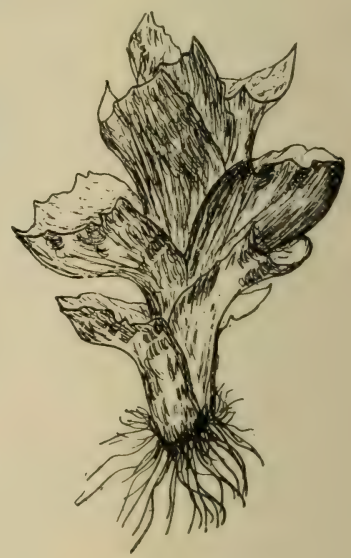

Fig. I9r.

Foliose liverwort, female plant with rhizoids.

quadrants, the wall forming four valves, which spread apart from the unequal drying of the cells, so that the spores are set free, as shown in fig. I94. Some of the cells inside of the capsule develop elaters here aiso as well as spores. These are illustrated in fig. 196.

332. In this plant we see that the sporophyte remains attached 
to the gametophyte, and thus is dependent on it for sustenance.

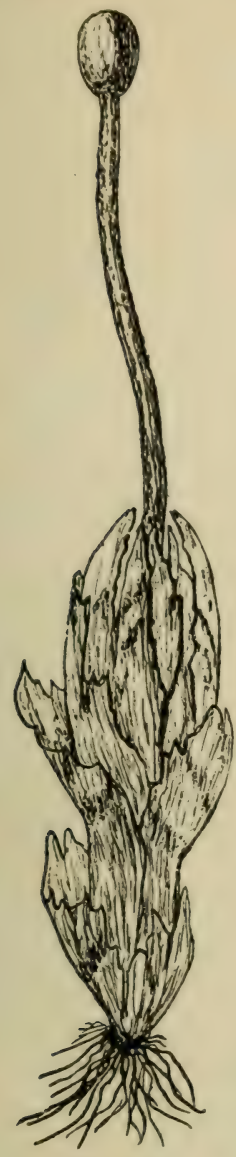

Fig. 192 .

Fruitıng plant of a foliose liverwort (jungermannia). Leafy part is the gametophyte; stalk and capsule is the sporophyte (sporogonium in the bryophytes).
This is true of all the plants of this group. The sporophyte never becomes capable of an independent existence, and yet we see that it is becoming larger and more highly differentiated than in the simple riccia.

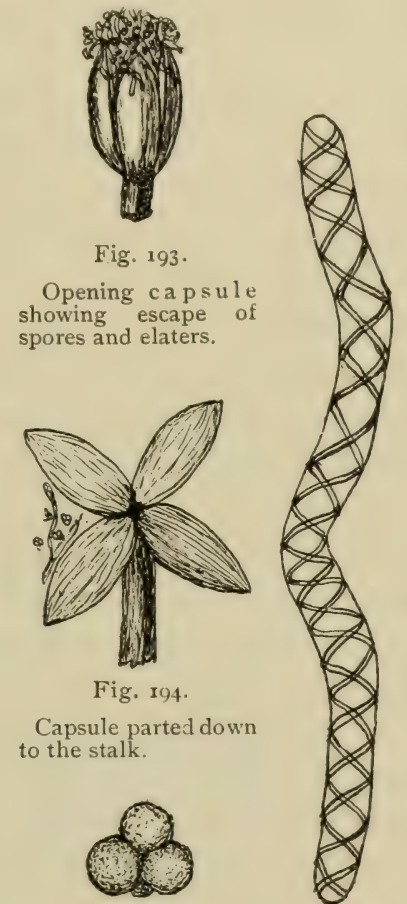

Fig. 195.

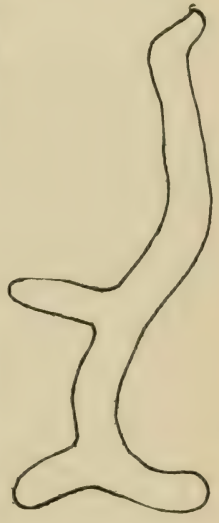

Fig. 196.

Four spores from Elaters, at left showing the two mother cell held in spiral marks, at right a branched a group. elater.

Figs. 193-196.-Sporogonium of liverwort (jungermannia) opening by splitting into four parts, showing details of elaters and spores. 


\section{CHAPTER XXIV.}

\section{MOSSES (MUSCI).}

333. We are now ready to take up the more careful study of the moss plant. There are a great many kinds of mosses, and they differ greatly from each other in the finer details of structure. Yet there are certain general resemblances which make it convenient to take for study almost any one of the common species in a neighborhood, which forms abundant fruit. Some, however, are more suited to a first study than others. (Polytrichium and funaria are good mosses to study.)

334. Mnium. - IVe will select here the plant shown in fig. I 97. This is known as a mnium (M. affine), and one or another of the species of mnium can be obtained without much difficulty. The mosses, as we have already learned, possess an axis (stem) and leaf-like expansions, so that they are leafy-stemmed plants also. Certain of the branches of the mnium stand upright, or nearly so, and the leaves are all of the same size at any given point on the stem, as seen in the figure. There are three rows of these leaves, and this is true of most of the mosses.

335. The mnium plants usually form quite extensive and pretty mats of green in shady moist woods or ravines. Here and there among the erect stems are prostrate ones, with two rows of prominent leaves so arranged that it reminds one of some of the leafystemmed liverworts. If we examine some of the leaves of the mnium we will see that the greater part of the leaf consists of a single layer of green cells, just as is the case in the leafy-stemmed liverworts. But along the middle line is a thicker layer, so that it forms a distinct miclrib. This is characteristic: of the leaves 
of mosses, and is one way in which they are separated from the leafy-stemmed liverworts, the latter never having a midrib.

336. The fruiting moss plant. - In fig. I 97 is a moss plant " in fruit," as we say. Above the leafy stem a slender stalk beas

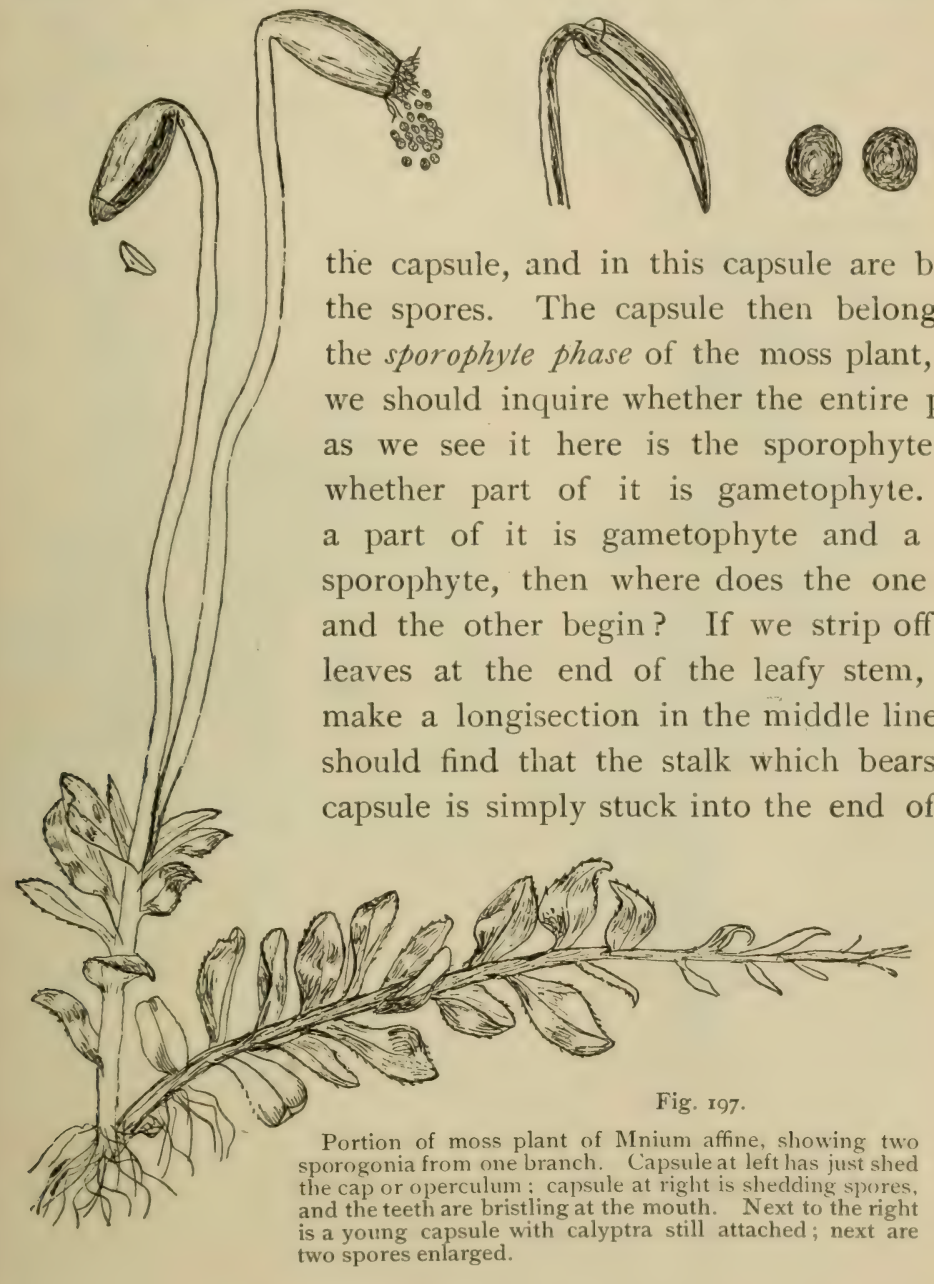

leafy stem, and is not organically connected with it. This is the dividing line, then, between the gametophyte and the sporophyte. We shall find that here the archegonium containing 
the egg is borne, which is a surer way of determining the limits of the two phases of the plant.

337. The male and female moss plants. - The two plants of mnium shown in figs. 198, 199 are quite different, as one can easily see, and yet they belong to the same species. One is a female plant, while the other is a male plant.

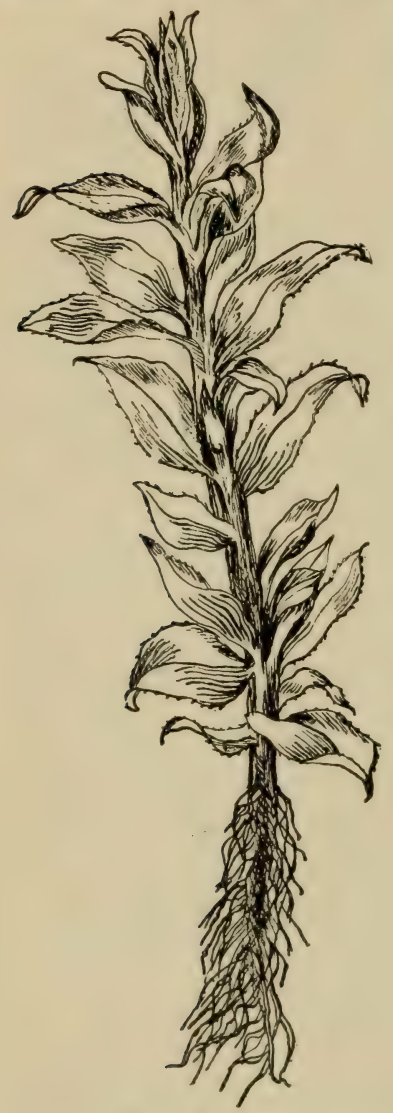

Fig. 198.

Female plant (gametophyte) of a moss (mnium), showing rhizoids below, and the tuit of leaves above which protect the archegonia.
The sexual organs then in mnium, as in many others of the mosses, are borne on separate plants. The archegonia are borne at the end of the stem, and are protected by somewhat narrower leaves which closely overlap and are wrapped together. They are similar to the archegonia of the liverworts.

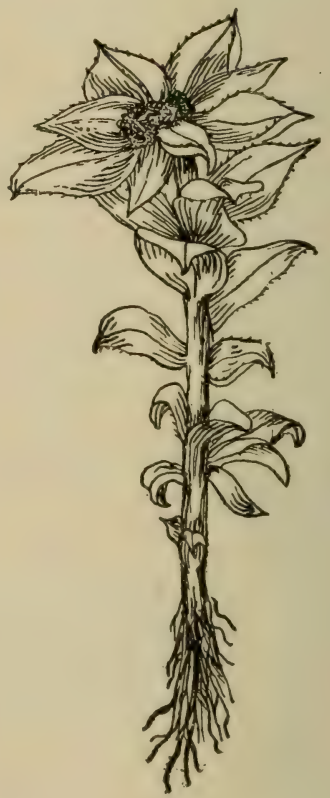

Fig. 199 .

Male plant (gametophyte) of a moss (mnium) showing rhizoids below and the antheridia at the center above surrounded by the rosette of leaves.

The male plants of mnium are easily selected, since the leaves at the end of the stem form a broad rosette with the antheridia, and some sterile threads packed closely together in the center. The ends of the mass of antheridia can be seen with the naked eye, as shown in fig. 199. When the antheridia 
are ripe, if we make a section through a cluster, or if we merely teatse out some from the end with a necelle in a drop of water on the sliste, then prepare for examination with the microsiope, we will see the form of the antheridia. They are somewhat clavate or cllptical in outline, as se'n in fig. 20r. Between them there stand short threads composed of several cells containing chlorophyll grains. These are sterile threads (paraphyses).

338. Sporogonium. - In fig. I97 we see illustrated a sporogonium of mnium, which is of course developed from the fertilized egg cell of the archegonium. There is a nearly cylindrical capsule, bent downward, and supported on a long

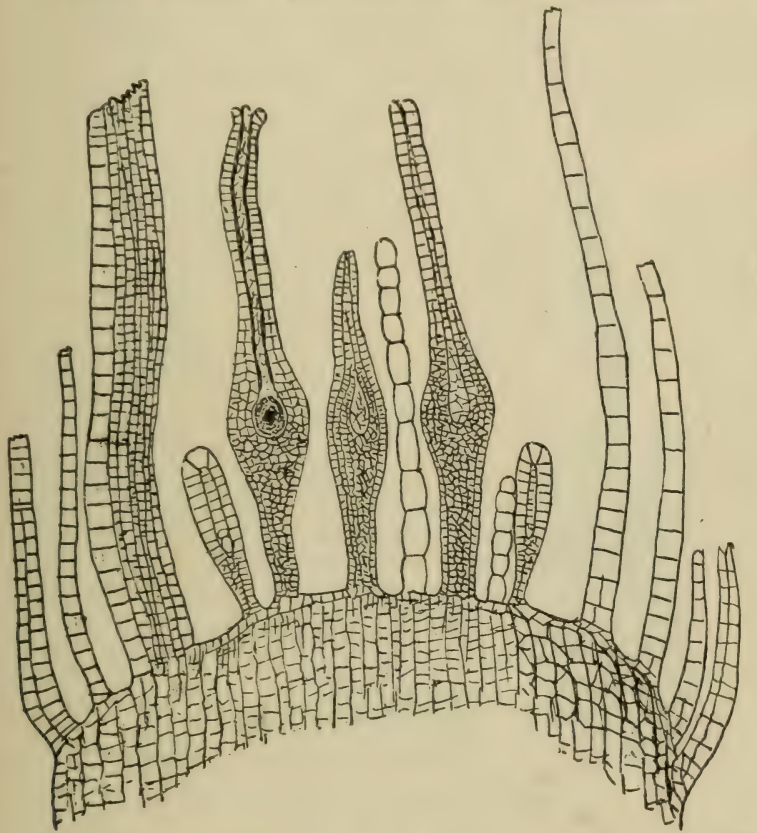

Fig. 200.

Section through end of stem of female plant of mnium, showing archegonia at the center. One archegonium shows the egg. On the sides are sections of the protecting leaves.

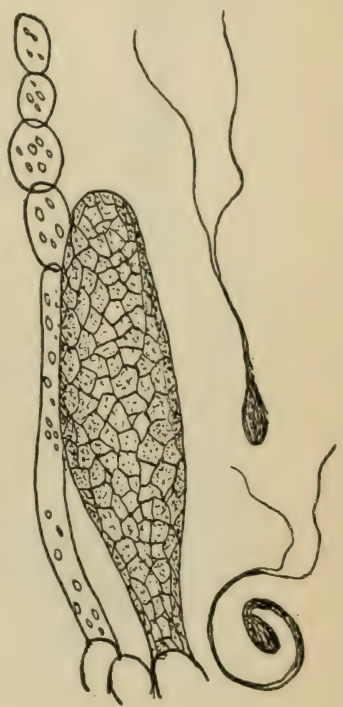

Fig. 20I.

Antheridium of mnium with jointed paraphysis at the left; spermatozoids at the right.

slender stalk. Upon the capsule is a peculiar cap,* shaped like a ladle or spatula. This is the remnant of the old archegonium, which, for a time surrounded and protected the young embryo of the sporogonium, just as takes place in the liverworts. In most of the mosses this old rumnant of the archegonium is borne aloft on the capsule as a cap, while in the liverworts it is thrown to one side as the sporogonium elongates.

339. Structure of the moss capsule.-At the free end on the moss capsule

* Called the calyptra. 
as shown in the case of mnium in Fig. 197, after the remnant of the archegonium falls away, there is seen a conical lid which fits closely over the end. When the capsule is ripe this lid easily falls away, and can be brushed off so that it is necessary to handle the plants with care if it is

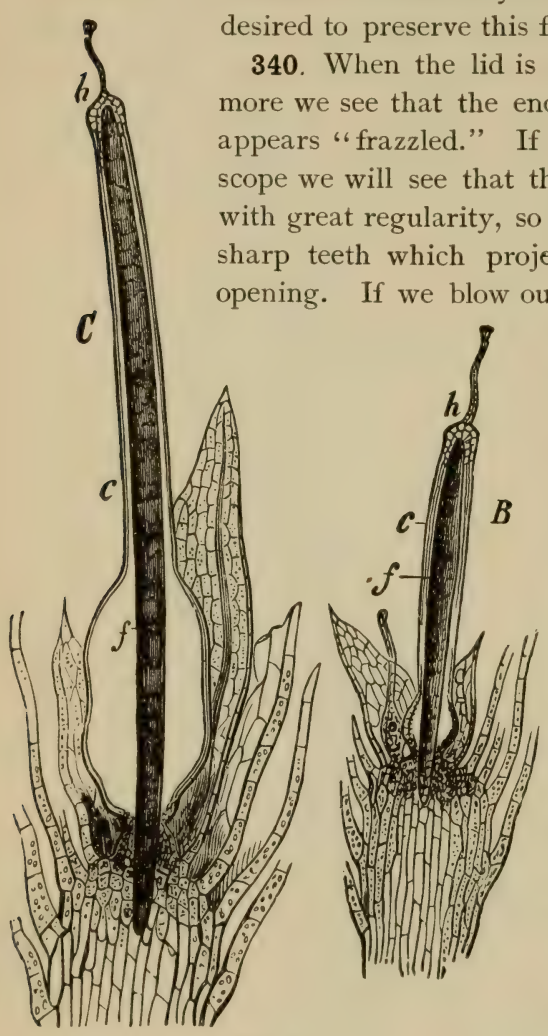

Fig. 202 .

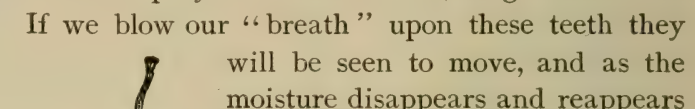
moisture disappears and reappears in the teeth, they close and open the mouth of the capsule, so sensitive are they to the changes in the humidity of the air. In this way all of the spores are prevented to some extent from escaping from the capsule at one time.

341. Note. If we make a section longitudinal of the capsule of mnium, or some other moss, we find that the tissue which develops the spores is much more restricted than in the capsule of the liverworts which we have studied. The spore-bearing tissue is confined to a single layer which extends around the capsule some distance from the outside of the wall, so that a central Two different stages of young sporogonium of cylinder is left of sterile tissue.
moss, still within the archegonium and wedg- This is the columella, and is presa moss, still within the archegonium and wedg- This is the columella, and is pres-
ing their way into the tissue of the end of the stem. The
$h$, neck of archegonium; $f$, young sporogonium. ent in nearly all the mosses. Each This shows well the connection of the sporophyte of the cells of the fertile layer
with the gametophyte.

divides into four spores.

342. Development of the sporogonium.-The egg cell after fertilization divides by a wall crosswise to the axis of the archegonium. Each of these cells continues to divide for a time, so that a cylinder pointed at both ends is formed. The lower end of this cylinder of tissue wedges its way down through the lase of the archegonium into the tissue of the end of the moss stem as shown in fig. 202. This forms the finot through which the nutrient 
materials are passed from the gametsphyte to the sporogonium. The upper part continues to grow, and finally the upper end differentiates into the mature capsule.

343. Protonema of the moss. - When the spores of a moss germinate they form a thread-like body, with chlorophyll. This thread becomes branched, and sometimes quite extended tangles of these threads are formed. This is called the protonema, that is first thread. The older threads become finally brown, while the later ones are green. From this protonema at certain points buds appear which divide by close oblique walls. From these buds the leafy stem of the moss plant grows. Threads similar to these protonemal threads now grow out from the leafy stem, to form the rhizoids. These supply the moss plant with nutriment, and now the protonema usually dies, though in some few species it persists for long periods. 


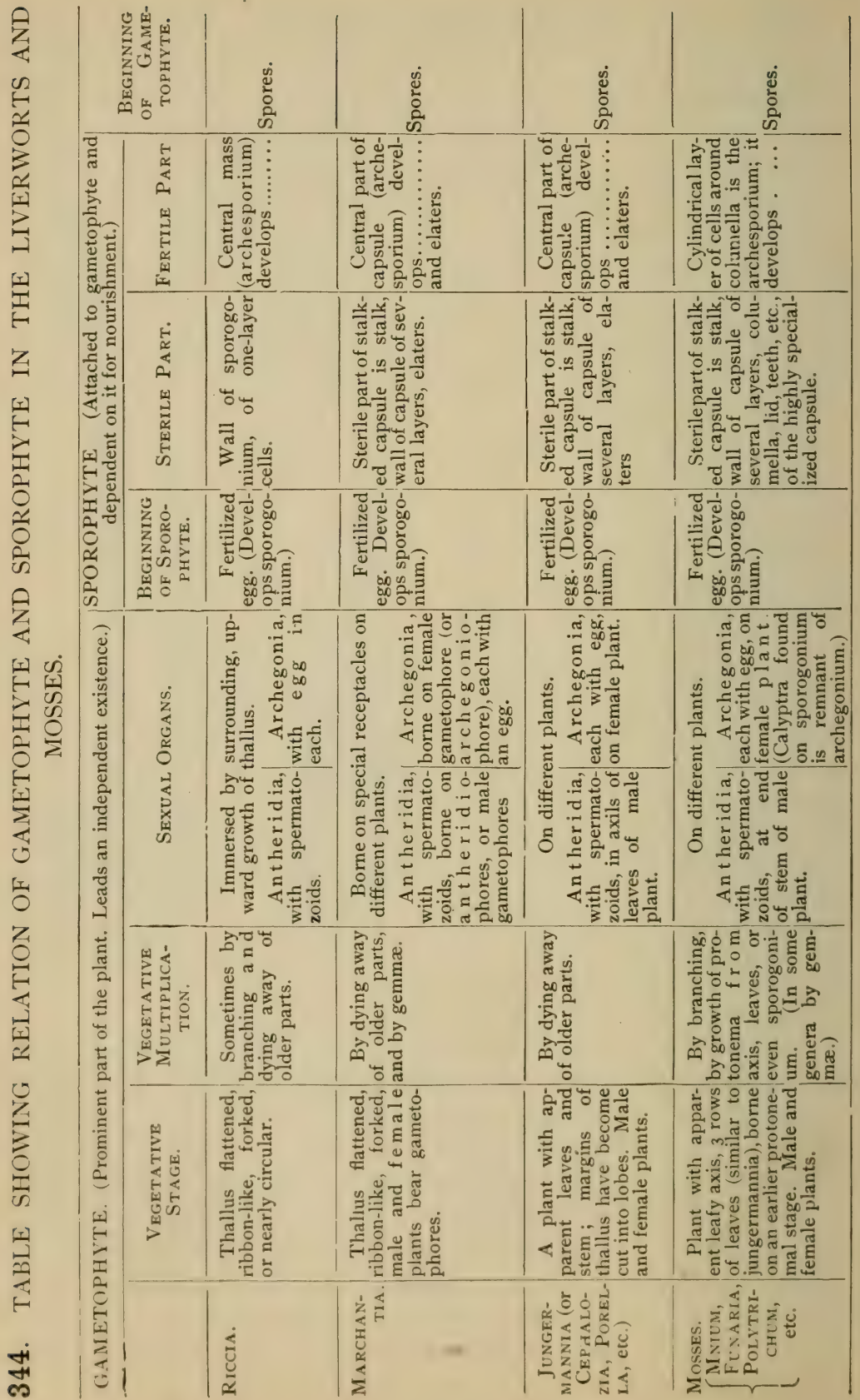




\section{CHAPTER XXV.}

\section{FERNS}

345. In taking up the study of the ferns we find plants which are very beautiful objects of nature and thus have always attracted the interest of those who love the beauties of nature. But they are also very interesting to the student, because of certain remarkable peculiarities of the structure of the fruit bodies, and especially because of the intermediate position which they occupy within the plant kingdom, representing in the two phases of their development the primitive type of plant life on the one hand, and on the other the modern type. We will begin our study of the ferns by taking that form which is the more prominent, the fern plant itself.

346. The Christmas fern.-One of the ferns which is very common in the Northern States, and occurs in rocky banks and woods, is the well-known Christmas fern (Aspidium acrostichoides) shown in fig. 203. The leaves are the most prominent part of the plant, as is the case with most if not all our native ferns. The stem is very short and for the most part under the surface of the ground, while the leaves arise very close together, and thus form a rosette as they rise and gracefully bend outward. The leaf is elongate and reminds one somewhat of a plume with the pinnæ extending in two rows on opposite sides of the midrib. 'These pinnæ alternate with one another, and at the base of each pinna is a little spur which projects upward from the upper edge. Such a leaf is said to be pinnate. While all the leaves have the same general outline, we notice that certain ones, especially those toward the center of the rosette, are much narrower from the 
middle portion toward the end. This is because of the shorter pinnæ here.

347. Fruit "dots" (sorus, indusium).- - If we examine the under side of such short pinnæ of the Christmas fern we see that there are two rows of small circular dots, one row on either side of

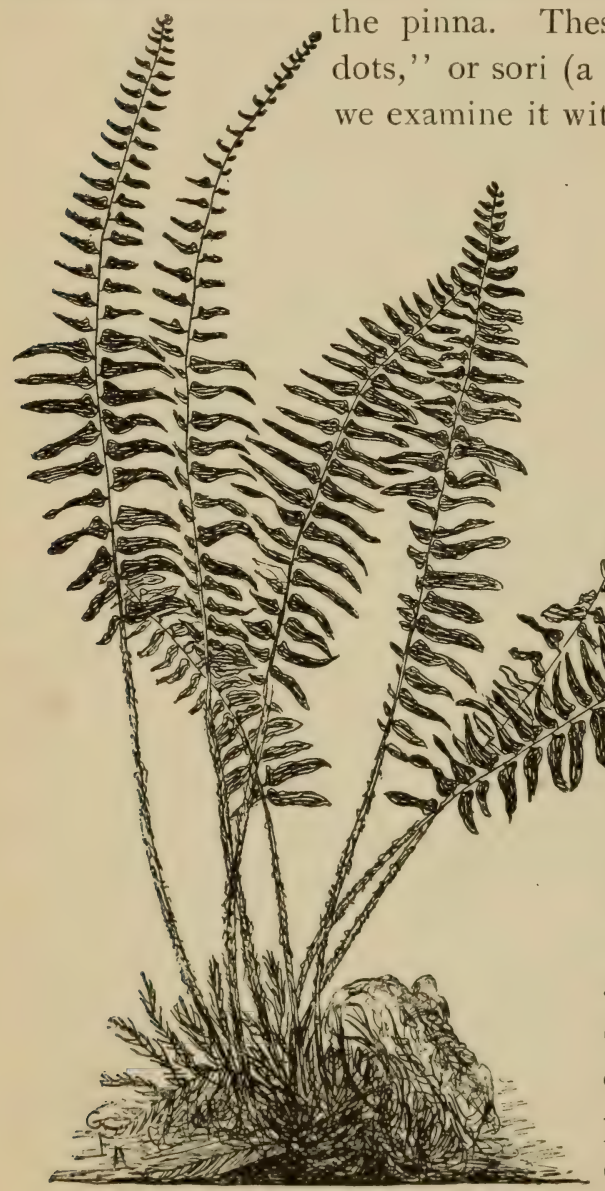

Fig. 203.

Christmas fern (Adiantum acrostichoides). jects underneath are the fruit bodies, which in the case of the ferns and their allies are called sporangia. This indusium in the case of the Christmas fern, and also in some others, is attached to the leaf by means of a short slender stalk 
which is fastened to the middle of the under side of this shield, as seen in cross section in fig. 209.

348. Sporangia. - If we section through the leaf at one of the fruit dots, or if we tease off some of the sporangia so that the

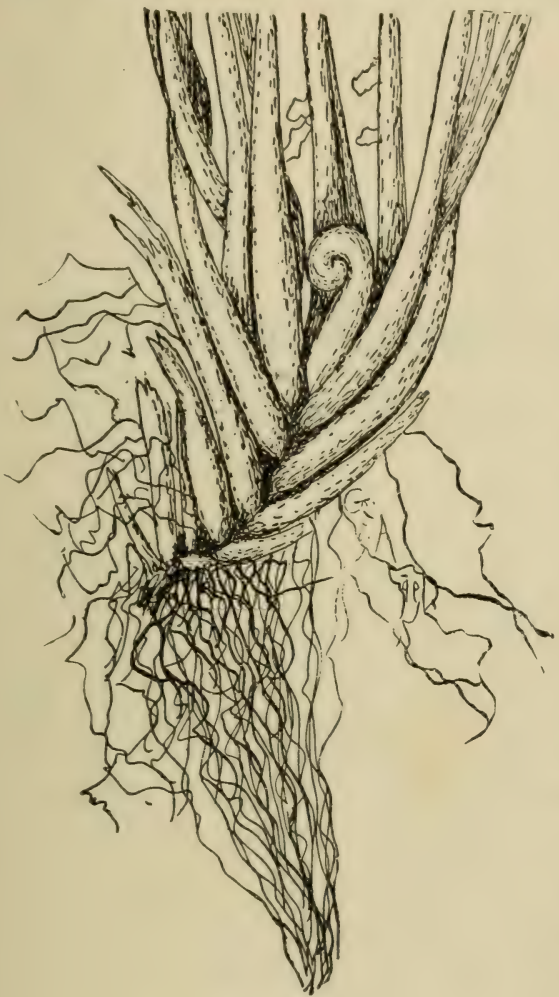

Fig. 204

stalks are still attached, and examine them with the microscope, we can see the form and structure of these peculiar bodies. Different views of a sporangium are shown in fig. 2 Io. The slender portion is the stalk, and the larger part is the spore-case proper. We should examine the structure of this spore-case quite carefully, since it will help us to understand better than we otherwise could the remarkable operations which it performs in scattering the spores.

349. Structure of a sporangium. - If we examine one of the sporangia in side view as shown in fig. $2 \mathrm{ro}$, we note a prominent row of

Rhizome with bases of leaves, and roots of the cells which extend around Christmas fern.

the margin of the dorsal edge from near the attachment of the stalk to the upper front angle. The cells are prominent because of the thick inner walls, and the thick radial walls which are perpendicular to the inner walls. The walls on the back of this row and on its sides are very thin and membranous. We should make this out carefully, for the structure of these cells is especially adapted to a special function which they perform. This row of cells 
is termed the annulus, which means a little ring. While this is not a complete ring, in some other ferns the ring is nearly complete.

350. In the front of the sporangium is another peculiar group

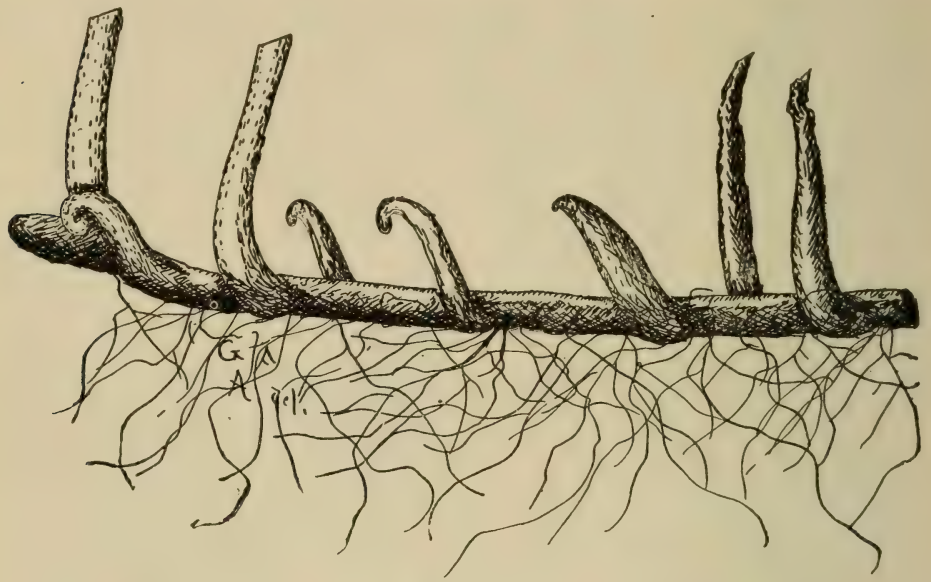

Fig. 205.

Rhizome of sensitive fern (Onoclea sensibilis).

of cells. Two of the longer ones resemble the lips of some creature, and since the sporangium opens between them they are sometimes termed the lip cells. These lip cells are connected with

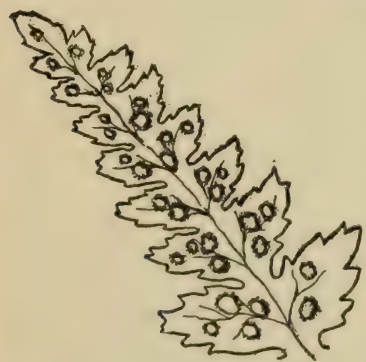

Fig. 206.

the upper end of the annulus on one side and with the upper end of the stalk on the other side by thin-walled cells, which may be termed connective cells, since they hold each lip cell to its part of the opening sporangium. The cells on the side of the sporangium are also thin-walled. If we now examine a sporangium from the back, or dorsal Underside of pinna of Aspidium edge as we say, it will appear as in the spinulosum showing fruit dots (sori).

left-hand figure. Here we can see how very prominent the annulus is. It projects beyond the surface of the other cells of the sporangium. The spores are contained inside this case. 


\section{Opening of the sporangium and dispersion of the} spores. - If we take some fresh fruiting leaves of the ('hristmas fern, or of any one of many of the species of the true ferns just at the ripening of the spores, and place a portion of it on a piece of white paper in a dry room, in a very short time we will see that the paper is being dusted with minute brown objects which fly out from the leaf. Now if we take a portion of the same leaf and place it under the low power of the microscope, so that the full rounded sporangia can be seen, in a short time we will note that the sporangium opens, the upper half curls backward as

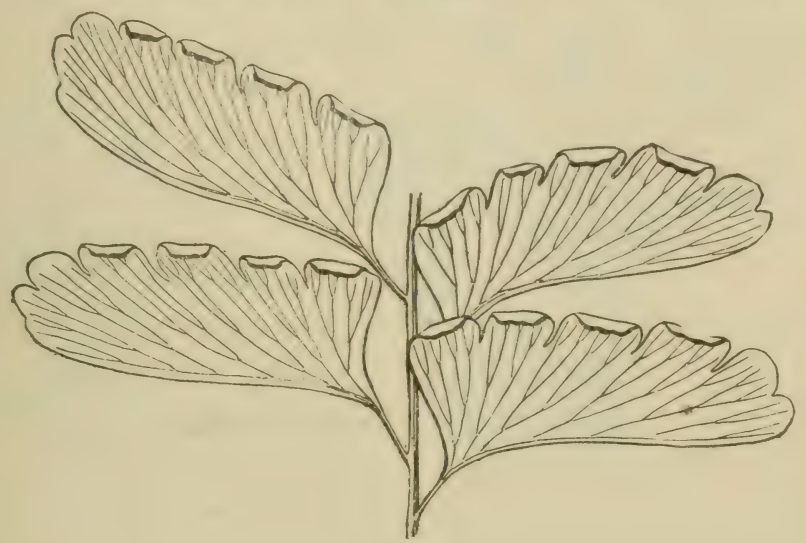

Fig. 207 .

Four pinnæ of adiantum, showing recurved margins which cover the sporangia.

shown in fig. $2 \mathrm{I} \mathrm{I}$, and soon it snalps quickly, to near its former position, and the spores are at the same time thrown for a considerable distance. This morement can sometimes lie seen with the aid of a good hand lens.

352. How does this opening and snapping of the sporangium take place? - We are now more curious than erer to see just how this opening and snapping of the sporangimm takes place. We should now mount some of the fresh sporangia in water and cover with a cover glass for microscopic examination. A drop of glycerine should he placed at one side of the cover glass on the slip so that the erlge of the glycerine will come in touch with the water. Now as one looks through the microscope to watch the 
sporangia, the water should be drawn from under the cover glass with the aid of some bibulous paper, like filter paper, placed at the

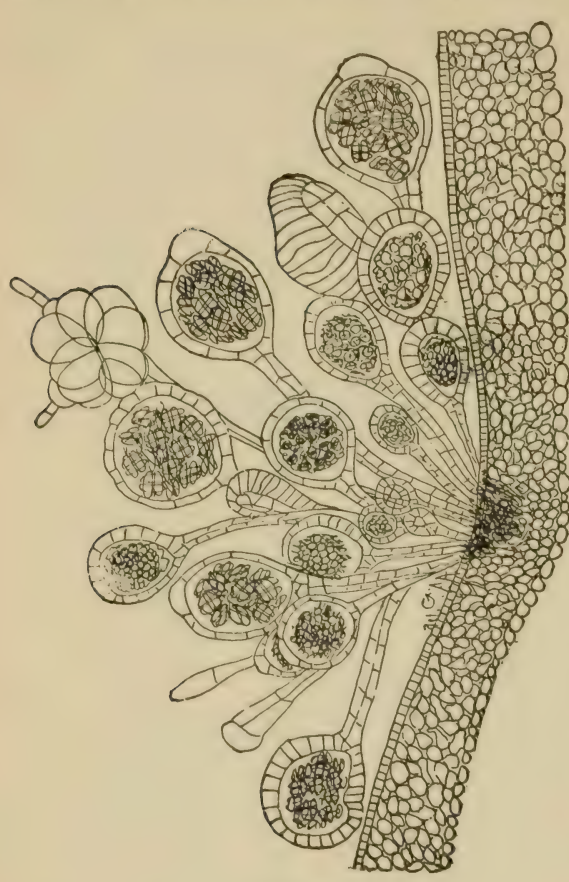

Fig. 208 .

Section through sorus of Polypodium vulgare showing different stages of sporangium, and one multicellular capitate hair. edge of the cover glass on the opposite side from the glycerine. As the glycerine takes the place of the water around the sporangia it draws the water out of the cells of the annulus, just as it took the water out of the cells of the spirogyra as we learned some time ago. As the water is drawn out of these cells there is produced a pressure from without, the atmospheric pressure upon the glycerine. This causes the walls of these cells of the annulus to bend inward, because, as we have already learned, the glycerine does not pass through the walls nearly so fast as the water comes out.

353. Now the structure of the cells of this annulus, as we have seen, is such that the inner walls and the perpendicular

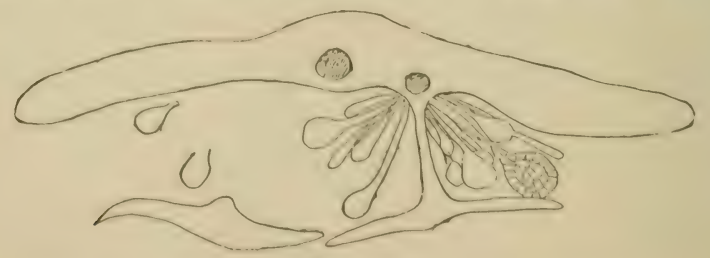

Fig. 209.

Section through sorus and shield-shaped indusium of aspidium.

walls are stout, and conseguently they do not bend or collapse when this pressure is brought to bear on the outside of the cells. 
The thin membranous walls on the back (dorsal walls) and on the sides of the annulus, however, yicld readily to the pressure and bend inward. This, as we can readily see, pulls on the ends of each of the perpendicular walls drawing them closer together. This shortens the outer surface of the annulus and causes it to first assume a nearly straight position, then curve backward until it quite or nearly becomes doubled on itself. The sporangium
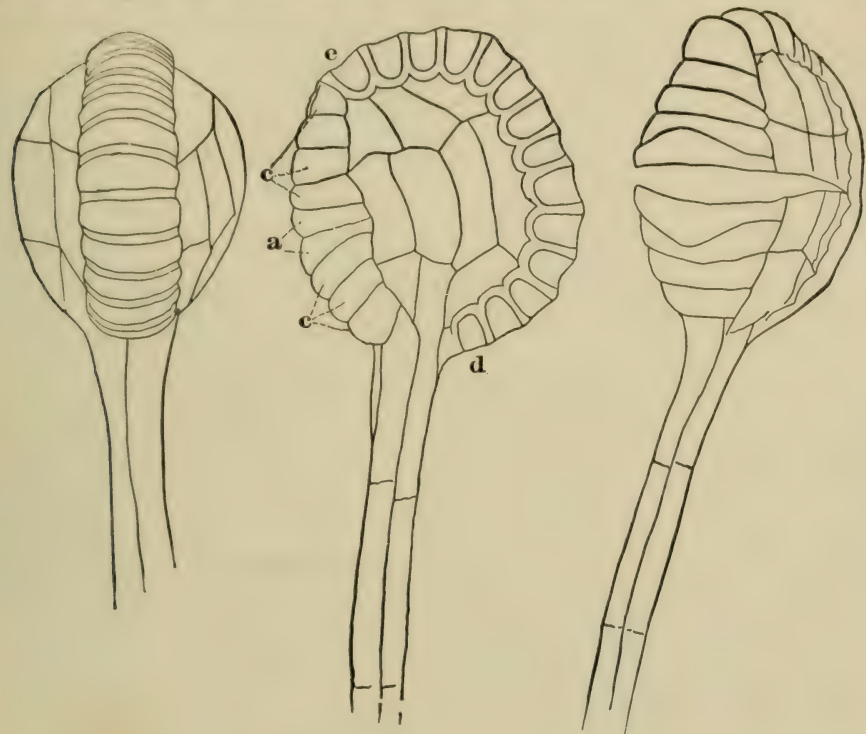

Fig. 2 ro.

Rear, side, and front views of fern sporangium. $d$, $e$, annulus; $a$, lip cells.

opens between the lip cells on the front and the lateral walls of the sporangium are torn directly across. The greater mass of spores are thus held in the upper end of the open sporangium, and when the annulus has nearly doubled on itself it suddenly snaps back again in position. While treating with the glycerine we can see all this movement take place. Each cell of the annulus acts independently, but often they all act in concert. When they do not all act in concert, some of them snap sooner than others, and this causes the annulus to snap in segments.

354. The movements of the sporangium can take place in old and dried material. - If we have no fresh material to study 
the sporangium with, we can use dried material, for the movements of the sporangia can be well seen in dried material, provided it was collected at about the time the sporangia are mature, that is at maturity, or soon afterward. We take some of the dry sporangia (or we may wash the glycerine off those which we have just studied) and mount them in water, and quickly examine

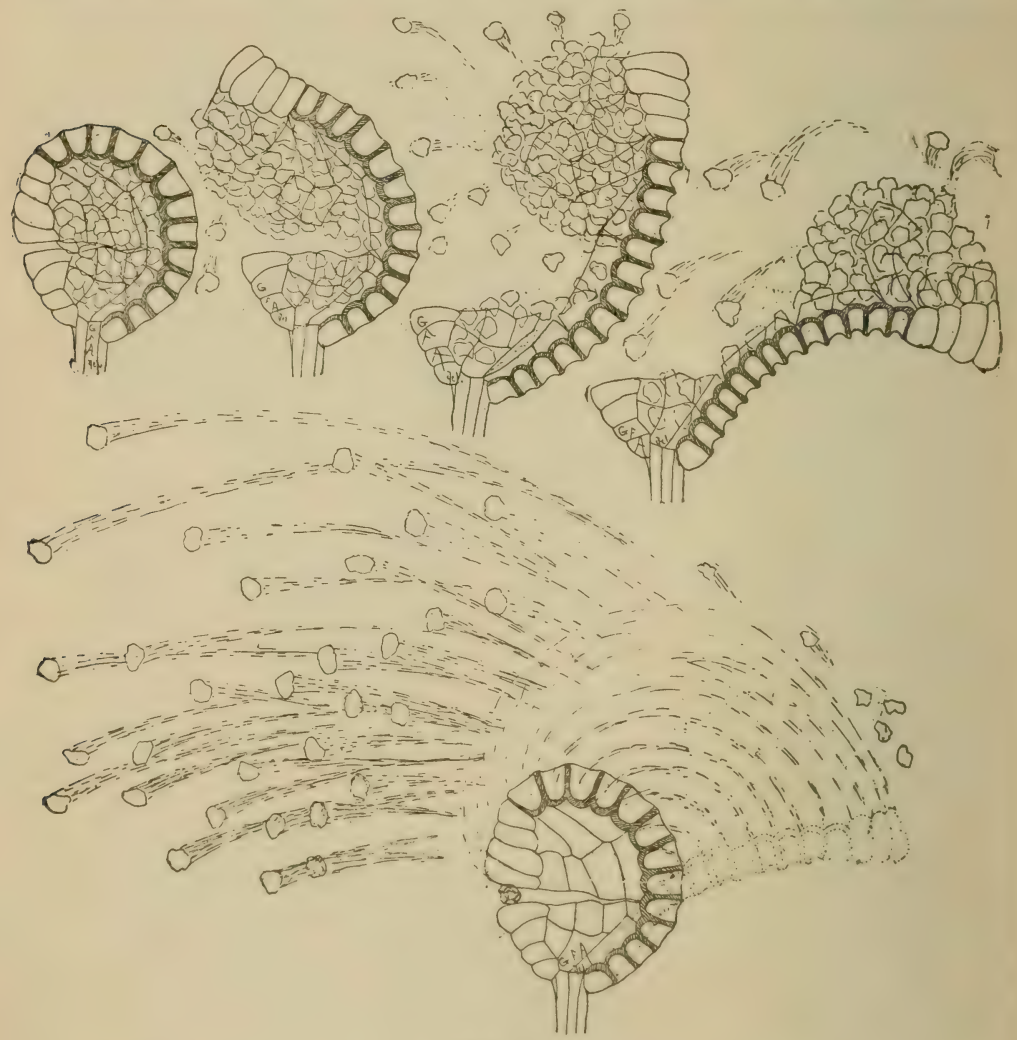

Fig. 2 II

Dispersion of spores from sporangium of Aspidium acrostichoides, showing different stages in the opening and snapping of the annulus.

them with a microscope. We notice that in each cell of the annulus there is a small sphere of some gas. The water which bathes the walls of the amnulus is absorbed by some substance inside these cells. This we can see because of the fact that this sphere of gas becomes smaller and smaller until it is only a mere 
dot, when it disappears in a twinkling. The water has been taken in under such pressure that it has absorbed all the gas, and the farther pressure in most cases closes the partly opened sporangium inore completely.

355. Now we should add glycerine again and draw out the water, watching the sporangia at the same time. We see that the sporangia which have opened and snapped once will do it again. And so they may be made to go through this operation several times in succession. We should now note carefully the annulus, that is after the sporangia have opened by the use of glycerine. So soon as they have snapped in the glycerine we can see those minute spheres of gas again, and since there was no air on the outside of the sporangia, but only glycerine, this gas must, it is reasoned, have been given up by the water before it was all drawn out of the cells.

356. The common polypody. - We may now take up a few other ferns for study. Another common fern is the polypody, one or more species of which have a very wide distribution. The stem of this fern is also not usually seen, but is covered with the leaves, except in the case of those species which grow on the surface of rocks. The stem is slender and prostrate, and is covered with numerous brown scales. The leaves are pinnate in this fern also, but we find no difference between the fertile and sterile leaves (except in some rare cases). The fruit-dots occupy much the same positions on the under side of the leaf that they do in the Christmas fern, but we cannot find any indusium. In the place of an indusium are club-shaped hairs as shown in fig. 208. The enlarged ends of these clubs reaching beyond the sporangia give some protection to them when they are young.

357. Other ferns. - We might examine a series of ferns to see how different they are in respect to the position which the fruit dots occupy on the leaf. The common brake, which sometimes covers extensive areas and becomes a troublesome weed, has a stout and smooth underground stem (rhizome) which is often I 2 to $20 \mathrm{~cm}$ beneath the surface of the soil. There is a long leaf stalk, which bears the lamina, the latter being several times pinnate. The margins of the fertile pinnæ are inrolled, and the sporangia are found protected underneath in this long sori along the margin of the pinna. The beautiful maidenhair fern and its relatives have obovate pinnx, and the sori are situated in the same positions as in the brake. In other ferns, as the walling fern, the sori are borne along by the side of the veins of the leaf.

358. Opening of the leaves of ferns. - The leaves of ferns open in a peculiar manner. The tip of the leaf is the last portion developecl, and the growing 
leaf appears as if it was rolled up as in fig. 204 of the Christmas fern. As the leaf elongates this portion unrolls.

359. Longevity of ferns. - Most ferns live from year to year, by growth adding to the advance of the stem, while by decay of the older parts the stem shortens up behind. The leaves are short-lived, usually dying down each year, and a new set arising from the growing end of the stem. Often one can see just back or below the new leaves the old dead ones of the past season, and farther back the remains of the petioles of still older leaves.

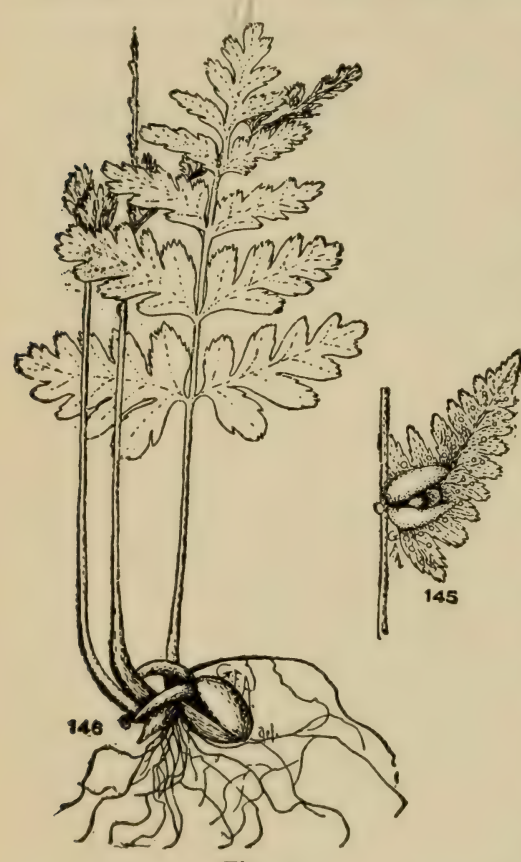

Fig. 212 .

360. Budding of ferns. - A few ferns produce what are called bulbils or bulblets on the leaves. One of these, which is found throughout the greater part of the eastern United States, is the bladder fern (Cystopteris bulbifera), which grows in shady rocky places. The long graceful delicate leaves form in the axils of the pinnæ, especially near the end of the leaf, small oval bulbs as shown in fig. 212. If we examine one of these bladder-like bulbs we see that the bulk of it is made up of short thick fleshy leaves, smaller ones appearing between the outer ones at the smaller end of the bulb. This bulb contains a stem, young root, and several pairs of these fleshy leaves. They easily fall to the ground or rocks, where, with the abundant moisture usually present in localities where the fern is found, the bulb Cystopteris bulbifera, young plant growing grows until the roots attach the plant from bulb. At right is young bulb in axil of to the soil or in the crevices of the
pinna of leaf.

one of these bulbils is shown in fig. 212 . rocks. A young plant growing from

361. Greenhouse ferns. - Some of the ferns grown in conservatories have similar bulblets. Fig. 213 represents one of these which is found abundantly. on the leaves of Asplenium bulbiferum. These bulbils have leaves which are very similar to the ordinary leaf except that they are smaller. The bulbs are also much more firmly attached to the leaf, so that they do not readily fall away.

362. Plant conservatories usually furnish a number of very interesting ferns, and one should attempt to make the acquaintance of some of them, for 
here one has an opportunity during the winter season not only to observe these interesting plants, but also to obtain matcrial for study. In the tree ferns which often are seen growing in such places we see examples of the massive trunks and leaves of some of the tropical species.

363. The fern plant is a sporophyte. - We have now studied the fern plant, as we call it, and we have found it to represent the spore-bearing phase of the plant, that is the sporophite (corresponding to the sporogoniun of the liverworts and mosses).

364. Is there a gametophyte phase in ferns?-But in the sporophyte of the fern, which we should not forget is the fern plant, we have a striking advance upon the sporophyte of the liverworts and mosses. In the latter plants the sporophyte remained attached to the gametophyte, and derived its nourishment from it. In the ferns, as we see, the sporophyte has a root of its own, and is attached to the soil.

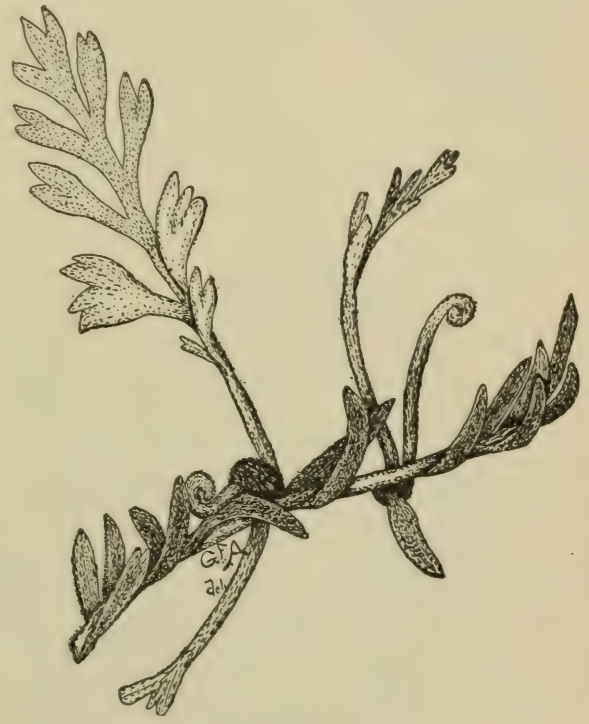

Fig. $2 \mathrm{r} 3$.

Bulbil growing from leaf of asplenium ( $A$, bulbiferum). Through the aid of root hairs of its own it takes up mineral solutions. It possesses also a true stem, and true leaves in which carbon conversion takes place. It is able to live independently, then. Does a gametophyte phase exist among the ferns? Or has it been lost? If it does exist, what is it like, and where does it grow? From what we have already learned we should expect to find the gametophyte begin with the germination of the spores which are developed on the sporophyte, that is on the fern plant itself. We should investigate this and see. 


\section{CHAPTER XXVI.}

\section{FERNS CONTINUED.}

\section{Gametophyte of ferns.}

365. Sexual stage of ferns. - We now wish to see what the sexual stage of the ferns is like. Judging from what we have found to take place in the liverworts and mosses we would infer

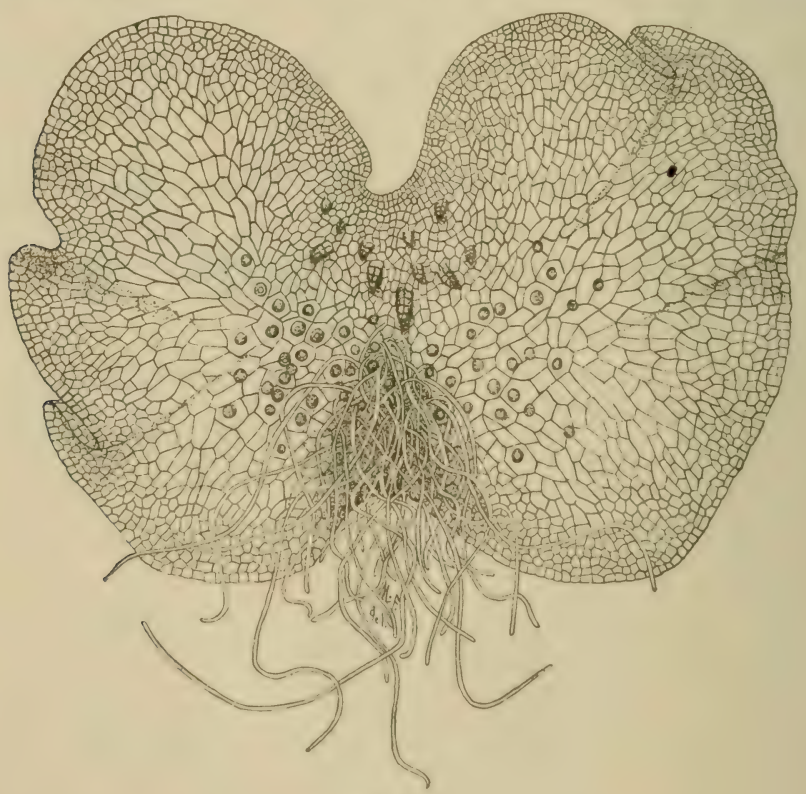

Fig. 214.

Prothallium of fern, under side, showing rhizoids, antheridia scattered among and near them, and the archegonia near the sinus.

that the form of the plant which bears the sexual organs is developed from the spores. This is true, and if we should examine old decaring logs, or deraying wood in clamp places in the near 
vicinity of ferns, we would probably find tiny, green, thin, heartshapeel growths, lying close to the sulstratum. These are also found ynite frepuently on the soil of pots in plant conservatories where ferns are grown. (jardeners also in conservatories usually sow fern spores to raise new fern plants, and usually one can find these heart-shaped growths on the surface of the soil where they have sown the spores. We may call the gardener to our aid in finding them in conservatories, or even in growing them for us if we cannot find them outside. In some cases they may be grown in an ordinary room by keeping the surfaces where they are growing moist, and the air also moist, by placing a glass bell jar over them.

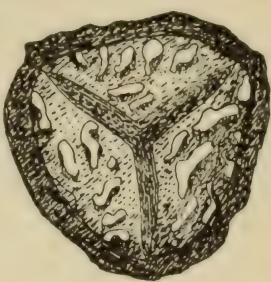

Fig. 215

Spore of Pteris serrulata showing the threerayed elevation along the side of which the spore wall cracks during germination.

366. In fig. $2 I_{4}$ is shown one of these growths enlarged. Upon the under side we see numerous thread-like outgrowths, the rhizoids, which attach the plant to the substratum, and which act as organs for the absorption of nourishment. The sexual

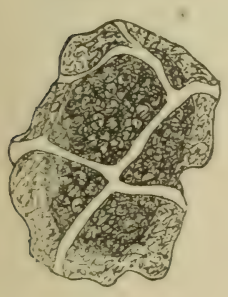

Fig. 216.

Spore of Adiantum acrostichoides with winged exospore.

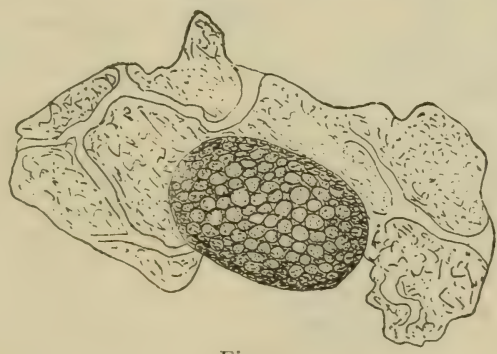

Fig. 217

organs are borne on the under side also, and we will study $\mathrm{them}$ later. This heart-shaped, flattened, thin, Spore crushed to remove exospore and green plant is show endospore.

the prothallium of ferns, and we should now give it more careful study, beginning with the germination of the spores.

367. Spores. - We can easily obtain material for the study of the spores of ferns. The spores vary in shape to some extent. Many of them are shaped like a three-sided pyramid. One of these is shown in fig. 2 I5. The outer wall is roughened, and on one end are three elevated ridges which radiate from a given 
point. A spore of the Christmas fern is shown in fig. 216 . The outer wall here is more or less winged. At fig. $2 \mathrm{I} 7$ is a spore

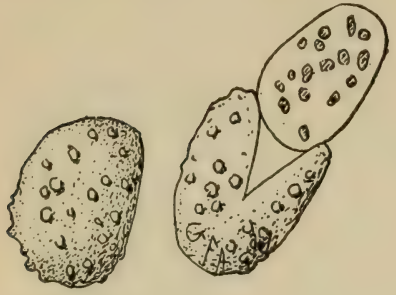

Fig. 218.

Spores of asplenium; exospore removed from the one at the right. of the same species from which the outer wall has been crushed, showing that there is an inner wall also. If possible we should study the germination of the spores of some fern.

\section{Germination of the spores.}

-After the spores have been sown for about one week to ten days we should mount a few in water for examination with the microscope in order to study the early stages. If germination has begun, we will find that here and there are short slender green threads, in many cases attached

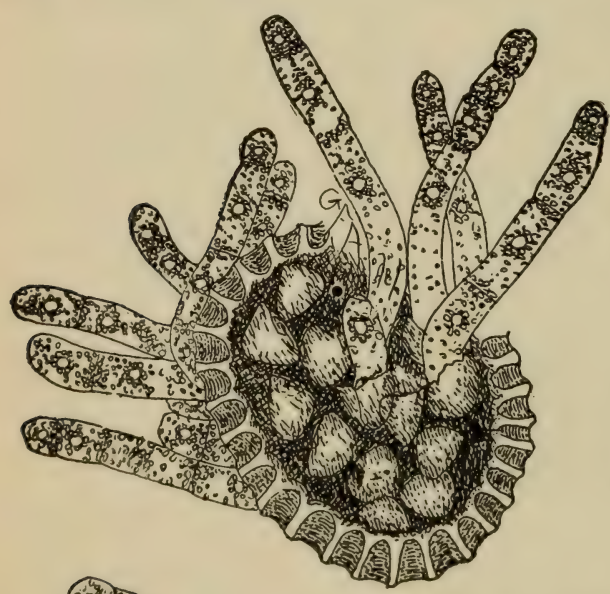
to brownish bits, the old walls of the spores. Often one will sow the sporangia along with the spores, and in such cases there may be found a number of spores still within the old sporangium wall that are germinating, when they will appear as in fig. $2 \mathbf{I} 9$.

369. Protonema.These short green threads

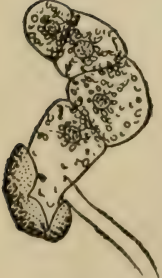

Fig. 219 are called protonemal threads, or protonema, which means a first thread, and it here signifies that this short thread only precedes a larger growth of the same object. In figs. 219,220 are shown several stages of germination of different spores. Soon after (jerminating : pores of the short germ tube emerges from the Pteris aquilina stil in the crack in the spore wall, it divides by the
sporangium. 
formation of a cross wall, and as it increases in length other cross walls are formed. But very early in its growth we see that a slender outgrowth takes place from the cell nearest the old spore wall. 'This slender thread is colorless, and is not divided into cells. It is the first rhizoid, and serves both as an organ of attachment for the thread, and for taking up nutriment.

370. Prothallium.-Very soon, if the sowing has not been so crowded as to prevent the young plants from obtaining nutriment sufficient, we will see that the end of this protonema is broadening, as shown in fig. 220. This is done by the formation of the cell walls in different directions. It now continues to grow in this way, the end becoming broader and broader, and new rhizoids are formed from the under surface of the cells. The growing point remains at the middle of the advancing margin, and the cells which are cut off from either side, as they become old, widen out. In this way the "wings," or margins of the bolus).

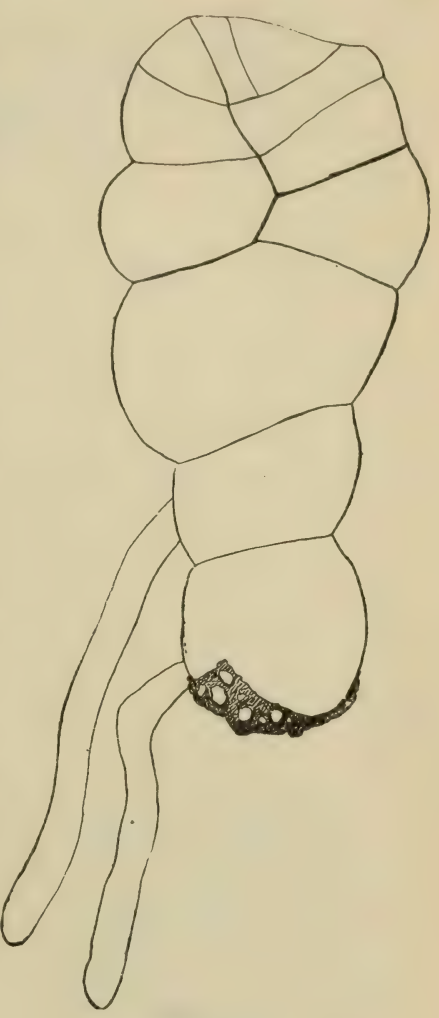

Fig. 220.

little, green, flattened body, are in advance of the growing point, and the object is more or less heart-shaped, as shown in fig. 2I4. Thus we see how the prothallium of ferns is formed.

371. Sexual organs of ferns. - If we take one of the prothallia of ferns which have grown from the sowings of fern spores, or one of those which may be often found growing on the soil 
of pots in conservatories, mount it in water on a slip, with the under side uppermost, we can then examine it for the

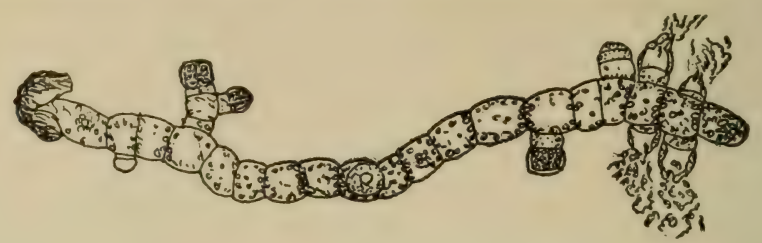

Fig. $22 x$.

Male prothallium of a fern (niphobolus), in form of an alga or protonema. Spermatozoids escaping from antheridia.

sexual organs, for these are borne in most cases on the under side.

372. Antheridia.--If we search among the rhizoids we will see small rounded elevations as shown in fig. 2 I 4 or 222 scat-
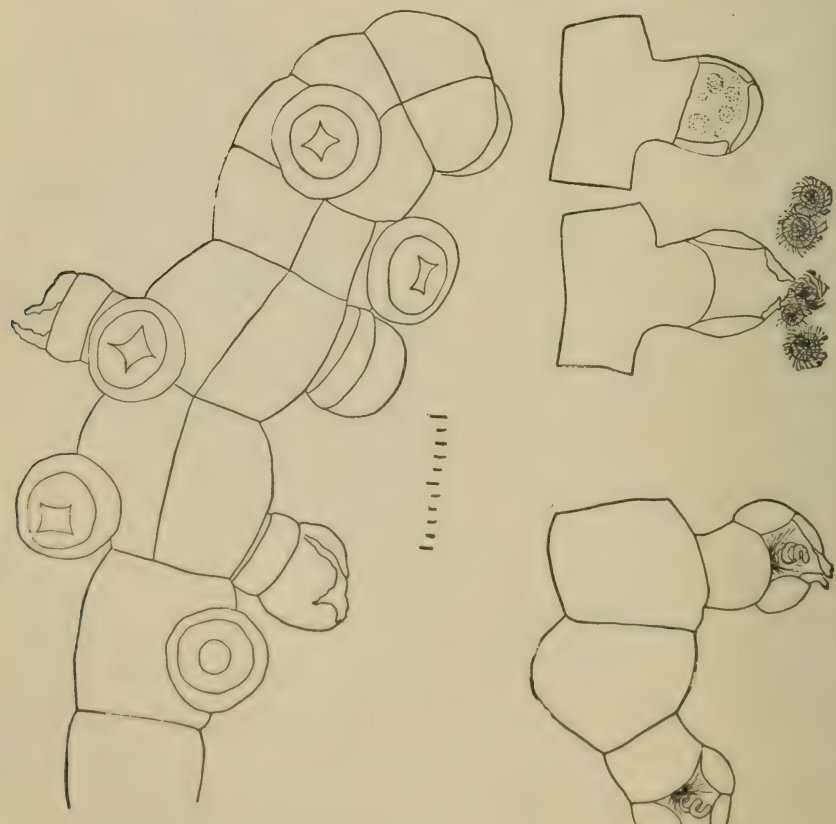

Fig. 222.

Male prothallium of fern (niphobolus), showing opened and unopened antheridia; 39 , section of unopened antheridium; fo, spermatossids escaping: 41 , spermatozoids which did not escape from the antheridium. 
tered over this portion of the prothallium. These are the antheridia. If the prothallia have not been watered for a day or so, we may have an opportunity of seeing the spermatozoids coming out of the antheridium, for when the prothallia are freshly placed in
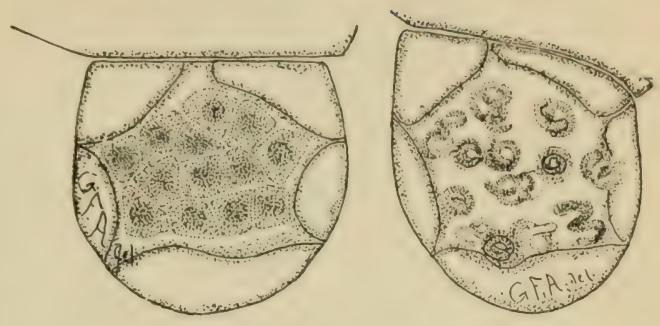

Fig. 223 .

Section of antheridia showing sperm cells, and spermatozoids in the one at the right.

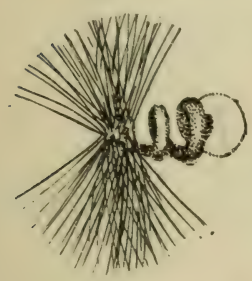

Fig. 224.

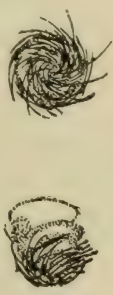

water the cells of the antheridium absorb water. This presses on the contents of the antheridium and bursts the cap cell if the antheridium is ripe, and all the spermatozoids are shot out. We can see here that each one is shaped like a screw, with the coils at Different views of spermatozoids; first close. But as the spermatozoid 42,43 , in a quiet condition; 44 , in legins to move this coil opens some-
motion (Adiantum concinnum). what and by the vibration of the long cilia which are on the smaller end it whirls away. In such preparations one may often see them spinning around for a long while, and it is only when they gradually come to rest that one can make out their form.

373. Archegonia.-If we now examine closely on the thicker part of the under surface of the prothallium, just back of the "sinus," we may see longer stout projections from the surface

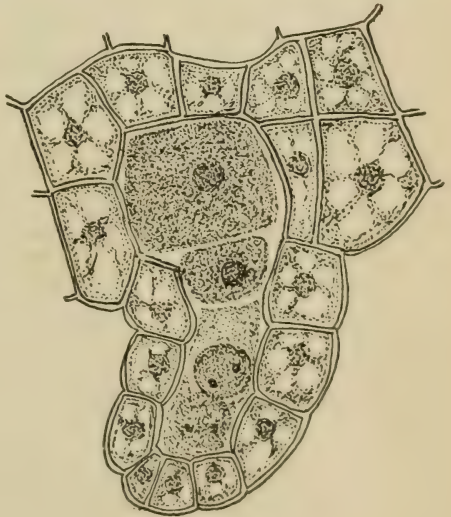

Fig. 225 .

Archegonium of fern. Large cell in the venter is the egg, next is the rentral canal cell, and in the canal of the neck are two cell, and in the canal
nuclei of the canal cell. of the prothallium. These are shown in fig. 214 . 'They are 
the archegonia. (One of them in longisection is shown in fig. 225. It is flask-shaped, and the broader portion is sunk in the

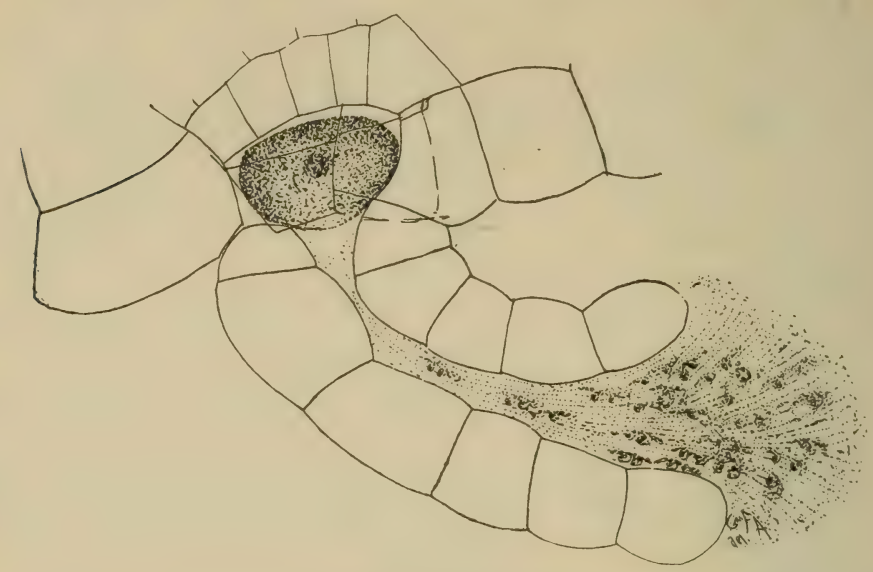

Fig. 226.

Mature and open archegonium of fern (Adiantum cuneatum) with spermatozoids making their way down through the slime to the egg.

tissue of the prothallium. The egg is in the larger part. The

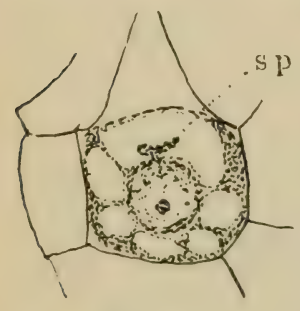

Fig. 227.

Fertilization in a fern (Marattia). ss, spermatozoid fusing with the nucleus of the egg. (After Campbell.)

phyte, which begins with the fertilized egg.

\section{Sporophyte.}

374. Embryo. - The egrg first divides into two cells as shown in fig. 228, then into four. Now from cach one of these quandrants of the embryo a definite part of the plant develops. from one the first leat, from one the stem, from one the root, and from the other the organ which is called the foot, and which 
attaches the embryo to the prothallium, and transports nourishment for the embryo until it can become attached to the soil and lead an independent existence. During this time the wall of the archegonium grows somewhat to accommodate the increase in size of the embryo, as shown in figs. 220, 230. But soon the wall of the archegonium is ruptured and the embryo emerges, the root attaches itself to the soil, and soon the prothallium dies.

The embryo is first on the under side of the prothallium, and the first leaf

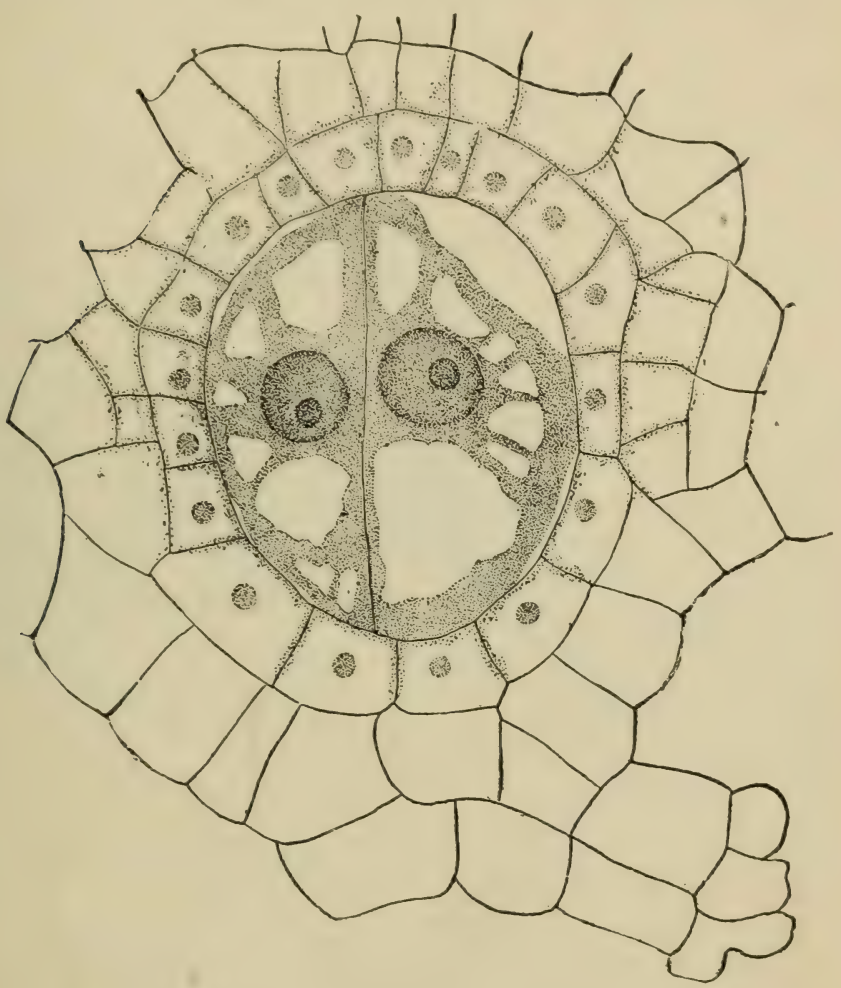

Fig. 228.

Two-celled embryo of Pteris serrulata. Remnant of archegonium neck below.

and the stem curves upward between the lobes of the heart-shaped body, and then grows upright as shown in fig. 23I. Usually only one embryo is formed on a single prothallium, but in one case I found a prothallium with two wellformed embryos, which are figured in 232.

375. Comparison of ferns with liverworts and mosses. - In the ferns then we have reached a remarkable condition of things as compared with that which we found in the mosses and liverworts. In the mosses and liverworts 
the sexual phase of the plant (gametophyte) was the prominent one, and consisted of either a thallus or a leafy axis, but in either case it bore the sexual organs and led an independent existence; that is it was capable of obtaining its nourishment from the soil or water by means of organs of absorption belonging to itself, and it also performed the office of carbon conversion.

376. The spore-bearing phase (sporophyte) of the liverworts and mosses, on the other hand, is quite small as compared with the sexual stage, and it is

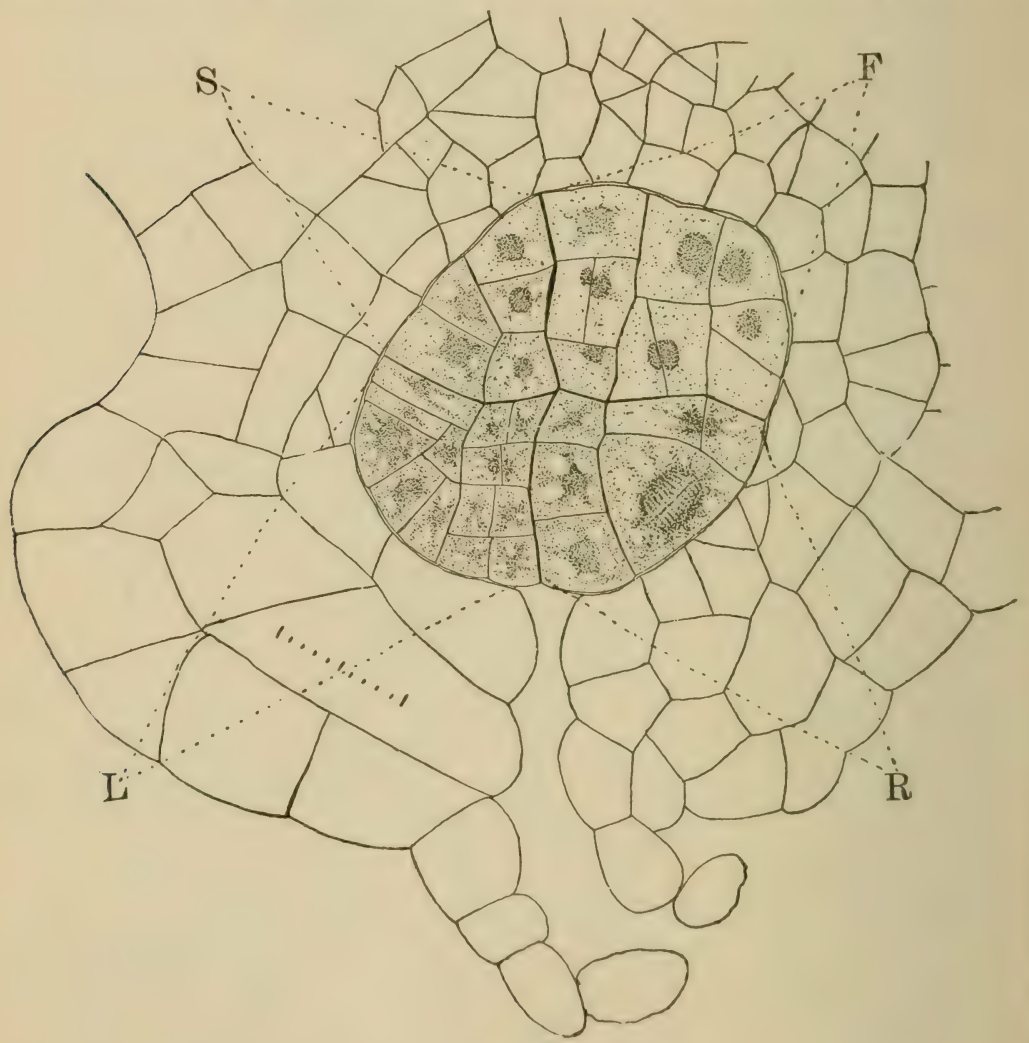

Fig. 229.

Young embryo of fern (Adiantum concinnum) in enlarged venter of the archegonium. $S$, stem ; $L$, first leaf or cotyledon; $R$, root ; $F$, foot.

completely dependent on the sexual stage for its nourishment, remaining attached permanently theoughout all its develepument, by means of the organ called a foot, and it dies after the spores are miture.

377. Now in the ferns we see several striking clifferences. In the first place, as we have already ob-erved. the spore-hearing phase (sporophyte) of 
the plant is the prominent one, and that which characterizes the plant. It also leads an independent existence, and, with the exception of a few cases, does not die after the development of the spores, but lives from year to year and develops successive crops of spores. There is a distinct advance here in the size, complexity, and permanency of this phase of the plant.

378. (In the other hand the sexual phase of the ferns (simetophyte), while it still is capplube of leateling an independent existence, is short-lived (with very few exceptions). It is also much smaller than most of the liverworts and

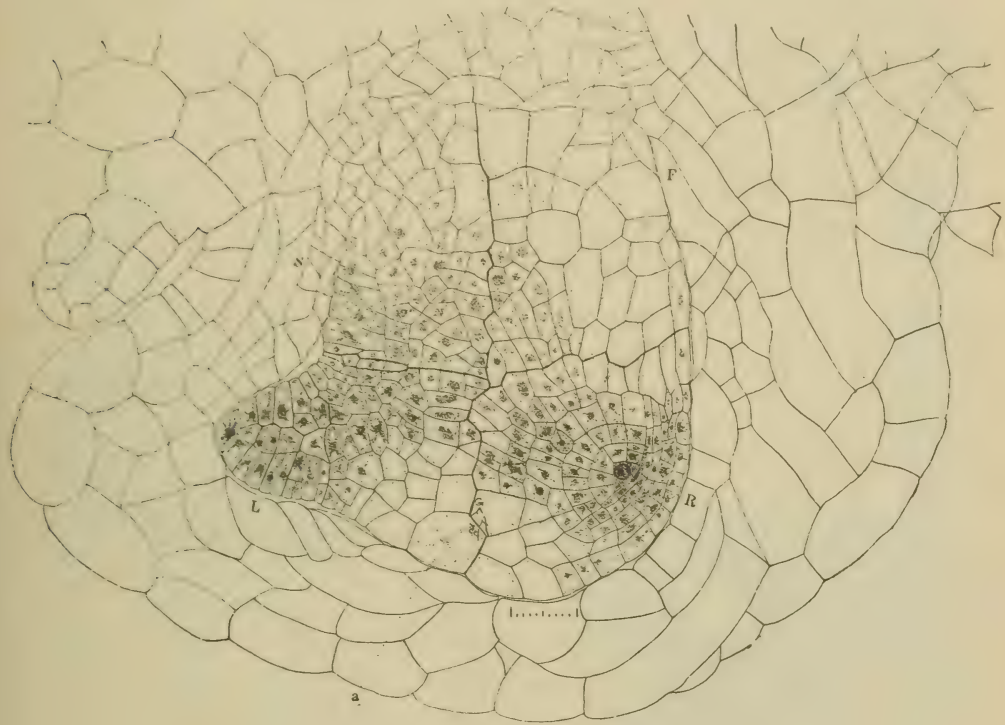

Fig. 230 .

Embryo of fern (Adiantum concinnum) still surrounded by the archegonium, which has grown in size, forming the "calyptra." $L$, leaf; $S$, stem; $R$, root ; $F$, foot.

mosses. especially as compared with the size of the spore-bearing phase. The gametophyte phase or stage of the plants, then, is decreasing in size and durance as the sporophyte stage is increasing. We shall be interested to see if this holds good of the fern allies, that is of the plants which belong to the same group as the ferns. And as we come later to take up the study of the higher plants we must bear in mind to carry on this comparison, and see if this progression on the one hand of the sporophyte continues. and if the retrogression of the gametophyte continues also. 


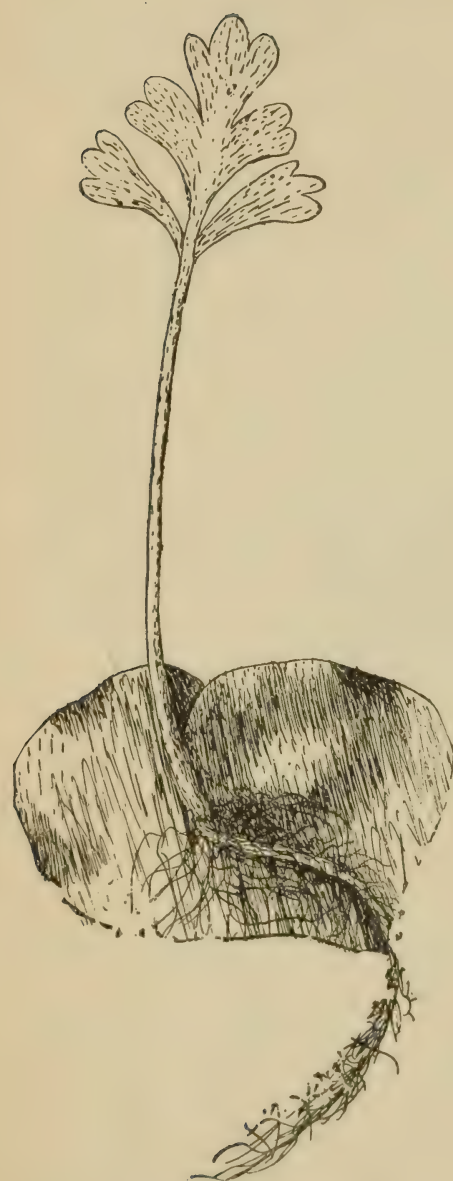

Fig. 23r.

Young plant of Pteris serrulata still attached to prothallium.

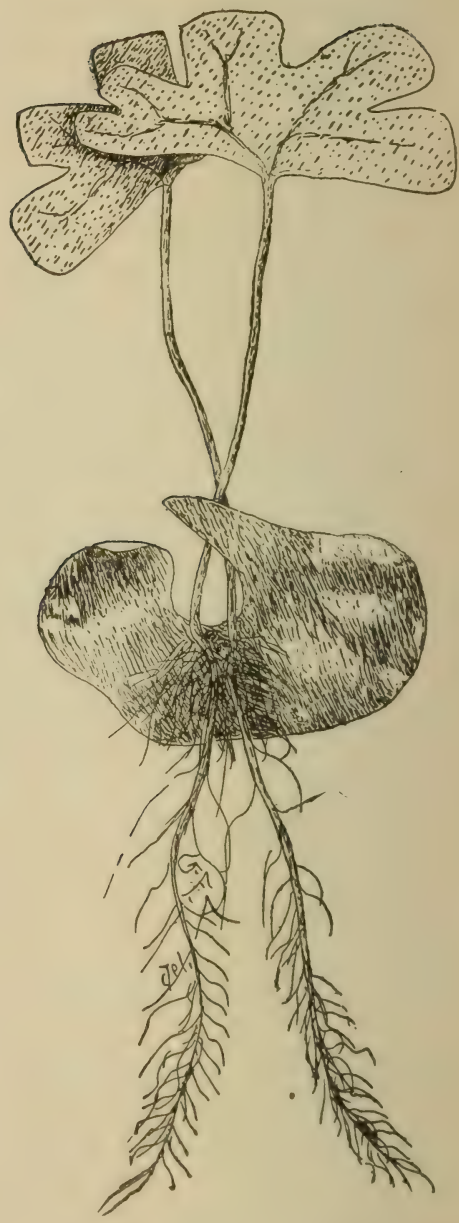

Fig. 232 .

Two embryos from one prothallium of Adiantum cuneatum. 


\section{CHAP'TER XXVII.}

\section{HORSETAILS.}

379. Among the relatives of the ferns are the horsetails, so called because of the supposed resemblance of the branched stems of some of the species to a horse's tail, as one might infer from the plant shown in fig. 23 3. They do not bear the least resemblance to the ferns which we have been studying. But then relationship in plants does not depend on mere resemblance of outward form, or of the prominent part of the plant.

380. The field equisetum. Fertile shoots.-Fig. 233 represents the common horsetail (Equisetum arvense). It grows in moist sandy or gravelly places, and the fruiting portion of the plant (for this species is dimorphic), that is the portion which bears the spores, appears above the ground early in the spring. It is one of the first things to peep out of the recently frozen ground. This fertile shoot of the plant does not form its growth this early in the spring. Its development takes place under the ground in the autumn, so that with the advent of spring it pushes up without delay. This shoot is from 10 to 20 $\mathrm{cm}$ high, and at quite regular intervals there are slight enlargements, the nodes of the stem. The cylindrical portions between the nodes are the internodes. If we examine the region of the internodes carefully we note that there are thin mem- fertile plant of branous scales, more or less triangular in outline, and whereshowing of connected at their bases into a ring around the stem leaves and the ruiting spike. 
Curious as it may seem, these are the leaves of the horsetail. The stem, if we examine it farther, will be seen to possess numerous ridges which extend lengthwise and which alternate with furrows. Farther, the ridges of one node alternate with those of the internode both above and below. Likewise the leaves . of one node alternate with those of the nodes both above and below.

381. Sporangia. - The end of this fertile shoot we see possesses a cylindrical to conic enlargement. This is the fertile

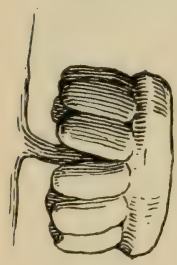

Fig. 234 . spike, and we note that its surface is marked off into regular areas if the spores have not yet been disseminated. If we dissect off a few of these portions of the fertile spike, and examine one of them with a low magnifying power, it will appear like the fig. 234. We see here that the angular area is a disk-shaped body, with a stalk attached to its inner Peltate sporo-
hyll of equisetum surface, and with several long sacs projecting from (side view) show-
ing sporangia on its inner face parallel with the stalk and surrounding under side. the same. These elongated sacs are the sporangia, and the disk which bears them, together with the stalk which attaches it to the stem axis, is the sporophyil, and thus belongs to the leaf series. These sporophylls are borne in close whorls on the axis.

382. Spores. -When the spores are ripe the tissue of the sporangium becomes dry, and it cracks open and the spores fall out. If we look at fig. 235 we will see that the spore is covered with a very singular coil which lies close to the wall. When the spore dries this uncoils and thus rolls the spore about. Merely breathing upon these spores is sufficient to make them perform very curious evolutions by the twisting of these four coils which are attached to one place of the wall. They are formed by the splitting up of an outer wall of the spore.

383. Sterile shoot of the common horsetail. - When the spores are ripe they are soon scattered, and then the fertile shoot dies down. Soon afterward, or even while some of the fertile shoots are still in good condition, sterile shoots of the 
plant begin to appear above the ground. One of these is shown in fig. 237. This has a much more slender stem and is pro-

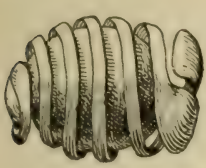

Fig. 235 .

Spore of equisetum with elaters coiled up.

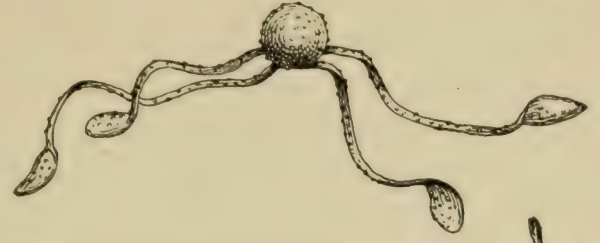

Fig. 236

Spore of equisetum with elaters uncoiled.

vided with numerous branches. If we examine the stem of this shoot, and of the branches, we will see that the same kind of leaves are present and that the markings on the stem are similar. Since the leaves of the horsetail are membranous and not green, the stem is green in color, and this performs the function of carbon conversion. These green shoots live for a great part of the season, building up material which is carried down into the underground stems, where it goes to supply the forming fertile shoots in the fall. On digging up some of these plants we see that the underground stems are often of great extent, and that both fertile and sterile shoots are attached to one and the same.

384. The scouring rush, or shave grass. -Another common species of horsetail in the Northern States grows on wet banks, or in sandy soil which contains moisture along railroad embankments. It is the scouring rush (E. hyemale), so called because it was once used for polishing purposes. This plant like all the species of the horsetails has

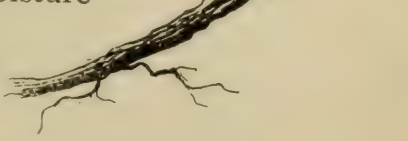

Fig. 237.

Sterile plant of horsetail (Equisetum arvensis) 
underground stems. But unlike the common horsetail, there is but one kind of aerial shoot, which is green in color and fertile. The shoots range as high as one meter or more, and are quite stout. The new shoots which come up for the year are unbranched, and bear the fertile spike at the apex. When the spores are ripe the apex of the shoot dies, and the next season small branches may form from a number of the nodes.

385. Gametophyte of equisetum. - The spores of equisetum have chlorophyll when they are mature, and they are capable of germinating as soon as mature. The spores are all of the same kind as regards size, just as we found in the case of the ferns. But they develop prothallia of different sizes, according to the amount of nutriment which they obtain. Those which obtain but little nutriment are smaller and develop only antheridia, while those which obtain more nutriment become larger, more or less branched, and develop archegonia. This character of an independent prothallium (gametophyte) with the characteristic sexual organs, and the also independent sporophyte, with spores, shows the relationship of the horsetails with the ferns. We thus see that these characters of the reproductive organs, and the phases and fruiting of the plant, are more essential in determining relationships of plants than the mere outward appearances. 


\section{CHAPTER XXVIII.}

\section{CLUB MOSSES.}

386. What are called the "(lul) mosses" make up another group of interesting plants which rank as allies of the ferns. They are not of course true mosses, but the general habit of some of the smaller species, and especially the form and size of the leaves, suggest a resemblance to the larger of the moss plants.

387. The clavate lycopodium.-Here is one of the club mosses (fig. 238) which has a wide distribution and which is well entitled to hold the name of club because of the form of the upright club-shaped branches. As will be seen from the illustration, it has a prostrate stem. This stem runs for considerable distances on the surface of the ground, often partly buried in the leares, and sometimes even buried beneath the soil. The leares are quite small, are flattened-awl-shaped, and stand thickly over the stem, arranged in a spiral manner, which is the usual arrangement of the leaves of the club mosses. Here and there are upright branches which are forked several times. The end of one or more of these branches becomes produced into a slender upright stem which is nearly leafless, the leaves being reduced to mere scales. The end of this leafless branch then terminates in one or several cylindrical

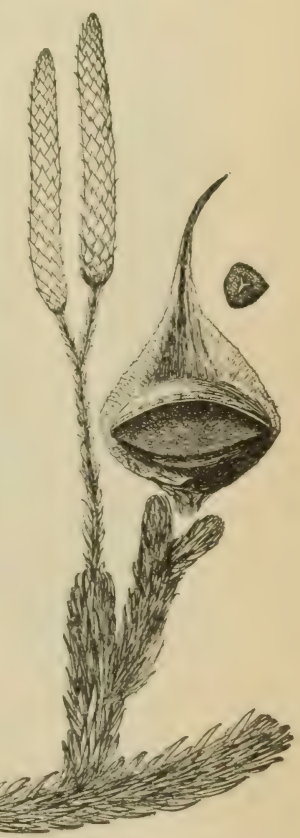

Fig. 23 ५.

I.joppoctium \& lavatum, branch bearing two fruiting spikes: at right sperroplisll with open sporangium; s ingle spore near it. heads which form the club. 
388. Fruiting spike of Lycopodium clavatum. - This club is the fruiting spike or head (sometimes termed a strobilus). Here the leaves are larger again and broader, but still not so large as the leaves on the creeping shoots, and they are paler. If we bend down some of the leaves, or tear off a few, we will see that in the axil of the leaf, where it joins the stem, there is a somewhat rounded, kidney-shaped body. This is the spore-case or sporangium, as we can see by an examination of its contents. There is but a single spore-case for each of the fertile leaves (sporophyll). When it is mature, it opens by a crosswise slit as seen in fig. 238 . When we consider the number of spore-cases in one of these clubshaped fruit bodies we see that the number of spores developed in a large plant is immense. In mass the spores make a very fine,

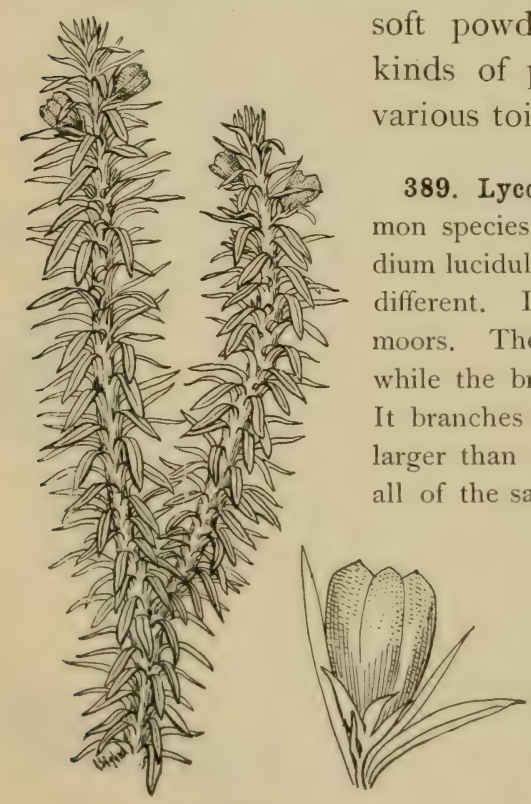

Fig. 239 .

Lycopodium lucidulum, bulbils in axils of leaves near the top, sporangia in axils of leaves below them. At right is a buibil enlarged. difference between the sterile and fertile ones. The characteristic club is not present here, but the spore-cases occupy certain regions of the stem, as shown at 239. In a single season one region of the stem may bear spore-cases, and then a sterile portion of the same stem is developed, which later bears another series of spore-cases higher up.

\section{Bulbils on Lycopodium} lucidulum. - There is onc curious way in which this club moss multiplies. One may see frequently among the upper leaves small wedge-shaped or heartshaped green bodies but little larger than the ordinary leaves. These are little 
buds which contain rudimentary shoot and root and several thick green leaves. When they fall to the ground they grow into new lycopodium plants, just as the bulbils of cystopteris do which were described in the chapter on ferns.

391. Note.-The prothallia of the species of lycopodium which have been studied are singular objects. In L. cernuum a cylindrical body sunk in the earth is formed, and from the upper surface there are green lobes. In I. phlegmaria and some others slender branched, colorless bodies are formed which according to Treub grow as a saphrophyte in decayed bark of trees. Many of the prothallia examined have a fungus growing in their tissue which is supposed to play some part in the nutrition of the prothallium.

\section{The little club mosses (selaginella).}

392. Closely related to the club mosses are the selaginellas. These plants resemble closely the general habit of the club mosses, but are generally smaller and the leaves more delicate. Some species are grown in conservatories for ornament, the leaves of

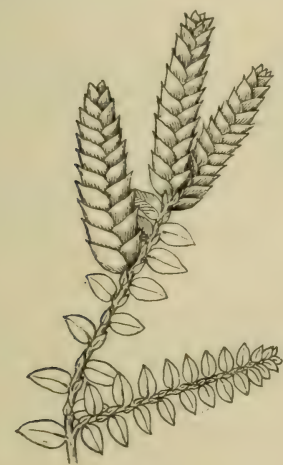

Fig. 240.

Selaginella wit $\mathrm{h}$ three fruiting spikes. (Selaginella apus.)

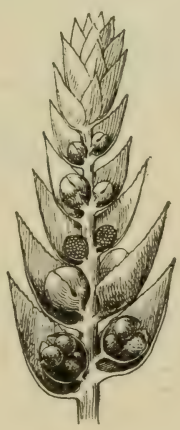

Fig. 24r.

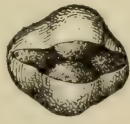

Fig. 242. Fig. 243 .

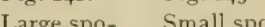
showing large and rangium. rangium. small sporangia.

such usually having a beautiful metallic lustre. The leaves of some are arranged as in lycopodium, but many species have the leaves in four to six rows. Fig. 240 represents a part of a selaginella plant (S. apus). The fruiting spike possesses similar leaves, but they are shorter, and their arrangement gives to the spike a foursided appearance. 
393. Sporangia.-On examining the fruiting spike, we find as in lycopodium that there is but a single sporangium in the axil of a fertile leaf. But we see that they are of two different kinds, small ones in the axils of the upper leaves, and large ones in the axils of a few of the lower leaves of the spike. The microspores are borne in the smaller spore-cases and the macrospores in the larger ones. Figures 24I-243 give the details. There are many microspores in a single small spore-case, but $3^{-4}$ macrospores in a large spore-case.

394. Male prothallia. - The prothallia of selaginella are much reduced structures. The microspores when mature are already divided into two cells. When they grow into the mature prothallium a few more cells are formed, and some of the inner ones form the spermatozoids, as seen in fig. 244. Here we see that
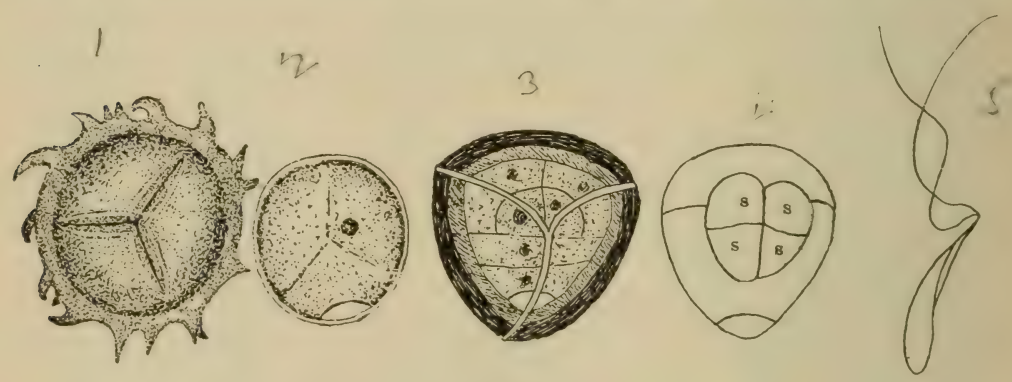

Fig. 244

Details of microspore and male prothallium of selagine!la : Ist, microspore : $2 \mathrm{~d}$, wall removed to show small prothallial cell below; $3 \mathrm{~d}$, mature male prothallium still within the wall; 4 th, small cell below is the prothallial cell, the remainder is antheridium with wall and three sperm cells within; 5 th spermatozoid. After Beliaieff and Pfeffer.

the antheridium itself is larger than the prothallia. Only antheridia are developed on the prothallia formed from the microspores, and for this reason the prothallia are called male prothallia. In fact a male prothallium of selaginella is nearly all antheridium, so reduced has the gametophyte become here.

395. Female prothallia. - The female prothallia are developed from the macrospores. The macrospores when mature have a rough, thick, hard wall. The female prothallium begins to develop inside of the macrospore before it leaves the sporangium. The protoplasm is richer near the wall of the spore and at the 
upper end. Here the nucleus divides a great many times, and finally cell walls are formed, so that a tissue of considerable extent is formed inside the wall of the spore, which is very different from what takes place in the ferns we have studied. As the prothallium matures the spore is cracked at the point where the three angles meet, as shown in fig. 246 . The archegonia are developed in this exposed surface, and several can be seen in the illustration.

396. Embyro. - After fertilization the egg divides in such a way that a long cell called a suspensor is cut off from the upper side,

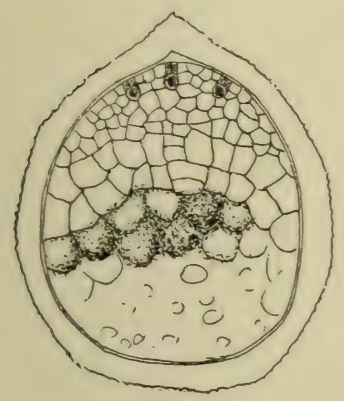

Fig. 245 .

Section of mature macrospore of selaginella, showing female prothallium and archegonia. After Pfeffer.

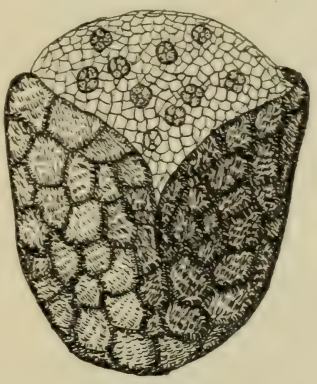

Fig. 246.

Nature female prothallium of selaginella, just bursting open the wall of macrospore, exposing archegonia. After Pfeffer.

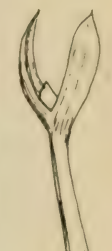

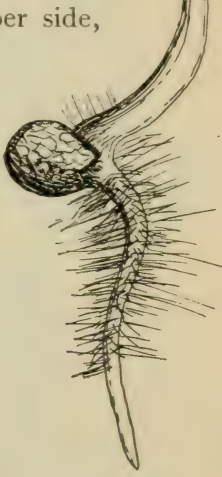

Fig. 247.

Seedling of selaginella still attached to the macrospore. After Cainpbell.

which elongates and pushes the developing embyro down into the center of the spore, or what is now the female prothallium. Here it derives nourishment from the tissues of the prothallium, and eventually the root and stem emerge, while a process called the "foot" is still attached to the prothallium. When the root takes hold on the soil the embyro becomes free. 


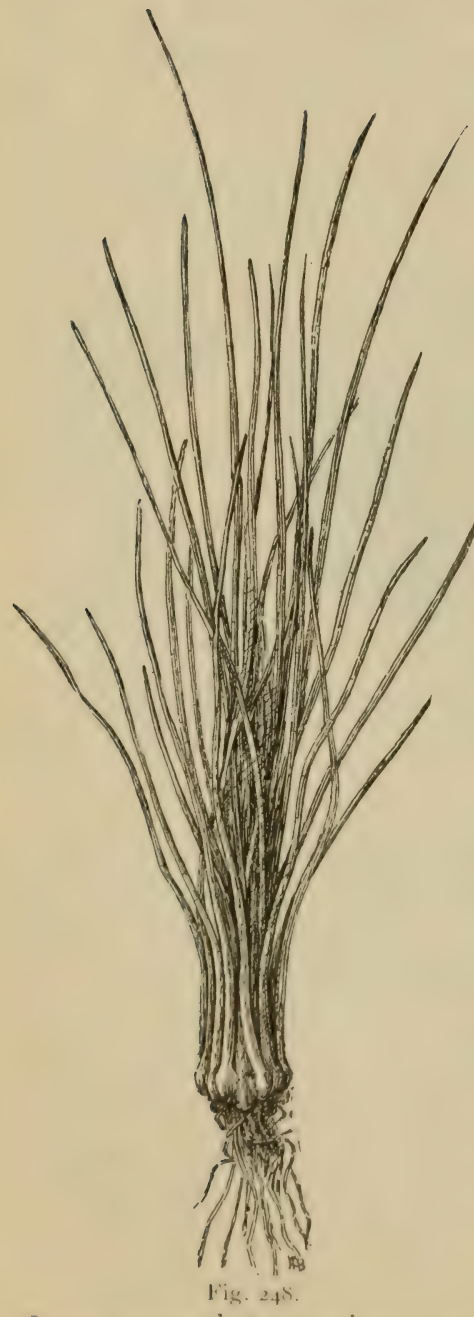

CHAPTER XXIX.

QUILLWORTS (ISOETES).

397. The quillworts, as they are popularly called, are very curious plants. They grow in wet marshy places. They receive their name from the supposed resemblance of the leaf to a quill. Fig. 248 represents one of these quillworts (Isoetes engelmannii). The leaves are the prominent part of the plant, and they are about all that can be seen except the roots, without removing the leaves. Each leaf, it will be seen, is long and needle-like, except the basal part, which is expanded, not very unlike, in outline, a scale of an onion. These expanded basal portions of the leaves closely overlap each other, and the very short stem is completely covered at all times. Fig. 250 is from a longitudinal section of a quillwort. It shows the form of the leaves from this view (side view), and also the Isoetes, mature plant, sporophyte stage. general outline of the short stem,
which is triangular. The stem is therefore a very short object. which is triangular. The stem is therefore a very short object. 
398. Sporangia of isocies. - If we pull off some of the leaves of the plant we see that they are somewhat spoon-shaped as in fig. 249. In the inner surface of the expanded liase we note a circular depression which seems to be of a different text-

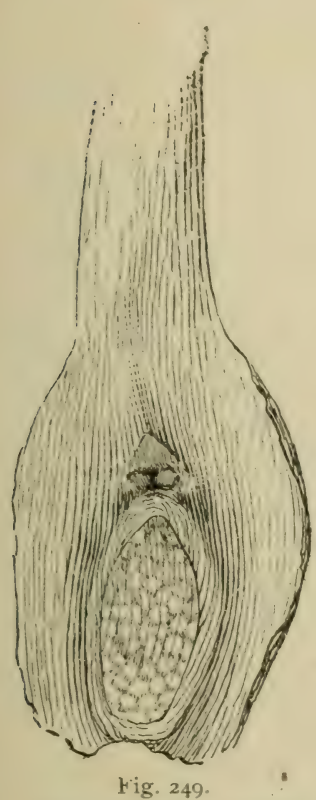

Base of leaf of isoetes, showing sporangium with macrospores. (Isoetes engelmannii.)

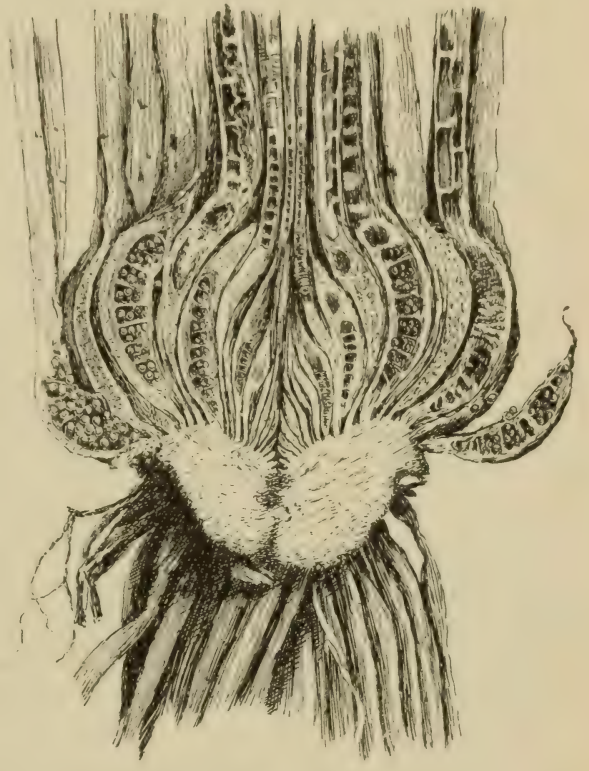

Fig. 250.

Section of plant of Isoetes engelmanii, showing cupshaped stem, and longitudinal sections of the sporangia in the thickened bases of the leaves.

ure from the other portions of the leaf. This is a sporangium. Beside the spores on the inside of the sporangium, there are strands of sterile tissue which extend across the cavity. This is peculiar to isoetes of all the members of the class of plants to which the ferns belong, but it will be remembered that sterile strands of tissue are found in some of the liverworts in the form of elaters.

399. The spores of isoetes are of two kinds, small ones (microspores) and large ones (macrospores), so that in this respect it agrees with selaginella, though it is so very different in other respects. When one kind of spore is l,orne in a sporan- 
gium usually all in that sporangium are of the same kind, so that certain sporangia bear microspores, and others bear macrospores. But it is not uncommon to find both kinds in the same sporangium. When a sporangium bears only microspores the number is much greater than when one bears only macrospores.

400. If we examine some of the microspores of isoetes we see that they are shaped like the quarters of an apple, that is they are of the bilateral type as seen in some of the ferns (asplenium).

401. Male prothallia.-In isoetes, as in selaginella, the microspores develop only male prothallia, and these are very rudimentary, one division of the spore having taken place before the spore is mature, just as in selaginella.

402. Female prothallia.-These are developed from the macrospores. The latter are of the tetrahedral type. The development of the female prothallium takes place in much the same way as in selaginella, the entire prothallium being enclosed in the macrospore, though the cell divisions take place after it has left the sporangium. When the archegonia begin to develop the macrospore cracks at the three angles and the surface bearing the archegonia projects slightly as in selaginella.

403. Embryo. - The embryo lies well immersed in the tissue of the prothallium, though there is no suspensor developed as in selaginella. 


\section{CHAPTER XXX.}

\section{COMPARISON OF FERNS AND THEIR RELATIVES}

404. Comparison of selaginella and isoetes with the ferns.-()n comparing selaginellit and isoctes with the ferms. we see that the sporophyte is, as in the ferns, the prominent part of the plant. It possesses root, stem, and leaves. While these plants are not so large in size as some of the ferns, still we see that there has been a great advance in the sporophyte of selaginella and isoetes upon what exists in the ferns. There is a division of labor between the sporophylls. in which some of them bear microsporangia with microspores, and some bear macrosporangia with only macrospores. In the ferns and horsetails there is only one kind of sporophyll, sporangium, and spore in a species. By this division of labor, or differentiation, between the sporophylls. one kind of spore, the microspore, is compelled to form a male prothallium. while the other kind of spore, the macrospore, is compelled to form a female prothallium. This represents a progression of the sporophyte of a very important nature.

405. On comparing the gametophyte of sclaginella and isoetes with that of the ferns. we see that there has been a still farther retrogression in size from that which we found in the independent and large gametophyte of the liverworts and mosses. In the ferns, while it is reduced, it still forms rhizoids, and learls an independent life, absorbing its own nutrient materials, aurl assimilating carbon. In selaginella and isoetes the gametophyte does not escape from the spore. nor does it form absorbing organs, nor develop assimilative tis:ue. The reduced prothallium develops at the expense of ford stored by the sporophyte while the spore is developing. Thus, while the gametophyte is separate from the sporophyte in selaginella and isoetes, it is really dependent on it for support or nourishment.

406. The important general characters pessessed by the ferns and their sn-callerl allies, as we have found. are as follows: The spore-bearing part. which is the fern plant. leads an independent existence from the prothallium. and forms root, stem, and leaves. The spores are borne in sporangia on the leaver. The prothallium also leads an independent existence, though in isextes and selaginella it has become almost entirely dependent on the sporor- 
phyte. The prothallium bears also well-developed antheridia and archegonia. The root, stem, and leaves of the sporophyte possess vascular tissue. All the ferns and their allies agree in the possession of these characters. The mosses and liverworts have well-developed antheridia and archegonia, and the higher plants have vascular tissue. But no plant of either of these groups possesses the combined characters which we find in the ferns and their relatives. The latter are, therefore, the fern-like plants, or pteridophyla. The living forms of the pteridophyta are classified as follows into families or orders.

407.

\section{Pteridophyta.}

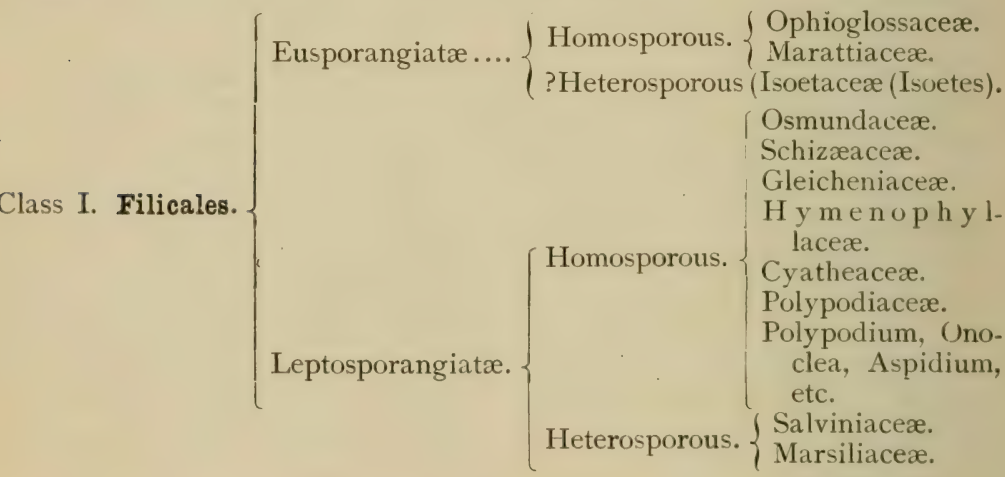

Class II. Equisetales. $\left\{\begin{array}{l}\begin{array}{c}\text { Equisetaceæ. } \\ \text { (Equisetum). }\end{array}\end{array}\right.$

Class III. Lycopodiales. $\left\{\begin{array}{l}\text { Homosporous. }\left\{\begin{array}{l}\text { Lycopodiaceæ (Lycopodium). } \\ \text { Psilotaceæ (tropical forms). } \\ \text { H'eterosporous. }\end{array} \text { (Selaginellaceæ (Selaginella). }\right.\end{array}\right.$ 


\begin{tabular}{|c|c|c|c|c|c|c|}
\hline 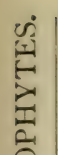 & 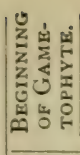 & & $\begin{array}{l}\text { ஹें } \\
\text { के } \\
\text { कू }\end{array}$ & 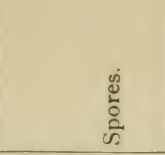 & 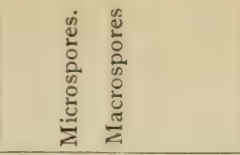 & 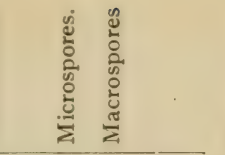 \\
\hline 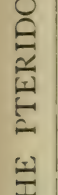 & 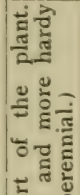 & 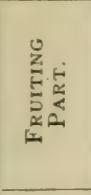 & 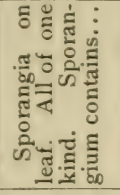 & 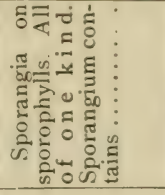 & 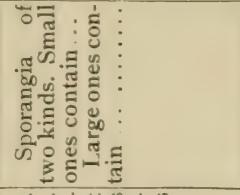 & 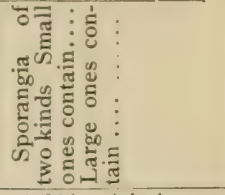 \\
\hline $\begin{array}{l}z \\
z \\
\vdots \\
\vdots \\
E\end{array}$ & 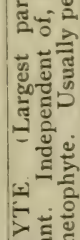 & 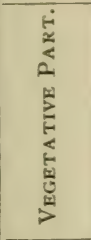 & 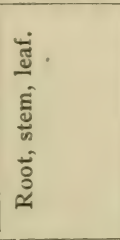 & 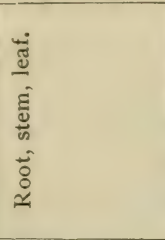 & 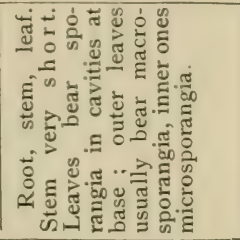 & 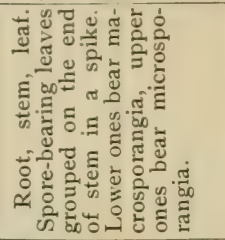 \\
\hline $\begin{array}{l}\frac{1}{0} \\
\frac{1}{s} \\
\theta\end{array}$ & 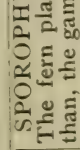 & 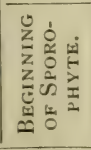 & 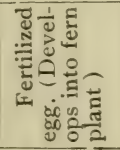 & 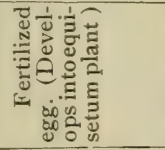 & 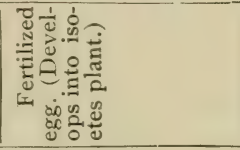 & 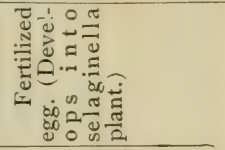 \\
\hline 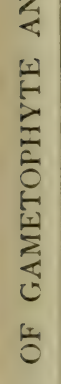 & 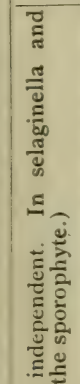 & 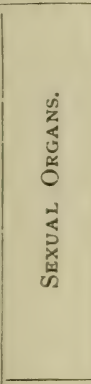 & 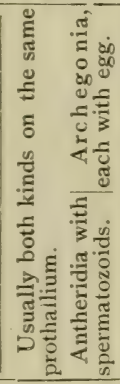 & 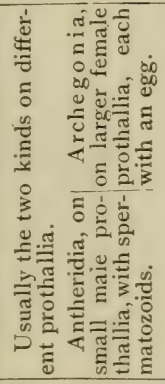 & 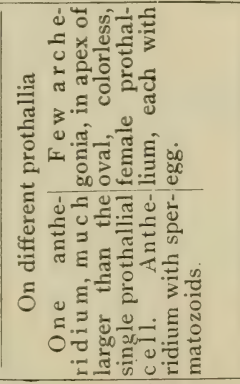 & 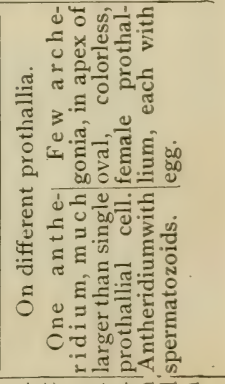 \\
\hline 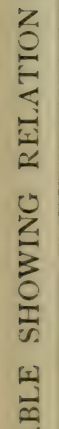 & 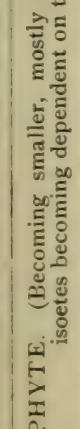 & 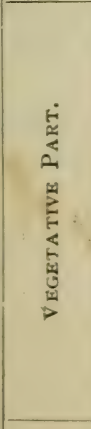 & 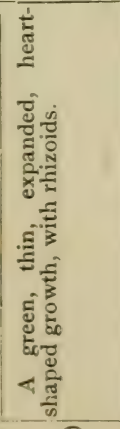 & 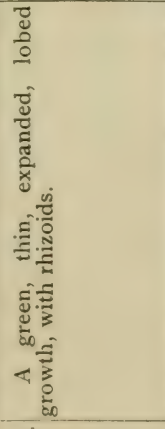 & 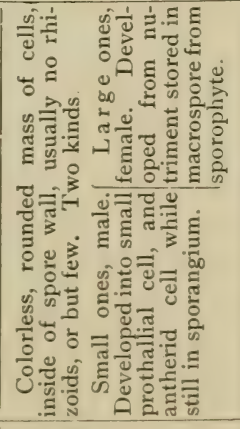 & 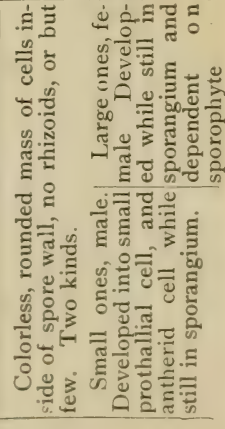 \\
\hline$\underset{\forall}{\infty}$ & $\underbrace{a}_{0}$ & & 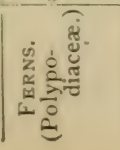 & 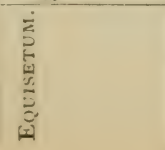 & 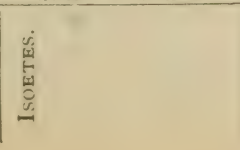 & 这离 \\
\hline
\end{tabular}




\section{CHAPTER XXXI.}

\section{GYM NOS PERM S.}

\section{, The white pine.}

409. General aspect of the white pine.-The white pine (Pinus strobus) is found in the Eastern United States. In favorable situations in the forest it reaches a height of about 50 meters (about I6o feet), and the trunk a diameter of over I meter. In well-formed trees the trunk is straight and towering; the branches where the sunlight has access and the trees are not crowded, or are young, reaching out in graceful arms, form a pyramidal outline to the tree. In old and dense forests the lower branches, because of lack of sunlight, have died away, leaving tall, bare trunks for a considerable height.

410. The long shoots of the pine.-The branches are of two kinds. Those which we readily recognize are the long branches, so called because the growth in length each year is considerable. The terminal bud of the long branches, as well as of the main stem, continues each year the growth of the main branch or shoot; while the lateral long branches arise each year from buds which are crowded close together around the base of the terminal bud. The lateral long branches of each year thus appear to be in a whorl. The distance between each false whorl of branches, then, represents one year's growth in length of the main stem or long branch.

411. The dwarf shoots of the pine.-The dwarf branches are all lateral on the long branches, or shoots. They are scattered over the year's growth, and each bears a cluster of five long, needle-shaped, green leaves, which remain on the tree for several years. At the base of the green leaves are a number of chaff-like scales, the previous bud scales. While the dwarf branches thus bear green leaves, and scales, the long branches bear only thin scale-like leaves which are not green. 
412. Spore-bearing leaves of the pine.-The two kinds of spore-bearing leaves of the pine, and their close relatives, are so different from anything which we have yet studied, and are so unlike the green leaves of the pine, that we would scarcely recognize them as belonging to this ategory. Incleed there is great uncertainty regarding their origin.

413. Male cones, or male flowers. - The male cones are borne in clusters as shown in fig. 25 I. Each compact, nearly cylindri-

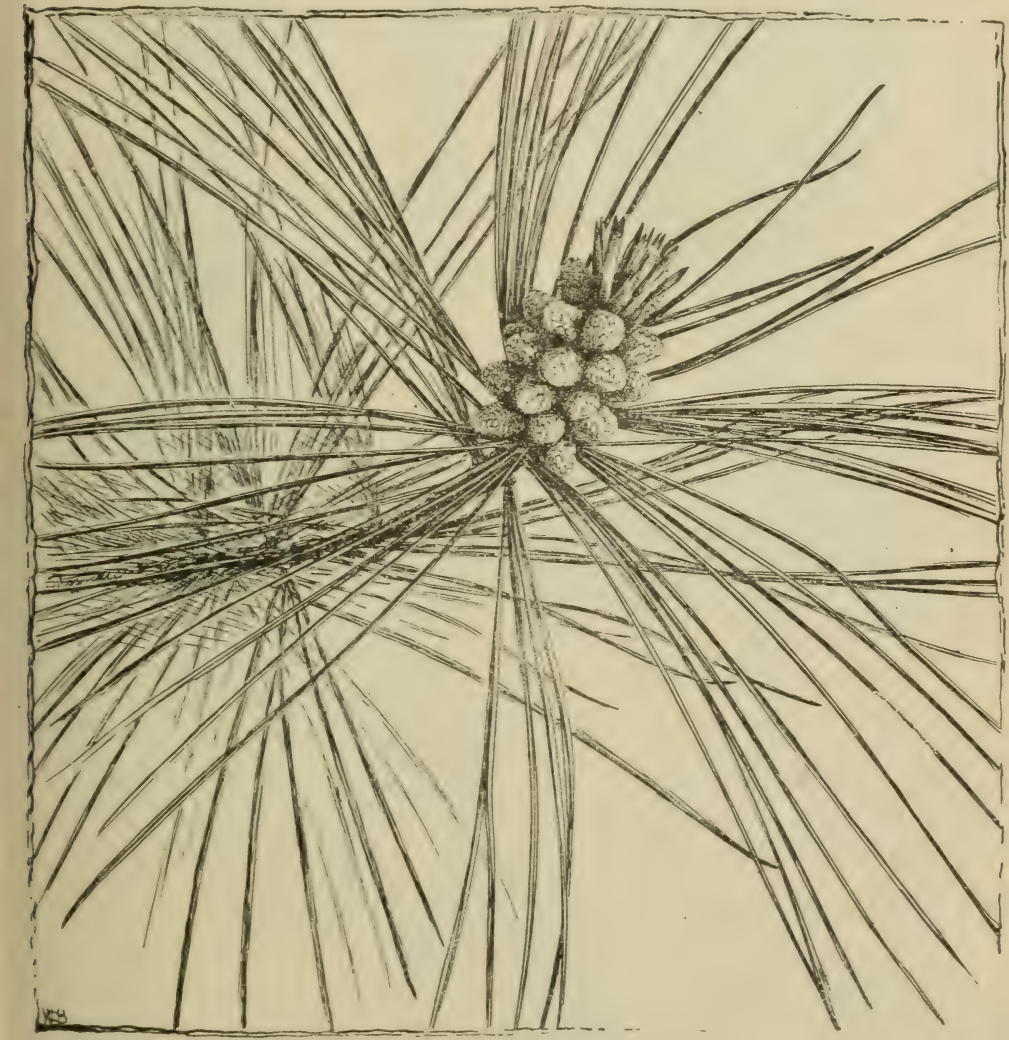

l'ig. 251

Spray of white pine showing cluster of male cones just before the scattering of the pollen

cal, or conical mass is termed a cone, or flower, and each arises in place of a long lateral branch. One of these cones is shown 
considerably enlarged in fig. 252. The central axis of each cone is a lateral branch, and belongs to the stem series. The stem axis of the cone can be seen in fig. 253. It is completely covered by stout, thick, scale-like outgrowths. These scales are obovate in outline, and at the inner angle of the upper end

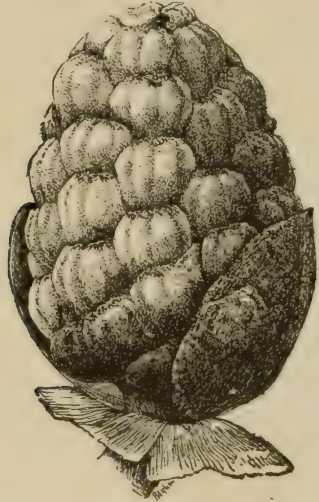

Fig. 252

Staminate cone of white pine, with bud scales removed on one side.

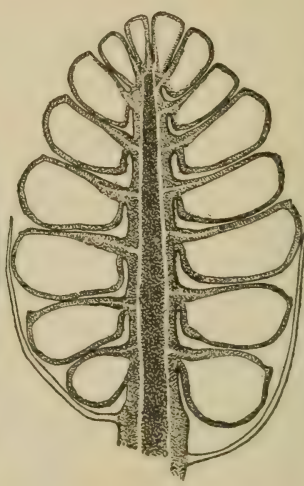

Fig. 253

Section of staminate cone, showing sporangia.

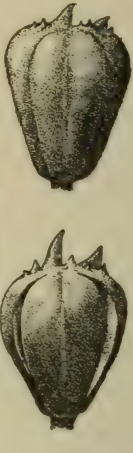

Fig. 254 .

Tw o sporophylls removed, showing opening of sporangia.

there are several rough, short spines. They are attached by their inner lower angle, which forms a short stalk or petiole, and continues through the inner face of the scale as a "midrib." What corresponds to the lamina of the scale-like leaf bulges out on each side below and makes the bulk of the scale. These prominences on the under side are the sporangia (microsporangia). There are thus two sporangia on a sporophyll (microsporophyll). When the spores (microspores), which here are ustially called pollen grains, are mature each sporangium,

or anther locule, splits down the middle as shown in fig. 254, and the spores are set free.

414. Microspores of the pine, or pollen grains.-A mature pollen grain of the pine is Fig. 255. Pollen grain of shown in fig. 255 . It is a queer-looking object,
white pine. possessing on two sides an air sac, formed by the upheaval of the outer coat of the spore at these two points. 
When the pollen is mature, the moisture dries out of the scale (or stamen, as it is often called here) while it ripens. When a limb, bearing a cluster of male cones, is jarred by the hand, or by currents of air, the split suddenly opens, and a cloud of pollen bursts out from the numerous anther locules. The pollen is thus borne on the wind and some of
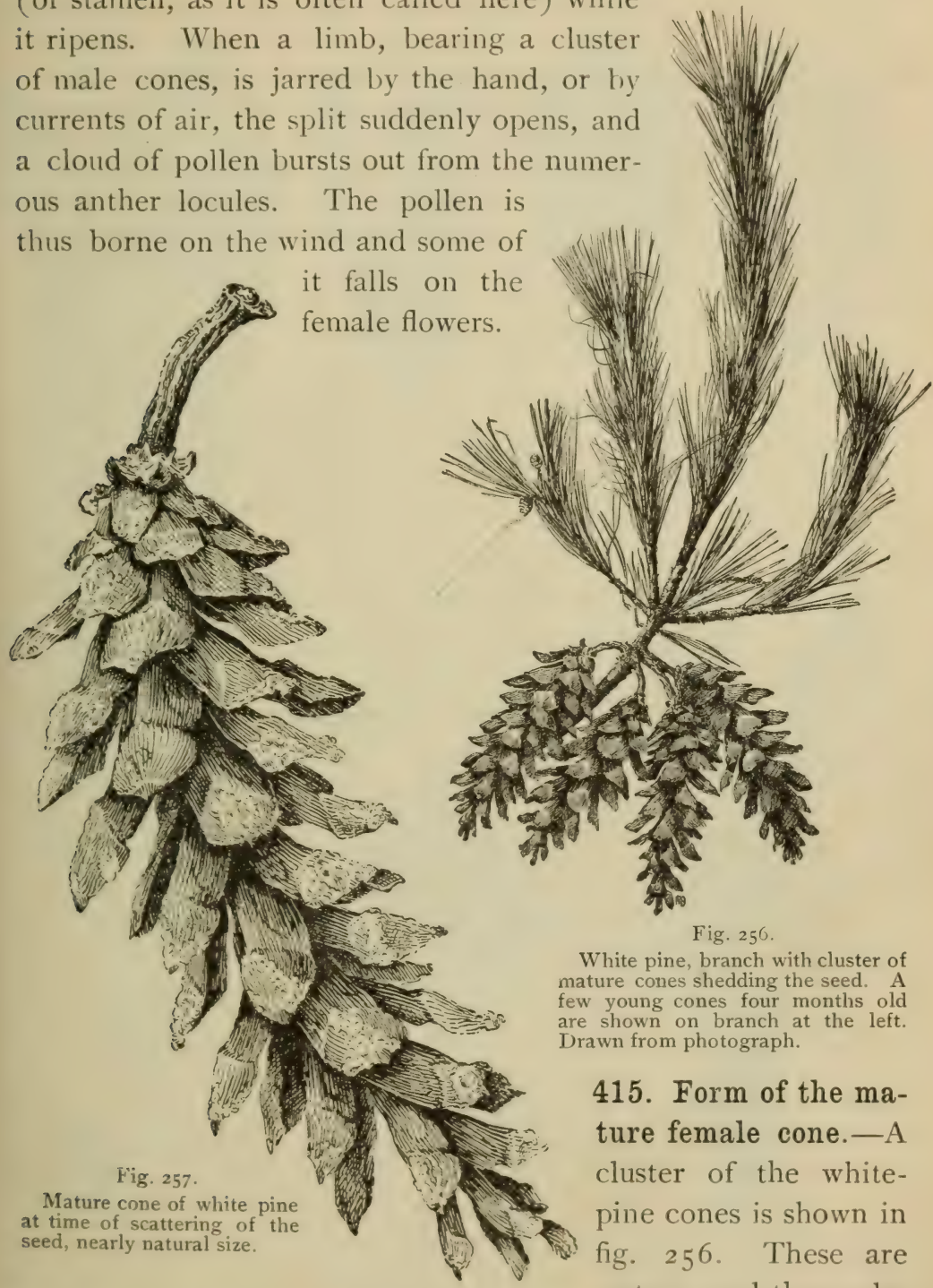

Fig. 256.

White pine, branch with cluster of mature cones shedding the seed. A few young cones four months old are shown on branch at the left. Drawn from photograph.

415. Form of the mature female cone.-A cluster of the whitepine cones is shown in fig. 256. These are mature, and the scales have spread as they do when mature and becoming dry, in order that the seeds may be set at liberty. 'The general out- 
line of the cone is lanceolate, or loing oval, and somewhat curved. It measures about $10-15 \mathrm{~cm}$ long. If we remove one

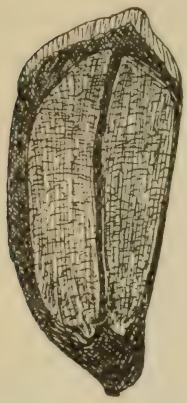

Fig. 258.

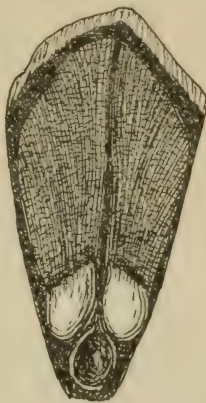

Fig. 259.

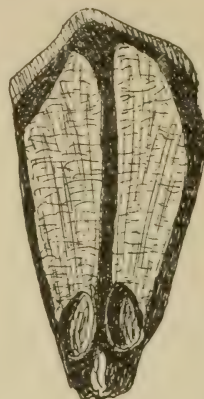

Fig. 260.

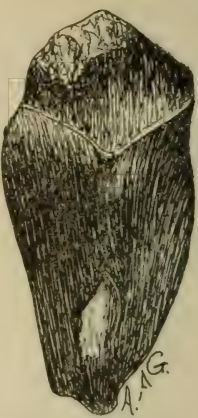

Fig. 26r.

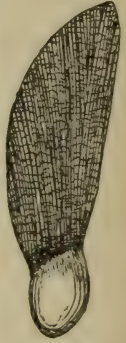

Fig. 262.

Sterile scale Se eds undeveloped.

Scale with we 11 - developed seeds. Seeds have scale.
Back of scale with small cover seed free from scale.
W in g e d scale.

Figs. 258-262.-White pine showing details of mature scales and seed.

of the scales, just as they are beginning to spread, or before the

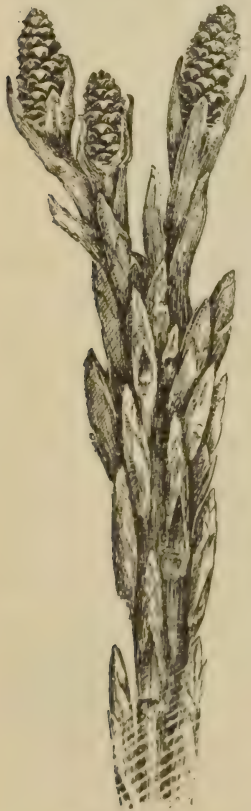

Firg. 26,3

seeds have scattered, we shall find the seeds attached to the upper surface at the lower end. There are two seeds on each scale, one at each lower angle. They are ovate in outline, and shaped somewhat like a biconvex lens. At this time the seeds easily fall away, and may be freed by jarring the cone. As the seed is detached from the scale a strip of tissue from the latter is peeled off. This forms a "wing " for the seed. It is attached to one end and is shaped something like a knife blade. On the back of the scale is a small appendage known as the cover scale.

416. Formation of the female pine cone.-The female flowers begin their development rather late in the spring of the year. They are formed from terminal buds of the higher branches of the tree. In this way the cone may terminate the main shoot of a branch, or of the lateral shoots in a whorl. After growth has proceeded

Female cones of the for some time in the spring, the terminal portion begins pine at time of pollination, about natural size. to assume the appearance of a young female cone or 
flower. These young female cones, at about the time that the pollen is escaping from the anthers, are long ovate, measuring about 6-IOmm long. They stand upright as shown in fig. $26_{3}$.

417. Form of a "scale" of the female flower. - If we remove one of the scales from the cone at this stage we can better study

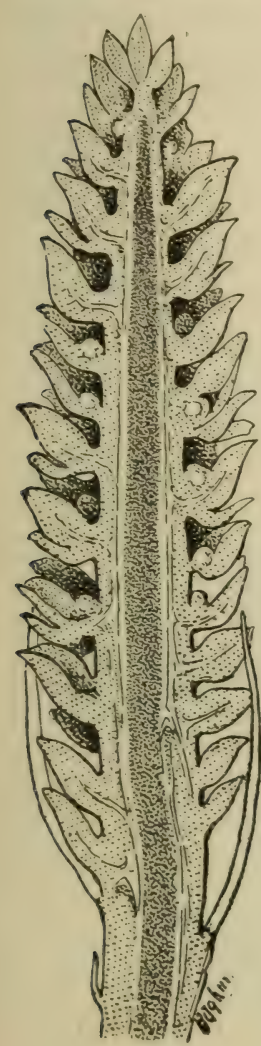

liig. 264 .

Section of female cone of white pine, showing young ovules (macrosporangia) at base of the ovuliferous scales.

it in detail. It is flattened, and oval in outline, with a stout "rib," if it may be so called, running through the middle line and terminating in a point. The scale is in two parts as shown in fig. 266 , which is a view of the under side. The small " outgrowth " which appears as an appendage is the cover scale, for while it is smaller in the pine than the other portion, in some of the relatives of the pine it is larger than its mate, and being on the outside, covers it. (The inner scale is sometimes called the ovuliferous scale, because it bears the ovules. )

418. Ovules, or macrosporangia, of the pine.-At each of the lower angles of the

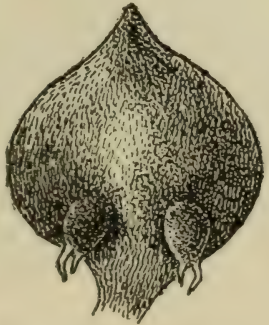

Fig. 265.

Scale of white pine with the two ovules at base of ovuliferous scale.

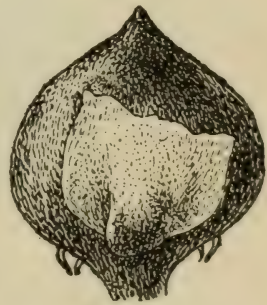

Fig. 266.

Scale of white pine seen from the outside, showing the cover scale.

scale is a curious oval body with two curved, forceps-like processes at the lower and smaller end. These are the macrosporangia, or, as they are called in the higher plants, the ovules. These orules, as we see, are in the positions of the seeds on the 
mature cones. In fact the wall of the ovule forms the outer coat of the seed, as we will later see.

419. Pollination. - At the time wher the pollen is mature the female cones are still erect on the branches, and the scales, which during the earlier stages of growth were closely pressed against

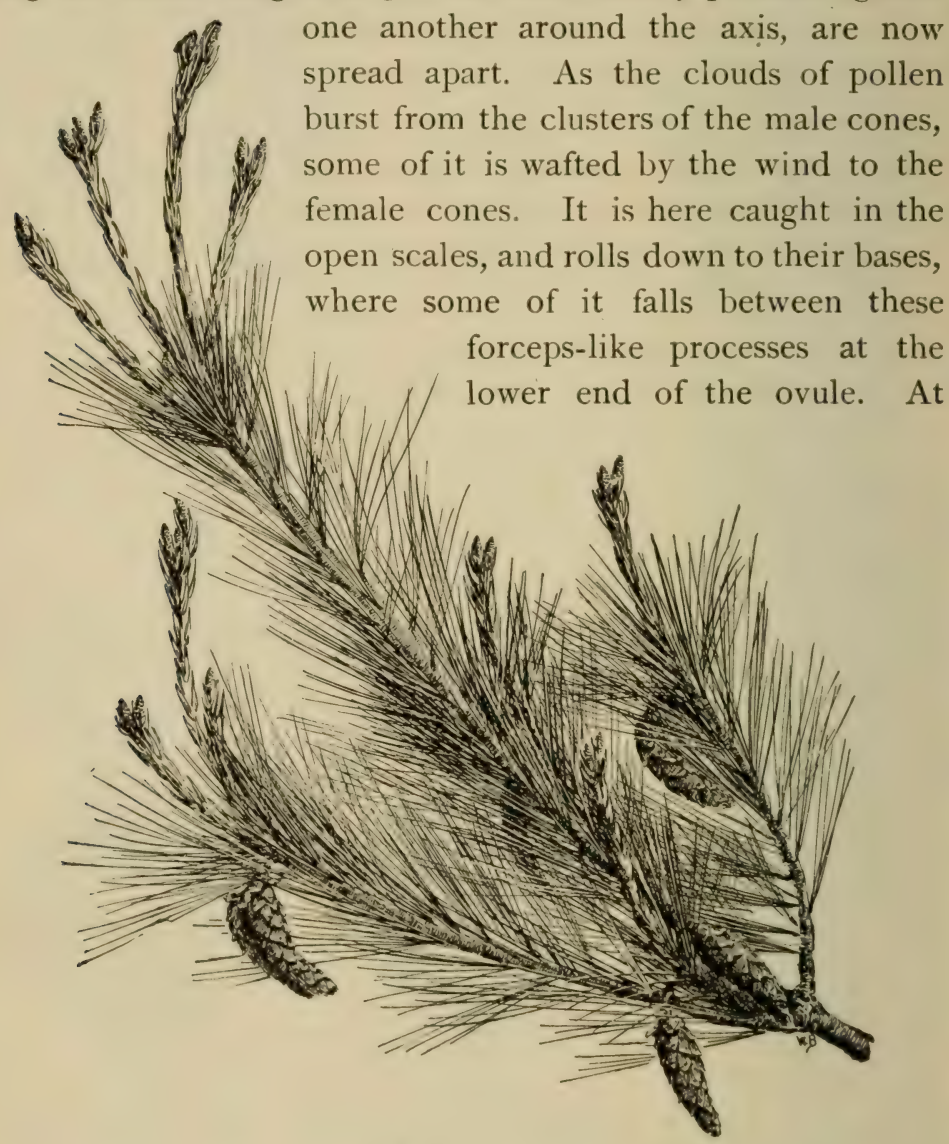

Fig. 267

Pranch of white pine showing young female cones at time of pollination on the ends of the branches, and one-year-old cones below, near the time of fertilization.

this time the ovule has exuded a drop of a sticky fluid in this depression between the curved processes at its lower end. The pollen sticks to this, and later, as this viscid substance dries up, it pulls the pollen close up in the depression against the lower 
end of the ovule. This depression is thus known as the pollen chamber.

420. Now the open scales on the young female cone close up again, so tightly that water from rains is excluded. What is also very curious, the cones, which up to this time have been standing erect, so that the open scale could catch the pollen, now turn so that they hang downward. This more certainly excludes the rains, since the overlapping of the scales forms a shingled surface. Quantities of resin are also formed in the scales, which exudes and makes the cone practically impervious to water.

421. The female cone now slowly grows during the summer and autumn, increasing but little in size during this time. During the winter it rests, that is, ceases to grow. With the coming of spring, growth commences again and at an accelerated rate. The increase in size is more rapid. The cone reaches maturity in September. We thus see that nearly eighteen months elapse from

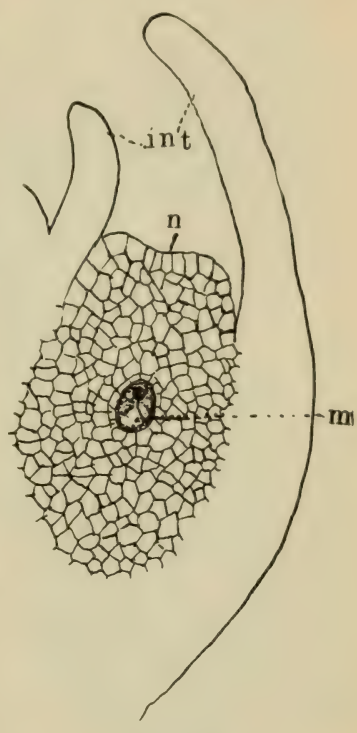

Fig. 268.

Macrosporangium of $\mathrm{p}$ in e (ovule). int, integument ; $n$, nucellus; $m$, macrospore. (After Hoffmeister.) the beginning of the female flower to the maturity of the cone, and about fifteen months from the time that pollination takes place.

422. Female prothallium of the pine.-To study this we must make careful longitudinal sections through the ovule (better made with the aid of a microtome). Such a section is shown in fig. 269. The outer layer of tissue, which at the upper end (point where the scale is attached to the axis of the cone) stands free, is the ovular coat, or integument. Within this integument, near the upper end, there is a cone-shaped mass of tissue, which farther down continues along next the integument in a thinner strip. This mass of tissue is the nucellus, or the macrosporangium proper. The elliptical mass of tissue within this, shown in fig. $27 \mathrm{I}$ is the female prothallium. or what is usually here called the endosperm. The conical portion of the nucellus fits over the 
prothallium, and is called the nucellar cap. Only one end of the endosperm (prothallium) is shown in fig. $27 \mathbf{1}$.

423. Archegonia. - In the upper end of the endosperm (prothallium) are several archegonia, and they aid us in determining what portion is the female

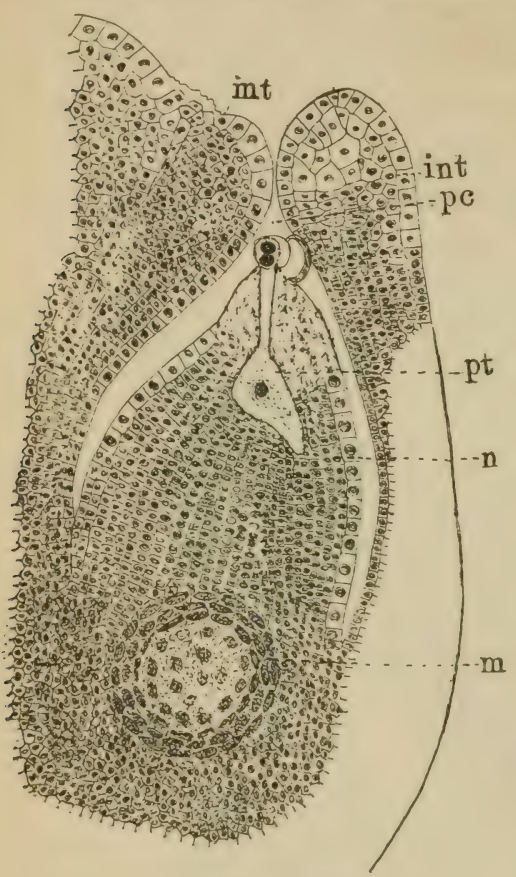

Fig. 269. prothallium. The nucellus is of course formed before the prothallium. The latter arises from a cell (macrospore) near the center of the nucellus. This cell is larger, and has a larger nucleus than its fellows (see fig. 268). The prothallium here is formed much in the same way as in selaginella, where we recollect it begins to develop before the macrospore has

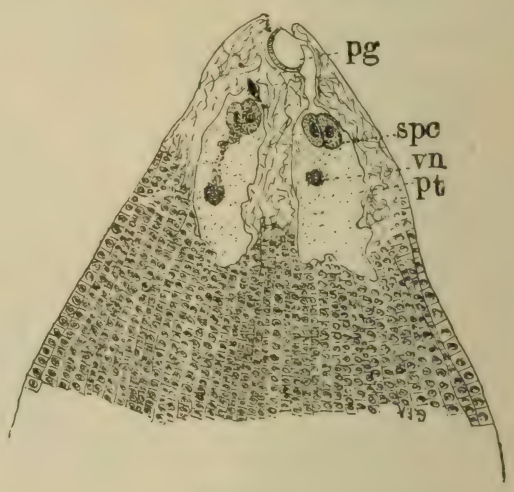

Fig. 270.

Upper portion of nucellus of white pine. $t_{s}$, pellen-grain remains; $s p c$, sperm cells; $v n$, vegetative nucleus; $p t$, pollen tube. ument ; $p$. pollen chamber; $t$, , pollen tube $n$, nucellus; $m$, macrospore cavity.

reached its full size, and where the archegonia begin to form before it leaves the macrosporangium.

424. Male prethallia.-By the time the pollen is mature the male prothatlum is alreatly partly formed. In fig. 255 we can see two well-formed cells. ()ther cells are satid to $\mid x$ fermed carlicr, but they become so flattened that it is difficult to make them out when the pollen grain is mature. At this stage of development the pesllen grain is loxlged at the mouth of the ovule. and is drawn up into the pollen chamber.

425. Farther growth of the male prothallium.--During the summer and autumn the male prothatlium makes some farther growth, but this is slow. The larger cell, called the vegetative cell, elongates by the formation of a tule, forming a sac. known as the pollen tube. It is cither simple or branched. Inside of this sate the cells of the prothillium are protected, and farther 
division of the cells takes place here, just as the female prothallium develops in the cavity of the nucellus, from the macrospore. The nucleus of the vegetative cell passes down the cavity of this tubular sac. The antherid cell, which is the smaller cell of the pollen grain, in the pine, divides by a cross wall into a so-called stalk cell, and a mother sperm cell, the latter corresponding to the central cell of the an-

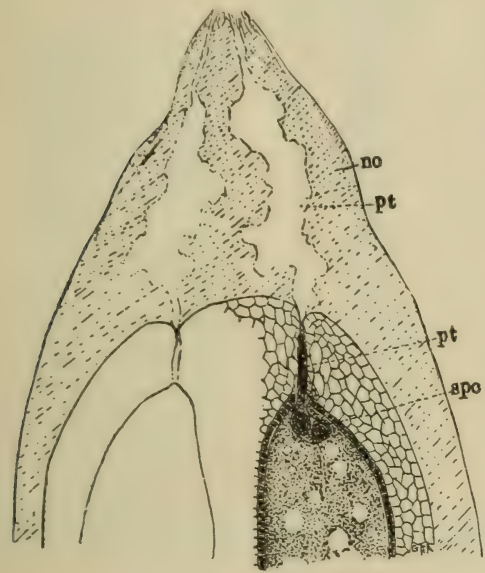

Fig. 271.

Section through upper part of nucellus and endosperm of white pine, showing upper portion of archegonium, the entering sperm cells, and track of pollen tube; $n c$, nucellus: $p t$, pollen tube; spc, sperm cells.

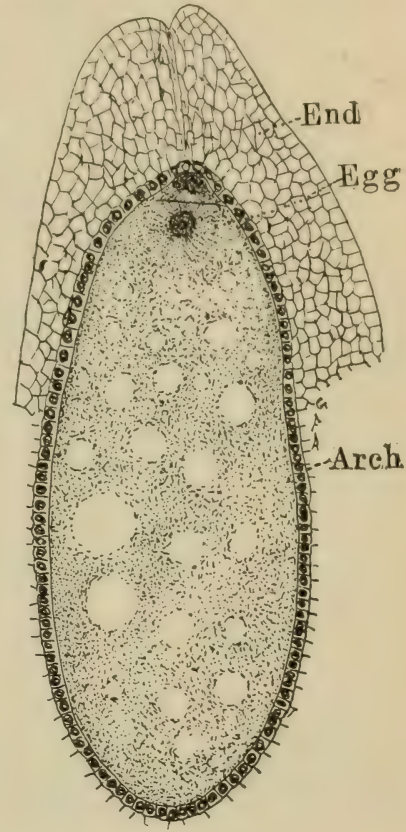

Fig. 272 .

Last division of the egg in the white pine cutting off the ventral canal cell at the apex of the archegonium. End, endosperm; Arch, archegonium.

theridium, there being no wall formed. The sperm mother cell also passes down the tubular sac, and divides again into two sperm cells, as shown in fig. 270. Abuut this time, or rather a little earlier, with the pollen tube part way through the nucellar cap, winter overtakes it, and all growth ceases until the following spring.

426. Fertilization. - In the spring the advance of the pollen tube continues, and it finally passes through the nucellar cap about the time that the archegonia are formed and the egg cell is mature, as shown in fig. 27 I. The pollen tube now opens and the sperm cells escape into the archegonium, and later one of them fuses with the egg nuclcus. The fertilized egg is now ready to develop into the embryo pine.

427. Homo'ogy of the parts of the female cone.-Opinions are divided as to the homology of the parts of the female cone of the pine. Some consider the entire cone to be homologous with a flower of the angiosperms. The en- 
tire scale according to this view is a carpel, or sporophyll, which is divided into the cover scale and the ovuliferous scale. This division of the sporophyll is considered similar to that which we have in isoetes, where the sporophyll

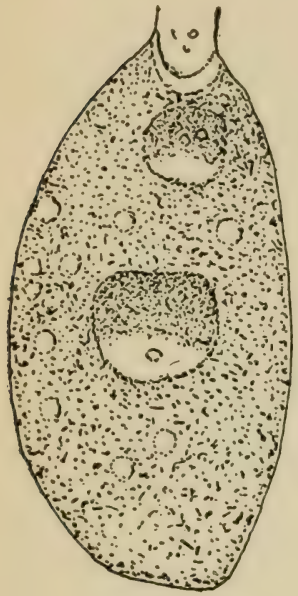

Fig. 273.

Archegonium of Picea vulgaris, sperm cell approaching the nucleus of egg cell.

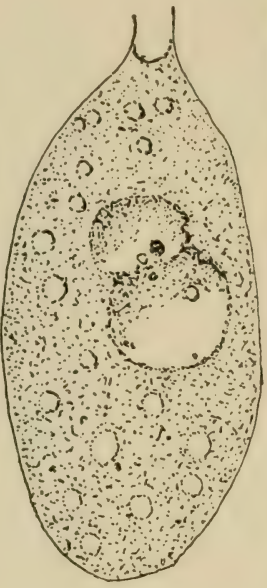

Fig. 274

Archegonium of Picea vulgaris showing fusion of sperm nucleus with egg nucleus.

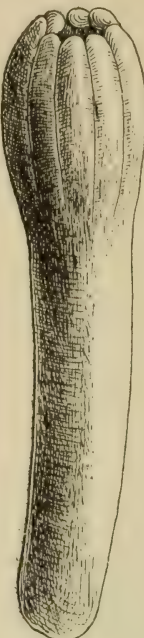

Fig. 275.

Embryo of white pine removed from seed, showing several cotyledons.

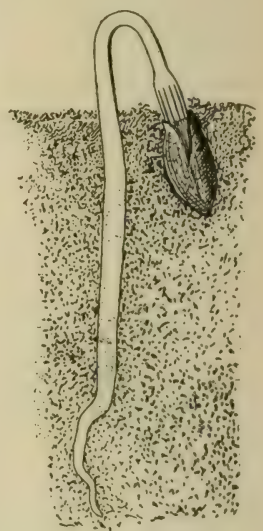

Fig. 276.

$\mathrm{P}$ in e seedling just emerging from the ground.

Figs. 273, 274.-Fertilization in picea. (After Strasburger.)

has a ligule above the sporangium, or as in ophioglossum, where the leaf is divided into a fertile and a sterile portion.

A more recent view regards each cone scale as a flower, the ovuliferous scale composed of three united carpels arising in the axil of a leaf, the cover scale. Two of the carpels are reduced to ovules, and the outer integument is expanded into the lateral portion of the scale. while the central carpel is sterile and ends in the point or mucro of the scale. 
GYMNOSPERMS: WHITE PINE.

2 I 3
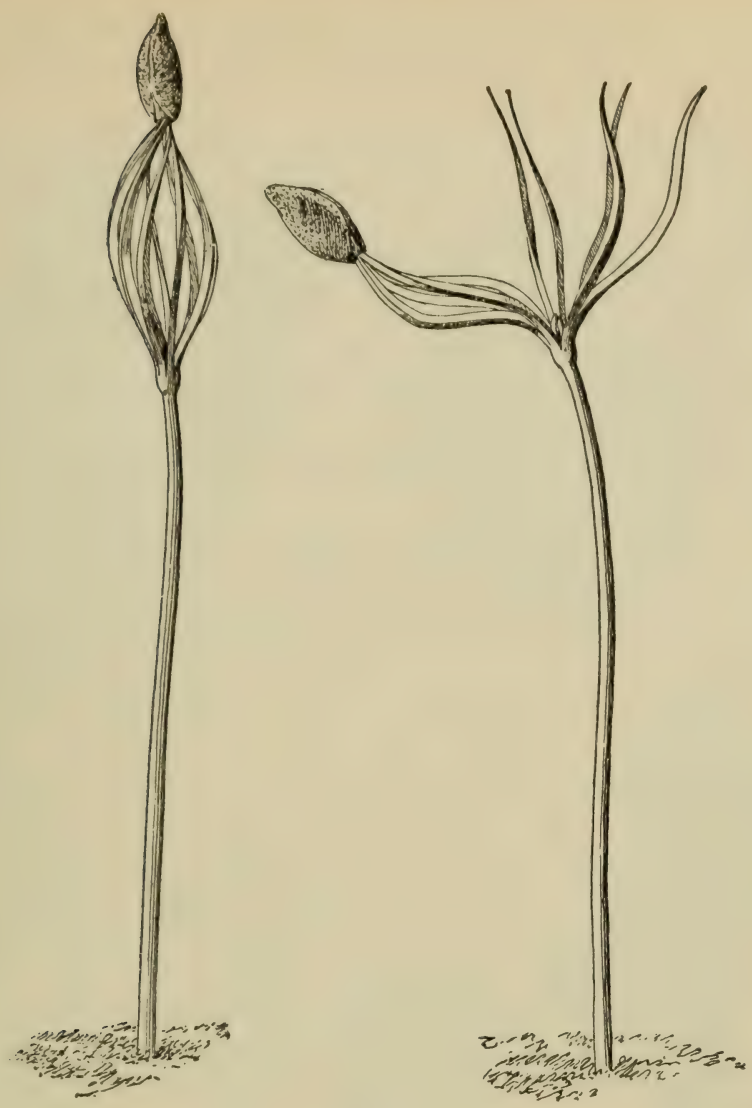

Fig. 277 . White-pine seedling casting seed coats. 


\section{CHAPTER XXXII.}

\section{FURTHER STUDIES ON GYMNOSPERMS.}

\section{Cycas.}

428. In such gymnosperms as cycas, illustrated in the frontispiece, there is a close resemblance to the members of the fern

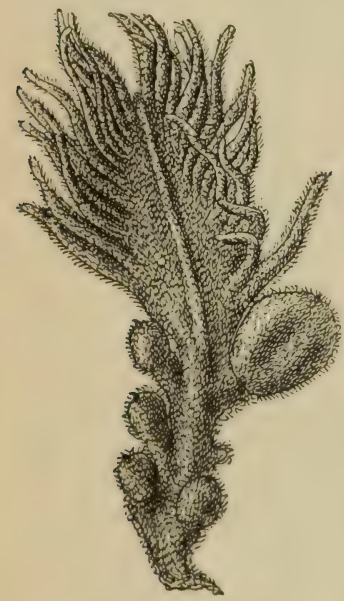

Fig. 278 .

Macrosporophyll of Cycas revoluta. group, especially the ferns themselves. This is at once suggested by the form of the leaves. The stem is short and thick. The leaves have a stout midrib and numerous narrow pinnæ. In the center of this rosette of leaves are numerous smaller leaves, closely overlapping like bud scales. If we remove one of these at the time the fruit is forming we see that in general it conforms to the plan of the large leaves. There are a midrib and a number of narrow pinnæ near the free end, the entire leaf being covered with woolly hairs. But at the lower end, in place of the pinnæ, we see oval bodies. These are the macrosporangia (ovules) of cycas, and correspond to the macrosporangia of selaginella, and the leaf is the macrosporophyll.

429. Female prothallium of cycas. - In figs. 279,280 are shown mature ovules, or macrosporangia, of cycas. In 280 , which is a roentgen-ray photograph of 279 , the oval prothallium can be seen. So in cycas, as in selaginella, the female prothallium is 
developed entirely inside of the macrosporangium, and derives the nutriment for its growth from the cycas plant, which is the

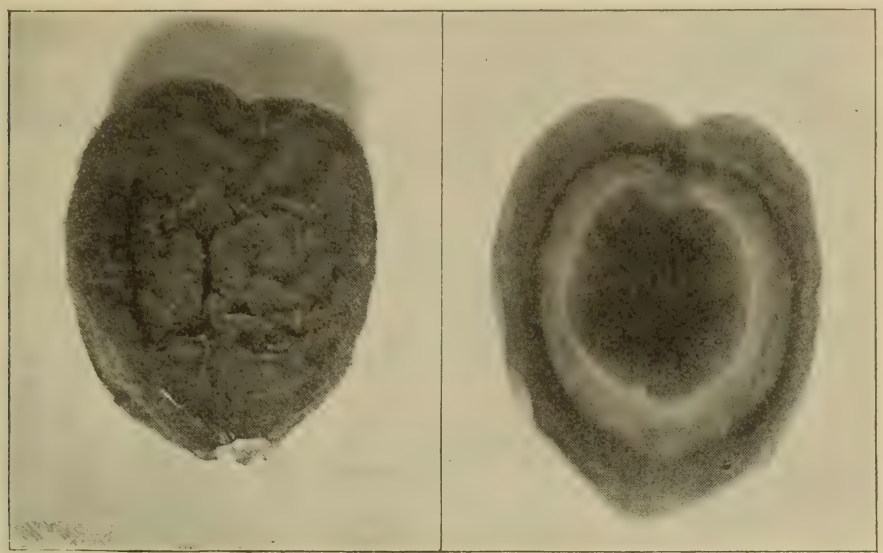

Fig. 279 .

Fig. 280.

Macrosporangium of Cycas revoluta

Roentgen photograph of same, showing female prothallium.

sporophyte. Archegonia are developed in this internal mass of cells. This aids us in determining that it is the prothallium. In cycas it is also called endosperm, just as in the pines.

430. If we cut open one of the mature ovules, we can see the endosperm (prothallium) as a whitish mass of tissue. Immediately surrounding it at maturity is a thin, papery tissue, the remains of the nucellus (macrosporangium), and outside of this are the coats of the ovule, an outer fleshy one and an inner stony one.

431. Microspores, or pollen, of cycas. - The cycas plant illustrated in the frontispiece is a female plant.
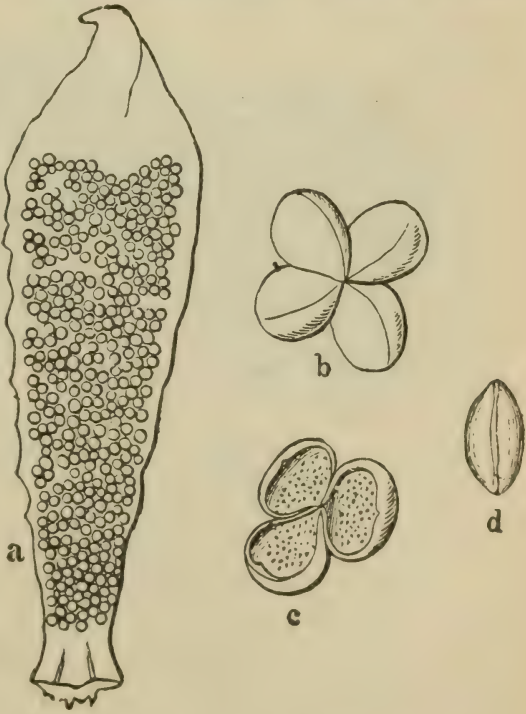

I.ig. 281 .

Male plants also exist which have $A$ sporophyll istamen) of cycas: sporangia in small leaves in the center that bear $\begin{gathered}\text { groups on the under side. ben sporangia. (From Warming.) } \\ \text {, groungia; }\end{gathered}$ 
only microsporangia. These leaves, while they resemble the ordinary leaves, are smaller and correspond to the stamens. Upon the under side, as shown in fig. 28I, the microsporangia are borne in groups of three or four, and these contain the microspores, or pollen grains. The arrangement of these microsporangia on the under side of the cycas leaves bears a strong resemblance to the arrangement of the sporangia on the under side of the leaves of some ferns.

432. The gingko tree is another very interesting plant belonging to this same group. It is a relic of a genus which

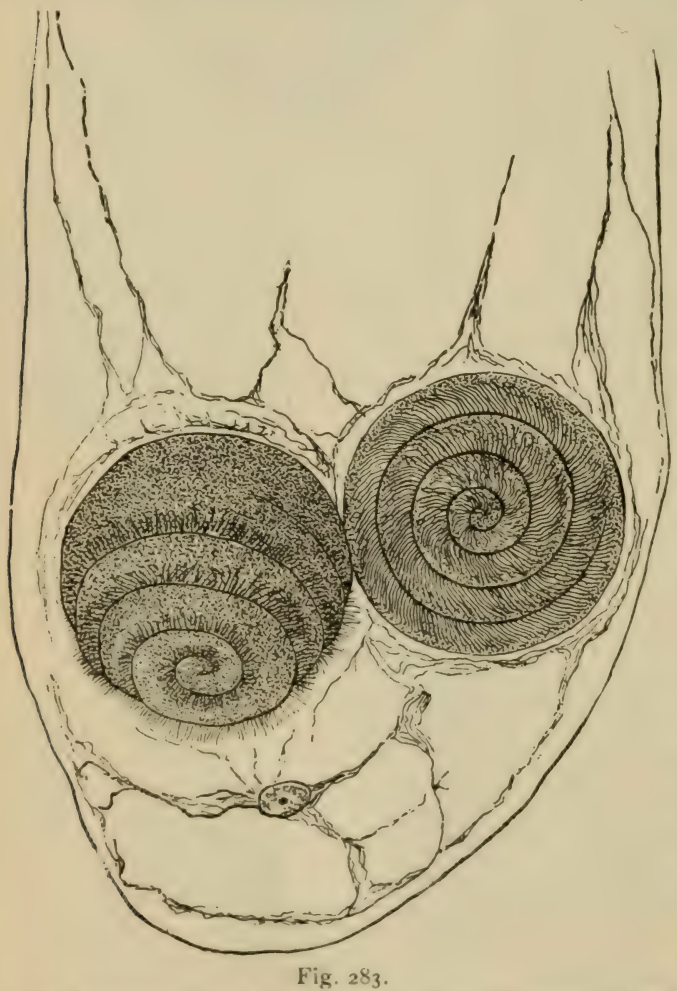

Two spermatozoids in end of pollen tube of cycas. (After drawing by Hirase and Ikeno.)

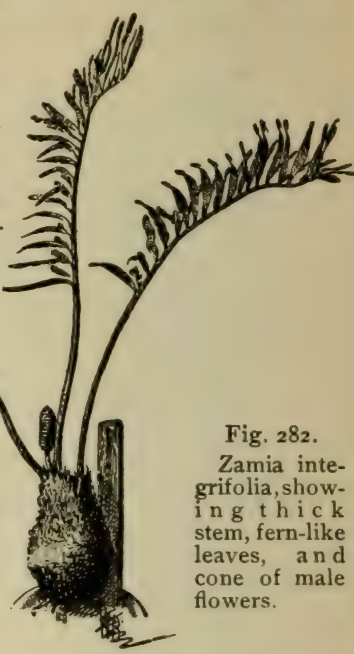

flourished in the remote past, and it is interesting also because of the resemblance of the leaves to some of the ferns like adiantum, which suggests that this form of the leaf in gingko has been inherited from some fern-like ancestor.

433. While the resemblance of the leaves of someof the gymnosperms to those of the ferns suggests fern-like ancestors for the members of this group, there is stronger evidence of such ancestry in the fact that a prothallium can well be determined in the ovules. The endosperm with its well-formed archegonia is to be considered a prothallium.

434. Spermatozoids in some gymnosperms. - But within the past two years it has beendiscovered in gingko, cycas, and zamia, all belonging to this 
group, that the sperm cells are well-formed spermatozoids. In zamia each one is shaped somewhat like the half of a hiconvex lens, and around the convex surface are several coils of cilia. After the pollen tube has grown down through the nucellus, and has reached a depression at the end of the prothallium (endosperm) where the archegonia are formed, the spermatozoids are set free from the pollen tube, swim around in a liquid in this depression, and later fuse with the egg. In gingko and cycas these spermatozoids were first discovered by Ikeno and Hirase in Japan, and later in zamia by Webber in this country. In figs. $283-286$ the details of the male prothallia and of fertilization are shown.

435. The sporophyte in the gymnosperms.In the pollen grains of the gymnosperms we easily recognize the characters belonging to the spores in the ferns and their allies, as well as in the liverworts and mosses. They belong to the same series of organs, are borne on the same phase or generation of the plant. and re practi- The egg protoplasm fills the cally formed in the same general way, the by Hirase and Ikeno.)

variations between the different groups not being greater than those within a single group. These spores we have recognized as being the product of the sporophyte. We are able then to identify the sporophyte as that phase or

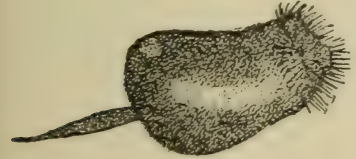

Fig. 285 . generation of the plant formed from the fertilized egg and bearing ultimately the spores. We see from this that the sporophyte in the gymnosperms is the prominent part of the plant, just as we found it to be in the ferns. The pine tree, then, as well as the gingko, cycas, yew, hemlockSpermatozoid of gingko, show- spruce, black spruce, the giant redwood of Caliing cilia at one end and tail at the other (After drawings by fornia, etc., are sporophytes.

Hirase and Ikeno.)

While the sporangia (anther sacs) of the male flowers open and permit the spores (pollen) to be scattered, the sporangia of the female flowers of the gymnosperms rarely open. The macrospore is developed within sporangium (nucellus) to form the female prothallium (endosperm).

436. The gametophyte has become denendent on the sporophyte. - In this respect the gymnosperms differ widely from the pteridophytes, though we see suggestions of this condition of things in isoetes and selaginella, where the female prothallium is developed within the macrospore, and even in selaginella begins, and nearly completes, its development while still in the sporangium. 
In comparing the female prothallium of the gymnosperms with that of the fern group we see a remarkable change has taken place. The female pro-

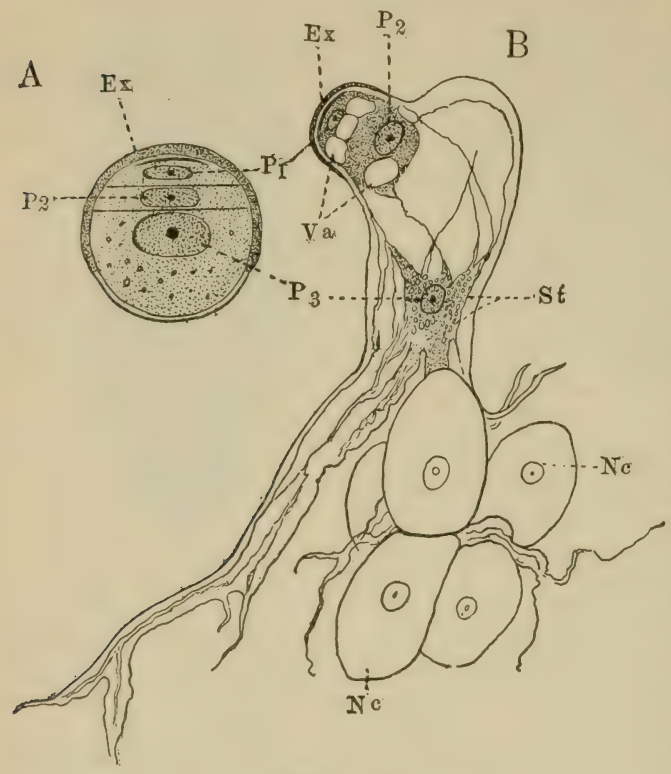

Fig. 286 .

Gingko biloba. $A$, mature pollen grain; $B$, germinating pollen grain, the branched tube entering among the cells of the nucellus; $E_{x}$, exine (outer wall of spore); $P_{1}$, prothallial cell; $P_{2}$, antheridial cell (divides later to form stalk cell and generative cell); $P_{3}$, vegetative cell ; $V a$, vacuoles; $N_{c}$, nucellus. (After drawings by Hirase and Ikeno.) thallium of the gymnosperms is very much reduced in size. Especially, it no longer leads an independent existence from the sporophyte, as is the case with nearly all the fern group. It remains enclosed within the macrosporangium (in cycas if not fertilized it sometimes grows outside of the macrosporangium and becomes green), and derives its nourishment through it from the sporophyte, to which the latter remains organically connected. This condition of the female prothallium of the gymnosperms necessitated a special adaptation of the male prothallium in order that the sperm cells may reach and fertilize the egg cell.

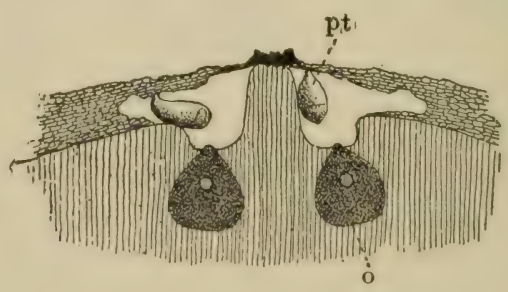

Fig. 287 .

Gingko biloba, diagrammatic representation of the relation of pollen tube to the archegonium in the end of the nucellus. $p t$, pollen tube; $o$, archegonium. (After drawing by Hirase and Ikeno.)

437. Gymnosperms are naked seed plants. - The pine, as we have seen, has naked seeds. That is, the seeds are not enclosed within the carpel, but 
are exposed on the outer surface. All the plants of the great group to which the pine belongs have naked seeds. For this reason the name "gymnosperms" has been given to this great group.

438. Classification of gymnosperms. - The gingko tree has until recently been placed with the pines, yew, etc., in the class conifera, but the discovery of the spermatozoids in the pollen tube suggests that it is not closely allied with the coniferæ, and that it represents a class

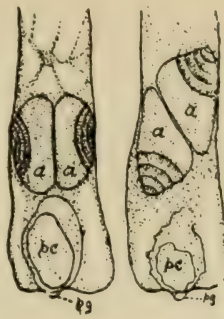

Fig. 288.

Spermatozoids of zamia in pollen tube $p g$, pollen grain; $a, a$, spermatozoids. (After Webber.)

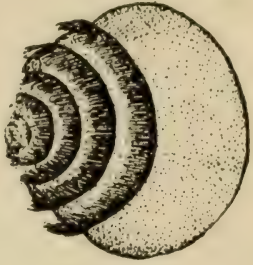

Fig. 289.

Spermatozoid of zamia showing spiral row of cilia. (After Webber.) coordinate with them. Engler arranges the living gymnosperms as follows :

Class I. Cycadales; family Cycadaceæ. Cycas, zamia, etc.

Class 2. Gingkoales; family Gingkoaceæ. Gingko.

Class 3. Coniferæ; family 1. Taxaceæ. Taxus, the common yew in the eastern United States, and Torreya, in the western United States, are examples.

family 2. Pinaceæ. Araucaria (redwood of California), firs, spruces, pines, cedars, cypress, etc.

Class 4. Gnetales. Welwitschia mirabilis, deserts of southwest Africa; Ephedra, deserts of the Mediterranean and of West Asia. Gnetum, climbers (Lianas), from tropical Asia and America. 
空

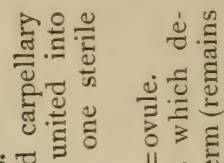

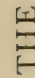

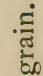

z

过

践

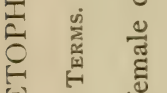

竎

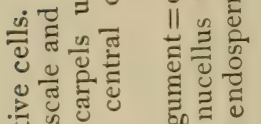

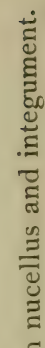

¿ूँ

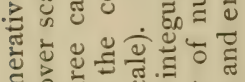

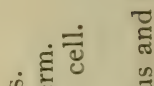

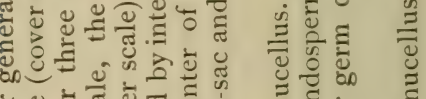
б。

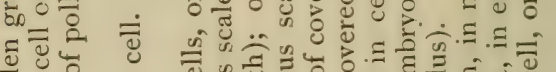
$\therefore \overbrace{\vec{E}}$ 选

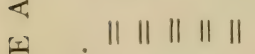

\section{|| || |}

II \|

|| || || || || || || || ||

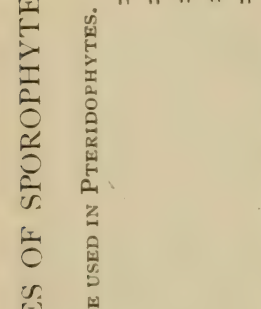

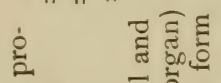

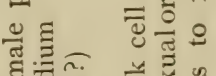

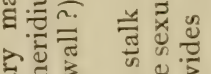

B⿺辶一兀)

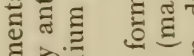

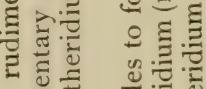

先

은 $\quad$ \&

Ђ

( )

Ð के

y

玄

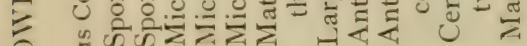

हีँ

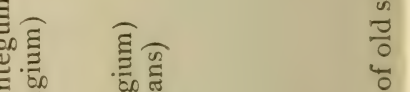

竞

些

弯
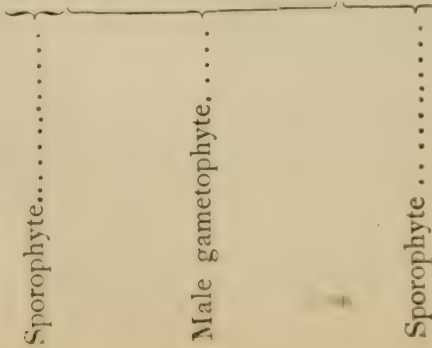

हैं 


\section{CHAPTER XXXIII.}

MORPHOLOGY OF THE ANGIOSPERMS: TRILLIUM ; DENTARIA.

\section{Trillium.}

440. General appearance.-As one of the plants to illustrate this group we may take the wake-robin, as it is sometimes called, or trillium. There are several species of this genus in the United States; the commonest one in the eastern part is the "white wake-robin" (Trillium grandiflorum). This occurs in or near the woods. A picture of the plant is shown in fig. 290. There is a thick, fleshy, underground stem, or rhizome as it is usually called. This rhizome is perennial, and is marked by ridges and scars. The roots are quite stout and possess coarse wrinkles. From the growing end of the rhizome each year the leafy, flowering stem arises. This is $20-30 \mathrm{~cm}$ ( $8-\mathrm{I} 2$ inches) in height. Near the upper end is a whorl of three ovate leaves, and from the center of this rosette rises the flower stalk, bearing the flower at its summit.

441. Parts of the flower. Calyx.-Now if we examine the flower we will see that there are several leaf-like structures. These are arranged also in threes just as are the leaves. First there is a whorl of three, pointed, lanceolate, green, leaf-like members, which make up the calyx in the higher plants, and the parts of the calyx are sepals, that is, each leaf-like member is a sepal. But while the sepals are part of the flower, so called, we easily recognize them as belonging to the leaf series. 
442. Corolla.-Next above the calyx is a whorl of white or

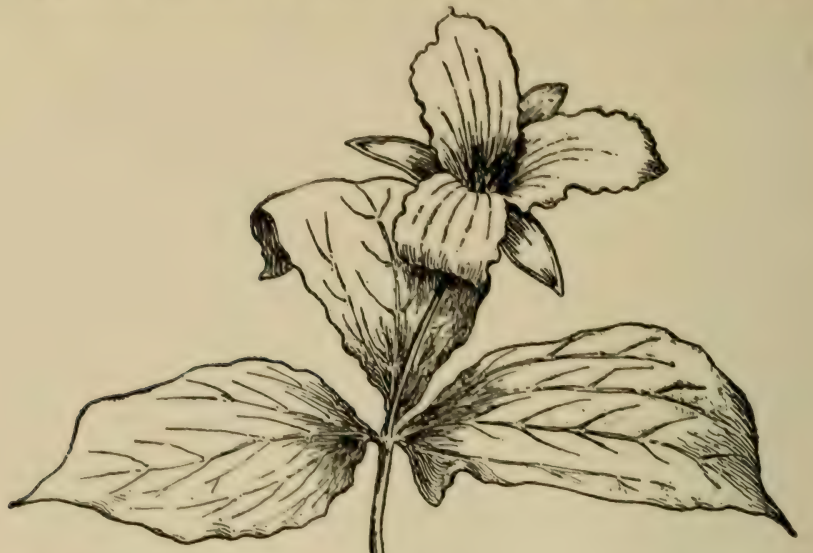

pinkish members, in are also leaf-like in form, being usually somewhat make up what is the and each member of the they are parts of the their form and posialso belong to the leaf

443. Andrœcium. tion of the corolla is of members which do not form. They are known As seen in fig. 29I each ament), and extending greater part of the length side. This part of the ridges form the anther Soon after the flower is ther sacs open also by a along the edge of the time we see quantities of or dust escaping from the

Trillium grandiflorum, which and broader than the sepals, broader at the free end. These corolla in the higher plants, corolla is a petal. But while flower, and are not green, tion would suggest that they series.

Within and above the inserfound another tier, or whorl, at first sight resemble leaves in in the higher plants as stamens. stamen possesses a stalk ( = filalong on either side for the are four ridges, two on each stamen is the anther, and the

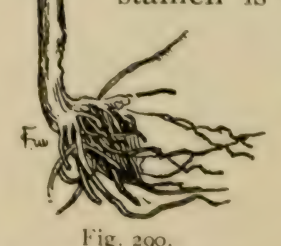

Fig. 290. sacs, or lobes. opened, these ansplit in the wall ridge. At this yellowish powder ruptured anther locules. If we place some of this under the microscope we see 
that it is made up of minute bodies which resemble spores; they are rounded in form, and the outer wall is spiny. 'They are in fact

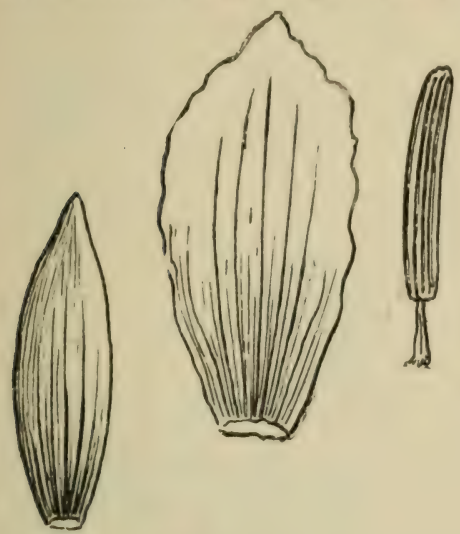

Fig. 29r.

Sepal, petal, stamen, and pistil of Trillium grandiflorum.

\section{The stamen a sporo-} phyll.-Since these pollen grains are the spores, we would infer, from what we have learned of the ferns and gymnosperms, that this member of the flower which bears them is a sporophyll; and this is the case. It is in fact what is called the microsporophyll. Then we see also that the anther sacs, since they enclose the spores, would be the sporangia (microsporangia). From this it is now quite clear that the stamens belong also to the leaf series. They are just six in number, twice the number found in a whorl of leaves, or sepals, or corolla. It is believed, therefore, spores, the microspores of the trillium, and here, as in the gymnosperms, are better known as pollen.

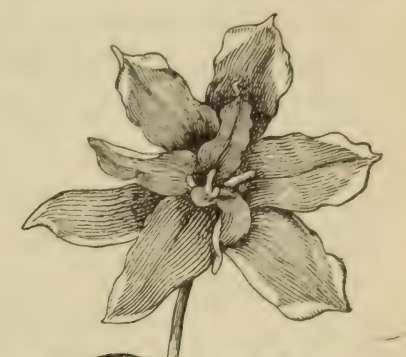
that there are two whorls of stamens in the flower of trillium.

445. Gynœcium. - Next above the stamens and at the center of the flower is a stout, angular, ovate body which terminates in three long, slender, curved points. This is the pistil, and at 
present the only suggestion which it gives of belonging to the leaf series is the fact that the end is divided into three parts, the number of parts in each successive whorl of members of the flower. If we cut across the body of this pistil and examine it with a low power we see that there are three chambers or cavities, and at the junction of each the walls suggest to us that this body may have been formed by the infolding of the margins of three leaf-like members, the places of contact having then become grown together. We see also that from the incurved margins of each division of the pistil there stand out in the cavity oval bodies. These are the ovules. Now the ovules we have learned from our study of the gymnosperms are the sporangia (here the macrosporangia).

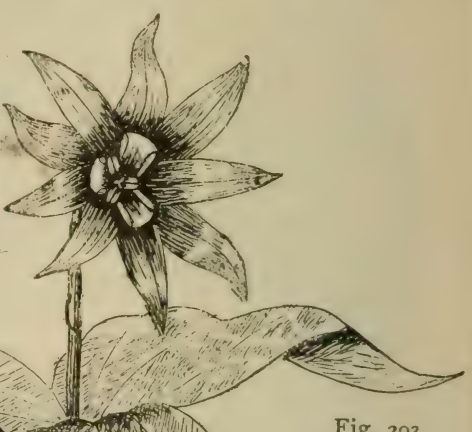

Fig. 293.

Abnormal trillium. The nine parts of the perianth are $\mathrm{green}$, and the outer whorls of stamens a re expanded into petal - li k e members.

It is now more evident that this curious body, the pistil, is made up of three leaf-like members which have fused together, each member being the equivalent of a sporophyll (here the macrosporophyll). This must be a fascinating observation, that

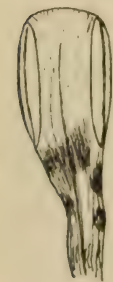

lige 204.

Transformed stamen of trillium showing anther Incules on the margin. plants of such widely different groups and of such different grades of complexity should have members formed on the same plan and belonging to the same series of members, devoted to similar functions, and yet carried out with such great modifications that at first we do not see this common meeting ground which a comparative study brings out so clearly.

446. Transformations of the flower of trillium. If anything more were needed to make it clear that the parts of the flower of trillium belong to the leaf series we could obtain evidence from the transformations which 
the flower of trillium sometimes presents. In fig. 293 is a sketch of a flower of trillium, made from a photograph. One set of the stamens has expanded into petal-like organs, with the anther sacs on the margin. In fig. 292 is shown a plant of Trillium grandiflorum in which the pistil has separated into three distinct and expanded leaf-like structures, all green except portions of the margin.

\section{Dentaria.}

447. General appearance.-For another study we may take a plant which belongs to another division of the higher plants, the common "pepper root," or " toothwort" (Dentaria diphylla) as it is sometimes called. This plant occurs in moist woods during the month of May, and is well distributed in the northeastern United States. A plant is shown in fig. 295. It has a creeping underground rhizome, whitish in color, fleshy, and with a few scales. Each spring the annual flower-bearing stem rises from one of the buds of the rhizome, and after the ripening of the seeds, dies down.

The leaves are situated a little above the middle point of the stem. They are opposite and the number is two, each one being divided into three dentate lobes, making what is called a compound leaf.

448. Parts of the flower.-The flowers are several, and they are borne on quite long stalks (pedicels) scattered over the terminal portion of the stem. We should now examine the parts of the flower beginning with the calyx. This we can see, looking at the under side of some of the flowers, possesses four scalelike sepals, which easily fall away after the opening of the flower. They do not resemble leaves so much as the sepals of trillium, but they belong to the leaf series, and there are two pairs in the set of four. The corolla also possesses four petals, which are more expanded than the sepals and are whitish in color. The stamens are six in number, one pair lower than the others, and also 
shorter. The filament is long in proportion to the anther, the

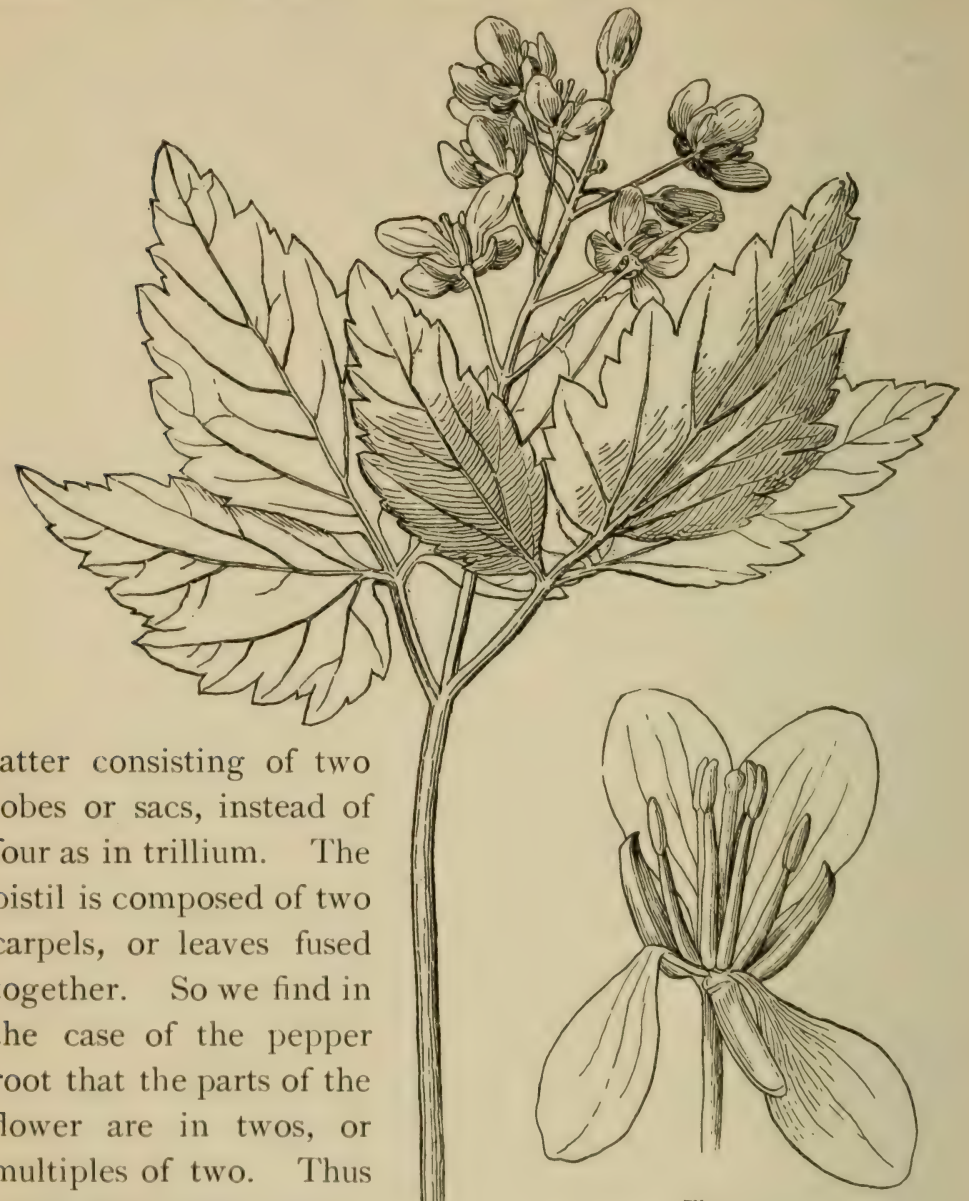

Fig. 296.

Flower of the toothwort (Dentaria with the leaves; and while we do not see such a strong resemblance between the parts of the flower here and the leaves, yet from the presence of the pollen diphylla).

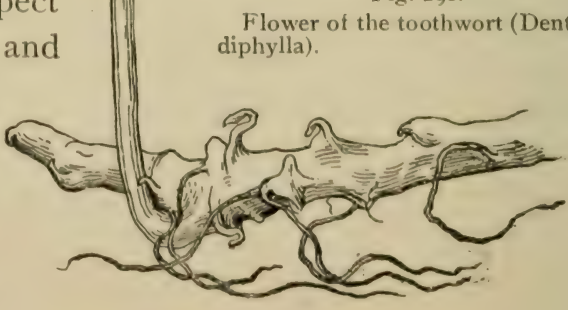

Fig. 295 .

Toothwort (Dentaria diphylla) 
(microspores) in the anther sacs (microsporangia) and of ovules (macrosporangia) on the margins of each half of the pistil, we are, from our previous studies, able to recognize here that all the members of the flower belong to the leaf series.

449. In trillium and in the pepper root we have seen that the parts of the flower in each apparent whorl are either of the same number as the leaves in a whorl, or some multiple of that number. This is true of a large number of other plants, but it is not true of all. A glance at the spring beauty (Claytonia virginiana, fig. 349) and at the anemone (or Isopyrum biternatum, fig. 355) will serve to show that the number of the different members of the flower may vary. The trillium and the dentaria were selected as being good examples to study first, to make it very clear that the members of the flower are fundamentally leaf structures, or rather that they belong to the same series of members as do the leaves of the plant. 


\section{CHAPTER XXXIV.}

\section{GAMETOPHYTE AND SPOROPHYTE OF ANGIO- SPERMS.}

450. Male prothallium of angiosperms. - The first division which takes place in the nucleus of the pollen grain occurs, in

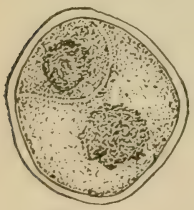

Fig. 297.

Nearly mature pollen grain of trillium. The smalier cell is the generative cell. the case of trillium and many others of the angiosperms, before the pollen grain is mature. In the case of some specimens of $\mathrm{T}$. grandiflorum in which the pollen was formed during the month of October of the year before flowering, the division of the nucleus into two nuclei took place soon after the formation of the four cells from the mother cell. The nucleus divided in the young pollen grain is shown in fig. 297. After this takes place the wall of the pollen grain becomes stouter, and minute spiny projections are formed.

451. The larger cell is the vegetative cell of the prothallium, while the smaller one, since it later forms the sperm cells, is the generative cell. This generative cell then corresponds to the central cell of the antheridium, and the vegetative cell perhaps corresponds to a wall cell of the antheridium. If this is so, then the male prothallium of angiosperms has become reduced to a very simple antheridium. The farther growth takes place after fertilization. In some plants the generative cell divides into the two sperm cells at the maturity of the

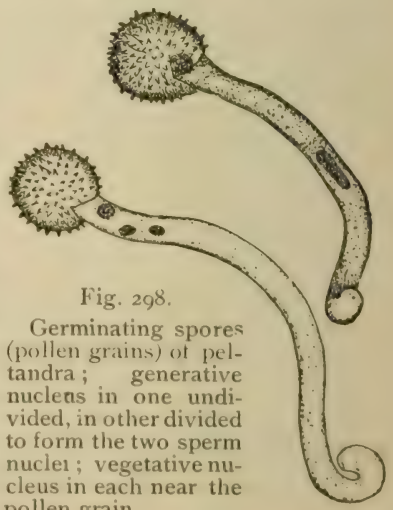
pellen grain. In other cases the generative cell divides in the pollen tube after the germination of the pollen grain. For study of the pollen tule the pellen may be grerminated in a weak solution of sugar, or on the cut surface 
of pear fruit, the latter being kept in a moist chamber to prevent drying the surface.

452. In the spring after flowering the pollen escapes from the anther sacs, and as a result of pollination is brought to rest on the stigma of the pistil. Here it germinates, as we say, that is it develops a long tube which makes its way down through the style, and in through the micropyle to the embryo sac, where, in accordance with what takes place in other plants examined, one of the sperm cells unites with the egg, and fertilization of the egg is the result.

453. Macrospore and embyro sac. three pistils or carpels are united into taria the two carpels are also united carpel. Simple carpels are found in example in the ranunculaceæ, the bine, etc. These simple carpels bear a

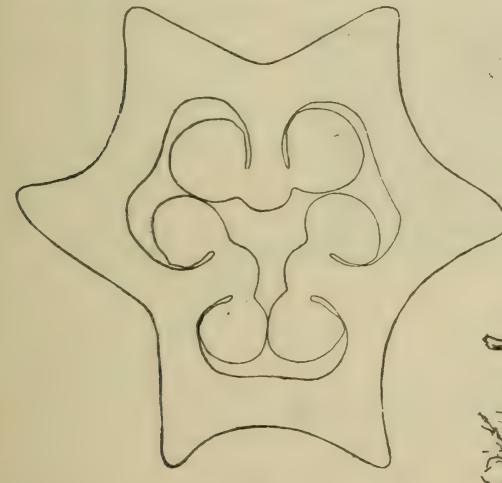

Fig. 299.
Section of pistil of trillium, showing position of orules (macrosporangia .

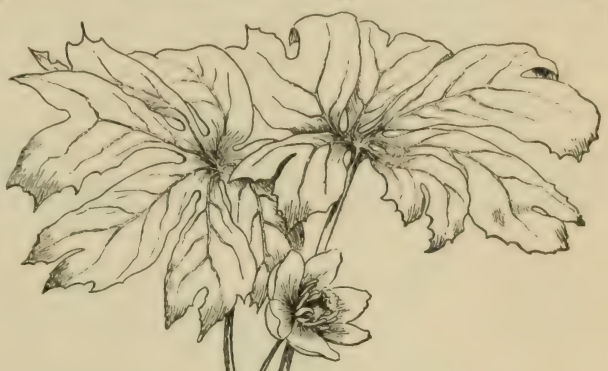

- In trillium the one, and in deninto one compound many plants, for buttercups, columgreater resemblance to a leaf, the margins of which are folded around so that they meet and enclose the ovules or sporangia.

454. If we cut across the compound pistil of trillium we find that the infoldings of the three pistils meet to form three partial partitions which extend nearly to the center, dividing off three spaces. In these spaces are the orules which are attached to the infolded margins. If we make cross sections of a pistil of the May- 
apple (podophyllum) and through the ovules when they are quite young, we will find that the ovule has a structure like that shown in fig. $30 \mathrm{r}$. At $m$ is a cell much larger than the surrounding ones. This is the macrospore. The tissue surrounding it is called here the nucellus, but because it contains the macrospore it must be the macrosporangium. The two coats or integuments of the ovule are yet short and have not grown out over the end of the nucellus. This macrospore increases in size, forming first a cavity or sac in the nucellus, the embryo sac. The nucleus divides

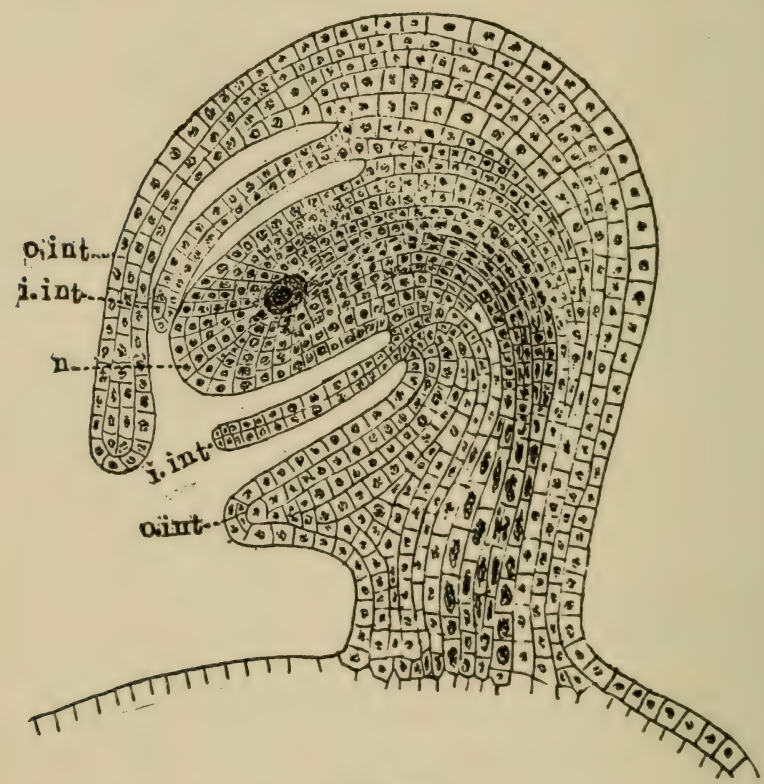

Fig. 301.

Young ovule (macrosporangium) of podophyllum. $n$, nucellus containing the one-celled stage of the macrospore; i.int, inner integument; o.int, outer integument.

several times until eight are formed, four in the micropylar end of the embryo sac and four in the opposite end. In some plants it has been found that one nucleus from each group of four moves toward the middle of the embryo sac. Here they fuse together to form one nucleus, the endosperm nucleus or definitive nucleus shown in fig. 302. One of the nuclei at the micropylar end is the egg, while the two smaller ones nearer the end are the 
synergids. The egg cell is all that remains of the archegonium in this reduced prothallium. The three nuclei at the lower end are the antipodal cells.

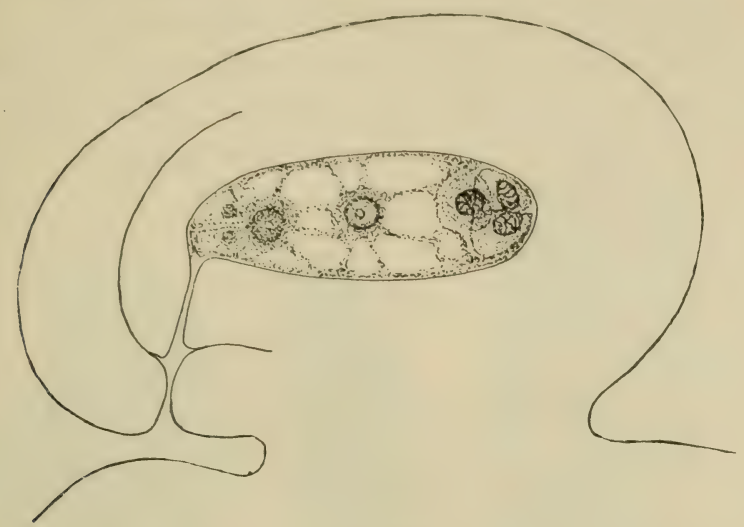

Fig. 302 .

Podophyllum peltatum, cvule containing mature embryo sac; two synergids and egg at left, endosperm nucleus in center, three antipodal cells at right.

455. Embryo sac is the young female prothallium.-In figures 303,305 are shown the different stages in the development of the embryo sac in lilium. The embryo sac at this stage is the young female prothallium, and the egg is the only remnant of the female sexual organ, the archegonium, in this reduced gametophyte.

456. Fertilization. - Before fertilization can take place the pollen must be conveyed from the anther to the stigma. (For Macrospore (one-celled stage) of lilium. the different methods of pollination see Part III.) When the pollen tube has reached the embryo sac, it opens and the sperm cell is emptied into the embryo sac near the egg. The sperm nucleus now enters the protoplasm surrounding the egg nucleus. The male nucleus is usually smaller than the female nucleus, and sometimes, as in the cotton plant, it grows to near or quite the 
size of the female nucleus before the fusion of the two takes place. In figs. 306 and 307 are shown the entering pollen tube with the sperm nucleus, and the fusion of the male and female nuclei.

457. Fertilization in plants is fundamentally the same as in animals. - In all the great groups of plants as represented by spirogyra, oedogonium, vaucheria, peronospora, ferns, gymno-
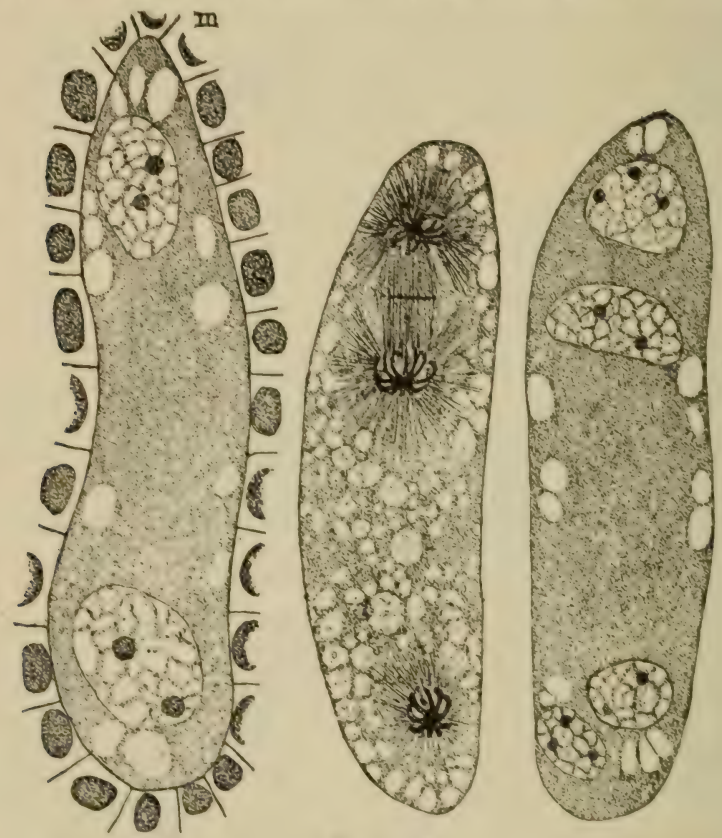

Fig. 304 .

Two- and four-celled stage of embry-sac of lilium. The middle one shows division of nuclei to form the four-celied stage. (Easter lily.)

sperms, and in the angiosperms, fertilization, as we have seen, consists in the fusion of a male nucleus with a female nucleus. Fertilization, then, in plants is identical with that which takes place in animals.

458. Embryo. - After fertilization the eggr develops into a short row of cells, the suspensor of the embryo. At the free end the embro develops. In figs. 309 and 310 is a young embryo of trillium.

459. Endosperm, the mature female prothallium.-During the development of the embryo the endosperm nucleus divides 
into a great many nuclei in a mass of protoplasm, and cell walls are formed separating them into cells. This mass of cells is the endosperm, and it surrounds the embryo. It is the mature female prothallium, belated in its growth in the angiosperms, usually developing only when fertilization takes place, and its use has been assured.

460. Seed. - As the embryo

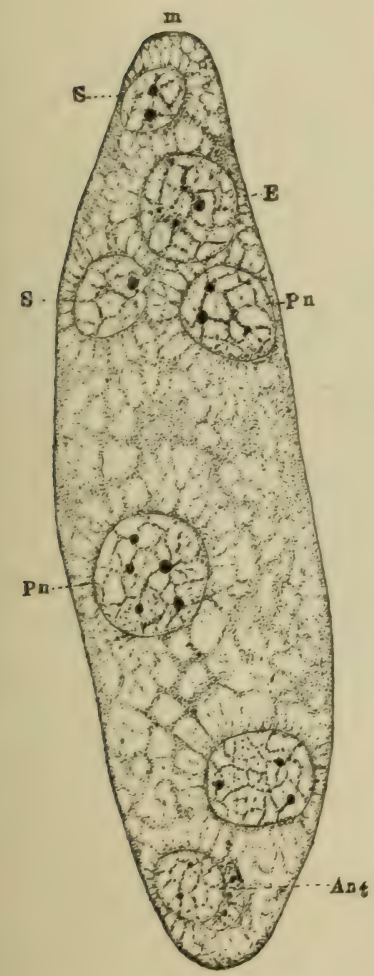

Fig. 305 .

Mature embryo sac (young prothallium) of lilium. $m$, micropylar end; $S$, synergids ; $E$, egg; $P n$, polar nuclei; Ant, antipodals. (Easter lily.)

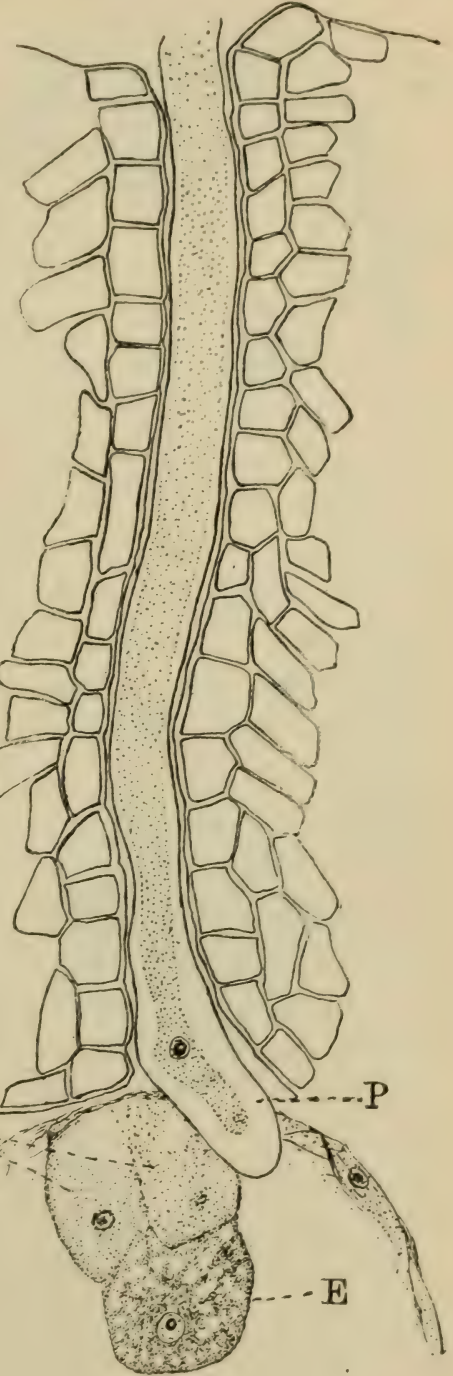

Fig. 306.

Section through nucellus and upper part of embryo sac of cotton at time of entrance of pillen tube. $E$, egs: $S$, synergids; $P$, pollen tube with sperm cell in the end. (Duggar.) 
is developing it derives its nourishment from the endosperm (or in some cases perhaps from the nucellus). At the same time

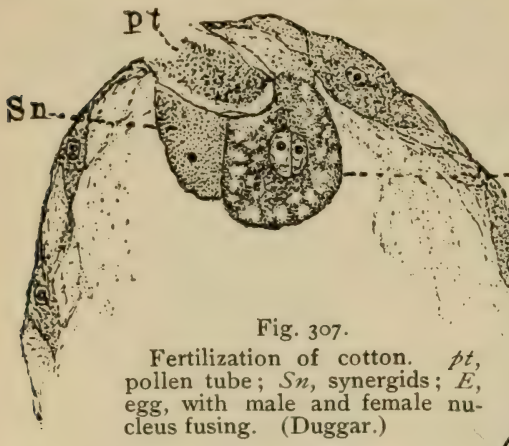

the integuments increase in extent and harden as the seed is formed.

461. Perisperm. - In most plants the nucellus is all consumed in the development of the endosperm, so that only minute fragments of disorganized cell walls remain next the inner integument. In some plants, however, (thewaterlily family, the pepper family, etc.,) a portion of the nucellus remains intact in the mature seed. In such seeds the remain-

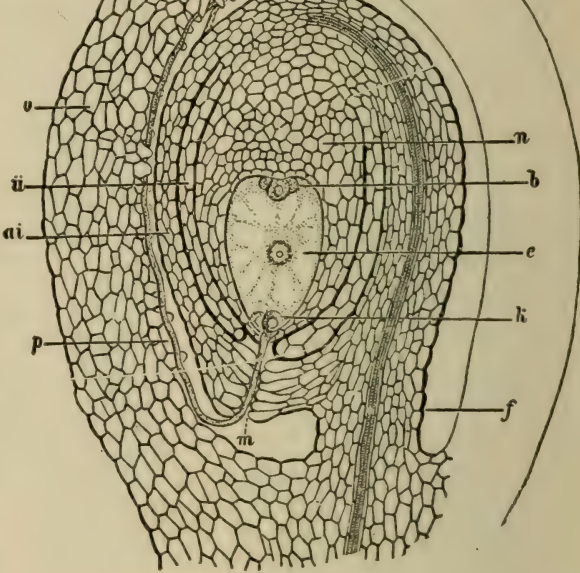

Fig. 308 .

Diagrammatic section of ovary and ovule at time of fertilization in angiosperm. $f$, funicle of cvule : $n$, nucellus; $m$, micropyle; $b$, antipodal cells of embryo sac; $e$, endosperm nucleus; $k$, egg cell and synergids; $a i$, outer integument of ovule ; $i i$, inner integument. The track of the pollen tube is shown down through the style, walls of the ovary to the micropylar end of the embryo sac. ing portion of the nucellus is the perisperm.

462. Presence or absence of endosperm in the seed.-In many of the angiosperms all of the endosperm is consumed by the embryo during its growth in the formation of the seed. This is the case in the rose family, crucifers, composites, willows, oaks, legumes, etc., as in the acorn, the bean, pea and others. In some, as in the bean, a large part of the nutrient substance pass- 
ing from the endosperm into the embryo is stored in the cotyledons for use during germination. In other plants the endosperm

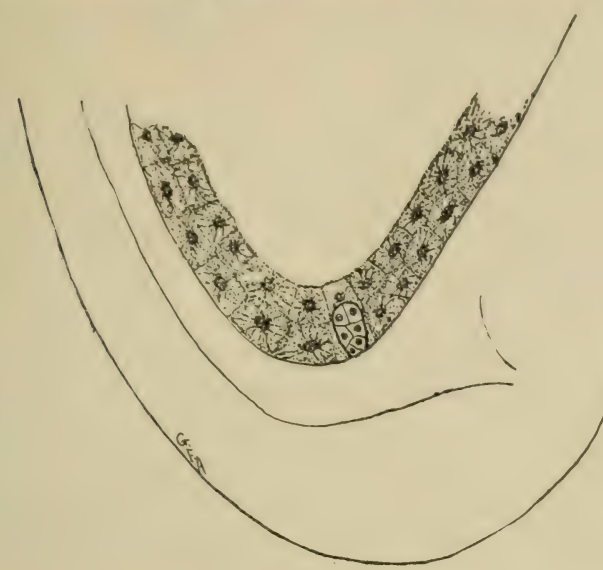

Fig. 309 .

Section of one end of ovule of trillium, showing young embryo in endosperm.
Fig. 3 ro.

Embryo e n larged.

is not all consumed by the time the seed is mature. Examples of this kind are found in the buttercup family, the violet, lily, palm,
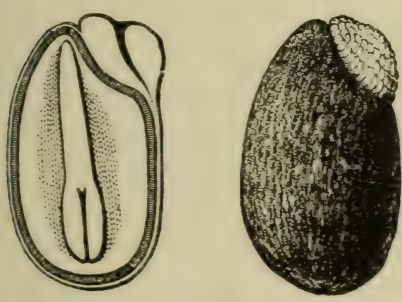

Fig. 3ir.

Seed of violet, external view, and section. The section shows the embryo lying in the endosperm.

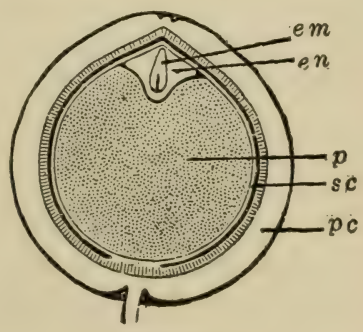

Fig. 312 .

Section of fruit of pepper (Piper nigrum), showing small embryo lying in a small quantity of whitish endosperm at one end, the perisperm occupying the larger part of the interior, surrounded by pericarp.

jack-in-the-pulpit, etc. Here the remaining endosperm in the seed is used as food by the embryo during germination.

463. Sporophyte is prominent and highly developed.-In the angiosperms then, as we have seen from the plants already studied, the trillium, dentaria, 
etc, are sporophytes, that is they represent the spore-bearing, or sporophytic, stage. Just as we found in the case of the gymmosperms and ferns, this stage is the prominent one, and the one by which we characterize and recognize the plant. We see also that the plants of this group are still more highly specialized and complex than the gymnosperms, just as they were more specialized and complex than the members of the fern group. From the very simple condition in which we possibly find the sporophyte in some of the algr like spirogyra, vaucheria, and coleochete, there has been a gradual increase in size, specialization of parts, and complexity of structure through the bryophytes, pteridophytes, and gymnosperms, up to the highest types of plant structure found in the angiosperms. Not only do we find that these changes have taken place, but we see that, from a condition of complete dependence of the spore-bearing stage on the sexual stage (gametophyte), as we find it in the liverworts and mosses, it first becomes free from the gametophyte in the members of the fern group, and is here able to lead an independent existence. The sporophyte, then, might be regarded as the modern phase of plant life, since it is that which has become and remains the prominent one in later times.

464. The gametophyte once prominent has become degenerate.-On the other hand we can see that just as remarkable changes have come upon the other phase of plint life, the sexual stage, or gametophyte. There is reason to believe that the gametophyte was the stage of plant life which in early times existed almost to the exclusion of the sporophyte, since the characteristic thallus of the algie is better adapted to an aquatic life than is the spore-bearing state of plants. At least, we now find in the plants of this group as well as in the liverworts, that the gametophyte is the prominent stage. When we reach the members of the fern group, and the sporophyte becomes independent, we find that the gametophyte is decreasing in size, in the higher members of the pteridophytes, the male prothallium consisting of only a few cells, while the female prothallium completes its development still within the spore wall. And in selaginella it is entirely dependent on the sporophyte for nourishment.

465. As we pass through the gymnosperms we find that the condition of things which existed in the bryophytes has been reversed, and the gametophyte is now entirely dependent on the sporophyte for its nourishment, the female prothallium not even becoming free from the sporangium, which remains attached to the sporophyte, while the remnant of a male prothallium, during the stage of its growth, receives nourishment from the tissues of the nucellus through which it bores its way to the egg-cell.

466. In the angiosperms this gradual degradation of the male and female prothallia has reached a climax in a one-celled male prothallium with two sperm-cells, and in the embryo-sac with no clearly recognizable traces of an archegronium to identify it as a female prothallium. The development of the endosperm subsequent, in most cases, to fertilization, providing nourishment 
for the sporophytic embryo at one stage or another, is believed to be the last remnant of the female prothallium in plants. 467. Synopsis of members of the sporophyte in angiosperms.

I ligher plant. Sporophyte phase
(or modern phase). $\left\{\begin{array}{l}\text { Root. } \\ \text { shoot. }\end{array}\left\{\begin{array}{c}\text { Stem. } \\ \text { I.eaf. }\end{array}\right.\right.$
Foliage leaves.

Perianth leaves.

Spore-bearing leaves with sporangia.

Flower. on shoot.) 

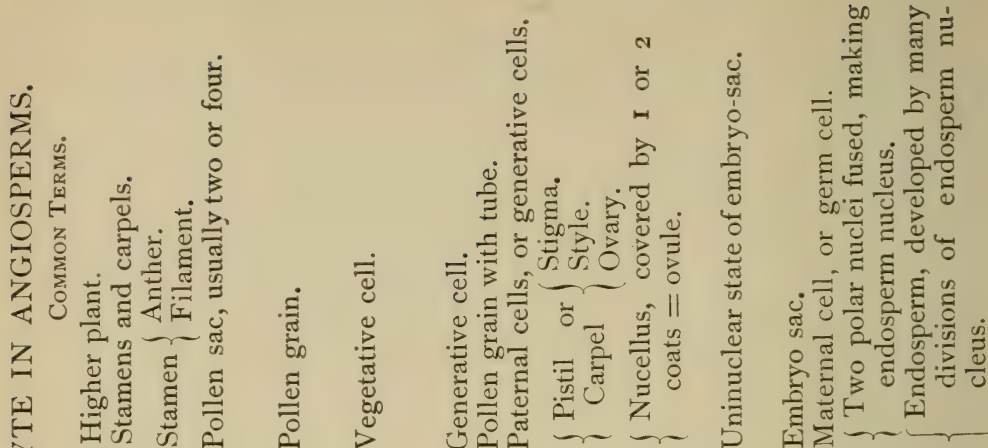

$\neq$ 江范

要 || || || |

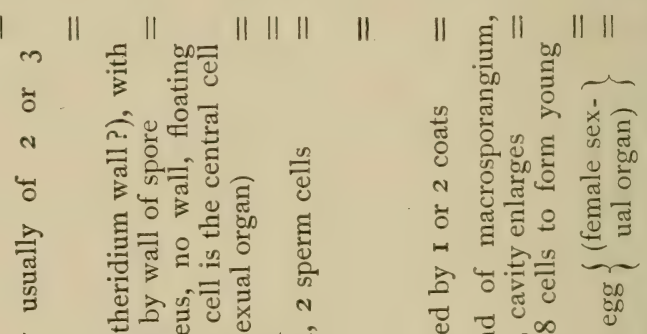

II

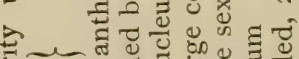

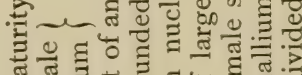

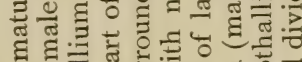
ฮँ

卌 ह क व

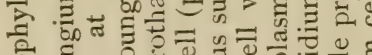

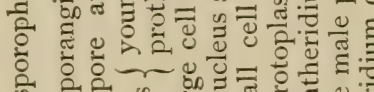

되

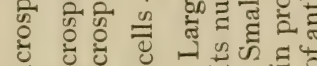

잉 究空

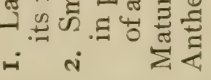

II

잉

尘

단)
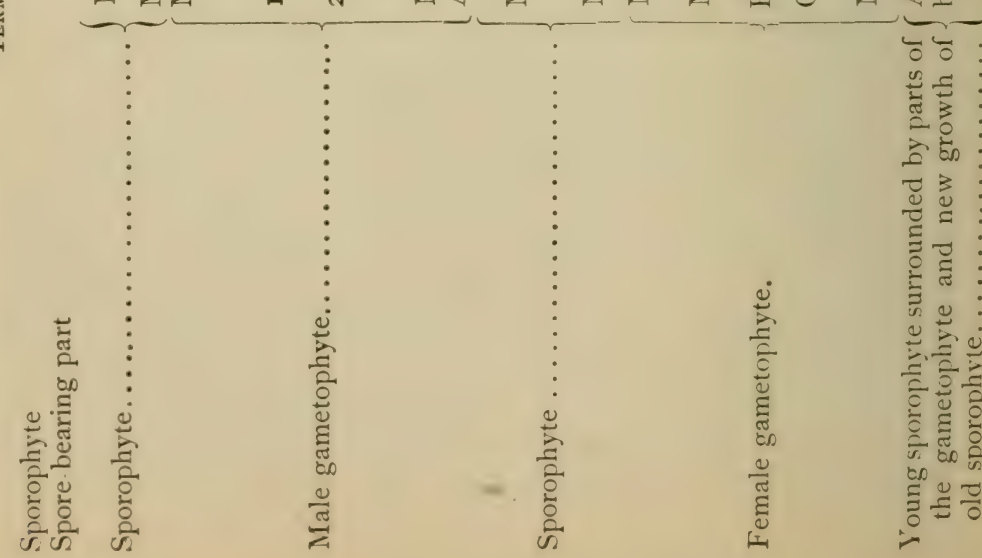


\section{CHAPTER XXXV.}

MORPHOLOGY OF THE NUCLEUS AND SIGNIFICANCE OF GAMETOPHYTE AND SPOROPHYTE.

469. In the development of the spores of the liverworts, mosses, ferns, and their allies, as well as in the development of the microspores of the gymnosperms and angiosperms, we have

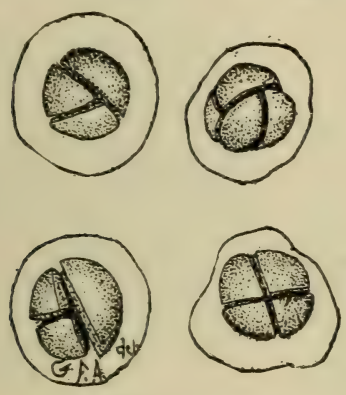

Fig. 313 .

Forming spores in mother cells (Polypodium vulgare). observed that four spores are formed from a single mother cell. These
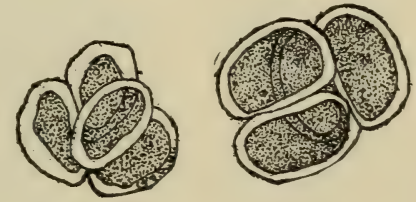

Fig. 314 .

Spores just mature and wall of mother cell broken (Asplenium bulbiferum).

mother cells are formed as a last division of the fertile tissue (archesporium) of the sporangium. In ordinary cell division the nucleus always divides prior to the division of the cell. In many cases it is directly connected with the laying down of the dividing cell wall.

470. Direct division of the nucleus. - The nucleus divides in two different ways. On the one hand the process is very simple. The nucleus simply fragments, or cuts itself in two. This is direct division.

471. Indirect division of the nucleus. - On the other hand very complicated phenomena precede and attend the division of 
the nucleus, giving rise to a succession of nuclear figures presented by a definite but variable series of evolutions on the part of the nuclear substance. This is indirect division of the nucleus, or karyokinesis. Indirect division of the nucleus is the usual method, and it occurs in the normal growth and division of the cell. The nuclear figures which are formed in the division of the mother cell into the four spores are somewhat different from those occurring in vegetative division, but their study will serve to show the general character of the process.

472. Chromatin and linin of the nucleus. - In figure $3^{\mathrm{I}} 5$ is represented a pollen mother cell of the May-apple (podophyl-
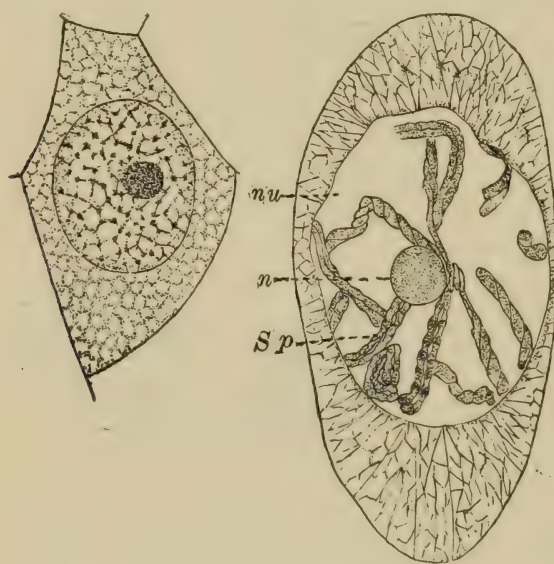

Fig. 316 .

Fig. 315.

Pollen mother cell of podophyllum, resting nucleus. Chromatin forming a network.

(Figures $315^{-3} 17$ after Mottier.)

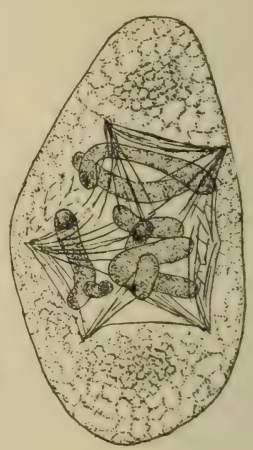

Fig. 317 .

Spirem stage of nucleus. Forming spindle, nu, nuclear cavity; $n$, nu- threads from protoplasm with several poles, roping $\mathrm{th}$ e chromosomes up to nuclear plate.

lum). The nucleus is in the resting stage. There is a network consisting of very delicate threads, the linin network. Upon this network are numerous small granules, and at the junction of the threads are distinct knots. The nucleolus is quite large and prominent. The numerous small granules upon the linin stain very deeply when treated with certain dyes used in differentiating the nuclear structure. This deeply staining substance is the chromatin of the nucleus. 
473. The chromatin skein.-One of the first nuclear figures in the preparatory stages of division is the chromatin skein or spirem. The chromatin substance unites to form this. The spirem is in the form of a narrow continuous ribbon, or band, woven into an irregular skein, or gnarl, as shown in figure $3 \mathrm{I} 6$. This band splits longitudinally into two narrow ones, and then each divides into a definite number of segments, about eight in the case of podophyllum. Sometimes the longitudinal splitting of the band appears to take place after the separation into the chromatin segments. The segments remain in pairs until they separate at the nuclear plate.

\section{Chromosomes, nuclear plate, and nuclear spindle.-} Each one of these rod-like chromatin segments is a chromosome.
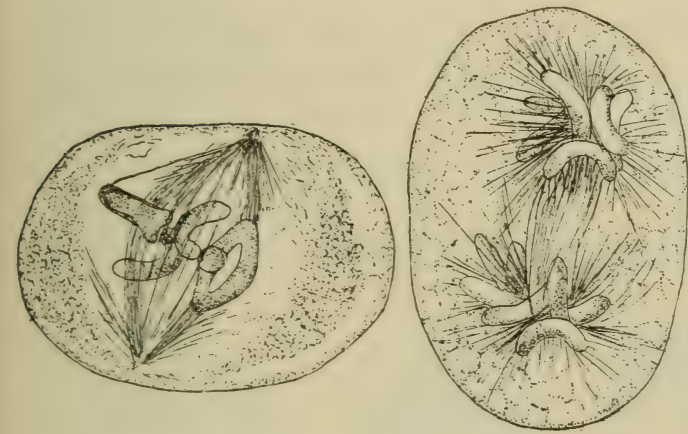

Fig. 318 .

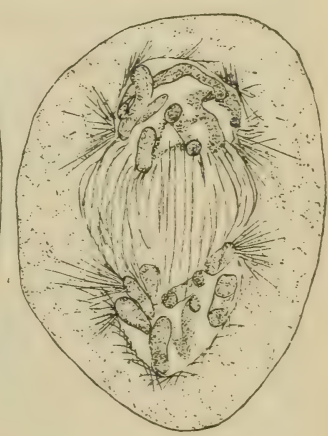

Karyokinesis in pollen mother cells of podophyllum. At the left the spindle with the cliromosomes separating at the nuclear plate; in the middle figure the chromosomes have reached the poles of the spindle, and at the right the chromosomes are forming the daughter nuclei. (After Mottier.)

The pairs of chromosomes arrange themselves in a median plane of the nucleus, radiating somewhat in a stellate fashion, forming the nuclear plaie, or monaster. At the same time threads of the protoplasm ( kinoplasm) become arranged in the form of a spindle, the axis of which is perpendicular to the nuclear plate of chromosomes, as shown in figure 3 I 8 , at left. Each pair of chromosomes now separate in the line of the division of the original spirem, one chromosome of each pair going to one pole of the spindle, 
while the other chromosome of each pair goes to the opposite pole. The chromosomes here unite to form the daughter nuclei.
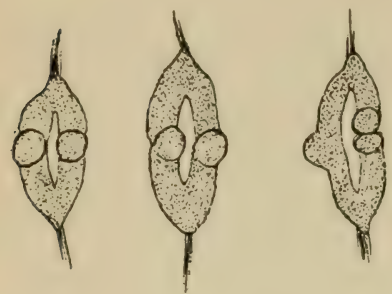

Fig. 319 .

Different stages in the separation of divided U-shaped chromosomes at the nuclear plate. (After Mottier) In podophyllum.

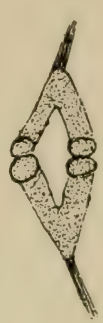

Each of these nuclei now divide as shown in figure 320 (whether the chromosomes in this second division in the mother cell split longitudinally or divide transversely has not been definitely settled), and four nuclei are formed in the pollen mother cell. The protoplasm about each one of these four nuclei now surrounds itself with a wall and the spores are formed.

The number of chromosomes usually the same in a given species throughout one phase of the plant.-In those plants which have been carefully studied, the number of chromosomes in the dividing nucleus has been found to be fairly constant in a given species, through all the divisions in that stage or phase of the plant, especially in the embryonic, or young growing parts. For example, in the prothallium, or gametophyte, of certain ferns, as osmunda, the number of chromosomes in the dividing nucleus is always twelve. So in the development of the pollen of lilium from the mother cells, and in the divisions of the antherid cell to form the generative cells or sperm cells, there are always twelve chromo- nuclei in pollen mother somes so far as has been chromosomes at poles.

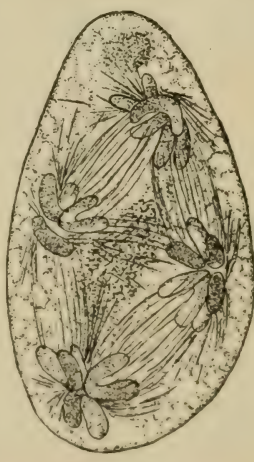

Fig. 320 .

Second division of

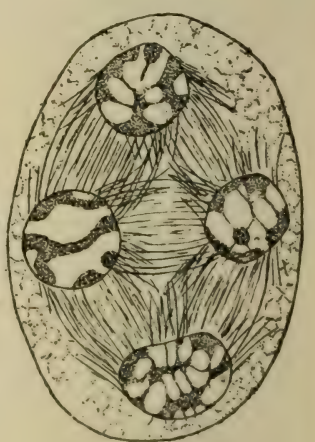

Fig. 321,

Chromosomes uniting at poles to form the nuclei of the four spores. (After Mottier.)

found. In the development of the egg of lilium from the macrospore there are also twelve chromosomes. 
When fertilization takes place the number of chromosomes is doubled in the embryo.-In the spermatozoid of osmunda then, as well as in the egg, since these are developed on the gametophyte, there are twelve chromosomes each. The same is true in the sperm-cell (generative cell) of lilium, and also in the eggcell. When these nuclei unite, as they do in fertilization, the paternal nucleus with the maternal nucleus, the number of chromosomes in the fertilized egg, if we take lilium as an example, is twenty-four instead of twelve; the number is doubled. The fertilized egg is the beginning of the sporophyte, as we have seen. Curiously throughout all the divisions of the nucleus in the embryonic tissues of the sporophyte, so far as has been determined, up to the formation of the mother cells of the spores, the number of chromosomes is usually the same

475. Reduction of the number of chromosomes in the nucleus. - If there were no reduction in the number of chromosomes
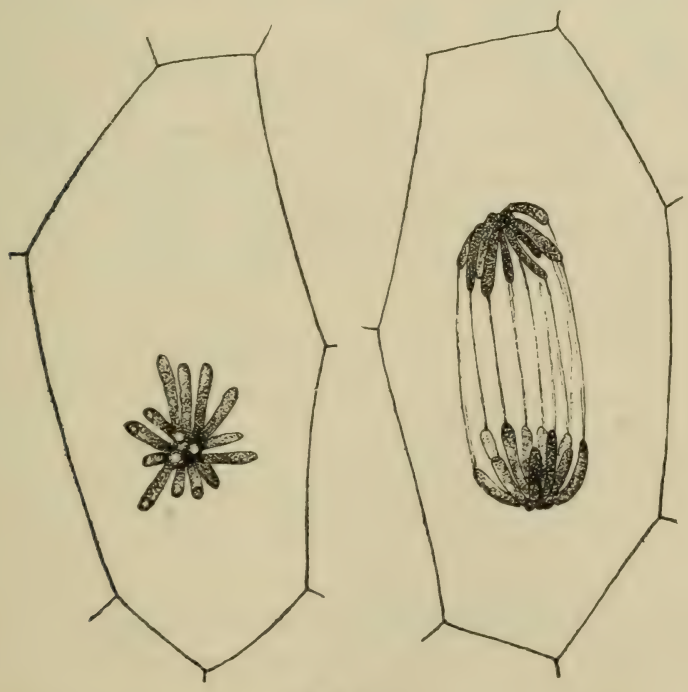

Fig. 322 .

Karyokinesis in sporophyte cells of podophyllum (twice the number of chromosomes here that are found in the dividing spore mother cells).

at any point in the life cycle of plants, the number would thus become infinitely large. A reduction, however, does take place. 
This usually occurs, either in the mother cell of the spores or in the divisions of its nucleus, at the time the spores are formed. In the mother cells a sort of pseudo-reduction is effected by the chromatin band separating into one half the usual number of nuclear segments. So that in lilium during the first division of the nucleus of the mother cell the chromatin band divides into twelve segments, instead of twenty-four as it has done throughout the sporophyte stage. So in podophyllum during the first division in the mother cell it separates into eight instead of into sixteen. Whether a qualitative reduction by transverse division of the spirem band, unaccompanied by a longitudinal splitting, takes place during the first or second karyokinesis is still in doubt.

476. Significance of karyokinesis and reduction. - The precision with which the chromatin substance of the nucleus is divided, when in the spirem stage, and later the halves of the chromosomes are distributed to the daughter nuclei, has led to the belief that this substance bears the hereditary qualities of the organism, and that these qualities are thus transmitted with certainty to the offspring. In reduction not only is the original number of chromosomes restored, it is believed by some that there is also a qualitative reduction of the chromatin, i.e. that each of the four spores possesses different qualitative elements of the chromatin as a result of the reducing division of the nucleus during their formation.

The increase in number of chromosomes in the nucleus occurs with the beginning of the sporophyte, and the numerical reduction occurs at the beginning of the gametophyte stage. The full import of karyokinesis and reduction is perhaps not yet known, but there is little doubt that a profound significance is to be attached to these interesting phenomena in plant life.

377. The gametophyte may develop directly from the tissue of the sporophyte.-If portions of the sporophyte of certain of the mosses, as sections of a growing seta, or of the growing capsule, be placed on a moist substratuin, under farorable conditions some of the external cells will grow directly into protonemal threads. In some of the ferns, as in the sensitive fern (onoclea), 
when the fertile leaves are expanding into the sterile ones, protonemal outgrowths occur among the aborted sporangia on the leaves of the sporophyte. Similar rudimentary protonemal growths sometimes occur on the leaves of the common brake (pteris) among the sporangia, and some of the rudimentary sporangia become changed into the protonema. In some other ferns, as in asplenium (A. filix-foemina, var. clarissima), prothallia are borne among the aborted sporangia, which bear antheridia and archegonia. In these cases the gametophyte develops from the tissue of the sporophyte without the intervention or necessity of the spores. This is apospory.

478. The sporophyte may develop directly from the tissue of the gametophyte.-In some of the ferns, Pteris cretica for example, the embryo fern sporophyte arises directly from the tissue of the prothallium, without the intervention of sexual organs, and in some cases no sexual organs are developed on such prothallia. Sexual organs, then, and the fusion of the spermatozoid and egg nucleus are not here necessary for the development of the sporophyte. This is apogamy. Apogamy occurs in some other species of ferns, and

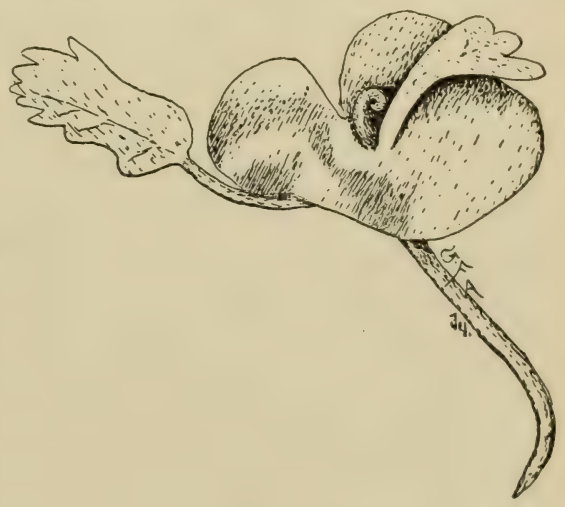

Fig. 323 .

Apogamy in Pteris cretica. in other groups of plants as well, though it is in general a rare occurrence except in certain species, where it may be the general rule.

479. Perhaps there is not a fundamental difference between gametophyte and sporophyte.-This development of sporophyte, or leafy-stemmed plant of the fern, from the tissue of the gametophyte is taken by some to indicate that there is not such a great difference between the ganetophyte and sporophyte of plants as others contend. In accordance with this view it has been 
suggested that the leafy-stemmed moss plant, as well as the leafy stem of the liverworts, is homologous with the sporophyte or leafy stem of the fern plant; that it arises by budding from the protenema; and that the sexual organs are borne then on the sporophyte. 


\title{
LESSONS ON PLANT FAMILIES.
}

\author{
CHAPTER XXXVI.
}

\section{RELATIONSHIPS SHOWN BY FLOWER AND FRUIT.}

\section{Importance of the flower in showing kinships among} the higher plants. - In the seed-bearing plants which we are now studying we cannot fail to be impressed with the general presence of what is called the flower, and that the flower has its culminating series in the spore-bearing members of the plant (stamens and carpels). Aside from the very interesting comparison of the changes which have taken place in passing from the simple and generalized sporophyte of the liverworts and mosses to the complex and specialized sporophyte of the higher plants, we should now seek to interpret the various kinds of aggregations of the spore-bearing members, here termed stamens and carpels. In the part of the book which deals with ecology we shall see how the grouping of these members of the plant is an advantage to it in the performance of those functions necessary for fruition.

481. While the spore-bearing members, as well as the floral envelopes, are thus grouped into "flowers," there is a great diversity in the number, arrangement, and interrelation of these members, as is suggested by our study of trillium and dentaria. And a farther examination of the flowers of different plants would reveal a surprising variety of plans. Nevertheless, if we compare the flower of trillium with that of a lily for example, or the flower of dentaria with that of the bitter-cress (cardamine), we shall at once be struck with the similarity in the plan of the 
flower, and in the number and arrangement of its members. 'This suggests to us that there may be some kinship, or relationship between the lily and trillium, and between the bittercress and toothwort. In fact it is through the interpretation of these different plans that we are able to read in the book of nature of the relationship of these plants. As we found in the case of the ferns that the most important characters of relationship among genera and species are found among the sporebearing leaves, so here the characters pertaining to the stamens and carpels are the principal guide posts, though the floral envelopes are only second in importance, and leaves also frequently demand attention.

Bearing these facts in mind, we can inquire of the plants themselves about some of the attributes of their families and tribes.

\section{NOTE FOR REFERENCE.}

482. Arrangement of flowers. - The arrangement of the flowers (inflorescence) on the stem is important in showing kinships. The flowers may be scattered and distant from each other on the plant, or they may be crowded close together in spikes, catkins, heads, etc. Many of the flower arrangements are dependent on the manner of the branching of the stem. Some of the systems of branching are as follows:

483. I. Dichotomous BRAnching.--True dichotomy (forking) does not occur in the shoots of flowering plants, but it does occur in some of the flower clusters.

484. II. LATERAL BRANCHING. - Two main types.

Monopodial branching.-This occurs where the main shoot continues to grow more vigorously than the lateral branches which arise in succession around the main stem. Examples in shoots, horse-chestnut, pines (see chapter on pine). Examples in flower clusters (from indeterminate inflorescence).

Raceme; lateral axes unbranched, youngest flowers near the terminal portion of long main axis; ex. choke-cherry, currant, etc.

Spike; main axis long, lateral unbranched axes with sessile and often crowded flowers; ex. plantain. Where the main axis is fleshy the spike forms a spadix, as in skunk's cabbage, Indian turnip, etc.; if the spike falls away after maturity of the flower or fruit it is a catkin or ament (willows, oaks, etc.). 
Umlerl; the main axis is shortened, and the stalked flowers appear to form terminal clusters or whorls, as in the parsley, carrot, parsnip, etc.

Head, or capitulum; the main axis is shortened and broadened, and bears sessile flowers, as in the sunflower, button-bush, etc.

Panicle; when the raceme has the lateral axes branched it forms a prinicle, as in the oat. When the panicle is flattened it forms a corymb.

Sympodial branching or cymose branching.- The branches, or lateral axes, grow more vigorously than the main axis, and form for the time false axes (form cymes).

I. Monochasium; only one lateral branch is produced from each relative or false axis.

Helicoid cyme; when the successive lateral branches always arise on the same side of the false axis, as in flower clusters of the forgetme-not.

Scorpioid cyme; when the lateral branches arise alternately on opposite sides of the false axis.

2. Dichasium; each relative, or false, axis produces two branches, often forming a false dichotomy. Examples in shoots are found in the lilac, where the shoot appears to have a dichotomous branching, though it is a false dichotomy.

Forking cyme; flower cluster of chickweed.

3. Pleiochasium; each relative, or false, axis produces more than two branches.

485. The fruit. - The fruit of the angiosperms varies greatly, and often is greatly complicated. When the gynocium is apocarpous (that is when the carpels are from the first distinct) the ripe carpels are separate, and each is a fruit. In the syncarpous gynocium (when the carpels are united) the fruit is more complicated, and still more so when other parts of the flower than the gynœcium remain united with it in the fruit.

Pericarp; this is the part of the fruit which envelops the seed, and may consist of the carpels alone, or of the carpels and the adherent part of the receptacle, or calyx; it forms the wall of the fruit.

Endocarp and exocarp. If the pericarp shows two different layers, or zones, of tissue, the outer is the exocarp, and the inner the endocarp, as in the cherry, peach, etc.

Mesocarp; where there is an intermediate zone it is the mesocarp.

I. Capsule (dry fruits). The capsule has a dry pericarp which opens (dehisces) at maturity. When the capsule is syncarpous the carpels may separate along the line of their union with each other longitudinally (septicidal dehiscence); or each carpel may split down the middle line 
(loculicidal dichiscence) as in fruit of iris; or the carpels may open by pores (poricidal dehiscence), as in the poppy.

Follicle; a capsule with a single carpel which dehisces along the ventral, or upper, suture (larkspur, peony).

Legrume or pod; a capsule with a single carpel which dehisces along both sutures (pea, bean, etc.).

Silique; a capsule of two carpels, which separate at maturity, leaving the partition wall persistent (toothwort, shepherd's-purse, and most others of the mustard family); when short it is a silicle or pouch.

Pyxidium or pyxis; the capsule opens with a lid (plantain).

II. DRY INDEHISCENT Fruits; do not dehisce or separate into distinct carpels.

Nuts; with a dry, hard pericarp.

Caryopsis; with one seed and a dry leathery pericarp (grasses).

Achen; with pericarp adherent to the seed (sunflower and other composites.

III. SCHIZocari'; a dry, several-loculed fruit, in which the carpels separate from each other at maturity but do not dehisce (umbelliferæ, mallow).

IV. BERRY; endocarp and mesocarp both juicy (grape).

V. PoME; mesocarp and outer portion of endocarp soft and juicy, inner portion of endocarp papery (apple).

VI. DRUPE, or STONE FRUT, endocarp hard and stony, execarp soft and generally juicy (cherry, walnut); in the cocoanut the exocarp is soft and spongy. 


\section{CHAPTER XXXVII. \\ MONOCOTYLEDONS.}

Topic I: Monocotyledons with conspicuous petals (Petaloideæ).

Lesson I. Lily Family (Liliacea).

CLASSIFICATION.

486. Species. - It is not necessary for one to be a botanist in order to recognize, during a stroll in the woods where the trillium is flowering, that there are many individual plants very like each other. They may vary in size, and the parts may differ a little in form. When the flowers first open they are usually white, and in age they generally become pinkish. In some individuals they are pinkish when they first open. Even with these variations, which are trifling in comparison with the points of close agreement, we recognize the individuals to be of the same kind, just as we recognize the corn plants grown from the seed of an ear of w corn as of the same kind. Individuals of the same

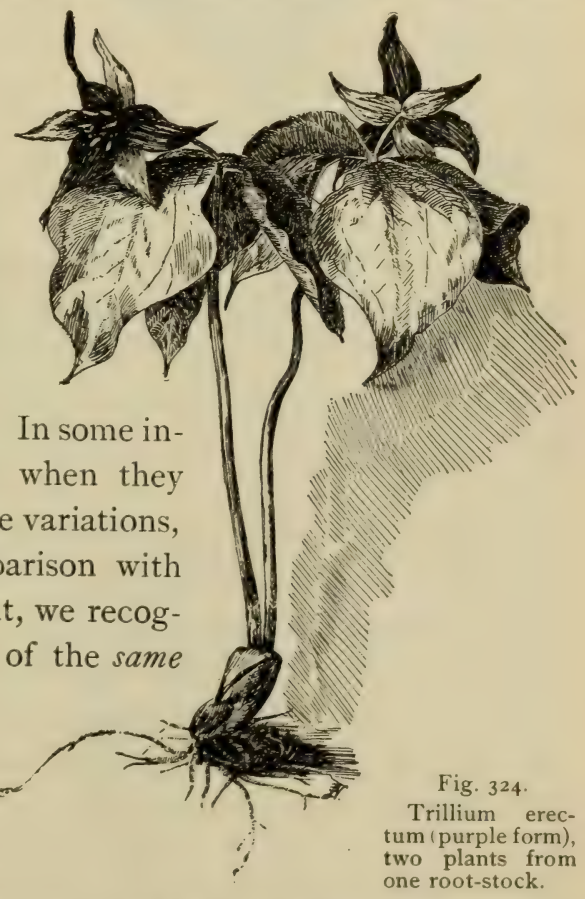
kind, in this sense, form a species. The white wake-robin, then, is a species. 
But there are other trilliums which differ greatly from this one. The purple trillium ( $\mathrm{T}$. erectum) shown in fig. 324 is very different from it. So are a number of others. But the purple trillium is a species. It is made up of individuals variable, yet very like one another, more so than any one of them is like the white wake-robin.

487. Genus. - Yet if we study all parts of the plant, the perennial root stock, the annual shoot, and the parts of the flower, we find a great resemblance. In this respect we find that there are several species which possess the same general characters. In other words, there is a relationship between these different species, a relationship which includes more than the individuals of one kind. It includes several kinds. Obviously, then, this is a relationship with broader limits, and of a higher grade, than that of the individuals of a species. The grade next higher than species we call genus. Trillium, then, is a genus. Briefly the characters of the genus trillium are as follows.

488. Genus trillium.-Perianth of six parts: sepals 3, herbaceous, persistent; petals colored. Stamens 6 (in two whorls),

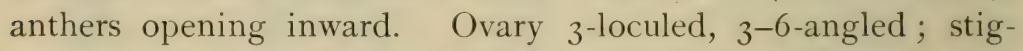
mas 3 , slender, spreading. Herbs with a stout perennial rootstock with fleshy scale-like leaves, from which the low annual shoot arises bearing a terminal flower, and 3 large netted-veined leaves in a whorl.

Note.-In speaking of the genus the present usage is to say trillium, but two words are usually employed in speaking of the species, as Trillium grandiflorum, T. erectum, etc.

489. Genus erythronium. - The yellow adder-tongue, or dog-tooth violet (Erythronium americanum), shown in fig. 325 , is quite different from any species of trillium. It differs more from any of the species of trillium than they do from each other. The perianth is of six parts, light yellow, often spotted near the base. Stamens are 6. The ovary is obovate, tapering at the base, 3 -valved, seeds rather numerous, and the style is elongated. The flower stem, or scape, arises from a scaly bull) deep in the soil, and is sheathed by two elliptical-lanceolate, mottled leaves. 
The smaller plants have no flower and but one leaf, while the bulb is nearer the surface. Each year new bulbs are formed at the end of runners from a parent bulb. These runners penetrate each year deeper in the soil. The deeper bulbs bear the flower stems.

490. Genus lilium. - While the lily differs from either the trillium or erythronium, yet we recognize a relationship when we compare the perianth of six colored parts, the 6 stamens, and the 3 -sided and lo $\mathrm{ng} \quad 3$-loculed ovary.

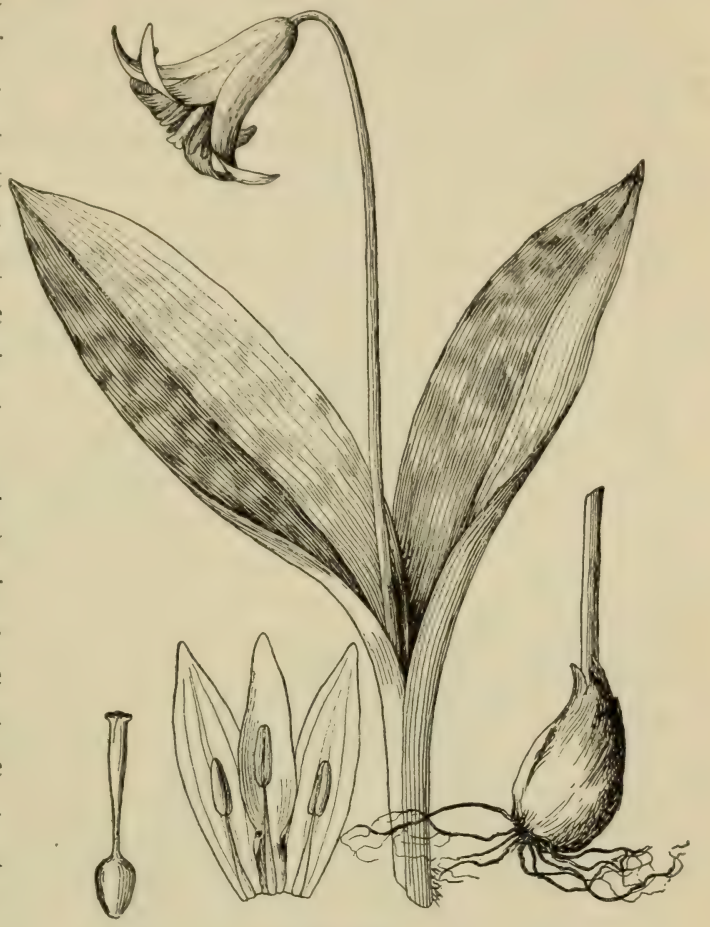

Fig. 325 .

Adder-tongue (erythronium). At left belowistil, and three stamens opposite three parts of the perianth. Bulb at the right.

491. Family liliaceæ.-The relationship between genera, as between trillium, erythronium, and lilium, brings us to a still higher order of relationship where the limits are broader than in the genus. Genera which are thus related make up the family. In the case of these genera the family has been named after the lily, and is the lily family, or Liliacece. This grouping of plants into species, genera, families, etc., according to characters and relationships is classification, or taxonomy.

The lily family is a large one. Another example is found in the "Solomon's-seal," with its elongated, perennial root-stock, the scars formed by the falling away of each annual shoot resem- 
bling a seal. The onion, smilax, asparagus, lily of the valley, etc., are members of the lily family. The parts of the flower are usually in threes, though there is an exception in the genus Unifolium, where the parts are in twos. A remarkable exception occurs sometimes in Trillium grandiflorum, where the flower is abnormal and the parts are in twos.

492. Floral formula. - A formula is sometimes written to show at a glance the general points of agreement in the flower among the members of a family or group. The floral formula of the lily family is written as follows : Calyx 3, Corolla 3, Androecium 6(3-3), Gynœcium 3. The formula may be abbreviated thus: $\mathrm{Ca}_{3}, \mathrm{Co}_{3}, \mathrm{~A}_{3}, \mathrm{G}_{3}$.

493. Adhesion and cohesion.- In the lily family all the sets, or whorls of parts, are free ; that is, no floral set is adherent to another. Farther, the parts of the calyx, corolla, and andrœcium are distinct. But the parts of the gynœcium are coherent, i.e. the three carpels are united into a single compound pistil. In the floral formula this cohesion of the parts of a set is represented by a small bracket over the figure, as in the gynœcium of the lily family.

494. Floral diagram. - The relation of the parts of the flower on the axis are often represented by a diagram, as shown in fig. 326 for the waterplantain family.

495. Note.-In the following lessons on plant families practical exercises may be conducted, employing representative plants in the several important

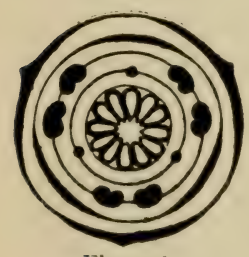

Fig. 326.

Diagram of alisma flower. (Vines.) families. Sketches should be made of the form of the leaves, their relation to the stem; stipules; parts of the flower, and other salient and important characters. Floral formulas and diagrams may be made. Brief notes and descriptions, made from the specimens themselves and not from the books, should be appended. The plants chosen here need not be insisted upon, for others equally good may be found. The studies presented are offered as suggestions to indicate the way in which relationships may be detected, and a familiarity with the characters of the families may be obtained. Several of these lessons are chosen among the monocotyledons, to which the lily family also belongs.

496. Water-plantain family (alismaceæ).-If we wish to begin with a more simple and primitive family, the water-plantain family will serve the purpise. The common water plantain (Alisma plantago) is an example. It occurs in ditches and muddy shores of streams and lakes. The flowers are in a lowse panicle and are inconspicuous. The leaves resemble those of the 
plantain, hence the common name of water-plantain. The flower is regular (all parts of a set are alike), and all the parts are distinct and free. This represents a simpler and more primitive condition than exists in the lily family, where the carpels are united. The floral formula is as follows: $\mathrm{Ca}_{3}$, Co3, A6, G6 - $\infty$; i.e. the parts are in threes or multiples of three. The stamens are in pairs in front of the sepals, and really represent but three stamens, since it is believed each one has divided, thus making three pairs. No stamens stand in front of the petals in the water plantain, but in the European genus Butomus one stamen in addition stands in front of each sepal.

497. The arrow leaf (genus sagittaria) roccurs in wet ground, or on the margins of streams and ponds. The leaves are very variable, and this seems to depend to some extent on the depth of the water. Several forms of this plant are shown in figs. 493-495. The flowers are monøecious or diøcious.

498. The orchid family (orchidaceæ).--Among the orchids are found the most striking departures from the arrangement of the flower which we found in the simpler monocotyledons. An example of this is seen in the ladyslipper (cypripedium, shown in fig. 464). The ovary appears to be below the calyx and corolla. This is brought about by the adhesion of the lower part of the calyx to the wall of the ovary. The ovary then is inferior, while the calyx and corolla are epigynous. The stamens are united with the style by adhesion, two lateral perfect ones and one upper

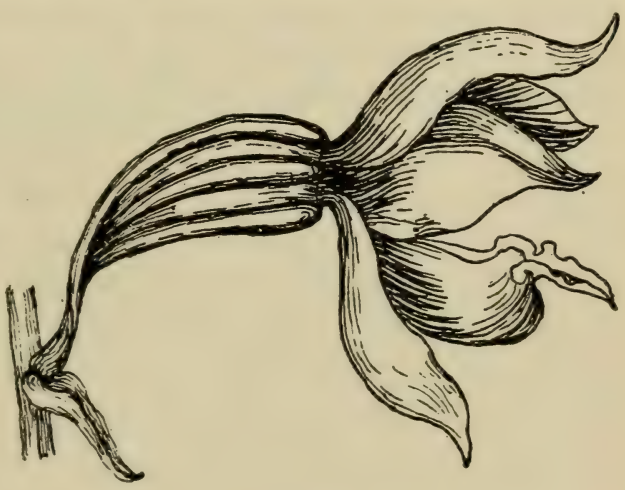

Fig. 327 .

Flower of an orchid (epipactis), the inferior ovary twisted as in all orchids so as to bring the upper part of the flower below.

imperfect one. The stamens are thus gynandrous. The sepals and petals are each three in number. One of the petals, the "slipper," is large, nearly horizontal, and forms the "lip" or "labellum" of the orchid flower. The labellum is the platform or landing place for the insect in cross pollination (see Part III, Pollination). Above the labellum stands one of the sepals more showy than the others, the "banner." The two lateral "strings" of the slipper are the two other petals. The stamens are still more reduced in some other genera, while in several tropical orchids three normal stamens are present.

499. There are thus four striking modifications of the orchid flower: Ist, 
the flower is irregular (the parts of a set are different in size and shape); $2 d$. alnation of all parts with the pistil; $3 d$, reduction and suppression of the stamens: fth. the ovary is twisted half way around so that the posterior side of the flower becomes anterior. Floral diagrams in fig. 328 show the posi-

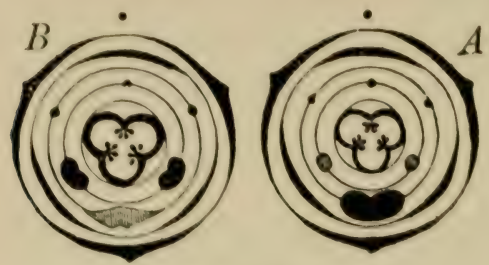

Fig. 328 .

Diagrams of orchid flowers. $A$, the usual type ; $B$, of cypripedium. (Vines.)

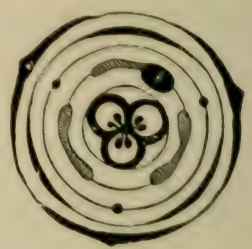

Fig. 329.

Diagram of flower of canna.

tion of the stamens in two distinct types. The number of orchid species is very large, and the majority are found in tropical countries.

500. Related to the orchids are the iris fumily, in which the stigma is expanded into the form of a petal, and the camma family. In the canna the flewer is irregular (see figs. 407,408 ) and the wary is inferior. (See chapter on pollination, Part III, for description of the canna flower.) 


\section{CHAPTER XXXVIII.}

\section{MONOCOTYLEDONS CONCLUDED.}

\section{Topic II: Monocotyledons with flowers on a spadix (Spadicifloræ).}

501. Lesson II. The arum fanily (araceæ).-This family is well represented by several plants. The skunk's cabbage (Spathyema foetida) illustrated in figs. $455-457$ is an interesting example. The flowers are closely crowded around a thick stem axis. Such an arrangement of flowers forms a "spadix." The spadix is partly enclosed in a large bract, the "spathe." The sepals and stamens are four in number, and the pistil has a four-angled style. The corolla is wanting. (See chapter on pollination, Part III, for farther characters of the fiower.)

502. The " jack-in-the-pulpit," also called "Indian turnip " (Arisæma triphyllum), shown in fig. $45^{8}$, the water arum (Calla palustris), and the sweet flag (Acorus calamus) are members of this family, as also are the callas and caladiums grown in conservatories. The parts of several of the species of this family, especially the corm of the Indian turnip, are very acrid to the taste. The floral parts are more or less reduced.

503. Related to the arum family are the "duckweeds." Among the members of this family are the most diminutive of the flowering plants, as well as the most reduced floral structures. (For description and illustration of three of these duckweeds, see chapter on nutrition in Part III.)

()ther related families are the cat-tails and palms. In the latter the spathe and spadix are of enormous size. The cocoanut is the fruit of the cocoanut palm. 


\section{Topic III: Monocotyledons with a glume subtending the flower (Glumifloræ).}

504. Lesson III. Grass family (gramineæ). 0at.-As a representative of the grass family (graminex) one may take the oat plant, which is widely cultivated, and also can be grown readily in gardens, or perhaps in small quantities in greenhouses in order to have material in a fresh condition for study. Or we may have recourse to material preserved in alcohol for the dis-

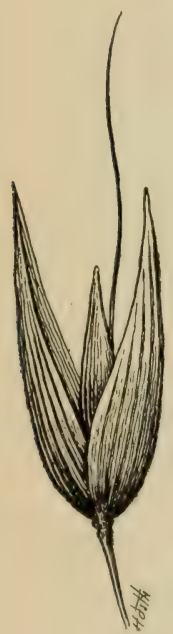

Fig. 330 .

Spikelet of o a t showing two glumes.

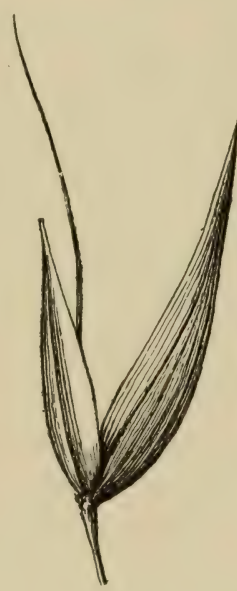

Fig. 33r.

One glume removed showing fertile flower.

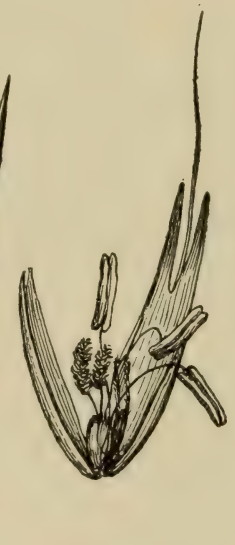

Fig. 332.

F lower opened showing two palets, three stamens, a $\mathrm{n} \mathrm{d}$ two lodicules at base of pistil.

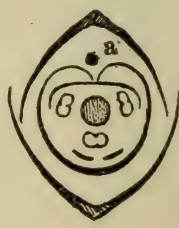

Fig. 333 .

Section showing ground plan of flower. $a$, axis. and the two lodicules in front.

section of the flower. The plants grow usually in stools; the stem is cylindrical, and marked by distinct nodes as in the corn plant. The leaves possess a sheath and blade. The flowers form a loose head of a type known as a panicle. Each little cluster as shown in fig. 330 is what is a spikelet, and consists usually here of one or two fertile flowers below and one or two undeveloped flowers above. We see that there are several series of overlapping scales. The two lower ones are "glumes," 
and because they bear no flower in their axils are empty glumes. Within these empty glumes and a little higher on the axis of the spike is seen a boat-shaped body, formed of a scale, the margins of which are folded around the flowers within, and the edges inrolled in a peculiar manner when mature. From the back of this glume is borne usually an awn. If we carefully remove this scale, the "flower glume," we find that there is another scale on the opposite (inner) side, and much smaller. This is the "palet."

505. Next above this we have the flower, and the most prominent part of the flower, as we see, is the short pistil with the two plume-like styles, and the three stamens at fig. 332. But if we are careful in the dissection of the parts we will see, on looking close below the pistil on the side of the flowering glume, that there are two minute scales (fig. 334). These are what are termed the lodicules, considered by some to be merely bracts, by others to represent a perianth, that is two of the sepals, the third sepal having entirely aborted. Rudiments of this third sepal are present in some of the $A$, abortive flower. gramineæ.

506. To the gramineæ belong also the wheat, barley, corn, the grasses, etc. The gramineæ, while belonging to the class monocotyledons, are less closely allied to the other families of the class than these families are to each other. For this reason they are regarded as a very natural group.

507. The sedge family (cyperaceæ). Carex.-As a representative of the sedges a species of the genus carex may he studied. If plants of Carex lupulina are taken from the soil carefully we will find that there is an under. 
ground stem or root-stock which each year grows a few inches, forms new attachments by roots to the soil, and thus the plant may spread from year to year. This underground stem, as seen, has only scaly leaves. The upright stems reach a height of two to three feet, and are prominently

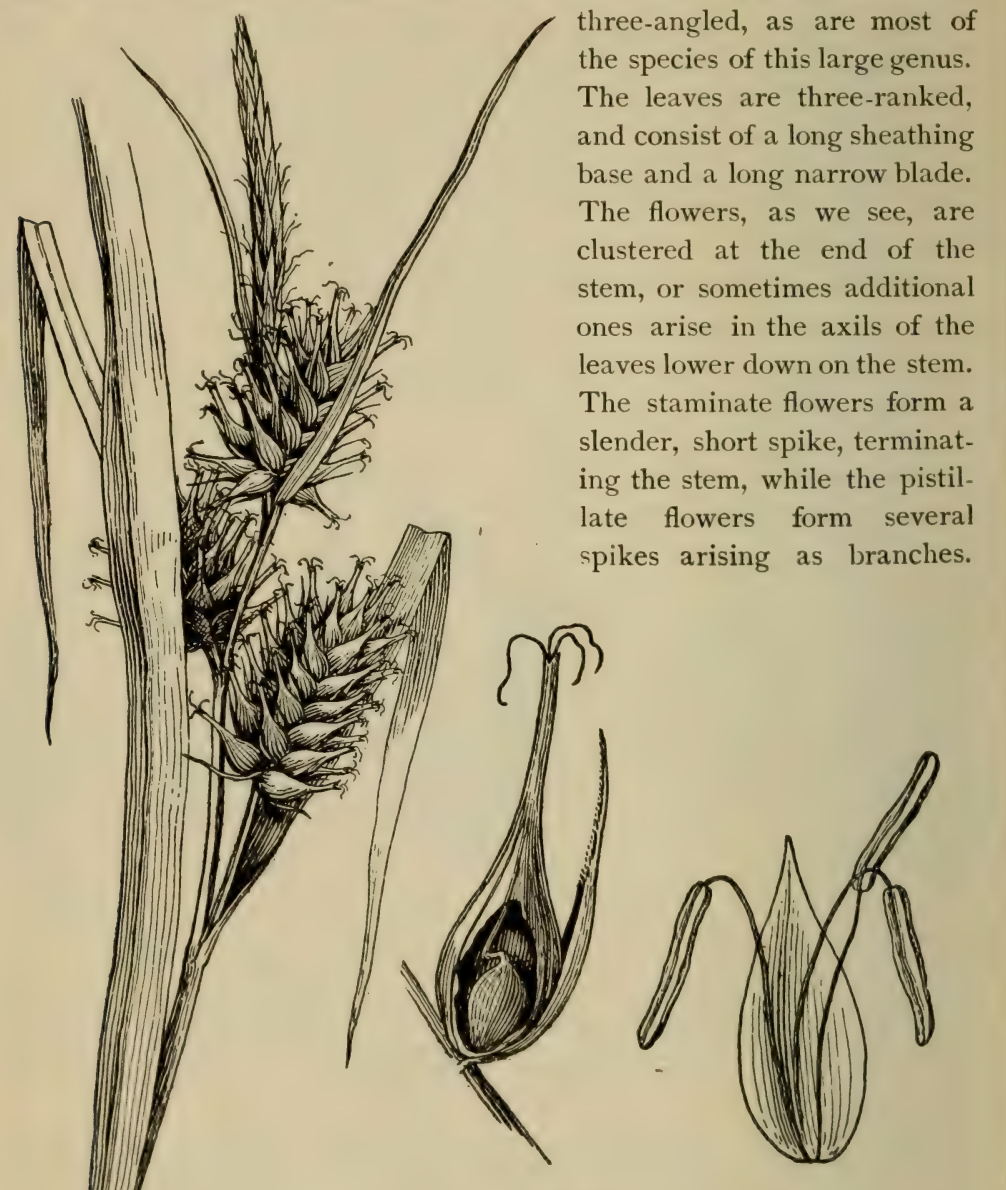

Fig. 336.

Flowers of Carex lupulina; staminate flower spike above, three pistlllate flower spikes below. Details of pistillate and staminate flowers shown at the right.

The flowers are very much reduced here, and each of the pistillate flowers consists of one pistil which is surrounded by a flask-shaped scale, the perigynium. These perigynia can be distinctly seen upon the spike. At the apex of the perigynia the three styles emerge. Just below each perigynium 
is a slender scale, the primary bract, from the axil of which the pistillate flower arises.

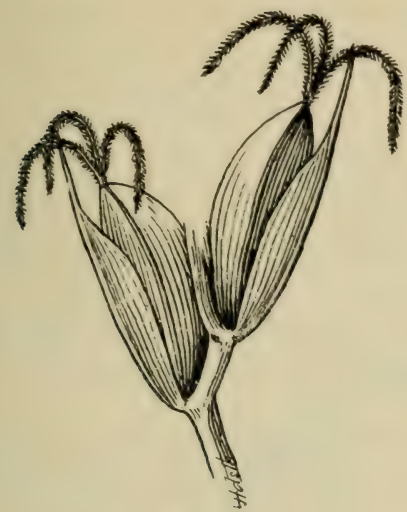

Fig. 337 .

Two carex flowers.

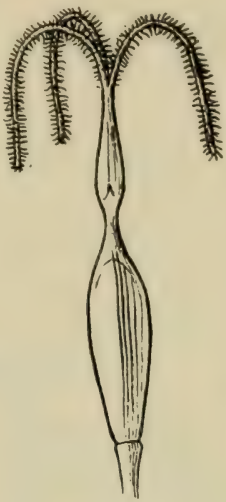

Fig. 338 .

Pistil of carex.

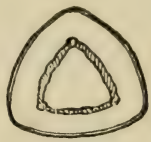

Fig. 339.

Section of pistil.

For the study of the flowers one must select material at the time the male flowers are in bloom. In fig. 340 is represented a portion of the staminate spike of Carex laxiflora. As seen here each staminate flower consists of three stamens. These stamens arise in the axil of a bract. Figure 337 represents a portion of the pistillate spike of the same species at the time of flowering. The fact that the parts, or members, of the flower are in threes suggests that there may be some relationship between the carex and the monocotyledons already studied, even though each flower has become so reduced in the number of its members.

508. In the bulrush (scirpus), another genus of this family, the flowers are perfect and complete (having all parts of the flower),

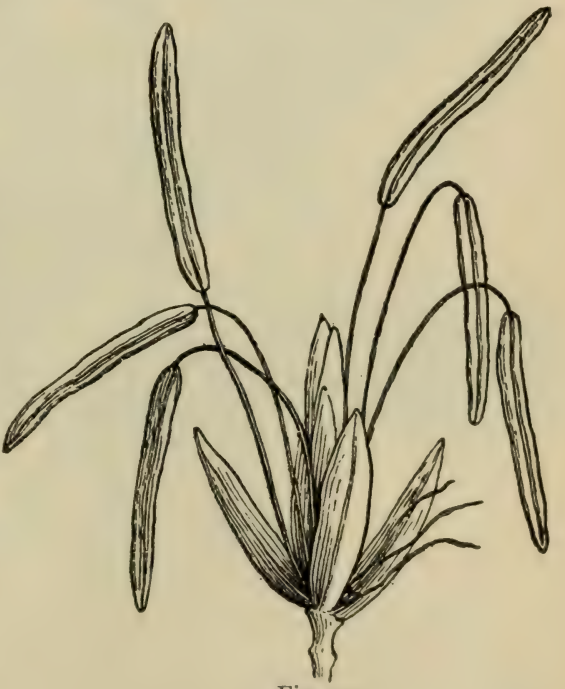

Fig. 340.

Two male flowers of Carex laxiflora. with the parts in threes or some multiple of three. Here there is a more obvious resemblance to the monocotyledenous type, 
CHAPTER XXXIX.

\section{DICOTYLEDONS.}

Topic IV: Dicotyledons with distinct petals, flowers in catkins, or aments; often degenerate.

509. Lesson IV. The willow family (salicaceæ).-The willows represent a very interesting group of plants in which the

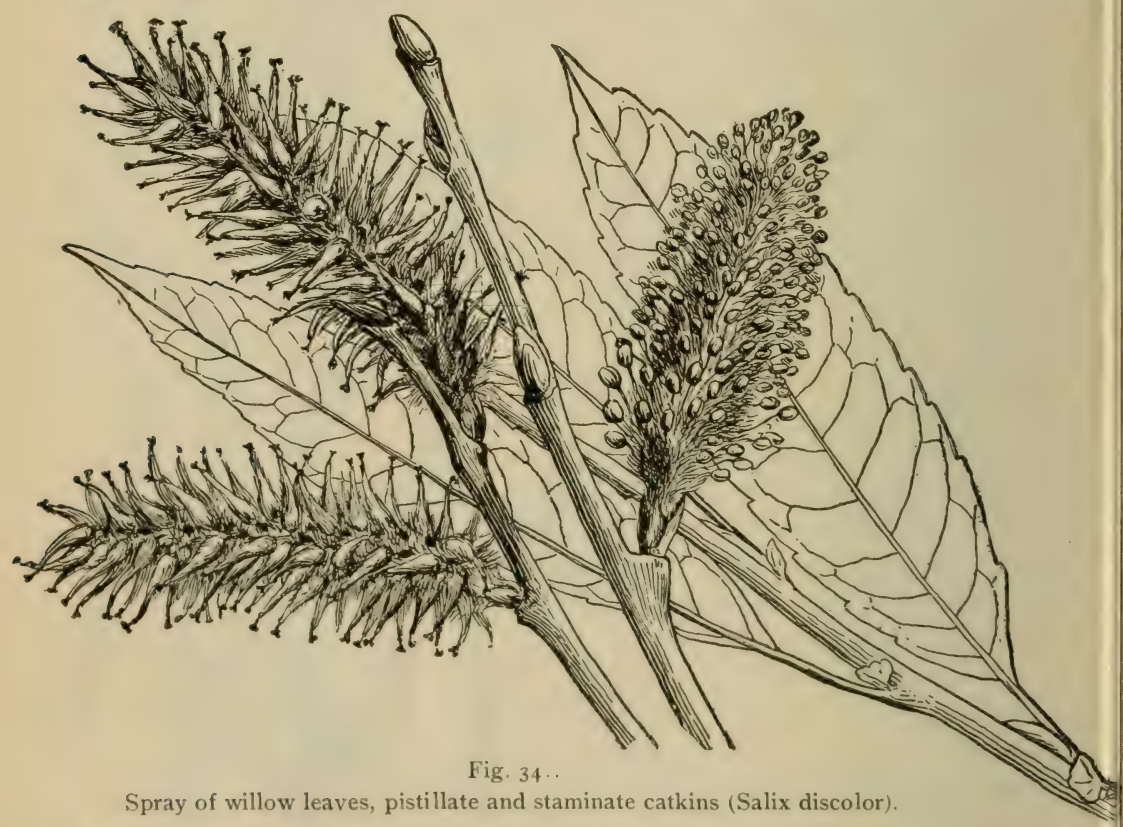

flowers are greatly reduced. The flowers are crowded on a more or less elongated axis forming a catkin, or ament. The ament is characteristic of several other families also. The willows are diøcious, the male and female catkins being borne 
on different plants. The catkins appear like great masses of either stamens or pistils. But if we dissect off several of the flowers from the axis, we find that there are many flowers, each one subtended by a small bract. In the male or "sterile" catkins the flower consists of two to eight stamens, while in the female or "fertile" catkins the flower consists of a single pistil. The poplars and willows make up the willow family.

510. Lesson V. The oak family (cupuliferæ).-A small branch of the red oak (Quercus rubra) is illustrated in fig. 342 .

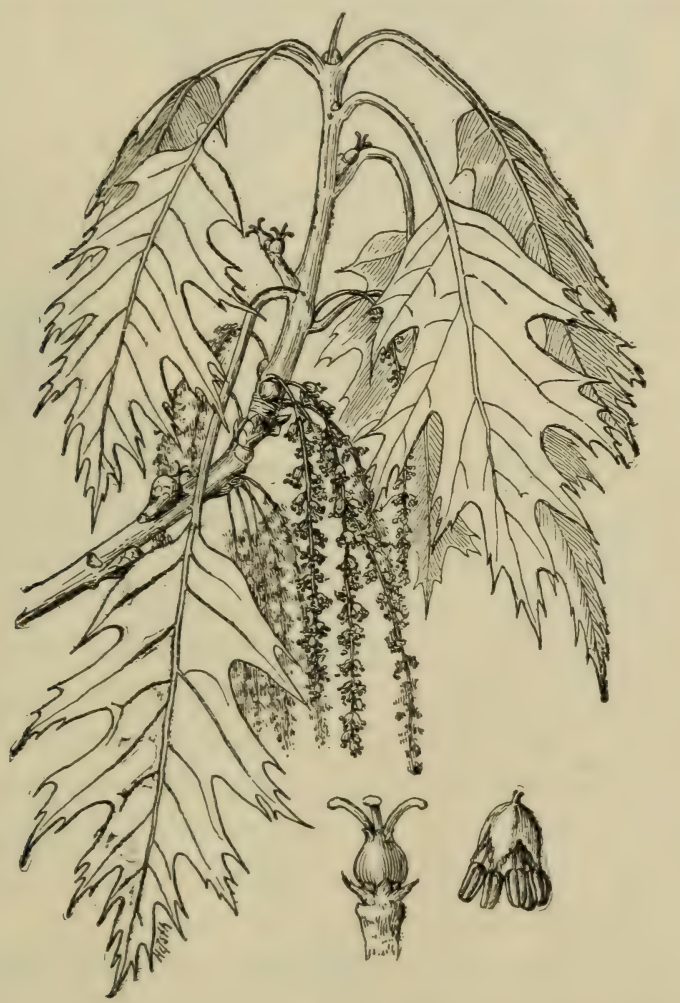

Fig. $34^{2}$.

Spray of nak leaves and flowers. Below at right is staminate flower, at left pistillate flower.

This is one of the rarer oaks, and is difficult for the beginner to distinguish from the scarlet oak. The white oak is perhaps in 
some localities a more convenient species to study. But for the general description here the red oak will serve the purpose. Just

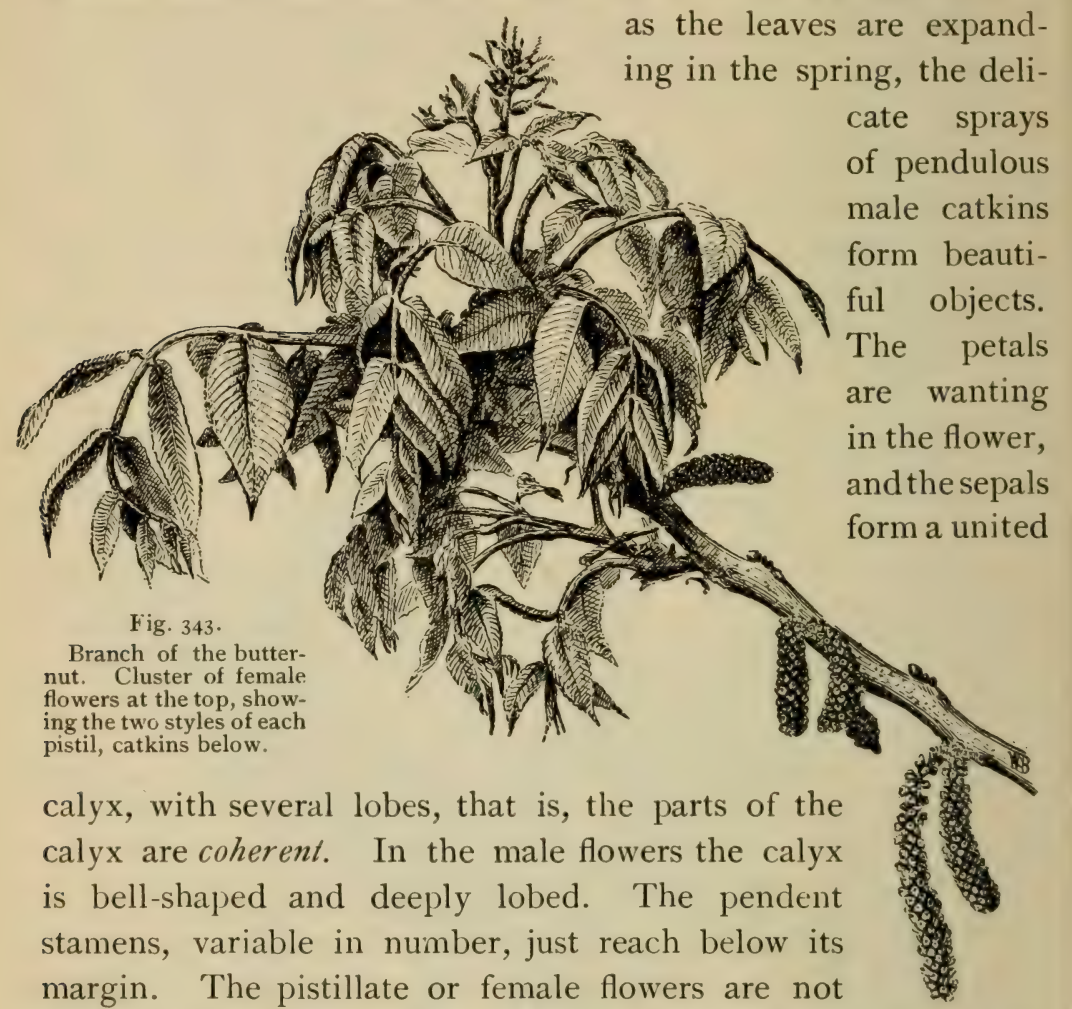
borne in catkins, but stand on short stalks, either singly or a few in a cluster. 'The calyx here is urn-shaped with short lobes. The ovary consists of three united (coherent) carpels, and there are three stigmas. Only one seed is developed in the ovary, and the fruit is an acorn. The numerous scales at the base of the ovary form a scaly involucre, the cup.

511. The beech, chestnut, and oak are members of the oak family.

512. The following additional families among the ament bearers are represented in this country : the birch family (birch, alder), the hazelnut family (hazelnut, hornbeam, etc.), walnut family (hickory, walnut), and the sweet-gale family (myrica). 


\section{CHAPTER XL.}

\section{DICOTYLEDONS CONTINUED.}

\section{Topic V: Dicotyledons with distinct petals and hypogynous flowers.}

\section{URTICIFLOR E.}

513. The nettle family (urticaceæ).-The nettle family receives its name from the members of one genus in which the stinging nettles are found (urtica). The diœcious nettle (U. dioica) has opposite, petioled leaves, which are ovate, with a heart-shaped base. The margins of the leaves are

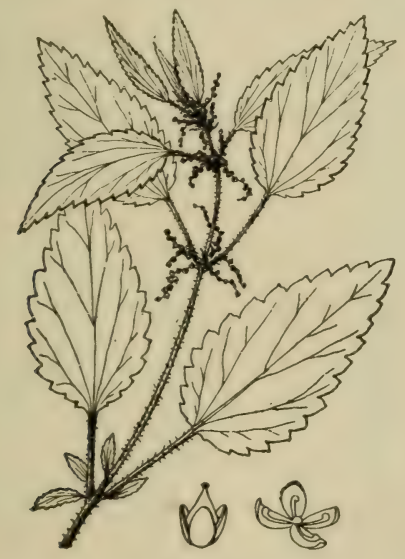

Fig. 344 .

The diøecious nettle (Urtica dioica) showing leaves, flower clusters, and below staminate flower at the right and pistillate flower at left.

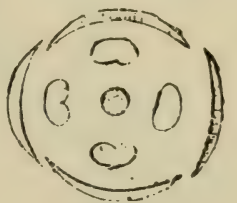

Fig. 345 .

Urtica, diagram of male flower.

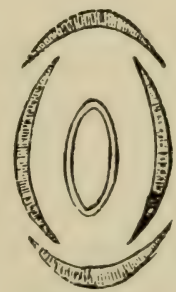

Fig. 346 .

Urtica, diagram of female flower.

deeply serrate, and the lower surface is downy. The stems and petioles of the leaves are armed with stinging hairs.

514. The greenish flowers are borne in dense clusters in the form of branched racemes which arise from the axils of the leaves. The staminate 
flowers have four small sepals and four stamens. The fertile flowers (pistillate) have also four sepals. The pistil has a two-loculed ovary; one of the locules is the smaller, and later lisappears, so that the fruit is a one-seeded achene. The parts of the flower are in twos, since the four sepals are in two pairs.

515. Lesson VI. The elm family (ulmaceæ). - The elm tree belongs to this family. The leaves of our American elm (Ulmus americana) are ovate, pointed, deeply serrate, and with an oblique base as shown in fig. 347. The narrow stipules which are

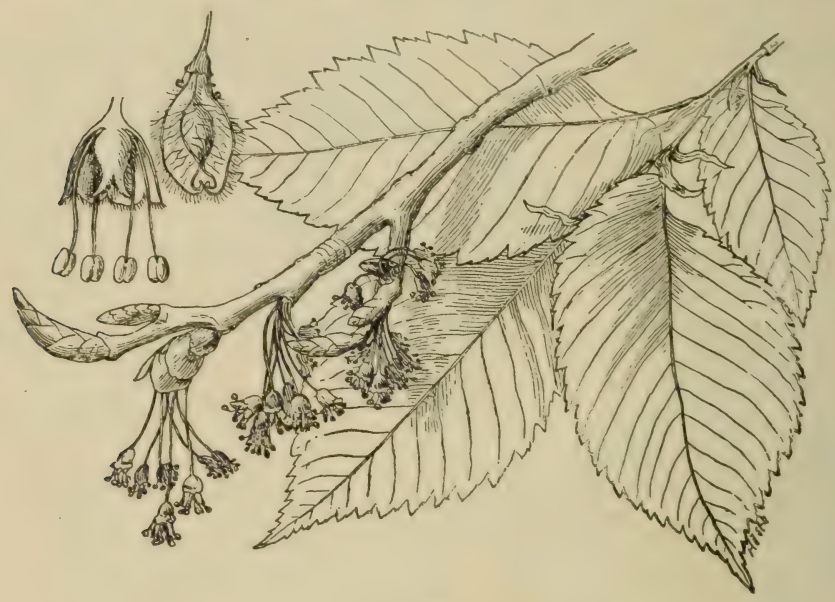

Fig. 347 .

Spray of leaves and flowers of the American elm; at the left above is section of flower, next is winged seed (a samara).

present when the leaves first come from the bud soon fall away. The flowers are in lateral clusters, which arise from the axils of the leaves, and appear in the spring before the leaves. They hang by long pedicels, and the petals are absent. The calyx is bell-shaped, and 4-9-cleft on the margin. The stamens vary also in number in about the same proportion. A section of the flower in fig. 347 shows the arrangement of the parts, the ovary in the center. The ovary has either one or two locules, and two styles. The mature fruit has one locule, and is margined with two winged explansions as shown in the figure. This kind of a seed is a samara. 


\section{POLYGONIFLORÆ.}

516. Buckwheat family (polygonaceæ). - Besides the common buckwheat. from which this family gets its name, the knotweeds are good representatives. Fig. 348 is of the arrow-leaved knotweed, or arrow leaved tear-thumb, so called because of the arrow-shaped leaves and from the prominent recurved prickles on the fourangled stem. The plant occurs in low grounds often i $n$ large clumps, and the slender branched stem is supported to some extent by neighboring plants. The flowers are in

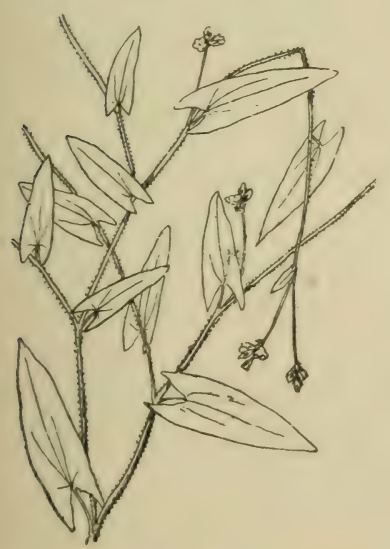

Fig. 348 .

Polygonum sagittatum, portion of plant.

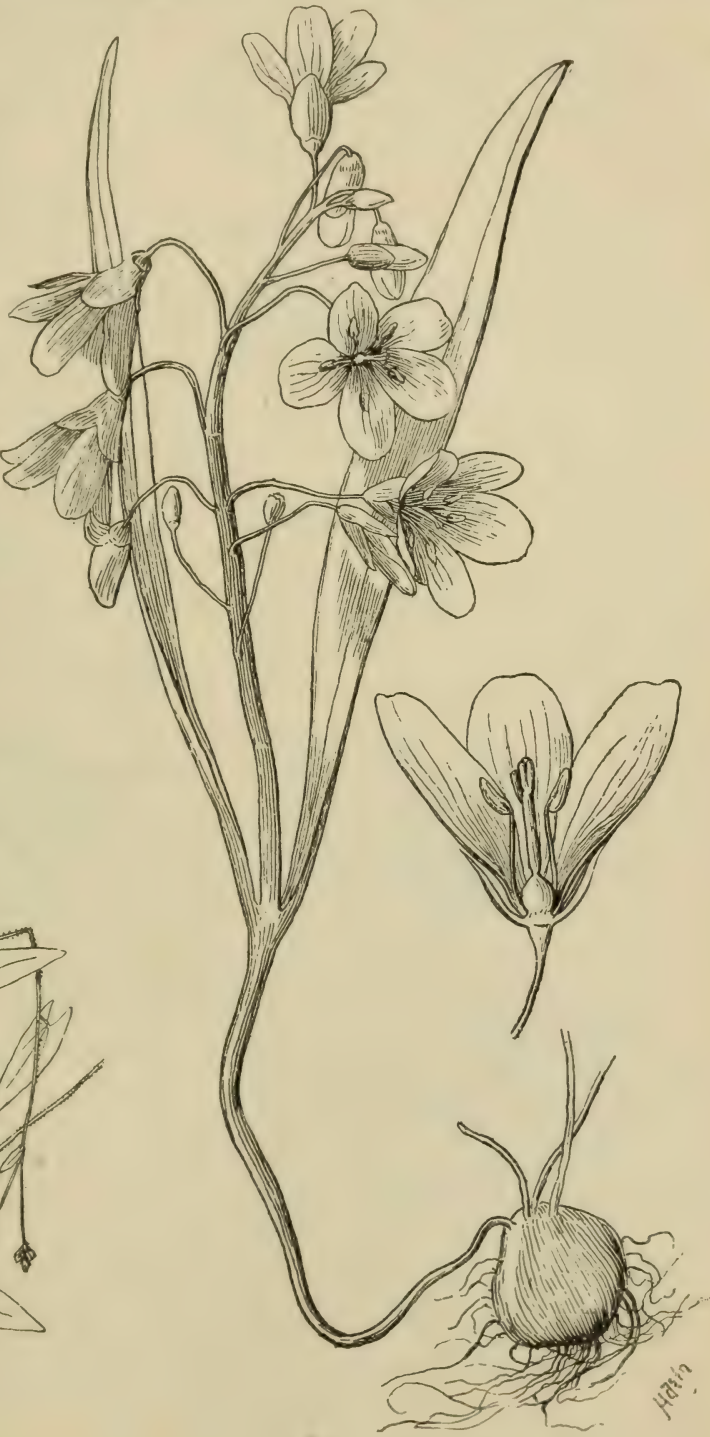

Fig. 349 .

Spring beauty (Claytonia virginiana). 
oval clusters borne on slender, long peduncles which arise from the axils of the leaves. Petals are wanting, and the calyx is usually five-parted, with the margin colored. The stamens are mostly eight, and the styles three on the compound ovary. There is a singie seed developed in the ovary which in ripening forms a three-angled achene like a buckwheat grain. The species of dock, and of field, or sheep, sorrel (rumex) also belong to this family.

\section{CURVEMBRY Æ.}

517. The purslane family (portulacaceæ).-The little spring beauty (Claytonia virginica), shown in fig. 349 , is a member of this family. It occurs in moist places. The stem arises from a deeply buried tuber, and bears, about midway, two long, narrow, fleshy, thick leaves. The upper part of the stem bears a raceme of pretty rose-colored flowers. The sepals are two. The petals are five in number, and the stamens of the same number are inserted on little claws at the base of the petals. The ovary has a long style, three-cleft at the apex, and in fruit it forms a three-valved pod. The ovule in claytonia and other members of the family is curved, and consequently the embryo is curved.

518. In some other related families, like the goosefoot family, the embryo
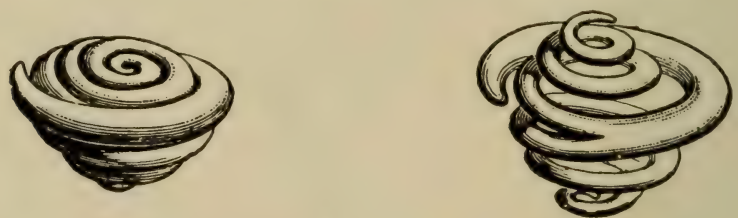

Fig. 350 .

Curved embryos of Russian thistle (Salsola soda). (Warming.)

is also curved. In fig. $35^{\circ}$ is shown the embryo of the Russian thistle (Salsola kali), a member of this family.

POLYCARPICA.

519. Lesson VII. The crowfoot family (ranunculaceæ).The marsh-marigold (Caltha palustris) is a member of this family. The leaves are heart-shaped or kidney-shaped, and the edge is crenate. The bright golden-yellow flowers have a single whorl of petal-like envelopes, and according to custom in such cases they are called sepals. The number is not definite, varying from 
five to nine usually. The stamens are more numerous, as is the

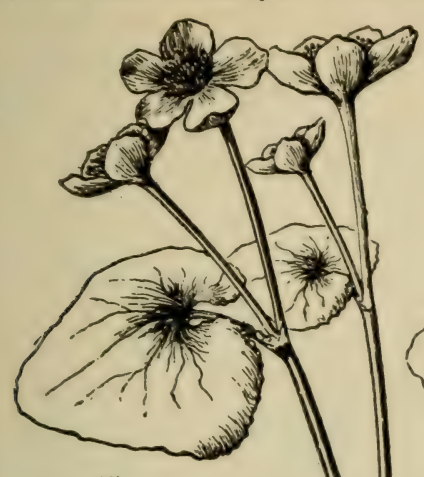

Fig. $35 \mathrm{r}$.

Caltha paiustris, marsh-marigold.

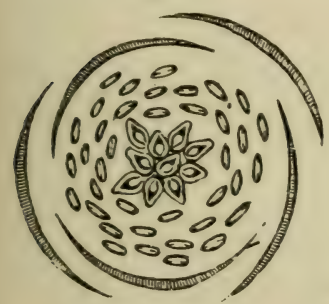

Fig. 352 .

Diagram of marsh marigoid flower.

general rule in the members of the family, but the number of the pistils is small. Each one is separate, and forms a little pod when the seed is ripe. The marshmarigold, as its name implies, occurs in marshy or wet places and along the muddy banks of streams. It is one of the common flowers in April and May.

520. Many of the crowfoots or buttercups (ranunculus) with bright yellow flowers grow in similar situations. The "wood anemone"' (anemone), small plants with white flowers, and the rueanemone (anemonella), which resembles it, both flower in woods in early spring. The common virgin's bower (Clematis virginiana) occurs along streams or on hillsides, climbing over shrubs or fences. The vine is somewhat woody. The leaves are opposite, petioled, and are composed of three leaflets, which are ovate, three-lobed, and usually . strongly toothed, and somewhat heart-shaped at the base. The flower clusters are borne in the axils of the leaves, and therefore may also be opposite. The clusters are much branched, forming a convex mass of Diagram of aquilegia flower. (Vines) beautiful whitish flowers. The sepals are colored and the petals 
may be absent, or are very small. The stamens are numerous, as in the nembers of the crowfoot family. The pistils are also numerous, and the achenes in fruit are tipped with the long plumose style, which aids them in floating in the air.

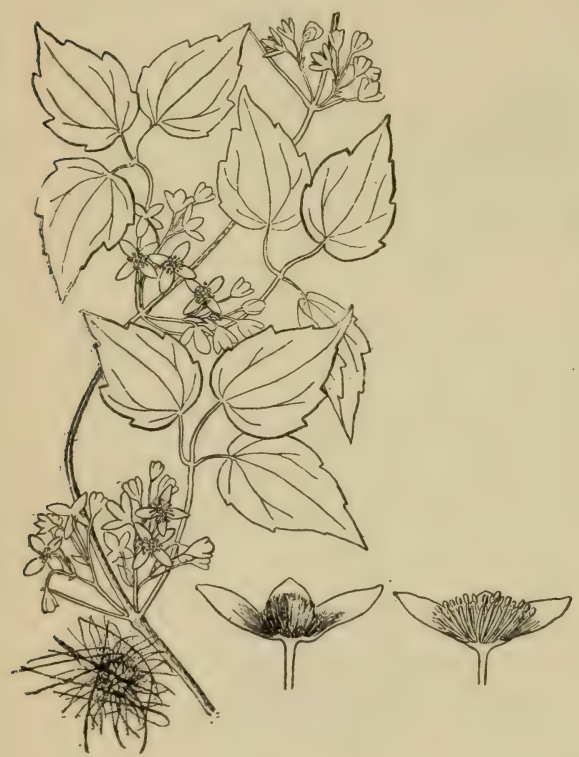

Fig. 354 .

Clematis virginiana; below at right are pistillate and staminate flowers.

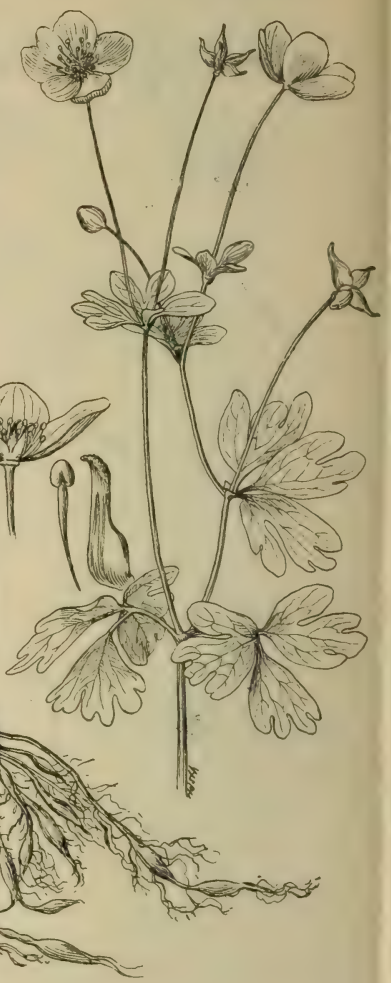

Fig. 355 .

Isopyrum biternatum.

521. Some of the characters of the ranunculaceæ we recognize to be the following: The plants are mostly herbs, the petals are separate, and when the corolla is absent the sepals are colored like a corolla. The stamens are numerous, and the pistils are either numerous or few, lut they are always separate from each other, that is they are not fused into a single pistil (though sometimes there is but one pistil). All the parts of the flower are separate from each other, and make 11) successive whorls, the pistils terminating the series. When the seeds are ripe the fruit is formed, and may lie in the form of a pod, or achene, or in the form of a berry, as in the baneberry (actæa). 
522. The following families are related to the crowfoot family. The waterlily family, the magnolia family, and the barberry family with the May-apple as an example (see figure 300). In all there is a relationship shown by the separate and usually numerous carpels. Together they form a large group, the polycarpicre.
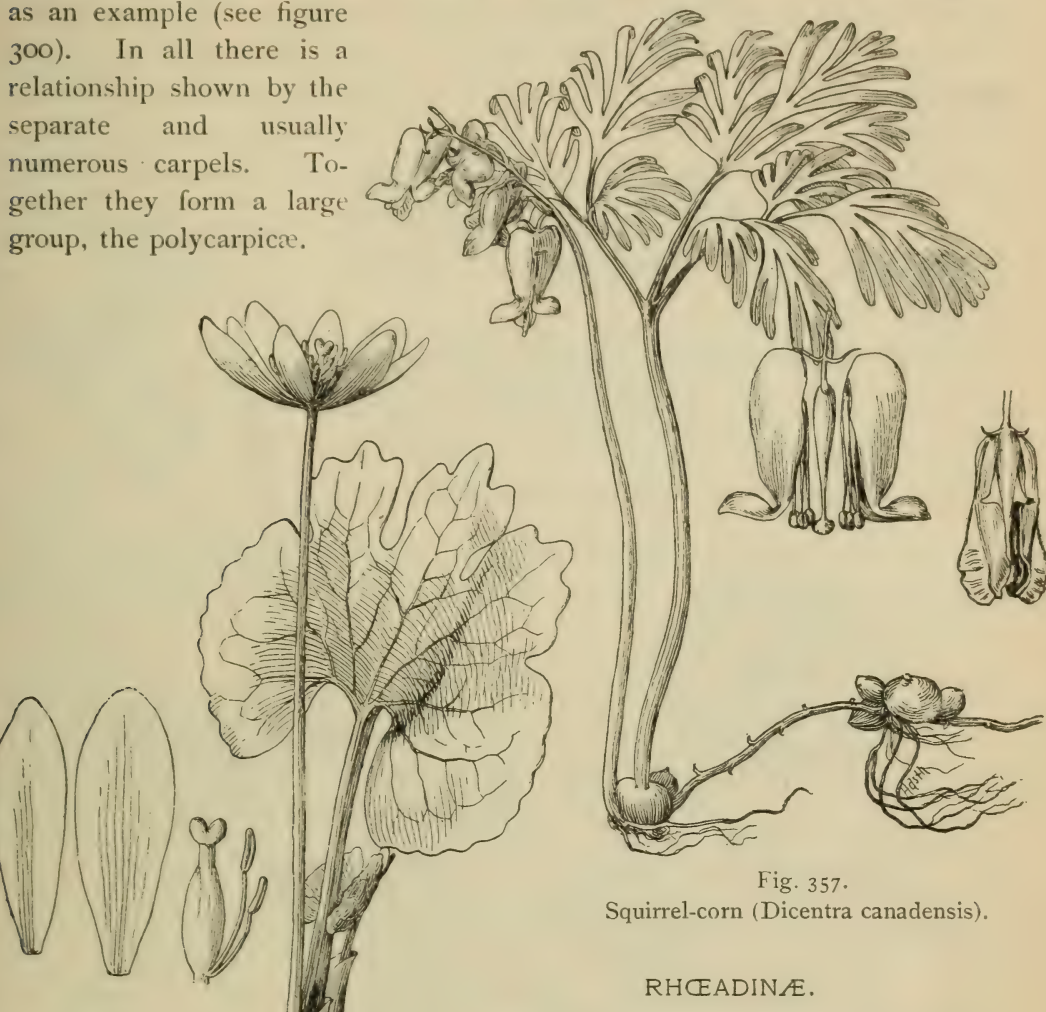

Fig. 357 .

Squirrel-corn (Dicentra canadensis).

RHCEDIN $Æ$.

523. The poppy family (papaveraceæ). -One of the commonest of the members of this family in the eastern United States is the bloodroot (Sanguinaria canadensis). It occurs in open woods in April and May. It derives its name from the abundant red juice (latex) in the perennial root-stock. The low annual shoot bears usually a single white flower, and one leaf, someFig. $35^{6}$.

Bloodroot (sanguinaria). Details of flower at left.

times more. The floral formula is as follows: $\mathrm{Ca}, \mathrm{Co} 8$ (or I0), A $\infty, \mathrm{G} 2$.

524. The fumitory family (fumariaceæ). - To this family belong the singular plants, "dutchman's breeches" and "squirrel-corn" (dicentra). They occur in rich woods in April and May. In the squirrel-corn (I). canadensis) there is a slender underground stem which bears here and there, as shown 
in fig. 357, small yellow tubers resembling grains of corn. The leaves are compound, and the lobes are finely dissected. The flower scape bears a slender raceme of curious pendulous, greenish-white flowers, sometimes tinged with rose color. The details are shown in the figure. The stamens are six in number, arranged in two groups of three (being in two groups they are diadelphous).

525. Lesson VIII. The mustard family (cruciferæ).-This is well represented by the toothwort (dentaria), which we studied in a former chapter.

These three families (poppy, fumitory, and mustard) are closely related as shown by the regular flowers, which are usually in twos (dimerous) or in fours (tetramerous).

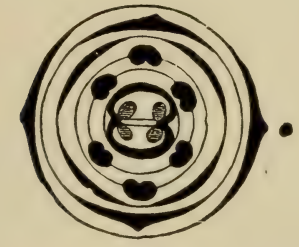

Fig. 358 .

Diagram of cruciferous flower.

GRUINALES.

527. Lesson IX. The geranium family (geraniaceæ). - The wild cranesbill has a perennial underground rootstock. From this in the spring arises the branched,

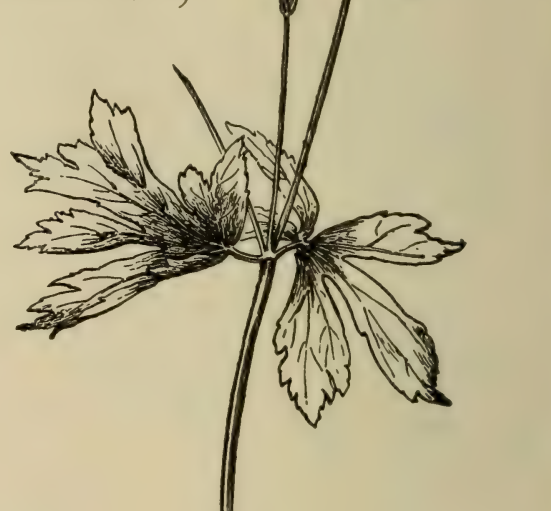
hairy stem. The leaves are showing upper leaves, flowers, and pods. deeply parted into about five wedge-shaped lobes, which are again cut. The peduncles bear several purple flowers (fig. 359). The floral formula is as follows: $\mathrm{Ca}_{5}, \mathrm{Co}_{5}, \mathrm{~A}_{10}, \mathrm{G}_{5}$. 'The woodsorrel (oxalis), the balsam or jewelweed (impatiens), sometimes called " touch-me-not," are members of the same family. 


\section{CHAPTER XILI.}

\section{DICOTYLEDONS CONTINUED.}

Topic VI: Dicotyledons with distinct petals and perigynous or epigynous flowers.

Many trees and shrubs.

ÆSCULINÆ.

528. Lesson X. The maple family (aceraceæ).-Figure 360 represents a spray of the leaves and flowers of the sugar maple

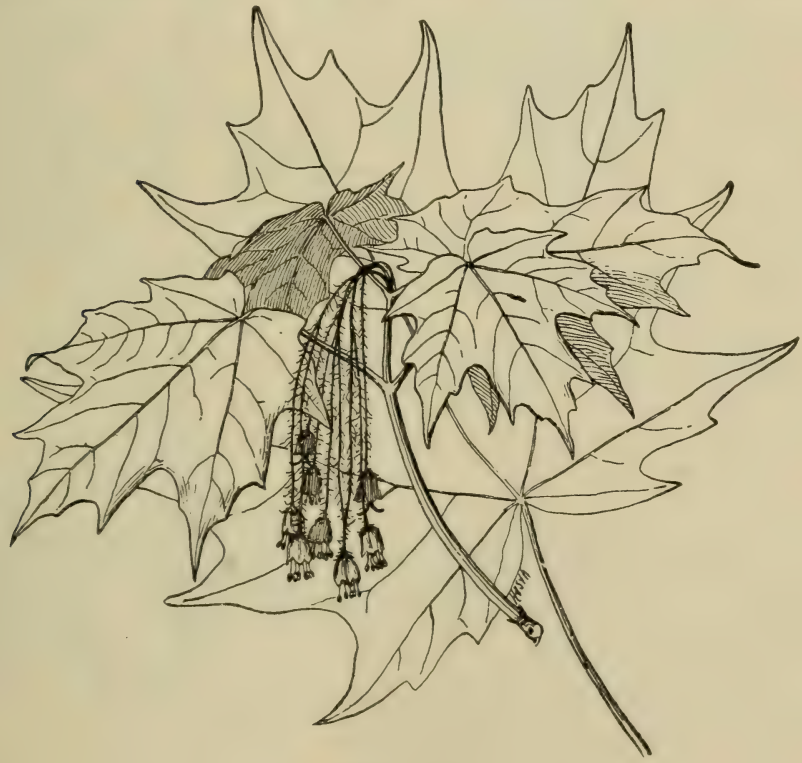

Fig. $360 a$.

Spray of leaves and flowers of the sugar maple.

(Acer saccharinum), a large and handsome tree. The leaves are opposite, somewhat ovate and heart-shaped, with three to five 
lobes, which are again notched. The clusters of flowers are pendulous on long hairy pedicels. The petals are wanting. The
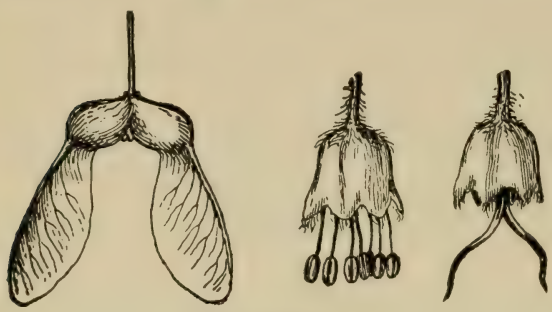

Fig. 3606 .

Seeds and flowers of sugar maple. At the right is a pistillate flower, in the middle a staminate flower, and at the left the two seeds forming a samara.

calyx is bell-shaped and several times lobed, usually five times. The stamens are variable in number. The ovary is two-lobed and the style deeply forked. 'The fruit forms two seeds, each with a long wing-like expansion as shown in the figure. The flowers of the maple are polygamo-dicecious, that is the male members (stamens) and female members (carpels) may be in the same flower or in different flowers.

SAXIFRAGINÆE.

529. The saxifrage family ( $\mathrm{sax}$ ifragaceæ). - The early saxifrage (Saxifraga virginiensis) is a small plant $10-25 \mathrm{~cm}$ high, and grows on rocky and dry hillsides (fig. 36r). The ovate or heart-shaped leaves Early saxifrage (Saxifraga virginiensis). have crenate margins, and are clustered near the ground. The scape bears a branched cluster of flowers at the summit. Floral formula $\mathrm{Ca}_{5}, \mathrm{Co}_{5}, \mathrm{~A}_{1}$,, $\mathrm{G}_{2}$. 
ROSIFLORA.

530. Lesson XI. - The rose-like flowers are an interesting and important group. In all the members the receptacle (the end of the stem which bears the parts of the flower) is an important part of the flower. It is most often widened, and either cup-shaped or urn-shaped, or the center is elevated. The carpels are borne in the center in the depression, or on the elevated central part where the receptacle takes on this form. The calyx, corolla, and the stamens are usually borne on the margin of the widened receptacle, and where this is on the margin of a cup-shaped or urnshaped receptacle they are said to be perigynous, that is, around the gynocium. 'The calyx and corolla are usually in fives. There are three fimilies, as follows.

531. The rose family (rosaceæ).-In this family there are five

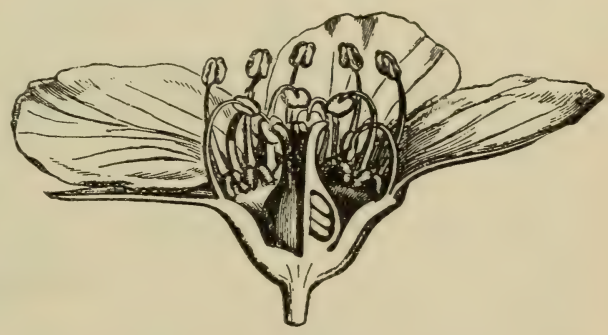

Fig. 362 .

Perigynous flower of spiræa (S. lanceolata). (From Warming.)

types, represented by the following plants and illustrations: Ist. In spiræa (fig. 362) the receptacle is cup-shaped. There

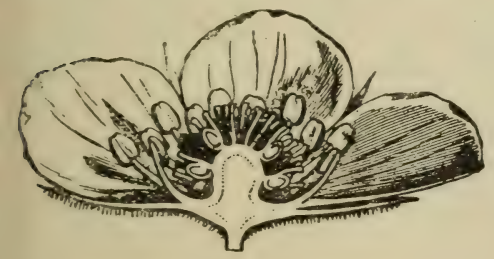

Fig. 363 .

Flower of Fragaria vesca with columnar receptacle (From Warming.) are five carpels, united at the base, but free at the ends. 2 d. In the strawberry the receptacle is conic and bears the carpels (fig. 363 ). The conic receptacle becomes the fleshy fruit, with the seeds in little pits over the surface. $3 \mathrm{~d}$. The raspberries, blackberries, etc., represented here by the flowering raspberry (Rubus odoratus), fig. 364 . 4th. This is represented by the roses. The receptacle is urn-shaped and constricted 


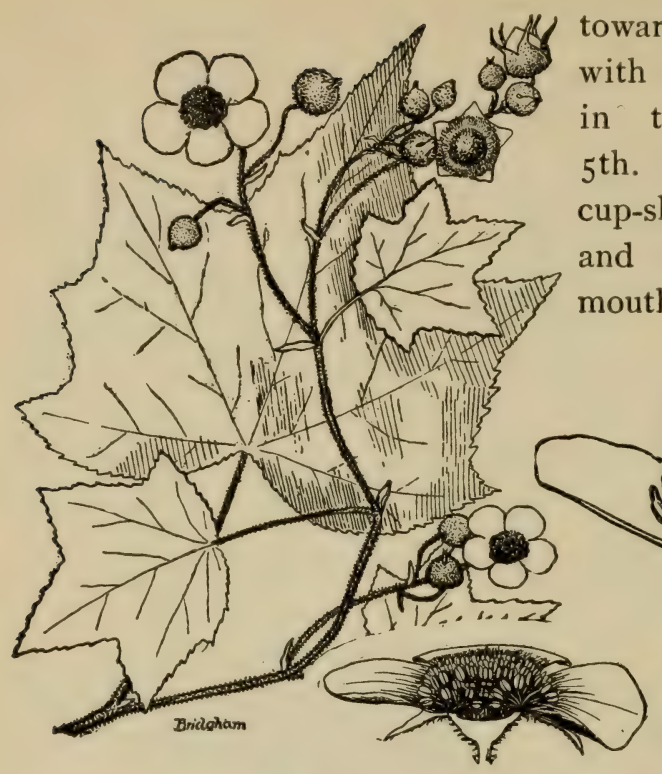

Fig. 364 .

Flowering raspberry (Rubus odoratus).

toward the upper portion, with the carpels enclosed the base (fig. $3^{6} 5$ ). 5 th. Here the receptacle is cup-shaped or bell-shaped and nearly closed at the mouth as in the agrimony. 
are at first perigynous, but become epigynous (upon the gynœcium) by the fusion of the receptacle with the carpels. The floral

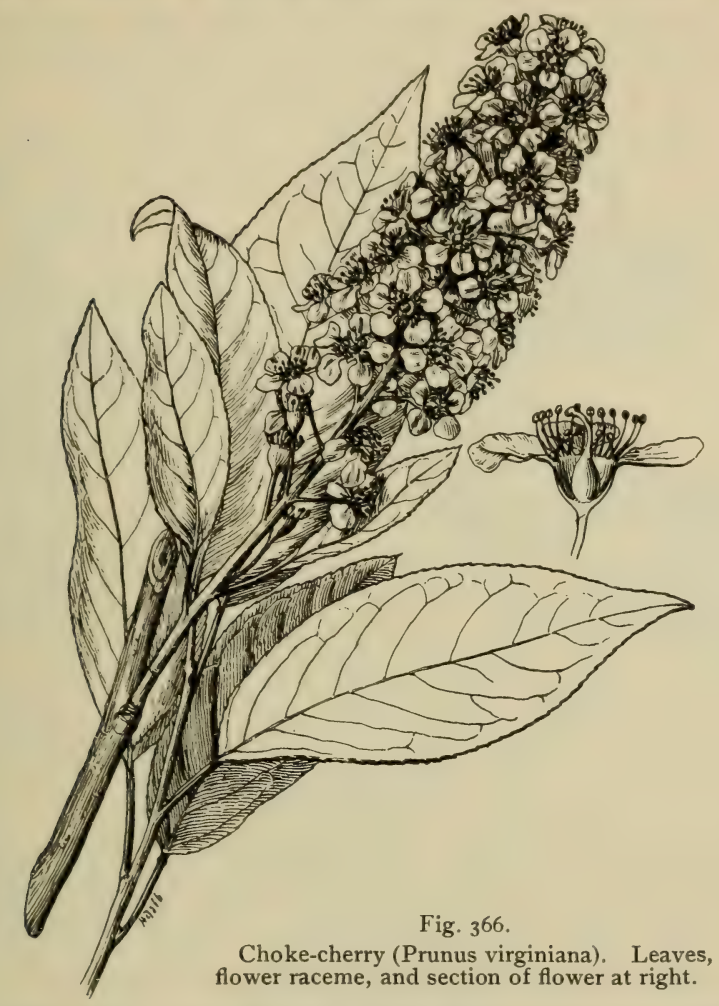

formula is thus $\mathrm{Ca}_{5}, \mathrm{Co}_{5}, \mathrm{~A}_{\mathrm{IO}}-5-5$ or $\mathrm{IO}_{-} \mathrm{IO}_{-5}, \mathrm{G}_{\mathrm{I}}-5$. The carpels

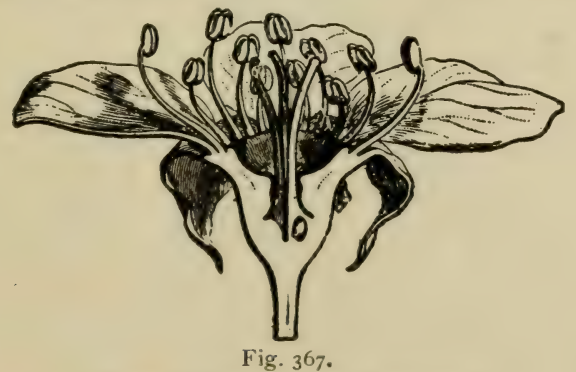

Flower of pear. (After Warming.)

are united, but the styles are free. In fruit the united carpels fuse more or less with the receptacle. 


\section{LEGUMINOSA.}

534. Lesson XIV. The pea family (papilionaceæ).-This family is well represented by the common pea. The flower is

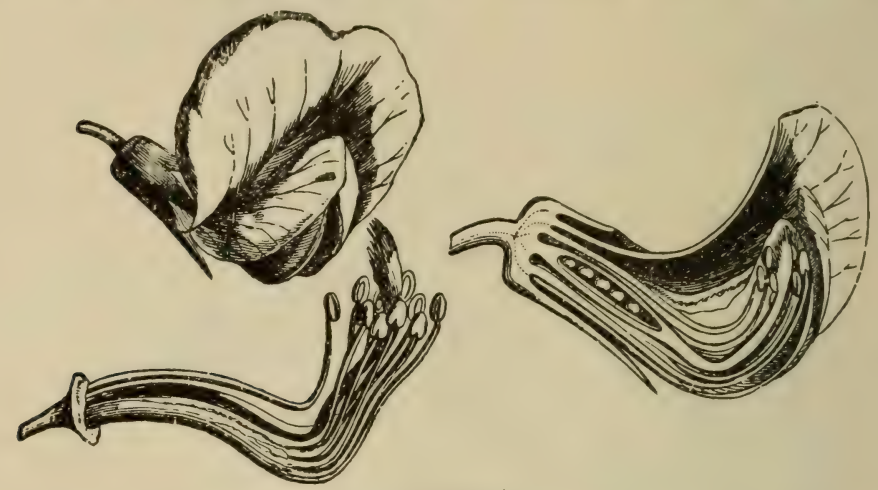

Fig. 368 .

Details of pea flower; section of flower, perianth removed to show the diadelphous stamens, one single one, and nine in the other group. (From Warming.)

butterfly-like or papilionaceous, and the showy part is made up of the five petals. The petals have received distinct names here because of the position and form in the flower. At fig. 369 the petals are separated and shown in their corresponding positions, and the names are there'given. The flower is irregular and the parts are in fives, except the carpel, which is single. The calyx is gamosepalous (coherent), the corolla polypetalous (distinct). The ten stamens are in two groups, one separate stamen and nine united; they are thus diadelphous (two brotherhoods). The fruit forms a pod or legume, and at petals forming keel. $k$, two maturity splits along both edges.

535. There are three families in the legmme-bearing plants: Ist, including the locusts, cassias, etc: $2 \mathrm{~d}$, the pea family, including peas, beans, clovers, ground-nuts, or peanuts, vetches, desmodium, etc.; $3 \mathrm{~d}$, including the sensitive plants like mimosa. 


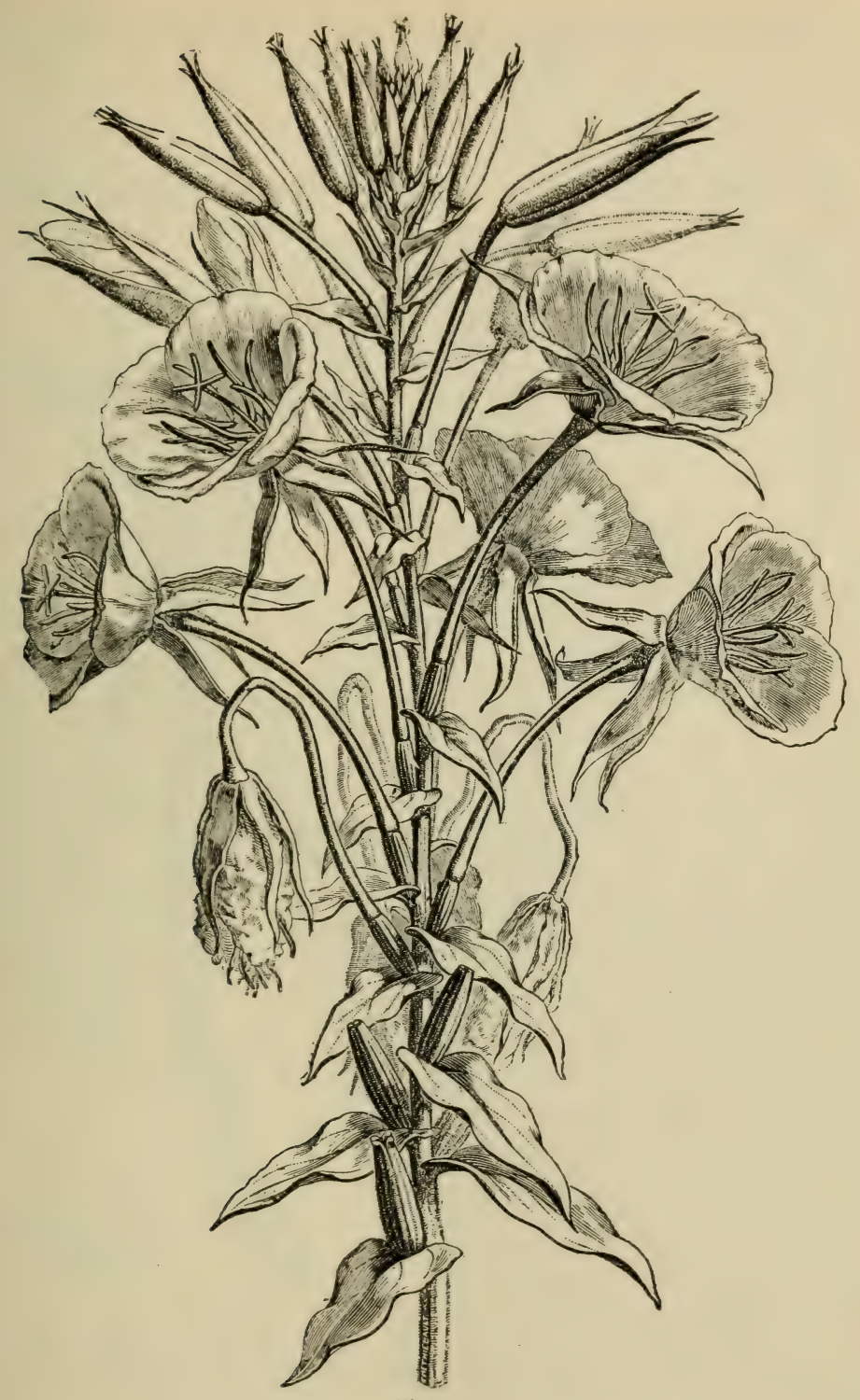

Fig. 370 .

Evening primrose (CEnothera biennıs) showing flower buds, flowers, and seed pods. (From Kerner and Oliver.) 
Topic VII: Dicotyledons with distinct petals and epigynous flowers.

\section{MYRTIFLORÆ.}

\section{Lesson XV. The evening-primrose family (onogra-} ceæ). - In the evening primrose (œnothera) the flowers are arranged in a loose spike along the end of the stem, each one situated in the axil of a leaflike bract. The flowers of the family are very characteristic, as shown here. They are sessile in the axil of the bract, and the calyx forms a long tube by the union of the sepals, only the end of the tube being divided into the individual parts, showing four lobes. On the edge of the open end of the calyx tube are seated the four, somewhat heartshaped, yellowish petals, and here are also seated the eight stamens. The four carpels are united into a single pistil within the base of the calyx tube and united with it, so that the calyx tube seems to be on the end of the pistil. The flowers soon fade and fall away from the pistil, and this grows into an elongated four-angled pod. Since the

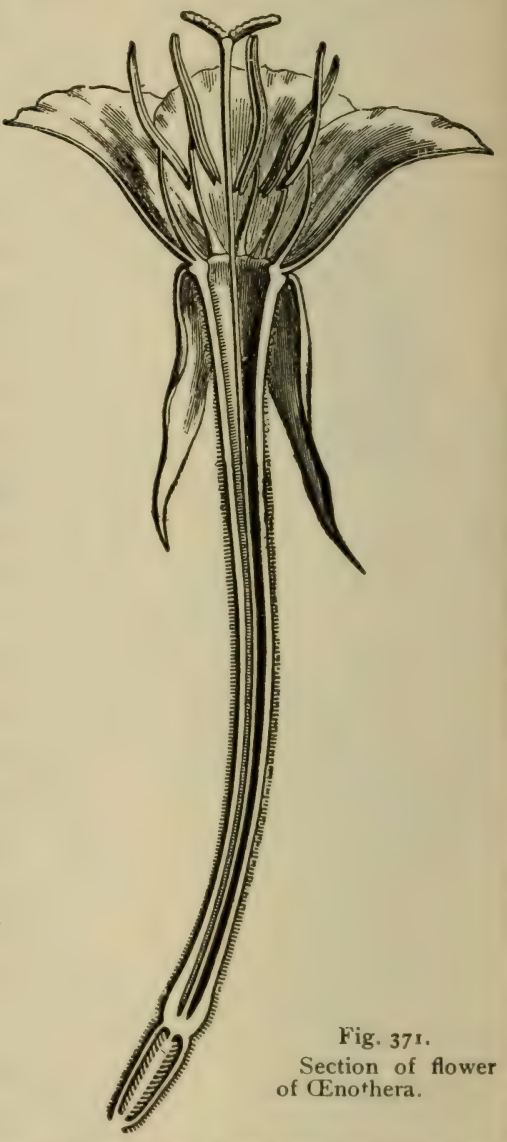
lower flowers on the stem are the older, we find nearly mature fruit and fresh flowers, with all intermediate grades, on the same plant.

The plants grow by roadsides and in old fields. They are from I $\mathrm{cm}$ to a meter or more high (one to five feet). The leaves are 
lanceolate or oblong, toothed and repand on the margin. In many of the species of the family the parts of the flower are in fours as in the evening primrose, but in others the number is variable.

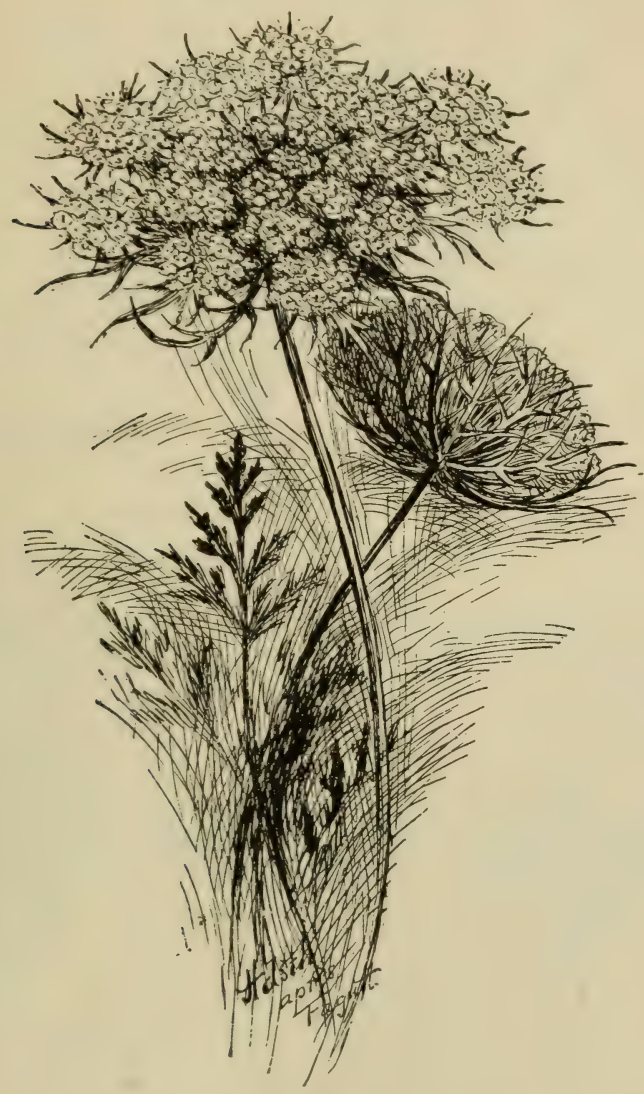

Fig. 372 .

Wild carrot.

\section{UMBELLIFLOR/E.}

537. The parsley family (umbelliferæ). - The wild carot (Daucus carota) is common by roadsides and in old fields during August and September. The leaves are deeply divided and the lobes are notched (pinnately decompound). The flowers form umbels, since the pedicels are all of about the same length, and many of them radiate from the same point. In the carrot, and in most of 
the parsley family, the umbel is a compound one, as shown in the illustration. The calyx is firmly united with the walls of the ovary, which is formed of two united carpels. The five white petals as well as the five stamens arise from the

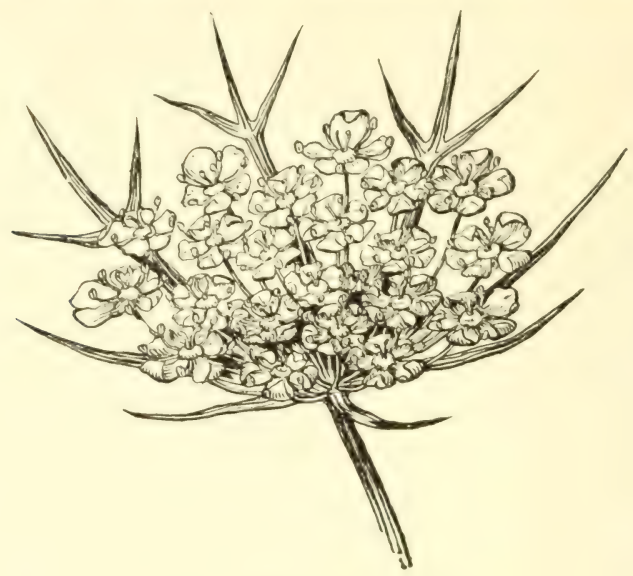

Fig. 373 .

Single umbel of the wild carrot.

margin of the ovary around the two styles. No portion of the calyx is free in the wild carrot, though in some other members of the family there are small

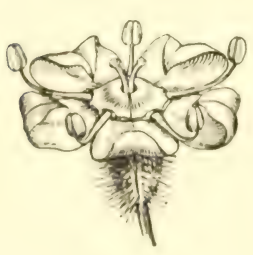

Fig. 374 .

Flower of wild carrot.

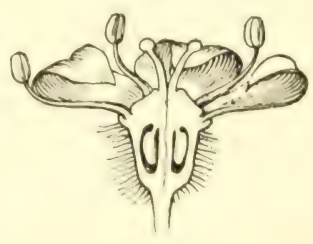

Fig. 375 .

Section of flower.

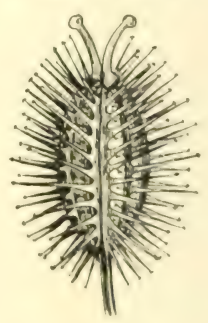

Fig. 376.

Seed of wild carrot.

calyx teeth. The fauit is bristly and the surface of the umbel becomes concave in age. The floral formula is as follows: Ca 5 , C $05, \mathrm{~A}_{5}$, G 2 .

The cornel or dogwood family and the aralia family both have the flowers in unbels, and are thus related to the parsley family. 


\section{CHAPTER XLII. \\ DICOTYLEDONS CONCLUDED.}

\section{SYMPETALÆ.}

538. In the remaining families the corolla is gamopetalous, that is, the petals are coherent into a more or less well-formed tube, though they may be free at the end. For this reason they are known as the sympetala.

\section{Topic VIII: Dicotyledons with united petals, flower parts in five whorls.}

\section{BICORNES.}

539. The pyrola family (pyrolaceæ).-The shin-leaf or wintergreen (Pyrola elliptica), not the aromatic wintergreen, is figured at 377. The oval or elliptical leaves are clustered at the base. The flower scape is $15-30 \mathrm{~cm}$ high and bears a raceme at the summit. The flowers hang singly from the axils of colorless bracts. The floral formula is as follows: Ca5, Co5, A I0, G5. The Indianpipe (monotropa) is also a member of the pyrola family.

540. Lesson XVI. The whortle-
berry family (vacciniaceæ).-The common whortleberry, or huckleberry (Gaylussacia resinosa), flowers in May and June. The shrubs are from $30 \mathrm{~cm}$ to I meter ( $\mathbf{I}-3$ feet) high, and are much branched. The leaves are ovate, and when young are more or less clanimy from numerous resinous dots, from which the plant gets its specific

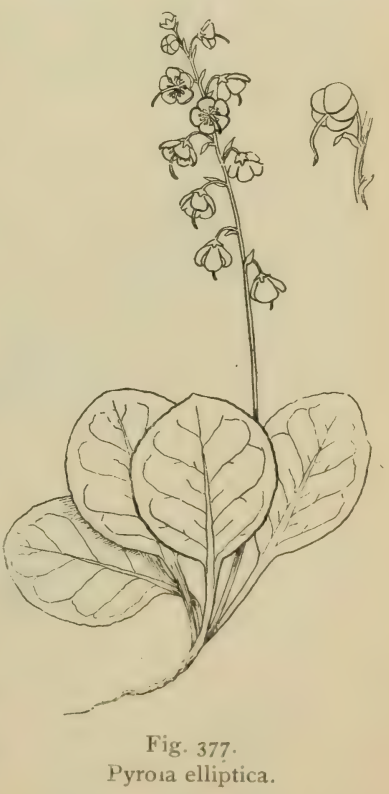
name (resinosa). The flowers are borne on separate shoots from 
the leaves of the same season, and hang in one-sided short racemes as shown in fig. 378 . The calyx is short, five-lobed,

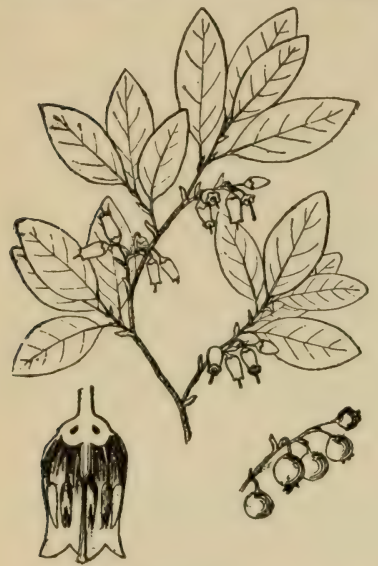

Fig. 378 .

Whortleberry (Gaylussacia resinosa). and adheres to the ovary. The corolla is tubular, at length cylindrical with five short lobes, and is whitish in color. The stamens are ten in number, and the compound ovary has a single style. The fruit is a rounded black, edible berry or drupe, with ten seeds.

541. The family ericaceæ

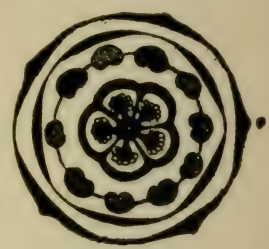

Fig. 379. Diagram of Erica. (Vines.) contains the trailing arbutus, cassandra, andromeda, cassiope, etc. The rhododendron family contains the rhododendrons, azaleas, kalmias, etc. These with the pyrola and whortleberry families are closely related and make up the order heaths, or Bicornes as they are sometimes termed, because the anther frequently has two horn-like appendages.

\section{PRIMULINÆ.}

542. The primrose family (primulaceæ). - The primroses (primula) represent well this family. In fig. 453 is represented the flower of the primrose grown in conservatories. It is gamosepalous and gamopetalous. There are five stamens, each one inserted on flower. (Vines.)

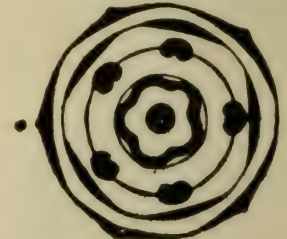

Fig. 380 .

Diagram of primula the tube of the corolla and opposite the lobe. (For a description of the flower see chapter on pollination, Part III.) The floral formula is $\mathrm{Ca}_{5}, \mathrm{Co}_{5}, \mathrm{~A}_{5}, \mathrm{G}_{5}$.

\section{Topic IX: Dicotyledons with united petals, flower parts in four whorls.}

\section{TUBIFLORÆ.}

543. The morning-glory or bindweed family (convolvulaceæ). - The hedge bindweed (Convolvulvus sepium) occurs in moist soil along streams. The stem is twining as in most of the members of the family. The leaves are 


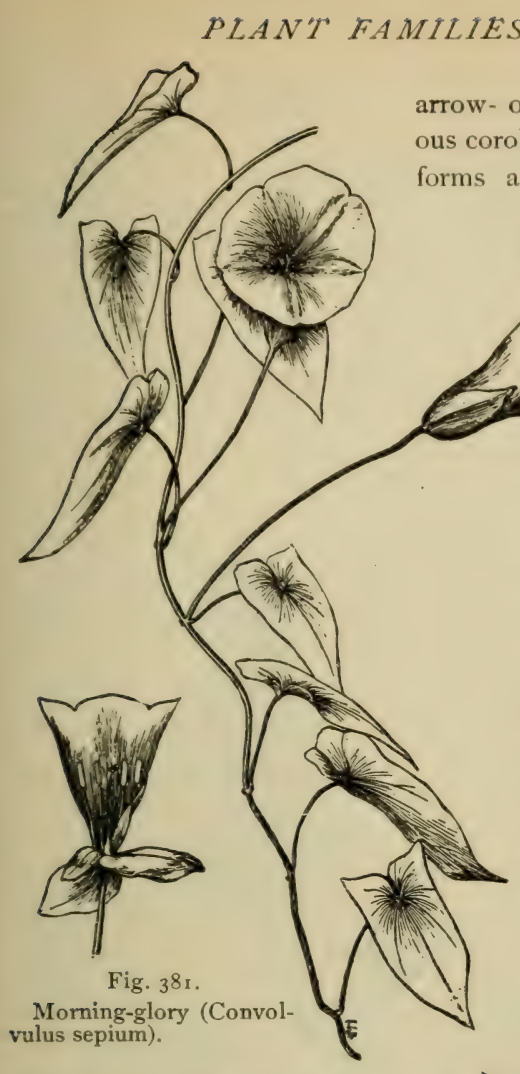

: PERSONATAE.

bacco, etc., are members of the nightshade family.

545. The figwort family (scrophulariaceæ). - The mullein (verbascum), toad-flax (linaria), turtlehead (chelone), etc , are members of the figwort family. The plants are mostly herbs. The stamens are usually didynamous (four in two pairs, one pair shorter than the other) or diandrous (two stamens). The stamens are inserted on the two lipped corolla tube, which is more or less irregular. In some genera there are five stamens, as in verbascum.

546. The borage family (boraginaceæ). - The pretty little forget-

PERSONATA.

544. The nightshade family (solanaceæ).-Fig. 382 represents the ground-cherry (physalis), a member of this family. The formula for the flower is $\mathrm{Ca}_{5}, \mathrm{Co}_{5}, \mathrm{~A}_{5}, \mathrm{G} 2$. The calyx becomes enlarged and inflated, enclosing the edible berry. The potato, egg-plant, tomato, to-

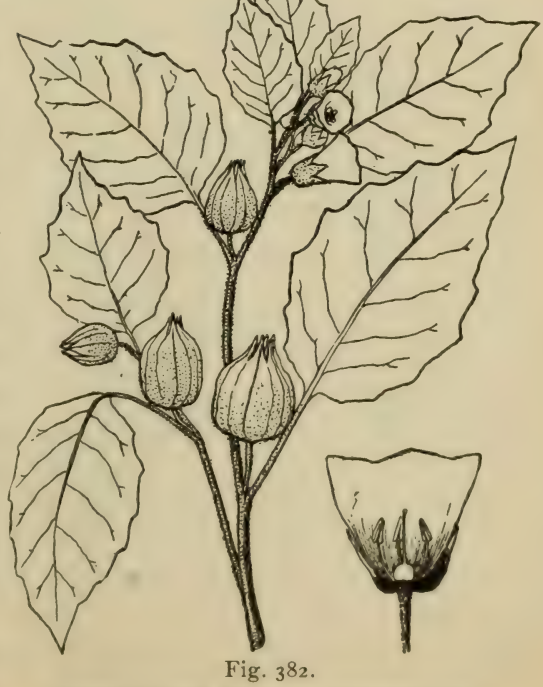

Ground-cherry (Physalis pennsylvanica). 
me-not belongs to this family. The flowers are borne in a curved and more or

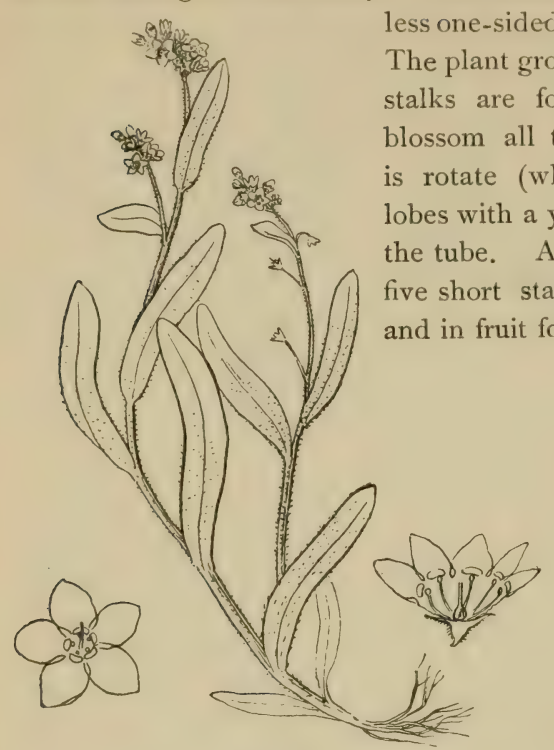

Fig. $3^{8}{ }_{3}$.

Forget-me-not.

NUCULIFERÆ.

\section{4\%. Lesson XVII. The mint} family (labiatæ).-The mint family contains a large number of genera and takes its common name from the mints, of which there are several species belonging to the genus mentha. In the figure of the " dead-nettle", (Lamium amplexicaule), which is also one of the members of this family, we see that the lobes of the irregular corolla are arranged in such a manner as to suggest two lips, an upper and a lower one. From this character of the corolla, which obtains in nearly all the members, the family receives its name of Labiatce. The calyx is five-lobed. The stamens, four in number, arise from the tule of the corolla, and converge in pairs. The ovary is divided into four lobes, and at the maturity of the seed 
these form four nutlets. The leaves are rounded, crenate on the margins, the lower ones petioled and heartshaped, and the upper ones sessile and clasping around the stem beneath the flower clusters. From the clasping character of the upper leaves the plant derives its specific name of amplexicaule. The plant occurs in waste places and is rather common.

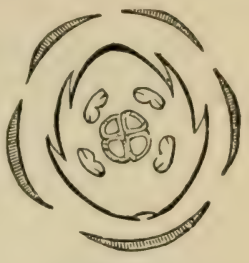

Fig. 385 .

Diagram of lamium flower.

\section{CONTORTA.}

548. The gentian family (gentianaceæ).-The gentians usually appear late in the summer or autumn. The fringed gentian (fig. 386) lingers often

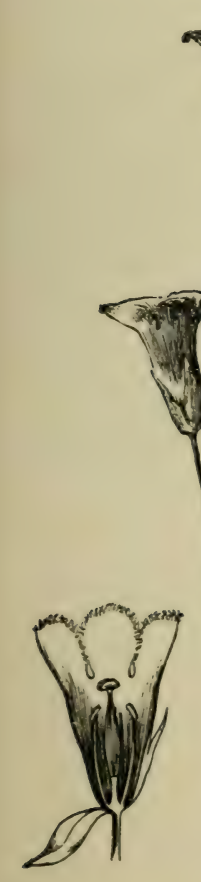

Fig. 386.

Gentian (G. crinita).

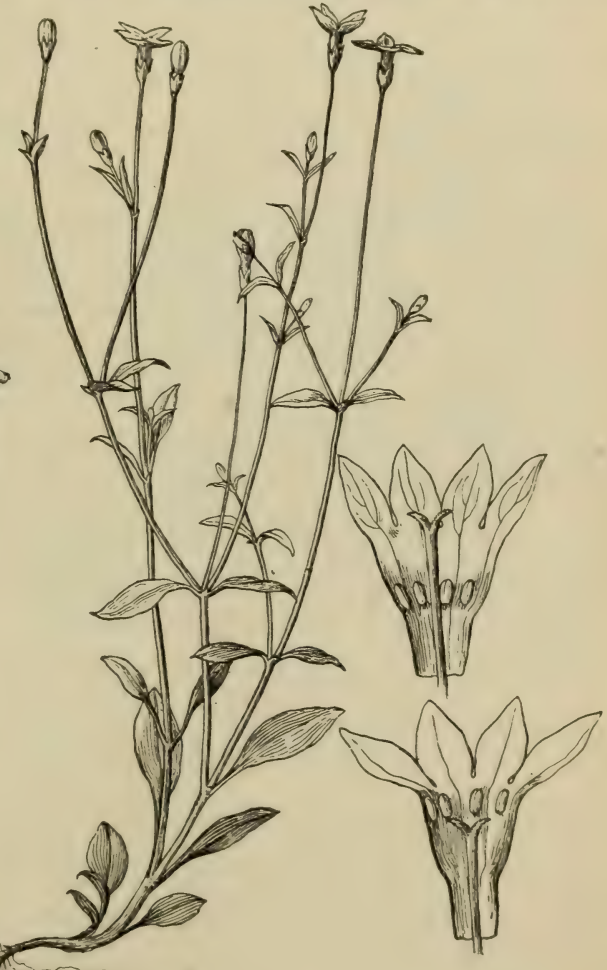

Fig. 387 .

The bluet (Houstonia cœrulea). 
until the snow arrives. The flower is gamosepalous and gamopetalous. The corolla is bell-shaped, with four lobes. The lobes are blue in color, somewhat spreading, and beautifully fringed on the margin. The members of the gentian family have opposite, simple leaves, and no stipules. The ovary has a single cavity, but is formed of two united carpels as shown by the two stigmas, and usually two placentæ.

\section{RUBIALES.}

549. Lesson XVIII. The honeysuckle family (caprifoliaceæ).-The members of this family are mostly shrubs (a few herbs) with opposite leaves. Flowers are gamosepalous and gamopetalous. The ovary is $2-5$-celled, and coherent with the

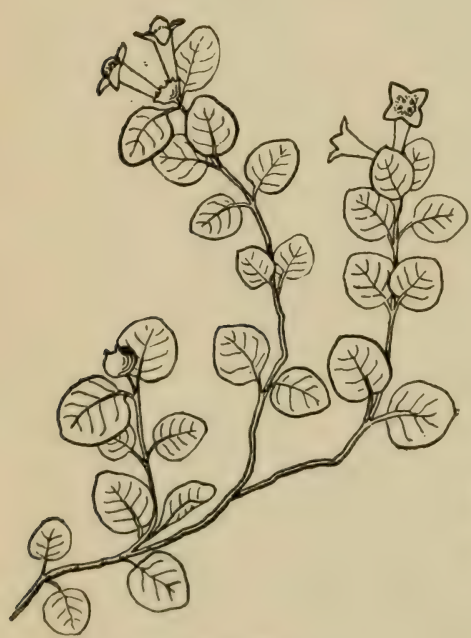

Fig. 388 .

Partridge-berry (Mitchella repens),

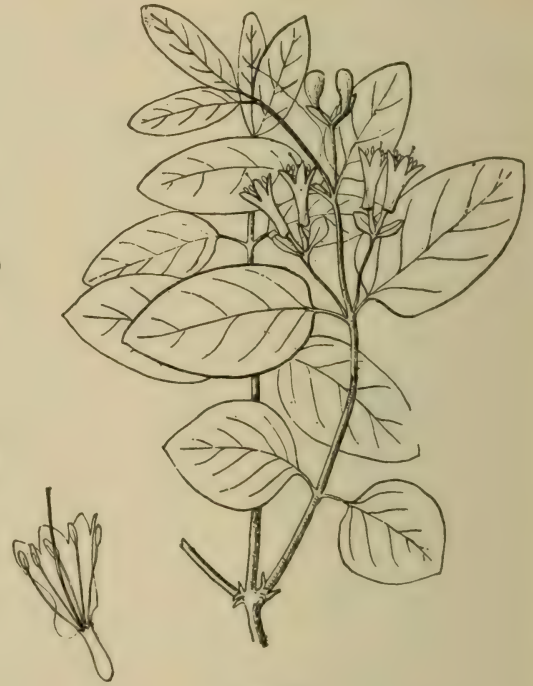

Fig. 389 .

Wild honeysuckle (Lonicera ciliata).

tube of the calyx. The corolla is tubular, or wheel-shaped, and the stamens are inserted on its tube. The fly-honeysuckle (Lonicera ciliata), shown in fig. 389 , is an example, with a tubular or funnel-shaped, nearly regular corolla. The corolla has a small spur at the base, and the flowers are in pairs.

550. The twin flower (Linnæa borealis) occurs in cold situa- 
tions in moors or damp woods, and blossoms in June. The stems are creeping and slender, the leaves rounded and crenate on the margin, tapering abruptly into short petioles. From the prostrate stems the flowering shoots arise 8-1ocm, leafy below, and above forking into two slender pedicels, each bearing a bell-shaped, purple and whitish flower. The calyx is coherent with the ovary, which has three locules. The five lobes of the calyx fall away as the flower dies. The corolla is five-lobed.

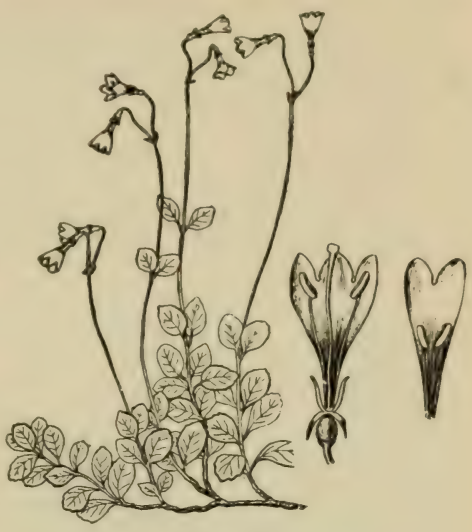

Fig. 390 .

Twin flower (Linnæa borealis). Four stamens, two of them shorter than the other two, are attached to the tube of the corolla.

551. Lesson XIX. The teasel family (dipsacaceæ).-This family is represented by the common fuller's teasel. The flowers are collected in a "head." They are separated from one another, however, by a small cup-shaped "epicalyx", which surrounds the inferior ovary. The limb of the calyx is short, and in some members of the family shows the five divisions. In the teasel there are four lobes on the limb of the corolla, which is unsymmetric and bilabiate (zygomorphic), two of the five parts of the corolia being completely united into one lobe, forming the upper lip. The stamens are not united by their anthers. (The distinct stamens and the presence of the epicalyx separating the flowers of the head are the most prominent characters separating the dipsacales from the aggregatæ.)

\section{CAMPANULINÆ.}

552. The bell-flower family (campanulaceæ). - The bell-flower (campanula) is illustrated in figure 458. The floral formula is as follows: $\mathrm{Ca}_{5}, \mathrm{Co}_{5}, \mathrm{~A}_{5}, \mathrm{G}_{2}$. The stamens are usually united by their anthers closely around the style. The style is provided with a brush of hairs, and in 
pushing its way up between the anthers brushes off some of the pollen and bears it aloft, where it becomes attached to visiting insects.

The lobelia family is related to the bell-flower family, and contains the cardinal-flower, great lobelia, and others.

\section{AGGREGAT $巴$}

553. Lesson $\mathbf{X X}$. The composite family (compositæ).-In

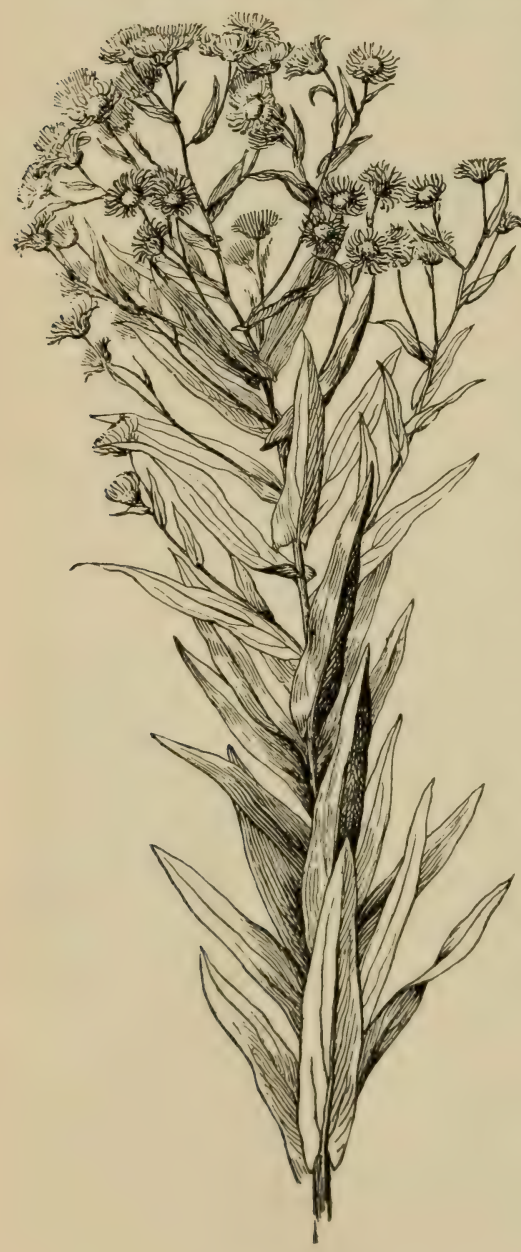

Fig. 391.

Aster novæ-angliæ.

all the composites, the flowers are grouped (aggregated) into "'heads," as in the sunflower, where each head is made up of a great many flowers crowded closely together on a widened receptacle. The family is a large one, and is divided into several sections according to the kinds of flowers and the different ways in which they are combined in the head. In the asters there is one common type illustrated in fig. $39 \mathrm{I}$ by the Aster nove-anglice. In the aster, as is well shown in the figures, the head is composed of two kinds of flowers, the

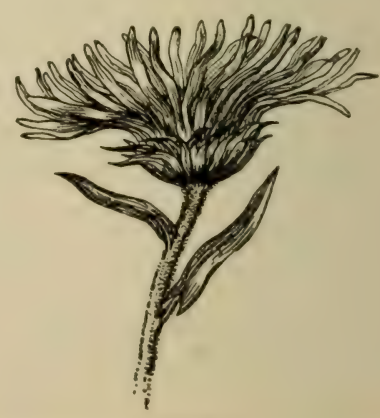

Fig. 392 .

Head of flowers of Aster novæ-angliæ. 
tubular flowers and the ray flowers. In the tubular flowers the corolla is united to form a slender tube, which is five-notched at the end, representing the five petals. In the ray flowers the corolla is extended on one side into a strap-shaped expansion. Together these strap-shaped corollas form the "rays" of the head. The corolla is split down on one side, which permits the end then to expand and form the "strap." This is a

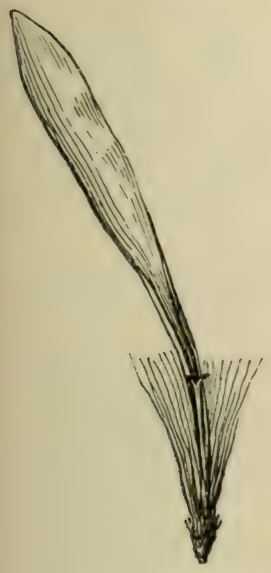

Fig. 393.

Ray flower of Aster nuvæangliæ.

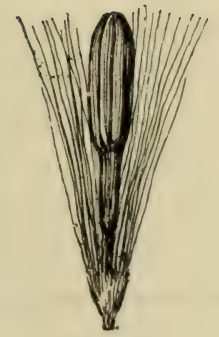

Fig. 394 .

Tubular flower of aster

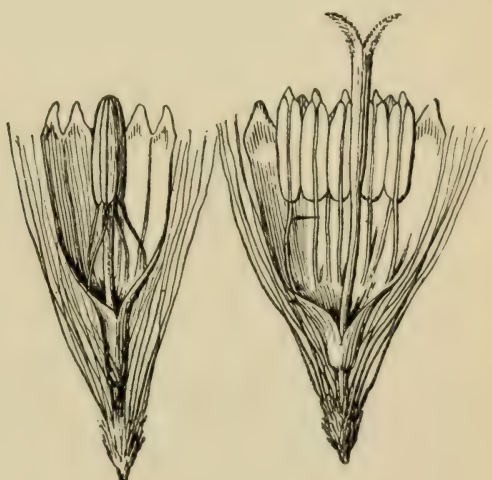

Fig. 395 .

Tubular flower opened to show syngenecious stamens.
Fig. 396.

Syngenecious stamens opened to show style and two stigmas.

ligula, or more correctly speaking a false ligula. In fact the ray flower is bilabiate. By counting the "teeth" of the false ligula there are found only three, which indicates that the strap here is made up of only three parts of the 5-merous corolla. The two other limbs of the corolla are rudimentary, or suppressed, on the opposite side of the tube. True ligulate flowers are found in the chicory, dandelion, or in the hieracium, where the five points are present on the end of the ligula.

554. The calyx tube in the aster, as in all of the composites, is united with the ovary, while the limb is free. In the aster, as in many others, the limb is divided into slender bristles, the pappus. (In some of the composites the pappus is in the form or 
scales.) The stamens are united by their anthers into a tube (syngenecious) which closely surrounds the style. (In ambrosia the anthers are sometimes distinct.) The style in pushing through brushes out some of the pollen from the anthers and bears it aloft as in the bell-flower, but the stigmatic surface is not yet mature and expanded, so that close pollination cannot take place. There are usually no stamens in the ray-flowers. The ovary is composed of two carpels, as is shown by the two styles, but there is only one locule, containing an erect, anatropous, ovule.

The floral formula for the composite family then is as follows: $\mathrm{Ca}_{5}, \mathrm{Co}_{5}, \mathrm{~A}_{5}, \mathrm{G}_{2}$.

555. The rattlesnake-weed (Hieracium venosum) is an example of another type, with only

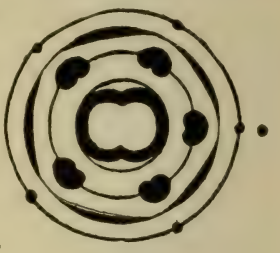

Fig. 397. Diagram of composite flower. (Vines.)

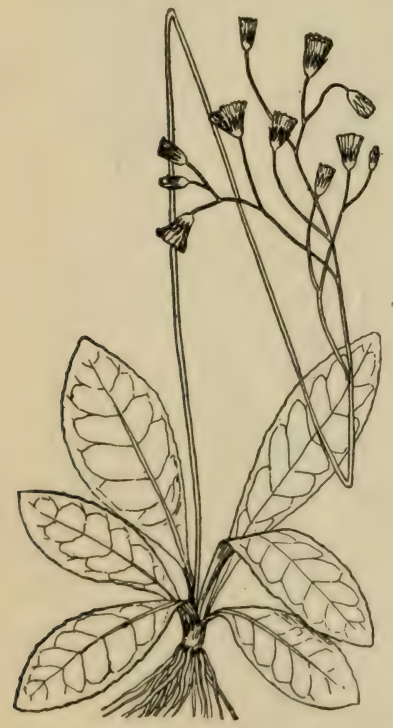

Fig. 398.

Rattlesnake-weed (Hieracium venosum).

late flower. The hawkweed, or devil's paint-brush (H. aurantiacum) is a related species, which is a troublesome weed. The dandelion and prickly lettuce are also members of the ligulateflowered composites. A number of the composites have only tubular flowers, as in the thoroughwort (eupatorium) and everlasting (antennaria).

556. The extent to which the union of the parts of the flower has been carried in the composites, and the close aggregation of the flowers in a head, represent the highest stage of evolution reached by the flowers of the angiosperms. The composites stand just above the bell-flowers and lobelias, at the termination of a series. The teasels show a relationship to the composites in the aggregation of the flowers in a head. But the consolidation of the parts of the flower has not been carried so far, and the flowers are each separated by an "epicalyx" in the form of a minute cupshaped involucre. The teasels stand at the termination of another series in 
which are the lonicera and valerian families. The gynœcium of the composites presents a highly specialized structure. The ovary is plainly made up of two carpels, as shown by the two styles and the internal structure, but it becomes reduced to a one-seeded achene. From the five carpels in the pyrolas to the composites there is a gradual tendency toward reduction in number of the carpels to two, and in the composites the highest specialization is reached in the consolidation of these into one achene in fruit. 


\section{CHAPTER XLIII.}

\section{OUTLINE OF TWENTY LESSONS IN THE ANGIOSPERMS.}

557. As a minimum study of the plant families in the angiosperms, the following twenty lessons are suggested to represent nine topics.

\section{MONOCOTYLEDONS.}

Topic I : Monocotyledons with conspicuous petals.

Lesson $I$ : Liliaceæ, lily family.

TOPIC II: Monocotyledons with flowers on a spadix.

Lesson 2: Araceæ, arum family.

Topic III: Monocotyledons with a glume subtending the flower.

Lesson 3: Gramineæ, grass family.

\section{DICOTYLEDONS.}

TopIC IV : Dicotyledons with distinct petals, flowers in catkins or aments, often degenerate.

Lesson 4: Salicaceæ, willow family.

Lesson 5: Cupuliferæ, oak family.

Topic V: Dicotyledons with distinct petals, and hypogynous flowers, not in true catkins.

Lesson 6: Ulmaceæ, elm family.

Lesson 7: Ranunculaceæ, crowfoot family. 
Lesson 8: Cruciferæ, mustard family.

Lesson 9: Geraniaceæ, geranium family.

TopIC VI : Dicotyledons with distinct petals, and perigynous or epigynous flowers. Many trees and shrubs.

Lesson IO: Aceraceæ, maple family.

Lesson II: Rosaceæ, rose family.

Lesson I 2: Amygdalaceæ, almond family.

Lesson I3: Pomaceæ, apple family.

Lesson I4: Papilionaceæ, pulse family.

Toprc VII : Dicotyledons with distinct petals and epigynous flowers.

Lesson I5: Onograceæ, evening primrose family; or Umbelliferæ, parsley family.

TopIC VIII : Dicotyledons with united petals, flower parts in five whorls.

Lesson I 6: Vaccineaceæ, whortleberry family.

Topic IX: Dicotyledons with united petals, flower parts in four whorls.

Lesson 17 : Labiatæ, mint family.

Lesson I8: Caprifoliaceæ, honeysuckle family.

Lesson I9: Dipsacaceæ, teasel family.

Lesson 20: Compositæ, composite family.

558. Synopsis of families studied in the angiosperms. The following synopsis of the families of the angiosperms is intended for reference in grouping the studies in order that the relationships of the families may be graphically represented. The tables therefore should not be memorized.

559. Table of families of monocotyledons studied.-In the monocotyledons there is a single cotyledon on the embryo; the leaves are parallel-veined; the parts of the flower are generally in threes, and endosperm is usually present in the seed. There are a few exceptions to all these characters. Thus a single character is not sufficient to show relationship in groups, but one must use the sum of several important characters.

The families of monocotyledons can be grouped into three large divisions as follows: 


\section{MONOCOTYLEDONS.}

Petaloide : Conspicuous petals (or perianth) are the charac teristic feature.

Alismacea; water-plaintain family, alisma, etc.

Liliacee; lily family, trillium, lily, etc.

Cannacee; canna family.

Orchidacee; orchid family.

SPADICIFLORÆ: The spadix and spathe are characteristic.

A racee ; arum family, skunk's cabbage, jack-in-the-pulpit, etc. Lemnacece; duckweed family, lemna, wolffia, etc.

Palmacec; palm family.

Glumiflorae: The subtending bract (glume) at the base of the flower is characteristic.

Graminece; grass family.

Cyperacea; sedge family.

560. Table of families of dicotyledons studied (a few other families are introduced in the scheme). In the dicotyledons there are two cotyledons on the embryo; the venation of the leaves is reticulate; the endosperm is usually absent, and the parts of the flower are frequently in fives. There are exceptions to all the above characters, and the sum of the characters must be considered, just as in the monocotyledons.

\section{I)ICOTYLEDONS.}

I. ChORIPETAlÆ; the petals are distinct.

*. Amentifere, ament- or catkin-bearing plants.

SAlicifloræ: Both kinds of flowers in catkins.

Salicacea ; willow family, poplars and willows.

Querciflore: Pistillate flowers in acorns or cones.

Betulacee; birch family, birch, alder, etc.

Corylacea; hazelnut family, hazelnut, hornbeam, etc.

Cupuliferce; oak family, oak, chestnut, beech.

JUGLANDIFLOR E: Pistillate flowers form nuts in fruit.

Juglandacee; walnut family.

**. Choripetalce proper, flower not degenerate. 


\section{Flowers hypogynous.}

URTICIFLORE: Flowers not in true aments.

Urticacee; nettle family.

Ulmacece; elm family.

POLYGONIFloræ: Fruit a triangular or lenticular achene.

Polygonacee ; knotweed family, knotweed, buckwheat.

Curvembryæ: Embryo curved in the seed.

Portulacacea; pursley family, claytonia (spring beauty).

Caryophyllacee; pink family, carnation, corn-cockle, etc.

Chenopodiacea; pigweed family, pigweed, beet, Russian thistle, etc.

POLyCARPICE: Carpels usually numerous and always distinct. Ranunculacea; buttercup family (crowfoot family), buttercups, marsh-marigold, clematis, etc.

Nympheacea; water-lily family.

Berberidacea; barberry family, mandrake, etc.

RHœADINÆ: The flowers are dimerous or tetramerous.

Papaveracea; poppy family, bloodroot, etc.

Fumariacea; fumitory family, squirrel-corn, dutchman'sbreeches.

Cruciferce; mustard family, toothwort, cabbage, turnip, etc.

Droseracea; sundew family, sundew, venus-flytrap, etc.

Violacee; violet family.

Sarraceniacece; pitcher-plant family.

Gruinales : Carpels united, styles prolonged into a beak.

Oxalidacea; oxalis family.

Linacea ; flax family.

Geraniacece; geranium family, cranesbill, etc.

Columififeræ: Stamens usually united by their filaments into a column.

Malvacee; mallow family, hollyhock, cotton, etc.

\section{Flowers perigynous or epigynous.}

Æsculine: Stamens arising from a glandular disk, trees or shrubs. 
Sapindacea; soap-berry family, horse-chestnut, etc. Aceracea; maple family.

Franguline: Includes the holly family, vine family, etc. SAXIFRAGINe: Flower generally perfect and regular, stamens 5 or io, carpels few $(2-5)$.

Saxifragacece; saxifrage family; also currant, witch-hazel, and sycamore families.

ROsiflore: Flowers regular, stamens and carpels usually numerous, trees and shrubs mostly.

Rosacea ; rose family, strawberry, blackberry, rose, etc. Amygdalacese; almond family, peach, apricot, plum, cherry, etc.

Pomacee; apple family, apple, quince, pear, hawthorn, juneberry, etc.

Leguminosæ: Flower papilionaceous, carpel single, forming a pod or legume.

Papilionacea; pulse family, pea, bean, vetch, etc.

Mimosacere; mimosa family, sensitive plants.

\section{Flowers epigynou}

PASSIFlorine: Fruit of three carpels, but with one locule and three parietal placentæ. Here belong the passion-flower, begonia, and cucurbit families.

Myrtifloræ: Calyx usually prolonged beyond the inferior ovary, flowers usually 4 -merous.

Onagracea; evening-primrose family.

Umbelifork: Flowers in umbels, sepals and petals small.

Cornacea ; dogwood family.

Umbelliferce; parsley family.

II. Sympetale. Petals coherent (gamopetalous).

I. Flowers pentacyclic, that is, parts in five whorls (stamens in two whorls).

Bicornis: Mostly shruls, flowers usually 4-5-merous, stamens frequently with two-horned anthers. 
Prrolacece; pyrola family, pyrola, Indian-pipe, etc.

Ericucer : heath family. (Also rhododendron and whortleberry families.)

Piimulnix: One-celled ovary, seeds on a rentral column, corolla salver-form.

Primulacea : primrose family.

2. Fluzers tetracuclic, that is, the parts in four whorls.

Timflor.t: (iamopetalous corolla not split, the five parts indicated by a slight unevenness of the margin, corolla twisted in bud.

Convoliulacere; bindweed family, morning-glory, dodder, etc.

PERsonAt: F: Flowers frequently bilabiate (the nightshade family represents this group).

Nuctiffer.e: Calyx gamosepalous; gamopetalous corolla usually bilabiate, carpels usually two, forming four nutlets. Boraginacece; borage family, forget-me-not, etc. Labiatce; mint family, dead-nettle, catnip, etc.

Contorte: The corolla is twisted in the bud, but is split into five lobes,

Gentianacea; gentian family.

Rubialfs: Leaves opposite with stipules, or verticillate.

Rubiacea ; madder family, bluet.

Caprifoliacea; honeysuckle family, lonicera, etc.

Dipsacales: Flowers in a head (in one family), no stipules, anthers distinct.

Valerianacece; valerian family.

Dipsacacea; teasel family.

Campanumix: Flowers not in heads, anthers united.

Campanulacece; bellflower family.

Composite: Flowers in heads, anthers united.

Composite; composite family, aster, solidago, sunflower, dandelion, etc. 


\section{ECOLOGY.}

\section{INTRODUCTION.}

561. While we are engaged with the study of the life processes concerned in nutrition and growth of plants, with the details of form, structure, and systematic relationship, we should not overlook the mutual relationships which exist among plants in their natural habitat, and the phenomena of growth recurring with the seasons, and influenced by environment, or due to inherent qualities. By a study of the life histories of plants, their habits and behavior under different conditions of environment, we shall broaden our concept of nature and cultivate our æsthetic, observational, and reasoning faculties. The subject is too large for full treatment within the limits of a part of an elementary book. The way here can only be pointed out, and the few examples and illustrations, it is hoped, will serve to open the book of nature to the young student, and lead him to study some of the problems which are presented by every region. This study of plants, in their mutual and environmental relationships, is ecology.

562. For beginning classes, where only a small part of the time is available, excursions can be made from time to time during the year for this purpose, taking certain subjects for each excursion. For example, in the autumn one may study means for the dissemination of seeds, protection of seeds, plant formations, zonal distribution of plants, formation of early spring flowers, etc. ; in the winter, twigs and buds, protection of plants against the cold; and in the spring, opening of the buds and flowers, pollenation, etc., and farther studies on plant societies, relation of plants to soil, topography, etc. 
563. In carrying on studies of this kind one should bear in mind the factors which influence plants in these relationships, that is, what are called the ecologic factors; in other words, those agencies which make up the environmental conditions of plants, all of which play a greater or lesser rôle in the habit or status of the plant concerned, and which, acting on all plants concerned, give the peculiar color or physiognomy to the plants of a region or of a more restricted community.

Such factors are climate, with its modifying meteorological conditions ; texture, chemistry, moisture content, covering, topography, exposure, etc., of the soil ; influence of light and heat ; of animals, of plants themselves, and so on. 


\section{CHAPTER XLIV.}

\section{WINTER BUDS, SHOOTS, ETC.}

564. Winter buds and how the young leaves are protected.-In plants like the pea, bean, corn, etc., which we have been studying, when the plant is mature it ripens its seed, and then dies. It grows only for one season, and the plants of the next, season are obtained from the seed again. Such plants are annual. In woody plants like trees and shrubs which grow from year to year, the young growing ends, where the elongation of the shoot or branch will take place the coming year, are usually provided with a special armature for protection during the cold of the winter, or through the resting pericr. This growing end is the bud. One of the very common means of protection of the buds through the rigor of the winter is by means of bud scales, which are formed at the close of the season's growth, and which overlap and closely hide the young and tender bud leaves within. Attention is called to a few of these buds here, and there will be no difficulty for the student to obtain quantities of material of several different kinds of trees and shrubs which it may be desirable to study, and which need not be mentioned here.

565. Twigs and buds of the horse-chestnut.-In fig. 399 is illustrated a shoot of the horse-chestnut. At the end of the shoot there is a large terminal bud, and at its base are two lateral buds. The terminal bud is broader than the diameter of the shoot, and is ovate in form. We notice that there are a number of scales which overlap each other somewhat as shingles do on a roof, only they are turned in the opposite direction. If we begin at the base of the bud, we can see that the two lowest scales are opposite each other, and that the two next higher ones are also opposite each other, and set at right angles to the position of the lower pair. In the same manner successive pairs of scales alternate, so that the third, fifth, seventh, etc., are exactly over the first, and the fourth, sixth, etc., are exactly over the second. Aside from the fact that these brown scales fit closely together over the bud, we notice that they are covered with a sticky substance which helps to keep out the surface water. Thus a very complete armature is provided for the protection of the young leaves inside.

566. Leaf sears. - The number of leaves developed during one season's 
growth in length of the shoot can be determined by counting the broad whitish scars which are situated just below each pair of lateral buds. Near the margin of these scars in the horse-chestnut are seen prominent pits arranged in a row. These little pits in the leaf scar are formed by the breaking away of the fibrovascular bundles (which run into the petiole of the leaf) as the leaf falls in the autumn.

567. Lateral buds. - The lateral buds, it is noticed, arise in the axils of the leaves. Each one of these by growth the next year, unless they remain dormant, will develop a shoot or branch. Just above the junction of the upper pair of branches we notice scars which run around the shoot in the form of slender rings, several quite close together. These are the scars of the bud scales of the previous year. By observing the location of these ring scars on the stem, the age of the branch may be determined, as well as the growth in length each year. Small buds may be frequently seen arising in the axils of the bud scales, that is after the scales have fallen, so that four to ten small buds may be counted sometimes on these very narrow zones of the shoot.

568. Bud leaves.-On removing the brown scales of the bud there is seen a pair of thin membranous scales which are nearly colorless. Underneath these are young leaves; successive pairs lie farther in the bud, in outline similar to the mature leaves, and each pair smaller than the one just below it. They are very hairy, with long white woolly fibres. These woolly fibres serve also to protect the young leaves from the cold or from sudden changes in the temperature, since they hold the air in their meshes very securely.

569. Opening of the buds in the spring.-As the buds "swell" in the spring of the year, when the growth of the young leaves and of the shoot begins, the bud scales are thrown backward and soon fall away as the leaves unfold, thus leaving the "ring scar" which marks the start of the new year's growth in length of the shoot.

570. A study of a number of different kinds of woorly shoots would serve to show us a series of very interesting variations in the color. surface marking, outline of the branch, arrangement of the leaves and consequently different modes of branching, variations in the leaf scars, the

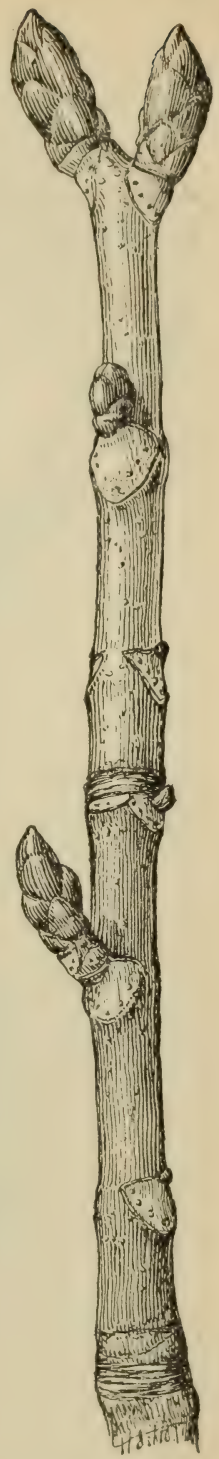

Fig. 399 .

Two year-old twig of horse - chestnut. showing buds and leaf scars. (A twig with a terminal bud should have been selected for this figure.) 
form, size, color, and armature of the buds, as well as great variations in the character of the bud scales. There are striking differences between the buds of different genera, and with careful study differences can also be seen in the members of a genus.

571. Growth in thickness of woody stems. - In the growth of woody perennial shoots, the shoot increases in length each year at the end. The

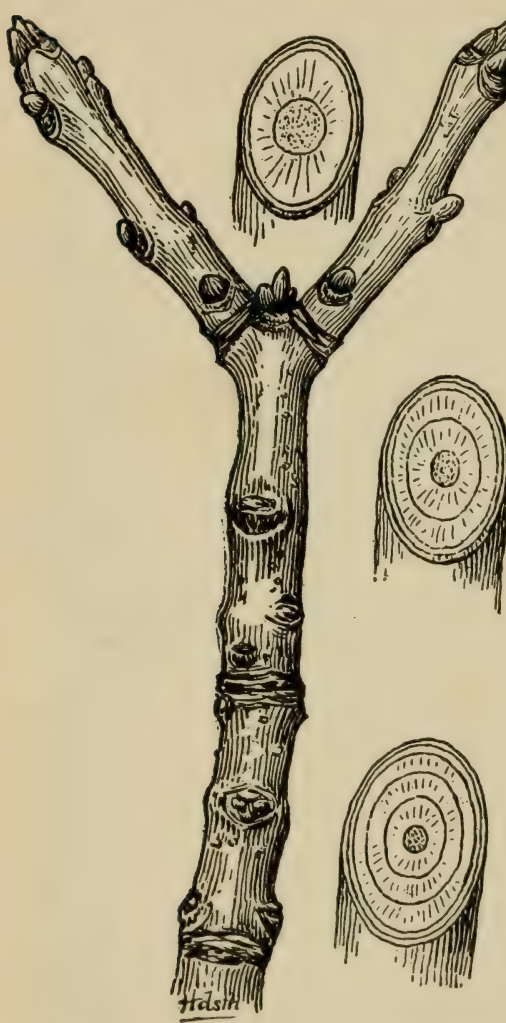

Fig. 400. shoot also increases in diameter each year, though portions of the shoot one year or more old do not increase in length. We can find where this growth in diameter of the stem takes place by making a thin cross section of a young shoot or branch of one of the woody plants. If we take the white ash, for example, in a cross section of a one-year-old shoot we observe the following zones: A central one of whitish tissue the cells of which have thin walls. This makes a cylindrical column of tissue through the shoot which we call the pith or medulla. Just outside of this pith is a ring of firmer tissue. The inner portion of this ring shows many woody vessels or ducts, and the outer portion smaller ducts, and a great many thick-walled woody cells or fibres. This then is a woody zone, or the zone of xylem.

572. The outer ring is made up of the bark, as we call it. In this part are the bast cells. Between the bark and the woody zone is a ring of small cells with thin and delicate walls, and

Three-year-old twig of the American ash, with sections of each year's growth showing annual rings.

the cells are richer in protoplasm. If the section is stained, these cells are apt to show a deeper color than either the wood zone or the bast zone. This is, as we will recollect from our study of the bundle in stems, the cambium zone, or the growing part of the older portions of the stem.

573. We may wish to know why these portions of the bundle here form a continuous or apparently a continuous ring in the stem of a woody plant. In the study of the sunflower stem, and also of impatiens, attention was called to the increase in the number of the bundles as the stem increased in age. 
If we happened to examine quite old portions of these stems, we would have observed that a large part or the entire portion of the thin-walled tissue, separating the woody portions of adjacent bundles, had changed to thick-walled or woody tissue, so that there is here in the older portions of the sunflower plant a continuous ring of xylem. This is the case also to some extent with the bast tissue. We already have noticed that the cambium ring in these stems is a continuous one, although the cambium between the bundles of the sunflower plant was not so active as that in the bundle proper. There is, however, a difference between the tissue lying between adjacent bundles and that of the bundle itself.

574. The bundles in the ash stem and in other woody stems lie very closely side by side, so that at first it might appear as if they were continuous. We note, however, that there are radiating lines which extend from the pith out toward the bast. These run between the bundles. These radiating lines are formed by the tissue lying between the bundles becoming squeezed into thin plates, which extend up and down between the bundles. They are termed the medullary rays, * since they radiate from the pith or medulla. These are shown well in a section of an oak stem.

575. Difference in the firmness of the woody ring.-We have already noted that the inner portion of the wood zone contains more and larger ducts than the outer zone, and that in the outer portion of the same zone the woody fibres predominate. The ducts are formed during the early spring growth, and later in the season the development of the fibres predominates.

576. Annual rings in woody stems. - If we now cut across a shoot of the ash which is several years old, we will note, as shown in fig. 400, that there are successive rings which have a similar appearance to the woody ring in the one-year-old stem. This can well be seen without any magnification. The larger size of the woody ducts which are developed each spring, and the preponderance of the fibres at the close of each season's growth, mark well the growth in diameter which takes place each year.

577. While the thickened walls of all the cells give strength to the wood, the different kinds of cells vary in the percentage of strength which they give. Thus the bast cells which have very thick walls are yet more flexible than the wood fibres, as can be seen if one strips off some of the bark of the basswood tree. Again, the woody fibres give more strength to wood than the same diameter of wood vessels, because they are much more firmly bound together, and the ends are long and tapering, and are spliced over each other where cells below and above meet. In the case of the wood vessels the ends do not taper out so much, or in some cases they meet adjacent cells below or above squarely.

578. Wood then which has a large number of wood vessels compared with the fibres, or in which the size of the vessels is great, is not so strong as

* Rays, or radiating plates, of tissue appear also in the bundle. 
wood which has a large percentage of fibrous elements, and in which the ducts are comparatively small. Wood with numerous large vessels is also more spongy, and therefore lighter than woods with a close fibrous structure. We should find it an exceedingly interesting study if we made a comparative examination of the growth and strength of the different woods.

579. Phyllotaxy, or arrangement of leaves. - In our study of the organs which utilize carbon for food, and in examining buds on the winter shoots of woody plants, we could not fail to be impressed with some peculiarities in the arrangement of these members on the stem of the plant. Even in the liverworts and mosses we note that where there is any indication of leaf-like expansions on a central axis there is a general plan of arrangement of these leaf-like structures over successive zones of the axis.

In the horse-chestnut, as we have already observed, the leaves are in pairs, each one of the pair standing opposite its partner, while the pair just below or above stand across the stem at right angles to the position of the former pair. In other cases (the common bed straw) the leaves are in whorls, that is several stand at the same level on the axis, distributed around the stem. By far the larger number of plants have their leaves arranged alcernately. A simple example of alternate leaves is presented by the elm (fig. 347), where the leaves stand successively on alternate sides of the stem, so that the distance from one leaf to the next, as one would measure around the stem, is exactly one half the distance around the stem. This arrangement is $\mathbf{I} / \mathbf{2}$, or the angle of divergence of one leaf from the next is $\mathbf{I} / 2$. In the case of the sedges the angle of divergence is less, that is $\mathbf{I} / 3$.

By far the larger number of those plants which have the alternate arrangement have the leaves set at an angle of divergence represented by the fraction $2 / 5$.

580. Other angles of divergence have been discovered, and much stress has been laid on what is termed a law in the growth of the stem with reference to the position which the leaves occupy. There are, however, numerous exceptions to this regular arrangement, which have caused some to question the importance of any theory like that of the "spiral theory" of growth propounded by Goethe and others of his time.

581. As a result, however, of one arrangement or another we see a beautiful adaptation of the plant parts to environment, or the influence which environment, especially light, has had on the arrangement of the leaves and branches of the plant. Access to light and air are of the greatest importance to green plants, and one cannot fail to be profoundly impressed with the workings of the natural laws in obedience to which the great variety of plants have worked out this adaptation in manifold ways. 


\section{CHAPTER XLV.}

\section{SEEDLINGS.}

582. An interesting period in the life of plants is during germination, when the embryo plant comes out of the seed and lifts its leaves and stem above the ground. In the germinating corn plant the young leaves are wrapped around one another and enclose the stem, forming a long, slender, pointed sheath, if it may be so called. As this pushes its way through the soil it stands erect, with the pointed end uppermost. Because of its form and the compactness with which the leaves are wrapped together, it easily wedges its way through the soil, with no harm to the tender leaves and stem.

583. The pea seedling comes out of the ground in a very different way. By the swelling of the two thick cotyledons the outer coat of the seed is cast partly off, the root emerges on one side, and the short stem is curved between the cotyledons in the form of an arch. The cotyledons remain in the soil, while the arched stem, as it elongates, pushes its way through the soil. The leaves of

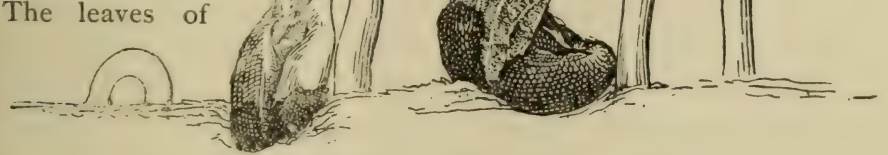

Fig. 4or.

How the garden bean comes out of the ground. First the looped hypocotyl, then the cotyledons pulled out, next casting off the seed coat, last the plant erect, bearing thick cotyledons, the expanding leaves, and the plumule between them. 
the pea are broader and shorter than the leaves of the corn, and cannot well form a long pointed covering for the stem. If the stem remained straight the friction of the leaves against the soil would tear them while they are so tender. But lifted out as they are, suspended from the bent stem, they are unharmed.

584. The common garden bean.-The bean also in swelling cracks open the outer coat, the root emerges from underneath the coat in the region of the scar (hilum) on the concave side, while the minute plumule lies curved between the edges of the cotyledons near one end. In the case of the bean, the part of the stem between the cotyledons and the root (called the hypocotyl in all seedlings) elongates, so that the cotyledons are lifted from the soil. The hypocotyl is the part of the stem here which becomes strongly curved, and the large cotyledons are dragged out of the soil as shown in fig. 40I. The outer coat becomes loosened, and at last slips off completely. The plumule (the young part of the stem with the leaves) is now pushing out from between the cotyledons. As the cotyledons are coming out of the ground the first pair of leaves rapidly enlarge, so that before the stem has straightened up there is a considerable leaf surface for the purpose of carbon conversion. The leaves are at first clasped together, but as the stem becomes erect
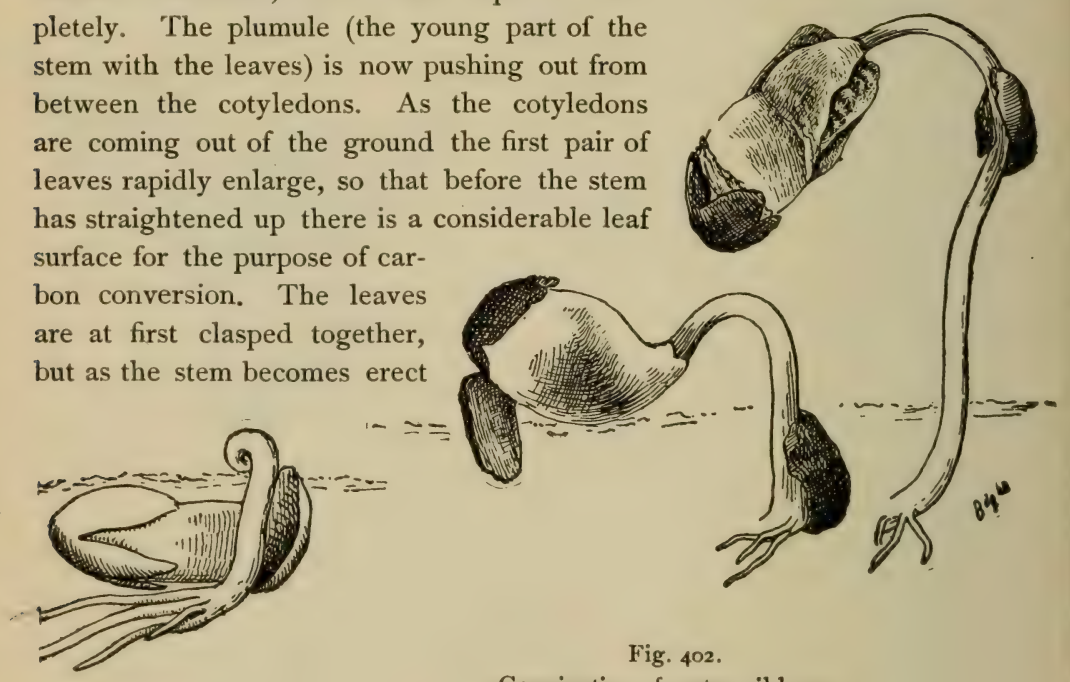

Fig. 402.

Germination of castor-oil bean.

they are gradually parted and come to stand out nearly in a horizontal position. Fig. 40I shows the different positions, and we see that the same provision for the protection of the leaves is afforded as in the case of the pea. As the cotyledons become exposed to the light they assume a green color. Some of the stored food in them goes to nourish the embryo during germination, and they therefore become smaller, shrivel somewhat, and at last fall off.

585. The castor-oil bean. - This is not a true bean since it belongs to a very different family of plants (euphorbiacex). In the germination of this seed a very interesting comparison can be made with that of the garden bean. As the "bean" swells the very hard outer coat generally breaks open at the 
free end and slips off at the stem end. The next coat within, which is also hard and shining black, splits open at the opposite end, that is at the stem end. It usually splits open in the form of three ribs. Next within the inner coat is a very thin, whitish film (the remains of the nucellus, and corresponding to the perisperm) which shrivels up and loosens from the white mass, the endosperm, within. In the castor-oil bean, then, the endosperm is not all absorbed by the embryo during the formation of the seed. As the plant becomes older we should note that the fleshy endosperm becomes thinner and thinner, and at last there is nothing but a thin whitish film covering the green faces of the cotyledons. The endosperm has been gradually absorbed by the germinating plant through its cotyledons and used for food.

586. How the embryo gets out of a pumpkin seed.-We should not fail to germinate some seeds of a pumpkin or squash. Some of the seeds should
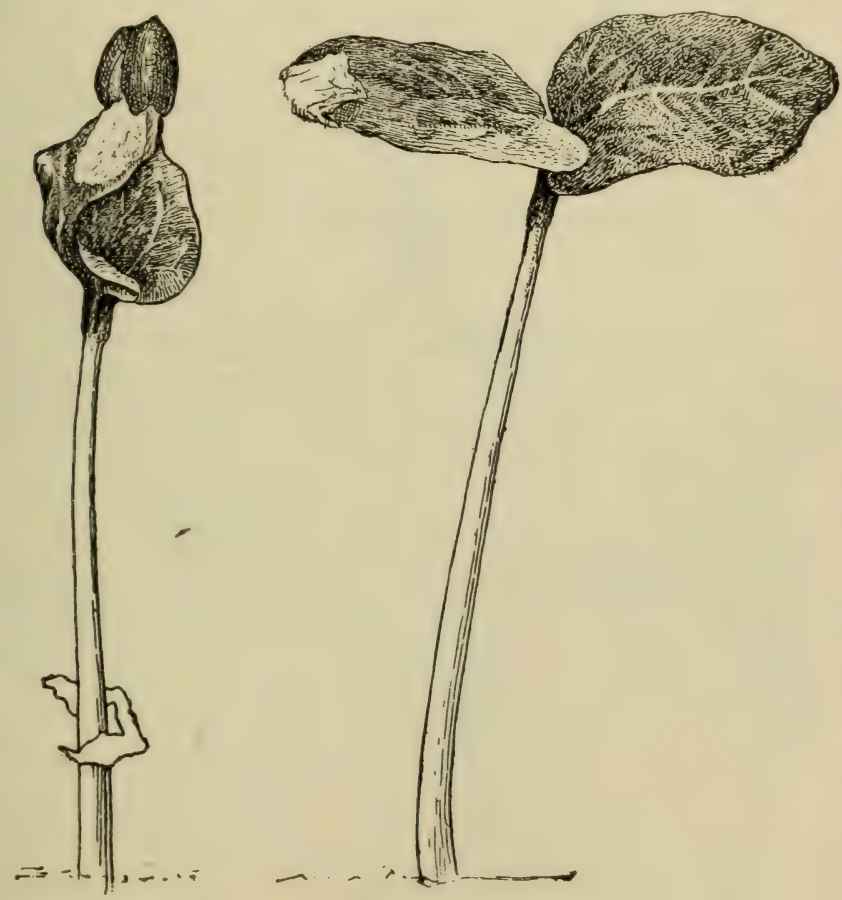

Fig. 403 .

Seedlings of castor-oil bean casting the seed coats, and showing papery remnant of the endosperm.

be sown in the soil, and some on damp sphagnum covered with moist paper, or between the folds of a damp cloth, first soaking them for ten to twelve 
hours. The pumpkin seed is the one we have selected for this study. It will be instructive first to examine those which have been germinated in the

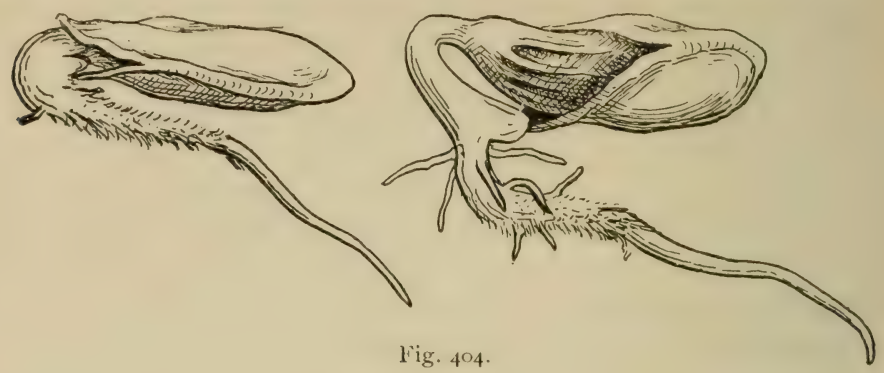

Germinating seed of pumpkin, showing how the heel or "peg " catches on the seed coat to cast it off.

folds of moist cloth and paper, so that they can readily be observed at all stages, without digging them up from the soil.

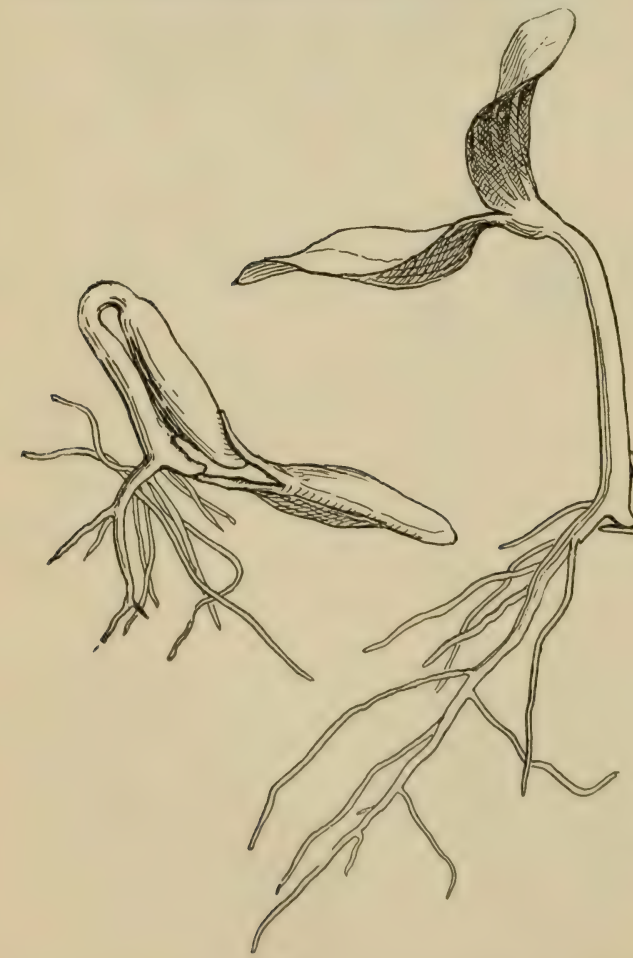

Fig. 405

Escape of the pumpkin seedling from the seed coats.

587. The root pushes its way out from between the stout seed coats at the smaller end, and then turns downward unless prevented from so doing by a hard surface. After the root is $2-4 \mathrm{~cm}$ long, and the two halves of the seed coats have begun to be pried apart, if we look in this rift at the junction of the root and stem, we will s e e that one end of the seed coat is caught against a heel, or "peg," which has grown out from the stem for this purpose. Now if we examine one which is a little more advanced, we will see this heel more distinctly, and also that the stem (hypocotyl) is arching out away from the seed coats, As 
the stem arches up its back in this way it pries with the cotyledons against the upper seed coat, but the lower seed coat is caught against this heel, and the two are pulled gradually apart. In this way the embryo plant pulls itself out from between the seed coats. In the case of seed which are planted deeply in the soil we do not see this contrivance unless we dig down into the earth. The stem of the seedling arches through the soil, pulling the cotyledons up at one end. Then it straightens up, the green cotyledons part, and open out their inner faces to the sunlight, as shown in fig. 406. If we dig into the soil we will see that this same heel is formed on the stem, and that the seed coats are cast off into the soil.

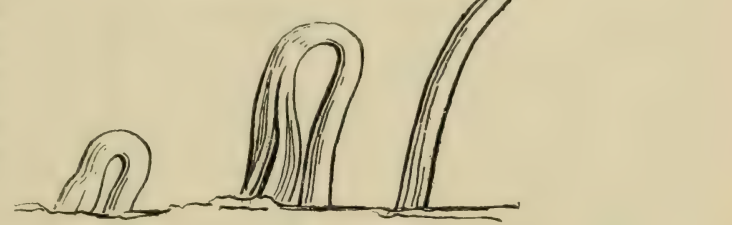

Fig. 406.

Pumpkin seedling rising from the ground.

\section{Arisæma triphyllum.}

588. Germination of seeds of jack-in-the-pulpit. - The ovaries of jack-inthe-pulpit form large, bright red berries with a soft pulp enclosing one to

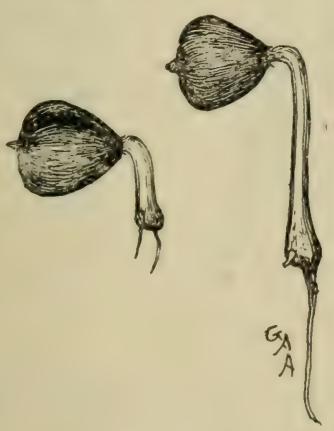

Fig. 407 .

Seedlings of jack-in-the-pulpit; embryo backing out of the seed.
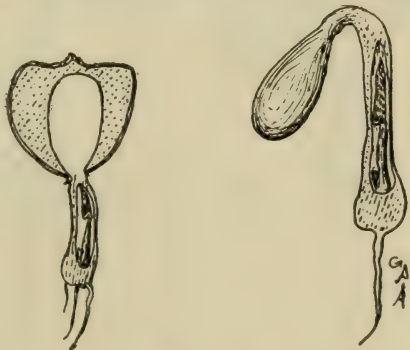

Fig. 408 .

Section of germinating embryos of jack-in-the-pulpit, showing young leaves inside the petiole of the cotyledon. At the left cotyledon shown surrounded by the endosperm in the seed; at right endosperm removed to show the club-shaped cotyledon.

several large seeds. The seeds are oval in form. Their germination is interesting, and illustrates one type of germination of seeds common among 
monocotyledonous plants. If the seed are covered with sand, and kept in a moist place, they will germinate readily.

589. How the embryo backs out of the seed.-The embryo lies within the mass of the endosperm; the root end, near the smaller end of the seed. The club-shaped cotyledon lies near the middle of the seed, surrounded firmly on all sides by the endosperm. The stalk, or petiole, of the cotyledon, like the lower part of the petiole of the leaves, is a hollow cylinder, and contains the younger leaves, and the growing end of the stem or bud. When germination begins, the stalk, or petiole, of the cotyledon elongates. This pushes the root end of the embryo out at the small end of the seed. The free end of the embryo now enlarges somewhat,

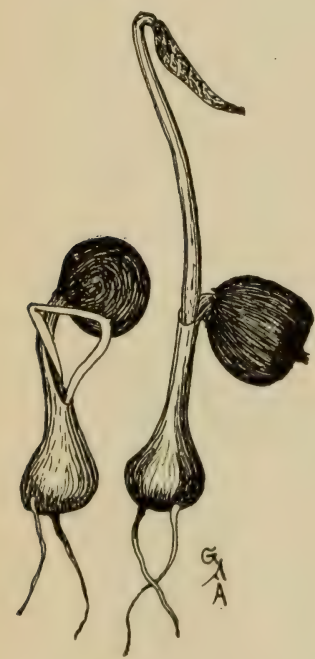

Fig. 409 .

Seedlings of jack-in-thepulpit, first leaf arching out of the petiole of the coty ledon.

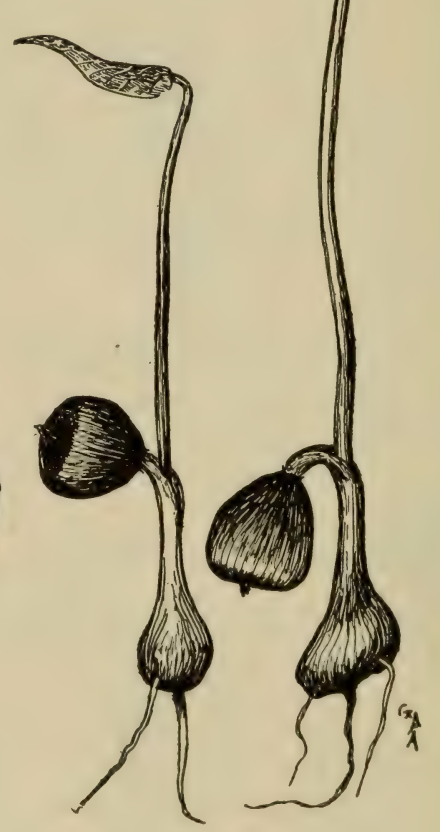

Fig. 4 ro.

Embryos of jack-in-the-pulpit still attached to the endosperm in seed coats, and showing the simple first leaf.
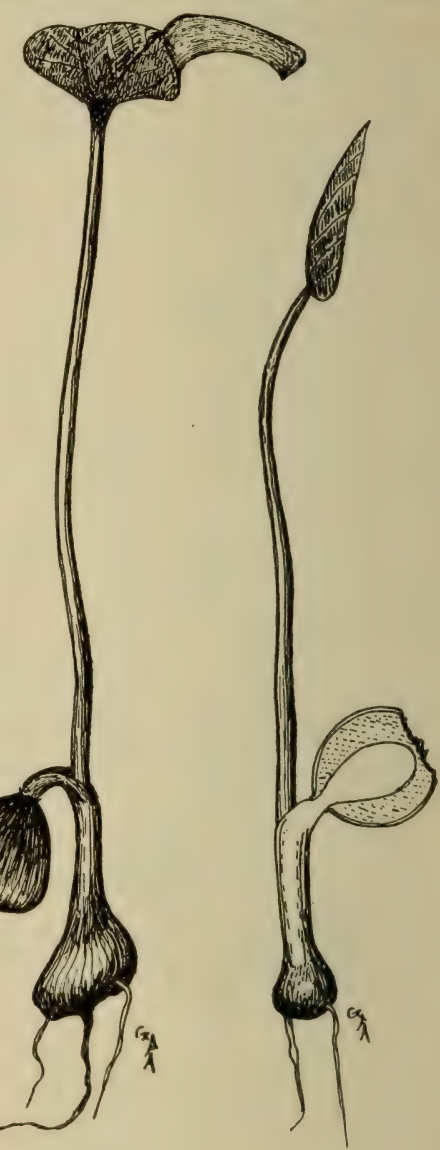

Fig. $41 x$.

Seedling of jack-inthe-pulpit; section of the endosperm and cotyledon.

as seen in the figures, and becomes the bulb, or corm, of the baby jack. At first no roots are visible, but in a short time one, two, or more roots appear on the enlarged end. 
590. If we make a longisection of the embryo and seed at this time we can see how the club-shaped cotyledon is closely surrounded by the endosperm. Through the cotyledon, then, the nourishment from the endosperm is readily passed over to the growing embryo. In the hollow part of the petiole near the bulb can be seen the first leaf.

591. How the first leaf appears. - As the embryo backs out of the seed, it turns downward into the soil, unless the seed is so lying that it pushes straight downward. On the upper side of the arch thus formed, in the petiole of the cotyledon, a slit appears, and through this opening the first leaf arches its way out. The loop of the petiole comes out first, and the leaf later, as shown in fig. 409. The petiole now gradually straightens up, and as it elongates the leaf expands.

592. The first leaf of the jack-in-the-pulpit is a simple one.-The first leaf of the embryo jack-in-the-pulpit is very different in form from the leaves which we are accustomed to see on mature plants. If we did not know that it came from the seed of this plant we would not recognize it. It is simple, that is it consists of one lamina or blade, and not of three leaflets as in the compound leaf of the mature plant. The simple leaf is ovate and with a broad heart-shaped base. The jack-in-the-pulpit, then, as trillium, and some other monocotyledonous plants which have compound leaves on the mature plants, have simple leaves during embryonic development. The ancestral monocotyledons are supposed to have had simple leaves. Thus there is in the embryonic development of the jack-in-the-pulpit, and others with compound leaves, a sort of recapitulation of the evolutionary history of the leaf in these forms. 


\section{CHAPTER XIVI.}

\section{FURTHER STUDIES ON NUTRITION.}

593. In our former studies on nutrition we found that such plants as the corn, pea, bean, etc., obtain their liquid food through the medium of root hairs. The liverworts and mosses obtain theirs largely through similar outgrowths, the rhizoids, while a majority of the algæ, being bathed on all sides by water, absorb liquid food through any part of the surface. We will find it instructive to study some of the different ways in which diverse plants obtain their liquid food.

594. Nutrition in lemna.-A water plant is illustrated in fig. 412. This is the common duckweed, Lemna trisulca. It is very peculiar in form and in

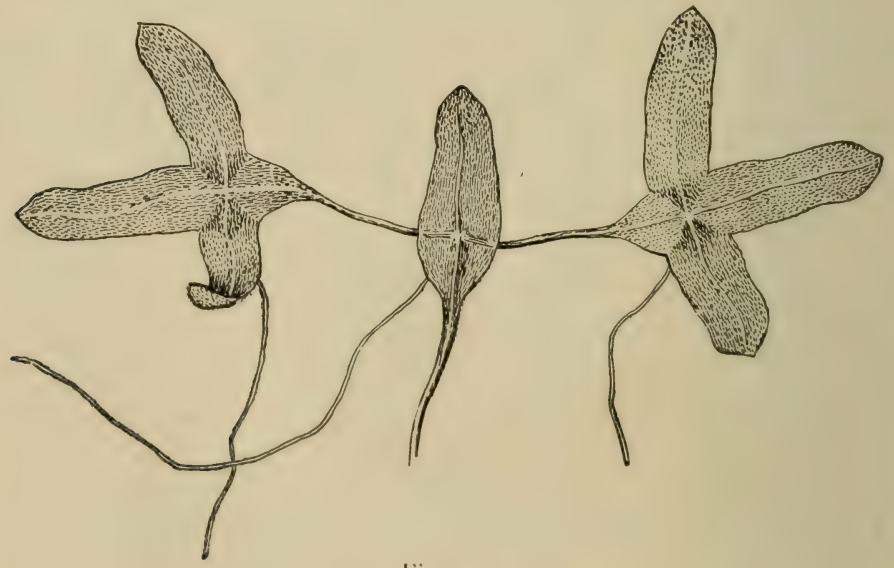

Fig. 412 .

Fronds of the duckweed (Lemna trisulca).

its mode of growth. Each one of the literal leaf-like expansions extends outwards by the elongation of the basal part, which becomes long and slender. Next, two new lateral expansions are formed on these by prolification from near 
the base, and thus the plant continues to extend. The plant occurs in ponds and ditches and is sometimes very common and abundant. It floats on the surface of the water. While the flattened part of the plant resembles a leaf it is really the stem. no leaves being present. This expanded green body is usually termed a " frond." A single rootlet grows sut from the under side and is destitute of root hairs. Absorption of nutriment therefore takes place through this rootlet and through the under side of the "frond."

595. Spirodela polyrrhiza.-This is a very curious plant, closely relater to the lemna and sumetimes placed in the same genus. It occurs in similar situations, and

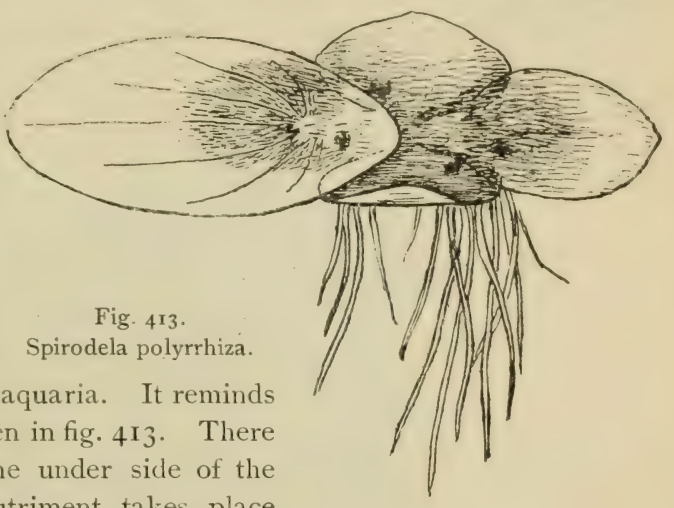
is very readily grown in aquaria. It reminds one of a little insect as seen in fig. 4r3. There are several rootlets on the under side of the frond. Absorption of nutriment takes place here in the same way as in lemna.

596. Nutrition in wolffia.-Perhaps the most curious of these modified water plants is the little wolffia, which contains the smallest specimens of the

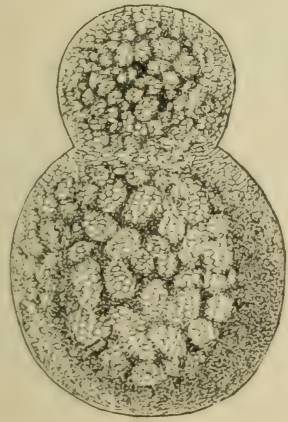

Fig. 414

Young frond of wolffia growing out of older one.

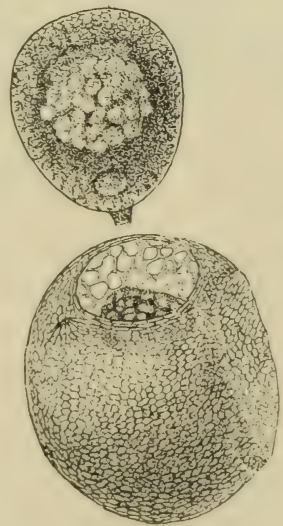

Fig. 415 . .

Young frond of wolffia separating fromolder one.

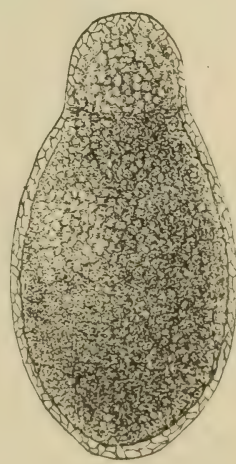

Fig. $4 \mathrm{I} 6$.

Another species of wolffia, the two fronds still connected.

flowering plants. Two species of this genus are shown in figs. 4I4-4I6. The plant body is reduced to nothing but a rounderl or oval green bexty; which 
represents the stem. No leaves or roots are present. The plants multiply by "prolification," the new fronds growing out from a depression on the under side of one end.

597. Nutrition of lichens. - Lichens are very curious plants which grow on rocks, on the trunks and branches of trees, and on the soil. They form leaf-like expansions more or less green in color, or brownish, or gray, or they occur in the form of threads, or small tree-like formations. Sometimes the plant fits so closely to the rock on which it grows that it seems merely to paint the rock a slightly different color, and in the case of many which occur on trees there appears to be to the eye only a very slight discoloration of the bark of the trunk, with here and there the darker colored points where fruit bodies

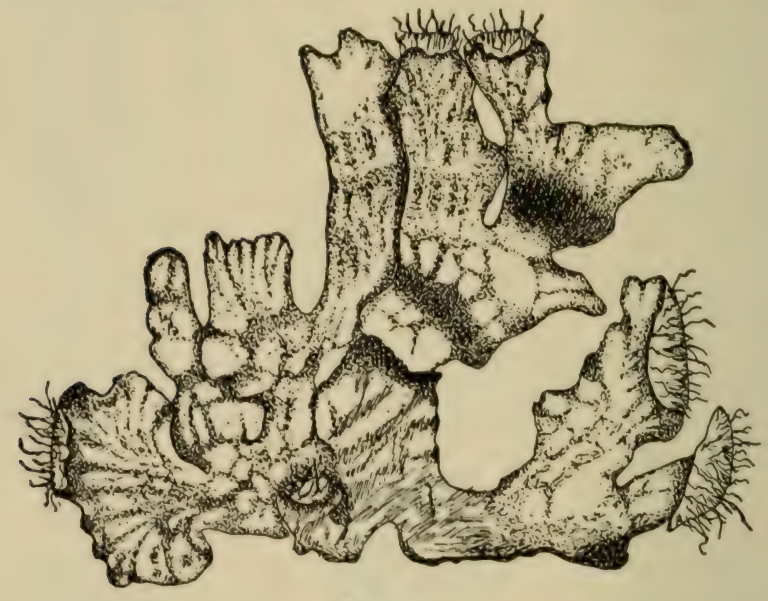

Fig. 417

Frond of lichen (peltigera), showing rhizoids.

are formed. The most curious thing about them is, however, that while they form plant bodies of various form, these bodies are of a "dual nature" as regards the organisms composing them. The plant bodies, in other words, are formed of two different organisms which, woven together, exist apparently as one. A fungus on the one hand grows around and encloses in the meshes of its mycelium the cells or threads of an alga, as the case may be.

If we take one of the leaf-like forms known as peltigera, which grows on damp soil or on the surfaces of batly decayed logs, we see that the plant body is flattened, thin, crumpled, and irregularly lobed. The color is duil greenish on the upper side, while the under side is white or light gray, and mottled with brown, especially the older portions. Here and there on the under surface are quite long slender blackish strands. These are composed entirely of fungus threads and serve as organs of attachment or holdfasts, and for the purpose of supplying the plant body with mineral substances 
which are in solution in the water of the soil. If we make a thin section of the leaf-like portion of a lichen as shown in fig. $4 \mathbf{1 8}$, we shall see that it is composed of a mesh of colorless threads which in certain definite portions contain entangled green cells. The colorless threads are those of the fungus, while the green cells are those of the alga. These green cells of the alga perform the function of chlorophyll bodies for the dual organism, while the threads of the fungus provide the mineral constituents of plant food. The alga, while it is not killed in the embrace of the fungus, does not reach the per-

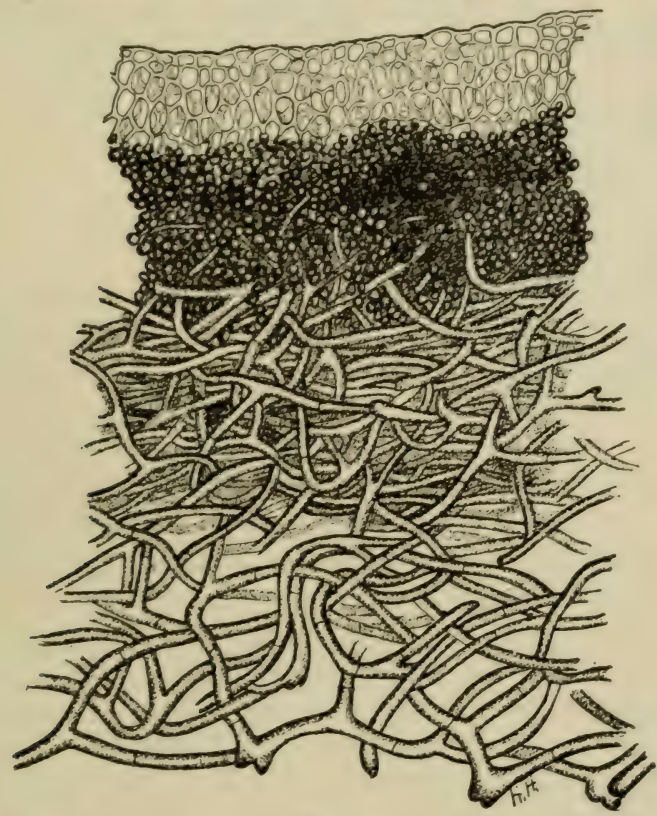

Fig. 418 .

Lichen (peltigera), section of thallus; dark zone of rcunded bodies made up largely of the algal cells. Fungus cells above, and threads beneath and among the algal cells.

fect state of development which it attains when not in connection with the fungus. On the other hand the fungus profits more than the alga by this association. It forms fruit bodies, and perfects spores in the special fruit bodies, which are so very distinct in the case of so many of the species of the lichens. These plants have lived for so long a time in this close association that the fungi are rarely found separate from the algæ in nature, but in a number of cases they have been induced to grow in artificial cultures separate from the alga. This fact, and also the fact that the algre are often found to occur separate from the fungus in nature, is regarded by many as an indication that the plant body of the lichens is composed of two distinct organisms, and that the fungus is parasitic on the alga. 
598. Others regard the lichens as autonomous plants, that is, the two organisms have hy this long-continued community of existence become unified inte an individualized organism, which pessesses a hathit and mode of life

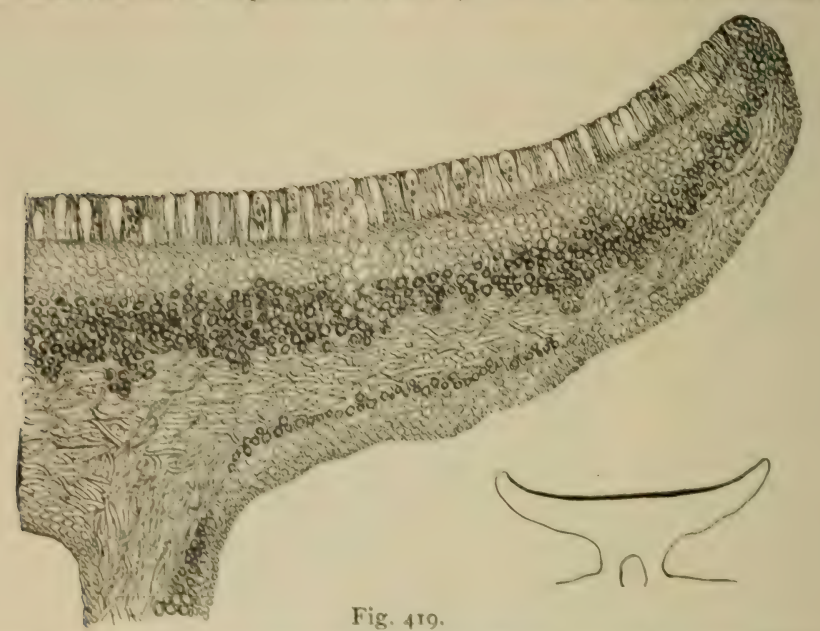

Section of fruit body or apothecium of lichen (parmelia), showing asci and spores of the fungus.

distinct from that of either of the organisms forming the component parts. This community of existence between two different organisms is called by some mutualism, or sumbiosis.

\section{Nitrogen gatherers.}

599. How clovers, peas, and other legumes gather nitrogen.--It has long

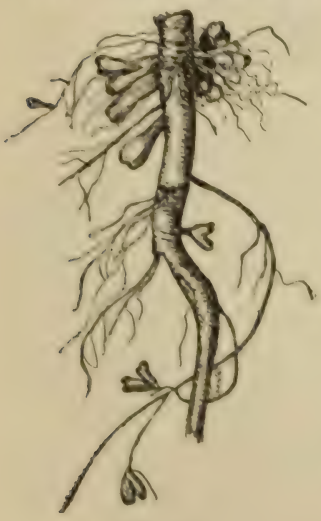

Fig. +20 ,

Root of the common retch, showing rout tubercles. been known that clover plants, peas, beans, and many other leguminous plants are often able to thrive in soil where the cereals do but poorly. Soil poor in nitrogenous plant food becomes richer in this substance where clovers, peas, etc., are grown, and they are often planted for the purpose of enriching the soil. Leguminous plants, especially in poor soil, are almost certain to have enlargements, in the form of nodules, or "root tubercles." A root of the common vetch with some of these root tubercles is shown in fig. 420 .

600. A fungal or bacterial organism in these root tubercles. - If we cut one of these root tubercles open, and mount a small portion of the interior in water for examination with the microscope, we will tind imall rol-shaped bolies, 
some of which resemble bacteria, while others are more or less forked into forms like the letter $\mathrm{Y}$, as shown in fig. 42I. These boxlies are rich in nitrogenous substances, or proteids. They are portions of a minute organism, of a fungus or bacterial nature, which attacks the roots of leguminous plants

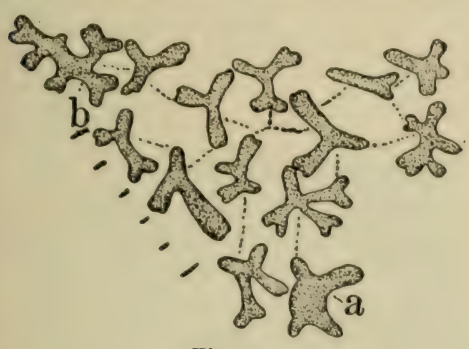

Fig. 421 .

Root-tubercle organism from vetch, old condition.
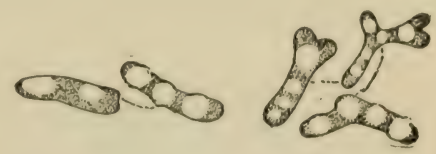

Fig. 422 .

Root-tubercle organism from Medicago denticulata.

and causes these nodular outgrowths. The organism (Phytomyxit leguminosarum) exists in the soil and is widely distributed where legumes grow.

601. How the organism gets into the roots of the legumes. - This minute organism in the soil makes its way through the wall of a root hair near the end. It then grows down the interior of the root hair in the form of a thread. When it reaches the cell walls it makes a minute perforation, through which it grows to enter the adjacent cell, when it enlarges again. In this way it passes from the root hair to the cells of the root and down to near the center of the root. As soon as it begins to enter the cells of the root it stimulates the cells of that portion to greater activity. So the root here develops a large lateral nodule, or "root tubercle." As this "root tubercle" increases in size, the fungus threads branch in all directions, entering many cells. The threads are very irregular in form, and from certain enlargements it appears that the rod-like bodies are formed, or the thread later breaks into myriads of these small "bacteroids."

602. The root organism assimilates free nitrogen for its host.-This organism assimilates the free nitrogen from the air in the soil, to make the proteid substance which is found stored in the bacteroids in large quantities. Some of the bacteroids, rich in proteids, are dissolved, and the proteid substance is made use of by the clover or pea, as the case may be. This is why such plants can thrive in soil with a poor nitrogen content. Later in the season some of the root tubercles die and decay. In this way some of the proteid substance is set free in the soil. The soil thus becomes richer in nitrogenous plant food.

The forms of the bacteroids vary. In some of the clovers they are oval, in vetch they are rod-like or forked, and other forms occur in some of the other genera. 


\section{Mycorhiza.}

603. Many others of the higher plants have fungi associated with their roots. Such roots are mycorhiza. In some genera of the orchids the roots form a compact mass resembling coral growth, as in the coral-root orchid. The curious Indian-pipe (monotropa) has roots which form a large closely branched mass of thickened short roots. In these cases the fungus lives in

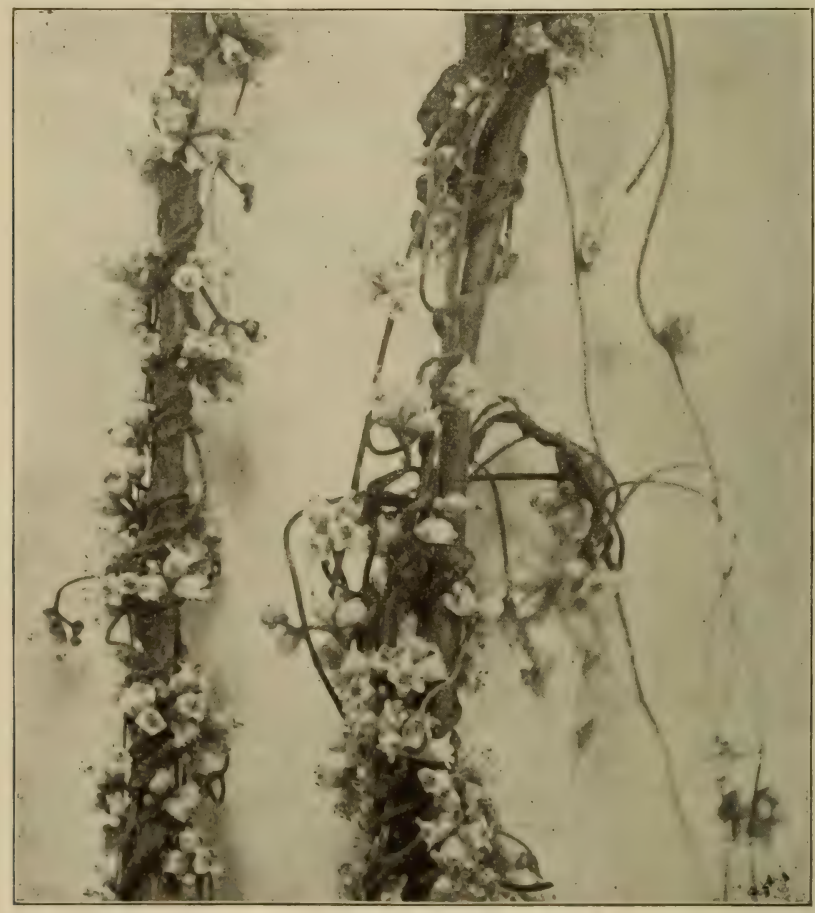

Fig. 423 .

Dodder.

the cells of the root and some of the threads of the fungus extend to the outside into the soil, and perhaps partly serve as absorbent organs since the root hairs are very rare or altogether absent on such roots. The Indianpipe plant possesses no chlorophyll, the fungus in its roots probably assimilates carbonaceous food from decaying organic matter in the soil, and gives it up to its host.

604. Mycorhiza with the fungus in the roots are endotropic mycorhiza. The root tulercles of the legumes also belong to this class. Ectotropic my- 
corhiza have the fungus on the outside of the roots. These often occur on the roots of the oak, beech, hornbeam, etc., in forests where there is a great deal of humus from the decaying leaves and other vegetation. The young growing roots of the oak, beech, hombeam, etc., become closely covered with a thick felt of the mycelium, so that no root hairs can develop. The root is also thickened. The fungus serves here as the absorbent organ for the tree. It also acts on the humus, converting it into available plant food and transferring it over to the tree.

605. Nutrition of the dodder.--The dodder (cuscuta) is an example of one of the higher plants that is parasitic. The stem twines around the stems of other plants, sending haustoria in their tissues. By means of these the nutriment is absorbed.

606. Carnivorous plants._-Examples of these are the well-known venus fly-trap and the common sundew.

607. Nutrition of bacteria.-Bacteria are very minute plants, in the form of short rods, which are either straight or spiral, while some are minute spheres. They are widely distributed ; some cause diseases of plants and animals, others cause decay of organic matter, while still others play an important rôle in coriverting certain nitrogen compounds into an available form for plant food. They absorb their food through the surface of their body. They may be obtained in abundance for study in infusions of plants or of meats. 


\section{CHAPTER XIVII.}

\section{FURTHER STUDIES ON NUTRITION CONCLUDED.}

608. Nutrition of moulds. - In our study of mucor, as we have seen, the

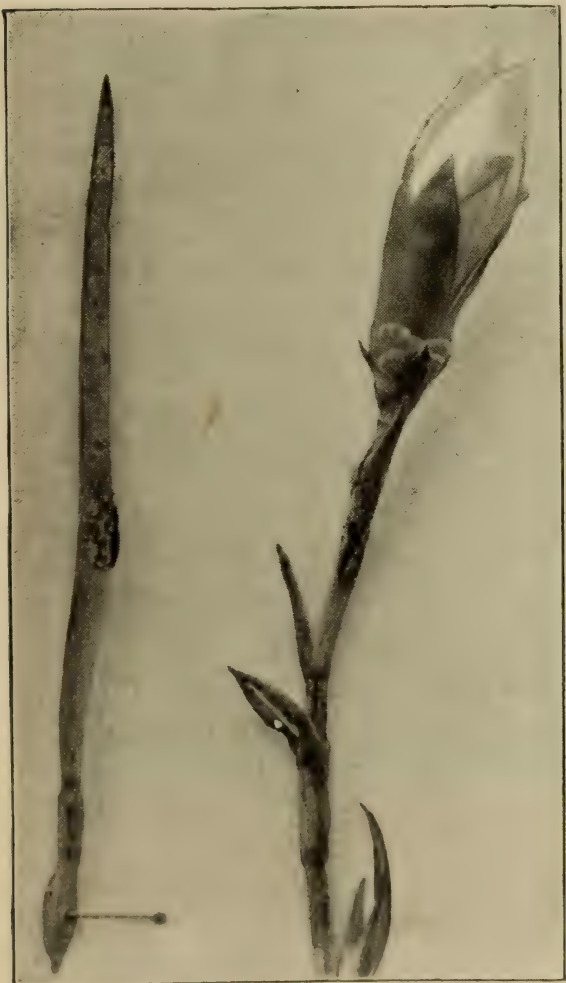

Fig. 424.

Carnation rust on leaf and flower stem. From photo graph. growing or vegetative part of the plant, the mycelium, lies within the substratum, which contains the food materials in solution, and the slender threads are thus bathed on all sides by them. The mycelium absorbs the watery solutions throughout the entire system of ramifications. When the upright fruiting threads are developed they derive the materials for their growth directly from the mycelium with which they are in connection. The moulds which grow on decaying fruit or on other organic matter derive their nutrient materials in the same way. The portion of the mould which we usually see on the surface of these substances is in general the fruiting part. The larger part of the mycelium lies hidden within the subtratum.

609. Nutrition of parasitic fungi.-Certain of the fungi grow on or within the pense. Such a fungus is called a parasite, and there are a large number 
of these plants which are known as parasitic fungi. The plant at whose expense they grow is called the " host."

One of these parasitic fungi, which it is quite easy to obtain in greenhouses or conservatories during the autumn and winter, is the carnation rust (Lromyce's caryophyllinus), since it breaks out in rusty dark brown patches on the leaves and stems of the carnation (see fig. 424). If we make thin cross sections through one of these spots on a leaf, and place them for a

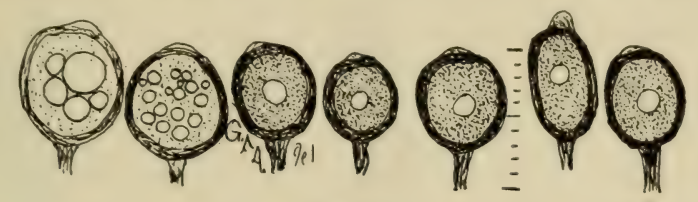

Fig. 425 .

Several teleutospores, showing the variations in form.

few minutes in a solution of chloral hydrate, portions of the tissues of the leaf will be dissolved. After a few minutes we wash the sections in water on a glass slip, and stain them with a solution of eosin. If the sections were care-

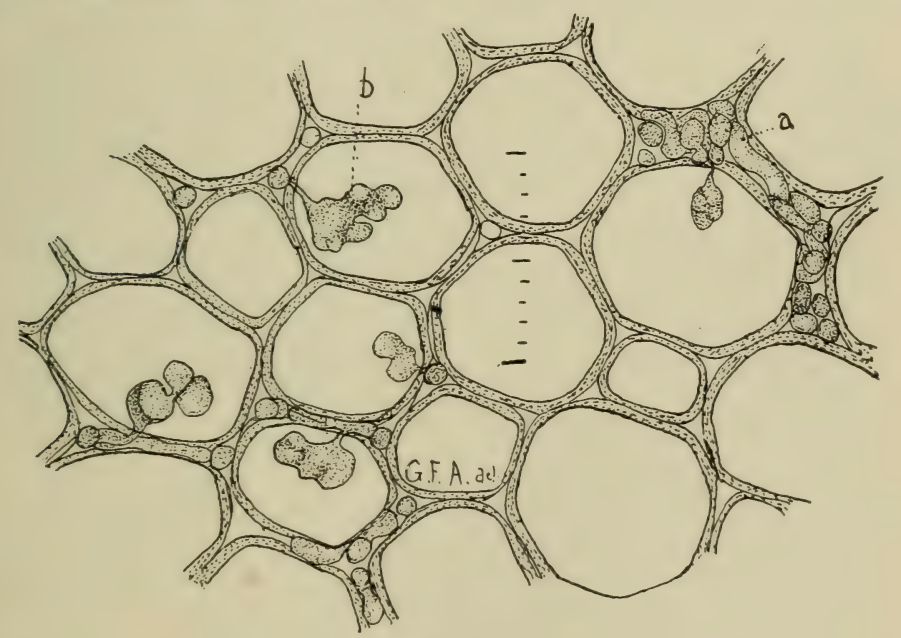

Fig. 426.

Cells from the stem of a rusted carnation, showing the intercellular mycelium and haustoria. Object magnified 30 times more than the scale.

fully made, and thin, the threads of the mycelium will be seen coursing between the cells of the leaf as slender threarls. Here and there will be seen short branches of these threads which penetrate the cell wall of the host and project into the interior of the cell in the form of an irregular knob. Such a branch is a haustorium. By means of this haustorium, which is here 
only a short branch of the mycelium, nutritive substances are taken by the fungus from the protoplasm or cell-sap of the carnation. From here it passes to the threads of the mycelium. These in turn supply food material for the development of the dark brown gonidia, which we see form the darklooking powder on the spots. Many other fungi form haustoria, which take up nutrient matters in the way described for the carnation rust. In the case

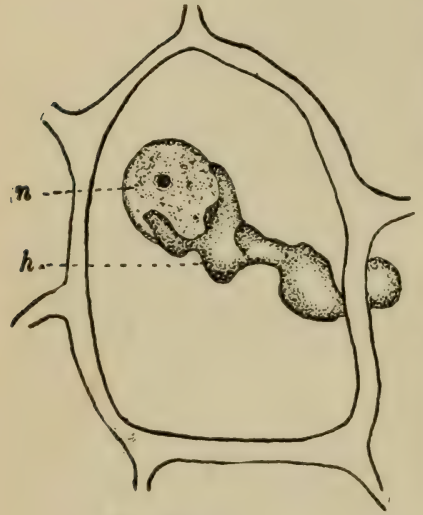

Fig. 427 .

Cell from carnation leaf, showing haustorium of rust mycelium grasping the nucleus of the host. $h$, haustorium; $n$, nucleus of host.

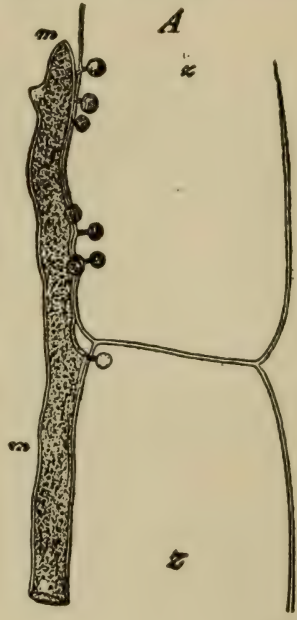

Fig. 428 .

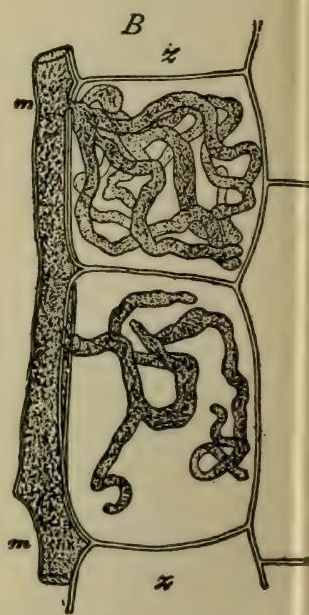

Intercellular mycelium with haustoria entering the cells. $A$, of Cystopus candidus (white rust); $B$, of Peronospora calotheca. (De Bary.)

of other parasitic fungi the threads of the mycelium themselves penetrate the cells of the host, while in still others the mycelium courses only between the cells of the host (fungus of peach leaf-curl for example) and derives food materials from the protoplasm or cell-sap of the host by the process of osmosis.

610. Nutrition of the larger fungi.-If we select some one of the larger fungi, the majority of which belong to the mushroom family and its relatives, which is growing on a decaying log or in the soil, we shall see on tearing open the log, or on removing the bark or part of the soil, as the case may be, that the stem of the plant, if it have one, is connected with whitish strands. During the spring, summer, or autumn months, examples of the mushrooms connected with these strands may usually be found readily in the fields or woods, but during the winter and 
colder parts of the year often they may be seen in forcing houses, especially those cellars devoted to the propagation of the mushroom of commerce.

611. These strands are made up of numerous threads of the mycelium which are closely twisted and interwoven into a cord or strand, which is called a mycelium strand, or rhizomorph. These are well shown in fig. 434, which is from a photograph of the mycelium strands, or "spawn " as the grower of mushrooms calls it, of Agaricus campestris. The little knobs or enlargements on the strands are the young fruit bodies, or "buttons."

612. While these threads or strands of the mycelium in the decaying wood or in the decaying organic matter of the soil are

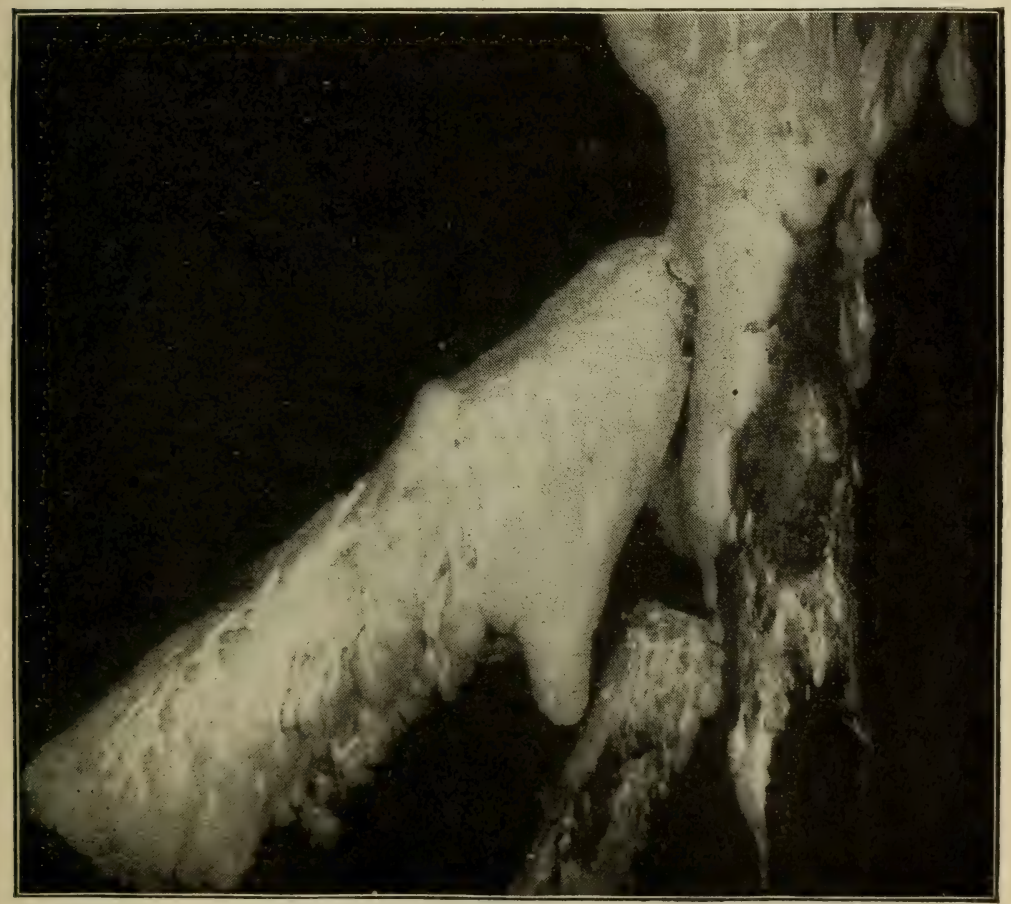

Fig. 429 .

Sterile mycelium on wood props in coal mine, 400 feet below surface. (Photographed by the author.) 
not true roots, they function as roots, or root hairs, in the absorption of food materials. In old cellars and on damp soil in moist places we sometimes see fine examples of this vegetative part of the fungi, the mycelium. But most magnificent examples are to be seen in abandoned mines where timber has been taken down into the tunnels far below the surface of the ground to support the rock roof above the mining operations. I have visited some of the coal mines at Wilkesbarre, Pa., and here on the wood props and doors, several hundred feet below the surface, and in blackest darkness, in an atmosphere almost completely saturated at all times, the mycelium of some of the wood-destroying fungi grows in a profusion and magnificence which is almost beyond belief. Fig. 429 is from a flash-light photograph of a beautiful example 400 feet below the surface of the ground. This was growing over the surface of a wood prop or post, and the picture is much reduced. On the doors in the mine one can see the strands of the mycelium which radiate in fan-like figures at certain places near the margin of growth, and farther back the delicate tassels of mycelium which hang down in fantastic figures, all in spotless white and rivalling the most beautiful fabric in the exquisiteness of its construction.

\section{Studies of mushrooms.}

613. Form of the mushroom. - A good example for this study is the common mushroom (Agaricus campestris).

This occurs from July to November in lawns and grassy fields. The plant is somewhat umbrella-shaped, as shown in fig. 430, and possesses a cylindrical stem attached to the under side of the convex cap or pileus. On the under side of the pileus are thin radiating plates, shaped somewhat like a knife blade. These are the gills, or lamellax, and toward the stem they are rounded on the lower angle and are not attached to the stem. The longer ones extend from near the stem to the margin of the pileus, and the V-shaped spaces between them are occupied by successively 


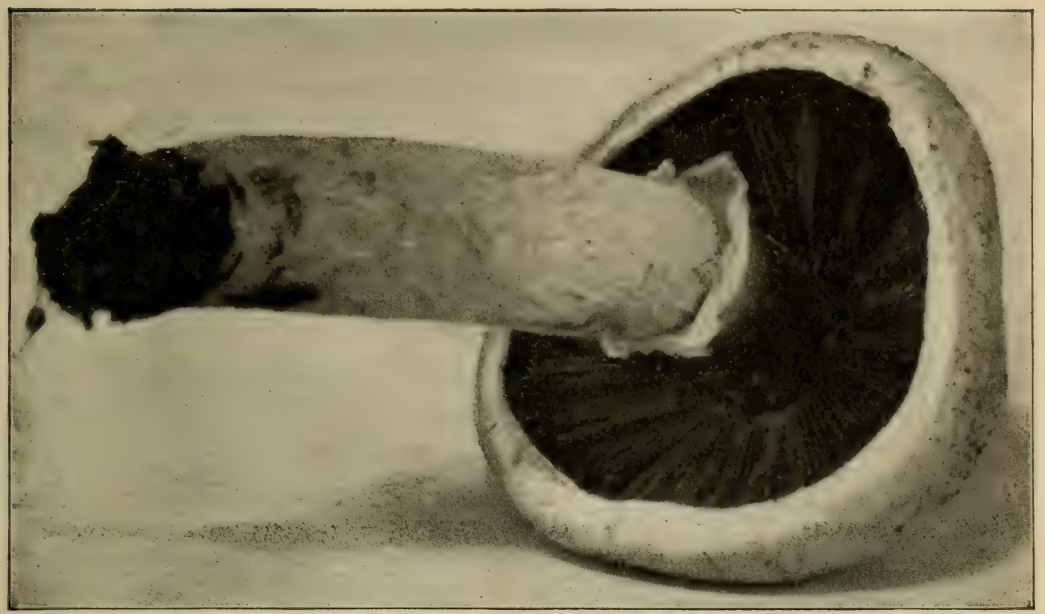

Fig. 430 .

Agaricus campestris. View of under side showing stem, annulus, gills, and margin of pileus.

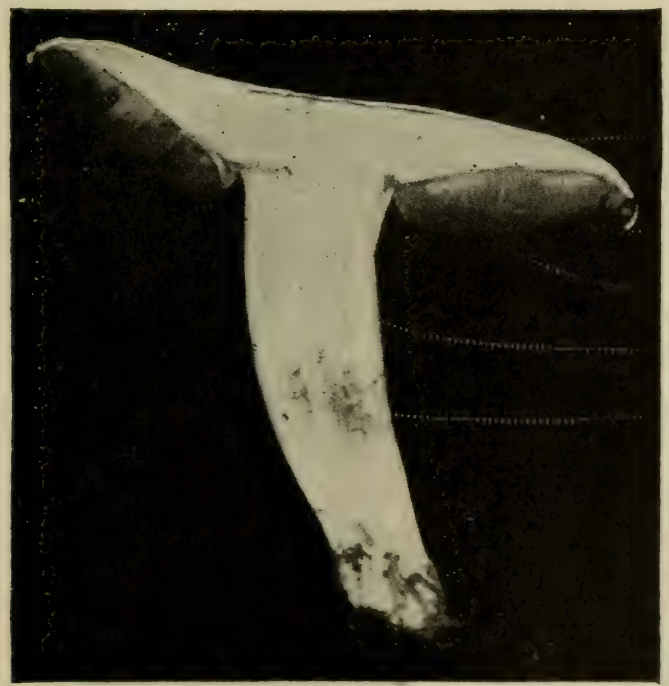

Fig. 43r.

Agaricus campestris. Longitudinal section through stem and pileus. $a$, pileus; $b$, portion of veil on margin of pileus; $c$, gill ; $f$, fragment of annulus; $e$, stipe. 
shorter ones. Around the stem a little below the gills is a collar, termed the ring or annulus.

614. Fruiting surface of the mushroom.-The surface of these gills is the fruiting surface of the mushroom, and bears the gonidia of the mushroom, which are dark purplish brown when mature, and thus the gills when old are dark in color. If we make a thin section across a few of the gills, we see that each side of the gill is covered with closely crowded club-shaped bodies, each one of which is a basidium. In fig. $43^{2}$ a few of these are en-

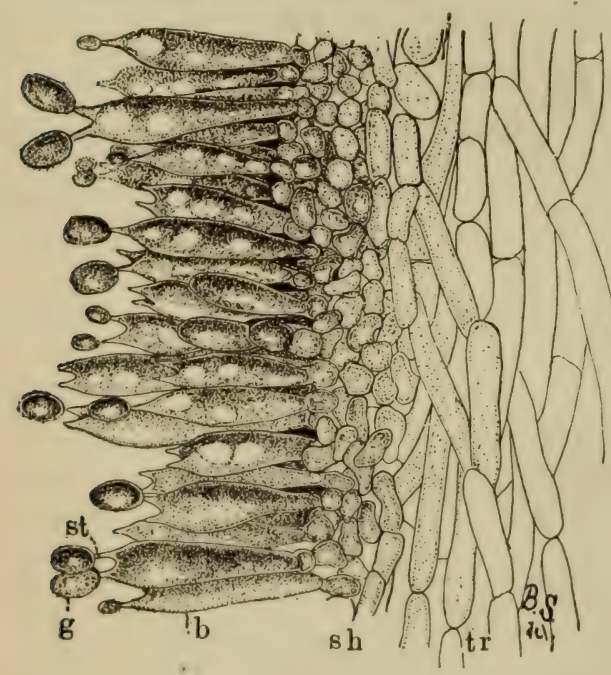

Fig. 432

Portion of section of lamella of Agaricus campestris. tr, trama ; sh, subhymenium ; $b$, basidium ; st, sterigma (pl. sterigmata); $g$, gonidium. larged, so that the structure of the gill can be seen. Each basidium of the common mushroom has

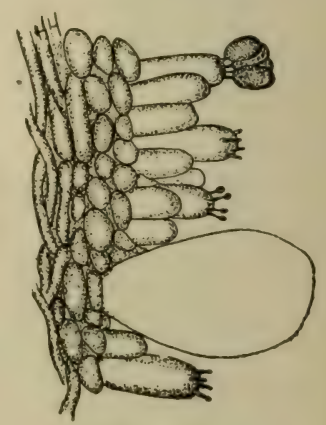

Fig. 433 .

Portion of hymenium of Coprinus micaceus, showing large cystidium in the hymenium.

two spinous processes at the free end. Each one is a sterig'ma (plural sterig'mata), and bears a gonidium. In a majority of the members of the mushroom family each basidium bears four gonidia. When mature these gonidia easily fall away, and a mass of them gives a purplish-black color to objects on which they fall, so that a print of the under surface of the cap showing the arrangement of the gills can be obtained by cutting off the stem, and placing the pileus on white paper for a time.

615. How the mushroom is formed.-The mycelium of the 


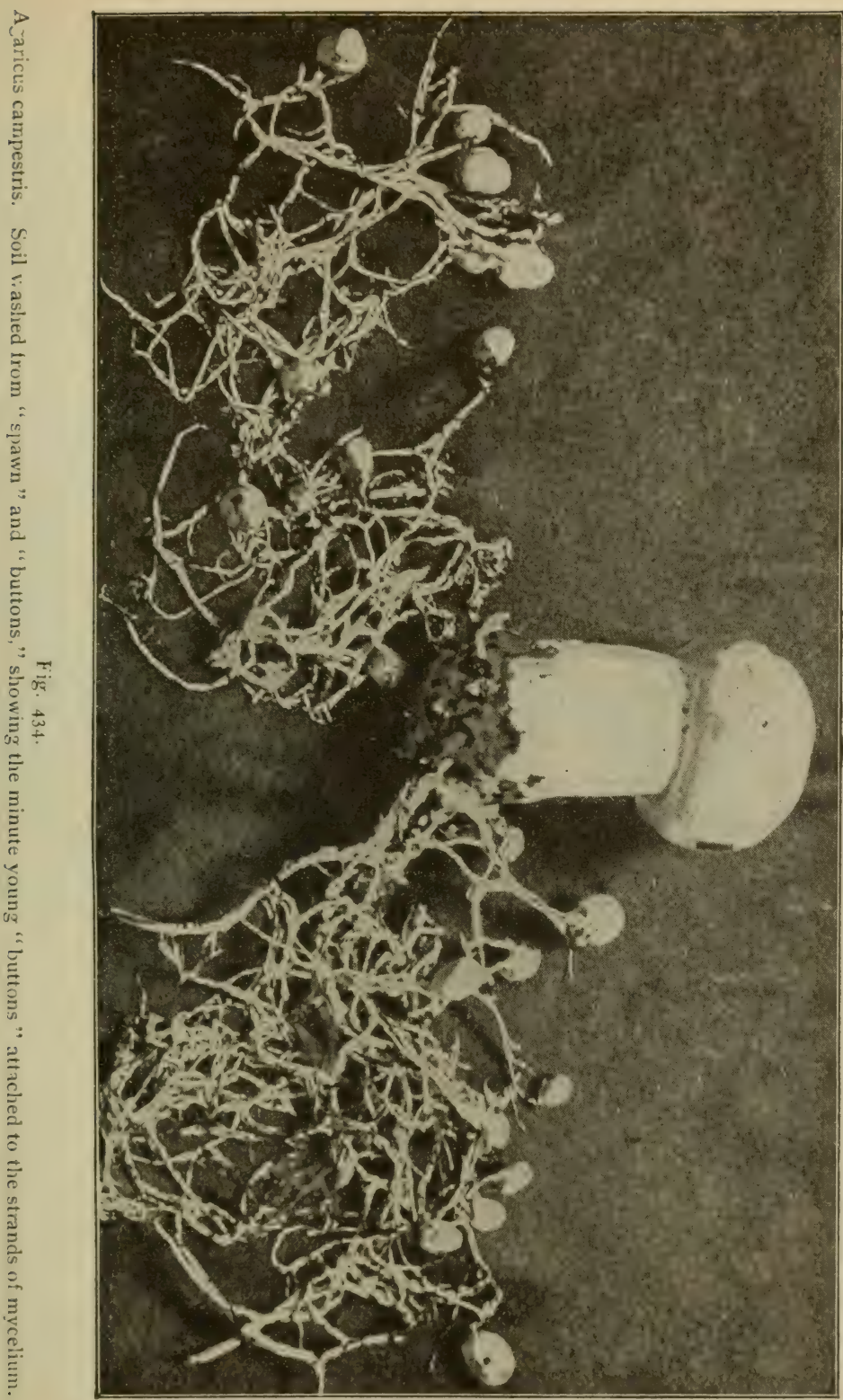


mushroom lives in the ground, and grows here for several months or even years, and at the proper seasons develops the mature mushroom plant. The mycelium lives on decaying organic matter, and a large number of the threads grow closely together forming strands, or cords, of mycelium, which are quite prominent if they are uncovered by removing the soil, as shown in fig. 434 .

616. From these strands the buttons arise by numerous threads growing side by side in a vertical direction, each thread growing independently at the end, but all lying very closely side by

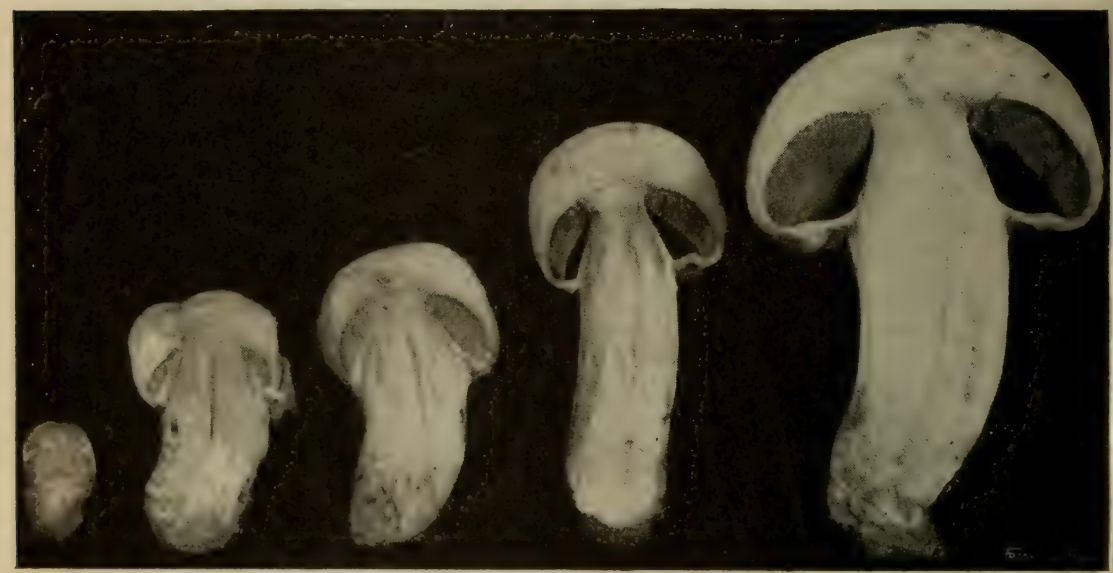

Fig. 435 .

Agaricus campestris; sections of "buttons" of different sizes, showing formation of gills and veil covering them.

side. When the buttons are quite small the gills begin to form on the under margin of the knob. They are formed by certain of the threads growing downward in radiating ridges, just as many of these ridges being started as there are to be gills formed. At the same time, threads of the stem grow upward to meet those at the margin of the button in such a manner that they cover up the forming gills, and thus enclose the gills in a minute cavity. Sections of buttons at different ages will show this, as is seen in fig. 435. This curtain of mycelium which is thus stretched across the gill cavity is the veil. As the cap expands more and more this is stretched into a thin and delicate texture as 


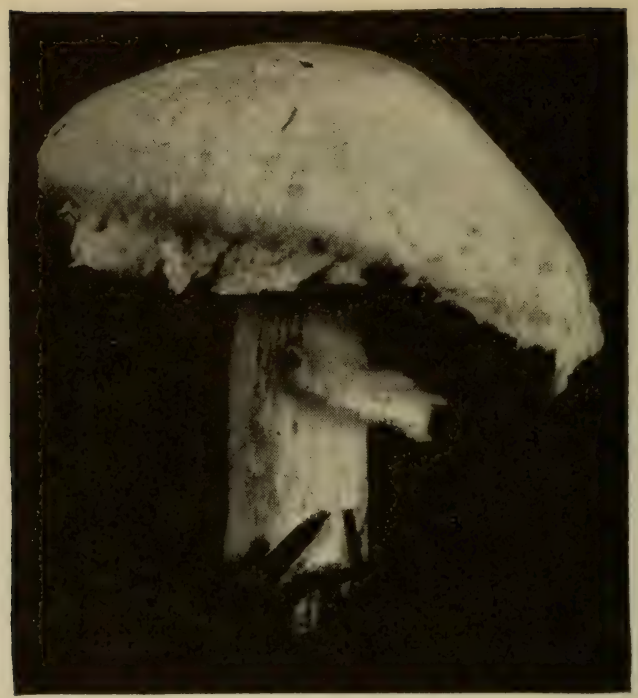

Fig. 438 .

Agaricus campestris; plant in natural position just after rupture of veil, showing tendency to double annulus on the stem. Portions of the veil also dripping from margin of pileus.

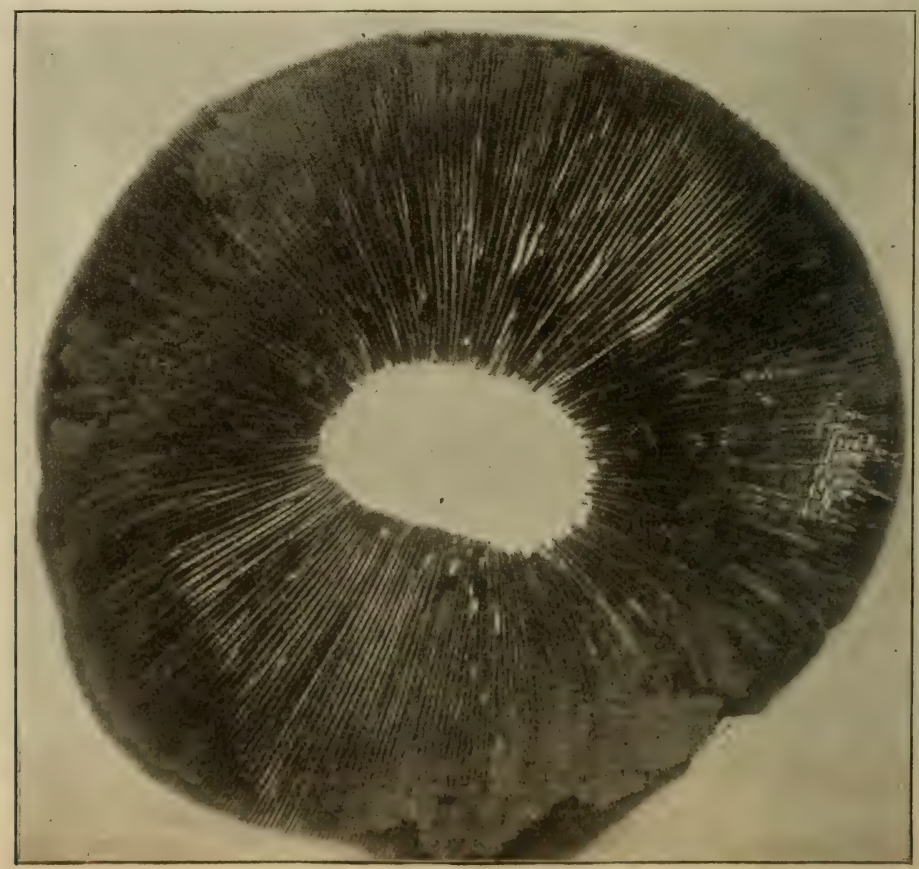

Fig. 439 .

Agaricus campestris ; spore print. 
to the stem as a collar, or a portion of it remains clinging to the margin of the cap. When the buttons are very young the gills are white, but they soon become pink in color, and

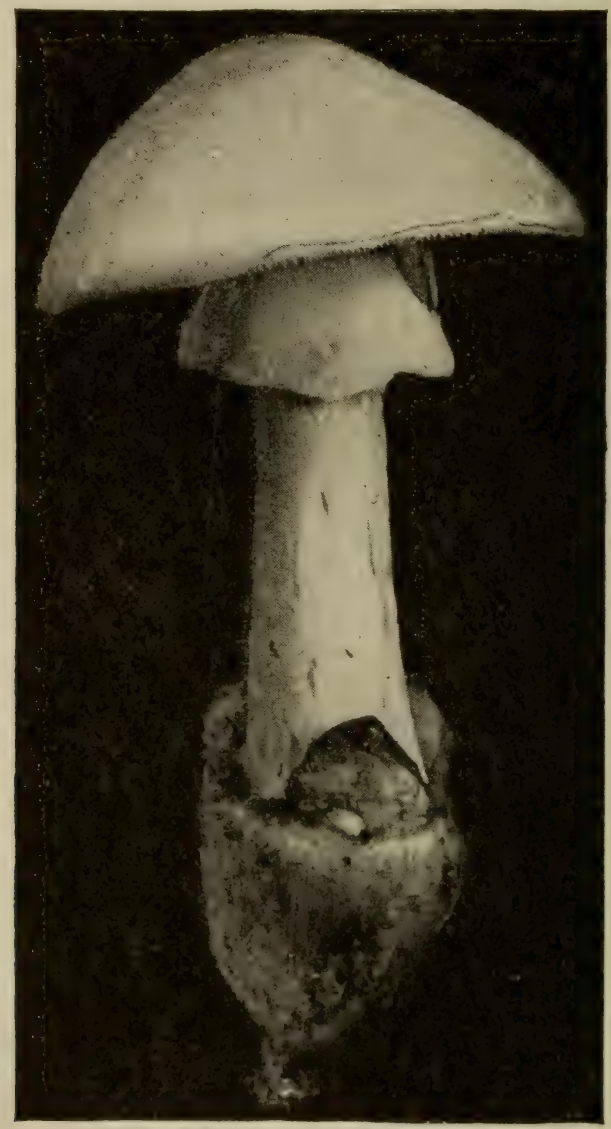

Fig. 44r.

Amanita phalloides; white form, showing pileus, stipe, annulus, and volva.

very soon after the veil breaks the gonidia mature, and then the gills are dark brown.

617. Beware of the poisonous mushroom.-The number of specics of mushrooms, or toadstools as they are often called, is very great. Besides the common mushroom (Agaricus campes- 
tris) there are a large number of other edible species. But one should be very familiar with any species which is gathered for food, unless collected by one who certainly knows what the plant is, since carelessness in this respect sometimes results fatally from eating poisonous ones.

618. A plant very similar in structure to the Agaricus campestris is the Lepiota naucina, but the spores are white, and thus the gills are white, except that in age they become a dirty pink. This plant occurs in grassy fields and lawns often along with the

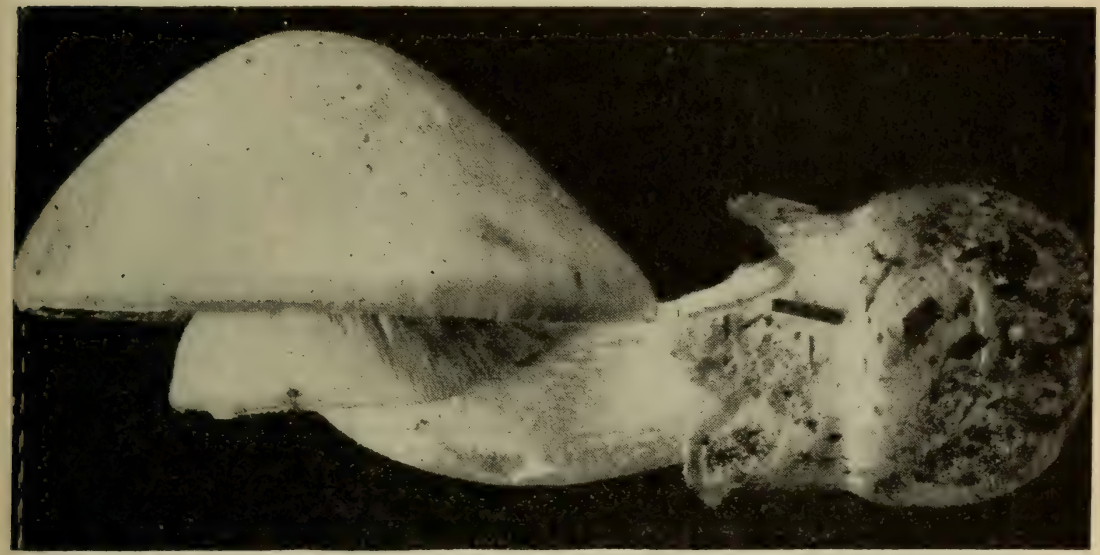

Fig. 442 .

Amanita phalloides; plant turned to one side, after having been placed in a horizontal position, by the directive force of gravity.

common mushroom. Great care should be exercised in collecting and noting the characters of these plants, for a very deadly poisonous species, the deadly amanita (Amanita phalloides) is perfectly white, has white spores, a ring, and grows usually in wooded places, but also sometimes occurs in the margins of lawns. In this plant the base of the stem is seated in a cup-shaped structure, the volva, shown in fig. 44I. One should dig up the sten carefully so as not to tear off this volva if it is present, for with the absence of this structure the plant might easily be mistaken for the lepiota, and serious consequences would result. 
619. Wood-destroying fungi.-Several thousand different species of mushrooms are known in different countries. A large number of them srow in the soil, deriving their nutriment from decaying organic matter in the soil. Others grow in decaying logs and plant parts. Still quite a large number of the mushrooms and their relatives are able to grow in the woody portions of the trunks of living trees, causing decay of the trunks. Still others are parasitic. The wood-destroying fungi not only do great damage in destroying the usefulness of some timber trees for lumber, but they often so weaken the tree trunk or roots of the tree that the trees are broken down during gales.

620. The mycelium enters the tree at wounds in the trunk, limbs, or roots. A limb of a tree broken during a heavy wind, or by falling trees, or by the weight of snow, makes an infection court for the mycelium. A falling tree may bruise and knock off the bark from a sound standing tree and thus open a way for the entrance of the wood-destroying mycelium. The roots of trees are sometimes injured by the wheels of passing vehicles. In some cases I have known fungi to enter through such injuries. Shade trees are also similarly injured as well by the gnawing of animals when allowed to stand near them. Severe pruning of many large limb of trees often renders them liahle to injury from the attacks of wood-destroying fungi, since the small amount of leaf surface remaining is too little for the manufacture of the necessary plant food for repair of the wounds. A few limbs should be taken off in a single season when necessary to prune, and extend the process over several scasons, rather than to prune so severely in a single season.

621. From our studies on the growth in thickness of woody stems we know that the living and growing part of a tree trunk is confined to a layer just underneath the bark. So when a liruise or break passes through this layer (cambium) and exposes the wood within, the mycelium of the wood-destroying fungi can easily enter. From this point it spreads for long distances in the interior of the tree, causing decay. Trees thus often become "hollow." Some of the topmost branches die. The mycelium 


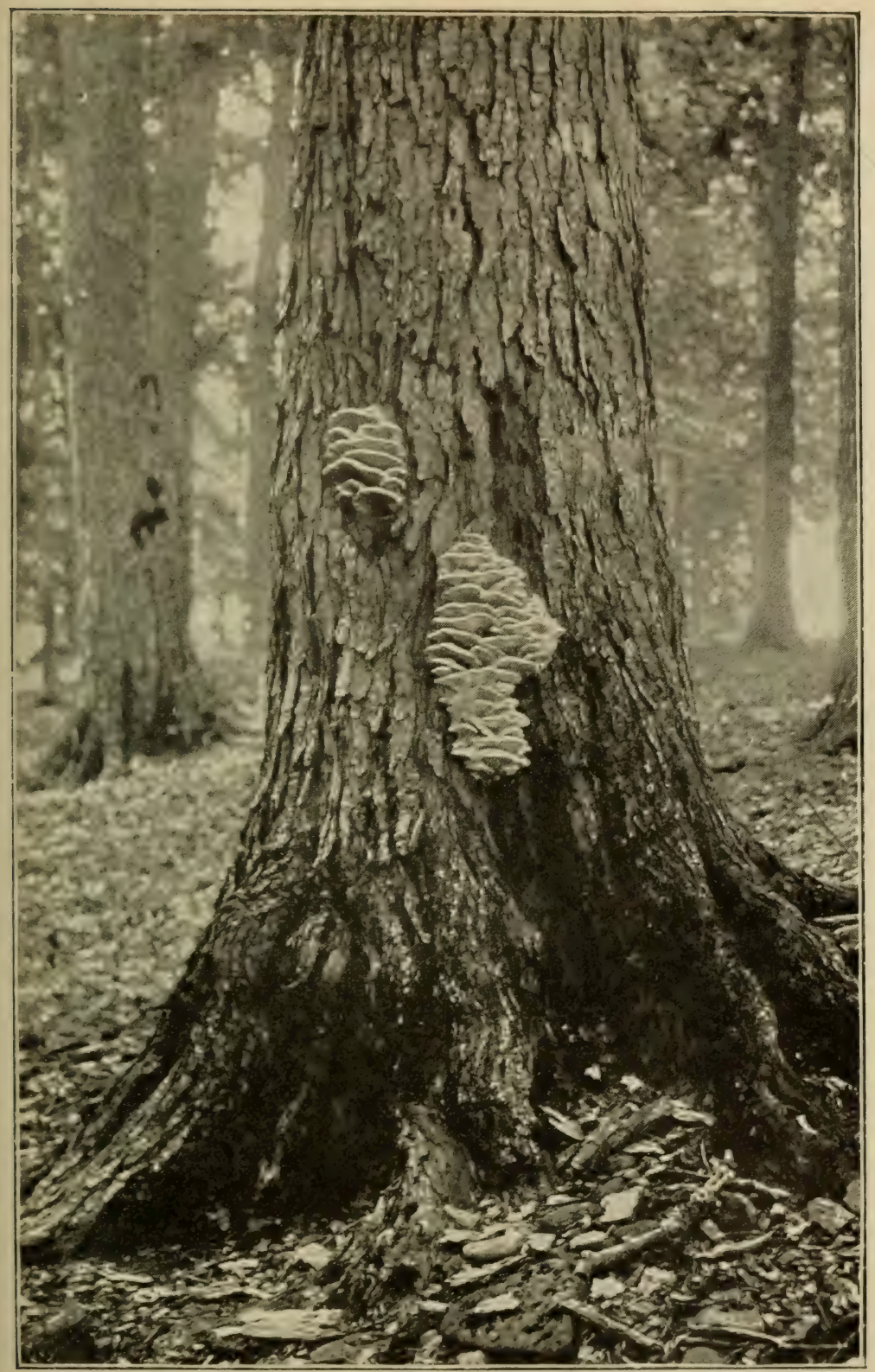

Fig. 443

Wood-destroying fungus (Hydnum septentrionale on living maple, reduced I/ 15 . (Photograph by the author.) 
eventually makes its way to the outside of the tree trunk in places, where large fruit bodies characteristic of the species are found. Figure 443 represents a large sugar-maple tree which is attacked by one of the wood-destroying fungi. The fruit bodies here are of the shelving form and overlap. The fruiting surface of this plant on the sugar maple is in the form of spines, instead of gills, and belongs to the genus hydnum. A number of large maple trees in the grove where this one stood were injured by wood-destroying fungi, and many of them were so weakened thereby that they were blown over during a southeast gale. Some shelving fungi possess gills like agaricus. Others have the under surface honeycombed as in polyporus.

622. The roots of trees are often attacked by a mushroom, the honey agaric (Agaricus melleus). The mycelium here forms long black strands underneath the bark of the root. These often extend from the roots up into the interior of the trunk of the tree, causing decay. The roots are sometimes so weakened by the fungus that they die and easily break when heavy winds arise. Figure 444 shows such a tree uprooted. Further, it is broken about midway of the trunk, because the trunk was weakened by the mycelium inside. Other trees weakened by fungi, and broken over during the same gale, are shown in the same figure. 


\section{CHAPTER XLVIII. \\ DIMORPHISM OF FERNS.}

623. In comparing the different members of the leaf series there are often striking illustrations of the transition from one form to another, as we have noted in the case of the trillium flower. This occurs in many other flowers, and in some, as in the water lily, these transformations are always present, here showing a transition from the petals to the stamens. In the bud scales of many plants, as in the butternut, walnut, currant, etc., there are striking gradations between the form of the simple bud scales and the form of the leaf. Some of the most interesting of these transformations are found in the dimorphic ferns.

624. Dimorphism in the leaves of ferns. - In the common polypody fern, the maidenhair, and in many other ferns, all the leaves are of the same form. That is, there is no difference between the fertile leaf and the sterile leaf. On the other hand, in the case of the Christmas fern we have seen that the fertile leaves are slightly different from the sterile leaves, the former having shorter pinnæ on the upper half of the leaf. The fertile pinnæe are here the shorter ones, and perform but little of the function of carbon conversion. This function is chiefly performed by the sterile leaves and by the sterile portions of the fertile leaves. This is a short step toward the division of labor between the two kinds of leaves, one performing chiefly the labor of carlon conversion, the other chiefly the labor of bearing the fruit.

625. The sensitive fern. - This division of labor is carried to an extreme extent in the case of some ferns. Some of our native 
ferns are examples of this interesting relation between the leaves like the common sensitive fern (Onoclea sensibilis) and the ostrich fern (O. struthiopteris) and the cinnamon fern (Osmunda cinnamomea). The sensitive fern is here shown in fig. 445 . The sterile leaves are large, broadly expanded, and pinnate, the

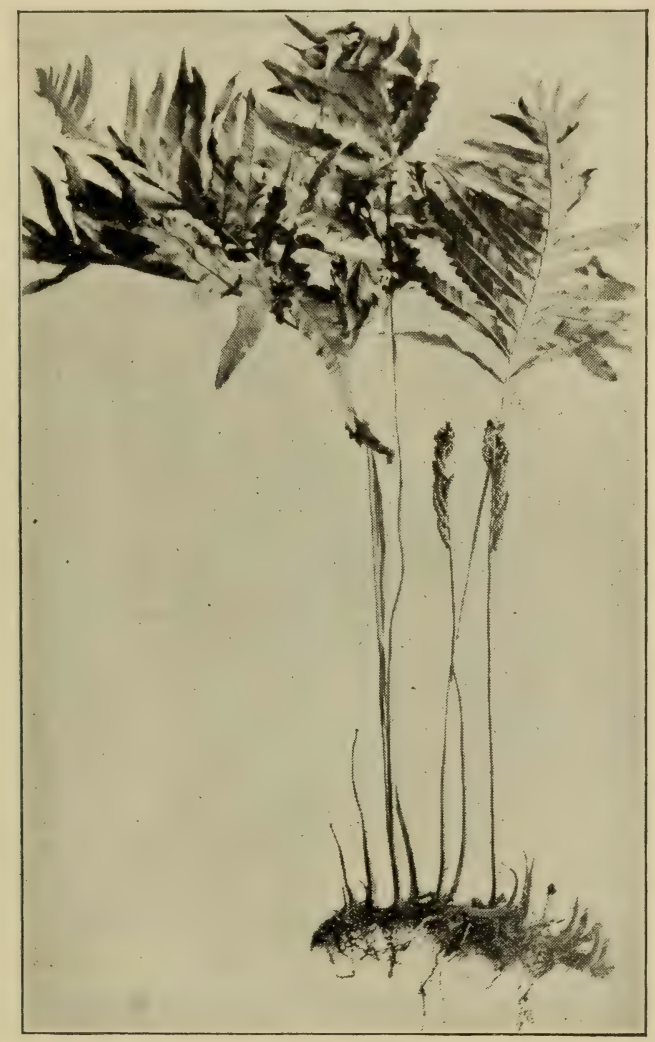

Fig. 445 .

Sensitive fern; normal condition of vegetative leaves and sporophylls.

pinnæ being quite large. The fertile leaves are shown also in the figure, and at first one would not take them for leaves at all. But if we examine them carefully we see that the general plan of the leaf is the same: the two rows of pinnæ which are here much shorter than in the sterile leaf, and the pinnules, or smaller 
divisions of the pinnæ, are inrolled into little spherical masses which lie close on the side of the pinnæ. If we unroll one of these pinnules we find that there are several fruit dots within protected by this roll. In fact when the spores are mature these

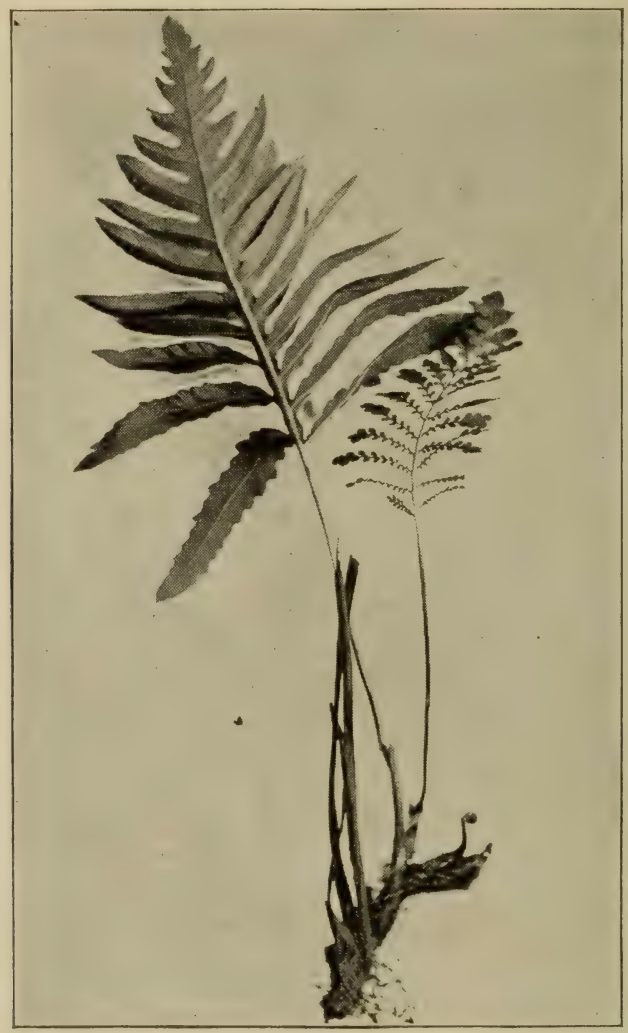

Fig. 446 .

Sensitive fern; one fertile leaf nearly changed to vegetative leaf.

pinnules open somewhat, so that the spores may lee disseminated.

There is very little green color in these fertile leaves, and what green surface there is is very small compared with that of the broad expanse of the sterile leaves. So here there is practically a complete division of labor between these two kinds of 
leaves, the general plan of which is the same, and we recognize each as being a leaf.

626. Transformation of the fertile leaves of onoclea to sterile ones. - It is not a very rare thing to find plants of the sensitive fern which show intermediate conditions of the sterile and the fertile leaf. A number of years ago it was thought by some that this represented a different species, but now it is known

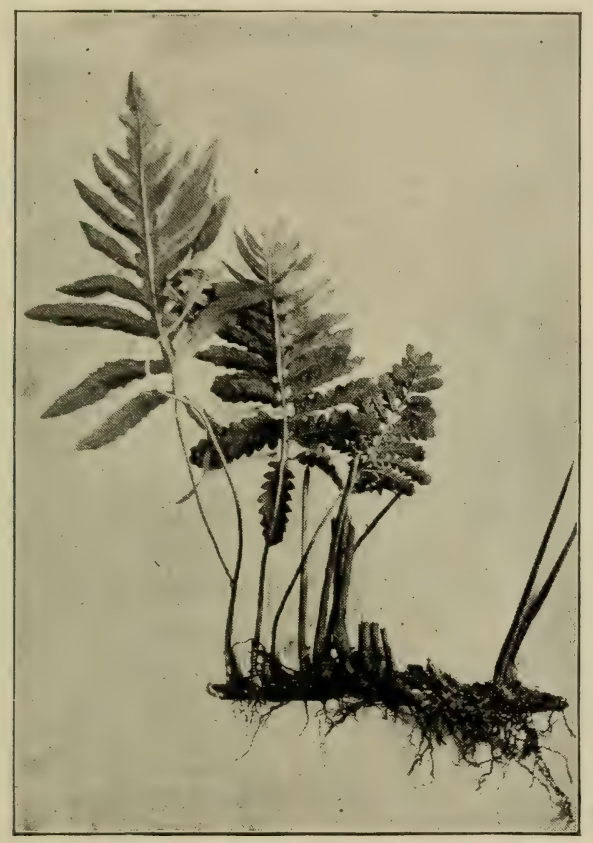

Fig. 447 .

Sensitive fern, showing one vegetative leaf and two sporophylls completely transformed.

that these intermediate forms are partly transformed fertile leaves. It is a very easy matter in the case of the sensitive fern to produce these transformations by experiment. If one in the spring, when the sterile leaves attain a height of I 2 to $16 \mathrm{~cm}$ (8-10 inches), cuts them away, and again when they have a second time reached the same height, some of the fruiting leaves which develop later will be transformed. I few years ago I cut off the 
sterile leaves from quite a large patch of the sensitive fern, once in May, and again in June. In July, when the fertile leaves were appearing above the ground, many of them were changed partly or completely into sterile leaves. In all some thirty plants

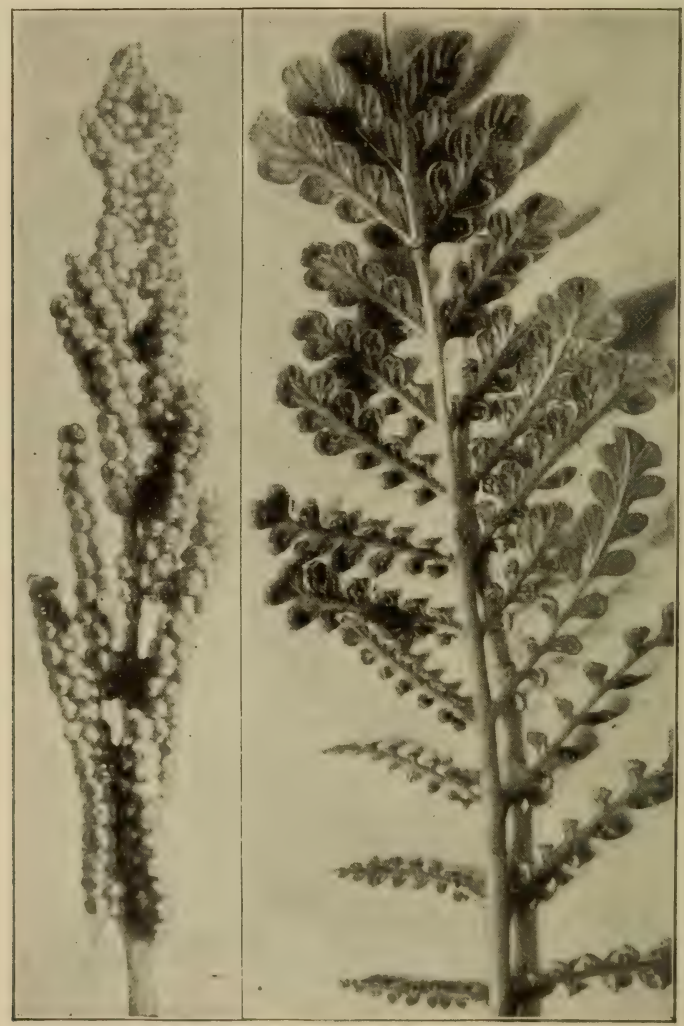

Fig. 448 .

Normal and transformed sporophyll of sensitive fern.

showed these transformations, so that every conceivable gradation was obtained between the two kinds of leaves.

627. It is quite interesting to note the form of these changed leaves carefully, to see how this change has affected the pinne and the sporangia. We note that the tip of the leaf as well as the tips of all the pinna are more expranded than the basal por- 
tions of the same. This is due to the fact that the tip of the leaf develops later than the basal portions. At the time the stimulus to the change in the development of the fertile leaves reached them they were partly formed, that is the basal parts of the fertile leaves were more or less developed and fixed and could not change. Those portions of the leaf, however, which were not yet completely formed, under this stimulus, or through correlation of growth, are incited to vegetative growth, and expand more or less completely into vegetative leaves.

628. The sporangia decrease as the fertile leaf expands. If we now examine the sporangia on the successive pinnæ of a partly transformed leaf we find that in case the lower pinnæ are not changed at all, the sporangia are normal. But as we pass to the pinnæ which show increasing changes, that is those which are more and more expanded, we see that the number of sporangia decrease, and many of them are sterile, that is they bear no spores. Farther up there are only rudiments of sporangia, until on the more expanded pinnæ sporangia are no longer formed, but one may still see traces of the indusium. On some of the changed leaves the only evidences that the leaf began once to form a fertile leaf are the traces of these indusia. In some of these cases the transformed leaf was even larger than the sterile leaf.

629. The ostrich fern.- Similar changes were also produced in the case of the ostrich fern, and in fig. 448 is shown at the left a normal fertile leaf, then one partly changed, and at the right one completely transformed.

630. Dimorphism in tropical ferns.-Very interesting forms of dimorphism are seen in some of the tropical ferns. One of these is often seen growing in plant conservatories, and is known as the staghorn fern (Platycerium alcicorne). This in nature grows attached to the trunks of quite large trees at considerable elevations on the tree, sometimes surrounding the tree with a massive growth. One kind of leaf, which may be either fertile or sterile, is narrow, and branched in a peculiar manner, so that it resembles somewhat the branching of the horn of a stag 
Below these are other leaves which are different in form and sterile. These leaves are broad and hug closely around the roots and bases of the other leaves. Here they serve to catch and

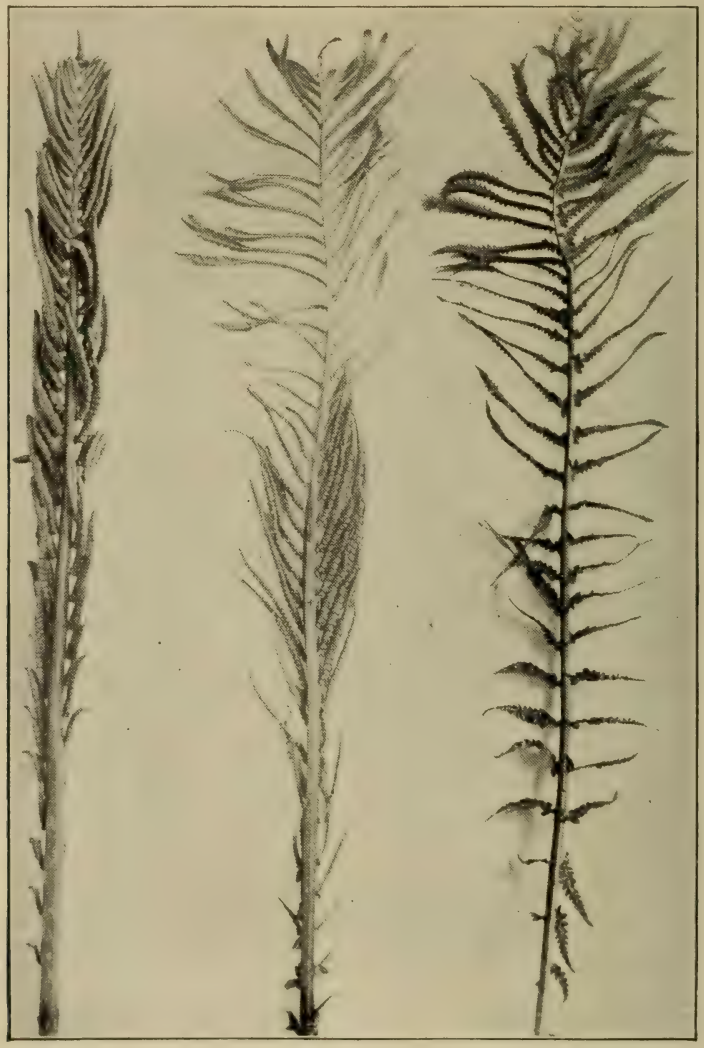

Fig. 449 .

Ostrich fern, showing one normal sporophyll, one partly transformed, and one completely transformed.

retain moisture, and they also catch leaves and other vegetable matter which falls from the trees. In this position the leaves decay and then serve as food for the fern. 


\section{CHAPTER XLIX.}

\section{FORMATION OF EARLY SPRING FLOWERS.}

631. Trillium. - As this white flower with its setting of green sepals is glinting to us out of copses and woodland like so many new fairies, few of us realize the long task which it has already begun in the silent depths of the soil in order that it may suddenly blossom again in season, when springtime returns. If we remove the old scales where the flowering stem joins the root-stock, we will see a pointed, conical, white bud, which is to develop into the next season's leafy plant and blossom. From June to August the new leaves and flower are slowly forming, protected by several overlapping, thick, whitish, soft scales, which form a conical roof to keep out water, and to protect against too sudden changes in cold during the autumn and winter season. In September we find that leaves and sepals are well formed and green, the petals are already white, and within are the six stamens and the angular pistil, all well formed. Where the sun reaches these copses and warms the soil well in autumn, sometimes the stamens are yellowish as early as September or October from the already formed pollen. In the cooler shades the pollen is not yet formed and the stamens remain whitish in color. But with the first onset of warm weather in the spring, or on warm days in the winter, before the flower bud lifts its head from its long winter sleep, snugly ensconced among the fallen leaves or spongy humus, the pollen quickly forms. Now all the plant has to do is to erect its standard, bearing aloft the opening blossom.

632. The ovules, begun in the autumn, are now being completed, pollenation takes place, and later fertilization, and the embryo begins to form in June. The pure white flowers soon 


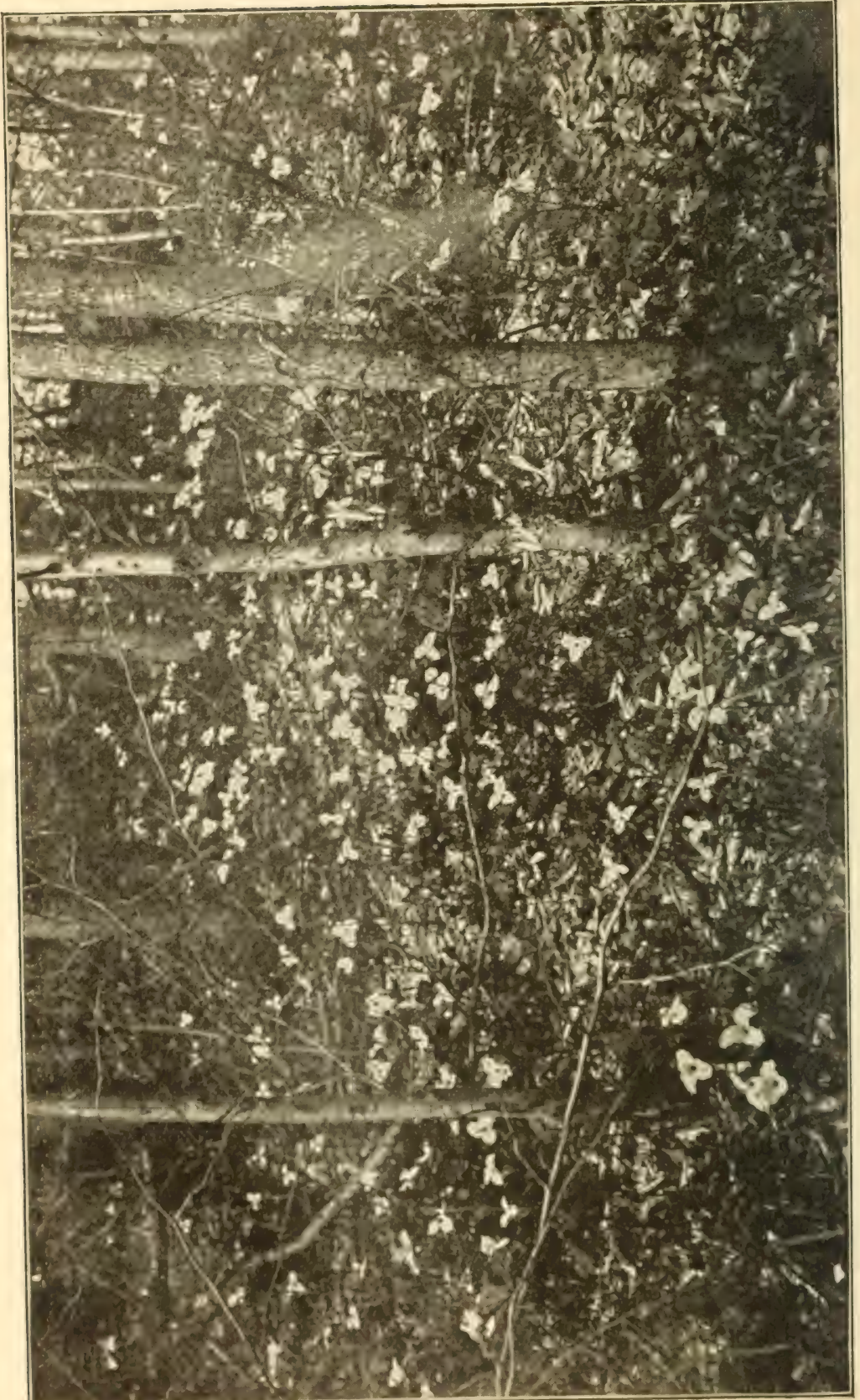


change to pinkish, the first evidence of decline. Finally they wither, and during the summer the fruit and seed are formed on the old flower stem, while the secret formative processes of the new blossoms are going on anew.

633. The adder-tongue (erythronium) comes out early in the spring to catch the sunlight gleaming through rifts in the woodland. It is not so forbidding as its name or its "darting", style would suggest. The rich color of its curved petals nodding from the fork of the variegated leaves lends cheer and brightness to the gray carpet of forest leaves. We are apt to associate the formation of the flower with the early springtime. But after the flower perishes, the bulb, deep in the soil, slowly builds the next season's flower, which is kept through the autumn and winter, much of the time encased in ice, waiting for springtime that it may rise and unfold.

634. Indian-turnip. - The "Indian-turnip," or " jack-in-thepulpit" (Arisæma triphyllum), loves the cool, shady, rich, alluvial soil of low grounds, or along streams, or on moist hillsides. A group of the jacks is shown in figure 457 as they occur in the rich soil on dripping rocks in one of our glens. At their feet is a carpet of moss. Often the violet sits humbly underneath its spreading three-parted leaves. The thin, strap-shaped spathe, unfolded at its base, bends gracefully over the spadix, the sterile end of which stands solitary in the pulpit thus formed. The fiowers are very much reduced, and the plants are "dimorphic" usually.

635. Female plants. - The large plants usually bear the pistillate flowers, which are clustered around the base of the spadix, each flower consisting of a single pistil, oval in form, terminating in a brush-like stigma. The stigma consists of numerous spreading, delicate hairs. The open cavity of the short style is hairy also, and a brush of hairs extends into the cavity of the ovary. Into this brush of internal hairs the necks of the several ovules crowd their way to the base of the style near its opening. Even when the stigma is not pollenated the ovary continues to grow in size, and the stigmatic brush remains fresh for a long time. 
636. Male plants. - Excepting some of the intermediate sizes, one can usually select on sight the male and female plants. The smaller ones which have a spathe are nearly all male and bear a single leaf, though a few have two leaves. The male flowers are also clustered at the base of the spadix, and are very much reduced. Each flower consists only of stamens, and singularly the stamens of each flower are joined into one compound stamen, the anther-sacs forming rounded lobes at the end of the short consolidated filaments.

637. In some plants both male and female flowers occur on a single spadix, the lower flowers being female, while the upper ones are male. The larger plants are nearly all female, and many, though not all, bear two leaves. In this dimorphism of the plant there is a division of labor apportioned to the destiny and needs of each, and in direct correspondence with the capacity to supply nutriment. The staminate flowers, being short-lived, need comparatively a small amount of nutriment, and after the escape of the pollen (dehiscence of the anthers) the spathe dies, while the leaf remains green to assimilate food for growth of the fleshy short stem (corm), where also is stored nutriment for the growth in the autumn and spring when the leaf is dead. The female plants have more work to do in providing for the growth of the embryo and seed, in addition to the growth of the corm and next season's flower. The smaller female plants thus sometimes exhaust themselves so in seed bearing that the corm becomes small, and the following season the plant is reduced to a male one.

638. The new roots each year arise from the upper part of the corm. The stored substances in the base of the corm are used in the early season's growth, and the old tissue sloughs off as the new corm is formed above upon its remains. 


\section{CHAPTER L.}

\section{POLLENATION.}

\section{Origin of heterospory, and the necessity for pollenation.}

639. Both kinds of sexual organs on the same prothallium.-In the ferns, as we have seen, the sexual organs are borne on the prothallium, a small, leaf-like, heart-shaped body growing in moist situations. In a great many cases both kinds of sexual organs are borne on the same prothallium. While it is perhaps not uncommon, in some species, that the egg cell in an archegonium may be fertilized by a spermatozoid from an antheridium on the same prothallium, it happens many times that it is fertilized by a spermatozoid from another prothallium. This may be accomplished in several ways. In the first place antheridia are usually found much earlier on the prothallium than are the archegonia. When these antheridia are ripe, the spermatozoids escape before the archegonia on the same prothallium are mature.

640. Cross fertilization in monœcious prothallia.-By swimming about in the water or drops of moisture which are at times present in these moist situations, these spermatozoids may reach and fertilize an egg which is ripe in an archegonium borne on another and older prothallium. In this way what is termed cross fertilization is brought about nearly as effectually as if the prothallia were diøcious, i.e. if the antheridia and archegonia were all borne on separate prothallia.

641. Tendency toward diœcious prothallia.- In other cases some fern prothallia bear chiefly archegonia, while others bear only antheridia. In these cases cross fertilization is enforced because of this separation of the sexual organs on different prothallia. These different prothallia, the male and female, are largely due to a difference in food supply, as has been clearly proven by experiment.

642. The two kinds of sexual organs on different prothallia.- - In the horsetails (equisetum) the separation of the sexual organs on different prothallia has become quite constant. Although all the spores are alike, so far as we can determine, some produce small male plants exclusively, while others produce 
large female plants, though in some cases the latter bear also antheridia. It has been found that when the spores are given but little nutriment they form male prothallia, and the spores supplied with abundant nutriment form female prothallia.

643. Permanent separation of sexes by different amounts of nutriment supplied the spores.-This separation of the sexual organs of different prothallia, which in most of the ferns, and in equisetum, is dependent on the chance supply of nutriment to the germinating spores, is made certain when we come to such plants as isoetes and selaginella. Here certain of the spores receive more nutriment while they are forming than others. In the large sporangia (macrosporangia) only a few of the cells of the spore-producing tissue form spores, the remaining cells being dissolved to nourish the growing macrospores, which are few in number. In the small sporangia (microsporangia) all the cells of the spore-producing tissue form spores. Consequently each one has a less amount of nutriment, and it is very much smaller, a microspore. The sexual nature of the prothallium in selaginella and isoetes, then, is predetermined in the spores while they are forming on the sporophyte. The microspores are to produce male prothallia, while the macrospores are to produce female prothallia.

644. Heterospory.-This production of two kinds of spores by isoetes, selaginella, and some of the other fern plants is heterospory, or such plants are said to be heterosporous. Heterospory, then, so far as we know from living forms, has originated in the fern group. In all the higher plants, in the gymnosperms and angiosperms, it has been perpetuated, the microspores being represented by the pollen, while the macrospores are represented by the em. bryo sac; the male organ of the gymnosperms and angiosperms being the antherid cell in the pollen or pollen tube, or in some cases perhaps the pollen grain itself, and the female organ in the angiosperms perhaps reduced to the egg cell of the embryo sac.

645. In the pteridophytes water serves as the medium for conveying the sperm cell to the female organ.-In the ferns and their allies, as well as in the liverworts and mosses, surface water is a necessary medium through which the generative or sperm cell of the male organ, the spermatozoid, may reach the germ cell of the female organ. The sperm cell is here motile. This is true in a large number of cases in the algre, which are mostly aquatic plants, while in other cases currents of water float the sperm cell to the female organ.

646. In the higher plants a modification of the prothallium is necessary. -As we pass to the gymnosperms and angiosperms, however, where the primitive phase (the gametophyte) of the plints has lecome ilependent solely on the modern phase (the sporophyte) of the plant, surface water no longer serves as the medium through which a motile sperm cell reaches the egg cell to fertilize it. The female prothallium, or macrospore, is, in nearly all 
cases, permanently enclosed within the sporangium, so that if there were motile sperm cells on the outside of the ovary, they could never reach the egg to fertilize it.

647. But a modification of the microspore, the pollen tube, enables the sperm cell to reach the eyg cell. The tube grows through the nucellus, or first through the tissues of the ovary, deriving nutriment therefrom.

648. But here an important consideration should not escape us. The pollen grains (microspores) must in nearly all cases first reach the pistil, in order that in the growth of this tube a channel may be formed through which the generative cell can make its way to the egg cell. The pollen passes from the anther locule, then, to the stigma of the ovary. This process is termed pollenation.

\section{Pollenation.}

649. Self pollenation, or close pollenation.-Perhaps very few of the admirers of the pretty blue violet have ever noticed that there are other flowers than those which appeal to us through the beautiful colors of the petals. How many have observed that the brightly colored flowers of the blue violet rarely "set fruit"? Underneath the soil or débris at the foot of the plant are smaller flowers on shorter, curved stalks, which do not open. When the anthers dehisce, they are lying close upon the stigma of the ovary, and the pollen is deposited directly upon the stigma of the same flower. This method of pollenation is self poilenation, or close pollenation. These small, closed flowers of the violet have been termed "cleistogamous," because they are pollenated while the flower is closed, and fertilization takes place as a result.

But self pollenation takes place in the case of some open flowers. In some cases it takes place by chance, and in other cases by such movements of the stamens, or of the flower at the time of the dehiscence of the pollen, that it is quite certainly deposited upon the stigma of the same flower.

650. Wind pollenation.-The pine is an example of wind pollenated flowers. Since the pollen floats in the air or is carried by the "wind," such flowers are anemophilous. Other anemophilous flowers are found in other conifers, in grasses, sedges, many of the ament-bearing trees, and other dicotyledons. Such plants produce an abundance of pollen and always in the form of "dust," so that the particles readily separate and are borne on the wind.

651. Pollenation by insects.-A large number of the plants which we have noted as being anemophilous are monœcious or diøcious, i.e. the stamens and pistils are borne in separate flowers. The two kinds of flowers thus formed, the male and the female, are borne either on the same individual (monoecious) or on different individuals (diœcious). In such cases cross pollenation, 
i.e. the pollenation of the pistil of one flower by pollen from another, is sure to take place, if it is pollenated at all. Even in monøecious plants cross pollenation often takes place between flowers of different individuals, so that

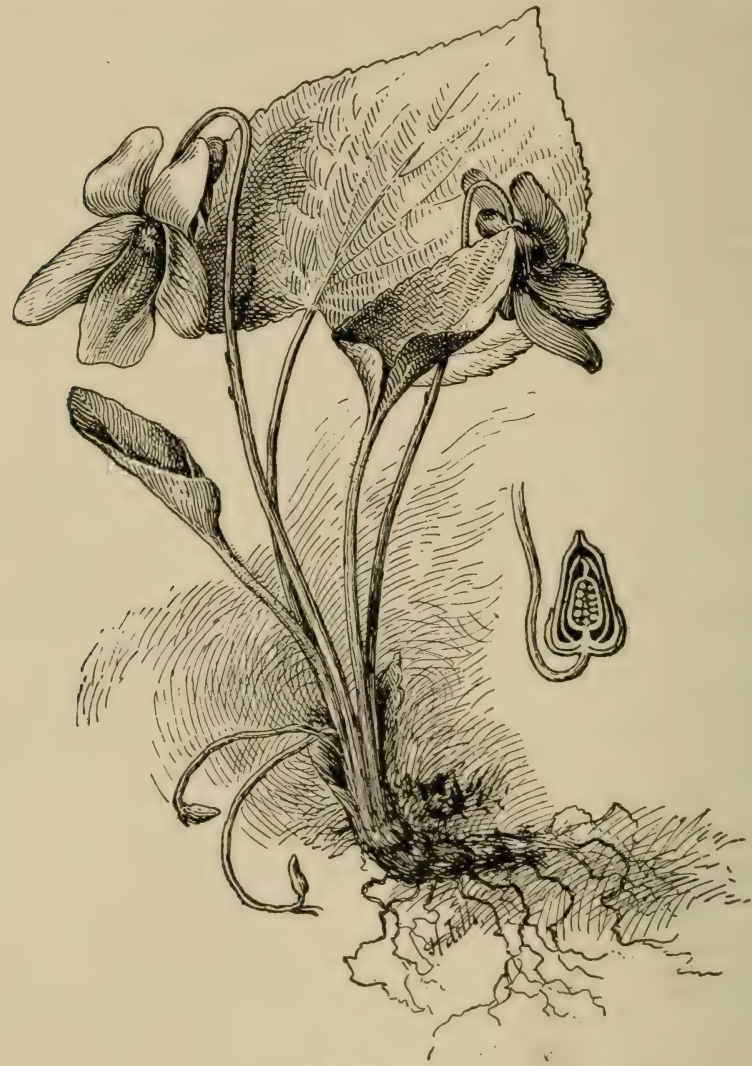

Fig. 451 .

Viola cucullata; blue flowers above, cleistogamous flowers smaller and curved below. Section of pistil at right.

more widely different stocks are united in the fertilized egg, and the strain is kept more vigorous than if very close or identical strains were united.

652. But there are many flowers in which both stamens and pistils are present, and yet in which cross pollenation is accomplished through the agency of insects.

653. Pollenation of the bluet.-In the pretty bluet the stamens and styles of the flowers are of different length as shown in figures $45^{2}, 453$. The stamens of the long-styled flower are at about the same level as the stigma of the short-styled flower, while the stamens of the latter are on 
about the same level as the stigma of the former. What does this interesting relation of the stamens and pistils in the two different flowers mean? As the butterfly thrusts its "tongue" down into the tule of the long-styled flower
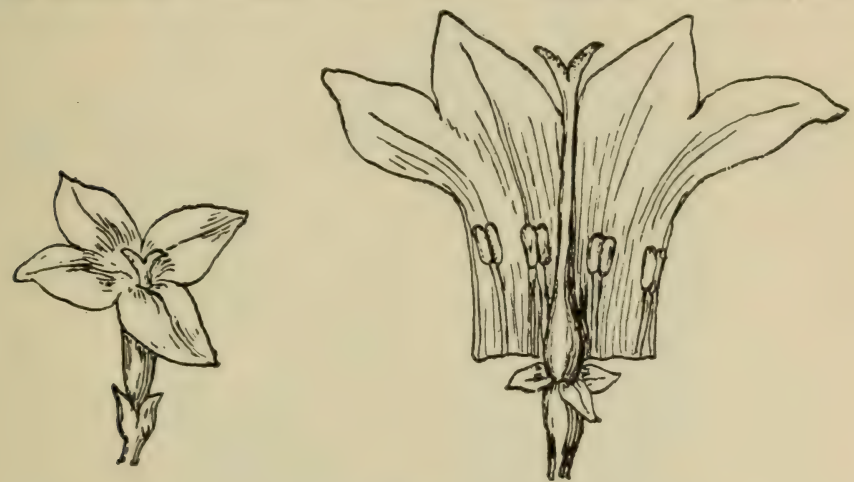

Fig. $45^{2}$

Dichogamous flower of the bluet (Houstonia cœrulea), the long-styled form.

for the nectar, some of the pollen will be rubbed off and adhere to it. When now the butterfly visits a short-styled flower this pollen will be in the right position to be rubbed off onto the stigma of the short style. The positions of
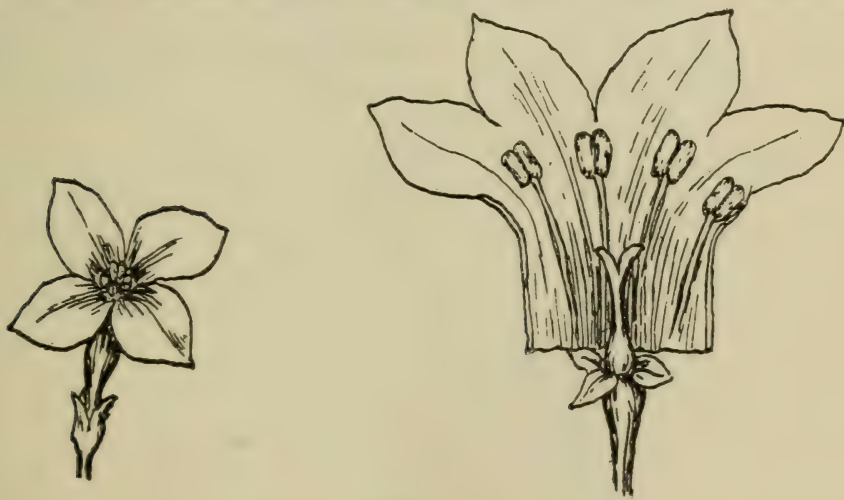

Fig. 453 .

Dichogamous flower of bluet (Houstonia cœrulea), the short-styled form.

the long stamens and long style are such that a similar cross pollenation will be effected.

654. Pollenation of the primrose.- In the primroses, of which we have examples growing in conservaturies, that blossom during the winter, we have almost identical examples of the beautiful adaptations for cross pollenation by insects found in the bluet. The general shape of the corolla is 
the same, but the parts of the flower are in fives, instead of in fours as in the bluet. While the pollen of the short-styled primulas sometimes must fall on the stigma of the same flower, Darwin has found that such pollen is
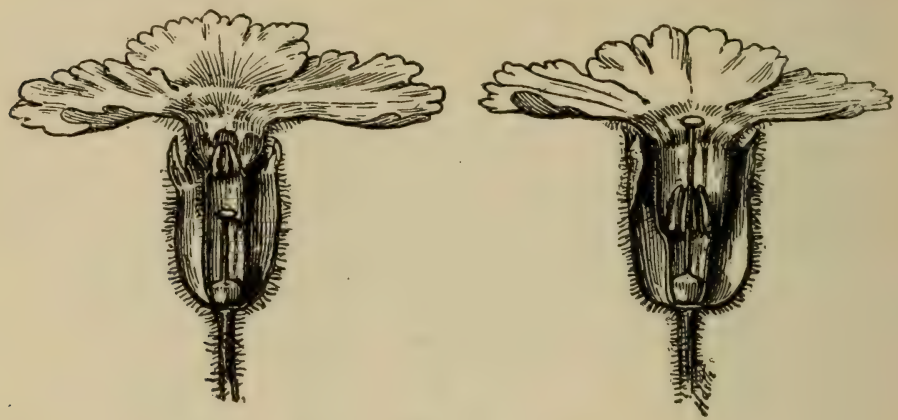

Fig. 454.

Dichogamous flowers of primula.

not so potent on the stigma of its own flower as on that of another, an additional provision which tends to necessitate cross pollenation.

In the case of some varieties of pear trees, as the bartlett, it has been found that the flowers remain largely sterile not only to their own pollen, or pollen of the flowers on the same tree, but to all flowers of that variety. However, they become fertile if cross pollenated from a different variety of pear.

655. Pollenation of the skunk's cabbage.-In many other flowers cross pollenation is brought about through the agency of insects, where there is a difference in time of the maturing of the stamens and pistils of the same flower. The skunk's cabbage (Sphathyema fotida), though repulsive on account of its fetid odor, is nevertheless a very interesting plant to study for several reasons. Early in the spring, before the leaves appear, and in many cases as soon as the frost is out of the hard ground, the hooked beak of the large fleshy spathe of this plant pushes its way through the soil.

If we cut away one side of the spathe as shown in fig. 456 we shall have the flowering spaclix brought closely to view. In this spadix the pistil of each crowded flower has pushed its style through between the plates of armor formed by the converging ends of the sepals, and stands out alone with the brush-like stigma ready for pollenation, while the stamens of all the flowers of this spadix are yet hidden beneath. The insects which pass from the spadix of one plant to another will, in crawling over the projecting stigmas, rub off some of the pollen which has been caught while visiting a plant where the stamens are scattering their pollen. In this way cross polleriation is brought about. Such flowers, in which the stigma is prepared 
POLLENATION: HETEROSPORY.

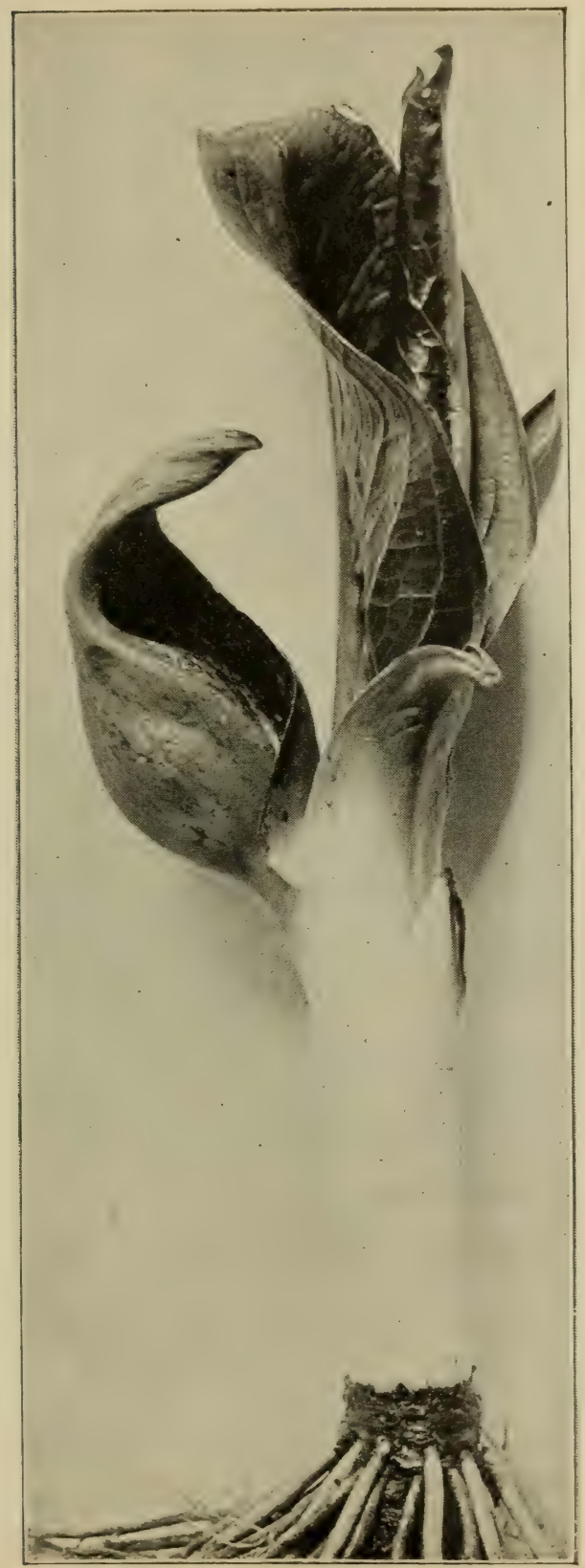

Fig. 455 .

Skunk's cabbage. 


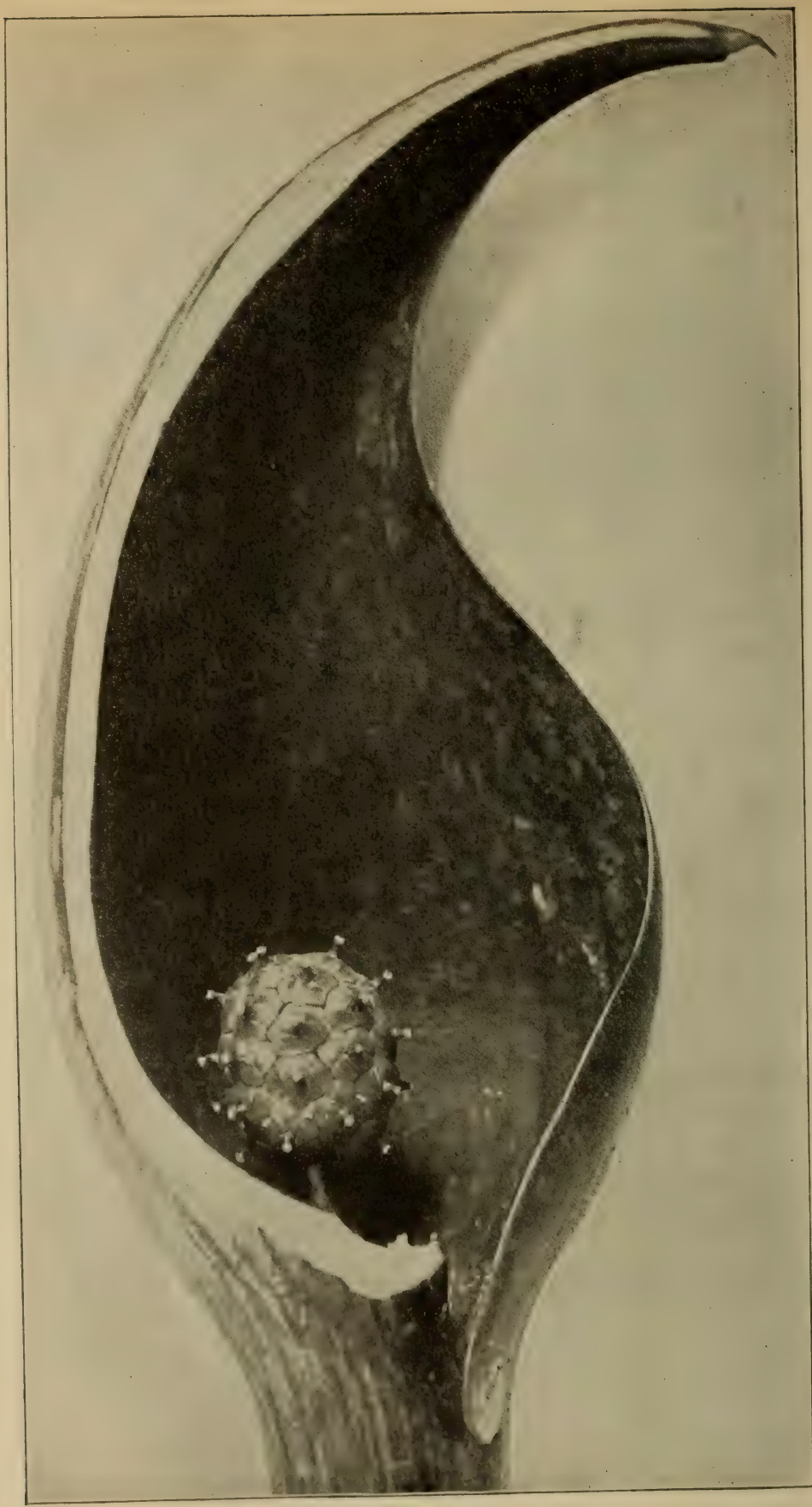

Fig. 456 .

Proterogyny in skunk's cabbage. (Photograph by the author.) 


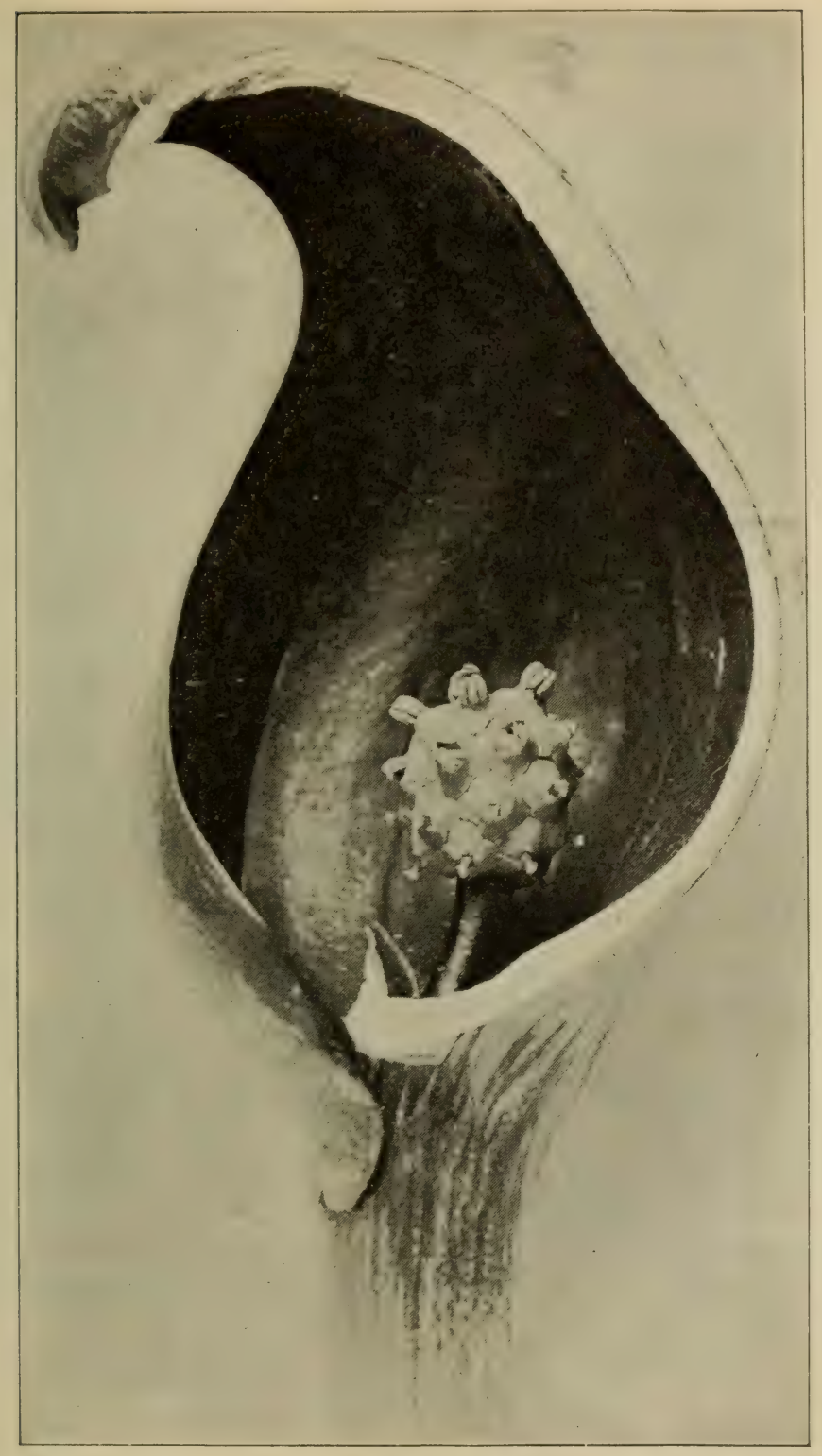

Fig. 457 .

Skunk's cabbage; upper flowers proterandrous, lower ones proterogynous. 
for pollenation before the anthers of the same flower are ripe, are proterogynous.

656. Now if we observe the spadix of another plant we may see a condition of things similar to that shown in fig. 457. In the flowers in the upper part of the spadix here the anthers are wedging their way through between the armor-like plates formed by the sepals, while the styles of the same flowers are still beneath, and the stigmas are not ready for pollenation. Such flowers are proterandrous, that is, the anthers are ripe before the stigmas of the same flowers are ready for pollenation. In this spadix the upper flowers are proterandrous, while the lower ones are proterogynous, so that it might happen here that the lower flowers would be pollenated by the pollen falling on them from the stamens of the upper flowers. This would be cross pollenation so far as the flowers are concerned, but not so far as the plants are concerned. In some individuals, however, we find all the flowers proterandrous.

657. Spiders have discovered this curious relation of the flowers and insects.-On several different occasions, while studying the adaptations of the flowers of the skunk's cabbage for cross pollenation, I was interested to find that the spiders long ago had discovered something of the kind, for they spread their nets here to catch the unwary but useful insects. I have not seen the net spread over the opening in the spathe, but it is spread over the spadix within, reaching from tip to tip of either the stigmas, or stamens, or both. Behind the spadix crouches the spider-trapper. The insect crawls over the edge of the spadix, and plunges unsuspectingly into the dimly lighted chamber below, where it becomes entangled in the meshes of the net.

Flowers in which the ripening of the anthers and maturing of the stigmas occur at different times are also said to be dichogamous.

658. Pollenation of jack-in-the pulpit.-The jack-in-the-pulpit (Arisæma triphyllum) has made greater advance in the art of enforcing cross pollenation. The larger number of plants here are, as we have found, diccious, the staminate flowers being on the spadix of one plant, while the pistillate flowers are on the spadix of another. In a few plants, however, we find both female and male flowers on the same spadix.

659. The pretty bellflower (Campanula rotundifolia) is dichogamous and proterandrous (fig. 459). Many of the composites are also dichogamous.

660. Pollenation of orchids. - But some of the most marvellous adaptations for cross pollenation by insects are found in the orchids, or members of the orchis family. The larger number of the members of this family grow in the tropics. Many of these in the forests are supported in lofty trees where they are brought near the sunlight, and such are called "epiphytes." A number of species of orchids are distributed in temperate regions. 
661. Cypripedium or lady-slipper.-One species of the lady-slipper is shown in fig. 465. The labellum in this genus is shaped like a shoe, as one

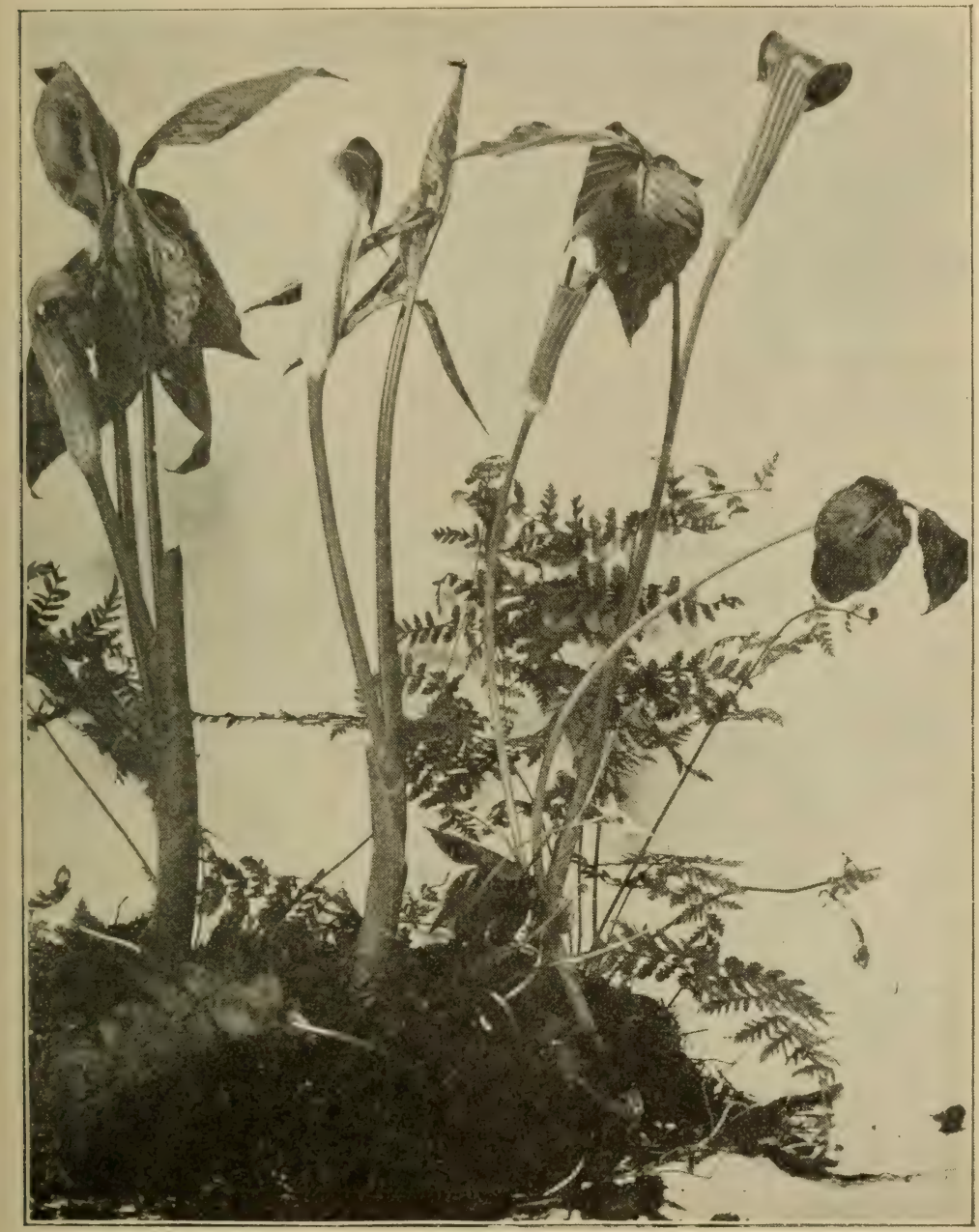

Fig. 458 .

A group of jacks.

can see by the section of the flower in fig. $46_{5}$. The stigmat is situated at st, while the anther is situated at $a$, upon the style. The insect enters about the middle of the boat-shaped labellum. In going out it pas-ens up and out 
at the end near the flower stalk. In doing this it passes the stigma first and the anther last, rubbing against both. The pollen caught on the head of
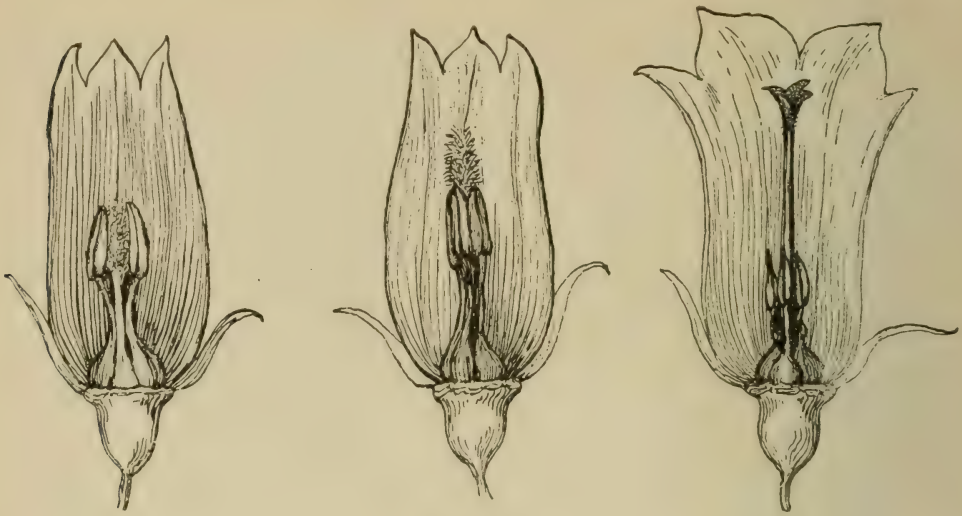

Fig. 459 .

Proterandry in the bell-flower (campanula). Left figure shows the svngenocious stamens surrounding the immature style and stigma. Middle figure shows the immature stigma being pushed through the tube and brushing out the pollen; while in the right-hand figure, after the pollen has disappeared, the lobes of the stigma open out to receive pollen from another flower.

the insect, will not touch the stigma of the same flower, but will be in position to come in contact with the stigma of the next flower visited.

662. Epipactis.-In epipactis, shown in fig. 466 , the action is similar to that of the blue iris.
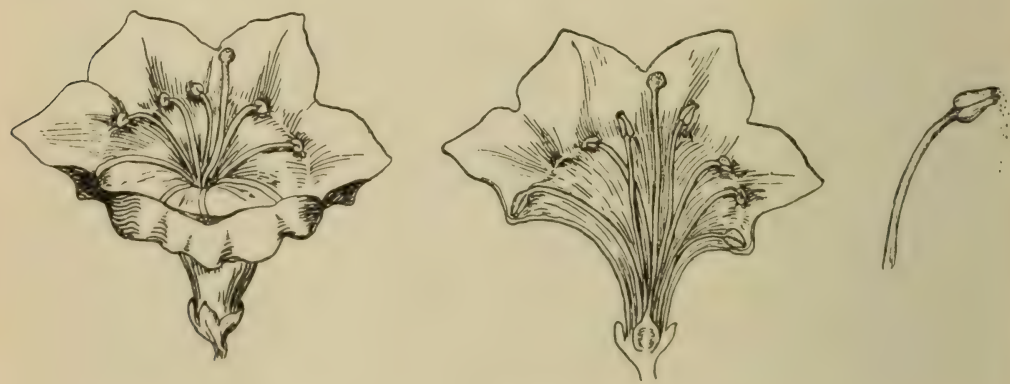

Fig. 460 .

Kalmia latifolia, showing position of anthers before insect visits, and at the right the scattering of the pollen when disturbed by insects. Middle figure section of flower.

663. In some of the tropical orchisls the pollinia are set free when the insect touches a certain part of the flower, and are thrown in such a way that the disk of the pollinium strikes the insect's head and stands upright. By the time the insect reaches another flower the pollinium has bent downward suffi. 
The calyx is green, adherent to the ovary, and the limb divides into three, lanceolate lobes. The petals are obovate and spreading, while the stamens have all changed to petal-like members, called staminodia. Only one still shows its stamen origin, since the anther is seen at one side, while the filament is expanded laterally and upwards to form the staminodium.

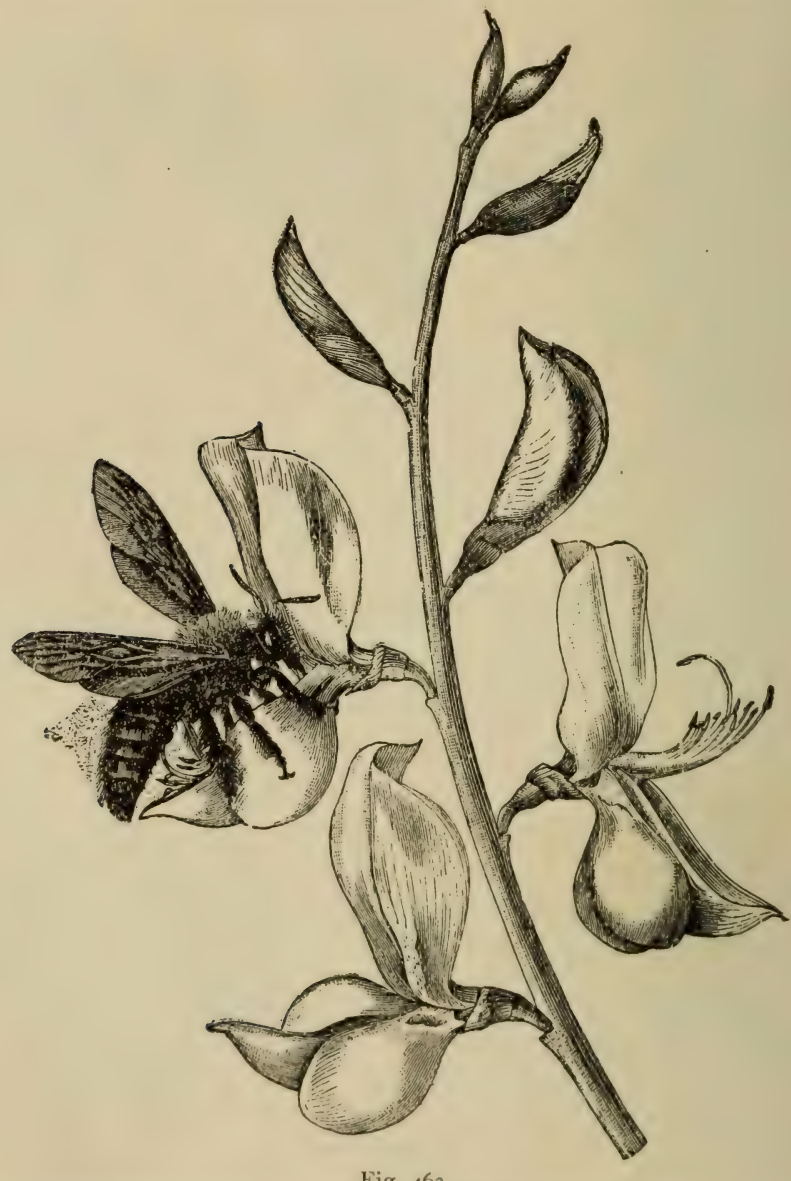

Fig. $46_{3}$.

Spartium, showing the dusting of the pollen through the opening keels on the under side of an insect. (From Kerner and Oliver.)

665. The ovary has three locules, and the three styles are usually united into a long, thin, strap-shaped style, as seen in the figure, though in some cases three, nearly distinct, filamentous styles are present. The end of this strap-shaped style has at peculiar curve on one side, the outline being some- 
times like a long narrow letter $S$. It is on the end of this style, and along the crest of this curve, that the stigmatic surface lies, so that the pollen

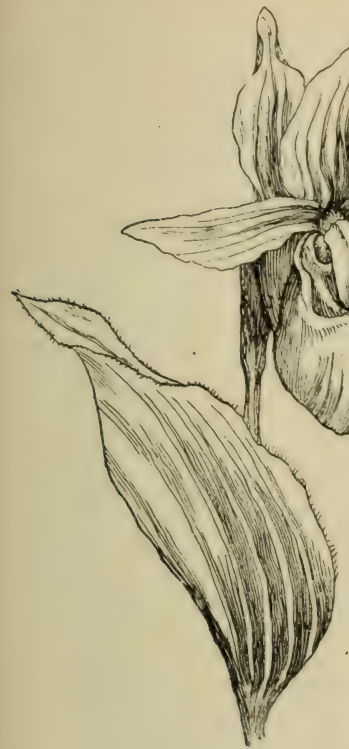

Fig. 464 .

Cypripedium

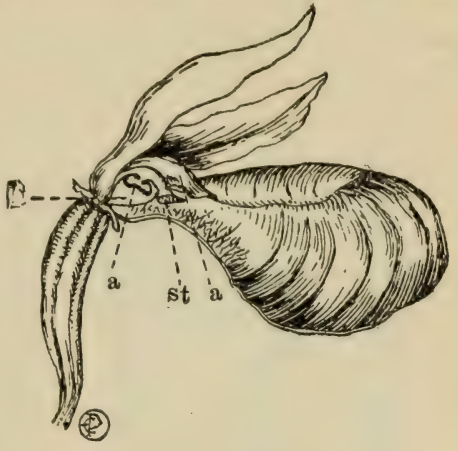

Fig. 465 .

Section of flower of cypripedium. st, stigma ; $a$, at the left stamen. The insect enters the labellum at the center, passes under and against the stigma, and out through the opening $b$, where it rubs against the pollen. In passing through another flower this pollen is rubbed off on the stigma.

must be deposited on the stigmatic end or margin in order that fertilization may take place.

666. If we open carefully, canna-flower buds which are nearly ready to open naturally, by unwrapping the folded petals and staminodia, we will see the anther-bearing
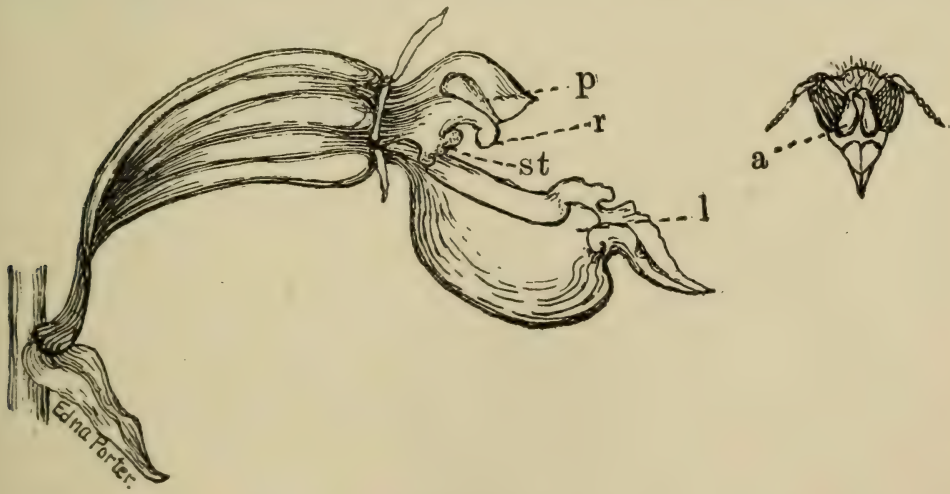

Fig. 466.

Epipactis with portion of perianth removed to show details. l, labellum ; st, stigma : $r$, rostellum : $p$, pollinium. When the insect approaches the flower its head strikes the disk of the pollinium and pulls the pollinium out. At this time the pollinium stands up out of the way of the stigma. By the time the insect moves to another flower the pollinia have moved downward so that they are in position to strike the stigma and leave the pollen. At the right is the head of a bee, with two pollinia $(a)$ attached. 
staminodium is so wrapped around the flattened style that the anther lies closely pressed against the face of the style, near the margin opposite that on which the stigma lies.

667. The walls of the anther locules which lie against the style become changed to a sticky substance for their entire length, so that they cling

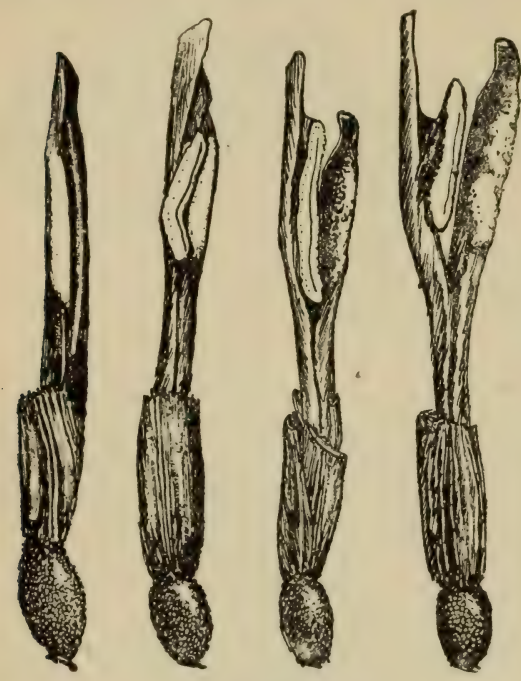

Fig. 467 .

Canna flowers with the perianth removed to show the depositing of the pollen of the style by the stamen. number of the flowers have just opened, and the bumblebees are humming around seeking for nectar, we may be able to unlock the secret.

669. We see that in a recently opened canna flower, the petal which directly faces the style in front stands upward quite close to it, so that the flower now is somewhat funnelshaped. This front petal is the labellum, and is the landing place for the bumblebee as he alights on the flower. Here he comes humming along and alights on the labellum with his head so close to the style that it touches it. But just the instant that the bee attempts to crowd down in the flower the labellum suddenly bends downward, as shown in fig. 468. In so doing the head of the bumblebee scrapes against the pollen, bearing some of it off. Now while the bee is sipping the nectar it is ton far below the stigma to deposit any pollen on the latter. When the bumblebee flies to another newly opened flower, as it alights, some of the pollen of the former flower is brushed on the stigma.

670. One can easily demonstrate the sensitiveness of the labellum of recently opened canna flowers, if the labellum has not already moved down in response to some stimulus. Take a lead-pencil, or a knife blade, or even 
the finger. and touch the upper surface of the labellum by thrusting it between the latter and the style. The labellum curves quickly downward.

671. Sometimes the bumblebees, after sipping the nectar, will crawl up wer the style in a blundering manner. In this way the flower may be pol-

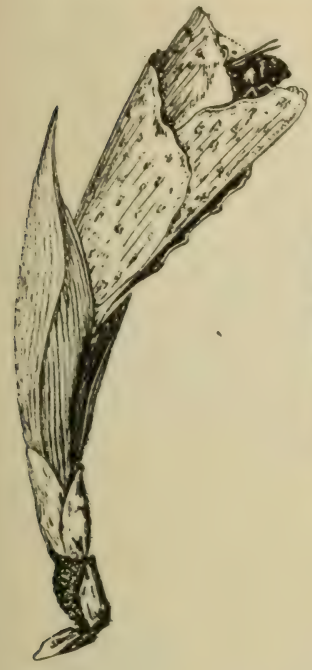

Pollenation of the canna flower by bumblebee.

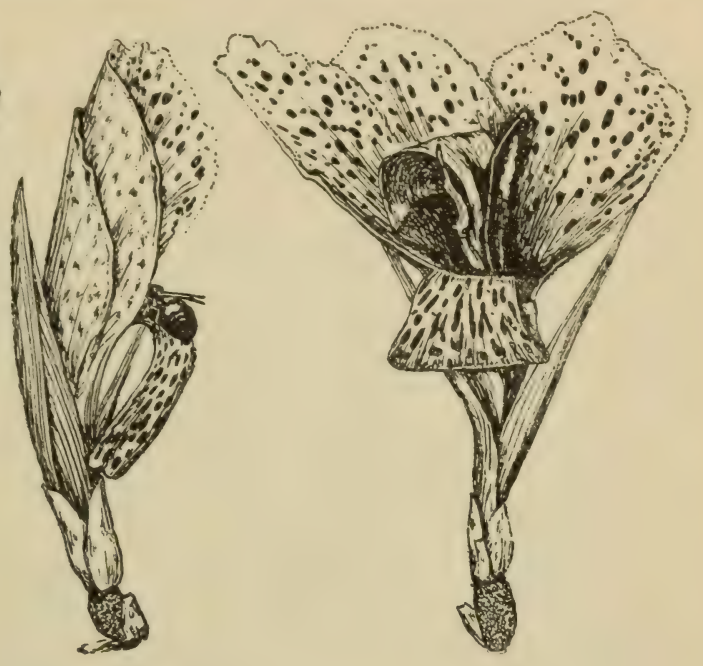

Fig. 468 .

Canna flower. Polien on style, stamen at left.

lenated with its own pollen, which is equivalent to self pollenation. Undoubrediy self pollenation dors take place often in flowers which are adapted, to a yreater or less degree, for cross pollenation by insects. 


\section{CHAPTER LI. SEED DISTRIBUTION.}

672. Means for dissemination of seeds. - During late summer or autumn a walk in the woods or afield often convinces us of the perfection and variety of means with which plants are provided for the dissemination of their seeds, especially when we discover that several hundred seeds or fruits of different plants are stealing a ride at our expense and annoyance. The hooks and barbs on various seed-pods catch into the hairs of passing animals and the seeds may thus be transported considerable distances. Among the plants familiar to us, which have such contrivances for unlawfully gaining transportation, are the beggar-ticks or stick tights, or sometimes called

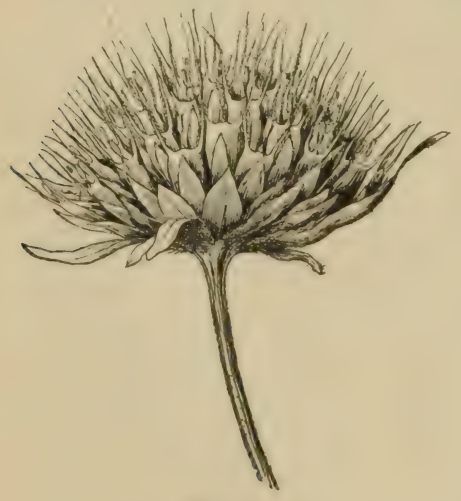

Fig. 469 .

Bur of bidens or bur-marigold, showing barbed seeds.

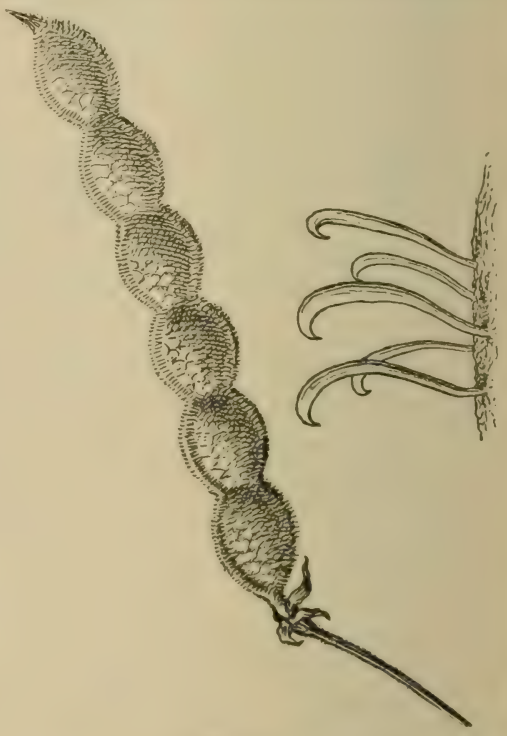

Fig. 470 .

Seed pod of tick-treefoil (desmodium); at the right some of the hooks greatly magnified.

bur-marigold (bidens), the tick-treetoil (desmodium), or cockle-bur (xanthium), and burdock (arctium).

673. Other plants like some of the sedges, etc., living on the margins of streams and of lakes, have seeds which are provided with floats. The wind or the flowing of the water transports them often to distant points. 
674. Many plants possess attractive devices, and offer a substantial reward, as a price for the distribution of their secds. Fruits and berries are devoured by birds and other animals; the secels within, often passing unharmed, may be carried long distances. Starchy and alluminous seeds and
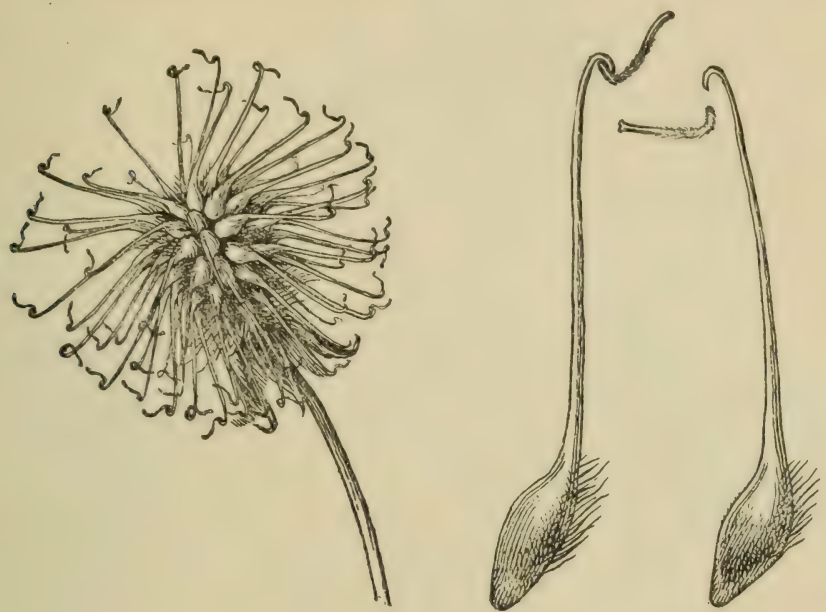

Fig. 47 I

Seeds of geum showing the hooklets where the end of the style is kneed.

grains are also devoured, and while many such seeds are destroyed, others are not injured, and finally are lodged in suitable places for growth, often remote from the original locality. Thus animals willingly or unwillingly become agents in the dissemination of plants over the earth. Man in the development of commerce is often responsible for the wide distribution of harmful as well as beneficial species.

675. Other plants are more independent, and mechanisms are employed for violently ejecting seeds from the pod or fruit. The unequal tension of the pods of the common vetch (Vicia sativa) when drying causes the valves to contract unequally, and on a dry summer day the valves twist and pull in opposite directions until they suddenly snip apart. and the seeds are thrown forcibly for some distance. In the impatiens, or touch-me-not as it is better known, when the pods are ripe, often the least touch, or a pinch, or jar, sets the five valves free. they coil up suddenly, and the small seeds are whisked for several yards in all directions. During autumm, on dry days, the pods of the witch hazel contract uncrually. and the valves are suddenly spread apart, when the seeds, as from a catapult, are hurled away.

Other plants have learned how useful the "wind" may be if the seeds are provided with . ffloats," ". parachute..." or wingerl devices which buoy them 
up as they are whirled along, often miles away. In late spring or early summer the pods of the willow burst open, exposing the seeds, each with a tuft of white hairs making a mass of soft down. As the delicate hairs dry,
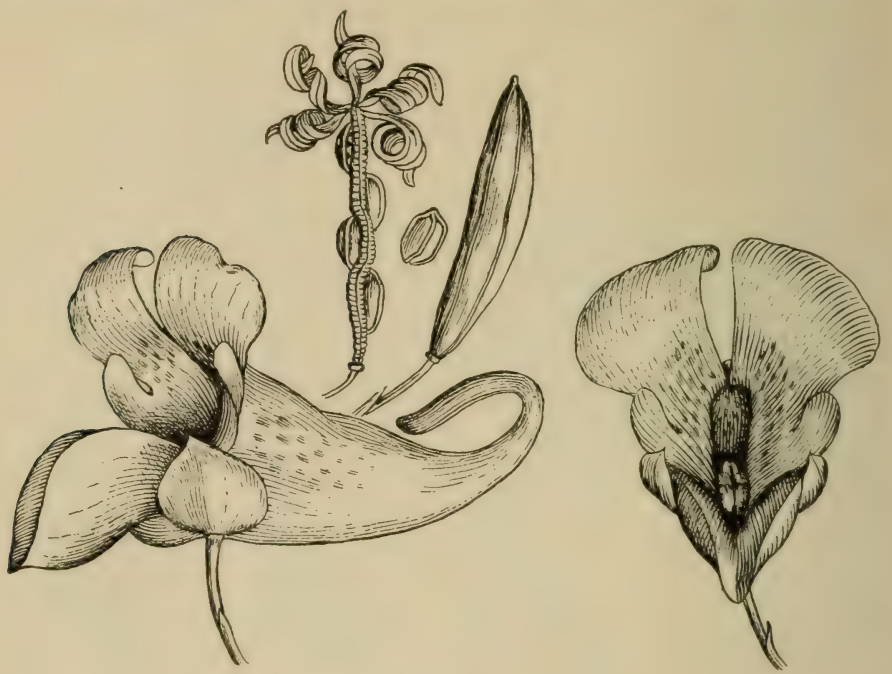

Fig. 472 .

Touch-me-not (Impatiens fulva); side and front view of flower below; above unopened pod, and opening to scatter the seed.

they straighten out in a loose spreading tuft, which frees the individual seeds from the compact mass. Here they are caught by currents of air and float off singly or in small clouds.

676. The prickly lettuce.-In late summer or early autumn the seeds of the prickly lettuce (Lactuca scariola) are caught up from the roadsides by the winds, and carried to fields where they are unbidden as well as unwelcome guests. This plant is shown in fig. 473 .

677. The wild lettuce. - A related species, the wild lettuce (Lactuca canadensis) occurs on roadsides and in the borders of fields, and is about one meter in height. The heads of small yellow or purple flowers are arranged in a loose or branching panicle. The flowers are rather inconspicuous, the rays projecting but little above the apex of the enveloping involucral bracts, which closely press together, forming a flower-head more or less flaskshaped.

At the time of flowering the involucral bracts spread somewhat at the apex, and the tips of the flowers are a little more prominent. As the flowers then wither, the bracts press closely together again and the head is closed. As the seeds ripen the bracts die, and in drying bend outward and downward, hugging the flower stem below, or they fall away. The seeds are 
thus exposed. The dark brown achenes stand over the surface of the receptacle, each one tipped with the long slender beak of the ovary. The "pappus," which is so abundant in many of the plants belonging to the composite family, forms here a pencil-like tuft at the tip of this long beak. As the involucral bracts dry and curve downward, the pappus also dries, and in doing so bends downward and stands outward, bristling like the spokes of a fairy wheel. It is an interesting coincidence that this takes place simultaneously wit h the pappus of all the seeds of a head, so that the ends of the pappus bristles of adjoining seeds meet, forming a many-sided dome of a delicate and beautiful texture. This causes the beaks of the achenes to be crowded apart, and with the leverage thus brought to bear upon the achenes they are pried off the receptacle. They are thus in a position to be wafted away by the gentlest zephyr, and they go sailing away on the wind like a miniature parachute. As they come slowly to the ground the seed is thus carefully low-

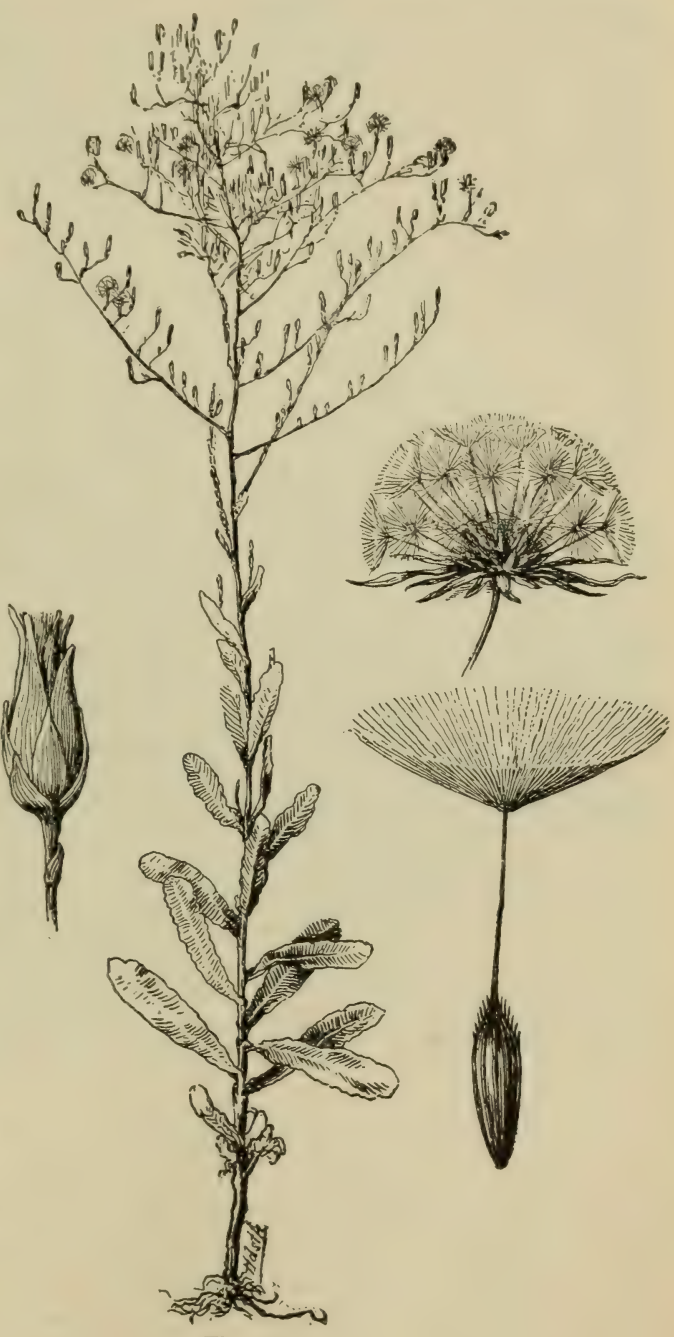

Fig. 473.

Lactuca scariola. ered first, so that it touches the ground in a position for the end which contains the root of the embrye to come in contact with the soil. 
678. The milkweed, or silkweed.-The common milkweed, or silkweed (Asclepias cornuti), so abundant in rich grounds, is attractive not only

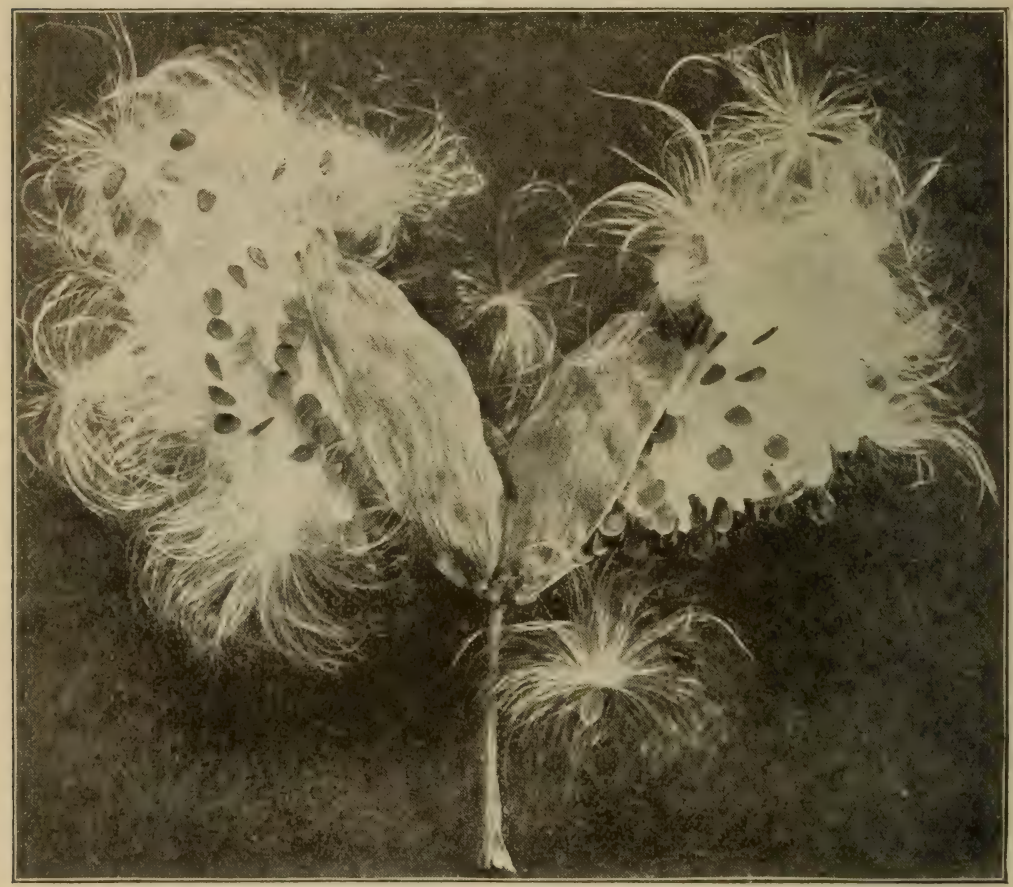

Fig. 474.

Milkweed (Asclepias cornuti); dissemination of seed.

hecause of the peculiar pendent flower clusters, but also for the beautiful floats with which it sends its seeds skyward, during a puff of wind, to finally lodge on the earth.

679. The large boat-shaped, tapering pods, in late autumn, are packed with oval, flattened, brownish seeds, which overlap each other in rows like shingles on a roof. These make a pretty picture as the pod in drying splits along the suture on the convex side, and exposes them to view. The silky tufts of numerous long. delicate white hairs on the inner end of each seed, in drying, bristle out, and thus lift the seeds out of their enclosure, where they are lifted like fairy balloons, buoyent as vapor, they go bearing the precious burden of an embryo plant, which is to take its place as a contestant in the battle for existence.

680. The virgin's bower. - The virgin's bower (Clematis virginiana), too, clambering over fence and thrtb. makes a show of having transformed its 
exquisite white flower clusters into grayish-white puffs. which scatter in the autumn gusts into hundreds of arrow-headed, spiral plumes. The achenes

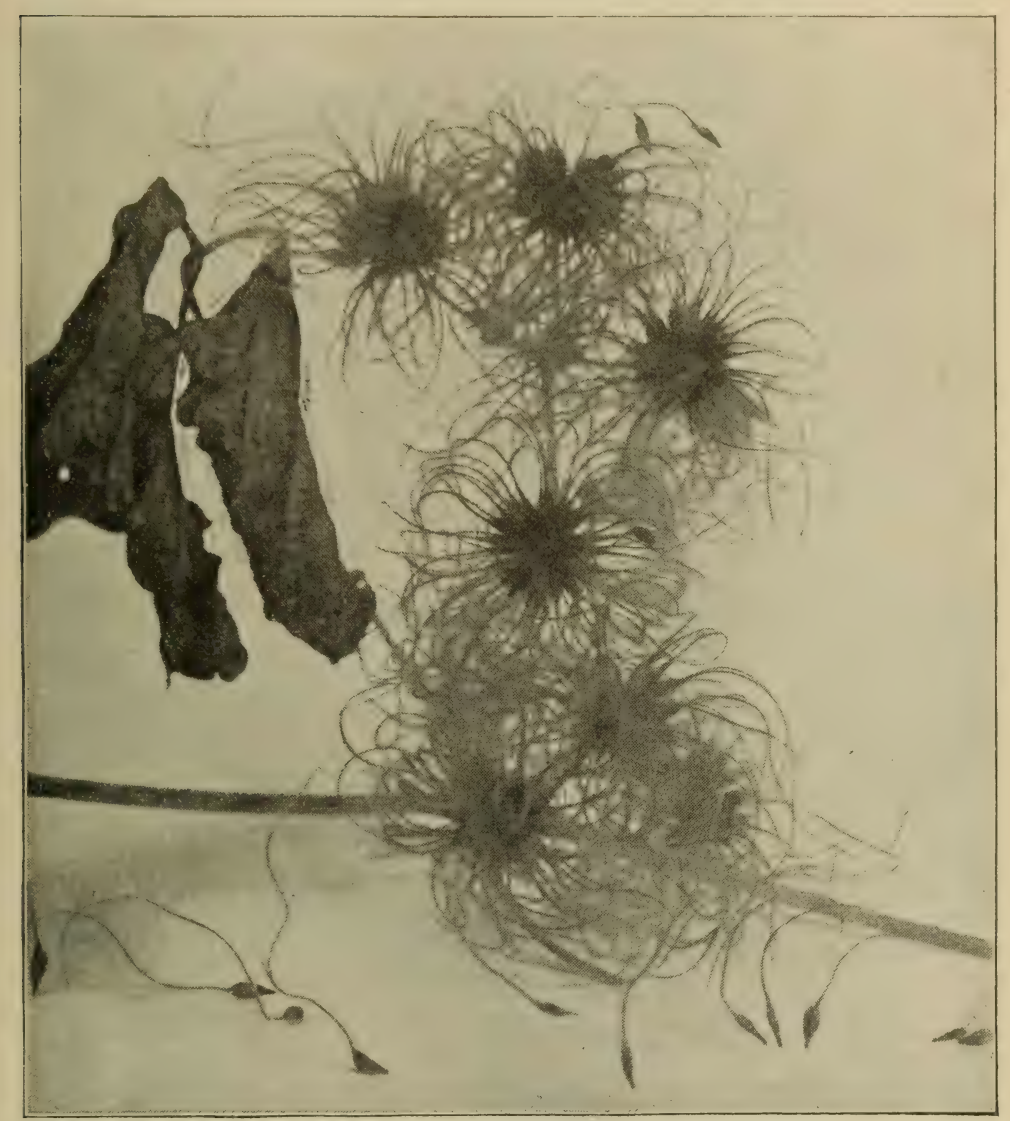

Fig. 475 .

Seed distribution of virgin's bower (clematis).

have plumose styles, and the spiral form of the plume gives a curious twist to the falling seed (fig. 474). 
CHAPTER LII.

STRUGGLE FOR OCCUPATION OF LAND.

681. Retention of made soil. - In the struggle of plants for existence, there are a number of species which stand ready to rush in where new opportunities present themselves by changed conditions, or by newly made soil. The permanent drainage of ponds or marshes brings changed conditions, and the flora there

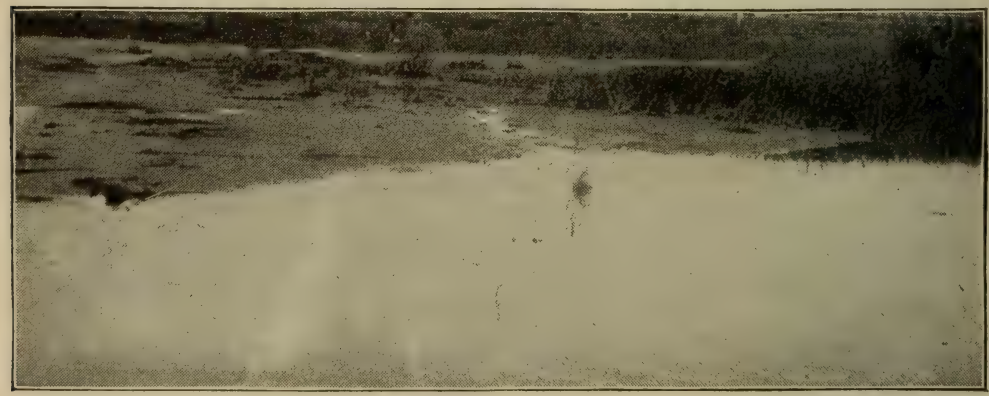

Fig. 476 .

Made soil at mouth of stream, being overgrown by plants. Ithaca, N. Y.

undergoes remarkable transformations. The deposits of the washings of streams in protected places along the shores, or at their mouths, where deltas or lateral plateaus are made by the accumulations of soil scoured off the banks of the stream, or washed off the fields during rains, make new ground. With such banks of newly made ground are deposited seeds carried along with the soil, or dropped there by the wind, by birds, or other agencies of seed distribution.

682. Figure 476 is from a photograph taken at the mouth of one of the streams emptying into Cayuga Lake. At the left is 


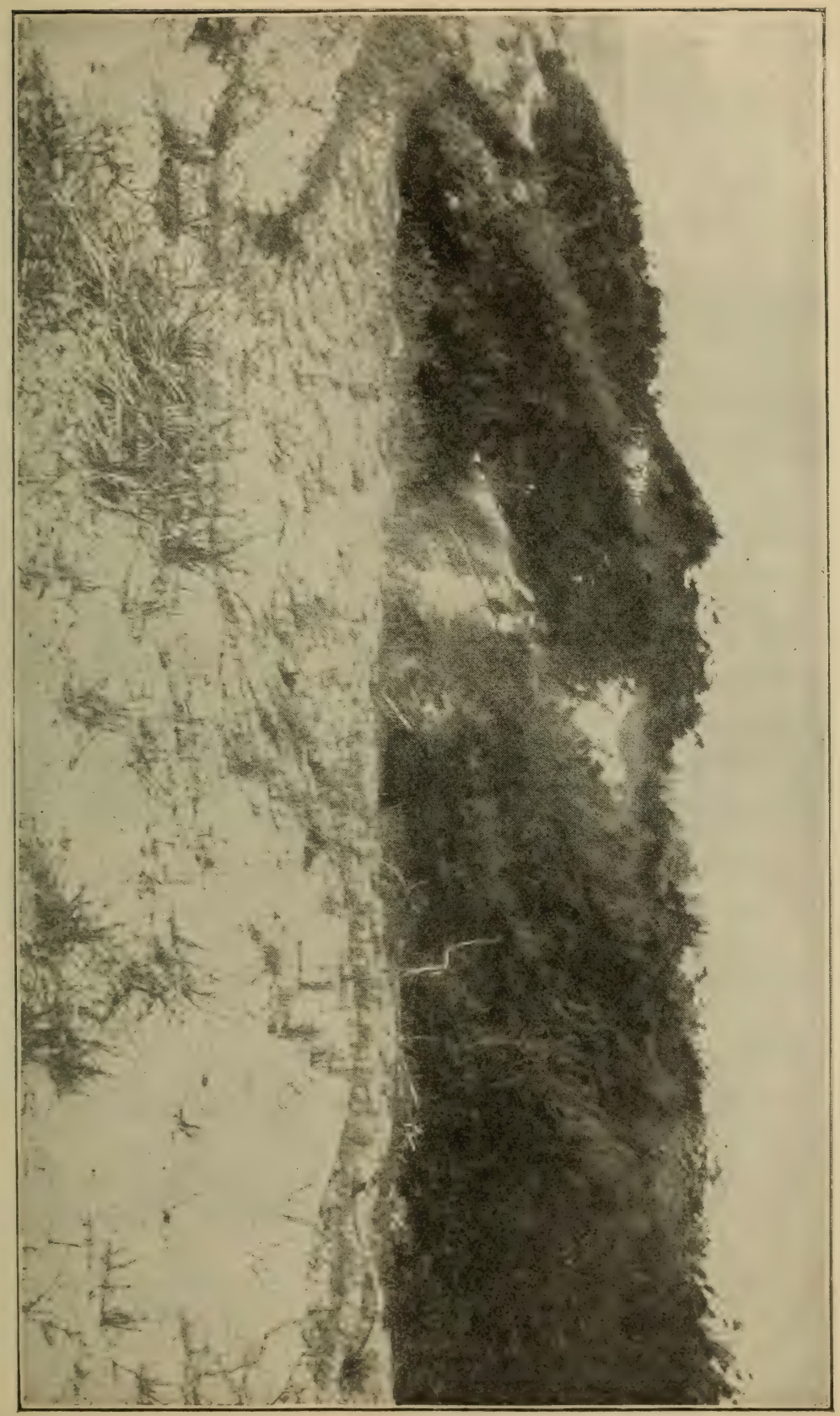


a newly made bank of soil. The species of bidens were here among the first to start in the soft black mud. These are followed later by grasses, by species of the arrowhead (sagittaria), pickerel-weed (pontederia), etc. The loose soil becomes permeated by a mass of roots, and year by year becomes more firm.

683. Vegetation of sand dunes.-Along the sandy beaches of lakes, or of the ocean, drift piles of the fine sand are formed, which often are moved onward by the wind. The surface particles are moved onward to the leeward of the drift, and so on. The form and location of the sand dune gradually changes. Such drifts sometimes slowly but surely march along over soil where a rich vegetation grows, and over valuable land. Even on these sand dunes there are certain plants which can gain a foothold and grow. When a sufficient number obtain a foothold in such places they retain the sand and prevent the movement of the dune.

684. Reforestation of lands. - When by the action of fire or wind, or through the agency of man, portions of forests are partially or completely destroyed, a new set of conditions is presented over these areas. One of the most important is that light is admitted where before towering trees permitted but a limited and characteristic undergrowth to remain. Hundreds of forms, which for years have been dormant, are now awakened from their long sleep, and new and recent importations of seeds which are constantly rushing in spring into existence to fill the gap, multiply their numbers, and make more sure the perpetuation of their kind.

685. The earliest to appear are not always the ones to endure the longest, and a battle royal takes place during years for supremacy. The weaker ones are gradually overcome by the more vigorous, and a new (rop) of trees, which often springs up in such places, finally usurps again the domain, in the name of the same or of a different species.

686. Domestic plants protected by man occupy cultivated fields. When cultivation ceases, or the (rop) is removed, or the fields are neglected, hundreds of species of feral plants, which 
are constantly springing up, now flourish, bear seed, and take more or less complete possession of the soil. Impoverished land, abandoned by man, becomes nurtured by nature. Weeds, grass, flowers, spring up in great variety often. Some can thrive but little better than the abandoned crops, while others, peculiarly fitted because of one or another adapted structure or habit, flour-

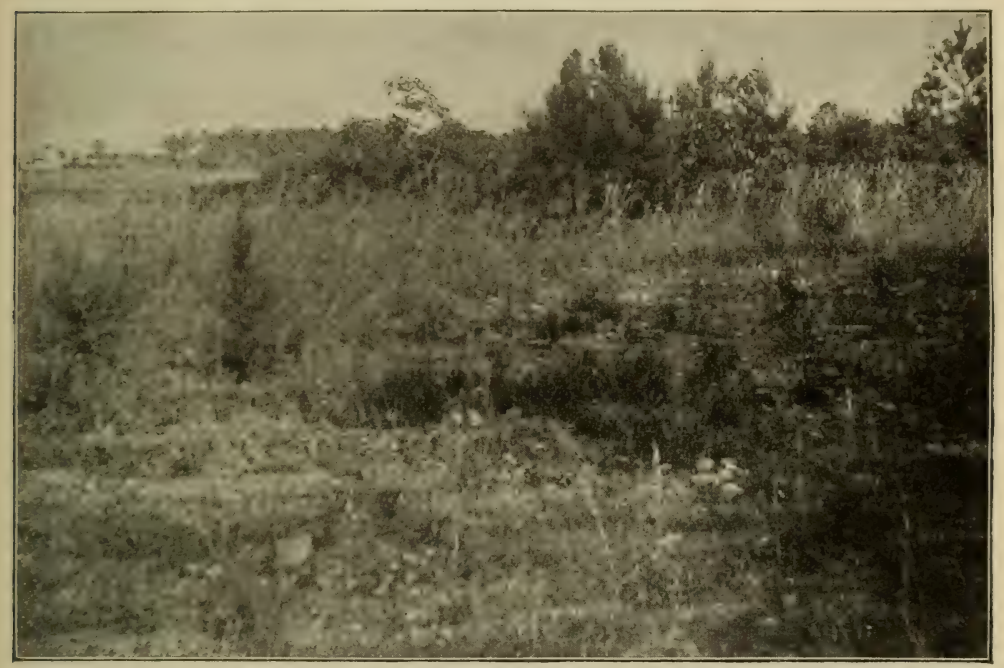

Fig. 478 .

Abandoned field, in Alabama, growing up to broom-sedge and trees. (Photograph by Prof. P. H. Mell.)

ish. Crab-grass and other low-growing plants often cover and protect the soil from the direct rays of the sun, and thus conserve moisture. The clovers which spring up here and there, by the aid of the minute organisms in their roots, gather nitrogen. The melilotus, the passion flower, and other deep-rooted plants reach down to virgin soil and lift up plant food. Each year plant remains are added to, and enrich, the soil. In some places grasses, like the broom-sedge (andropogon) succeed the weeds, and a turf is formed.

687. Seeds of trees in the mean time find lodgment. During the first few years of their growth they are protected by the 
herbaceous annuals or perennials. In time they rise above these. Each year adds to their height and spread of limb, until eventually forest again stands where it was removed years before. In the Piedmont section of the Southern States such a view as is

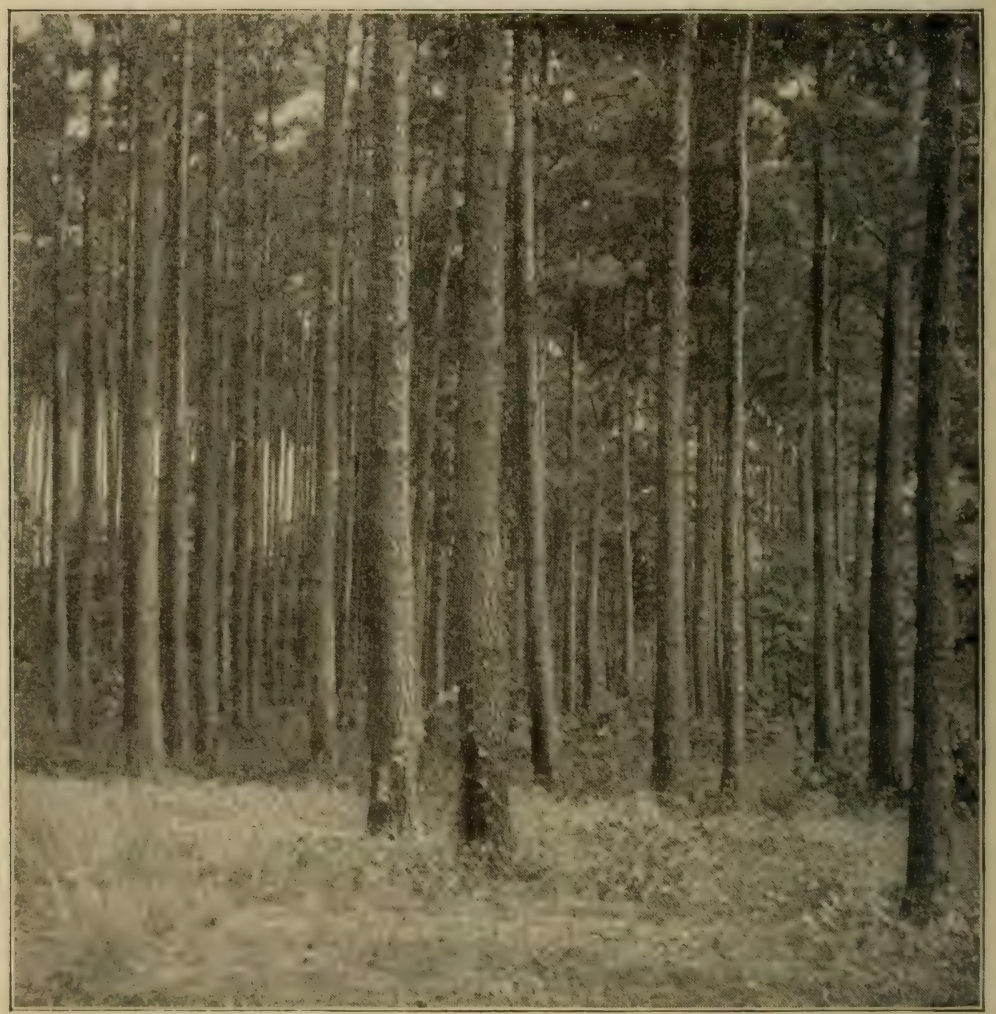

Fig. 479.

Abandoned field, Alabama, self reforested by pines. (Photograph by Prof. P. H. Mell.)

presented in fig. 478 represents how abandoned fields are taken by the broom-sedge, to be followed later by pines, and later by a forest as shown in fig. 479 .

688. In New York State many abandoned hillsides are being reforested slowly by nature with the white pine. Fig. 480 represents a group of self-sown pines ranging from three to six 
meters high (10-20 feet), growing up in an abandoned orchard near Ithaca. In this reforestation of impoverished lands, man can give great assistance by timely and proper planting.

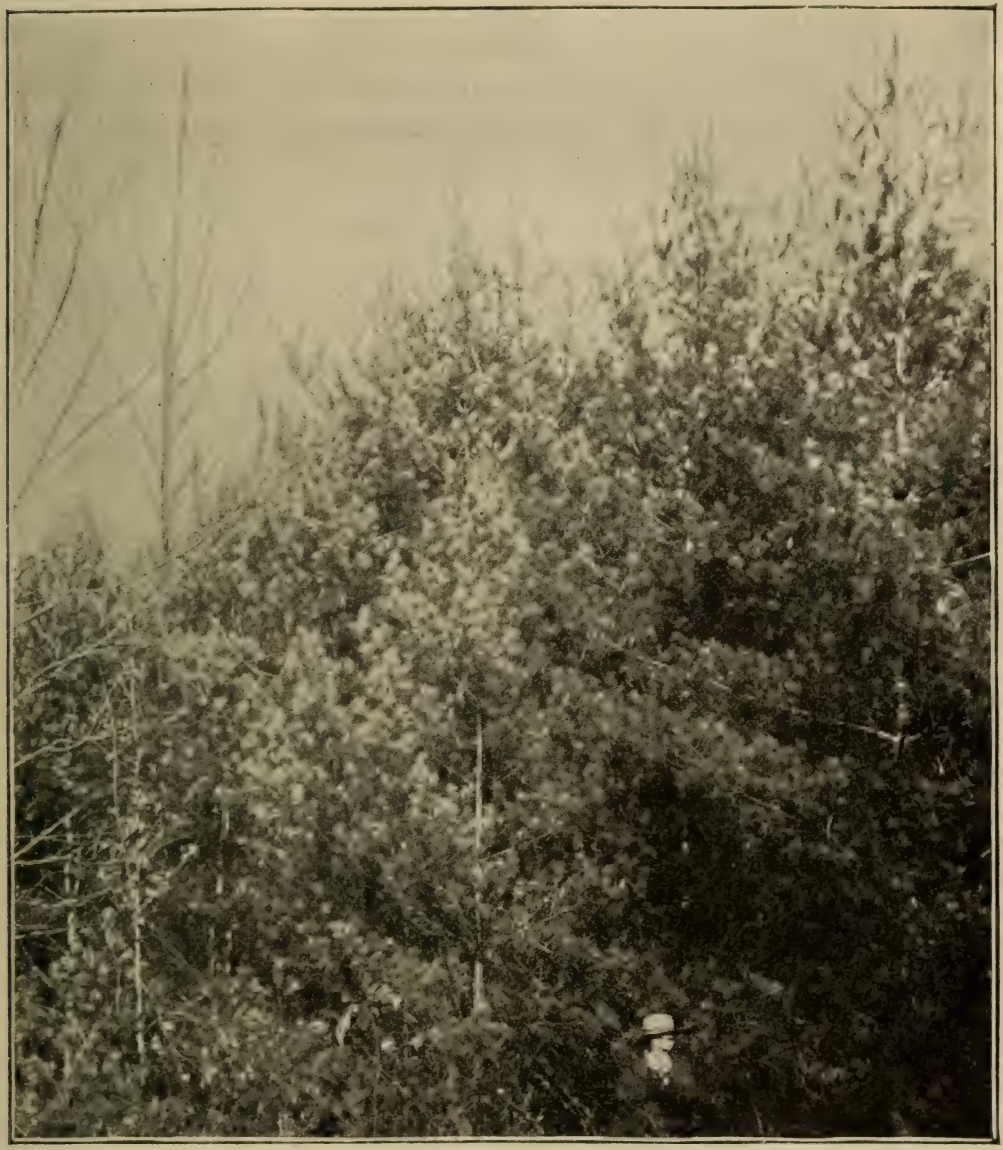

Fig. 480 .

Seif-sown white pine in abandoned orchard; trees 9-20 years old. Near Ithaca. (Photograph by the author.)

689. Beauty of old fields.-During one season from my window I beheld a marvellously heautiful sight. The scene was located in a portion of an old field on a hillside, in a rapidly growing part of the city. New buildings had sprung up all 
around, and this was waiting sale or improvement. But there were innumerable seeds of a great variety of plants in that vacant lot. They sprang into growth to occupy the land, and a great tangle of luxuriant vegetation was the result. Burdock, towering pigweeds, grasses, beggar-ticks, mullein, St. John's wort, masses of giant goldenrods, blue-rayed asters, occupied every inch of the ground in a grand medley of kind and color. Through this mass, briers and blackberry bushes pushed their thorny sprays, laying hold on you if you attempted entrance. Children plucked the beautiful flowers, but the flowers they cared not, neither took they thought for the future day when they must give way under the influence of man to stone walls and a plain greensward, so joyous were they in the mere thought of existence and radiant beauty. 


\section{CHAPTER LIII.}

\section{SOIL FORMATION IN ROCKY REGIONS AND IN MOORS.}

\section{Lichens.}

690. Many of the lichens are small and inconspicuous. They often appear only as bits of color on tree trunk or rock. One of the conspicuous ones on stones lying on the ground is the grayish-green thallus of Parmelia contigua (fig. 48I). Its pretty, flattened, forking lobes radiate in all directions, advancing at the margin, and covering year by year more and more of the stone surface. Numerous cup-shaped fruit bodies (apothecia) are scattered over the central area. The thallus clings closely to the rock surface by numerous holdfasts from the under side, which penetrate minute crevices of the rock. The lichen derives its food from the air and water. By its closely fitting habit it retains in contact with the rock certain acids formed by the plant in growth, or in the decay of the older parts, which slowly disintegrate the surface ot the rock. These disintegrated particles of the rock, mingled with the lichen débris, add to the soil in those localities.

691. Lichens are among the pioneers in soil making.The habit which many lichens have of flourishing on the bare rocks fits them to be among the pioneers in the formation of soil in rocky regions which have recently become bared of ice or snow. The retreat of glaciers from peaks long scoured by ice, or the unloading of broken rocks along its melting edge, exposes the rocks to the weathering action of the different elements. Now the lichens lay hold on them and invest them with fantastic 
figures of varied color. Disintegrating rock, débris of plants and animals, join to form the virgin soil. Certain of the bluegreen algæ, as well as some of the mosses, are able to gain a foothold on rocks and assist in this process of soil formation.

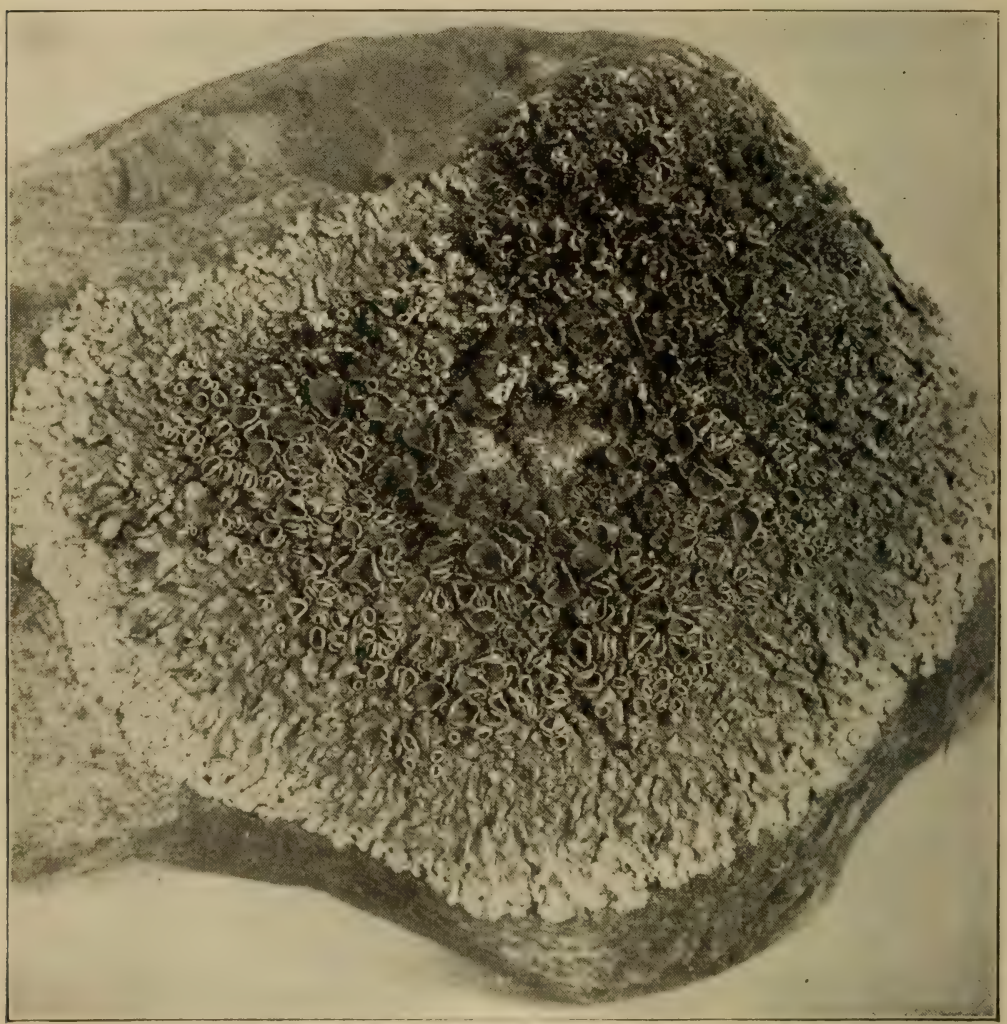

Fig. $48 \mathbf{r}$.

Rock lichen (Parmelia contigua).

A view of rocks thrown down by the melting and retreating edge of a glacier in Greenland is shown in fig. $48 \mathrm{I}$. These rocks at the time the photograph was taken had no plant life on them. At other places in the vicinity of this glacier, rocks longer uncovered by ice were being covered by plant life. One of the greenland rock lichens are shown in fig. 483 . 
SOIL FORMATION: ROCK DISINTEGRATION. 383

692. Dther plants of rocky regions. - Certain of the higher plants also find means of attachment to the bare rocks of the arctic and mountain regions. The roots penetrate into narrow crevices in the rock, and are able to draw on the water which is

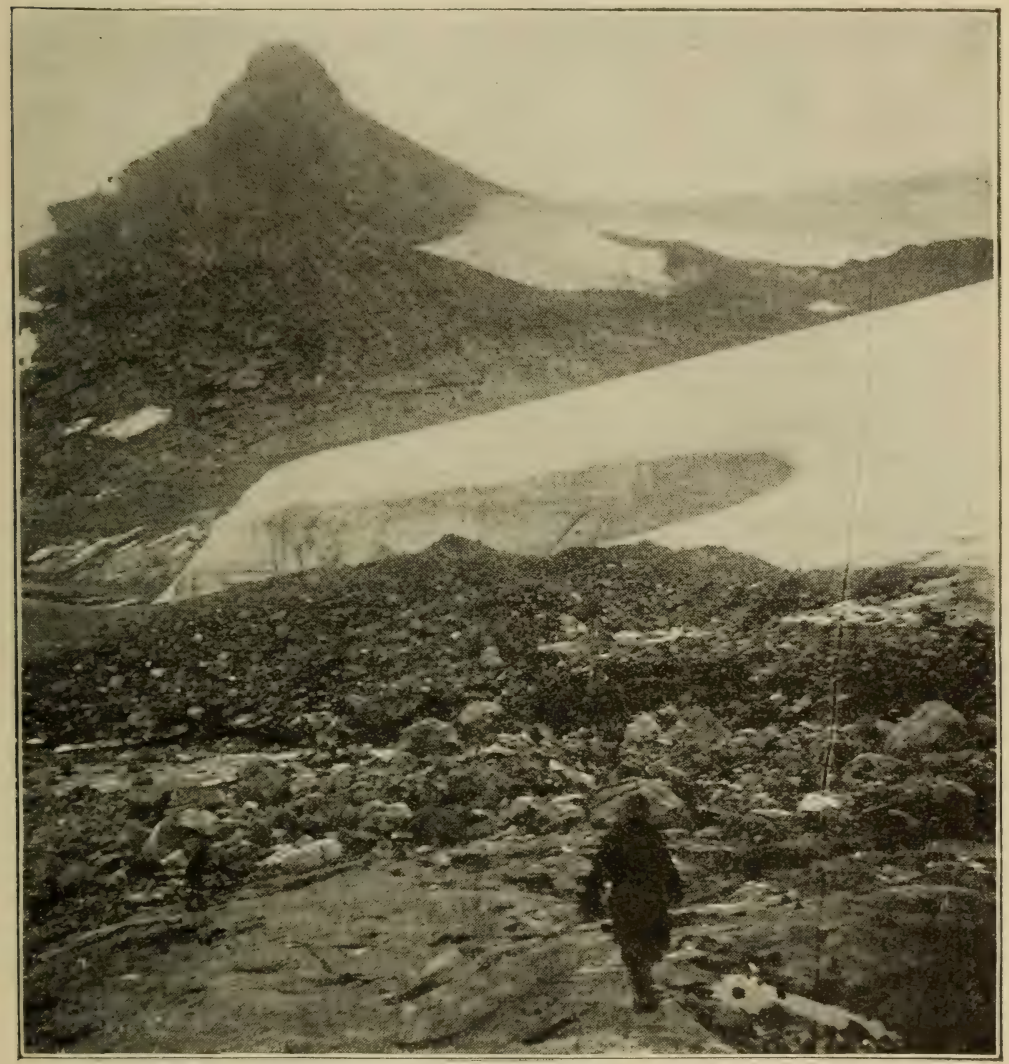

Fig. 482 .

Edge of glacier in Greenland, showing freshly deposited rocks. (From Prof. R. S. Tarr.)

elevated by capillarity. Such plants, however, which live on bare rocks, whether in the arctic or in mountain regions, have leaves which enable them to endure long periods of drought. These plants have either succulent leaves like certain of the stone- 
crops (sedum), or small thick leaves which are closely overlapped as in the Saxifraga oppositifolia.

693. Few of us, unfortunately, can make the trip to the arctic regions to study these interesting plants which play such an important rôle in the economy of nature. Rocky places, however,

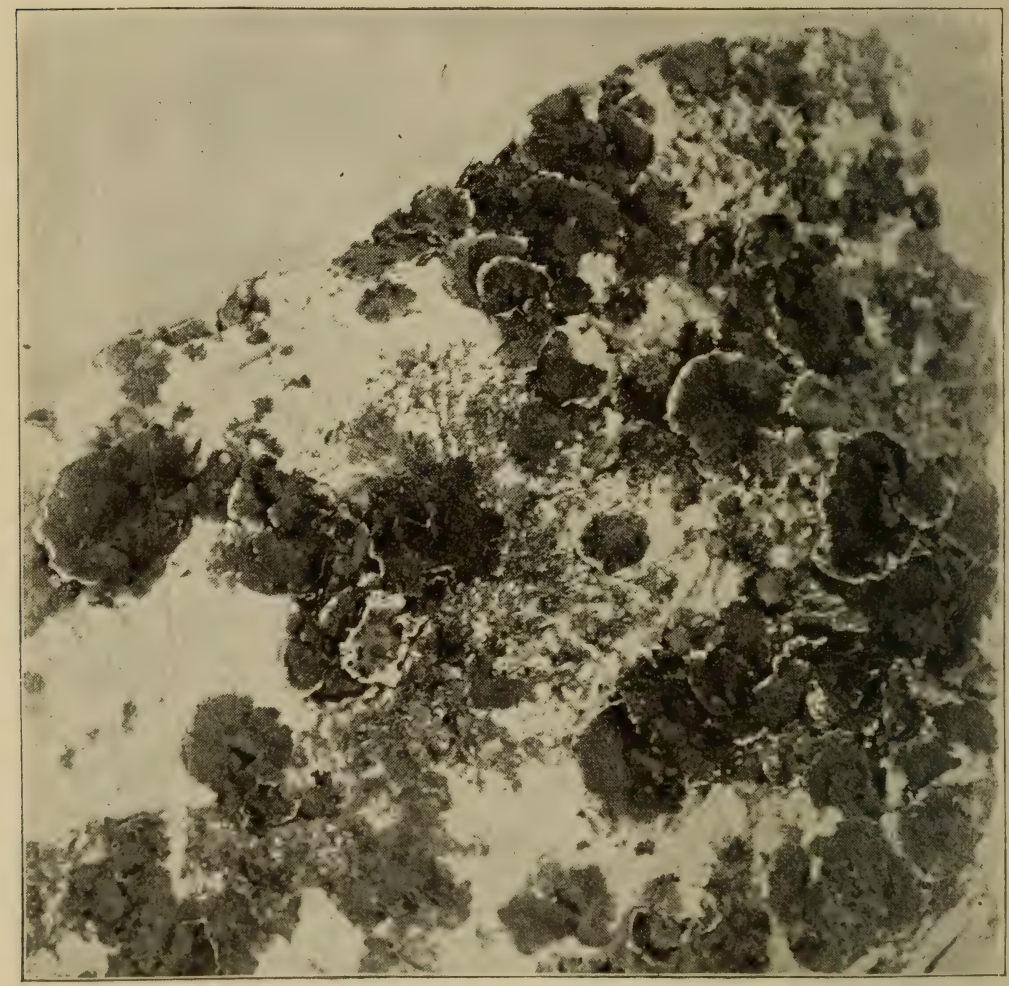

Fig. $4 \times 3$.

Rock lichen (umbilicaria) from Greenland.

or loose stones are common nearer home. Observation of their flora, and the means by which such plants derive nutriment, store moisture, or protect themselves from drought, will well rejay outdoor excursions.

694. Filling of ponds by plants. - Not only are plants important agencies in the formation of soil in rocky regions, they 
are slowly but surely playing a part in the changes of soil and in the topography of certain regions. This is very well marked in the region of small ponds, where the bottom slopes gradually out to the deeper water in the center. Striking examples are sometimes found where the surface of the country is very broken or hilly with shallow basins intervening. In what are termed morainic regions, the scene of the activity of ancient glaciers, or in the mountainous districts, we have opportunities for studying plant formations, which slowly, to be sure, but nevertheless certainly, fill in partly or completely these basins, so that the water is confined to narrow limits, or is entirely replaced by plant remains in various stages of disintegration, upon which a characteristic flora appears.

695. A plant atoll. - In the morainic regions of central New York there are some interesting and striking examples of the effects of plants on the topography of small and shallow basins. These formations sometimes take the shape of " atolls," though plants, and not corals, are the chief agencies in their gradual evolution. Fig. 484 is from a photograph of one of these plant atolls about I 5 miles from Ithaca, N. Y., along the line of the E. C. \& N. R. R. near a former flag station known as Chicago. The basin here shown is surrounded by three hills, and is formed by the union of their bases, thus forming a pond with no outlet.

696. Topography of the atoll moor.-The entire basin was once a large pond, which has become nearly filled by the growth of a vegetation characteristic of such regions. Now only a small, nearly circular, central, pond remains, while entirely around the edge of the earlier basin is a ditch, in many places with from $30-60 \mathrm{~cm}$. of water. There is a broad zone of land then lying between the central pond and the marginal ditch. Just inside of the ring formed by the ditch is an elevated ring extending all around, which is higher than any other part of the atoll. On a portion of this ring grow certain grasses and carices. The soil for some depth shows a wet peat made up of decaying grasses, carices, and much peat moss (sphagnum). In some places one element seems to predominate, and in other cases another element. On 
some portions of the outer ring are shrubs one to three meters in height, and occasionally small trees have gained a foothold.

697. Next inside of this belt is a broad, level zone, with Carex filiformis, other carices, grasses, with a few dicotyledons. Intermingled are various mosses and much sphagnum. The soil formation underneath contains remains of carices, grasses, and sphagnum. This intermediate zone is not a homogeneous one. At certain places are extensive areas in which Carex filiformis predominates, while in another place another carex, or grasses predominate.

698. A floating inner zone--But the innermost zone, that which borders on the water, is in a large measure made up of the leather-leaf shrub, cassandra, and is quite homogeneous. The dense zone of this shrub gives the elevated appearance to the atoll immediately around the central pond, and the cassandra is nearly one meter in height, the "ground" being but little above the level of the water. As one approaches this zone, the ground yields, and by swinging up and down, waves pass over a considerable area. From this we know that underneath the mat of living and recent vegetation there is water, or very thin mud, so that a portion of this zone is "floating."

699. The inner, or cassandra, zone is more unstable, that is it is all "afloat," though firmly anchored to the intermediate zone. The roots of the shrubs interlace throughout the zone, firmly anchoring all parts together, so that the wind cannot break it up. Between the tufts of the cassandra are often numerous open places, so that the water or thin mud on which the zone floats reaches the surface, and one must exercise care in walking to prevent a disagreeable plunge. No resistance is offered to a pole two to three meters long in thrusting it down these holes. Grasses, carices, mosses, sphagnum, and occasionally moor-loving dicotyledons occur, anchored for the most part about the roots of the cassandra. Standing at the inner margin of the cassandra zone, one can see the mud, resembling a black ooze, formed of the titrated plant remains, which have floated out from the bottom of the older formations. In some places this lies very near 


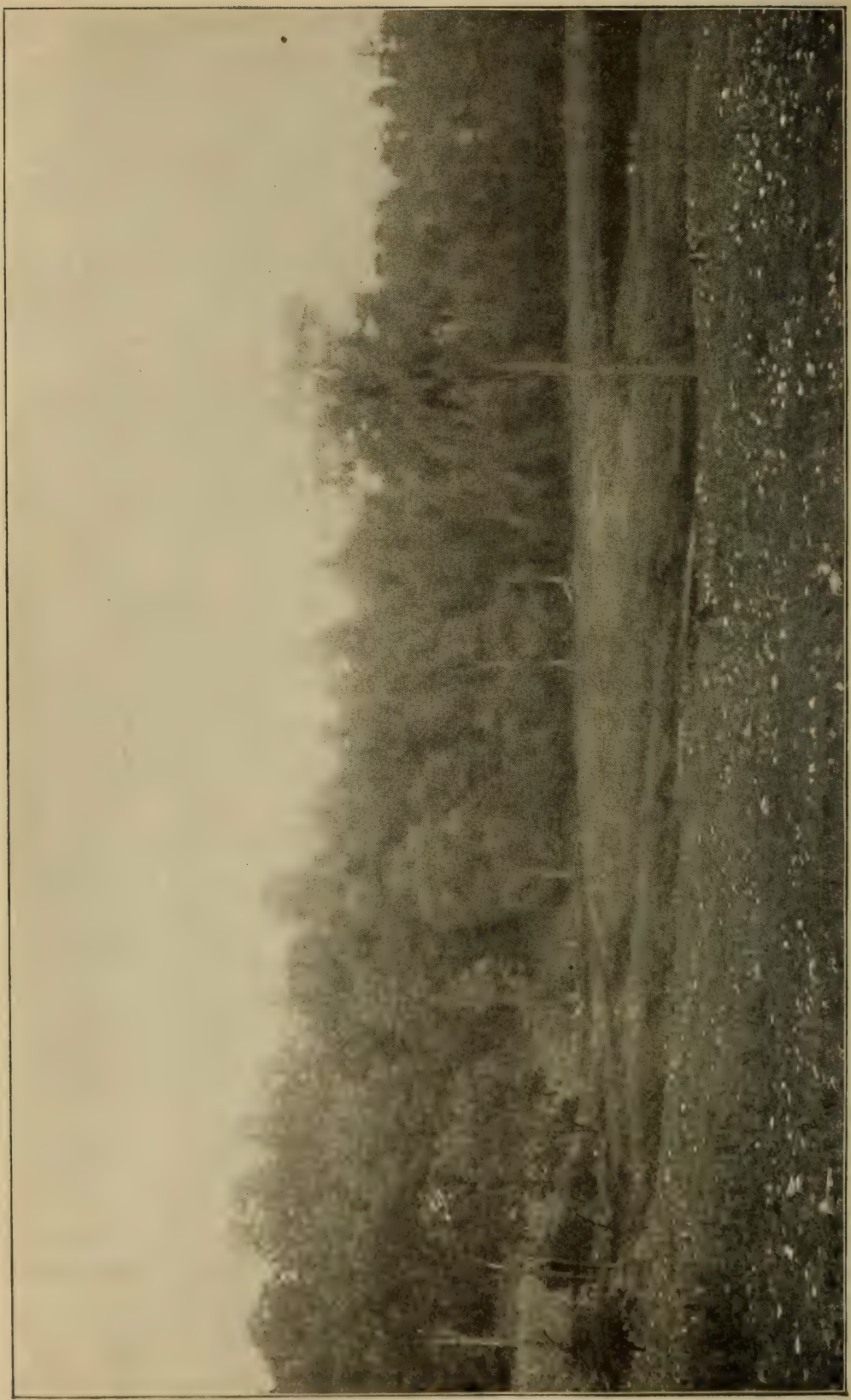


the surface, and then certain aquatic plants like bidens, and others, find a footing. Upon this black ooze the formation can continue to encroach upon the central pond. Agitated by the wind, more and more of the ooze passes outward, so that in time there is a likelihood that the pond will cease to exist, yielding, as it has in other places, the right of possession to the contentious vegetation.

700. How was the atoll formed?-In the early formation of the atoll, it is possible that certain of the water-loving carices and grasses began to grow some distance (three to four meters) from the shore, where the water was of a depth suited to their habit. The stools of these plants gradually came nearer the surface of the water. As they approach the surface, other plants, not so strong-rooted, like mosses, sphagnum, etc., find anchorage, and are also protected to some extent from the direct rays of sunlight. Partial disintegration of the dead plant parts and mingling with the soil gradually fills on the inside of the zone, so that the depth of the water there becomes less. Now the zone of the carices can be extended inward.

701. The continued growth of the sphagnum and the dying away of the lower part of the plant add to the bulk of the plant remains in the zone, and finally quite a firm ground is formed, shutting off the shallow water near the shore from the deeper water of the pond. As time goes on other plants enter and complicate the formation, and even make new ones, as when the cassandra takes possession.

702. The original pond here was rather oblong, and one end possibly much shallower than the other, so that it filled in much more rapidly, leaving the central pond at the east end. Over a portion of the west end there is an extensive cassandra formation, with some ledum (labrador tea), but separated from the circular cassandra zone by an intermediate zone. In this endcassandra formation other shrubs, and white pines five to fifteen years old, are gaining a foothold, and in a (puarter of a century or more, if left undisturbed, one may expect considerable changes in the flora of this atoll. It is possible that a rise of the water 


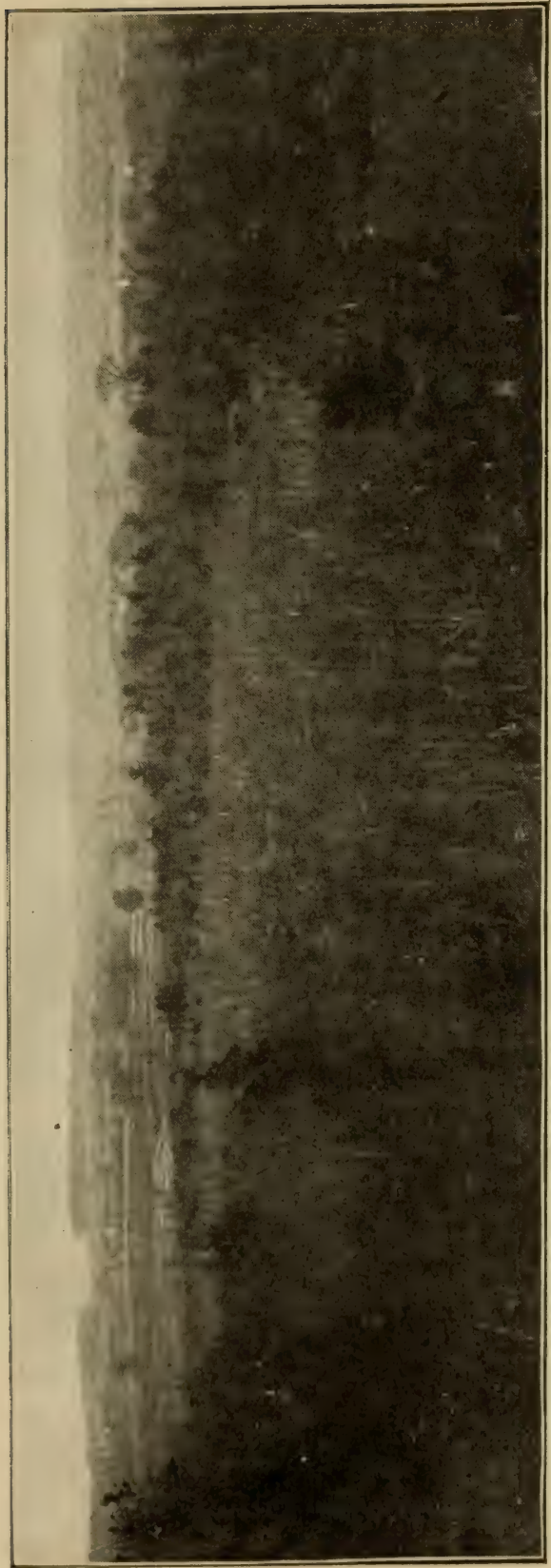

for a number of years when the earlier zones were floating accounts for the circular elevation and atoll formation.

703. A blackspruce moor.-A somewhat similar but more advanced ฐึ plant formation ocสี curs east of Freeville, N. Y., and Æ about nine miles distant from Ithaca.

The center of the basin, which was 焉 perhaps shallower के than the former है one, has become completely filled, ¿ू and all of the cenके tral formation is 总 more elevated than the margin by the shore of the basin. All around the margin in wet weather the ground is more or less submerged, while all the central portion is so elevated that the numerous stools or $\mathrm{hum} \mathrm{mocks}$ of 
grasses t.ke eriophorum, with its white tufts sparkling in the sunlight like a firmament of stars, shrubs like cassandra, pyrus, nemopanthes, etc., support one in walking above the water which rises in the intervening spaces. Sphagnum, polytrichum, and other mosses grow, especially in the stools of the other plants, where they now are shaded by the larger growth, and in drier seasons catch the water which trickles down during rain.

Years ago the forest encroached on this formation, and trees of the hemlock-spruce, black spruce, larch, etc., of considerable size gained a footing, first along the margin, then along the more elevated zone a short distance within. The black spruce trees spread all over the center of the formation, attaining a height of one to six or eight meters, while the trees of the marginal zone where they first entered, and the ground is somewhat more elevated, attained a much greater height.

704. Fall of the trees on the marginal zone when the wind break was removed.-These large trees of the marginal zone, though they were rooted to a great extent in loose soil, nevertheless were protected from winds by the forests on the surrounding hills. When, however, these hills on three sides were cleared for cultivation the wind had full sweep, and many of the large trees were uprooted by the force of the gales. This view is supported by the fact that the western hill is still covered by forest, and large spruce trees of the marginal zone are still standing, though several were uprooted September, I 896, during a fierce southeastern gale, the wind from this direction having full play upon them.

705. Dying of the spruce of the central area.-This removal of the forests from the surrounding hills very likely had its influence in hastening the melting of the winter snows on the hills, so that excessive quantities of water from this source rushed quickly down into the swamp, flooding it at certain seasons much higher than the normal high-water mark during former times, when the hills were forest-covered. Also during rains the water would now rush quickly down into the swamp, flooding it at these times. This greater quantity of water has had its 
effect, probably, in causing many of the young spruces over the center of the formation to die off.

706. This may also have been hastened by fires which would now more often sweep over the swamp during dry seasons. In partial evidence of this are many young spruce trees with scars near the ground where the bark has been destroyed. This gives admittance to wood-boring insects which farther aid in the proc-

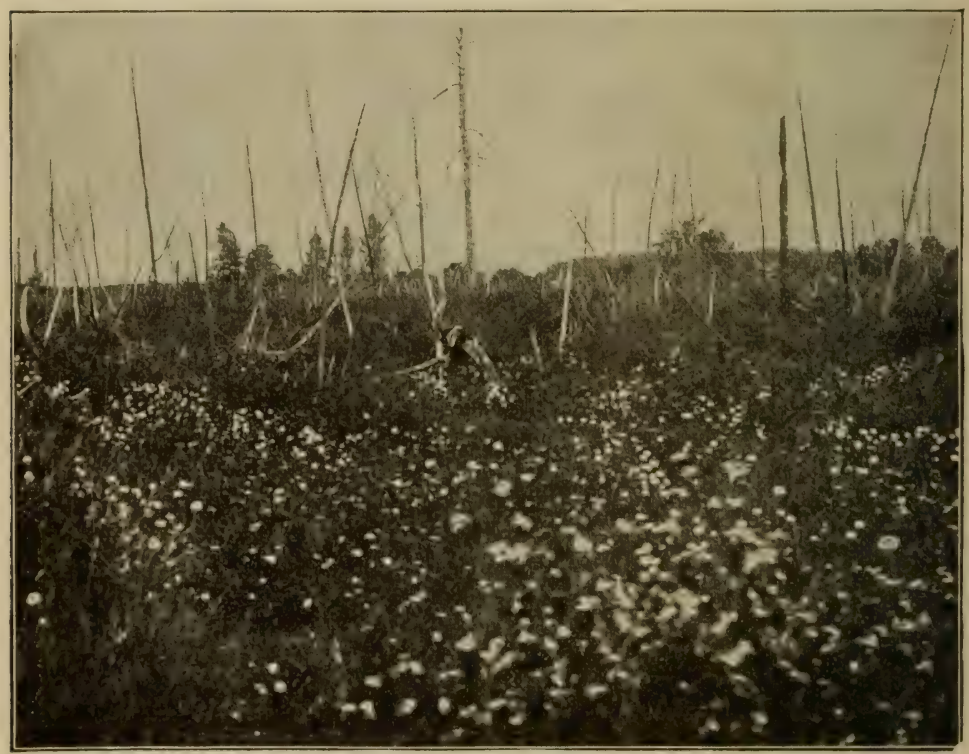

Fig. 487 .

Dying black spruce in moor. (Photograph by the author.)

ess of weakening and debilitating the trees. The dying off of the lower limbs of these marsh spruces suggests both the action of fire, as well as excessive moisture at times. Nany of them now present only a small convex top of living branches. It is interesting to observe the gradation in this respect in different trees.

707. The weird aspect presented by a clump of these dying young spruce trees is heightened also by the changes in the form of the branches as they die. The living branches have a graceful sigmoid sweep with their free ends curving upwards as in many 
conifers. As the branches die, the free ends curve downward more and more, all gradations being presented in a single tree. A group of such dying spruce trees is shown in fig. 487 . Some have been long dead; only the knotted, weather-beaten trunks still remain tottering to their final condition. Others with leafless, dried, sprawling branches go swirling with every wind, while a few struggle on in the presence of these untoward conditions.

708. 0ther morainic moors. - In other basins, where the hills on all sides are still forest-clad, more equable temperature and moisture conditions are conserved. This permits plants to flourish here which in the exposed basins are disappearing from the formations or only leading a miserable existence. This is strikingly true of some sphagnum formations. In the atoll formation described the evidence suggests that sphagnum formerly played a more active part in the evolution of that type of moor than has been the case since the hills were denuded of their trees. So also in the spruce moor, sphagnum probably was at one time a prominent factor in the formation of the early vegetation. But excessive drought during certain seasons, and full exposure to the sun and wind, have served to lessen its influence and importance. But where protected from the wind, to a large extent from the heat of the sun, and supplied with a suitable moisture condition, the sphagnum flourishes. It grows either alone in shallow water, encroaching more and more on the center of the basin, or follows after and anchors among water-loving grasses and carices. In some cases it may thus largely cover such earlier formations. An examination of the sphagnum plant shows us how well it is adapted to flourish under such conditions. The main axis of the plant bears lateral branches nearly at right angles, but with a graceful downward sweep at the extremity. These primary lateral branches bear secondary branches, which arise, usually several, from near the point of attachment to the main axis. They hang downward, overlap on those below, and completely cover the main axis or stem. The leaves of sphagnum are peculiarly adapted for the purpose of 
taking up quantities of water. Not all the cells of the leaf are green, but alternate rows of cells become broadened, lose their

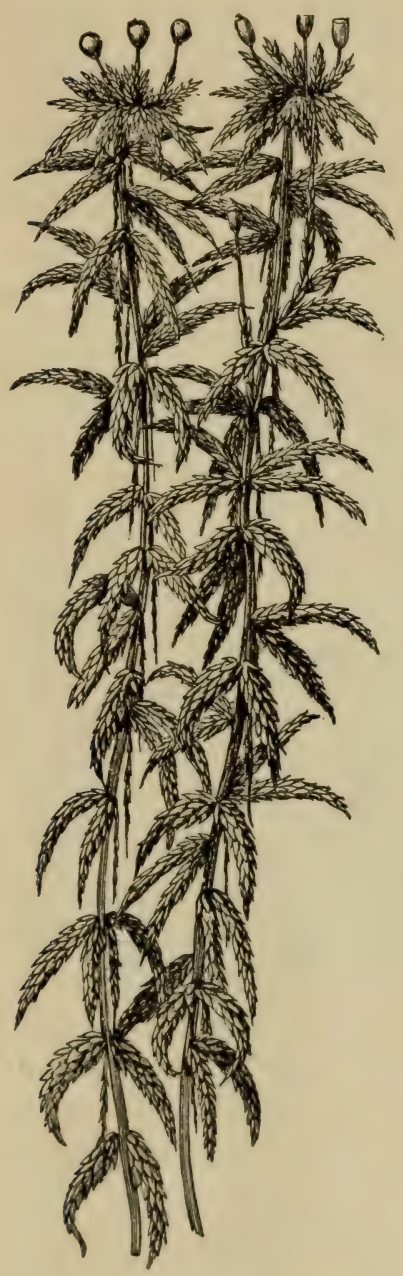

Fig. 488 .

Two fruiting plants of sphagnum. (From Kerner and Oliver.) chlorophyll, and their protoplasm collapses on the inner faces of the cell walls in such a way as to form thickened lines, giving a peculiar sculpturing effect to them. Perforations also take place in the walls. These empty cells absorb large quantities of water, and by capillarity it is lifted on from one cell to another. These pendent branches, then, which envelop the sphagnum stem, lift water up from the moist substratum to supply the leaves and growing parts of the plant which are at the upper extremity.

709. Year by year the extension of the sphagnum increases slowly upward by growth of the ends of the individual plants, while the older portions below die off, partly disintegrate, and pass over into the increasing solidity and bulk of the peat. It thus happens sometimes that the centers of such basins or moors are more elevated than the margins, because here a greater amount of water exists in the depths which is pumped up for use by the plants themselves. Such a formation is sometimes called a " high moor."

710. Because of the peculiar topographic features of these basins, together with the conditions of moisture, etc., changes in their form are quite readily observed. But no less important are the influences of plants on soil conditions on the hills, and 
in more level areas. Old plant parts, and plant remains, by decay add to the bulk, fertility, and changing texture and physical condition of the soil.

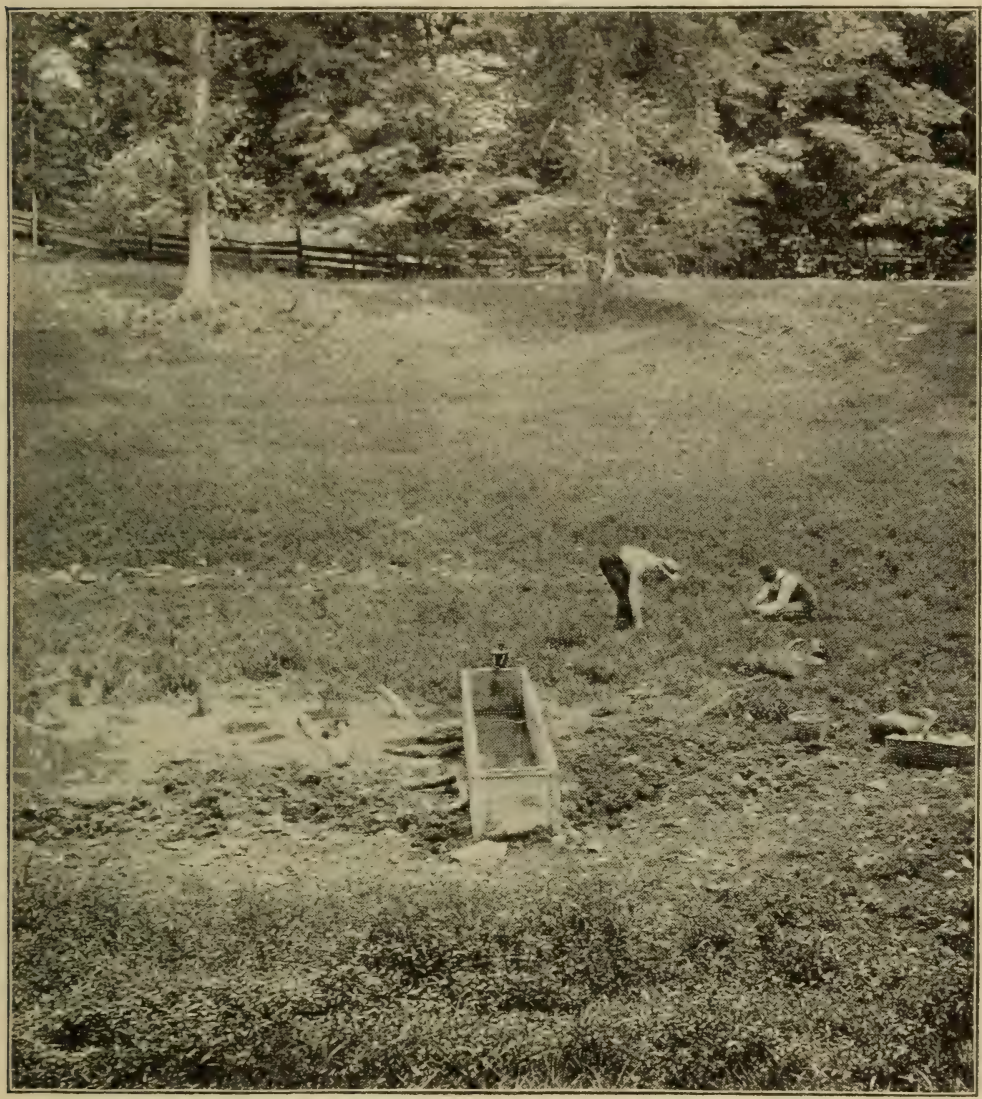

Fig. 480

Where isoetes grows. A sisuil morainic basin near Ithaca. (Photograph by the author.)

711. The bald cypress (Taxodium distichum).-Very characteristic are the formations presented by the forests of the bald cypress of the South, which grows in swampy or marshy places. The "knees" on the roots of this cypress make grotesque figures in the cypress forest. These take the form of upright, columnar outgrowths, broader at the base or point of attachment to the 
horizontal root, and possess a fancied resemblance to a knee. These knees are said to occur at points on the horizontal root above and opposite the point where a root branch extends downward into the soft marsh soil. They thus give strength to the

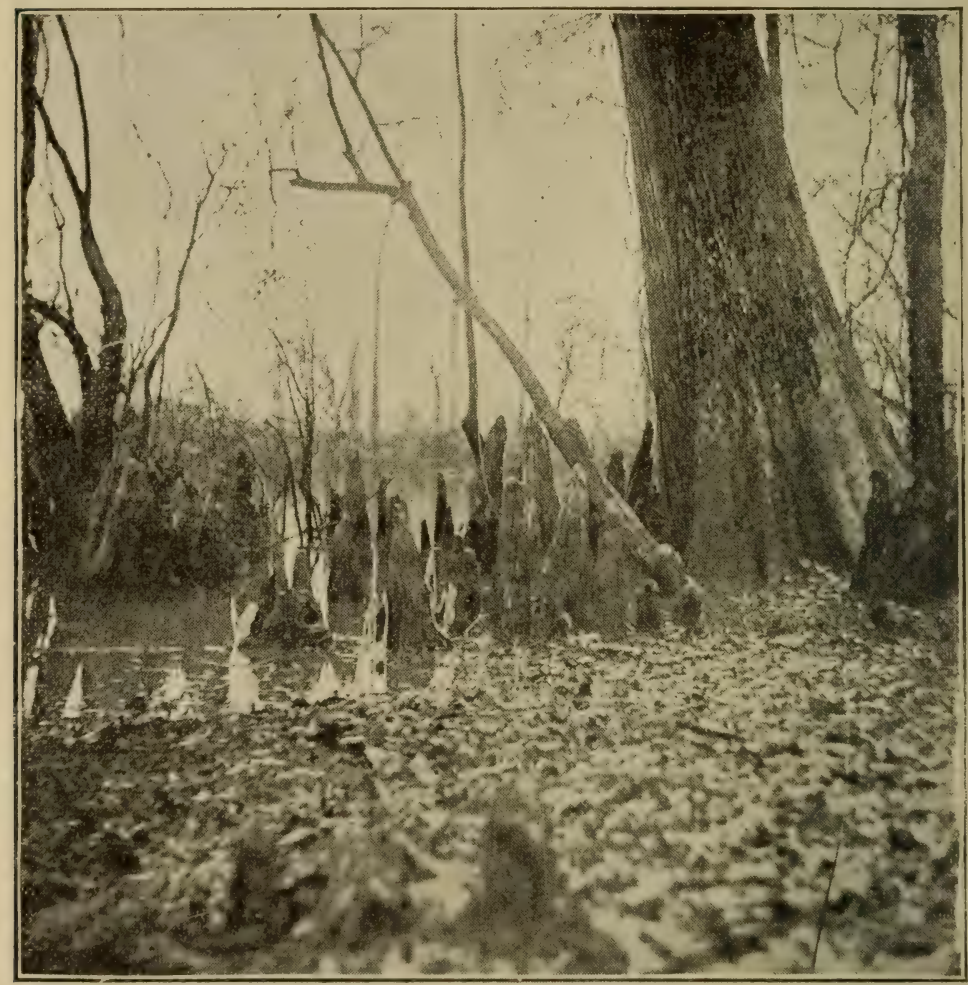

Fig. 490.

Cypress knees, Mississippi. (Photograph by H. von Schrenk.)

horizontal root at the point of attachment of the branch which penetrates into the soft soil, and during gales they hold these root branches more rigidly in position than would be the case if the horizontal root could easily bend at this point. The knees thus are supposed by some to strengthen the anchor formed by the root in the loose soil. Their development may be the result of mechanical irritation at these points on the horizontal root, 
brought about by the strain on the roots from the swaying of the tree. Others regard them as organs for aerating the portions of the root system which are usually submerged in water or wet soil. The knees catch and hold floating plant remains during floods, and by the decay of this débris the fertility of the soil is increased. In deeper water where the lower part of the tree is constantly submerged, peculiar buttresses are sometimes formed on the trunk, as shown in figure 49I. 


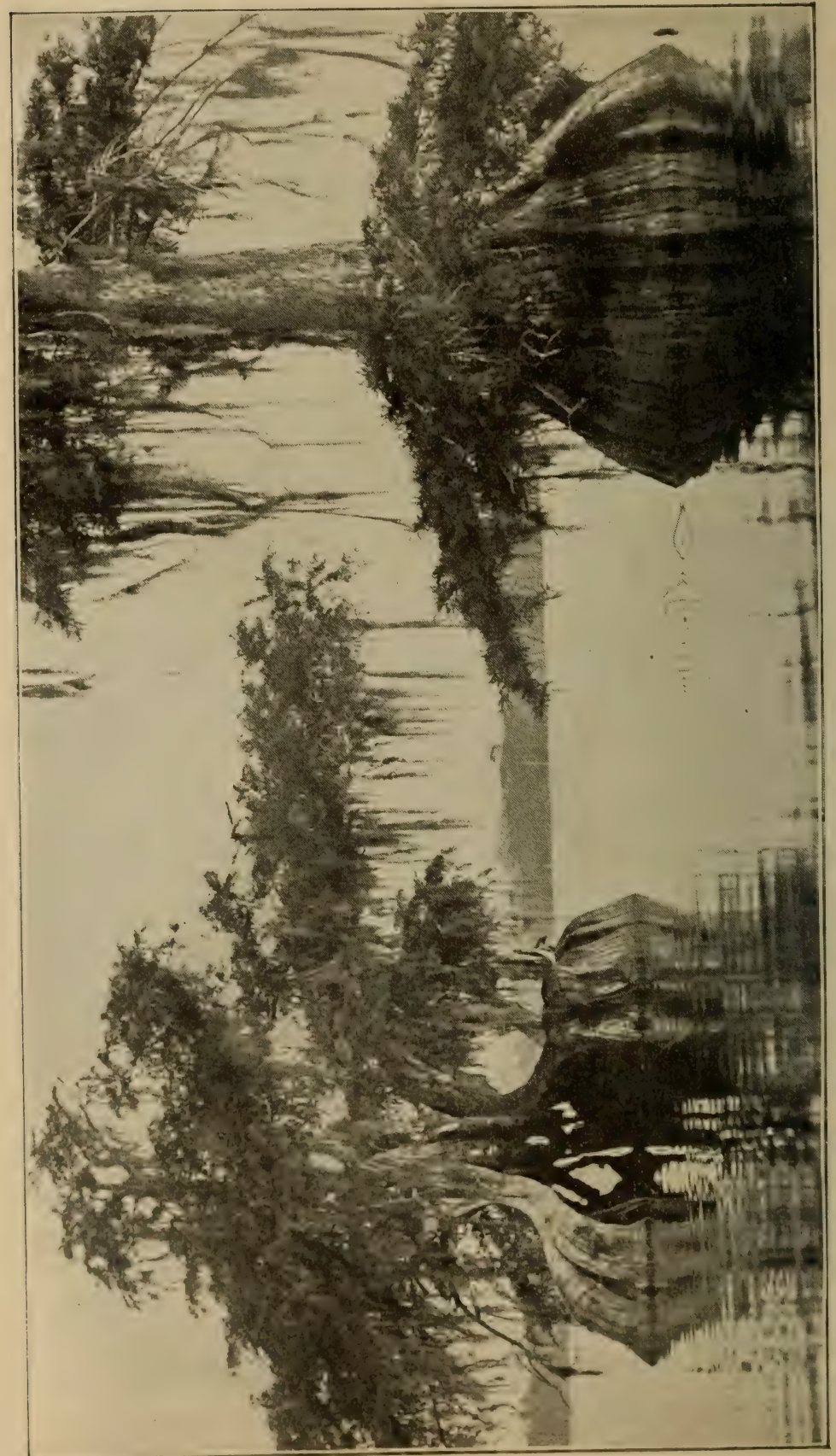




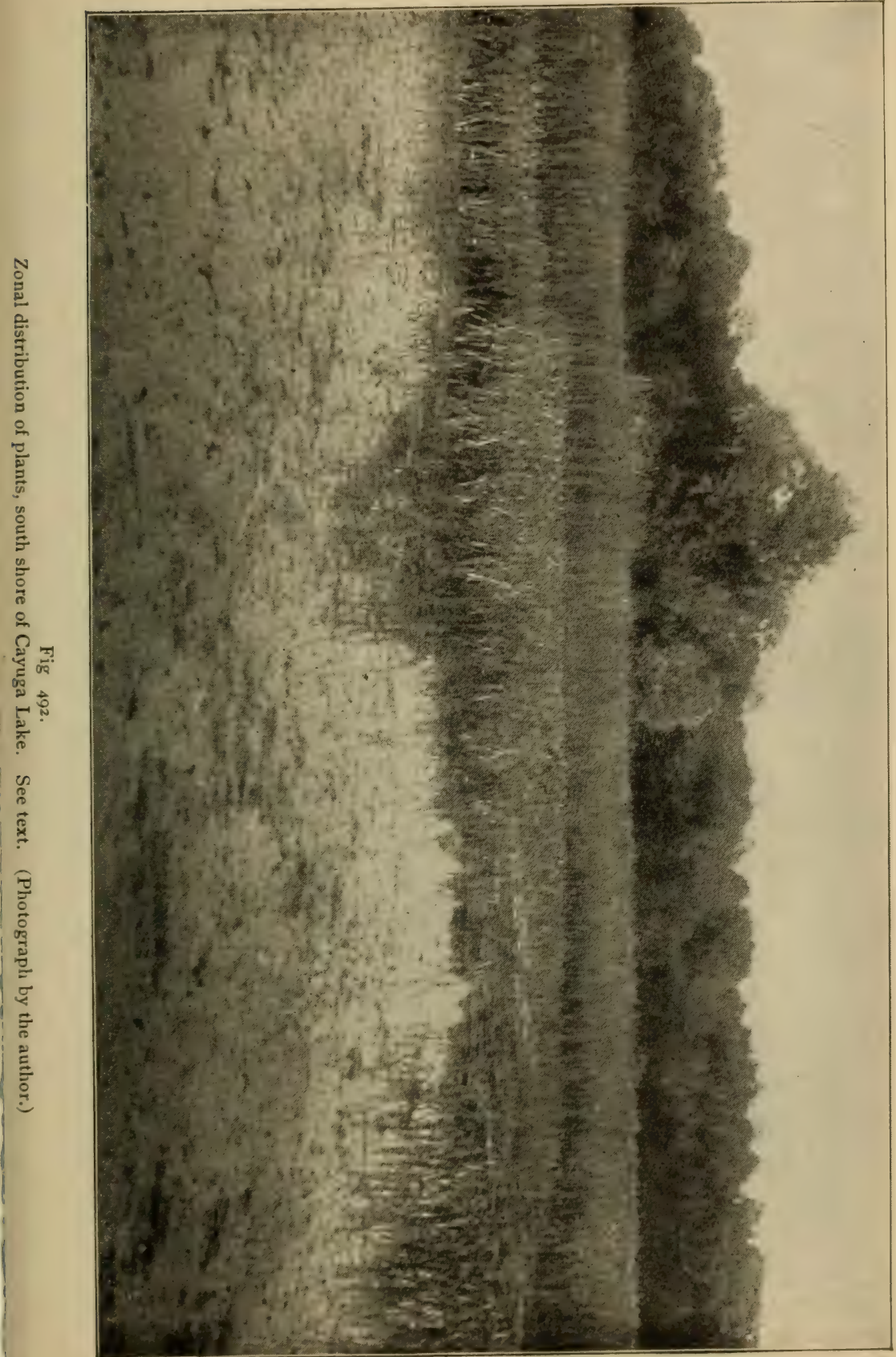




\section{CHAPTER LIV.}

\section{ZONAL DISTRIBUTION OF PLANTS.}

712. On the margins of lakes or ponds, where the slope is gradual from the land into the water, one often has an oppor-

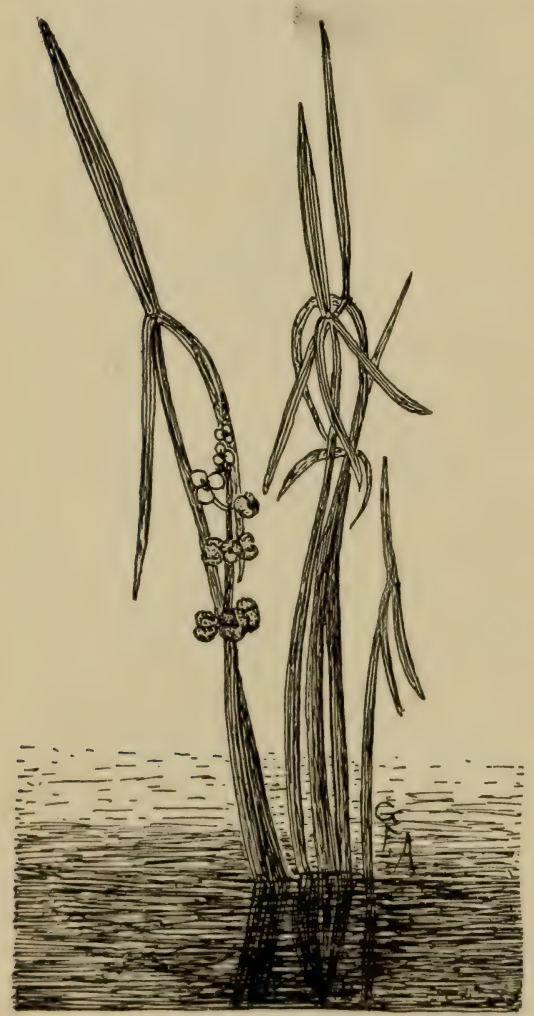

Fig. 493 .

Sagittaria variabilis. tunity to study the relation of various plants to different conditions of soil and water. In rowing near the south shore of Lake Cayuga, I have often been impressed with the definite areas occupied by certain plants. Figure 492 is from a photograph, taken from the boat, of the shore distribution of these plants. The most striking feature here is the grouping of certain kinds of plants in definite lines or zones. Here the limitations of the zones are quite distinct, so that the transition from one zone to another is quite abrupt, though there is some mixture of the kinds at the zone of transition, or tension line.

713. This arrangement of plants under such environmental influences is termed "zonal distribution of plants." The 
slope where this photograph was taken is so symmetrical that plants suited by their long habit of growing at certain depths of water, or in soil of a certain moisture content, are readily drawn

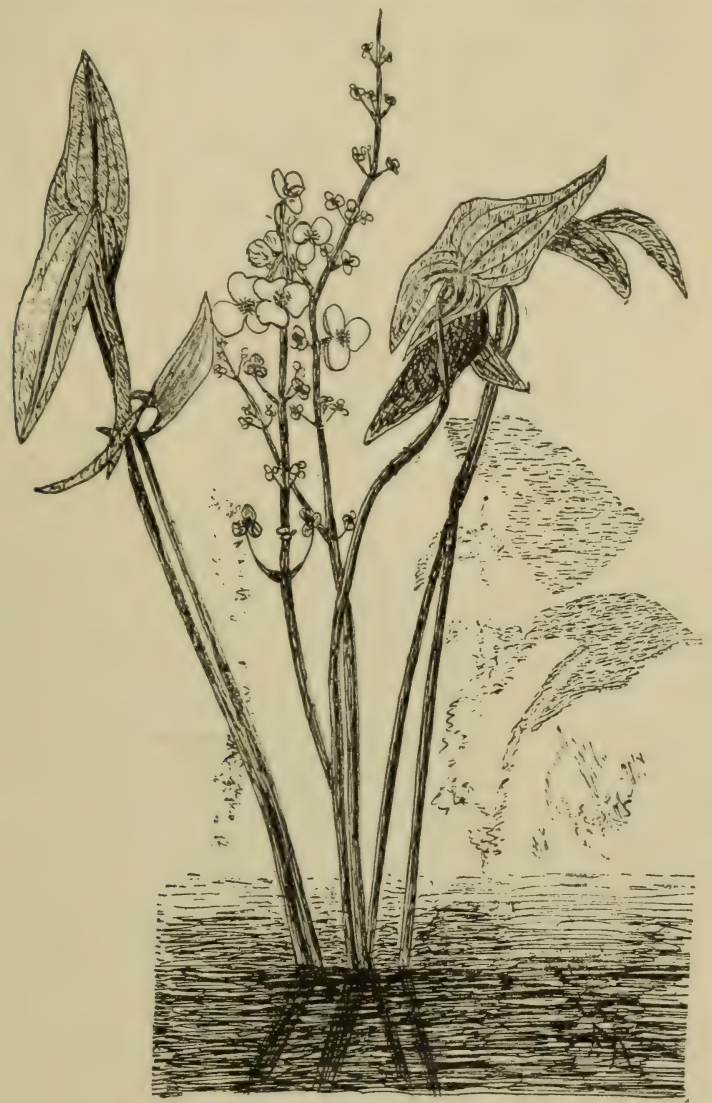

Fig. 494 .

Sagittaria variabilis.

into zones parallel with the shore line. Several zones can be readily made out in this region; two of them at least do not show in the picture since they are submerged.

714. If we treat of the two submerged zones, the first one is in the rear of the point from where the photograph was taken, and consists of extensive areas of chara in four to five meters of 
water. The second zone then is in the water shown in the foreground of the picture. The plants here are also submerged, or only a small portion reaches the surface of the water, and so the

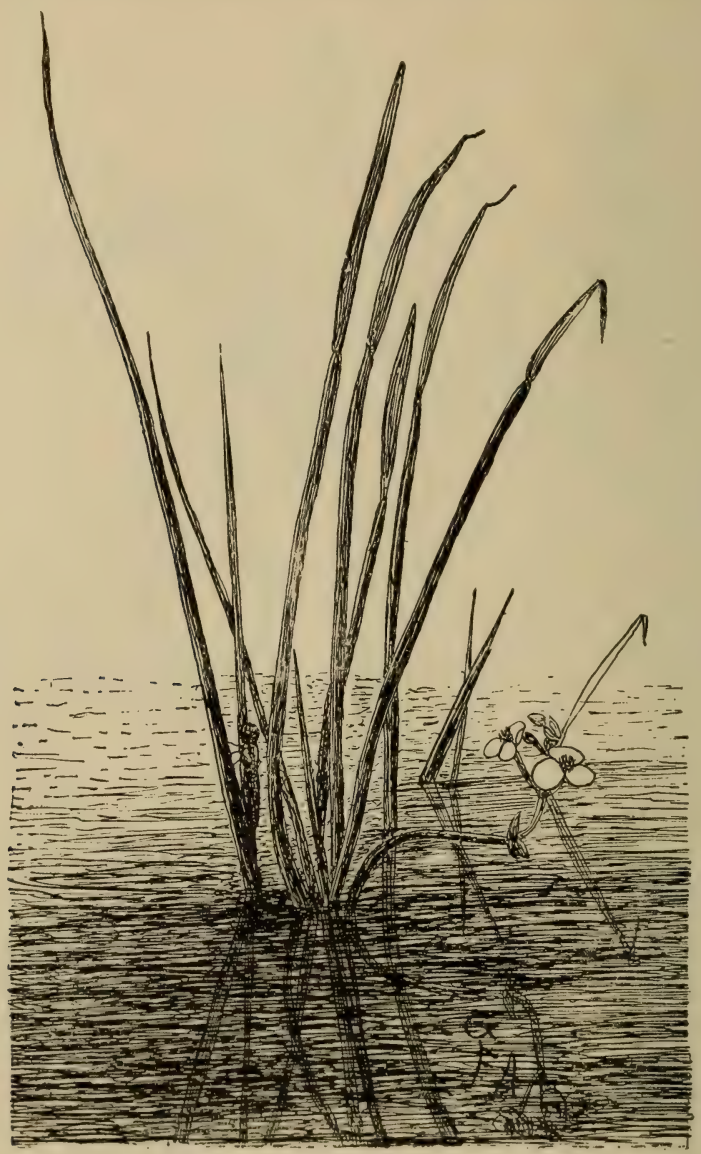

Fig. 495 .

Sagittaria heterophylla. Often forms a zone just outside of the Sagittaria variabilis.

zone does not show. In this zone occurs the curious Vallesneria spiralis, with its corkscrew flower stem, and various potamogetons.

715. In the third zone, or the first one which shows in the picture, are great masses of the arrow-leaf (sagittaria) so variable 
ZONAL DISTRIBUTION OF PLANTS.

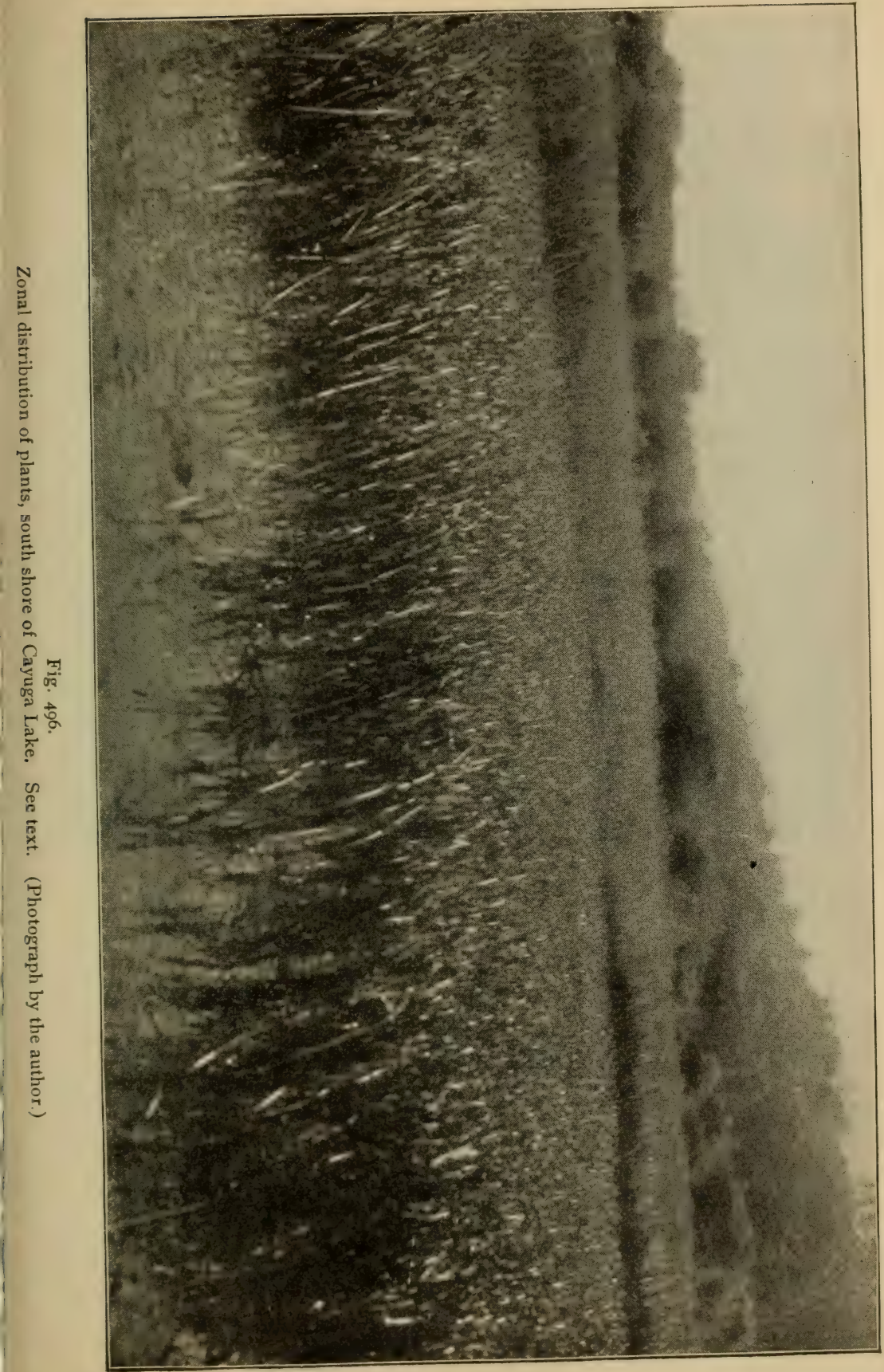




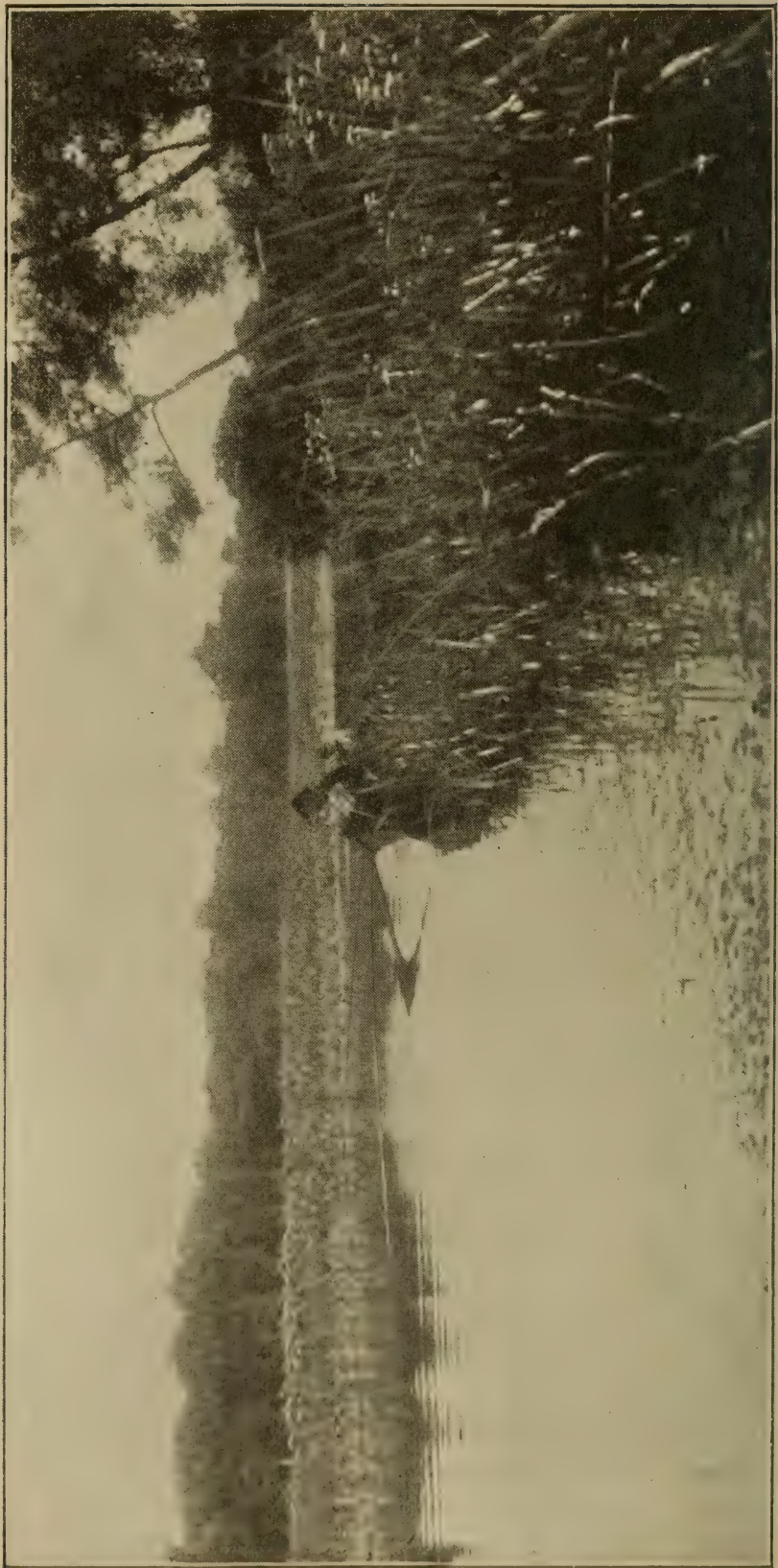

定 
in the form of its leares. Next is the fourth zone, made up here chiefly of bullrushes (scirpus), and occasionally are clumps of the cattail flag (typha). Behind this is the fifth zone, only to be distinguished at this distance by the bright flower heads of the boneset (Eupatorium perfoliatum) and joepye-weed (Eupato-

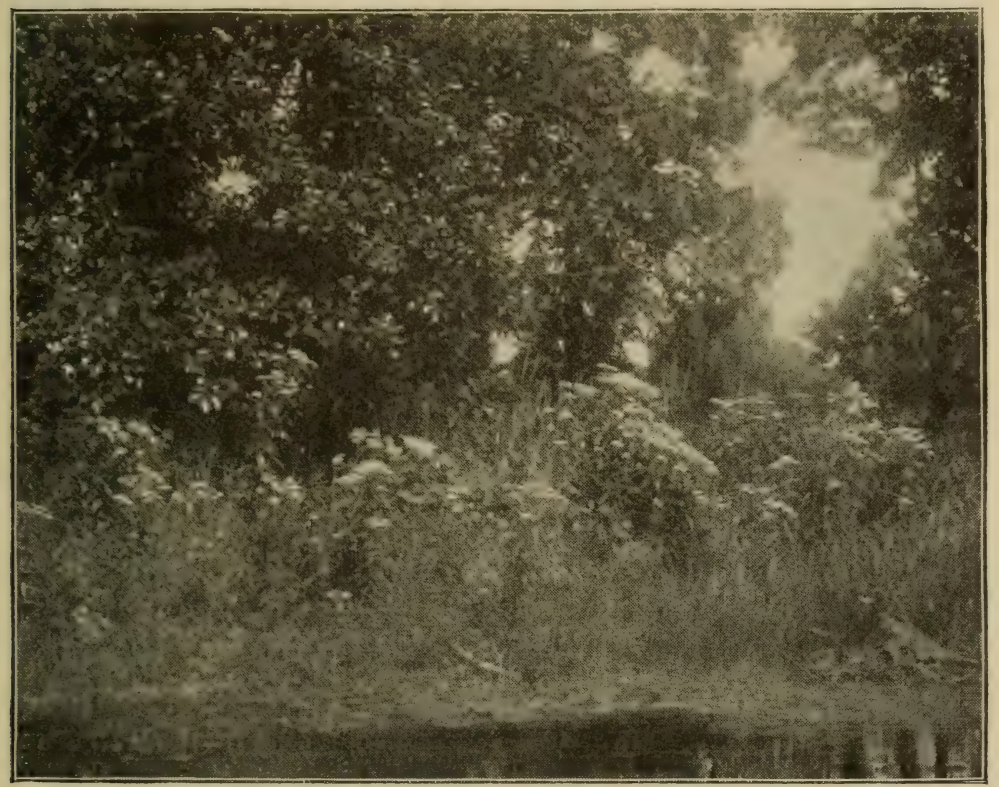

Fig. 498.

Bank of joepye-weed, Eupatorium purpureum. (Photograph by author.)

rium purpureum), and the blue vervain (Verbena hastata), which occurs on the land. Willows make a compact and distinct sixth zone, while at the right, shown in figure 496 taken alongside this view, the oaks on the hillside beyond form a seventh zone, and still farther back is a zone of white pines, making the eighth.

716. On the banks of a stream emptying into this end of the lake, after pursuing its sinuous course through wooded flats, are living pictures, which present a wealth of beauty in color and harmony of association and environment, charming to behold 
and delightful to study. At the entrance (figure 497) a broad sweep of typha margins a projecting arm of the land which affords a quiet nook for the repose of mats of green algæ, of such sorts

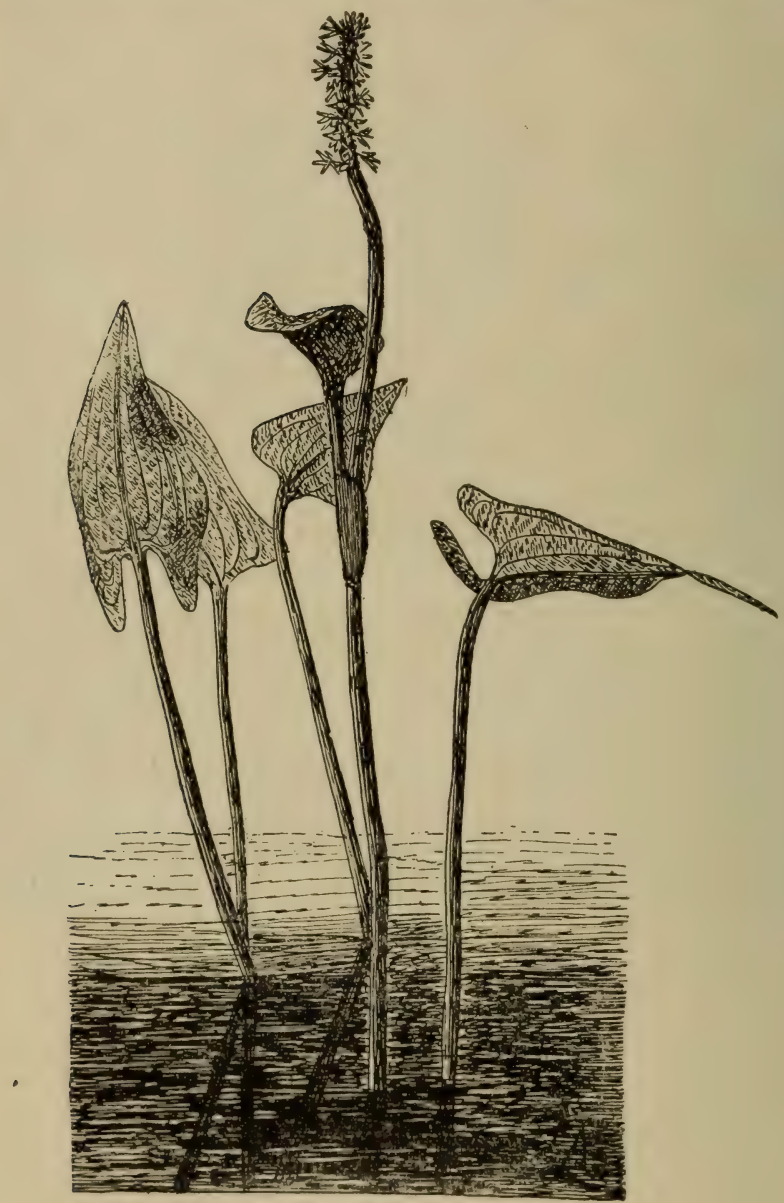

Fig. 499.

Pontederia, showing leaves and flower spike.

as spirogyra, odogonium, cladophora, etc., floating on the placid water in the foreground. Slender stems of zizania rise like shooting stars among the flags, with scirpus crowding near, while masses of the flowers of the thoroughwort are sheltered by 
overhanging willows. On the left, pond-weeds (Potamogeton natans) and the yellow water lily, or spatter-dock (nuphar),

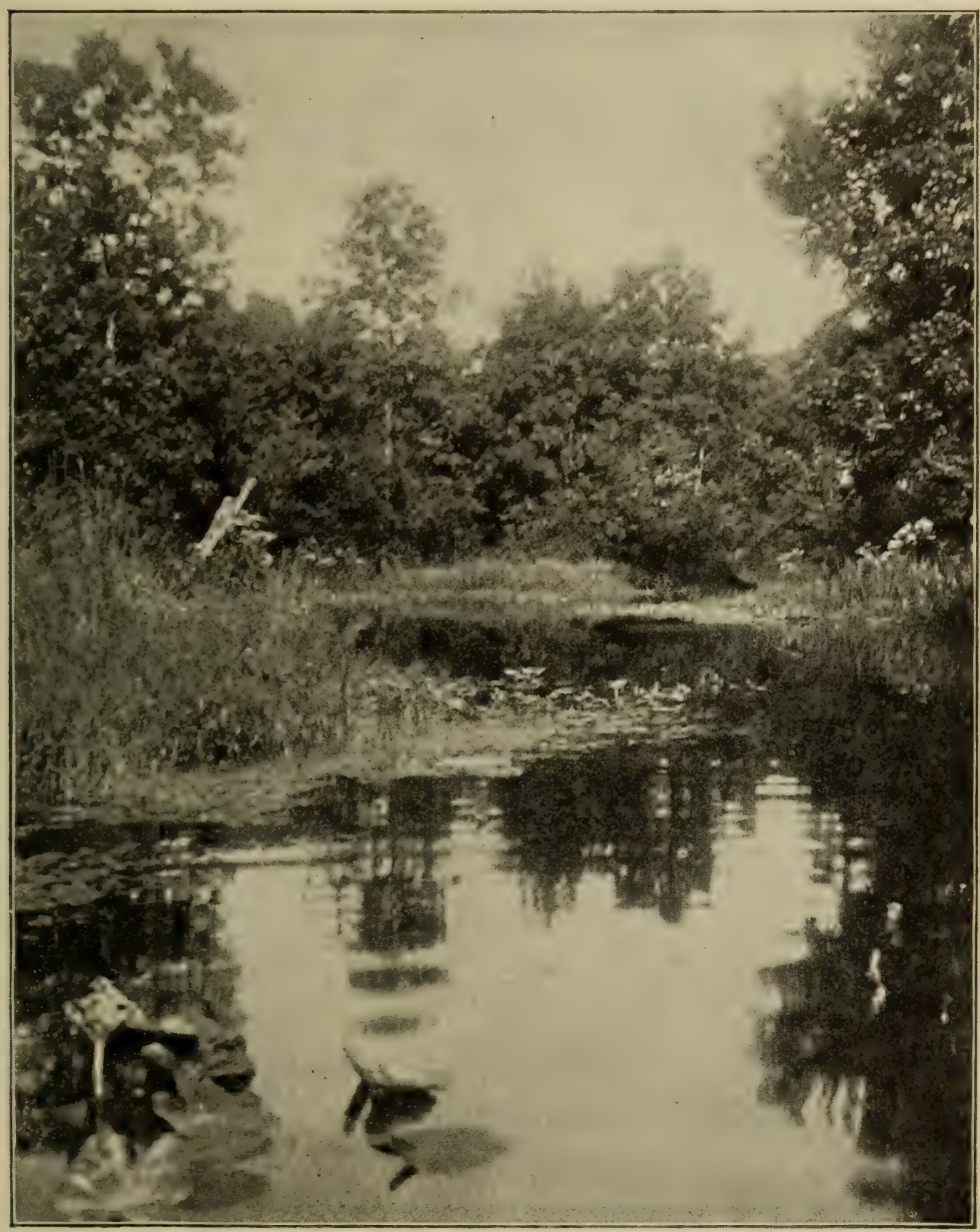

Fig. 500 .

Yellow water lily on jutting arm in stream. (Photograph by the author.)

float their leaves and flowers on the quiet water, while the small yellow flowers of the mud plantain (Heteranthera graminifolia) glitter in the sunlight. The arrow-leaf (Sagittaria heterophylla, 
and variabilis) stand to their necks in the water. The shore near by is lined with sedges. Beyond these on the banks are masses of the white and purple eupatorium, with a goodly sprinkling of the swamp milkweed, its blossoms ablaze with color, while a long bank of willows forms a background of satisfying green.

717. Rowing up the stream, one passes in review minor formations, which exhibit less regularity of distribution and fewer individuals of one species. Pontederia still lingers along near the shore, nearly touching the feet of the purple eupatorium on the bank. The yellow water lily, in groups here and there, points out the shallows, or traces the jutting arms of the shore, which in the distance seem to intercept the course, and the wavelets on the water toss into fantastic figures the mirrored shrubs and trees. In the quiet nooks the sunlight blazes down upon umbels of the blue cornel and the pendent fruit clusters of the trailing nightshade. Banks of goldenrod are massed on one hand, and here and there stand gorgeous clusters of the arrow-leaved polygonum and of the yellow touch-me-not, while every now and then the sickly, blighting form of the cuscuta holds its victims in a crushing embrace.

718. Successions of waves running along the sunny shore throw lights and shadows, which chase each other up the trunks of werhanging trees in the form of rings of sunlight and shade, and then throw a quivering, shimmering light over the foliage. Fallen trees stretch their weather-beaten and bleached trunks over the stream, and their mirrored ghosts dance in the waves at your approach, while the towering elms leyond, smothered in the foliage and embrace of the poison ivy, add to the weird beauty of the scene. 


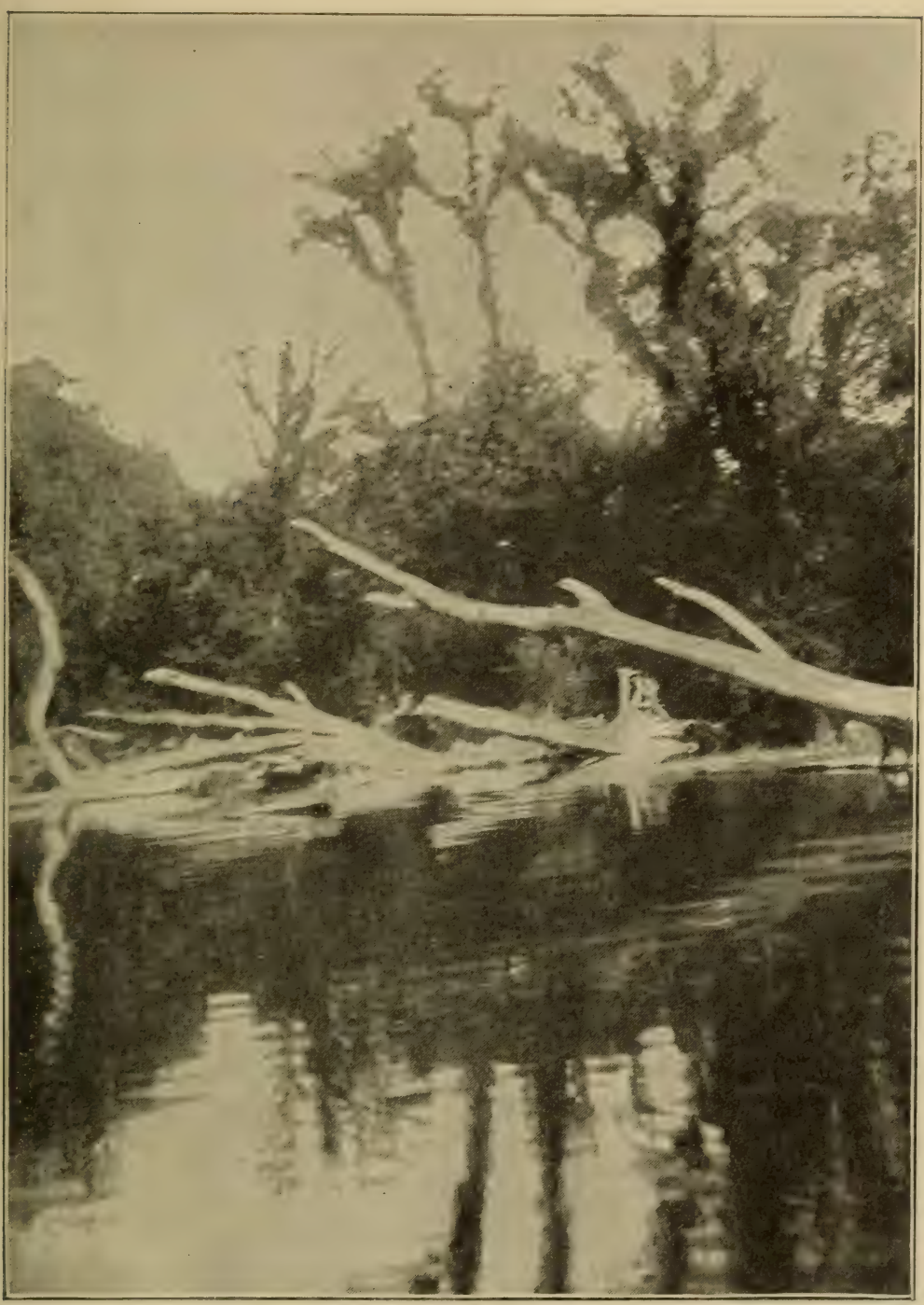

Fig. 50r.

Elms in background covered by poison ivy. (Photograph by the author.) 


\section{CHAPTER LV.}

\section{PLANT COMMUNITIES: SEASONAL CHANGES.}

719. One of the interesting subjects for observation in the study of the habits and haunts of plants is the relation of plants to each other in communities. In the topography of the moors, and of the land near and on the margins of bodies of water, we have seen how the adaptation of plants to certain moisture conditions of the soil, and to varying depths of the water, causes those of a like habit in this respect to be arranged in definite zones. Often there is a predominating species in a given zone, while again there may be several occupying the same zone, more or less equally sharing the occupation. Many times one species is the dominant form, while several others exist by sufferance.

720. Plants of widely different groups may exist in the same community.-So it is that plants of widely different relationships have become adapted to grow under almost identical environmental conditions. The reed or grass growing in the water is often accompanied by floating mats of filamentous algæ like spirogyra, zygnema ; or other species, as oedogonium, coleochæte, attach themselves to these higher lords of creation; while desmids find a lodging place on their surface or entangled in the meshes of the other algæ. Chara also is often an accompaniment in such plant communities, and water-loving mosses, liverworts, and fern-like plants as marsilia. Thus the widest range of plant life, from the simple diatom or monad to the complex flowering plant, may, by normal habit or adapted form, live side by side, each able to hold its place in the community.

721. In field or forest, along gliale or glen, on mountain slope or in desert regions, similar relationships of plants in 
communities are manifest. The seasons, too, seem to vegetate, blossom, and fruit, for in the same locality there is a succession of different forms, the later ones coming on as the earlier ones disappear.

722. Seasonal succession in plant communities.-The wooded slopes in springtime teem with trillium, dentaria, podophyllum, and other vernal blossoms, while on the steeper hillsides the early saxifrage is to be found. In the rocky portions

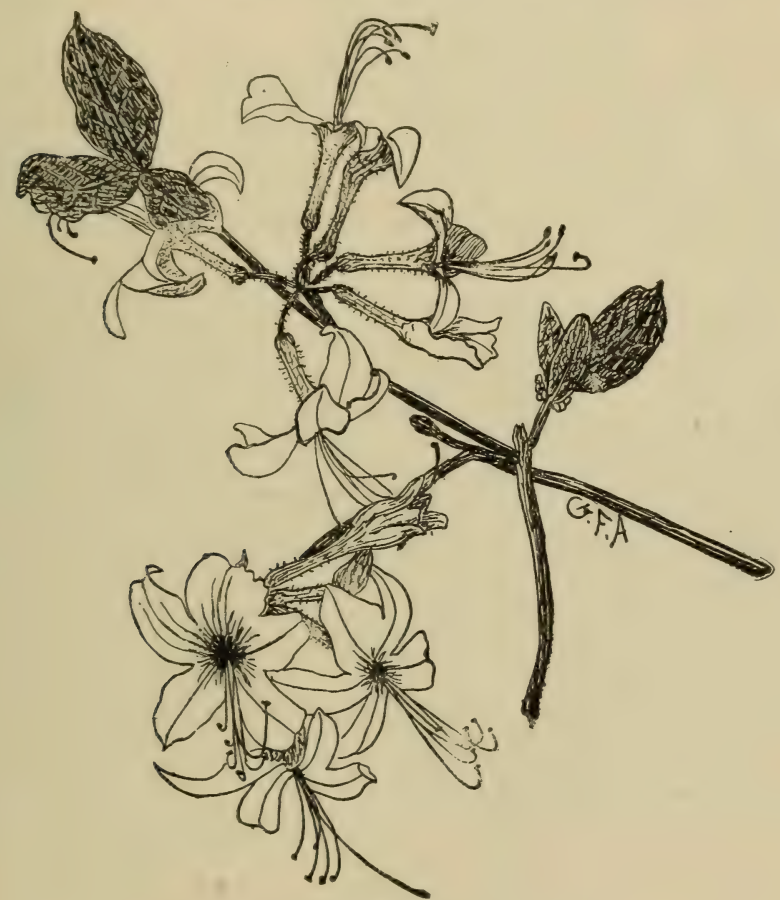

Fig. 502.

Azalea (Rhododendron nudicaulis).

of the glen, which is also a favorite lodgment for this pretty, white saxifrage, the wild columbine loves to linger and dangle its spurred flowers. The lichen-colored ledge is wreathed with moss and fern. On the partly sunlit slopes the clusters of azalea are radiant with blossoms, while here and there the shad-bush, or service-berry (amelanchier), with its mass of white flower- 


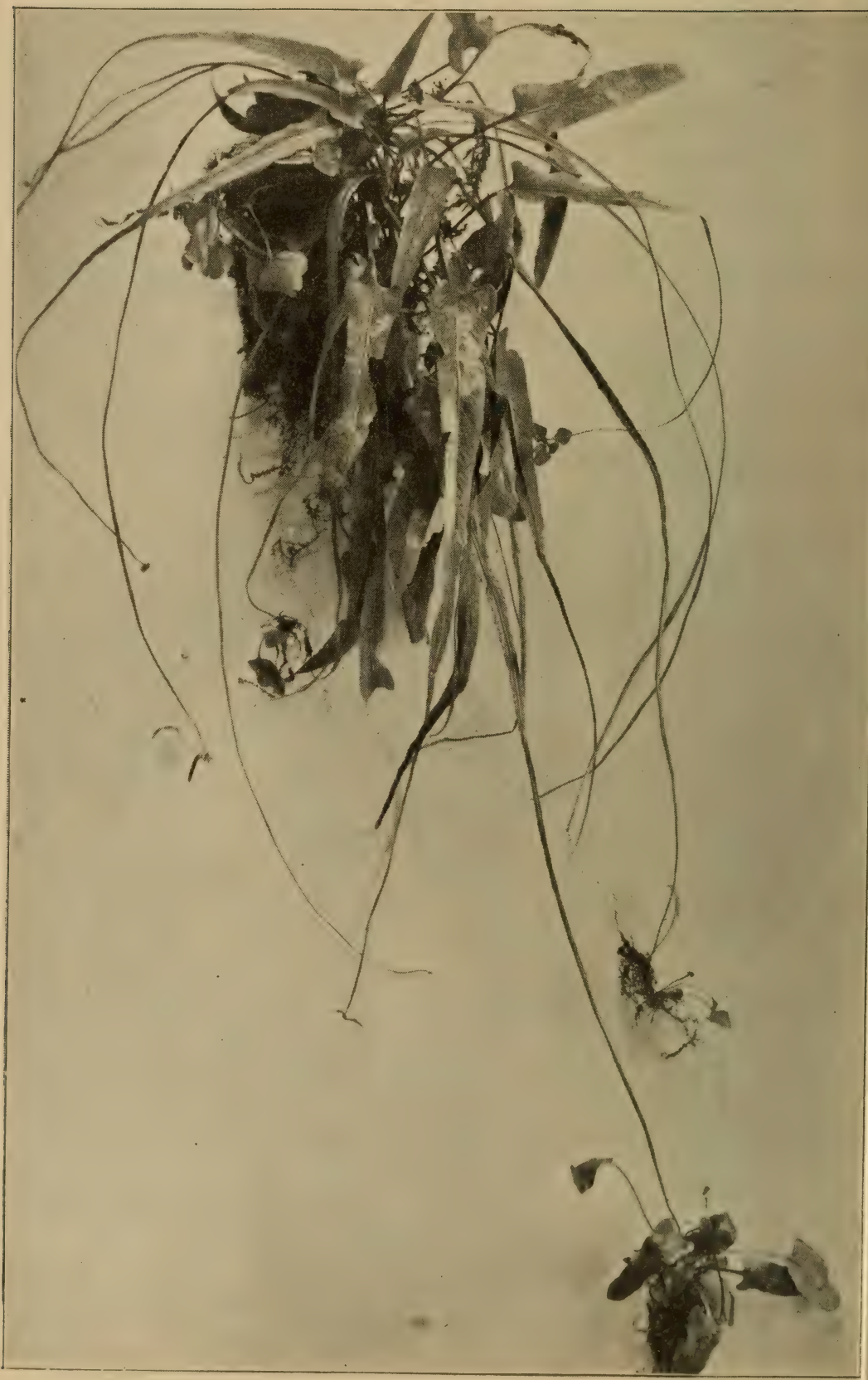

Fig. 503.

Walking fern, climbing down a hillside. 
sprays, overhangs some cliff, and the cockspur thorn (cratregus) vies with it in the profusion of floral display. Near by sheets of water pour themselves unceasingly on the rocks below, scattering spray on the thirsty marchantia. Out from the steep slopes above rise the graceful sprays of yew (taxus), shaded by the towering hemlock spruces. The "walking-fern "' here, holding fast above, climbs downward by long graceful strides.

723. But the scene shifts, and while these flowers cast their beauty for the season, others put on their glory. The flowering

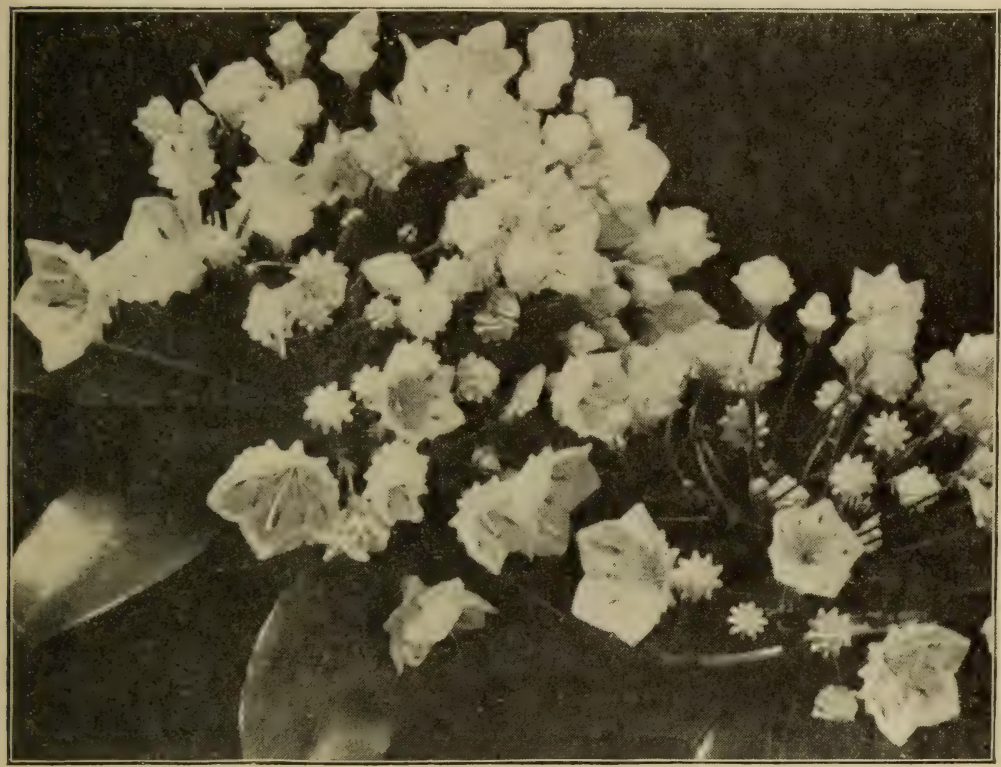

Fig. 504.

Spray of kalmia flowers.

dogwood spreads its deceptive bracts as a halo around the clusters of insignificant flowers. The laurel (kalmia) with its clusters of fluted pinkish blossoms is a joy only too brief. Smaller and less pretentious ones abound, like the whortleberries, amphicarpæa, bush-clover (lespedeza), sarsaparilla, and so on.

724. In the autumn the glen is clothed with another robe of beauty. With the fall of the "sere and yellow leaf," golden- 
rod and aster still linger long in beauty and profusion. When the leaves have fallen the witch-hazel (hamamelis) begins to

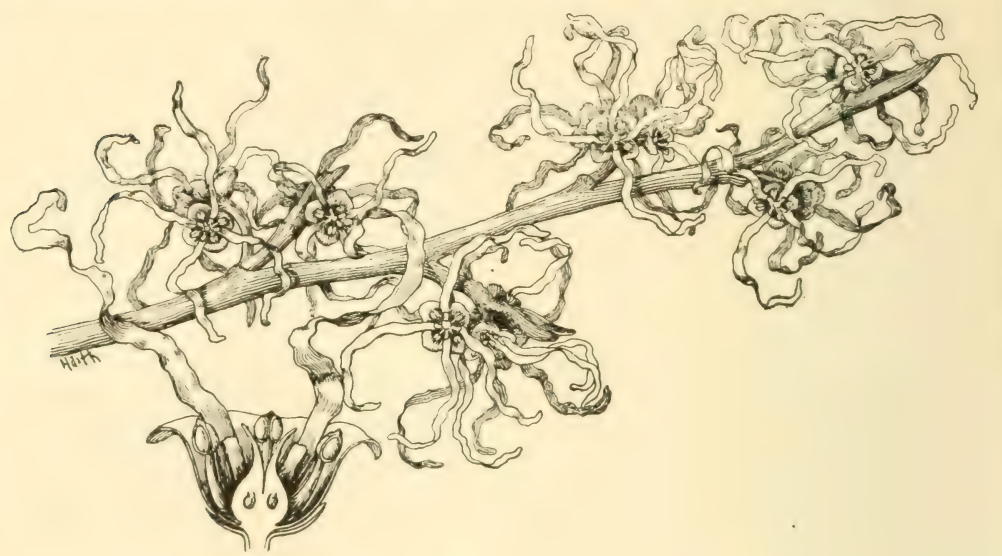

Fig. 505.

Spray of witch-hazel (hamamelis) with flowers; section of flower below.

flower, and the snows begin to come before it has finished spreading its curled yellow petals.

725. The landscape a changing panorama.-In our temperate regions the landscape is a changing panorama; forest and field, clothed with a changing verdure, don and doff their foliage with a precision that suggests a self-regulating mechanism.

In the glad new spring the mild warmth of the sun stirs the dormant life to renewed activity. With the warming up of the soil, root absorption again legins, and myriads of tiny root hairs pump up watery solutions of nutriment and various salts. These are carried to the now swelling buds where formative processes and growth elongite the shoot and expand the leaf. Buds longr wrapped in winter sleep toss back the protecting scales. In a multitude of ways the different shrubs and trees now discard the winter armature which has serverl so good a purpose, and tiny bud leaves show a multitude of variations from simple bud scale to perfect leaf, a remarkable diversification in which the plant from lateral members of the stem forms organs to serve such a bariety of purpose under such diametrically opposed environmental conditions. 
PLANT COMMUNTTIES: SEASONAL CHANGES. $4 \mathrm{I} 5$

726. Refoliation of bare forests in spring.-There is a certain charm watching the refoliation of the bare forests, when the cool gray and brown tints are slowly succeeded by the light yellow-green of the young leaves, which presents to us a warming

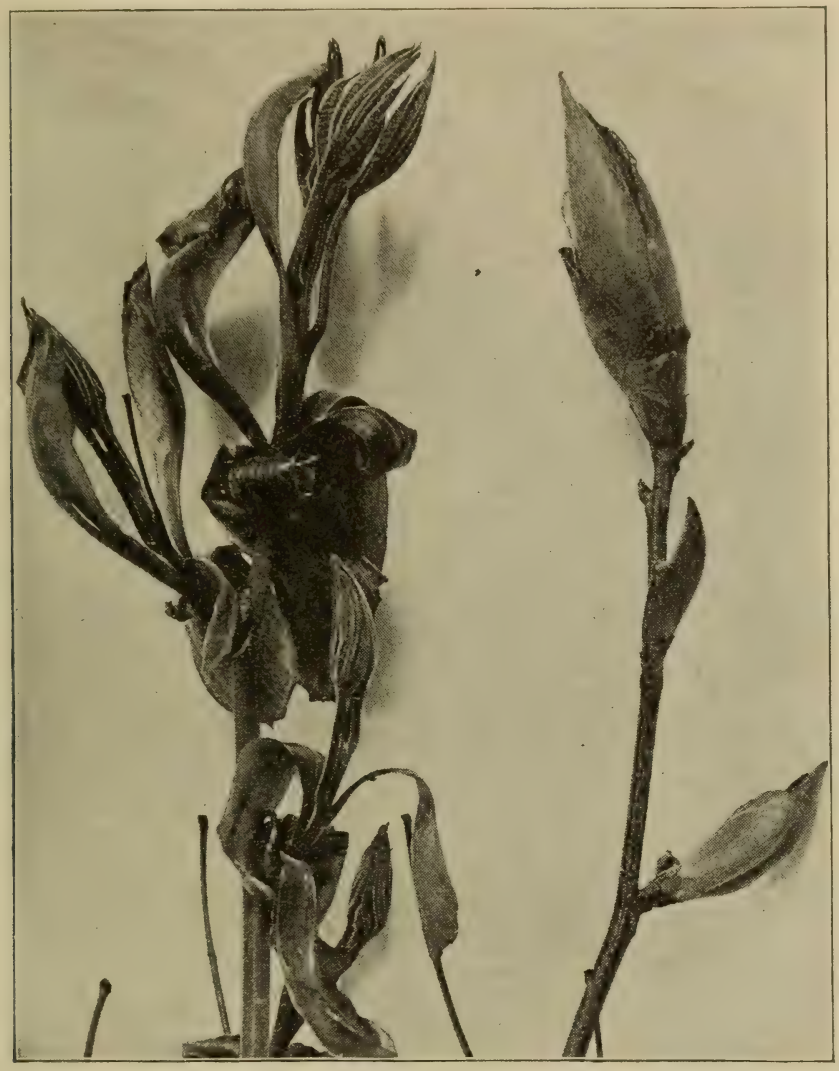

Fig. 506.

Opening buds of hickory.

glow of color. Then the snow-clad fields change to gray, and soon are enveloped in a living sea of color. The quiet hum of myriads of opening buds and flowers in harmony with the general awakening of nature, and the trickling streamlets which unite into the gurgling brooks, makes sweet music to our attentive minds. 
727. The evergreens display a striking contrast of color. The leafy, fan-shaped branches of the hemlock-spruce (tsuga) are

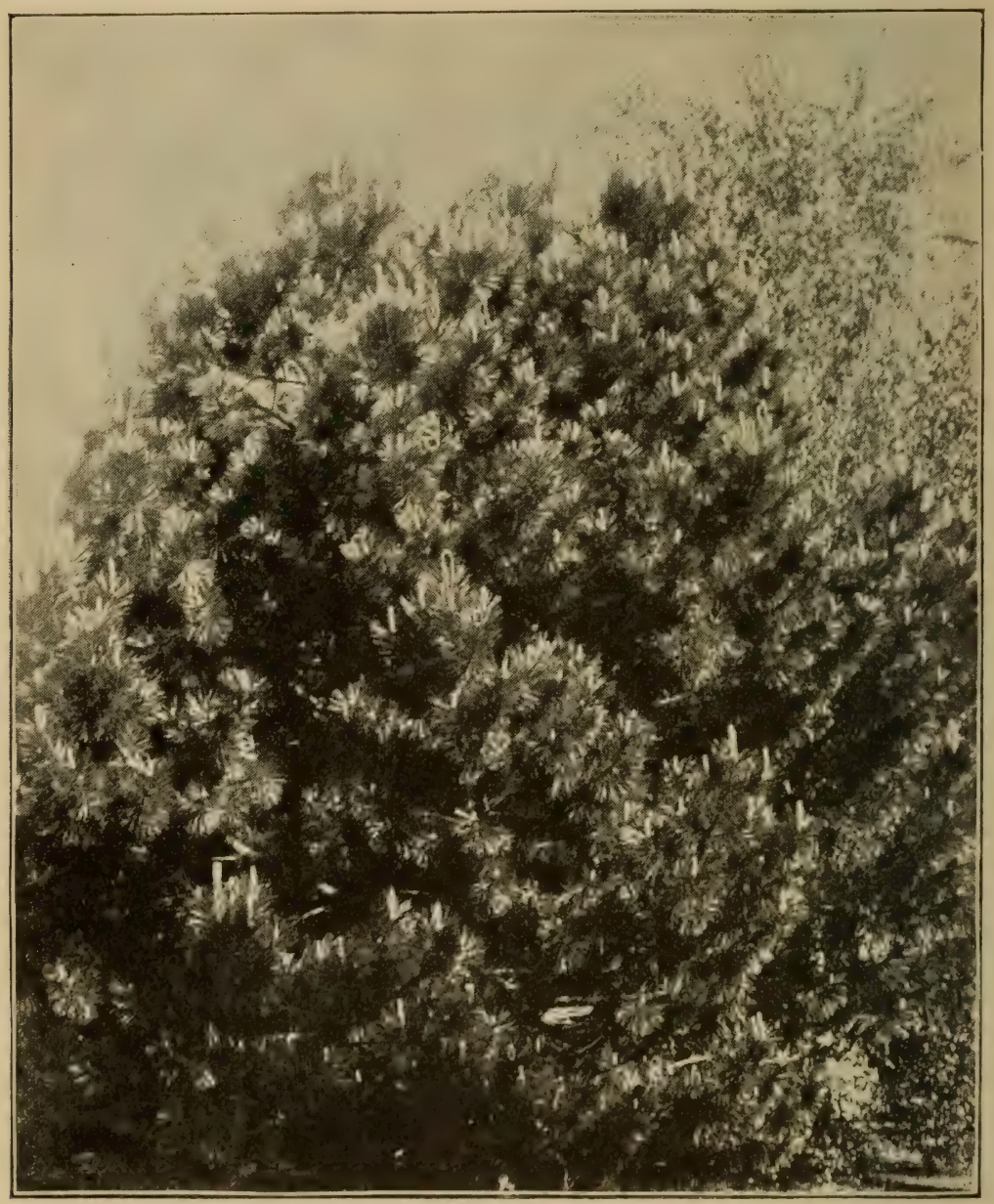

Fig. 507

Austrian pine, showing young growth of branches in early spring.

fringed with the light green of the new growth. The pines lift up numbers of cylindrical shoots, with the leaf fascicles for a time sheathed in the whitened scales, while the shoots are tipped with the brown or flame-colored female flowers, reminding one 
of a Christmas tree lighted with numerous candles. The numerous clusters of staminate flowers suggest the bundles of toys and gifts, and one inquires if this beautiful aspect of some pines when putting on their new growth did not suggest the idea of the Christmas tree at yule time.

728. The summer tints are more subdued.-As summertime draws on the new needles of the pine are unsheathed, the light green tints of the forest are succeeded by darker and subdued colors, which better protect the living substance from the intense light and heat of midsummer. The physiological processes for which the leaf is fitted go on, and formative materials are evolved in the countless chlorophyll bodies and transported to growing regions, or stored for future use. In transpiration the leaf is the terminus of the great water current started by the roots. Here the nutrient materials, for which the water serves as a vehicle, are held back, while the surplus water evaporates into the air in volumes which surprise us when we know that it is unseen.

729. Autumn colors. - As summer is succeeded by autumn, a series of automatic processes goes on in the plant which fits it for its long winter rest again. Long before the frosts appear, here and there the older leaves of certain shrubs lose more or less of the green color and take on livelier tints. With the disintegration of the chlorophyll bodies, other colors, which in some cases were masked by the green, are uncovered. In other cases decomposition products result in the formation of new colors. These coloring substances to some extent absorb the sun's rays, so that much of the nitrogenous substances in the leaf may not be destroyed, but may pass slowly back into the stem and be stored for future use.

730. Fall of the leaf. - The gorgeous display of color, then, which the leaves of many trees and shrubs put on is one of the many useful adaptations of plants. While this is going on in deciduous trees, the petiole of the leaf near its point of attachment to the stem is preparing to cut loose from the latter by forming what is called a separative layer of tissue. At this point the cells 
in a ring around the central vascular bundle grow rapidly so as to unduly strain the central tissue and epidermis, making it brittle. In this condition a light puif of wind whirls them away in eddies to the ground. The frosts of autumn assist in the separation of the leaf from the stem, but play no part in the coloration of the leaf.

As the cold weather of autumn and winter draws slowly on, these trees and shrubs cast off their leaves, and thus get rid of the extensive transpiration suriace, or in same cases the dead leaves may cling for quite a long period to the trees. However in the death and fall of the leaves of these deciduous trees and shrubs, or the dying back of the aerial shoots of perennial herbaceous plants, there is a most useful adaptation of the plant to lay aside, for the cold period, its extensive transpiration surface. For while the soil is too cool for root absorption, should transpiration go on rapidly, as would happen if the leaf surface remained in a condition for evaporation, the plants would lose all their water and dry up. 


\section{CHAPTER LVI.}

\section{ADAPTATION OF PLANTS TO CLIMATE.}

731. Some characteristics of desert vegetation. - One of the important factors in plant form and distribution is that of climate, which is modified by varying conditions, as temperature, humidity of the air, dryness, etc. In desert regions where the air and soil are very dry, and plants are subject to long periods of drought, there is a very characteristic vegetation, and a variety of forms have become adapted to resist the drying action of the climate.

732. Some of the plants, especially the larger ones, have very succulent stems or trunks, or they are more or less expanded but thickened, while the leaves are reduced to mere spines or hairs, as in the cacti. If plants in desert regions had thin and broadly expanded leaves, transpiration would be so rapid, and so great, as to kill them. In these succulent stems there is a proportionately small surface area exposed, so that transpiration is reduced. The chlorophyll resides here in the stems, and they function as foliage leaves in many other plants do.

733. Other plants of the desert, which do not have succulent stems, are provided with closely appressed and small, thick, scale-like leaves. The leaves in many of these plants have an epidermis of several layers of cells, so that transpiration does not take place so rapidly. In addition to this the stomata are sunk in pits, or cavities, so that the guard cells are not so exposed to the drying action of currents of air at the surface.

734. In still other cases the leaves and stems are covered with a dense felt of hairs which serves as a cushion to protect them 


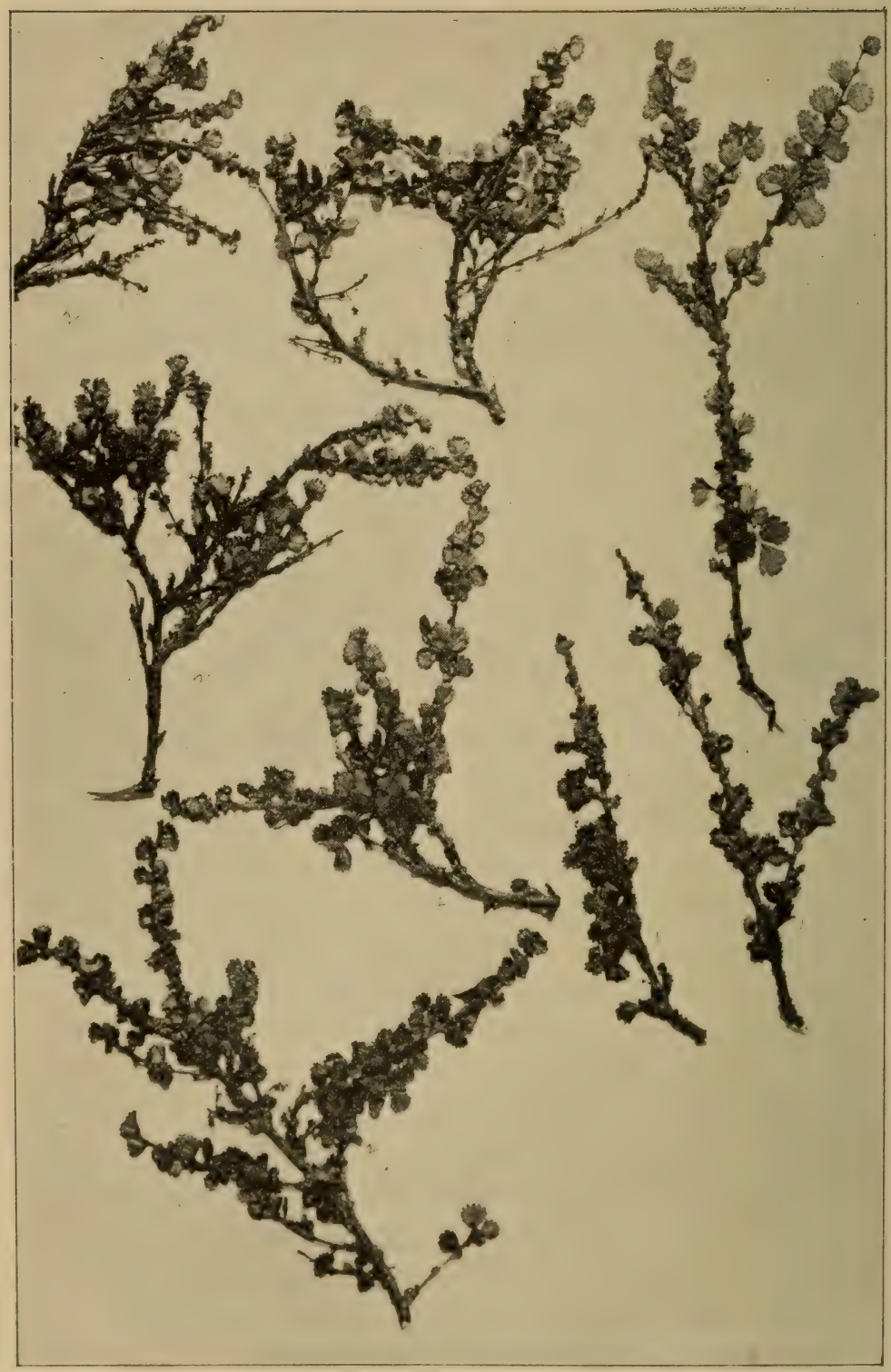

FIG. 508.

Birch trees from Greenland, one third natural size. 
from the direct rays of the sun, and also from the fierce blasts of dry air which frequently sweep over these regions. The hairs are so close, and so interwoven, that the air caught in the interstices is not easily displaced, and the leaves are not then subject to the drying effects of the passing winds.

735. Some plants of temperate regions possess characters of desert vegetation.-Even in temperate regions in localities where the climate is more equable, certain plants, strangely, are similarly modified, or provided with protecting armor. The common purslane (portulacca) is an example of a succulent plant, and we know how well it is able to resist periods of drought, even when cut free from the soil. With the oncoming of rains it revives, and starts new growth, while in wet weather cutting it free from its roots scarcely interferes with its growth.

736. Similarly the common mullein (Verbascum thapsus), the leaves and stems of which are so densely covered with stellate hairs, is able to resist dry periods. One can see how efficient this panoply of trichomes is by immersing the leaves in water. It is very difficult to remove the air from the interstices of the interwoven trichomes so as to wet the epidermis.

737. Alpine plants with desert characteristics.-Alpine plants (those on high mountains), as well as arctic plants, are similarly modified, having usually either succulent stems and leaves, or small, thick and appressed leaves, or leaves covered with numerous hairs. Cassiope, occurring on mountain summits of the northeastern United States, and far northward, has numerous needle-shaped, closely imbricated leaves. The plants need the protection afforded them by these peculiarities in these alpine and arctic regions because of the dry air and winds, as well as because of the bright sunlight in these regions. Because of the bright sunlight in alpine and arctic regions many of the plants are noted for the brilliant colors of the flowers.

738. Low stature of alpine plants a protection against wind and cold.-Another protection to plants from winds and from the cold in such regions is their low stature. Many of the herbaceous plants have very short stems, and the leaves lie close to 


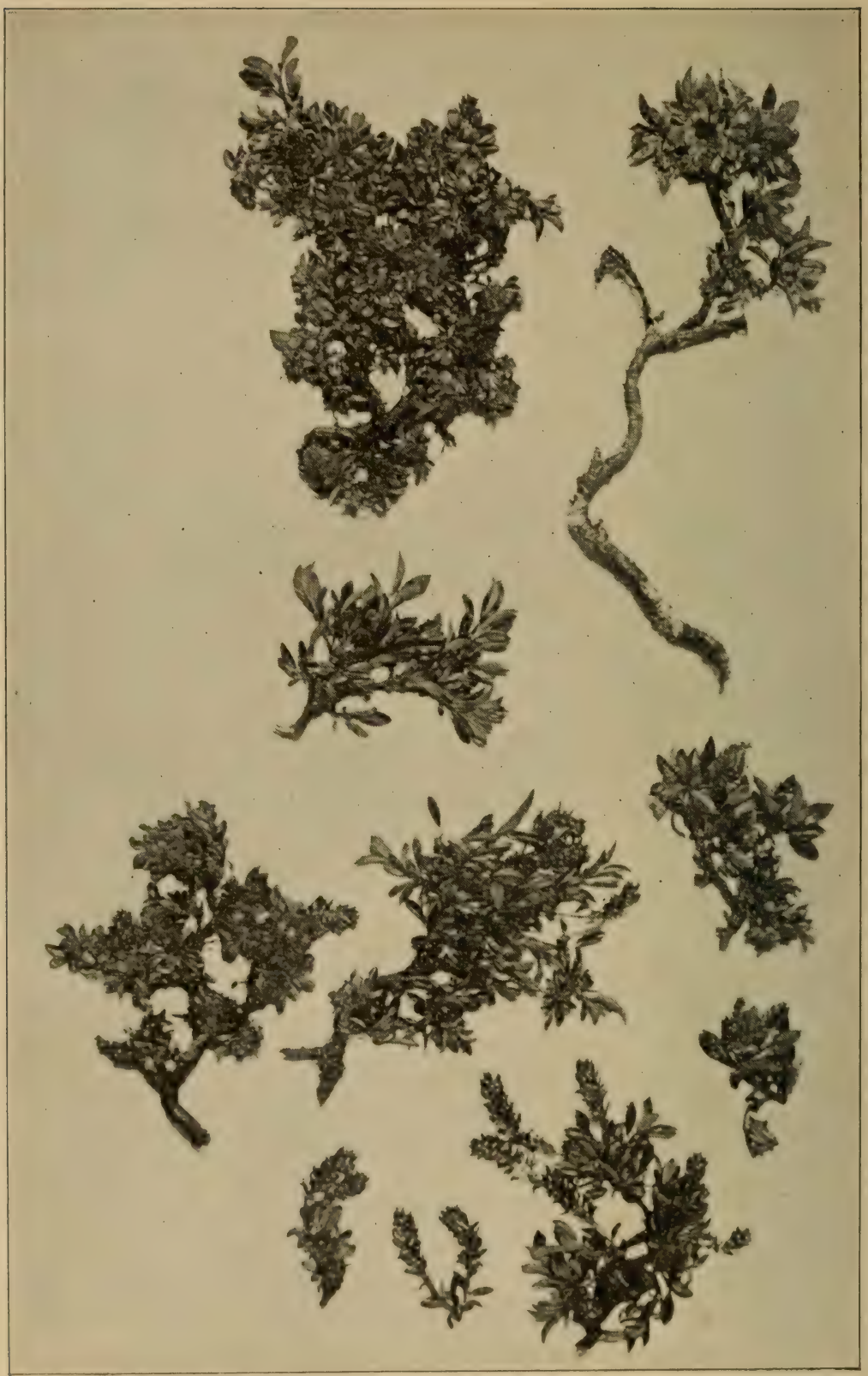

Fig. 509

Willows from Greenland. ov: third natural size. 
the soil, the plants and flowers sometimes half covered with the snow. The heat absorbed by the soil is thus imparted to the plant. Trees in such regions (if the elevation or latitude is not beyond the tree line) have very short and crooked stems, and sometimes are of great age when only a foot or more high, and the trunk is quite small. In figure 508 are shown some birch trees from Greenland, one third natural size, the entire tree being here shown. Similarly figure 509 represents some of the arctic willows, one third natural size.

739. Some plants of swamps and moors present characters of arctic or desert vegetation.-Nany of the plants of our swamps and moors have the characters of arctic or of desert vegetation, i.e. small, thick leaves, or leaves with a stout epidermis. The labrador tea (Ledum latifolium), an inhabitant of cold moors or mountain woods, has thick, stout leaves with a hard epidermis on the upper side, and the lower side of the leaves is densely covered with brown, woolly hairs. Transpiration is thus lessened. This is necessitated because of the cold soil and water of the moor surrounding the roots, which under these conditions absorb water slowly. IVere the leaves broad with a thin and unprotected epidermis, transpiration would be in excess of absorption, and the leaves would wither. Cassandra, or leather-leaf, and chiogenes, or creeping snowberry, are other examples of these shrubs growing in cold moors.

740. Hairs on young leaves protect against cold and wet. Hairs on young leaves in winter buds afford protection from cold and from the wet. The young leaves of the winter buds of many of our ferns are covered with a dense felt of woolly hairs. In species of osmunda this is very striking. The leaves are quite well formed, though small, during the autumn, and the sporangia are nearly mature. The hairs are so numerous, and so closely matted together, that they can be torn off in the form of a thick woolly cap. 



\section{APPENDIX.}

\section{COLLECTION AND PRESERVATION OF MATERIAL.}

Spirogyra may be collected in pools where the water is present for a large part of the year, or on the margins of large bodies of water. To keep fresh, a small quantity should be placed in a large open vessel with water in a cool place fairly well lighted. In such places it may be kept several months in good condition.

Mucor may be obtained by placing old bread, etc., or horse dung, in a moist covered vessel. In the course of a week there should be an abundance of the mycelium and gonidia. From this material cultures may be made, if desired, in nutrient gelatin or nutrient agar.

Saprolegnia, or water mould, can be used for a study of protoplasm. Collect several dead house flies from window sills of neglected rooms. Immerse them in alcohol, then rinse in water to remove the alcohol. Then throw them in vessels of water containing freshly collected algæ from several different places. In the course of a week there should be a tuft of whitish threads of the water mould surrounding the fly.

Nitella is obtained in rather deep pools or ponds, or in slowrunning water, at a depth of one to three feet usually.

Stamen hairs or tradescantia can usually be obtained in greenhouses from flower buds just ready to open or just after opening.

Edogonium is often found in floating mats in ponds, or on the margins of slow-running streams, or of lakes. Frequently it is attached to other aquatic plants. Fruiting plants can be 
detected by certain of the cells being rounded and broader than others, and some of them at least usually containing the spores, a single spore nearly or quite filling the large cell, or oogonium. When it cannot be studied fresh it may be preserved in $2 \%$ formalin or in $70 \%$ alcohol, first placing it successively in $25 \%$ and $50 \%$ alcohol for a few hours.

Some species of vaucheria occur in places frequented by œdogonium or spirogyra, while others occur in running water, or still others on damp ground. Frequently fine specimens of vaucheria in fruit may be found during the winter growing on the soil of pots in greenhouses. The jack-in-the-pulpit, also known as Indian turnip, growing in damp ground I have found when potted and grown in the conservatory yields an abundance of the vaucheria, probably the spores of the alga having Been transferred with the soil on the plants. When material cannot be obtained fresh for study, it may be preserved in advance in formalin or alcohol as described for œdogonium.

Coleochæte scutata is not so common as the œdogonium, spirogyra, or vaucheria. But it may be sometimes found with the small circular green disks adhering to rushes, grasses, or other aquatic plants in large ponds or on the margins of lakes. When found it is well to make permanent mounts of material killed in formalin, either in glycerine or glycerine jelly.

Wheat rust. - The cluster-cup stage may be collected in May or June on the leaves of the barberry. Some of the affected leaves may be dried between drying-papers. Other specimens should be preserved in $2 \%$ formalin or in $70 \%$ alcohol. If the cluster cup cannot be found on the barberry, other species may be preserved for study.

The uredospore and teleutospore stages can usually be found abundantly on wheat and oats, especially on late-sown oats which ripen in autumn. The affected leaves and stems may be preserved dry.

The powdery mildews are common during summer and autumn on a variety of leaves of shrubs, herbs, and trees. They can be recognized by the mildewed spots, or by the numerous 
minute black specks on the surface of the leaf. The leaves should be preserved dry after drying under pressure.

\section{Liverworts.}

Marchantia.-The green thallus (gametophyte) of marchantia may be found at almost any season of the year along shady banks washed by streams, or on the wet low shaded soil. Plants with the cups of gemma are found throughout a large part of the year. They are sometimes found in greenhouses, especially where peat soil from marshy places is used in potting. In May and June male and female plants bear the gametophores and sexual organs. These can be preserved in $2 \frac{1}{2} \%$ formalin or in $70 \%$ alcohol. If one wishes to preserve the material chiefly for the antheridia and archegonia a small part of the thallus may be preserved with the gametophores, or the gametophores alone.

In July the sporogonia mature. When these have pushed out between the curtains underneath the ribs of the gametophore, they can be preserved for future study by placing a portion of the thallus bearing the gametophore in a tall vial with $2 \%$ formalin. Plants with the sporogonia mature, but not yet pushed from between the curtains on the under side, can be collected in a tin box which contains damp paper to keep the plants moist. Here the sporogonia will emerge, and by examining them day by day, when some of the sporogonia have emerged, these plants can be quickly transferred to the vials of formalin before the sporogonia have opened and lost their spores. In this condition the plant can be preserved for several years for study of the gross character of the sporogonia and the attachment to the gametophyte. From some of the other plants permanent mounts in glycerine jelly may be made of the spores and elaters.

Riccia.-Riccia occurs on muddy, usually shaded ground. Some species float on the surface of the water. It may be preserved in $2 \%$ formalin or $70 \%$ alcohol.

Cephalozia, ptilidium, bazzania, jungermannia, frullania, and other foliose liverworts may be found on decaying logs, on the 
trunks of trees, in damp situations. They may be preserved in formalin or alcohol. Some of the material may also be dried under pressure.

Mosses are easily found and preserved. Male and female plants for the study of the sexual organs should be preserved in formalin or alcohol. In all these studies whenever possible living material freshly collected should be used.

\section{Ferns.}

For the study of the general aspect of the fern plant, polypodium, aspidium, onoclea, or other ferns may be preserved dry after pressure in drying sheets. A portion of the stem with the leaves attached should be collected. These may be mcanted on stiff cardboard for use. The sporangia and spores can also be studied from dried material, but for this purpose the ferns should be collected before the spores have been scattered, but soon after the sporangia are mature. But when greenhouses are near it is usually easy to obtain a few leaves of some fern when the sporangia are just mature but not yet open. To prevent them from opening and scattering the spores in the room before the class is ready to use them, immerse the leaves in water until ready to make the mounts; or preserve them in a damp chamber where the air is saturated with moisture.

For study of the prothallia of ferns, spores should be caught in paper bags by placing therein portions of leaves bearing mature sporangia which have not yet opened. They should be kept in a rather dry but cool place for one or two months. Then the spores may be sown on well-drained peat soil in pots, and on bits of crockery strewn over the surface. Keep the pots in a glass-covered case where the air is moist and the light is not strong. If possible a gardener in a conservatory should be consulted, and usually they are very obliging in giving suggestions or even aid in growing the prothallia.

Lycopodium, equisetum, selaginella, isoetes, and other pteridophytes desired may be preserved dry and in $70 \%$ alcohol.

Pines. - The ripe cones should be collected before the seeds 
scatter, and be preserved dry. Other stages of the development of the female cones should be preserved either in $70 \%$ alcohol or in $2 \frac{1}{2} \%$ formalin. The male cones should be collected a short time before the scattering of the pollen, and be preserved either in alcohol or formalin.

Angiosperms. - In the study of the angiosperms, if it is desired to use trillium in the living state for the morphology of the flower before the usual time for the appearance of the flower in the spring, the root-stocks may be collected in the autumn, and be kept bedded in soil in a box where the plants will be subjected to conditions of cold, etc., similar to those under which the plants exist. The box can then be brought into a warm room during February or March, a fëw weeks before the plants are wanted, when they will appear and blossom. If this is not possible, the entire plant may be pressed and dried for the study of the general appearance and for the leaves, while the flower may be preserved in $2 \frac{1}{2} \%$ formalin, of course preserving a considerable quantity. Other material for the study of the plant families of angiosperms may be preserved dry, and the flowers in formalin, if they cannot be collected during the season while the study is going on.

Demonstrations.-Upon some of the more difficult subjects in any part of the course, especially those requiring sections of the material, demonstrations may be made by the teacher. The extent to which this must be carried will depend on the student's ability to make free-hand sections of the simpler subjects, upon the time which the student has in which to prepare the material for study, and the desirability in each case of giving demostrations on the minuter anatomy, the structure of the sexual organs and other parts, in groups where the material should be killed and prepared according to some methods of precision, now used in modern botanical laboratories. The more difficult demonstrations of this kind should be made by the instructor, and such preparations once made properly can be preserved for future demonstrations. Some of them may be obtained from persons who prepare good slides, but in such cases fancy preparations of 
curious structures should not be used, but slides illustrating the essential morphological and developmental features. Directions for the preparation of material in this way cannot be given, in this elementary book, for want of space.

Method of taking notes, etc.-In connection with the practical work the pupil should make careful drawings from the specimens; in most cases good outline drawings, to show form, structure etc., are preíerable, but sometimes shading can be used to good advantage. It is suggested that the upper $2 / 3$ of a sheet be used for the drawings, which should be neatly made and lettered, and the lower part of the page be used for the brief descriptions, or names of the parts. The fuller notes and descriptions of the plant, or process, or record of the experiment should be made on another sheet, using one, two, three, or more sheets where necessary. Notes and drawings should be made only on one side of the sheet. The note-sheets and the drawing-sheets for a single study, as a single experiment, should be given the same number, so that they can be bound together in the cover in consecutive order. Each experiment may be thus numbered, and all the experiments on one subject then can be bound in one cover for inspection by the instructor. For example, under protoplasm, spirogyra may be No. I, mucor No. 2, and so on. In connection with the practical work the book can be used by the student as a reference book; and during study hours the book can be read with the object of arranging and fixing the subject in the mind, in a logical order.

The instructor should see that each student follows some wellplanned order in the recording of the experiments, taking notes, and making illustrations. Even though a book be at hand for the student to refer to, giving more or less general or specific directions for carrying on the work, it is a good plan for every teacher to give at the beginning of the period of laboratory work a short talk on the subject for investigation, giving general directions. Even then it will be necessary to give each individual help in the use of instruments, and in making preparations for study, until the work has proceeded for some time, 
when more general directions usually answer. The author does not believe it a good plan for the student to have written, minute, directions for preparing the plants and experiments. General directions and specific help where there is difficulty, until the student learns to become somewhat independent, seems to be a better plan.

\section{APPARATUS AND GLASSWARE.}

The necessary apparatus should be carefully planned and be provided for in advance. The microscopes are the most expensive pieces of apparatus, and yet in recent years very good microscopes may be obtained at reasonable rates, and they are necessary in any well-regulated laboratory, even in elementary work.

Microscopes. The number of compound microscopes will depend on the number of students in the class, and also on the number of sections into which the class can be conveniently divided. In a class of 60 beginning students $I$ have made two sections, about 30 in each section; and 2 students work with one microscope. In this way 15 microscopes answer for the class of 60 students. It is possible, though not so desirable, to work a larger number of students at one microscope. Some can be studying the gross characters of the plant, setting up apparatus, making notes and illustrations, etc., while another is engaged at the microscope with his observations.

The writer does not wish to express a preference for any pattern of microscope. It is desirable, however, to add a little to the price of a microscope and obtain a convenient working outfit. For example, a fairly good stand, two objectives ( $2 / 3$ and $I / 6)$, one or two oculars, a fine adjustment, and a coarse adjustment by rack and pinion, and finally a revolver, or nosepiece, for the two objectives, so that both can be kept on the microscope in readiness for use without the trouble of removing one and putting on another. Such a microscope, which I have 
found to be excellent, is Bausch \& Lomb's AAB (which they recommend for high schools), costing about $\$ 25.00$ to $\$ 28.00$. I have compared it with some foreign patterns, and the cost of these is no less, duty free, for an equivalent outfit. Of course, one can obtain a microscope for $\$ 18.00$ to $\$ 20.00$ without some of these accessories, but I believe it is better to have fewer microscopes with these accessories than more without them. Of the foreign patterns the Leitz (furnished by Wm. Krafft, 4 I I W. 59th St., N. Y.) and the Reichert are gcod, while Queen \& Co., Philadelphia, Pa., and Bausch \& Lomb, Rochester, N. Y., furnish good American instruments.

Glass slips, $3 \times \mathrm{I}$ inch; and circle glass covers, thin, $3 / 4 \mathrm{in}$. diameter.

Glass tubing of several different sizes, especially some about $5 \mathrm{~mm}$ inside diameter and $7 \mathrm{~mm}$ outside measurement, for rootpressure experiments.

Rubber tubing to fit the glass tubing, and small copper wire to tighten the joints.

Watch glasses, the Syracuse pattern (Bausch \& Lomb), are convenient.

$\mathrm{U}$ tubes, some about $20 \mathrm{~mm}$ diameter and $10-15 \mathrm{~cm}$ long. Corks to fit.

Small glass pipettes ("medicine droppers") with rubber bulbs.

Wide-mouth bottles with corks to fit. Reagent bottles. (Small ordinary bottles about $10 \mathrm{~cm} \times 4 \mathrm{~cm}$ with cork stoppers will answer for the ordinary reagents. The corks can be perforated and a pipette be kept in place in each ready for use. Such bottles should not be used for strong acids.)

Small vials with corks for keeping the smaller preparations in. Small glass beakers or tumblers.

A few crockery jars for water cultures.

Fruit jars for storing quantities of plant material.

Glass graduates; I graduated to $1000 c c$, I graduated to 1 $000 \mathrm{c}$.

Funnels, small and medium ( 6 and $10 \mathrm{~cm}$ in width). 'Test 
tubes. A few petrie dishes. Bell jars, a few tall ones and a few low and broad. Thistle tubes. Chemical thermometer.

Balance for weighing. A small hand-scale furnished by Eimer \& Amend, 205-2 I I 3d Ave., N. Y., is fairly good (\$2.00).

For pot experiments, the "Harvard trip-scale," Fairbanks Scale Co. (about \$6.00).

Apparatus stand, small, several, with clamps for holding test tubes, $\mathrm{U}$ tubes, etc.

Agate trays, very shallow, several centimeters long and wide. Agate pans, deep, for use as aquaria, etc., with glass to cover.

Paraffin or wax, for sealing joints in setting up transpiration apparatus.

Mercury, for restoration of turgidity, and for lifting power of transpiration.

Sheet rubber, or prepared vessels for enclosing pots to prevent evaporation of water from surface during transpiration experiments.

Litmus paper, blue, kept in a tightly stoppered bottle. Filter paper for use as absorbent paper. Lens paper (fine Japanese paper) for use in cleaning lenses; benzine for first moistening the surface, and as an aid in cleaning.

For materials for culture solution, see Chapter III.

\section{REAGENTS.}

Glycerine, alcohol of commercial (95\%) strength, formalin or formalose of $40 \%$ strength, chloral hydrate crystals, iodine crystals, eosin crystals, fuchsin crystals, potassium iodide, potassium hydrate, potash alum. It is convenient also to have on hand some ammonia, sulphuric acid, nitric acid, and muriatic acid in small quantity.

REAGENTS READY FOR USE AND FOR STORING PLANT MATERIAL IN.

Alcohol. Besides the $95 \%$ strength, strengths of $30 \%, 50 \%$, and $70 \%$, for killing material and bringing it up to $70 \%$ for storage. 
Formalin. Usually about a $2 \frac{1}{2} \%$ is used for storing material, made by taking $97 \frac{1}{2}$ parts water in a graduate and filling in $2 \frac{1}{2}$ parts of the $40 \%$ formalin.

Salt solution 5\%; sugar solution I $5 \%$ (for osmosis).

Iodine solution. Weak-to $300 \mathrm{cc}$ distilled water add 2 grams iodide of potassium ; to this add I gram iodine crystals.

Strong-use less water.

Eosin. Alcoholic solution. Distilled water 5occ, alcohol $50 c c$, eosin crystals $\frac{1}{5}$ gram, potash alum 4 grams.

Aqueous solution. Distilled water I oocc, eosin crystals I gram.

Chloral hydrate; aqueous solution, nearly sat. sol.

Schimper's solution. Chloral hydrate 5 parts, water 2 parts, iodine to make a strong color.

\section{STUDENT LIST OF APPARATUS.}

Several glass slips $3 \times \mathrm{I}$ inch, and more circle glass covers, thin and $\frac{3}{4}$ inch diameter.

One scalpel.

One pair forceps, fine points.

Two dissecting needles (may be made by thrusting with aid of pincers a sewing needle in the end of a small soft pine stick).

Lead-pencils, one medium and one hard.

Note paper; a good paper, about octavo size, smooth, unruled, with two perforations on one side for binding. Several manila covers or folders to contain the paper, perforated also. Enough covers should be provided so that notes and illustrations on different subjects can be kept separate.

\section{REFERENCE BOOKS.}

The following books are suggested as suitable ones to have on the reference shelves, largely for the use of the teacher, but sev- 
eral of them can with profit be consulted by the students also. There are a number of other useful reference books in German and French, and also a number of journals, which might be possessed by the more fortunate institutions, but which are too expensive for general use, and they are not listed here.

Kerner and Oliver, Natural History of Plants. Blackie \& Son, London, I895. Henry Holt \& Co., New York, I 895.

Strasburger, Noll, Schenck \& Schimper, A Text Book of Botany, translated by Porter. The Macmillan Co., New York, I 898 .

Vines, Student's Text Book of Botany. The Macmillan Co., New York, I 895 .

Atkinson, The Biology of Ferns. The Macmillan Co., New York, 1894 .

MacDougal, Experimental Plant Physiology. Henry Holt \& Co., New York, I 895.

Spalding, Introduction to Botany. D. C. Heath \& Co., Boston, I 895 .

Bessey, Essentials of Botany. Henry Holt \& Co., New York.

Goebel, Outlines of Classification and Special Morphology of Plants. Oxford, Clarenden Press, I 887.

Warming \& Potter, Hand Book of Systematic Botany. Macmillan \& Co., New York, I895.

DeBary, Comparative Morphology and Biology of the Fungi, Mycetozoa, and Bacteria. Oxford, Clarenden Press, I 887.

Underwood, Our Native Ferns and their Allies. Henry Holt \& Co., New York.

Bailey, Lessons in Plants. Macmillan \& Co., New York, I 898 .

Gray, Lessons and Manual of Botany. American Book Co., New York.

Müller, The Fertilization of Flowers. Macmillan \& Co., New York.

Darwin, Insectivorous Plants. D. Appleton \& Co., New York. 
Darwin, The Power of Movement in Plants. D. Appleton \& Co., New York.

Darwin, Cross and Self Fertilization in the Vegetable Kingdom. D. Appleton \& Co., New York.

Warming, Oekologische Pflanzengeographie. Gebrüder Bornträger, Berlin.

Papers by Macmillan in the Bulletin of the Torrey Botanical Club and Minn. Bot. Studies, by Shaler in the 6th, Ioth, and I 2 th Annual Reports of the United States Geological Survey, and by Ganong in Trans. Roy. Soc. Canada, sec. ser. vol. 3, I $897-98$, should be consulted by those interested in ecology.

Where materials cannot be readily collected in the region for class use, they can often be purchased of supply companies.

The Cambridge Botanical Supply Co., Cambridge, Mass., supplies plant material of several groups for study, as well as apparatus and paper.

The Ithaca Botanical Supply Co., Ithaca, N. Y., will supply plants for study in various groups, and upon order will prepare permanent slides for demonstration of the more difficult topics, such as the structure of the sexual organs of liverworts, mosses, ferns, etc. 


\section{INDEX.}

Absorption, I3

Aceraceæ (A-cer-a ce-æ), 273, 275,298

Acer saccharinum (A'cer saccha-ri'num), 275

Adder tongue, formation of flower, 349

Adiantum (A-di-an'tum), I69, I73

Adiantum concinnum, spermatozoids of, I8I; embryo, I84, I85

Adiantum cuneatum, fertilization, I82; embryo, 186

Ecidiospore (Æ-cid'i-o-spore), I3I

Ecidium (Æ-cid'i-um), I32

Æsculinæ (Æs-cu-lin’æ), 273, 297

Agaricus campestris (A-gar'icus cam-pes'tris), I36, 326-331

Agaricus melleus, 338

Aggregatæ, 290, 299

Alga, Algæ, 2

Alismaceæ (A-lis-ma'ce-æ), 254, 255

Alisma plantago, 254

Amanita phalloides (Am-a-ni'ta phal-loi'des), 334, 335

Almond (family), 276

Amygdalaceæ (A-myg-da-la' (e-æ), 276, 295, 298

Anemophilous, 353

Angiosperms, comparative table of, 238

Angiosperms, morphology of, $221-236$

Antheridiophores, I45

Antheridium, of vaucheria, I07; œdogonium, IOI, IO2; coleochæte, II2; saprolegnia, I23; erysiphe, I38; liverworts, I4I, I45, I46; mosses, I60, I6I; ferns, I80, I8I; selaginella, I94; isoetes, 198

Antipodal cells, 23r, 233

A pogamy, 245
Apogeotropic (Ap-o-ge-ot'ropic), 83

A pogeotropism (Ap-o-ge-ot'ropism), 83

Apospory, 245

Apple, 276

Araceæ (A-ra'ce-æ), 257, 294, 296

Archegonia (Ar-che-go'ni-a) of liverworts, I4I, I42, I55, I56; mosses, I60, I6I: ferns, I76, I8I, I82; selaginella, I95; isoetes, I98; gy mnos perms, 2 IO, 2 I I Archegoniophore, 147

Archesporium (Ar-che-spor'ium), I 53, 239

Arisæma triphyllum (Ar-i-sæ'ma tri-phyl'lum), 257; germination of, and embryo, 3II, 3I3; pollenation of, $360,36 \mathrm{I}$

Asclepias cornuti (As-clep'i-as cor-nu'ti), dissemination of seed, 372

Ascomycetes (As-co-my-ce'tes), I38, I39

Ascospore, I37-I39

Ascus (pl. Asci), I37-r 39

Ash (American), 304

Aspidium acrostichoides, I65, I72, 177

Aspidium spinulosum, I68

Asplenium bulbiferum, I74, I75. 239

Aster novæ-angliæ, 290, 29I

Atoll, made by plants, 386

Azalea, 4I I

Bacteria, nutrition of, $32 \mathrm{I}$

Bald cypress, 395,396

Basidiomycetes (Ba-sid-i-o-myce'tes), 136, I39

Bast, 44; fibres, 48; parenchyma, 48

Batrachospermum (Ba-tra-chosper'mum), I 6 
Bean, germination of, 307,308

Beet, osmose in, I5, I6, I7, I8

Bell flower, 289

Bicornes, 283, 284, 298

Bidens, seed of, 368

Bindweed, 284

Black rust, I29

Black spruce moor, 390

Blasia, 155

Bloodroot, 271

Blue-green algæ, II 8

Bluet, pollenation of, 354,355

Borage, 285

Boraginaceæ (Bor-ag-i-na'ce-æ), 285,299

Buckwheat, 267

Bur marigold, seeds of, 368

Brown algæ, II 5 , II 8

Bryony, tendril of, 88

Butomus, 255

Callithamnium, II9

Caltha palustris, 268, 269

Cambium, 44, 48

Campanula, 289; pollenation of, 362

Campanulaceæ, 289, 299

Campanulinæ, 289, 299

Canna, pollenation of, $363-367$

Caprifoliaceæ (e-æ), 288, 296, 299

Carbon conversion, 59, 6I, 67, 68; rays of light concerned in, 67

Carbon dioxide, absorption of, $5 \mathrm{I}$; loss of, 54

Carbon, food of plants, 59-64

Carex laxiflora, 26r

Carex lupulina, 260

Carnation rust, 323,324

Castor oil bean, germination of, 308,309

Cattails, 257

Cell, 3

Cell sap, 3

Cephalozia (Ceph-a-lo'zi-a), r 55

Chætophora (Chæ-toph'o-ra), I03

Champia, I 9

Chiamydospores (Chlam-yd'ospores), of mucor, 123

Chlorophyceæ (Chlo-ro-phy'ceæ), I1 8

Chlorophyll, 2. 65-69; band, 2; bodies, 66; movement of chlorophyll bodies, 68,69
Chloroplastid, 67

Chloroplasts, 66, 68; starch formed in, 68

Choke cherry, 276, 277

Christmas fern, I65-I67

Chromatin, 240

Chromatin skein, 24I

Chromoplasts, 68

Chromosomes, 24I-243

Claytonia virginiana, 267

Cleistogamous, 353, 354

Clematis virginiana, 269,270 : disseminatlon of seed, 372,373

Closterium, 98

Cosmarium, 98

Club mosses, I9I-I95

Cluster cup, I3I, I32, I35

Coleochæte (Co-le-o-chæ te), IIoII 3

Coleochæte scutata, IIO, II 2

Coleochæte soluta, II 2

Columella, of rhizopus, I2I, I23

Compositæ, 290, 296, 299

Conferva, IO3

Confervoideæ (Con-fer-voi'de-æ), I03, II 8

Conjugatæ (Con-ju-ga tæ), 98, II 8

Conjugation, 94, 96

Contortæ, 287

Convolvulaceæ (Con-vol-vu-la' (e-æ), 284, 299

Convolvulus (Con-vol'vu-lus), 284,285

Cortex, 44

Cruciferæ (Cru-cif'er-æ), 272, 295, 297

Cupuliferæ (Cu-pu-lif'er-æ), 263, 294,296

Curvembryæ (Curv-em'bry-æ), 268, 297

Cuticularized, 37

Cyanophyceæ (Cy-an-o-phy'ceæ), 118

Cycas, 2I4-2I7 (see also frontispiece.)

Cyclosis (Cy-clo'sis), 9

Cyperaceæ (Cy-per-a'ce-æ), 259261,296

Cypress knees, 396

Cypripedium, 36r, 365

Cytisus (Cy-ti'sus), scattering of pollen, 363

Cystocarp, II6-II9

Cystopteris bulbifera, 174 
Cystopus candidus, haustoria of, 324

Cytoplasm (Cy'to-plasm), 5

Daucus carota, 28I

Dentaria, 221, 225, 227

Desert vegetation, characters of. 419

Desmids, 98

Desmodium (Des-mo'di-um), dissemination of seeds, 368

Diadelphous (Di-a-del'phous), 272

Diageotropism (Di-a-ge-ot'ropism), 83

Diaheliotropic (Di-a-he-li-ot'ropic), 84,86

Diaheliotropism (Di-a-he-li-ot'ro-pism), 84,86

Dicentra canadensis (Di-cen'tra can-a-den'sis), 271

Dichogamous (Di-chog'a-mous), 360

Dicotyledons, 262-293

Diffusion, I3

Dionæa muscipula (Di-o-næ'a mus-cip'u-la), 90

Dipsacaceæ (Dip-sa-ca'ce-æ), 289, 296, 299

Dipsacales (Dip-sa-ca'les), 289, 299

Dodder, nutrition of, 32 I

Dorsiventral, 88

Downy mildews, 128

Drosera (Dros'e-ra), 90

Duck weeds, 314, 315

Ecology (sometimes written acology), 300-423

Elaters, I50

Embryo, of angiosperms, 232, 235

Embryo sac, 229-233

Endosperm, 209-211, 234, 235

Epidermal system, 48

Epigynous, 255

Epinastic (Ep-i-nas tic), 86

Epinasty (Ep-i-nas'ty), 86

Epipactis, pollenation of, 362,365

Equisetum arvense, $187-189$; gametophyte of, Igo

Equisetum hyemale, 189

Erica, 284

Erythronium americanum (Er-ythro'ni-um), 252, 253; formation of flower, 349
Etiolated plants (E-ti-o-la'ted), 65

Euastrum (Eu-as'trum), 98

Eupatorium purpureum (Eu-pato'ri-um pur-pu're-um), 405

Evaporation, 35,36

Evening primrose, 279, 280

Ferns, I65-I86; dimorphism of, $340-345$

Fertilization, in fucus, II5, II7; œdogonium, IO2; peronospora, I 27 ; saprolegnia, I25 ; spirogyra, 97 ; sphærotheca, I38; vaucheria, I08: picea, 212: angiosperms, 23I-234; cycas, 2I 7

Fibro-vascular system, 48, IIo

Figwort (family), 285

Flagellates, II 9

Florideæ, II 7

Forget-me-not, 286

Fragaria vesca, 275, 276

Frullania, 72, I54, I55

Fucus, II5, II6, II 8

Fumariaceæ (Fu-ma-ri-a'ce-æ), 27 I

Fumitory, 27I

Fundamental system, 48

Fungi, 56,65 ; classification of, I39; nutrition of, 332-337; respiration in, 56; wood destroying, 336,337

Gametangium (Gam-e-tan'gium), 97

Gamete (Gam'ete), 95-97, 107, I09

Gametophore (Gam-e'to-phore), I 45, I47

Gametophyte (Gam-e'to-phyte), I43, I44, I59, I64, I75, I76, I99; of angiosperms, 228 ; significance of, 239-246

Gamopetalous (Gam-o-pet'alous), 284

Gamosepalous (Gam-o-sep'alous), 278,283

Gases, diffusion of, 49-53

Gaylussacia resinosa (Gay-lussa'ci-a), 283,284

Gemmæ of mucor, 22 ; of marchantia, 153

Gentian, 287

Gentiana crinita, 287

Gentianaceæ, 287, 299 
Geotropism (Ge-ot'ro-pism), 82, 84

Geraniaceæ (Ger-a-ni-a'ce-æ), $272,295,297$

Geum, dissemination of seed, 369

Gingko, 216, 218

Glacier (Greenland), 383

Glumifloræ (Glu-mi-flo'ræ), 258, 296

Gonidangium (Go nid-an'gi-um), I 2 I

Gonidiophores, I26, I23

Gonidium (pl. gonidia), 75, 76, I 21,123, I 26,127

Gracillaria, II6, II8, II9

Gramineæ, 258, 294, 296

Ground cherry, 285

Growth, 75-8I

Gruinales, 272, 297

Guttation, 40, 4I

Gymnosperms, 202-220 ; classification of, 2I9; comparative table of, 220

Gynandrous, 255

Hamamelis, 4I4

Haustoria (Haus-to'ri-a), of fungi, 323,324

Heliotropism (He-li-ot'ro-pism), 84,85

Hepaticæ, I40

Heterospory (Het-er-os'po-ry), origin of, $35 \mathrm{I}-353$

Hickory, opening buds, 4I 5

Hieracium venosum, 292

Holdfasts, 93, 98, II 5

Honeysuckle, 288

Horse-chestnut, 302, 303

Horsetails, I87-I9o

Houstonia cœrulea, 287

Huckleberry, 283

Hydnum, 337, 338

Hydrotropism (Hy-drot'ro-pism), 90

Hypocotyl (Hy-po-cot'yl), 307, 308

Hyponastic (Hy-po-nas'tic, 86

Hyponasty (Hy-po-nas'ty), 86

Impatiens fulva, 370

Indian corn, osmose in cells of, I6

Indian-pipe, 283; mycorhiza of, 320
Indian turnip, 3II, 313: formation of flower, 349

Indusium, I66, I70

Inferior ovary, 255

Insectivorous plants, 90

Integument, 209

Irritability, 82-92

Isoetes (I-so'e-tes), I96-I99; habitat of, 395

Isopyrum biternatum, 270

Jack-in-the-pulpit, 3II, 3I3, 349, 350

Jamin's chain, 48

Jungermannia ni-a), I56, 157

Kalmia latifolia, 362, 4I3

Karyokinesis, 240-244

Kinetic energy, 67

Kinoplasm, 24I

Labiatæ, 286, 295, 299

Lactuca canadensis, dissemination of seed, 370,371

Lactuca scariola, dissemination of seed, 370. 371 ; paraheliotropism, 88

Lamium amplexicaule, 286

Leaf, epidermis of, 37 ; structure of, $36-38$

Leguminosæ, 278,298

Lemanea, II 6

Lemna trisulca, nutrition of, 314

Lepiota naucina, 335

Lettuce, prickly, dissemination of seed, 370, 371; wild, 370, 371

Leucoplasts, 68

Lichens, nutrition of, 316-318; soil formation by, $38 \mathrm{r}, 384$

Ligula, 29I

Liliaceæ, 25 I-253, 294, 296

Linin, 240

Linnæa borealis, 288,289

Liquids, movement of in plants, $42-48$

Liverworts, I40; nutrition of, $70-72$

Lodicules, 259

Lonicera ciliata, 288

Lycopodium cernuum, 193

Lycopodium clavatum, I9I, 192

Lycopodium lucidulum, 192

Lycopodium phlegmaria, 193 
Macrosporangium, 194-199; of pine 207, 209; of cycas, 214; of trillium, 224

Macrospore, I94-I99; of angiosperms, 229

Maple, 273, 274

Marattia, fertilization, 182

Marchantia, nutrition of, 70, 7I; structure and development, I $44-153$

Marsh marigold, 268, 269

Medicago denticulata, 3 I 9

Medulla, 44

Micrasterias (Mi-cras-te'ri-as), 98

Microsomes (Mi'cro-somes), 6

Microsphæra (Mi-cro-sphæ'ra), I38

Microspore, I94, I97, I99; of pine, 204 ; of cycas, 215 ; of trillium, 223

Milkweed, dissemination of seed, 372

Mint family, 286

Mitchella repens, 288

Mnium affine (Mni'um af'fi-ne), 72,74, I 58-I6I

Monaster, 24I

Monocotyledons, 25I-26I, 294, $290^{\circ}$

Monotropa, 283

Morning glory, 284

Mosses, nutrition of, 72 ; structure of, $158-I 63$

Mougeotia (Mou-ge-o'tia), 98

Moulds, nutrition of, 322

Mucor, 6-8, I20-123; osmose in, I5: mycelium, 6

Mushrooms I36; studies of, 326337: poisonous, 334,335

Mustard, 272

Mutualism, 318

Mycelium 6, 76, I21, I36; sterile in coal mines, 325,326

Mycorhiza, 320

Myrtifloræ, 280, 298

Nettle (diœcious), 265

Nightshade (family), 285, 299

Nitella, 8, 9

Nitrogen, gathered by plants, 318

Nostoc, II 8

Nucellus, 209-2II

Nuclear plate, $2+\mathrm{r}$
Nuclear spindle, $24 \mathrm{I}$

Nucleolus, 4

Nucleus 3 ; morphology of, 239244

Nuculiferæ, 286

Nutation, 8o

Nutrient solution, 22

Nutrition, means for, 70-72; further studies in, 3I 4

Oak, 263

Oat, 258

(Edogonium (E-do-go'ni-um), 99-IO3

Enothera biennis, 279, 280

Onoclea sensibilis (On-o-cle'a sen-sib'i-lis), rhizome, I68; dimorphism of, 340-345

Onograceæ, 280, 298

Oogonium (O-o-go'ni-um), 99, IOO, I02, I07, IO8, II2, I 23, I24, I 27

Oospore, I00, I08, I 28

Orchidaceæ, 255, 256, 296

Orchids, pollenation of, $360-363$

Oscillatoria (Os-cil-1a-to' ri-a), I 8

Osmose, 13, I8

Ostrich fern, 345,346

Ovule of pine, 207; of trillium, 224

Oxygen, 5I, 52, 54

Palisade cells, 37

Palms, 257; cocoanut palms, 257

Papaveraceæ, $27 \mathrm{I}$

Papilionaceæ, 278, 295, 298

Pappus, 29I

Paraheliotropic, 88

Paraheliotropism(Par-a-he-li-ot'ro-pism), 90

Parasitic fungi, nutrition of, 322 , 323

Parenchyma, 44, 48

Parmelia, fruit of, 318

Parsley, 28I

Parthenogenesis, 127

Partridge berry, 288

Passiflorinæ, 298

Pea (family), 278

Pear, 277

Peltigera, 316, 317

Pepper, 235

Pepper root, 225

Perigynium, 260 
Perigynous, 275

Perisperm 234

Perithecium, I36-I38

Peronospora alsinearum (Per-onos'po-ra al-sin-e-a'rum), I25, I27, 128

Peronospora calotheca, haustoria of, 324

Personatæ, 285, 299

Petaloideæ (Pet-al-oi'de-æ), 25 I, 296

Phæophyceæ (Phæ-o-phy'ce-æ), I I 5, II 8

Phloem (Phlo'em), 45, 47, 48

Photosyntax, 6I

Photosynthesis, 6I

Phycomycetes (Phy-co-my-ce'tes), I 28

Phyllotaxy, 306

Phytophthora infestans (Phytoph'tho-ra in-fes'tans), I26, I27, 128

Picea vulgaris, 2I2; fertilization in, 212

Pine, new growth, $4 \mathrm{I} 6$

Pine, white, 202-213

Pines, reforestation by, 378,379

Pinus strobus, 202-22O

Piper nigrum endosperm and perisperm of, 235

Plant body, 72, 73; members of, 73,74 ; leaf series, 74 ; stem series, 73 ; root, 74

Plant communities, 4 Io

Plasmolysis (Plas-mol'y-sis), I9

Plasmopora viticola (Plas-mop'ora vi-ti'co-la), I25, I26, I 28

Platycerium alcicorne, 345

Pleurococcus (Pleu-ro-coc'cus), I 8 , I I9

Plum (family), 276

Plumule, 308

Podophyllum peltatum, 229-231 ; karyokinesis in, 240-243

Pollen, of pine, 204: of cycas, 215 ; of trillium, 223

Pollenation, 35I-367; of pine, 206, 208

Polycarpicæ (Pol-y-car'pi-cæ) 268, 297

Polygonaceæ (Po-lyg-o-na'ce-æ), 267, 297

Polygonifloræ, 267, 297

Polygonum sagittatum, 267
Polymorphic, 135

Polypetalous, 278

Polypodium vulgare, I70, 239

Polyporus (Pol-yp'o-rus), 338

Pomaceæ, 276, 295, 298

Pontederia, 406

Poppy (family), 27I

Porella, 155

Portulacaceæ, 268, 297

Potential energy, 67

Powdery mildews, 136

Primrose, 355, 356

Primula, 284; pollenation of, 356

Primulaceæ, 284, 299

Primulinæ, 284, 299

Procambium strands, 47

Progeotropism (Pro-ge-ot ropism), 82, 83

Promycelium (Pro-my-ce li-um), I34-I 36

Proterandrous, 360

Proterandry, 362

Proterogynous, 360

Prothallium, of ferns, 176-182; of pine, 209, 210; of cycas, 214. 215; of angiosperms, 228-233

Protococcoider (Pro-to-coc-coi'de-æ), II8, II9

Protococcus (Pro-to-coc'cus), II 8 , II 9

Protonema (Pro-to-ne'ma), I63, I $78, \mathbf{1} 80$

Protoplasm, I-I2; movement of, 7-II

Prunus virginiana, 277

Pteridophyta (Pter-i-doph'y-ta), 200, 201

Pteris aquilina, 178

Pteris cretica, 245

Pteris serrulata, spores of, 177 ; embryo of, 183,186

Puccinia graminis, $129-136$

Pumpkin, roots of, 77,78

Pumpkin seed, germination of, 309-3I I

Purslane, 268

Pyrenoid, 2

Pyrolaceæ, 283, 299

Pyrola elliptica, 283

Quercus rubra, 263

Quillworts, $196-198$

Ranunculaceæ, 268, 294, 297 
Rattlesnake-weed, 292

Red aigæ, II6, II9

Red rust, I 29

Red-snow plant. II8, II9

Reforestation of lands, 376, 379

Respiration, 54-58; intramolecular, 58

Rhabdonia (Rhab-do'ni-a), II7, II 9

Rhizoids (Rhi'zoids), 7I, 72

Rhizome, of trillium. $22 \mathrm{I}$

Rhizomorphic (Rhi-zo-mor'phic), 325

Rhizopus nigricans (Rhi'zo-pus ni'gri-cans), I 20-I 23

Rhododendron nudicaulis, 4II

Rhodophyceæ (Rho-do-phy'ceæ), I 6,119, I39

Rhœadineæ, 271, 297

Rock lichens, 382-384

Root hairs, 24; absorption by, I9, 25. 26; acidity of, 27 ; corrosive action of, 27

Root pressure, 3I, 32, 39, 40 ; periodicity of, 32; variation of, 32

Root tubercles, 318

Rosa, 276

Rosaceæ, 275, 295, 298

Rose (family), 275

Rosifloræ, 275, 298

Rubiales, 288

Rubus odoratus, 275,276

Russian thistle, 268

Rusts, I 29

Sac fungi, $136-138$

Sagittaria, 255

Sagittaria heterophylla, 402-404

Sagittaria variabilis, 400, 404

Salicaceæ, 262, 294, 296

Salsola soda, 268

Sand dunes, vegetation of, 376

Sanguinaria canadensis, $27 \mathrm{I}$

Saprolegnia, I23-I 26

Saxifraga virginiensis, 274

Saxifragaceæ, 274, 298

Saxifraginæ, 274, 298

Scorophulariaceæ, 285. 299

Seeds, distribution of, 368,373

Selaginella, 193-195, 199-20I

Sensitive fern, dimorphism of, 340-346

Sensitive plants, 89,90
Silkweed, dissemination of seeds, 372

Silphium laciniatum, 88

Siphoneæ (Si-pho'ne-æ), Io9, Ir8

Skunk's cabbage, 356,357

Soil formation, $38 \mathrm{I}-388$

Solanaceæ, 285, 299

Sorus, of ferns. I66, I70, 173

Spadicifloræ, 257, 296

Spadix, 257

Spartium, scattering of pollen, 364

Spathe, 257

Spathyema fœtida, 257

Spectrum, bands in, 67 ; absorption bands of, 67

Spermagonia, I32

Spermatia, I32

Spermatozoids in gymnosperms, 2I6-2I9

Sperm cells, I 46

Sphærella nivalis (Sphæ-rel'la ni-va'lis), I 8

Sphærotheca (Sphæ-ro-the'ca), I38

Sphagnum in moors, 386-394; structure of leaves, 394

Spiderwort, II

Spirodela polyrrhiza, 3I 5

Spirogyra, 2, 93-98

Spơrangium, of ferns, I67-I75

Spores, of riccia, I43; of ferns, I69-I72; of equisetum, I88

Sporidium, J34, 136

Sporocarp, II 2 , II 3

Sporogonium (Spor-o-go'ni-um) of riccia. I42 ; of marchantia, I49, I5O; of foliose liverworts, I55-157; of mosses, I6I, I62

Sporophyte (Spor'o-phyte), I43, I 44, I $50,152,156$, I 57 , I59, I64. I75, I82, I99; of angiosperms, 228 ; significance of, $239-246$

Squirrel corn, 27 I

Staghorn fern, 345

Starch, 59; test for, 59, 60; translocation of, 6r; where found, $60,6 \mathbf{I}, 63$

Starch grains, form of, 63

Staurastrum (Stau-ras'trum), 98

Sterigma, I34

Stoma (pl. Stom'a-ta), 38 ; action of, 39 ; demonstration of, $4 \mathrm{I}$

Strobilus, I92 
Sundew, 90

Symbiosis, 318

Sympetalæ, 283,298

Synergids (Syn-er'gids), 23I, 233

Taxodium distichum, 395

Teasel, 289

Teleutospore, I30, I35

Temperature, $9 \mathrm{I}, 92$

Tensions, tissue, 29, 30

Tetraspores, II 7

Tissues, synopsis of, 48

Touch-me-not, dissemination of seed, 370

Transpiration, 33-4I

Trichomes, 48

Trillium erectum, 25I

Trillium grandiflorum, 22I-224; formation of flower, 347,348

Tubifloræ, 284, 299

Turgescence, 14,28

Turgescent, I5

Turgid, I5

Turgidity, 28 ; restoration of, 28

Twin flower, 289

Ulmaceæ, 266, 294, 297

Umbellifloræ, 28I, 298

Uncinula, 136,138

Unifolium, 254

Uredineæ(U-re-din'e-æ), I29-136, I 39

Uredospore, I3I, I 35

Uromyces caryophyllinus, 323

Urtica, 265

Urticaceæ, 265, 297

Urticifloræ, 265, 297

Vascular bundle, 43 ; structure of, $44-47$

Vaucheria, I05-109

Vaucheria geminata, Io8
Vaucheria sessilis, I06-I07

Vessels, 45, 46

Vetch, root tubercles of, 3I8, 3I9

Vicia sativa, dissemination of seed, 369

Viola cucullata, 354

Violet, endosperm and embryo, 235: pollenation of, 353,354

Virgin's bower, 269, 270; dissemination of seed, 372,373

Volva, 334, 335

Wake robin, 22 I

Walking fern, I73, 4I3

Water moulds, $123-126$

Water plantain, 254

Water vapor, 34

Wheat rust, I29

Whortleberry, 283

Wild carrot, 28I, 282

Willow, 262

Witch hazel, 4I 4

Wolffia, 3I 5

Wood fibres, 48 ; parenchyma, 48

Xanthidium, 98

Xylem, 44, 45, 47, 48

Yellow water lily, 407

Zamia, 219

Zamia integrifolia, 216

Zonal distribution of plants, 400-408

Zoogonidium (Zo-o-go-nid'i-um), IOI, I02, I05, I06

Zoospores, IOI, IO3, III, II 2

Zygnema (Zyg-ne'ma), 98

$Z$ ygomorphic, 289

Zygospore (Zy'go-spore), 2, 95. $97,98,122$

Zygote (Zy'gote), 95, 122 



\title{
SCIENCE
}

\section{REFERENCE AND TEXT-BOOKS}

\author{
PUBLISHED BY \\ HENRY HOLT \& COMPANY,
}

\author{
29 West 23D Street, New York.
}

Books marke * are chiefly for reference and supplementary use, and art to be found in Henry Holt \& Co.'s List of Works in General Literature. For further particulars about books not so marked see Henry Holt \&o Co.'s Descriptive Science Catalogue. Either list free on application. Excepting JAMEs' Psychologies and WalkeR's Political Economies, both in the American Science Series, this list contains no works in Philosophy or Polutical Economy. Postage on net books 8 per cent. additional.

\section{Amerícan \$cience Đeríes}

I. Astronomy. By SimnN Newcomb, Professor in the Johns Hopkins University, and EDWARD S. HOLDEN, Director of the Lick Observatory, California. Advanced Course. 512 pp. 8vo. \$2.00 net.

The same. Briefer Course. $35^{2}$ pp. rmo. \$r.iz net.

2. Zoology. By A.S. PAckard, Jr., Professor in Brown University. Advanced Course. $722 \mathrm{pp}$. 8vo. \$2.40 net.

The same. Briefer Course. 338 pp. (Revised and enlarged 1897.) 12mo. \$1.12 net.

The same. Elementary Course. 290 pp. $12 \mathrm{mo}$. 80 cents net.

3. Botany. By C. E. Bessey, Professor in the University of Nebraska. Advanced Course. 611 pp. 8vo. \$2.20 net.

The same. Briefer Course. (Entirely new edition, 1896.) 356 pp. $12 \mathrm{mo}$. \$1.12 net.

4. The Human Body. By H. Newell Martin, sometime Professor in the Johns Hopkins University.

Advanced Course. (Entirely new edition, 1896.) 685 pp. 8vo. \$2.50 net. Copies without chapter on Reproduction sent when specially ordered.

The same. Briefer Course. 377 pp. 12mo. \$1.20 net.

The same. Elementary Course. 26r. pp. 12mo. 75 cents net.

The Human Body and the Effect of Narcotics. 26r pp. I2mo. \$r.20 net.

5. Chemistry. By IRA Remsen, Professor in Johns Hopkins University. Advanced Course (Inorganic). (Entirely nervedition, 1898.) 850 pp. 8vo. $\$ 2.80$ net.

The same. Briefer Course. (Entirely newv edition, 1893.) 435 Pp. \$1.12 net.

The same. Elementary Course. 272 pp. 12mo. 80 cents net.

Laboratorv Manual (to Elementary Course). I96 pp. ${ }^{2 m o}$. 40 cents, net.

Chemical Experiments. By Prof RemSen and Dr. W. W. RANDAlL, IFor Briefer Course.) No blank pages for notes. $15^{8} \mathrm{pn}$ 12mo. $50 \mathrm{c}$. "ot.

6. Political Economy. By Francis A. WALKer, President Massachusetts Institute of Technology. Advanced Course, 537 pp. 8vo. \$2.00 net.

The same. Briefer Course. 415 pp. 12mo. \$1.20 net.

The same. Elementary Course. $423 \mathrm{pp} .12 \mathrm{mo}$. \$1.00 net.

7. General Biology. By Prof. W. T. SEDGWICK, of Massachusetts Institute of Technology, and Prof. E. B. Wilson, of Columbia College. (Revised and enlarged, 1896.) $23^{x}$ pp. 8vo. \$1.75 net.

8. Psychology. By William James, Professor in Harvard College. Advanced Course. $689+704$ pp. 8 vo. 2 vols. $\$ 4.80$ net.

The same. Briefer Course. $47^{8}$ pp. 12mo. \$1.60 net.

9. Physics. By George F. Barker, Professor in the University of Pennsylva. nia. Adranced Course, 90: pp. 8.7o, \$3.50 net.

10. Geology. By Thomas C. Chamberi.in and Rollin D. Salisbury, Professore in the University of Chicago. (In Preparation.) 
Allen's Laboratory Exercises in Elementary Physics. By CHARLES R. Allen, Instructor in the New Bedford, Mass., High School. Pupil's Edition : $\mathrm{x}+209$ pp. I2mo. Soc., net. Teachers' Eaition; \$1.00, net.

Arthur, Barnes, and Coulter's Handbook of Plant Dissection. By J. C. Arthur, Professor in Purdue Univ., C. R. Barnes, Professor in Univ, of Wisconsin, and JoHN M. Coulter, President of Lake Forest University. xi 256 p. I2mo. \$I.20, net.

Atkinson's Elementary Botany. By Geo. F. AtKinson, Professor in Cornell. For beginners. Fully illustrated.

Barker's Physics. See American Science Series.

Barnes' Plant Life. By C. R. BARNes, Professor in University of Chicago. Illustrated. $\mathrm{x}+428$ pp. I2mo.

Beal's Grasses of North America. For Farmers and Students. By W. J. BEAL, Professor in the Michigan Agricultural College. 8vo. Copiously Ill'd. Vol. I., 457 pp. \$2.50, net. Vol. II., 707 pp. \$5, net.

Bessey's Botanies. See American Science Series.

Black and Carter's Natural History Lessons. By George Ashton BlaCK, Ph.D., and KATHLEen Carter. (For very young pupils.) $\mathrm{x}+98 \mathrm{pp}$. I 2 mo. 50c., net.

Bumpus's Laboratory Course in Invertebrate Zoology. By H. C. Bumpus, Professor in Brown University. Revised. I57 pp. I2mo. $\$ \mathrm{I}$, net.

Cairns's 'Quantitative Chemical Analysis. By FreD'K A. CAIRns. Revised and edited by Dr. E. WAller. 4I7 pp. 8vo. \$2, net.

Champlin's Young Folks' Astronomy. By John D. Champlin, Ir., Editor of Champlin's Young Folks' Cyclopadias. Illustrated. vi +236 pp. I6mo. $48 \mathrm{c}$., net.

Congdon's Qualitative Analysis. By Ernest A. Congdon, Professor in Drexel Institute. $64 \mathrm{pp}$. Interleaved. 8 vo. 6oc., net.

Crozier's Dictionary of Botanical Terms. 202 pp. 8 vo. \$2.40, net.

Hackel's The True Grasses. Translated from "Die natürlichen Pflanzenfamilien" by F. LAMSON-SCribner and EFfie A. SOUTHWORTH. $\mathrm{v}+228$ pp. 8vo. \$I.50.

Hall's First Lessons in Experimental Physics. For young beginners, with quantitative work for pupils and lecture-table experiments for teachers. By EDwin H. Hall, Assistant Professor in Harvard College. viii + I2O pp. I2mo. 65c., net.

Hall and Bergen's Text-book of Physics. By Edwin H. HAll, Assistant Professor of Physics in Harvard College, and JosepH Y. Bergen, Jr., Junior Master in the English High School, Boston. Greatly enlarged edition. 596 pp. I2mo. \$1.25, net.

Postage 8\% additional on net books. Descriptive list free. 
Kerwig's General Prineiples of Zoology. From the Third Edition or Dr. Richard Hertwig's Lehrbuch der Zoologie. Translated and edited by George Wilton Field, Professor in Brown University. 226 pp. 8vo. \$r.6o net.

Howell's Dissection of the Dog. As a Basis for the Study of Physiology. By W. H. Howell, Professor in the Johns Hopkins University. IOO pp. 8vo. \$I.00 net.

Jackman's Nature Study for the Common Schools. (Arranged by the Months.) By Wilbur Jackman, of the Cook County Normal School, Chicago. I1l. 448 pp. I2mo. \$r.20 net.

Kerner \& Oliver's Natural History of Plants. Translated by Prof. F. W. Oliver, of University College, London. fto. 4 parts. With over Iooo illustrations and I6 colored plates. \$I5.00 net.

Kingsley's Elements of Comparative Zoölogy. By J. S. Kingsi.ey, Prof. in Tufts College. With abundant laboratory drill. 357 pp. I2mo. \$I.20 net.

Macalister's Zoology of the Invertebrate and Vertebrate Animals. By Alex. Macalister. Revised by A. S. Packard. 277 pp. I6mo. 80 cents net.

MacDougal's Experimental Plant Physiology. On the Basis of Oels' Pfanzenphysiologische Versuche. By D. T. MacDougal, University of Minnesotav vi $+88 \mathrm{pp}$. 8vo. \$I.00 net.

Macloskie's Elementary Botany. With Students' Guide to the Examination and Description of Plants. By George Macloskie, D.Sc., LL.D. 373 pp. I2mo. \$1.30 net.

McMurrich's Text-book of Invertebrate Morphology. By J. Playfair McMurrich, M.A., Ph.D., Professor in the University of Cincinnati. vii $+66 \mathrm{I}$ pp. 8vo. New Edition. \$3.00 net.

McNab's Botany. Outlines of Morphology, Physiology, and Classification of Plants. By William Ramsay MCNAB. Revised by Prof. C. E. Bessey. 400 pp. I6mo. 8oc. net.

Martin's The Human Body. See American Science Series.

* Merriam's Mammals of the Adirondack Region, Northeastern New York. With an Introductory Chapter treating of the Location and Boundaries of the Region, its Geological History, Topography, Climate, General Features, Botany, and Faunal Position. l3y Dr. C. Hart Merriam. 3i6 pp. 8vo. \$3.50 net.

Newcomb \& Holden's Astronomies. See American Science Series.

* Noel's Buz; or, The Life and Adventures of a Honey Bee. By MAurice Noel. I3t pp. I2mo. \$r.oo.

Noyes's Elements of Qualitative Analysis. By WM. A. Noyrs, Professor in the Rose Polytechnic Institute. 9I pp. 8vo. 80c. net.

Packard's Entomology for Beginners. For the use of Young Folks, Fruit-growers, Farmers, and Gardeners. By A. S. PAckard. xvi +367 pp. r2mo. Third Edition, Revised. Sr.40 net.

Postage 8 per cent additional on net books. Descriptive list free. 
Packard's Guide to the Study of Insects, and a Treatise on those Injurious and Beneficial to Crops. For Colleges, Farm-schools, and Agriculturists. By A. S. Packard. With 15 plates and 670 wood-cuts. Ninth Edition. 715 pp. 8 vo. \$4.50 net.

Out'ines of Comparative Embryology. By A. S. PACKard. Copiously illustrated. 243 pp. 8 vo. \$2.00 net.

- Zoologies. See American Science Series.

i : isins's Outlines of Electricity and Magnetism. By CHAS. A. PERKINS, i'rofessor in the University of Tennessee. $277 \mathrm{pp}$. $12 \mathrm{mo}$.

i I ro net.

Pierce's Problems in Elementary Physics. Chiefly numerical. By E. Dana Pierce, of the Hotchkiss School. I94 pp. I2mo. 6oc. net.

*Price's The Fern Collector's Handbook and Herbarium. By Miss SAdiE F. Price. 72 plates, mostly life-size, with guide. 4to. \$2.25.

Randolph's Laboratory Directions in General Biology. I63 pp. 16 mo. 8oc. net.

Ramsen's Chemistries. See American Science Series.

Scudder's Butterflizs. By S. H. Scudder. 322 pp. I2mo. \$I.20 net.

Brief Guide to the Commoner Butterflies. By SAMUEL H. SCU1) In. $\mathrm{xi}+206 \mathrm{pp}$. I2mo. \$I oo net.

The Life of a Butterfly. A Chapter in Natural History for the General Reader. By S. H. Scudiner. I 86 pp. I6mo. 8oc. net.

Sedgwick and Wilson's Biology. See American Science Series.

* Step's Plant Life. By Edward Step. Popular Papers on the Phenomena of Botany. I2mo. I48 Illustrations. \$1.00 net.

Underwood's Our Native Ferns and their Allies. By LuCIEN M. Underwood, Professor in DePauw University. Revised. I56 pp. I $2 \mathrm{mo}$. \$1.00 net.

Williams's Elements of Crystallography. By GEORgE Huntington WIILliams, late Professor in the Johns Hopkins University. $\mathrm{x}+270$ pp. I2mo. Revised and Enlarged. \$I.25 net.

Wiilliams's Geological Biology. An Introduction to the Geological llistory of Organisms. By Henky S. Williams, Professor of Geology in Yale College. 8vo. 395 pp. \$2.80 net.

Woodhull's First Course in Science. By John F. WoodHull, Professor in the Teachers' College, New York City.

1. Book of Experiments. xiv +79 pp. 8vo. Paper. 5oc. net.

II. Text-Book. $\mathrm{xv}+\mathrm{I} 33 \mathrm{pp}$. I2mo. Cloth. 65c. net.

III. Box of Apparaius. \$2.OO net (actual cost to the publishers).

Zimmermann's Botanical Microtechnique. Translated by JAMEs ELLIS HumpHREY, S.C. xii +296 pp. 8vo. \$2.50 net.

HENRY HOLT \& CO., 29 WEST 23D ST., NEW YORK. 


\title{
KERNER'S NATURAL HISTORY OF PLANTS.
}

\author{
Translated by Professor F. W. Oliver, of University College, \\ London. A work for reference or continuous reading, at once \\ popular and, in the modern sense, thoroughly scientific. With \\ 16 colored plates and 1000 wood engravings. Four parts. 4to. \\ Cloth. \$15.00 net.
}

The Nation: "The author evidently planned at the outset to take every attractive teature of plants of all grades, and place these attractive features in the very best light. For this purpose he has skillfully employed a brilliant style of exposition, and he has not hesitated to use illustrations in black and in color with the freest hand. The purpose has been attained. He has succeeded in constructing a popular work on the phenomena of vegetation which is practically without any rival. The German edition has been accepted from the first as a useful treatise for the instruction of the public ; in fact, some of its illustrations have been taken bodily from the volumes by museum curators, to enrich exhibition cases designed for the people. With two exceptions, the full-page colored plates leave little to be desired, and might well find a place in every public museum in which botany has a share. Most of the minor engravings are unexceptionable. They are clear, and almost wholly free from distracting details which render worthless so many iflustrations in popular works on natural history. Professor Kerner's style in German is seldom obscure-it is what one might fairly call easy reading; but it is no disparagement to him and his style tostate that the translation is clearer than the original throughout. . In the first two issues the author was engaged chiefly with the study of the structure of the plant, and its adaptation to its surroundings. In this concluding volume he considers the plant from the point of view of its relation to others. Therefore he begins with a full and absorbingly interesting account of reproduction in the vegetable kingdom, and then passes to an examination of species. . With this book, there is no excuse for even busy people to be ignorant of how the other half, the plant-half, lives."

Botanical Gazette: "Kerner's work in English will do much toward bringing modern botany before the intelligent public. We need more of this kind of teaching that will bring those not professionally interested in botany to some realization of its scope and great interest."

Professor J. E. Humphrey: "It ought to sell largely here to colleges and public libraries, as well as to individuals, and I can heartily commend it."

John M. Macfarlane, Professor in University of Pennsylvania : "It is a work that deserves a wide circulation."

Professor John M. Coulter in The Dial: "It is such books as this that will bring botany fairly before the public as a subject of absorbing interest; that will illuminate the botanical lecture-room : that will convert the Gradgrind of our modern laboratory into a student of nature."

Nere York Times: "A magnificent work, with its careful text and superb illustrations. The whole process of plant life is explained, and all the wonders of it."

The Critic: "In wonderfully accurate but easily comprehended descriptions, it opens to the ordinary reader the results of botanical research down to the present time."

The Outlook: ". . For the first time we have in the English languagea great work upon the living plant, profound, in a sense exhaustive, thoroughly reliable, but in language simple and beautiful enough to attract a child. . . The plates are most of them of unusual beauty. Author, translator, illustrators, publishers, have united to make the work a success."

\section{HENRY HOLT \& C0., 29 West 23d Street, New York.}




\section{HENRY HOLT \& CO.'S RECENT BOOKS}

The Publishers' Catalogue of GENERAL LiTERATURE, including History, Biography, Travels, Fine Arts, Fiction, etc., etc., or their new Educational Catalogue. free on application to $29 \mathrm{~W}$. $23 d$ St., New York.

\section{PUGH'S TONY DRUM, A COCKNEY BOY}

With a cover and ten most striking illustrations in color by WiLLiAM Nicholson, whom so great an authority as Whistler has called the greatest living English illustrator. The author is already known through his versatile and forceful volume of stories, King Circumstance. $12 \mathrm{mo}$.

For King Circumstance, see page 2 of this circular.

\section{CORNISH'S CONCISE DICTIONARY OF GREEK}

\section{AND ROMAN ANTIQUITIES}

Based on Sir William Smith's larger work and edited by $F$. Warre Cornish, Vice-Provost of Eton College. ४vo. \$4.0o, net.

The latest and perhaps the best book on the subject. inspired throughout by the most recent result of excavation. It has 829 pages and some r1oo illustrations.

\section{LANGLOIS \& SEIGNOBOS' INTRODUCTION TO}

\section{THE STUDY OF HISTORY}

Translated by G. G. BERRY. With a preface by F. York Poivell. $12 \mathrm{mo}$. \$2.25, net, special.

A practical book on method for historians and students of history. It discusses the problem of investigation, such as the Search for Documents, Textual Criticism, and the Critical Ciassification of Sources; also the Problems of Construction, such as the Grouping of Facts, Constructive Reasoning, and Exposition.

\section{- A NEW VOLUME IN THE AMERICAN SERIES}

\section{THE SCIENCE OF FINANCE}

By Henry C. Adams, Professor in the University of Michigan. 8vo.

The author is probabiy the leading American authority on the subject, and here lays special stress upon the necessities of thAmerican people.

\section{TARBET'S FIGHTING FOR FAVOUR}

A Romance of Sixteenth-century Scotland. 12mo. \$1.25.

$N$. Y. Times: "The style is pleasing. . . The movement is rapid and the interest well sustained."

Buffalo Express: "The fighting and love-making are more than commonly real and exciting." 


\section{RINGWALT'S MODERN AMERICAN ORATORY}

$12 \mathrm{mo}$. \$1.00, net.

Schurz's General Amnesty, Black's Trial by Fury, Phillips' Daniel O'Connell. Depew's Inauguration of Washington, Curtis' The Leadership of Educated Men, Grady's The New South, and Beecher's The Sepulchre in the Garden. With a discussion of modern oratory, notes, and a bibliography by RALPH C. RINGWALT.

\section{FORD'S THE FEDERALIST}

The well-known collection of papers on the Constitution by Hamilton, JAY, and MADison. Edited by PaUL Leicester Ford, editor of The Writings of Thomas Fefferson. With foot-notes showing relation of subsequent events to views in the text, an appendix of $x_{49}$ pages, including the Constitution with the Senate "case references," etc., and a full index. 12mo. $\$ 2.50$, net.

Roger Foster, author of Commentaries on the Constitution: "The best edition that has been published."

The Right Hon. Fames Bryce, M.P.: "Far the best [edition] I have seen, and the most likely to be useful to students of political science"

New York Tribune: "Mr. Ford's editing is nothing less than perfect. . . . This is an invaluable edition."

The Rerieze of Reviezs: "For the purposes of critical study and precise reference, Mr. Ford's edition, it seems to us, must of necessity exclude all others."

\section{JENKS' LAW AND POLITICS IN THE MIDDLE}

AGES With a synoptic table of sources. 8vo. \$2.75, net.

Harvard Law Review: "A valuable contribution to legal history. ... A book of great merit, which displays wide learning."

\section{PUGH'S KING CIRCUMSTANCE}

12mo. \$1.25.

Boston Transcript: "A volume of short stories, each of which has its own strong, peculiar vein of interest and reality. . . Each story is in itself strikingly complete. . . . The writer of these short stories displays decided talent.'

\section{ELLIOTT'S THE DURKET SPERRET}

A Romance of the Cumberland Mountains. (Uniform with the author's Ferry, fohn Paget, and The Felmeres.) 12mo. \$1.25.

The Nation:" A homespun heroine in whose possibility one is glad to believe."

Literary World: "It can bear re-reading and is remembered with pleasure."

New York Tribune: "Worth reading a second time."

New Vork Commercial Advertiser: "Strengthens Miss Elliott's reputation as a novelist. . . Each character is sustained and vigorous."

Independent: "Decidedly above the common. Its descriptive pages are good; its sketches of mountain life and the character of the mountain girl chosen for the heroine are excellent."

New YorkTimes: "The utter sincerity and naturalness of dialogue are features that should claim particular attention," 
13th IMPRESSION OF A "POWERFUL NOVEL"

VOYNICH'S THE GADFLY

r2mo. \$1.25.

New York Tribune: "It is nothing more or less than one of the most powerful novels of the decade. . . It is a thrilling book and absolutely sober."

\section{A BOOK FOR OLD AND YOUNG}

\section{LUCAS' A BOOK OF VERSES FOR CHILDREN}

With covers and title-page in colors. I2mo. \$2.00.

The Critic: "We know of no other anthology for children so complete and well arranged."

Chicago Post: "Will interest the old hardly less than the young."

BURROW'S THE FIRE OF LIFE

I2mo. \$1.25.

Boston Transcript: "Exceedingly entertaining and taking. . . . Delightfully written.',

The Independent: "This charmingly simple and sweet novel .. belongs to a class (far too small) of fiction that leaves a good taste in the mind after reading.'

4th IMPRESSION OF A CHARMING BOOK

JEROME'S SKETCHES IN LAVENDER, BLUE,

AND GREEN With 40 illustrations. 12mo. \$1.25.

Boston Transcript: "A humorist whose humor is of the exquisitely pleasing kind that delights by its delicate exaggeration of the common faults and foibles of humanity, without offending by descending to mere burlesque; ... there is in his work much of both wit and philosophy. ... Several of the tales have a strong emotional interest; they are all original and well told."

$L$ ist of $M r$. Ferome $K$. Ferome's books on application.

5th IMPRESSION OF A WORK ON CUBA TO-DAY

ROWAN \& RAMSEY'S ISLAND OF CUBA

With maps, points of international law, etc. r6mo. \$r.25.

Boston Transcript: "So graphic, at times picturesque, that reading for information is an intellectual delight."

28th IMPRESSION OF THE AMERICAN NOVEL

FORD'S THE HON. PETER STIRLING

I2mo. \$r.5o.

A NEW FOUR-VOLUME EDITION OF TAINE'S ENGLISH LITERATURE

With 28 portraits. Gilt tops. In box. $\$ 7.50$.

The Dial: "The most satisfactory edition for library use that we have in English."

\section{KERNER'S NATURAL HISTORY OF PLANTS}

With over 2000 illustrations ( 6 of them in colors).

4 parts. 8vo. Cloth, \$1 5.00, net; carringe \$r.oo.

New York Times: "A magnificent work; . . superb illustrations." The Nation: "The lucidity of style is remarkable." 


\section{5th IMPRESSION OF THE SEQUEL TO "THE PRISONER OF ZENDA"}

\section{HOPE'S RUPERT OF HENTZAU}

With eight illustrations by Charles Dana Gibson. 12mo. \$r.5o.

Critic: "Even better than 'The Prisoner of Zenda.' . . Moving swiftly, from a simple beginning to an impressive climax."

Life: "Does not let down one bit the high standard of chivalrous love which was the charm of that romance " ["Zenda "].

Dial: "Our chief regret is that further volumes in the series are, at least, improbable."

E. A. Dithmar in N.Y.Times" Saturday Revierv : "A sequel for a wonder as vigorous and powerful as its original."

Geo. W. Smalley in N. Y. Herald" "A story which lays a spell upon you. The animation is unceasing.'

\section{A NEW ILLUSTRATED EDITION OF} HOPE'S PRISONER OF ZENDA

(Being the 48 th Impression of this romance.)

With five full-page illustrations by C. D. GiBson, and a view and plan of the castle by HowARD INCE. I2mo. \$r.50.

\section{OTHER BOOKS BY ANTHONY HOPE}

With frontispieces by RACKHAM, RUSSELL, and WECHSLER, $18 \mathrm{mo}$. $75 \mathrm{c}$. each.

The Indiscretion of the Duchess, 12th Impression: The Dolly Dialogues, roth Impression: A Change of Air, gth Impression: is Man of Mark, 9th Impression; Sport Royal, etc., $4^{\text {th }}$ Impression.

4th IMPRESSION OF A HUMOROUS TALE

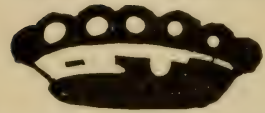
WELLS' (D. D.) HER

\section{LADYSHIP'S ELEPHANT}

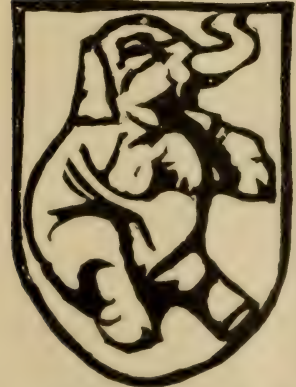

From the back of Wm Nicholson's coner for "Her Ladyship's Elephant."

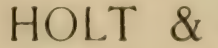

With cover by WM. Nicholson. 12mo. \$1.25.

The Nation: "He is probably funny because he cannot help it. . . Its author must consent to be regarded as a benefactor of his kind without responsibility."

$R$. H. Stoddard in New York Mail and Express: "Mr. Wells has more than enough humor to tell his story in a very natural and laughable way. He has a great deal of comic talent."

Chicago Evening Post: "An instantaneous success. ... The most read story of the season."

New Vork Tribune: "Mr. Wells allows his sense of humor to play about the personalities of half a dozen men and women whose lives, for a few brief, extraordinary days, are irextri cably intertwined with the life of the aforesaid monarch of the jungle. . . Smacks of fun which can be created by clever actors placed in excruciatingly droll situations."

HENRY HOLT \& CO. 28 west 23 New York 


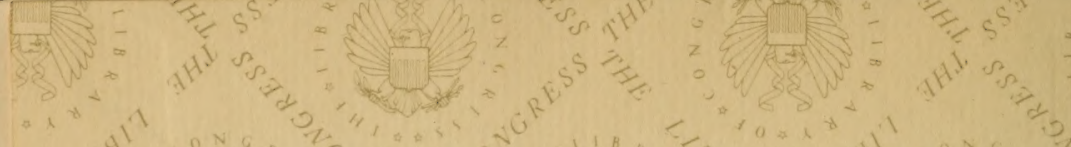

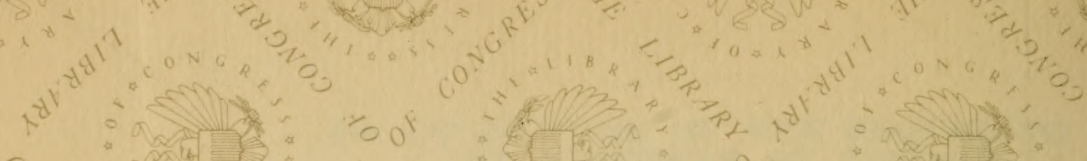

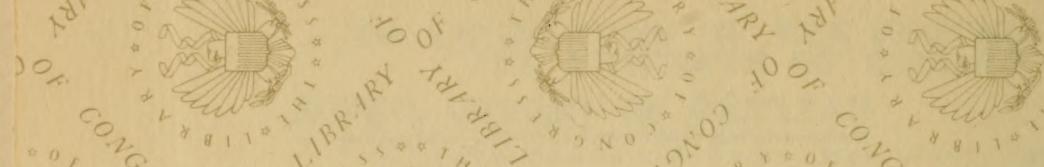

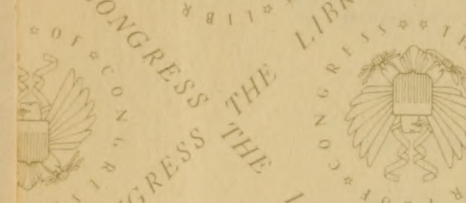

201

$0^{3}, 2$

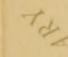

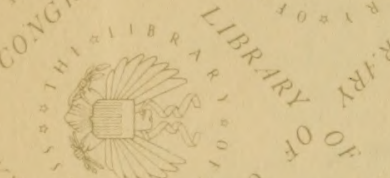

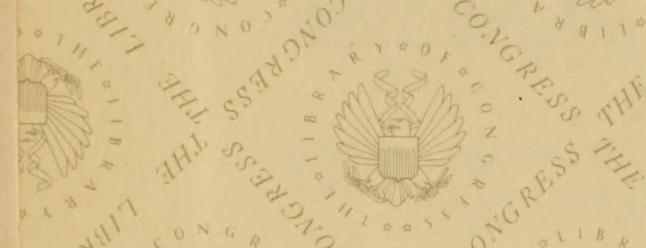

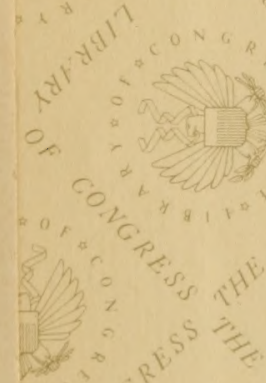

03

100

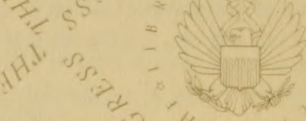

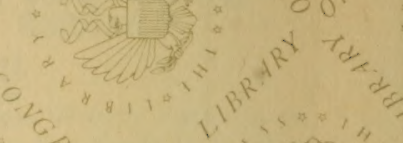




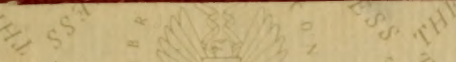

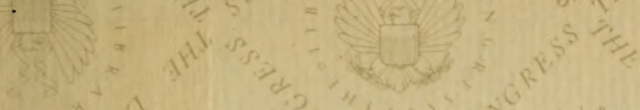

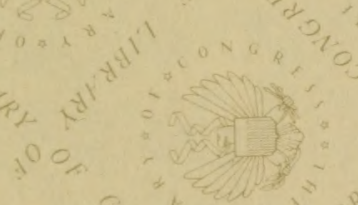

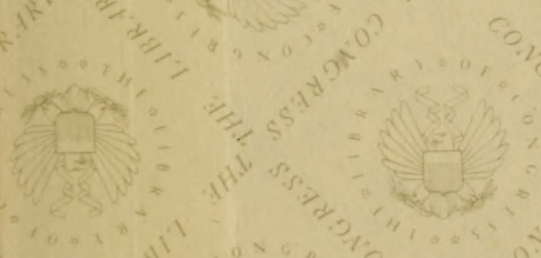

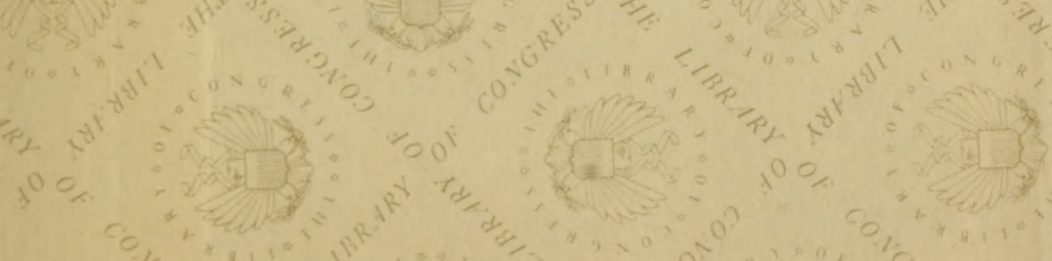

$\lim _{\operatorname{lin}}$ 


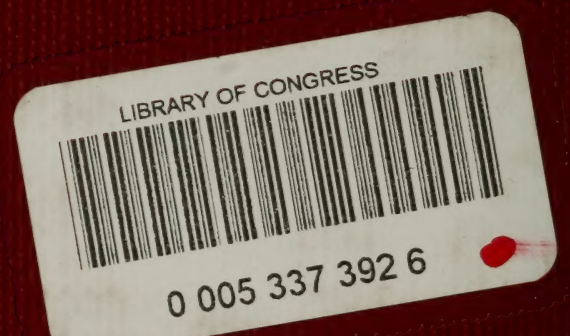

